



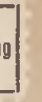
HAMBURG 
Groteine Gammlung won Werfen zeitgenöifiicher Edbriftiteller Band 129:

Buftav Frenjien, Die $\mathfrak{B r i b e r}$

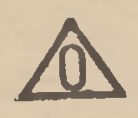





\title{
Di $\mathfrak{i} \mathfrak{B} \mathfrak{r} \mathfrak{i} \mathfrak{D} \mathfrak{e} \mathfrak{r}$
}

\author{
Eine Erodalung
}

bon

Orutay Fenfien

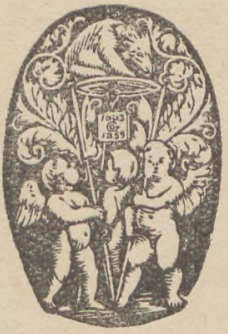

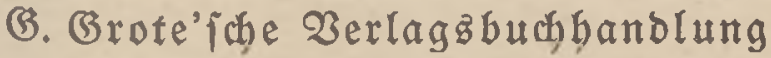
Berlin 1917 


\section{0}

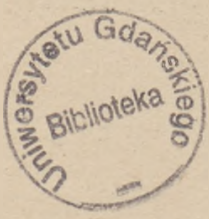

BIBLIOTEKA

UNIWERSYTETU GDAŃSKIEGO

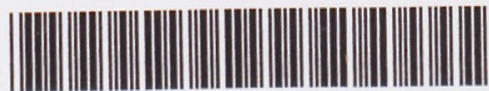

*1101081331*

Uffe Redite, ingbefonbere baz ber l̈berjesung in andere Epracten, vorbebalten. Einbanbzeidinung von Grib Preip. Drut von Fifdier \& 2 ittig in Leipsig. 


\section{Gubaltzuerzeichniz}

Gelte

1. Ravitel: Der Sof . . . . . . . . . 1

2. Rapitel: Der Dfeifer . . . . . . . . . 11

3. Rapitel: Der Rued)t . . . . . . . . . 28

4. Rapitel: Die Befđuldigung . . . . . . . 40

5. Rapitel: Bruber Reimer . . . . . . . 58

6. Rapitel: Daş Fähnlein . . . . . . . . 79

7. Rapitel: Eorgen . . . . . . . . . . 93

8. Rapitel: Der $\mathfrak{B}$ efuch . . . . . . . . . . . 111

9. Rapitel: Die englifke Manmírbaft. . . . . 128

10. Rapitel: Neto Gort . . . . . . . . . . 143

11. Rapitel: Somburg. . . . . . . . . . . 160

12. Rapitel: Wilhelmछ̨havert . . . . . . . 178

13. Rapitel: Der Gtropp. . . . . . . . . 193

14. Rapttel: Der शarr . . . . . . . . . 209

15. Rapitel: Der Ubfall von ber "Zlten Riebe" . 227

16. Rapitel: Paftor 230 ten . . . . . . . . 235

17. Rapitel: Der Rranz. . . . . . . . . 254

18. Rapitel: Die Nutter . . . . . . . . . . 272

19. Rauitel: Die gute Prife . . . ... . . 294

20. Rapitel: Qobrebe auf G. N. G. Belotw', . . . 321

21. Rapitel: Geuerbranb . . . . . . . . . . 334

22. Sapitel: Die Seilung Des Simmermanns . . 350

23. Rapitel: Die Begegnung vorm Elagerraf . . . 366

24. Rapitel: Oh, mein Bruber Reimer! . . . . 384

25. Rapitel: Der Radhtmarid. . . . . . . . 396

26. Rapitel: Urbeit. . . . . . . . . . 412

27. Rapitel: Qï̧beth . . . . . . . . . 432

28. Rapitel: Emma. . . . . . . . . . 450

29. Sapitel: Mebr Betenntntfre . . . . . . 471

30. Rapitel: U 233 . . . . . . . . . . . . 488

31. Rapitel: Der Pflïger . . . . . . . . . 504

32. Rapitel: Ser Sobannisbeerwein . . . . . . 522

33. Rapitel: Bater Ott . . . . . . . . 536

34. Rapitel: Berföbnung .... Der Rrieg . . . . 551 

Die $2 \mathfrak{B} \mathfrak{u} \mathfrak{D} \mathfrak{x}$ 



\section{Rapitel \\ Der Sof}

Ctroas abfeitş vom Rirchipiel Altenfiel - bie Porofee ift nur eine Gtunbe fern - liegt mitten im eignen Felo, von alten Pappeln umitanden, ein fleiner Bauern* bof, wie bunderttaujende in Deutichland. Auf diejem Sof - bas Bebäude war etra fünfzig Sabre alt und nod) woblerbalten - wobnte feit Renjchengedenten eine Gamilie Ott, bie immer einen guten Kuf gelgabt batte. Gie ftanden aber etroaz abieitz nom Leben unb Ireiben bes übrigen Rirchipiels uno twaren ein renig beripalt und bereiniamt. Wenn aud roobl eine Fabel taar, baß fie nur einen einzigen guten Rioc batten, Den immer ber angog, der einen Gang inz Dorf ober in bie nahe Soafenjtadt zu machen batte, und daj fie, um Goblen gu fhonen, um die Selegraphenpfäble berum=

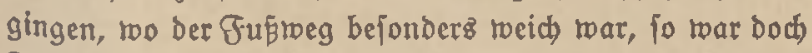
Satjactje, baj fie fich jebr jelten zeigten und fich jebr ungern in Ericheimung fegten, uno wenn fie einmal erfocinen mubten, fich am liebften in ben binteriten Reiben und in ber Ecfe bielten. Gie waren zwar Peute bon großer, ja getwaltiger Erjheinung, bager, mit großem Gdritt, breiten Gaultern, aber fie maren intwendig nidht ficher. Sie nahmen bas Leben nicht jo bin, wie es ifft und twie es eincm aufgetijat wiro, fondern betrad)teten es und begleiteten es mit allerlei Bebenfen und Benundern. SAnd Da fie auf bieje Weife intendig ein menig bange ober twenigftenz bedentlich vor bem Qcben itanden, griffen fie es auch nicht feft uno auch nicht ridstig an, uno tamen nidjt

Frenffen, Die gruber. 
weiter, und wie ez ponft bier uno ba geidjiebt. (Fine ganze 3eitlang fonnten fie ben $B e f i k$ nur fo erbalten, baf fie ben ziemlids langen Stall mit frembem Bieh füllten, bas fie um geringen Berbienit burdy ben Winter brad)ten. Se mebr fie aber von ber Welt, ibrem Bertebr und ibren Erfolgen fernblieben, um fo mebr - roie man das jo bat - bielten fie untereinander zujammen, fo als fürchtete fï ein jeber ber Eamilie, eines Tagz böllig ein [am in ber Welt Dazujteben. Da fie fich aber fo von ben Menjchen $a b=$ fonderten uno fich nidft meb̆r täglich an ibnen maßjen, fammelten fie einen tüchtigen Soaufen beimlid)en Etolzes, und meinten imwendig - Eciner bon ifnen prach aนz -, Daj es eine joldhe Eamilie, wie Die Otten, fo rechtlich), fo fittfam, fo fleipig, fo tlug — fie batten in Der Fat gute Röpfe - eigentlich itberbaupt im ganzen Land und in ber ganzen Welt nicht gäbe.

Der jesige ßefíger, fünfzigiährig, raar förperlich und geiftig ein rechtez abbild Der Familie. Er war ein breitjdultriger, langer Mann von fd)led)ter, bängender Saltung und mit langem bedähtigen Bang, Dem man

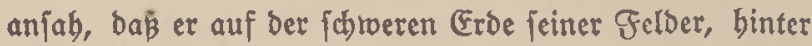
bem Pflug heritolperno, unzäblige fatwere und unfict)ere Gdrifte getan. Er rar jebr twortfarg; oft war ez ibm ftunbenlang unmöglich, bie 3ähne auşeinander zu nebmen, und man bärte ihn niemals foserzen oder gar lachen ober gar fingen; er roar immer in gleicher Weife fleifig, fatweigfam, unberocglich. Slno jo bätte ibn einer, ber oberfläclid) binfab unb urteilte, für einten gleiçmütigen, ja faft lecren Menichen balten tönnen. Wer aber genau 


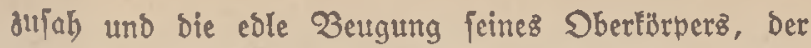

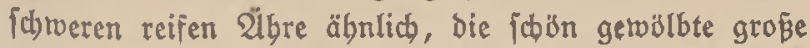
Gtirn, Die tiefen findlichen Augen beobadtete, ber erfannte,

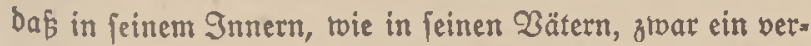

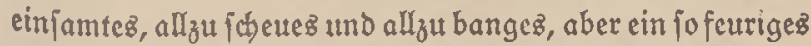
uno volles Qeben toobnte, fo wie es manthe Reuchte bes Yolfz nicht be ftarlen Gtofies von außen ber, und bieje Fülle brad) beraus uno loberte auf, zur gropenen Berwunderung für jedermann. Slno biefer Gtóp follte ihm auch fommen. Und zroar non feiner Frau ber, und von Dem Beblüt, Damit fie bie Gtuben und Rammern jeines Soufes gefüllt hatte.

Dic Frau twar nämlich bon anderm Ed)lag. Wäbrend bie Borfabren bes Nannes inmer Randleute gewelen niemals war ciner, fo nalye fie war, zur Gee gefaljren, ia, fie fheuten bie Gee und prad)en nicht gut pon ibren Befabrern -, ftammten bie Borfabren Der Frau alle auz ben Heinen Soafen ber Landichaft und waren alle Gchiffer und gar noch alle bon jener bertwegenen, Iofen, rechtbaberijchen Gorte, bie teinen Gag aus ibrem Munbe bringen fönnen, obne ben rechtliden, rubigen Lanomann zu fränten und abzuitopien. Gie war, obgleich nicht gerabe großs, ba fie fich gerabe und feil bielt, eine gropifieinente, ftattlidbe Figut und hatte belle fobone Garben bei rots blondem Saar. Wenn fie erregt wurbe, was jeben Sag toenigftens cinmal gefhah - Denn fie war eine feurige und etroas jäbe शatur - jei eв, baß́ Rinder ober

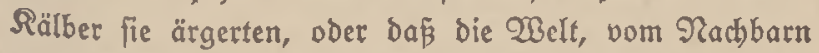
angefangen biz zum Soerrgott, ibr nicht nach bem Ropf 
waren, tat fie unter jähem zornigen 2lugenfunteln einen eigenen ralben Briff über ibr Saar hin und vermitrte es

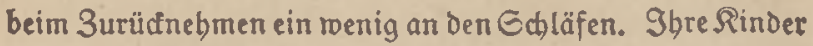
nannten biefe Bervegung den Gecrüubergriff uno gingen ib̆r Dann aus Dem Weg; Denn fie mar Dann ungerecht und batte auch ein $a_{j} u$ lojes Sanogelent.

Die beiben batten vicle Rinder, und jwar Derart, baß bie Frau faft breißig Sabre lang, bon ibrem neunzebnten biz zu ibrem fiebenundvierzigften Sabr, Sinder gebar. Das Saus wimmelte davon, bejonders an Gonn- und Geittagen, wenn Die 2̈llteren zum ßejuch tamen. Dern obgleich zret icton berbeiratet waren unb andere bier und ba herumarbeiteten und Dienten, betrachteten fie noch alle das Elternhaus als ibre Seimat uno ibren Salt.

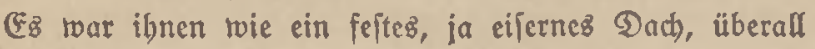
in Der Welt zu feben: Gahus, Dabin zu laufen, Liebe, Dabin zu Denten, SIauben, fí Darauf zu verlaffen; und fie taten barin allzuviel.

214e bie Rinder einzeln zu nennen unb zu zeigen, ift unmöglich; Dazu twaren ez̧ zu vicle. Man tann nur von benen fprectsen, bie noch in Soufe waren ober bocy oft babin lamen und zurzeit bie WBichtigiten uno bie Sö̈upter waren.

Slno ba war ber erfte und größte, Sarm, der 3immer= mann, bellbaarig und ztwanzig Sabre alt. Er batte in Rrabenjahren Sebrer reeden roollen. 2ber er batte in ber Hleinen Sofenitabt einen Zertwandten, einen 3immermann und Zauunternebmer, ber batte famt $\mathfrak{B}_{\mathrm{eib}}$ uno Sindern ein 20 blgefallen an bem frifhen, fiteilen Sungen genommen uno ibn oft eingeladen. (Er fpielte 
mit den Sinaben, betliebte fich früb in eins Der Mäbchen, liế fich vom $\mathfrak{Z}$ ater necfen uno von ber Dutter verzieben. Slnd da fam ibm allmäblich, ba er eis munterer Sunge twar, ber fich gern in Gefellichaft fab, bie Neinung, Daß biejes helle Sauz, Didt an ber Etrape gelegen, und biefer Simmerplab, fo brcit und fchön am Safenftrom, bunter und fhb̈ner twären, als allez, was in ben Büchern ftände. Slnd er trandte fíd jählingz bon ben 3 üchern ab und nabm bie 2rat. Sunb wenn er aud in feiner Lebrzeit bie Erfabrung gemadt batte, ba解 aud auf Dieiem Plah, wie überall in Der $201 t$, zutweilen ftürmte und fancite, fo bereute er feine Enticheibung bod nicht. Fr toar ein wacferer 3immermann getwotben und wat

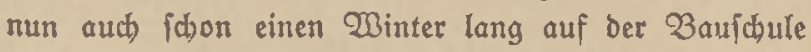
getwejen, wobin ibn ber Ontel auf leine Soiten gejanbt batte, in ber Meinung, daß er biejez an bem, Der einmal fein Gdniegerfohn würbe, fun müffe. Er fam alle Gonntage auf feinem $\Re a d$, das er befonders jauber und glängend bielt - vorn auf ber Penlitange ftand eine fleine fübne Fabne mit Den Deutfchen Garben; und er act) tete aufz peinlich) fte barauf, ठaß́ fie immer aużochte nach feinem (Elternbaus, two fich bann alle feiner 2nfunft freuten und ftolz auf ibn traten. Denn er war bei bellem Soar fomuct und jtraff bon Eriheinung und über feine Sabre binaus ein bedäbtiger Beift. Gein Bater, fo wenig ex fonit mit feinen Rindern iprach, beridjtete biefem Gobn zumeilen mit einem furzen Gab, ras in der 230 che im Grall oder auf bem Felde geidichen twar und wie es itand, und freute fich offenbar feines guten, rubigen Ulteils. Die Dutter, weld)e dic Gabe ber Rube und 
Geredtigfeit nicht batte, warb gerabezu um ibn und jeine 3uftimmung. Gobald fie ibn allein baben fonnte - toas bei bem volfteichen Soaule nidht leicht war, am leichteften nod) an Gonnabendabend - Deutete fie mit Der Sand auf Die andere Geite des Geuerb, baß ex fich Dabin iese, fegte fich felbit mit ihrer gervidtigen Figur auf bie andere, und rebete in ibrer rajめen Weife, bie Feuerzange in ber Sond und bann und twann gegen Den Rojt ftopend, auf ihn ein, und war ordentlich froh, wenn fie auth nur feine balbe 3 uftimmung batte und fcine rubige ZuBeinanderjełung anbörte. (Er aber füblte wobl, Daß̄ feine Eltern, jeber in jeiner 21rt, unfichere Reute waren und nach Meinungen auşaben und ba etroas gaben. Fr rourde aber barum fein Rart. Im Begenteil. Ez gebieh ifm zur Borficht und früben Orbnung feines jungen Geelentvejenz, und er murbe für feine Sabre ein berftändiger und orbentlicher und geiegter Menich). Ulno bie Putter, bie es mit beimlichem beftigen (Ebrgeiz $\{a b$, twie er aufz befte gebieb, meinte, baß fie ibm mit Recht den ermiten, guten Ramen Sarm gegeben batte, weil er jo rubig und perjtändig ausgejeben batte, als fie ihm zuerjt inz Beficht gejeben.

Der zrmeite, fiebzebnjäbrig, batte von Der Mutter, bie ibren Rindern gleid) bei Der (Beburt fijarf auf bie Raje ¡ah, Den aufgeregten शamen Eggert befommen, und audb diefer शame war zu Recht gegeben. Denn er war rotblono uno fommeriprofiig, unb batte rajche und beftige Betregungen, und war ftolz uno jehr leicht verlegt, und gehörie fomit ganz zum (Beichlecht ber Nutter, in roelchem Denn auch) Der Name Eggert bäufig war. (Ex balf Dem 
Zater in ber Wirtichaft und war barin auch fleipig uno tüctitig; aber ba er fo anderer, ja entgegengejester $\mathcal{A} r t$ twar, wie ber langjame, ftille und bebäctitige Bater, fo fhlug ibm oft Slnlujt ins (Bemüt, und man mertte an feinem Gefint, Daß er bie 2lrbeit mit 3orn tat. Wenn aber jein Sagenert beendet und Daz 2benbbrot eingenommen war, lief er alsbald aus ber Etalltür, rannte ben Feldrweg entlang bis zum Rachbarbof, zog Dort am (Brabenrand nach einer wunberlichen Qaune - um rafdher fortzulommen oder um bie Gtiefel zu jobnen - Grube und Strümpfe aนs und rannte barfǘ, quer über Die Felder und Gräben, nach Dem (Deich, und fá Da ben ganzen 2lbend in Dem Soufe Dez Gifdhers Lubroig, einer redsten Fifheripp. (c) aft, uno plauberte mit ifnen uno fpielte por ihnen bie Nunobarmonifa und bie Flöte, bie er zu Soauje nicht an ben Muno nabm, uno fano oft fpät nad) Sauje. Den Bater ärgerte biejer Berfebr. Nicht, Daß er fürchtete, daß fein Gobnn einmal zur Gce liefe - ex war mit Eifer Ranowirt -; aber er jab in ibm jelbjt und in Dicjem Berfebr bie Eigenjafaften und 2 rt jeiner Grau, Die er bei ihr żwar über alleż liebte, bei feinen Gäbnen aber nur gefäbrlich fand. Slno jo fam es oft zu barten 3ujammen[tößen ziwijhen dem Bater und biejem Sobn. Der $3 a t e r$ tabclte ign und verwies ifm dies und bas, und ber Gohn, Der laut nichts zu jagen rogte, murmelte zornige Worte vor fich hin, warf uno fitiés mit dem (Bejchirr und Den Berätichaften um fich, und beflagte fịh, rafch in bie Rübe und an Den Soerd tretend, mit leifer, bibiger Etimme bei ber Putter, unb beutete ben Bee=

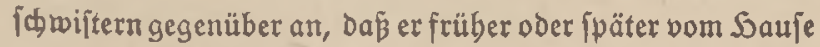


fort molle, um anbersiwo etwas Süd)tiges au lernen; bern auf biejem Sof ginge es ibm zu langfam und zu ichief ber. Der Bater, in feiner ungeichictien, ihwarz. feberifhen Weile, trug Rummer um biejen Gobn. Die Mutter, Die füblte, DáB biejer threr 21rt am nädfiten ftano, liebte ibn mit bejonderem Geuter; fie roar aber täglid in beipen Gorgen um ibn, baßi er, wenn bas Edbictjal ez wollte, leid) in bie 3 tühe geben tönnte. Seine (Be(4) wijter batten ibn gern, weil er immer, wenn auth ganz unauffälig, voller Qicbe uno Güriorge für fie war. Gie necten iffn gern, was er fich mit ernjten, beobachtenden

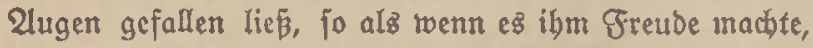
gu felyn, ras in biejem 2lugenblid in ibrer Geele vorginge. Sie nannten ibn ben $\mathfrak{B a r f u ̈ B e r , ~ o b e r ~ a u c h ~}$ soegen feiner roten Saare und oft jäben Wejens:

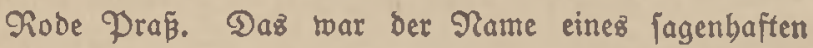
Borfabren, Den ber Lebrex, ber gern in alten Sdyriftftücten ftoberte, auzgegraben batte.

Rach Diefem (Fggert oder Barfüßer fam einer, ber war fünfzebn Sabr alt und bieß Reimer. Der war bunfel von Soupt und Saar, war auch) Hleiner. Er batte einen langen, (d)malen Supf und liebte es fajon in feiner Rinbbeit, jein Soar lang z $^{4}$ tragen, uno jo bing $e 8$ ibm denn leid)t bis an ben Roctfragen, uno ba ez surveilen ein wenig barauf bing, betam es ba cine fleine Biegung,

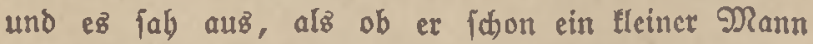

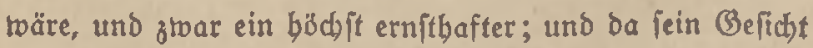
aud) fonit rein uno von feinem Edynitt war und bübiche

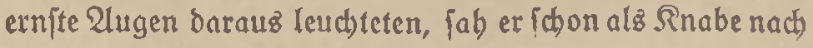
etwas 3 ejonderem aus. (Ex ging noh) in bie Gdule; 
arbeitete bort aber, ba er ben ganzen Relirplan aušs twendig gelernt batte, für fich, indern er fich bei ben ihtweriten Gtellen nacbbentlich uno bedädtig über Das lange, fhliçte Saar itrid uno ez jäuberlich über ben Rodfragen legte. Er befam vom Lebrer uno vielen Befannten allerlei Büder, gute und tweniger gute, bod) fblechte nidht; und in biefen lebte er. Go wie bie Gdutwalbe im Gonnenidein Durch bie Grablen, in ber Ruft blizend, fliegt, fo gand und gar in biefem ibrem Element, untvif̄end, $\delta a \tilde{\beta}$ ez eine barte, mübfhaffende Erbe gibt, fo leid)t und ficher, mit blinden \&ugen, von jelbit Den $23 \mathrm{cg}$ wiflend, fdrwang fich jeine Geele Durch

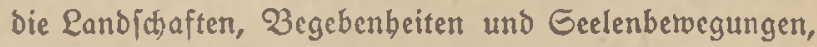
relche bie 2 üb)er vor feiner Geele ausbreiteten. Ex

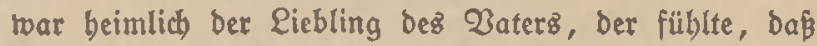

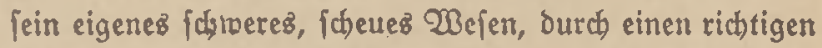

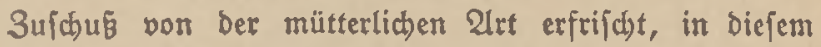
Rnaben leicht und fajỏn aufblübte, und er war ber

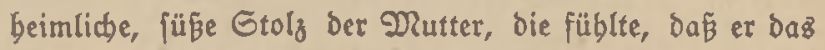
batte, twas fie, bie derbe, rein irdifhe, an bem Zater, Dem Riebften ibrer Natur, fo beís liebte: Das unirbijक Gachliche, bas menichlich Reine. (Er wollte Rebrer werben und zeitlebenz, ein mutiger Siegfried - vertoundbar nur

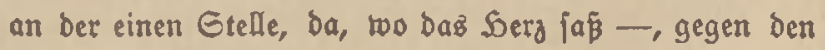
Linbwurm tämpfen.

Der Rejt ber Rinber, Mäbden und Rnaben, war ein Berwujel von bellen und rotblonden Rappen, die bon Den Eltern und grbßeren Riniern Damit erledigt wurben, Daß́ man fie fauber erbielt, den gröberen, bie fhon bie

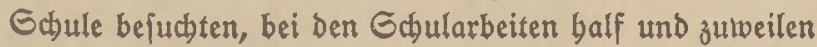


ein fallidtes 2 ort fagte, unb Den fleineren, die in Rüche und Gtall berumitanden, einige Male am Sag über ben Ropf ftrich. Dabei wurbe aber, inwendig im Serzen, jedes aufz heftigfte geliebt. SUllo wem einez frant war, oder in Der Gdulle ober auf ber Straje in Gefabr Des Qebens oder ber Egre geriet, ftand die Gorge in aller Bemüt und alle ftanden mit fliegender Geele zu feinem Gdus bereit. Für einen, Der nicht zum Sauje gehörte, war

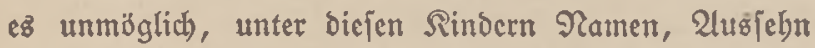
und Oronung zu bebalten; bazu twaren es zu viele uno Eamen immer ricber neue. Denn bie Mutter war nicht glüflid), wenn fie nicht ein Rindd)en auf bem Edjo uno an der Bruft batte.

Und fo war biez Saltz Der Otten wobl alz ein

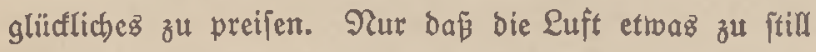
und zu Dumpf twar und bie Leute ettras zu eng ancin= ander Hlebten und fich alle etroas zu widtig nabmen, jeber in jeiner Weije, und für etras Bejonderez bielten. 


\section{Rapitel \\ Der Pfeifer}

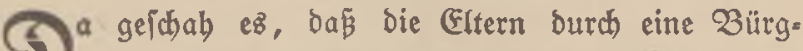
jifaft, bie ber Bater für einen feiner Wertwandten übernommen batte, cine Gumme Geldes verloren, bie in Zerbältniz zu dem Soof gró war. Gie war lo gró, baß́ fie bon nun an idiwer an Binjer zu tragen batten, ¡a, je wetter, Daß fich) über Den Soeidehyügeln ber alten Siüjte ober über ber Gee erbob, und bor allem den groß̄en Sinztag, Den erften November, fürchten muften. Der Yater quälte fich in feiner übergewiffenbaften $2 \mathfrak{n t}$ unjagbar, Dá er ben Bitten jenes Berwandten, der fich nun als ein $23 i n d$ hund erwiejen, nact)gegeben utro darüber

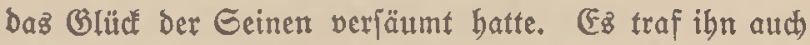
aufs härtejite, Daß̃ er burch bieje Gache in aller Reute

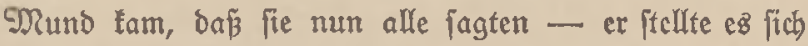
in feiner empfindfamen Geele ganz beutlich vor, ia, er börte gertau ibre Etimme - " „Es ift fidade um Den alten Reimer Ott. Er ift fo fleifig und er gibt feinen $\mathfrak{G r o j}$ hen

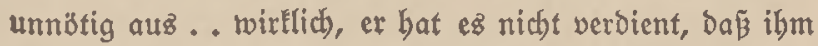
Dies gefdieht! Mber warum übernabm er bie 3 ürgldhaft? Er bätte bie Sänbe Davon laffen follen! 2lber er bat fo

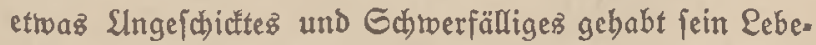
lang." $\Im_{a}$, fo fagten fie! Die Nutter, ftolz wie fie mar, quälte fidh auds mit diefem (Bercoe. 2(ber biel mebr betwegte es jie, dás inre Rinder, ibre Hleine Serbe, ibr Blut und Eigentum, nun faít Den ganzen Reft bes guten alten Ertbes verloren bätten; und fie tonnte ez in ibrer 


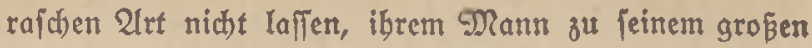
Qeio noch Borwürfe zu machen.

Die Rinder verbielten fich nad) ibrer Rafur ganz ver. fthieden. Sarm, Der Bimmermann, der nach jeiner Be. mobnbeit am Gonnabendabend auf icinem blinenden Tiab zum Bejuch tam, ferte fich Der Mutter gegenüber auf ben Soerb und rebete ibr Nut zu: DaÉ fie ja fo viele wären... jeßst elf; und alle zufammen gefunde Qeute... Daß jeder von ibnen fein tleines Blüd und fleinen Erfolg baben twürbe ... ja, ber eine ober Der anbere - er bachte babei bejonders an fich felbit -

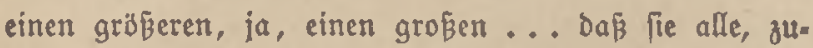
fammenbaltend, ben Berlujt wobl wiltben wieder einbringen tönnen. Fieimer, ber junge ßühermann, fam mit einem Band Ediller - Braut oon Nefina aus jeiner Rammer, ftellte fid zu ihnen, märmte feine Sänbe an ber Flamme, die Iangfam um den Reffel fpielte, uno freute fich an ibrem Gpiel, börte eine Weile zu und meinte bann, baßi man fich um (Beld boch leine Gorgen machen dürfe. Wären fie nidht gefund? Sätten fie nidjt zu elien? Soätten fie nidht Grieben in Sauje? "Du glaubfit nicbt, Nutter, toaz ez für furdtbare, finne verwirrende Edbredniffe in ber Welt gibt! Goldbe Gdbredt. niffe ... bie fund ein Slnglüa ... aber bies!? U Und er ftrich ibr lieblojend ben $21 \mathrm{rm}$ und ging roieder in peine Rammer und bachte nicht tweiter Daran. Geine Geele war ganz auf Soffnung geftelt und fab bier teine Sot. 2ber in Eggert, Dem Barfüßer, wie feine Befwrifter ihn nannten, twurbe ber Wideriprud)\&geift, Der fhon lange in ibm lebte, nun fabr lebendig und tätig. Die 
jäbe, fornige Natur ber Nutter, bie er in fiळ batte, bie in Der Nutter Durch die Licbe Des 3 łutcz gebändigt, ia beribgnt wurbe, in ibm aber jung, obne शaß und obne 3udt twar, brach twild aus thm beraus. Rafd

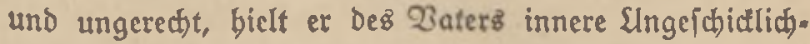
teit für unmännliche $G$ đrräche und Srägbcit. War ber Yater nicht fhlaff? Gah man ez nicht fibon an feinem Bang, feiner Soltung, jeiner langfamen und feltenen Rede? Genug, bie erfte maß̄loje Miännlichleit dez Gieb. zebnjäbrigen twallte auf und tmurrte gegen Den Zater, redete alttlug über Menjhyen und Dinge and murrte barte Zortoürfe. Sätte er nod) Damit aufgebistt, nur bie eine Sandlung Des Yaters, bie S̈bernabme ber 3 ürgid)aft, zu tabeln, fo twäre es erträglich getweien; Denn ber Zater rar bart genug gegen fich), ja überbart, und befannte in fich felbft fein Sinred)t und war gern bereit, fich felbit von einem balbrwüchfigen Rnaben einen Borrourf bieten ou lailen, ja, es freute ibn roobl gar, da er in feinem Gobn ben feurigen, zugreifenden Beift ertannte, ben er jelbft nidst hatte und barum an jeiner Grau to beiß verichtriegen liebte. Da Der Rnabe aber in Naß̄lofigleit der Sugend Daş ganze Wejen uno Reben bes Zaters angriff, fo als wenn er fein rechter Mann toäre, fonnte er es nicht ertragen. Go graufig es feiner ernften vornebmen Natur war, ex muß̃te ibn bart an= fabren und ihm Beboriam gebicten, folange er noch unmündig in jeinem \$aule träre. Der Sunge bucte fich;

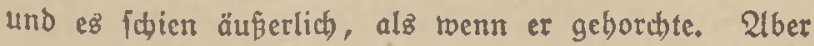
bex Multer zeigte er in rafdhen bigigen Aušrufen, alz er in ber Siuche mit igr allein trar, twie verbittert und 
frosig fein Bemuit trar; und abentos, nach bem Effen, fprang er barfǘ aus jeinem Sammerfenjter, lief über bie Felder nad Dem Deid), und faß̉ ba bie halbe Racht bei Munobarmonifa, Sartenlpiel uno Geplauder. Es geichab bort nichts Sunredstes; auch begte man ibn nicht gegen feine Eltern; aber man beftärtte ign boch in feinem $\mathfrak{W e}\{e n, b a s$ fich in ibm umtrieb und nach einem eigenen, abjonderlichen $\mathscr{B}_{\text {eg }}$ und $\mathscr{W}$ ejen cine Sür juthte.

Go verging bie 3eit biz Mitte Sanuar bin. Einige rebeten zum beften, bie andern jobroiegen. 2lud Eggert werbielt fid wieder ftiller. Ulno es jwien faft, als twenn ber Gtreit einfdhliefe und alles roieder in bie alte, rubige, etwas langweilig bumpfe Oronung bineingeriete. Da geī)ab einez Tages folgendez.

Fines Tagez, im Sanuar, an einem bejonders früben Abend, als bie Magd und der junge, frembe Snecht, Den ber Bater turz vor Weifnacht gemietet batte, in Der Dämmerung zufammen auf Der Tenne Sell beg= (c) afften, bas fie porber vom 3 oden berabgetworfen hatten, fam von bem groß̈en, Dunfeln Boden berab ein beller, fait foriller, langgezogener Pfif. Die Mago fubr er= jobrocten, ja entiegt zujammen, und ftarrte ben Rnecht an. Diejer, ber einige zebn Gduritt von ibr entfernt twar, ftand auch fill und ftart, und jab nach bem 30 den binauf und borchte. Dann jagte er Ianglam: "Wुazె war Denn Daż?" und binlte - ex batte in Folge einez ichweren Oberichenfelbruches ein etwaz getürztez 2 ein an ben Fuß ber Qeiter und jab nach oben und borwte trieder, und jagte bann leid)tbin in jeinem fremben alemannifjen Dialeft: "Das wirb ber Eggert fein, Der madjt fich cin 
Epäple mit unz." 2lber bie SMago behauptete, Eggert twäre in ber Gdheune, und forderte in wạ̧fender 2ngft ben Rnecht auf, er möbte boch mit ber Laterne binaufgeben, ob er bort jemanden fände. (Ex rollte aber nicht; ftand noc) und lebnte es ab. Sndem fam Ott felbjt von ber Rüđe her nach der Diele; und bie Mago jagte ez ifm, uno ber Rned)t fügte naゆlälfig binzu: es roäre wobl det Eggert getwejen, ber fich einen Gpá mit ibnen gemacht und nun itber ben Bacthausboden nach ber Gdeune gegarngen wäre. Ars ber Zater nachfragte, und erfubr, Daß an bem Pfiff łein 3weifel wäre und

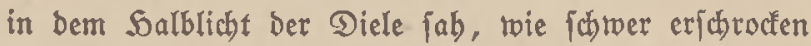
bas Mäbden war, ftellte er fich an bie Reiter und rief binauf, ob da jemand wäre; ber folle fich meloen. alber eв fam fein Qaut vom Boben berunter. Da bolte er Die Qaterne und ftectte fie an und ging bie Qeiter binauf und leuchtete alles $a b$, vom Rornboden unter ben Borber. fenftern biz auf ben niebrigen 3 oben über Den $P$ ferbe= ftällen und ben (Bang nach dem Bacthauz; a aber er fand nichtş und fant wieder berunter und jagte, fie müpten fich beibe getäujht baben, ober ez twäre ein Qaut einez Sierç geweien; und ging nach ber Gacune hinüber, wo Eggert twar, fand ifn bei feiner getoolnten 2 rbeit, ging um ibn berum, tat irgendeine Frage und ging wieder nach bem Soauje zurüct und in bie Gtube zu jeinet 3eitung.

Die anbern im Sraufe achteten ber Begebenbeit zuerit roenig, ba fie nicht mit erlebt batten. Da aber bie Nagd cine ziemliche Begabung ber Darftellung Gatte und cin (ebbafter Penfd) war, uno mit gropem Eifer und immer roachjender Ungit bavon iprach, ob 
ber Pfiff ficts wieberbolen toürbe, unb iftn miteber und twieder, in Rüche, Rammer und Etall beimlich nachmachte, murden fie allmäblich alle mitberwegt und beredeten bie Gadse. Bcjonder die Sicinen tamen in grope Snrub.

Go verging eine ziemlidte Reibe von Sagen, toobl zebn Doer ztodlf, in benen nichts geid)ab. Da ftand einez 2 bendz ber Rnecht mit Der Mago bei eben derjelben 2rbeit; Denn ungefäbr alle zebn Sage wurbe Seu bom Boden beruntergeftojen. Da tam von oben berab ber. felbe Pfiff. Der fharfe, feine, lange Laut, ber bie ein langgezogener, aber jäber Degenjtoß ourch ben ganzen Raum zucte, war taum zu Ende, ba ftand Die शago ithon mit gefträubtem Soar bor ber Nutter am Soero und fagte: fie tönne es in biejem Souje, in bem es (pute, nicht mebr aushalten, fie würbe feinen 2lugenblid

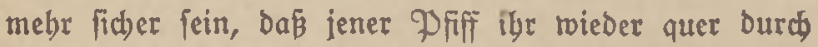
bie 2 rujt fabre; fie bäte um ibren Lobn und toolle gebn. Die Eltern tamen beide beraus und fragten ben Rnecht und bie beiben Rleinen, bie zufällig auds auf ber groß̈en Diele gervelen. Die beftätigten alle brei bie Tat;ache. Sa, es raäre gand beutlich uno genau fo trie

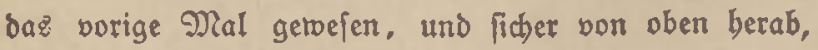
und zwar fhiene es ibnen, es fei bon der Geite, wo über ben Rälberftällen daz viele Berümpel läge, herunter = getommen, oder viclmebr: ei pon jener Etclle ber auzgegangen unb bätte fid) Dann über Den ganzen ßoden berbreitct. Da ging Der Yater mit langen Edritten burc Den Pferdeftall nach Der Gdeune binüber uno fand Eggert bort bei feiner gerobnten 2lrbeit und redete ibn an, wie baz vorige Nial, Dodb fo, oaj er ibn bies. 
mal fragte, $\mathrm{ob}$ er vielleidjt einen Nenfdhen hätte über bie Soffitelle laufen jeben. Der fiüttelite aber ben Ropf,

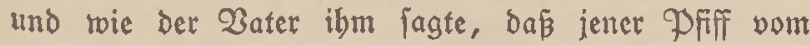
Zoden ber fich roiederbolt babe, bob er bie Gdjulter, als trenn er fagen twollte: Darüber fann id nichts jagen ober: baz weís der Seufel - und fubr in feiner $\mathfrak{A}$ rbeif

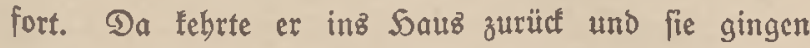
alfe - bic Nagd aus lauter 21ngit, bamit fie nicht allein unten bliebe, auch mit — bie Leiter binauf, burchjud)ten ben ganzen Zoden und fanden nichtż. 2ln Demjelben 2beno verliés die Mago daz Sauz. 2ln ihre Gitle trat eine, die an Den Ohren und an ber Eeele balbtaub rar, und, toie es folien, bie 23 elt für noch tauber bielt; Denn fie ging famm und teilnabmlos ibrer 2lrbeit nad) und Eümmerte fid um nichts weiter.

(Einige Sage-nach biejem zweiten Pfiff tam eine Sochter, Emma, fünfzehn $\mathfrak{J a h t}$ alt, ats eincm andern Rirchpipiel, wo fie ein Sahy lang bei einer Souszfrau in Rücbe und Rinderftube Dienjte getan - um SInterjwicd lennen zu lernen, bie man zu jagen pflegt - ins Eltern= baus zurüa und wirtjdaftete barin z'wijchen Nutter uno Ragd. Sie twar ber 3rillitig von bem Bruber Reimer, Dem Büd)ermann, uno war bager, Dod) twoblgeformt, und batte bei fhlichtem blonden Saar und Dunflen fhöngebogenen Brauen und langem Gefid)t wunder: faböne Farben, aus Denen ifre 2lugen wie eine fanfite, fobstne und ftille Flamme friedjam und rein in bie Welt faben. Gie war nämlich wie ibr Bruber Reimer, ibs 3rilling, ein zartez Bemüt. Shre fleine Geele rourbe immerzu von Grenifen, Die ßrüber. 
bie fie in ber blauen Luft, im Grau des Regenbunftez, im Feuer bez Serbez uno in fhroärzelten (Dunfel des Winterabends por fíd) fah. 2Ils fie ein tleinez Rino trar, fo fieben Sabr alt, fand einer ber Zriuber fie an einem Dunllen traurigen Regentag, trie fie auf ber Gteinbrücte am Sauje Eauette und einen mittelgroßen Frofih gegen bie $3 a n d$ rarf . . . einmal ... ztweimal ... Dreimal ... und Dazu murmelte. Gie fragten fie vermunbert, roas fie da mache. Gie jagte, fie roolle mal feben, ob biejer Froid nicht ein Rönig ober boch ein Pring träre. Wenn fie ibn gegen bie Wano mürfe, unb es wäre ein Pring in ibm, würbe er fid vermandeln. Go lebte fie von Bilbern, bie fich auperbalb ber Wirt lidtfeit vor ibren inneren 2lugen berwegten, und toar vor biejen Bilbern ftill und jab ibnen verwundert und finnend nath. Slnd allmählich, ba bie/e Bilder immer feclifh blicben, nie Wirtlichteit nurben, lam eine leife Gdtrer. mut über fie, fo in bem Befübl, alz roäre fie irregegangen und in ciner bertchrten Welt. Dieje Gditwer. mut blieb aber ben 2lugen der Nenichen nod) verborgen, ba fie ja nod) in jungen Sabren war, ba ber Nenid noch nidbt fidter und ballig in feinem Weicn bauft und bie (Broßen ifn auch nuch überbältigen und ibm und feinem $23 e j e n$ in ihm zu fhtweigen gebieten. Gie fdien fid aus ber Befchichte von Dem Pfeifer - fo nannte man im Sauje das Wefen, pon Dem jener Son aus. ging - bie man ifer natürlich fofort und mit fobon unrubig geworbener Gecle erzäblte, nicht viel zu maden. 2ber nach einigen Sagen, als fie in ben Racbbarbäujern umber ibre früberen Gøulgefäbctinuen begrüït batte, 
fam fie boch untubig nach Saur. SInd als am Gonntag. vormittag Darauf ibr 3 ruber Sarm, Der 3immermann, nach Saufe tam, fuchte fie mit ibm allein ou tommen und ibn $b^{\mathfrak{u}}$ fragen. Sie traf ibn, rie er in ber talten frifhen Früblingsfonne neben ber Sauztür ftand, unb erjäblte $i b m$, Dá̉ Die Nago, die fortgegangen rar, too fie ginge uno ftände bon bem "Pfeifer" fpräche, und

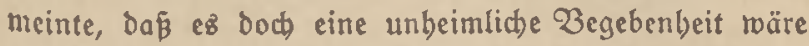
und vỏlig rätjelbaft. (Fr fab fie von ber Geite an und

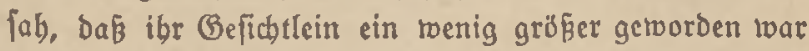
und einen weiden Gdbroung betommen, und füblte, wie febr fie unberwandert war in oer $\mathscr{W}$ elt und ibrer Üngite und fich oor ber eriten 2lngit fürchtete, uno redete ihr gut 3u und meinte: es märe roohl irgendeine शatur. erjocinung getwejen und rürbe nun robl nicht roieder geideben, und fie roüroe fich benn bald berubigen. Sie börte ibm mit gropen, nach allem in ber Welt fragenden Uugen gu, und bing fich an fein $W_{0}$ rt unb berubigte fich.

2ll ber 3 ruder fortgegangen war, da die Mutter ibn rief, und fie ba nod ftand, fam ber junge Sinedit ums Soas und blicb in einer Entfernung von ifr fteben und fab libers Land. Da verbarte fie, wo fie fitand, und redete bics und das mit ibm. Eie batte gleid bei ibrer Rüctebr ins Soaus erfabren, daß́ er fleiß̧ig und in allem feltfam getranbt twar und ein immer frcumblicher und bilfabereiter Nienfch. Befonders bie Rleinen liebten ibn, weil er ibnen allerlei Gdynurren und (Ecidbichten erzäblte. Eo batte er einmal, als er am Bactlbaus cinen biclen 2lft burdfägte, gejagt: fie pollen fich mal alle unt ibn verjammeln, er würbe iGnen 
gleich etwas zeigen, twas nod) niemano auf ber 2 Belt gefehen bätte. 2llz fie ilgn frogten, wober es bent erfcheinen würbe, in ber Luft ober von ber Gdyeume ber Dder bom Sauje ober gar aub der Croe, batte er gejagt, Daz molle er nicht fo genau jagen, damit ibre Über-

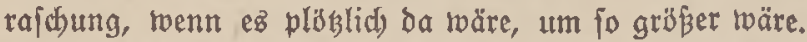
Und batte fie, obne im geringften zu lügen, fo neugierig gemad)t, daź fie mit alugen twie Seetaffen $u$ m ibu geftanden batten; und da batte er Denn, alz ber 2 lit Durd)gefägt twar uno auzcinanber fiel, auf bie beiben Gdynistfläd)en gezeigt: das wäre ez ... Das bätte noch fein Renfis auf ber Welt gelehen! Ein andermal hatte er gefagt: ob fie das grope Sier fennten ... Das

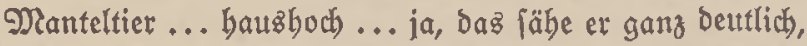
ie nadjom, wie er fich binftelle... Ia ... wenn er fo fiände... Dann fäbe er es nicht . . a aber wenn er fich fo fitelle, bann tönne er es feben ... und er ftellte fích fo, bå er an ber alten Edheune vorüberiab. Ia, es bätte

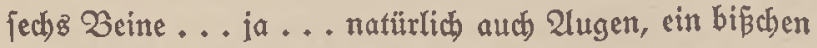
trüb freilich. Sind er malte es alles aufz genautepte aus und fab an ber alten Gcheune vorbei. Sie aber faben

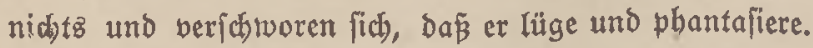
Slno nachber war eb die alte Gabume jelbjt, bie ibnen mun in ber Tat plöblich ... mit $i b r e m$ ungebeuren Echindelbach fajt bis auf bie Erbe und ibren fhlweren Mauerrippen, fects an jeber Geite, und den trüben Genftern wie ein gropeses Tier eridjien. Goldhe Edherze Fannte er und madbte er viele mit ihnen, indem er

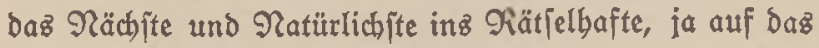
Gebiet Des $\mathscr{Z}$ underbaren verferte, und fie Dann, inden 
er esి plişlich wieder an feiner ordentlichen, bellerleudjteteli Gtelle auftaucben und ericbeinen lieb, in Berwunderung feste. Fr mufte peine Bejhidsten immer wieberbolen und wubte immer neue, und fie twurben nicht mübe, ibm zuzuhören, und er nidbt, ibnen zu erzäblen. alles bas batte fie von ibm gebört und es batte ibrer freuno. lichen Heinen Geele gut getan. Dazu batte feine figur,

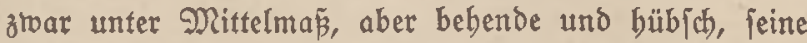
Hare, cole Gtirn und füblid)freundiche Gprache ibr jeltjam gefallen. 3ulest - bieje Dinge fann fein Denich bis auf den Grund erfennen - modbte ihre Geele daoon erregt werben, dá er dies Ieidte Sinten batte, das ibrem phantaftifben Bemut wie eine Serftellung, wie eine Dertleioung, ober boch, bei feinem feinen Wejen, wie eine Frniebrigung eridheinen modte. 3ulegt batte fie, eine fleine Eva wie alle, toobl gemertt, baj er flare, fragende, fucbende 2ugen, getwiffermaß̄en twie aus ber Ferne, auf fie richtefe, fobalo er ibrer anfichtig wurbe. Rurz, fie trar ibm, in ibrem findlichen, jungfräulicben Serzen leife zugetan und roar guter Dinge, fröblich und glüdlich, wie fonft nicht, toenn fie mit ibm fprach uno ifn anjah, uno fab, wie er fudte; und war bes allen bölig unbervust. 2llo erzäblte fie ibm nun, toas die Tachbarn rebeten.

Er fam mit feinem leichten Sinfen näber an fie beran und fagte: "Sa ... es ift etwas mertwüroiges uno rätjelbaftes... wer fann es raten? 2uch ich zerbreche mix ben Ropf, mas es toobl fein fönnte, was da efwa berauşfकauen fönnte. Erit dachte ich, es wäre irgend.

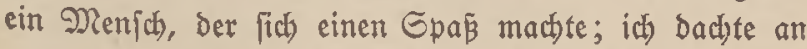


Den Eggert, Der ja jo gut maultronmeln und fibten fann, und id mertte robl, Dak ber Reifter . . Io nannte er ben Bater - Dasjelbe Dachte. 2lber Der Eggert ift ez nidt; Der Eggert rar beibemal in ber Gcheune, er ift auch viel zu ernit baß̧u, um einen fold)en Poffen zu fpiclen. Rein, Dazu gebört cin $\sigma_{d} d m$, und waż für ein ge= mandter! Nein ... wir bier alle im Sauje ... mir baben ez nich)t getan; wir finb ja faft wie bie lieben Sociligen, Die auf ben Qltären fteben und nicht ein einzigez $\mathfrak{W}$ örtlein fdrbätzen. Slnd fo dente ich wie Starm: es ift vielleicht ein Bogel gerefen, ein feltener, ber fonft zur Winter: zeit megfliegt, aber biesmal, weil er fid in ber 3eit berrechnet, bier im Lanbe geblicben ift, und im WBinter. traum unb recil es ifm gar zu langrweilig ift, diefe Söne ausftobt. Was meinit Du Dazu?" Ulnd er läh)elte und fab fie mit finen fdmuten, lebbaften 2lugen an.

Jhr gcfiel daz Wunder, und jeine 2ugen nod mebr; fie batte fie nod) nie fo nabe geichen. (Er batte überbaupt noch) nie fo allein bei ibr geítanden und mit ibr allein geredet. (58 murde ibr gar trarm ums Serz; und fie meinte: daz tönne ez wobl gelvejen fein.

"Waz geichicht nicht allez??" jagte er. "(Ez ge= fidshen bie rounderbarften Dinge. 2l(z idh vor ztwei Sabren im Winter um biefe 3eit auf einem Bauernbof in Offfriczland biente, too ztwei ältere twunderlict) Qeute

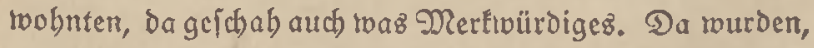
Dente bir, bie Rübe wunderlich! $E_{z}$ fing in allen (Ecten bes Gtallz, ja in ben Bäuchen Der Rübe, an zu rumoren und zи murmeln. (Es geichah immer beim abenomelten, im Dunfeln. Sch babe feibjt oft genug gebist; Denn 
(ih) twat meift babei. (Es war zumeilen wabrbaftig io, als toenn bie Sühe rebeten. Du tannft bir benten, wie bie beiden शä̈bden, bie ein wenig bumm uno taprig twaren,

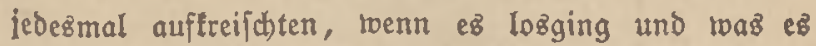
tiberbaupt für einen Lärm und ein Berede gab."

Gie batte atemlos gugebört, Dic fanften, gläubigen 2ugen voll auf feinem (Beficht. "Slnd was wurbe baraus?" fagte fie.

"Эa, twas wurbe baraus?! Esz gab viel 2uffehen und Geidnäł ba auf bem Sof unb im ganzen Rirdipiel. Die meiften lachten und madhten fidh über Den Sof ein twenig luftig, ber jo ein bißshen berichimmelt twar, fo ein bischen langtweilig, weißst bu, und ichläfrig. Benug, es gab eine orbentlide tleine Seg. Sth ging bann weiter und weiß nicht, twas Daraus getworben ifit."

Er fab fie forfchend und fragend an, fo als ob er jagen roollte: Veritehit bu mich?

2ber Das Mägdlein twar in biejem 2ugenblia gand anders befangen; ez tlang ibr gar zu fanft, Dás er fie bu nannte, gumal er bas $230 r t$ getwiffermaḱen mit reiner, borfichtiger Gtimme autziprach, uno ez rar ibr gar beimlid und roblig, da备 fie nun aud ibn fo nennen tonnte. "Du bift roobl weit umbergetommen," pagte fie.... "wobl butch ganz Deutfalland? $\mathfrak{W O}_{0}$ ift beine Seimat?"

"Sक bin ganz oben vom Rbein," fagte er, "auts Den Zergen an ber Gdweizer Grenze; aber meine Brobmutter wat vom Rieberrbein uno ber bin is alynlich und babe von ibr bie Liebe zum ebenen Land; und fo bin ich in biefe Gegend gefommen, erft zum 
Onfel nad) Sëln und baberum, und bann inmer taciter biz bierber."

"Wab rar bein Onfel, ber bich aufnahm?"

(Er lah fie mit einem langen Blict an, in bem ein vornebmeş uno ein wenig bangez Bitten und Fragen

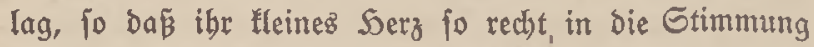
fam, in ber eż war, alsె fie ben Grofh) an bie $23 a n d$ warf, und getwärtig war, er wäre im allernäcbiten 2lugen= blicf ein Prinz, und es ganz warm und itfer bie Má̄en froh murbe. "Sch fage es jonft feinem," jagte er, "aber bir mödte ich ez freilich fagen. Ez if nichtz Ģlimmez... Dá̧ Du daz nicht Denffit! 2(ber ez ijt ein 2 eruf, ber bejonderz bei ben $\mathfrak{B}$ auern beradfet ijt. Mein Onfel zog roeit umber, won Martt zu Martt, von Röln bis uach Siitland binauf, und ich ơg mit, und ez ift nicht un= möglich, baj ou mich fchon mal auf eurem Sabrmartt gejeben bajt ... Mein Onfel“ und unfid)er - "batte cine Wunderbude."

Gie ftaunte und murbe langfam rot, baß fie bier mit einem Meniden itand, ber ein Leben gefübrt batte, bas ibr fo fremb, ja fo unbeimlich war. 2ber fogleid, im felben 2lugenblict, wäbreno fie erribtete, getwann roieber Daz andere Befübl bei reitem die Sberband und twurbe

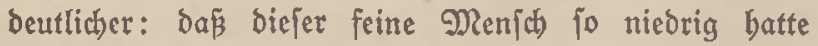
leben mît fen, fo da $\tilde{\beta}^{\text {fie }}$ nun nod) einmal errötete, aber nut vor Greube, dap fie ibm belfen und gut mit ifm

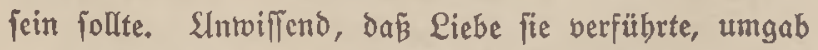
fie ihn im $\Re u$ mit allem Gchimmer ibrez guten phanta. fifichen Serzenz. Sie fah ihm mit einem unjäglich f̧jönen, bertwirten Blanz in ben 2lugen an und fagte 
Leife, alz twenn fie bas beiligfte (Gebeimnis trug: "Dut tannjt bich barauf verlaffen, Daß id) ez niemandem jage," uno mit zartem (Eifer feste fie binzu: "Slno aud) bu musit ez feinem Menjuden jagen. Die Qeute verjteben bier fo ctwaz nicht."

Die Eüptgteit ibrer Etimme und ibrer \&ugen über= wältigte jeine lebendige rbeinijd)e Ratur. Er bolte jäh und tief 2ltem und fagte mit feuchten 2ugen und mit 3ittern in feiner bübichen, rocichen Gtimme: "Id) bin immer, von Rino an, unter fremben Leuten gewejen. Du bift ber erfte Menf(h), Der wirflid) gut mit mir ift. Ulz ich) ein Rind twar, war bie beilige 2lnna lieb mit mir, bie in unjerem Dorf in ber Rirche am 2lltar ftand. Der bift bu äbnlich, und id babe bich fo lieb, mie ich jene batte."

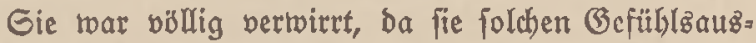
bruch) durchaus nicht Eannte, und bas heilige Wrejen, bas er ibr genannt batte, ihe vollig fremb roar, und fagte mit ftoctenber Etimme, räbrend ein Befühl jeliger Freude Durch ibr fleinez Soerz fubr: "Id) bab” ez roirflid) fo gemeint, wie ich ez̊ gejagt babe!" Slno ba fie weiteres nid)t ertragen bätte, fagte fie: "Slno num rill id bincin= gebn ....ez wird falt bier braukent." Slnd ging.

Rach etwa einer $\mathfrak{W o c h e , ~ w a ̈ l r e n d ~ n i c h t z ~ v o r f i e l , ~}$ waren ber alte Sagelöbner, ber feit oreifig Jabren auf Dem Sof arbeitete, uno ber Rnecht im halbounfeln Gtall Dabci, Die Pferbe zu ftriegeln, wäbrend Emma unter einer $\Omega u b$ fafi, bie gefalbt batte, und meltte. Ganz an anbern Ende bez Gtallz ftand Reimer, ber eigentlich ben Foblenfall ftreuen follte, an Dem Eleinen balbblinden, 
pinnenberbangenen Genjter und las in cintem Duch beuticher Gagen. Da tönte bon oben berab trieder Der Priff.

Reimer, am Ende bezి Gtalls, auzి ber Ticfe feinesి Buches jäh aufgeidbrectt, fdhrie laut auf; auch ber alte

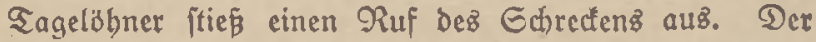
Rnecht, nur ztwei Dferbe von $i 5 m$, ftand aufred)t und wartete einen 2lugenblid ... io, alz wenn ex weiteres ertwartete. 2llz aber allez fill blieb, fprang er aus bem Futtergang und juchte nach Der Gtelle zu febn, wo Emma bei ben Rüben raar, fah bin, und rief in plög= licher, fdhredticher 2Ingit ben Tagelishner und lief Den Gang entlang.

Das junge Ding ftand aufrecht und biclt mit ber linfen Sand wie im Rrampf bie Ratte, die etwa in bet

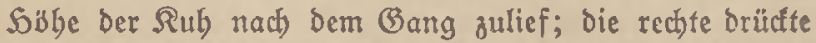
fie feit aufz Sorz. In ibrem tobbleichen, veränglteten (Beficht und ihren farrenben 2 ugen fab man, roie fie fich) mübte zu fhreien und fu geber, und rie grof ibr

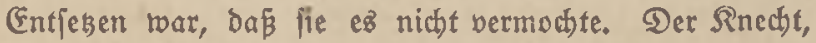

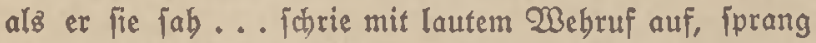
binzu und faşte fie an. Nun liefen auch ber alte Tages lobner und Reimer heran. Gie nabmen fie in bie Mitte und bracten bie Willenlole mit porfidtigem Drängen aus bem Gtall über bie Diele nach ber Gdjlafitube, too fie unter Dem $23 e b l l a g e n$ Der Mutter uno bem fetmerz* vollen (Befidjt Dez Baters aufz Bett gelegt wurde.

Diezmal machte fich nur ber alte Tagelobner die

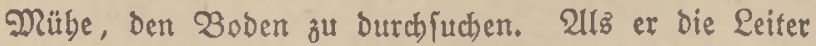
wieber berunterfam, ftano ber Bauer da an ber offenen 
Sür ber Diele und lagte mit heiferer Etimme: "Du... wo ift Eggert? Meine Grau fagt, ex ift nach ber Nühle -; aber id feb' ibn nid)t auf bem $23 \mathrm{cg}$... too ift er?"

Der Ulte fagte, er riffe es nicht anderz, alz ba er zur DRüble gegangen wäre... "Id) rill mal nad) Der Gabeune binübergebn uno nachlebn," jagte er.

(Fr trabte binüber und fam gleid) wieder und melnete: "Er ifit noch ba und beim Füttern... ex rwill gleich) "ach der Mlühle gelyn."

Da fam ein 3 ug unenblichen Leibez und $\mathfrak{B e b s ~ u ̈ b e r ~}$ bas fitlle, lange (Beficht bez Bauern; er rante fid $a b$ und ging roicber nach ber Etube zurüd und fetste fich an $D_{a B}$ Bett feines Rindez, Da\& zwifchen Obnmacht und Salbidjlaf in wirren Sräumen zudte, und blieb ba bie Pacht, bie tleine, immer wieder bebende Soand in feiner gropen Urbeitshand. Wenn feine Grau ibn ans rebete und etwas jagen wollte, fah er fie mit abwejendem (Befic)t an.

$21 \mathrm{~m}$ andern Norgen ftanben bie Rinber in Saufen berftört in ber Rühe. Der Rnecht ftectte alle balbe Gtumben ben Ropf in bie Rühentür und fragte, twic es fründe. Gein bübides (Befidst toar totenblaß̧ und in

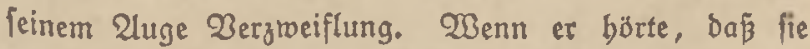
now immer fo läge, traf es ihn wie ein Gallag, und er ging wieder. Eie runderfen fich weiter niकt barüber, ba es zu feinem ganzen $\mathscr{B}_{\text {ejen }}$ paßjte, Daß er, lvie er mit ibnen gelad)t batte, nun nit ibnen in Rot roar. 


\section{3. $\Re \mathfrak{a p i t e l}$ \\ Der $\mathfrak{R} \mathfrak{e c h} \mathfrak{t}$}

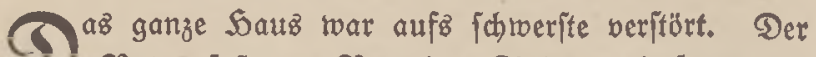
Zater fá am Bett bez Rindez und jagte fein Wott. Die Mutter nabm fich zujammen, folange fie neben ihm ftand, tröftete und redete iftem Mann uno ben Rindern Nut zu; wenn fie aber in bet Rüche mit Dem (Beficht Dem Serd zugetwandt ftand, weinte fie, Da baż Feuer in taujend Funfen iprïbte. Die Ghar ber Rleinen jaß verídübtert in ber Rammer, bie nur wenig erwärmt toar. Reimer ging mit feinem $2 u$ th in ber Sano, in bem er nicht laz, auf ber eišalten Dicle auf und $a b$ und fitrid) fich burch bas Soar auf Dem Rodffragen. Eggert im Etall bob bie Echultern bis an die Ofyen, fagte wenig und arbeitete twie ein Pferb,

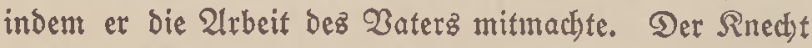

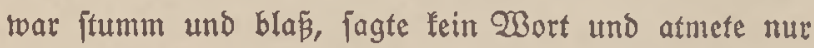
fdhwer. Seder mied ez, den andern anzujeben; es toar, als wenn er fürchtete, eв tonnte auts ben Augen oder

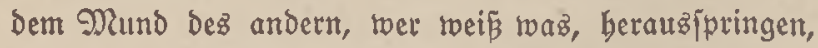
eine Sere ober ein Trrjinn ober fonjt taas. Dabei waren fie nid)t abergläubifक. Aber gerabe bies, Da fie ez nidst waren, madjte fie bilflojer. Wären fie abergläubijch gewejen, ober rid)tiger gejagt, bätten fie einen befitimmten Ģlauben gelabt, to bätten fie fidh gegen bie Ërifteinung gewelhrt. Sie bätten entweder im dhriftlichen Blauben Gott und Den Seiland zur Silfe gerufen oder im undriftlichen, ber ja noch nicht ganz auşgeitorben ift, irgendine 3auberformel gebraud)t, und 
bätten Darin, wenn nicht Silfe fo boch Salt gefunden. 2lber nun waren fie ganz ratlos, irrfen und jagten mit ibren (Bedanfen zicllog umber und entrannen boch) Dicjer Macht nicht, bie bod) fo flein war, bie nid)tz war, als ein nicht febr lauter, langer, bobler Diff, ber aber butch feine Sorkunft ats we jenlofem Raum und burd feine bobe, eintönige, finn= und feelenloje art die Dhantafie zerrí̄.

(E⿱ w wäre vielleicht beffer abgelaufen, ez wäre irgend= toie eine Qojung Der Epannung eingetreten, wenn ber rechte Pfarrer ober Qebrer im Ort gewejen wären. 2lber Der Paftor, zwar ein ermiter und tüthtiger Nann, litt oumeilen an eirem 3ujtand ber Rränflichleit und $\mathfrak{B e r}=$ büfterung und batte mit fids felbft genug zutun, und ber Echrer war zufällig ber Menfchenjeelen nicht fundig uno läufig. Slnd irgend ein anderer Nen[ch, flug, gütig, feurig, Der ein Recht batte ober ez fich nabm, ben verwirten, fchwerfälligen, ungeidictfen Menjchen zu belfen, war aud nicht ba. Tie vielen aber, benen bie Not ber ebren= werten Gamilie leio tat, brachten ez nicht über fid), ibnen Diez fabine Gefübl, in bem joviel Sroft und Gtärfung liegt, zu befennen; fie füblten aud) Dem verztwickten, rätịls vollen Fall gegenüber ibre völlige Ungeichictichleit. Die. jenigen, die mit einem Blied Der Familie zufammentrafen und ein $W_{0 r t}$ jagen musten, umgingen entrpeber bie Gache ober redeten diez oder baz über fie, worin nichtz von cirmunterung lag, roobl aber 2 efchëmung und Mebrung fowobl der SInficherbeit wie ber Not. Die meiften, Die ferner ftanden, begleiteten im Borübergehen ibren ftummen Grú̃ mit verijhloffenen Gefichtern oder gar mit einem Yeijen, roeijen uno (pöttijđjen Lächeln. 
Die SMenge bez Rirchipielz berebete in Gtuben und Gtällen, je nach) $\mathfrak{B e r j t a n o ~ u n d ~ ( B e m u ̈ t z a r t , ~ b i e ~ f e l t j a m e ~}$ Gahe mit Getheneit oder mit 3edauern ober mit Brauen; und fuchte fie mit allem Eifer zu ergründen. Die Rlugen und Ralten unter ibnen tamen etwa gu dem

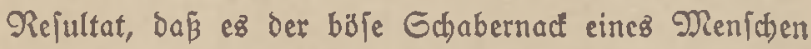
wäre, der in befonderer Weife feine eigene Gtimme von fic) entfernen lönnte', und ricten dabei in vorfichtiger Weife bald auf Eggert, Den BarfüB̈er, Der bei Den Rublvigs berfebite und bie Maultrommel ppielte und ifnen in manctem ein Rätfel und fremb twar, balb auf Den Rnecht und bald auf bie taube Nago; die Epiele=

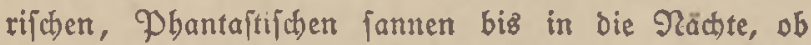
und wie fie eine vollig neue und feltjame frtlärung fänden, bie ber Ratur und ibrer Runde oder ben Wunder geidhichten aller 3citen eine netre Enthecfung binzufügte; die Etillen und Sinnigen - und das roaren robl bie meifter, (d)on weil bie Rinder in ber Mehrzabl waren - glaubten,

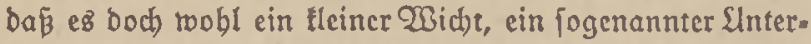
irbifcher märe, wie fie nach uraltem (Blauben, Dem eigentlich alle noch) trauten, im Dachgebälf und Den buntlen Gtalleden aiter (Bebjifte hauiten, und iprachen von "Dem Pfeifer" oder "Dem Hleinen Pfeifer", als twüß̈ten fie fither fein Wefen uno (Bcljaben. Und es gab in ben Rinderftuben mand) einen leijen 2ufichrei; uno grofie 2lugen [aben noch lange ins Tunfel, uno faben es voll rätjelbaften Lebenż. Soarm, Der Simmermann, Der am britten Sag, bem Gonntag, rieder nach. Sauş fam, Durdfuchte nod ein= mal fundenlang ben Koden und bas ganze Sauts. Darnach fragte er in feiner etwas fchrweren, gründlichen 
nnb orbentlichen Weife bie, weldhe dabei gewefen. Der Rnecht uno Der Sagelbhner erzählten ibm allez, roaz fie gebïrt und cmpfunden batten, rourīten aber nichts neuez binzuzufügen. Eggert jagte aus feiner troßigen Stimmung

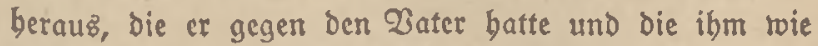
Fis in ber 3 ruft zu fteben faien: "T3as foll id fagen?" unb er fubr fich, wie feine Mutter es tat, mit jälyer Sanbbewegung über bas rotblonde Saar . . "Еళ gibt

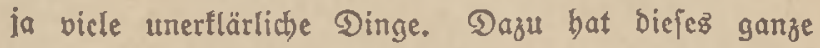
Saus twas 2 bifiges uno Nuffiges; aljo ift bier ja ber rechte Ort für foldhe Dinge. $I m$ übrigen reif ich nicht, Ob man bem Snedjt trauen Darf. Nidjt, Dá er fdlecht

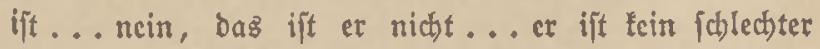

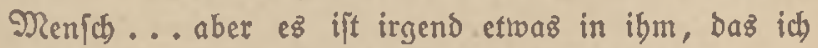
nicht raten fant. S屯 perjtebe z. 3 . nicht, warum er bier bei unz ift und leben mag... mit ben sindern bat er ja freilich feinen $\sigma_{p a \beta}$ unb von Emma bält er ficher biel ... aber ez ift doch flar, dá̉ er fo ganz anders if́t twie twir, und Daß̧ er uns mit 2 ertwundes rung beobadtet... Go, und das ift alles was ich benfe,

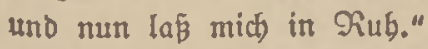

Da ging Sarm nach Der Etube zutrü und feste fich) neben ben Bater an bas Zett, daz in bie $230 b n$ ftube gef́tellt war, uno fagte, twas er mit benen draupen befprochen bätte; und jagte fo bies und bas, was die beiden ermutigen follte. Slnd fagte Dann auch: ob es trobl möglich wäre... ob fie nidbt auch auf Den Be. Danten gefommen wärcn, Den Bruber Eggert vorbin auşgefproden bätte: ఏaß ílimme Gdelmerei pon Dem Rnecht wäre. 
Der Bater zucte auf und fhivieg eine Weile und jagte bann mit Garter, bittrer Gtimme: "Eo ... 10 ... Eggert bejchuldigt den Rnecht. Wo hat er benn irgends wie einen Betreis bafür? Slno wie follte ex ez ansz fübren, ba er boch mitten unter ben anderen ftand?" Die Rranfe, bie num etras rwacher und rubiger getworden war, fhüttelte nit groß̄en vortwurfzoollen 2lugen Den Ropf, als wenn fie fagen wollte: ,Der? ... Der gute, liebe Menfch? Der? $\mathscr{D a}$ gab er ez auf, diejen $\mathfrak{B e r}=$ bacht weiter zu erörtern, uno fing an, ihnen auseinander=

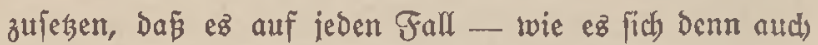
erfläre - eine natürliche Errfbeinung wäre ... felbit = veritändlich! Slnd $\delta a \tilde{\beta}$ fie fich nun entrveder nicht twieber= bolen rwürde, ober aber, roenn fie fid twiederbolte, fid ser eines Sageż, und ztwar bald, aufgetlärt und aufgebcčtt

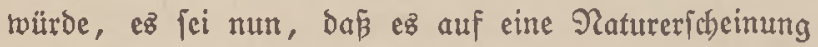
ober auf eine menfdhliche Bosbeit binauzliefe. Slno barum follte bie Gdumefter ibre Heine Geele boch pöllig berubigen und aus biejer inneren Gidherbeit und $\mathfrak{B}_{e}$ rubigung beraus von $\mathfrak{S a g}$ z̆ Tag mehr gefunden.

Die Eleine Rrante Görte Dem Bruber, Den fie twegen

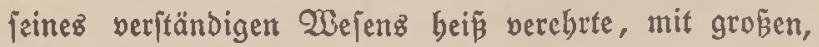
ftummen 2lugen $z^{u}$, und man mertte, wie bie Worte ihr gut taten. Die 2lugen befamen wieder mebr den fitllen, fanften Gdbein, Den fie gebabt, und bie zierlichen Wangen wurben leije rot. Gie lag, nad) bem er gerebet batte, mit meniger gejpanntem und geängftetem Beficht und mit rubigerem 2ltmen in ibren Riffen und bordste auf Reimer, ber ibr mit leijer, aber reiner uno fejtlid)er Gtimme ein ettwas langatmiges Früblingslied 
borlus̆. Slnd als am felben Mbend Die Mutter, Da fir ibr Bett für bie शad)t bereitete, ibr in einem ftürmijo)en 2usbruch ber mütterlid)en Liebe mit beiß̄ herborbred)endem

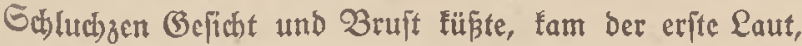
ein fanftez Gtöbnen aus ibrer Seble uno Dann bie enften (d)wad)en 230 rte.

Dieje frobe Rachriatt berbreitete fich rajh Durchs gange Saus und alle finder famen ber Reibe nach an ibr Bcttlein, um ibr bie SHand zu ftreidjeln. Der Rnecht aber lié im Etall, als er eş vernabm, bie Forfe fallen und fabrie auf und fam mit jeinem leidhten Sinfen in Die Gtube gefdyolen, trat an ibr. Bett und jagte, über feir ganzes bübjhes Befitht jtrablend, twie trunfen von ihrer Gejundung uno von bem, waz er fagte: "Sörc, Elein Emma, licbes Rinb! Gagte id) Dir nidft jubon,

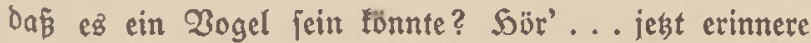
ich) mich gans genau, was ich einnal in meiner Seimat gebßzt babe ... i ch habe brei शächte barüber gegrübelt... ich babe es immer bin und ber gewand in meinem Ginn ... Ith babe einmal gehört ... es gibt einen Heinen 2logel, einen Retbbetwohner... jo von Der 2let ber Robrbommel, aber viel fleiner... Der foll für getröbnlich ausibandern... 3ttweilen aber, fagt man, rirb ex burch bas weiche Wetter verlocít zu bleiben, uno dann ... wenn ber falte, fharfe Wino einfert. . . Foll er in bem alten Reth Des Sattzobachs Gduuts fuchen... und fich barin vertriechen... und wenn er nun aufs träumt, fo in feinem Edlaf... tann ez nid)t fo ge= wefen fein? ... dann fdreit er laut und lang...

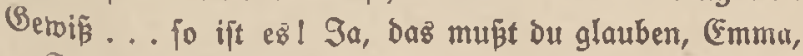
Frenife, कle Briber. 
liebes Rino! Du mußst benfen: ei, der fleine träumende Yogel in unjerem $\mathfrak{D a c h}$ ! Sa, das muft du Denfell, wenn einmal wieberfommt. 2(ber icl) glaube fait, eв fommt nicht wieder; denn, fieb, es gebt ja ichon ftarf in Daв Grübjabr binein ... Er wiro feinen Gdjlaf uno feine Iräume von fich gefdüttelt baben und fich bavon gemad)t baben." Go (prach er in feiner zierliden, rajhen alemanniן⿲丿丨 2 eife.

Gie hörte ibm mit blanten 2lugen ${ }^{u} u$, daz lange, edle (Bejicht boll ichweren, füben Ernitez und faft Feier. licjfeit, fo als trenn er igr cine goldene Rrone auf Die Decte legte.

$\mathfrak{A n}$ biefem abend fprad ber Rned)t beim $\mathfrak{A}$ bend $=$ brot Davon, dáp er einen 3 rief bon feinem Onfel aus RoIn befommen bätte, Der ertranlt wäre, und Dá̉ er 100 bl Dabintreifen und feinen Dienit aufgeben müffe. Er

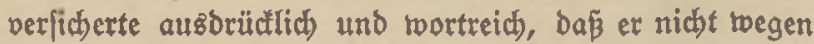
Der elenden Pfeiferei fortgebe; bas traue igm auth wobl niemand im Sauje zu. Fr gebe, tweil fein Ontel ernftlich ertrantt wäre unb nach ihm gerufen bätte und weil $\mathfrak{e r}$ cinfabbe, Daßj fie bier auf Dem Sof jest auth obne ibn fertig werben tônnfen, Da bie Siere aนช bem Gtall tämen.

(Ex pacte Dann an einem ber näbjten Tage feine Gad)en, ging nod mal inz Dorf und faufte für jebez Sino einige Rleinigfeiten und fant zurüa und verteilte, tras er getauft batte, an bie Siteinen. Dann tam er in Die Gtube zu Emma, bie nun ichon am Genjter im Qebnitubl faß roie ein Grofchen fo gró, auf bie Rniedecte und bat

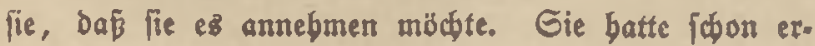


fobren, daßj er fortginge, und weinte beimlid barum uno เoubte nicht, เoaz ez mit iģr war. Gie nabm baz Serzchen mit freubigem Erröten in Die blä getworbene Sand, fah ez an und freute fich über bie edfe Frorm. Zber bie Mutter, crfabrener, fah, Daj es edtyt twar, und fagte mit Zertwunbern, obgleid) fie fid mit ibrem Rinde über feine Freundichteit freven wollte: "Das baber Gie nidyt im Dorf getauft."

"Prein," fagte er offen, "Das babe ich aud nicht. Sch babe ez von meiner Edjwelter geerbt, die jung ge= ftorben ift und bic id nidft gefannt babe. Shb bitte bie

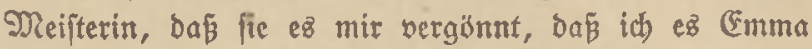
zur Erinnerung folbenfe, oa ich nun reggebe." Dann trandte er fich wieber zu ibr und lagte: "Oent" an ben fleinen Sogel im Reth! 3reiffe Darin nicht! S Ind fo roerbe rajh wieber gefund und froblich..." Ex mollte noch mebr fagen, aber ez brachen ibm Sränen berauš. (Er füpte ibe in plöslichem überiftömenden Gefübl bie Band und ging binaus.

In ber Riidbe fagte die Mutter, bie thm in Berroirung nachgegangen war, aus freundlichem Serzen, ex ntödte boch einmal twieder von fid) bibren laffen. Sie bätten ibn alle gern gebabt. Uud fie meinte.

(Er veriprach) eB. "2lber erfit nac) Sabren," fagte er. Slnd nod cimmal, mit groperem शachbruct: "Pla屯 Sabren werbe id) won mir büren la\|en, Meijterin! Erit etroas Südhtiges fdhaffen, Deifterin; und älter uno ver: Itändiger twerben! Dann roifl id) nod einual wieber

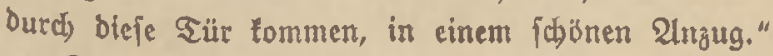

Damit ging er. 
Ez fam aber nicht [0, wie Der Sinecht und fie alle gemeint batten. Daв Wfeifen freilich, Daв ja j(h)on cine Wadhe gefdrwiegen batte, fhbieg aud tweifer. 2lber Der 3utand Emmaz blieb betrüblid). Shr Sizrper ge. wann ztwar bald wieder bie ichmale Etraffbeit; aber bie freilich nicht iđhweren Rrämpfe, bie gleid) nach jenem Ereignis cingetreten waren, wieberbolten fid) alle vicr

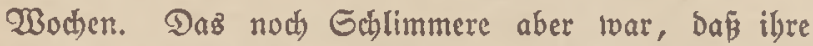
Ecele gleichgültig gegen bie Dinge und bie Garben un fie rurbe und in ein fotwermuitiges uno finnierendes Weien geriet. Die Anlage zur Gdjwermut, bie von Saus aus alz Frbe pom Bater in ibr toar, fam num zutage uns rurbe allen fichtbar. Der Sincht war

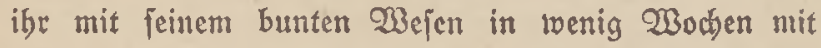
binreísender Getwalt bie Gtelle getworden, wo ihr bie

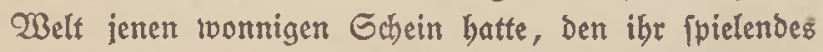

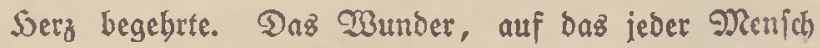
wartet, Daz cr nie fiebt, folange cr lebt, war ibr in ifm begegnet. Slno mun war er fort... fort in bie weite, unbefannte 2 elt. Gie prach fein 23 ort über ibn; fie fiswieg audy über bas, toas er ibr bon feirem Itgendleben anbertiaut batte; fie batte baš Gefübl,

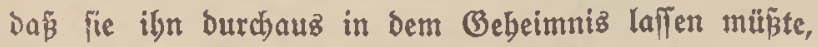
Das ifn umgab; aber fie bachte immer an ibn. Slno allmäblich nahm ínr Denfen bie Form ber 2lnflage uns Trauer an. Gie gerief in Den Blauben binein, Dá̃ et burch) (Bottez Gührung uno Weişbeit in ihr Sauz getommen räre uno eş an ibr gelegen bätte, ibm zu belfen, ibu aแB peiner Berlaffenheit, Erniedrigung und Berfapptheit 34 libjen. QUber fie war nicht treu, nicht gütig, nic)t 
wach) genutg getwejen, feiner armen, umitridten Geele zu belfen. Gie batte es verjäunt. Eo ranberte er mun trieber beimatlos in der fonnenarmen Welt; uno fie trug die Gdyuld. Wie twar es bod gefomment... nun eben... fie war nicht treu, nicht fromm, nidst gütig gemug! SInd fie begann aแz einem liberzarten und überreizfen Gewiffen Geraus in ifrem Hleinen fauberen feelis

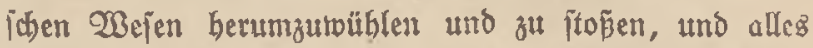
Imiauber uno unerflärlich zu finden, und fich fictwer an= zutlagen, fo, als twäre fie trichts wert und als wäte fic bon Bott unl feinen Engeln verlafīen, tmo nichts mit iff und igrem Qeben. Slno es fam ein gropes Gündengefübl über fie und fie twar traurig und betete, und ging in bic Rircte, uno gewann boch nicht Das Befübl Der Dergebung uno deళ̃ Troftes unb tveinte beimlich ftill vor fich bin. Slno bie fdyon immer ein roenig abfeitz Beftandene trennie fith mun faft ganz bou ifren Bejpielen, ja, pon bem Sreiben aller Menjaden.

Der Water war barïber bart bedriaft. Der tägliche Znblicf feiner fohmutten, zarten, gebrodhenen Sochter, bie er bejonocrs liebte und um bie er bejonders forgte, ba er mobl füblte, daß̄ fie dem Leben und Der Welt ebenjo unficher gegenüheritand, wic er jelbit, lié ibn die Lajt feiner wirtichaftrichen 2lot noch idfwerer exjcheinen. 3ur Edtwermut geneigt mie biez fein నind, fing et an, bie ganze Not, bie ifn und jein Saus betroffen hatte, mit bunfler Gecle anzuleben, io, alz roenn Sats und Familie von folimmen शRädten verfübrt und bejtraft merbe und vergeblic) gegen fie tämpfen miiffe; und cr geriet in Mtip̄trauen über ben guten Ginn des Qebenz̄, 
all ben et bisher, bom Biür begünftigt, umringt von feinem mutigen, lebenżpolfen Weib und gejuno beran. twadjenden Rinbern, tros jeines bunflen und zarten Bemüts mit einem treuhergigen Mut immer geglaubt batte. Und das erfte bäje Wert biejes Miptraueng

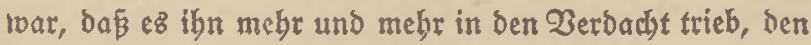
er gegen feinen Gohn Eggert, ben Barfü̈̈er, batte:

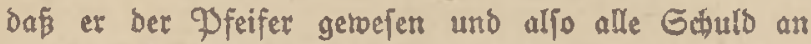
Der Rranthcit bes Rindes bätte.

Ulm bieje 3eit, cinige Wochen nach bem Weggange des Rrtedites, entfand auch im Rirchfpiel, auf lauter Mutmaßjung bin, Der Glaube, Dás biejer Eggett, ber vielen roegen feinez einfanen unb zumeilen wunberlichen ober bod) rounberlich icheinenden 23 ejens fremb und un= ertlärlid war, Der "Pfeifer" träre. SIno biejer (3laube wie es bent mit Blauben fo geht, went er exft 2luflang und 2nbang gefunden bat - peste fich raich burd und beberridate bald alle. (Es lag ja auch (brunb oor zu foldjem Blauben. Da war fein Gtreit mit feinem Zater, und jein æumfh voin Sauje fortzutommen. Da toar

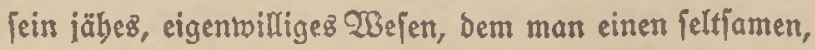

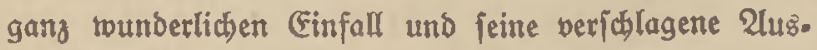
fübrung nobl zutrauen tonnte. Da war fein abendlictes

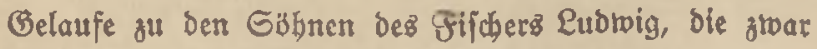
burchaus feine verrufenen Reute, aber bod) ein vertwegenes und abenteuerlictes (sejhlect)t waren. - Da war endlid) jein Dunobarmonitablajen, baş er zumeilen - fo erzäblte man... mif grober Rumft burch ein eigentümlicjes unb rilles Sremolieren und Pfeifen unterbract und unterbaltlicber mactite. Diez lebte gab ben etroa nod bor- 
banbenen Sweiflern Den Rejt. Die ganze Eacbe ijt übrigenz niemalz vülig flar geworben. Fs liegen da vielleicht nod) andere butntle Dinge vor. (Fs ifft fpäter iiber bieje ganze Begebenbeit in Der Gegend viel bin= Itnd bergerebet worden; aber bie rechte beutlid)e Sertunft bat man nidt gefunden. (Bెenug, ez fकhien Damalż, im Frübjabr 1912, allen Har ... nein, ez trar allen

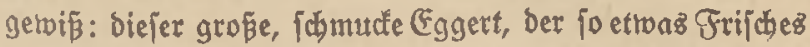
uno शratürliches gur Gchau trug, war in aller Soeim.

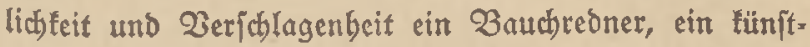
lider Pfeifer, 'ein verrud)ter Ed)elm. Er hatte bieje ebenjo bitterbije, twie unbeimliche Gade ins Werl ge= fegt, um firb auf biejem 2 ege an feinem $\mathfrak{B a t e r}$ und feiner ganzen Familie, ber er grollte, zu räd)en, uno über bie Bertwirrung, bie ex jo angerichtet, eine Belegenbeit zut finben, aus bem Sauje und von ber 21rbeit weg in bie Welt zu tommen, nach ber er fich fefnte.

Go glaubte man; und ez balf nichtz, dá̧ die Lubrigs, als fie es borten, bebaupteten, etroas OJerrüctteres toäre noch niemals gefagt worben, und jebem bringenb rieten, es ibm jellbft ja nicht ju jagen, twie benn auth fie $e z$ niemals wagen würben; benn wer es ihm fagte, rofithe im näbjten 2lugenblict übertannt fein uno bluteno auf bem Riliden liegen.

Eo bielt fich Denn jebermann roblweizliđ zurüd,

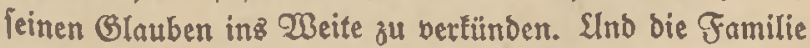
felbit erfubr nichts pon bem Gerede, uno ber Ingeiकuldigte noch viel weniget. 


\section{Rapitel \\ Die $\mathfrak{B e f d} u$ lbigung}

Q1 ber cines Tagz erfubr ez unglüfliduetweife ber 2 Bater. 21เ $\mathrm{Ott}$ nämlich frübmorgenz mit einem Bejpann Yferde wartend por Der Tür ber Edhmiede ftano, bie nodb nidst geöffintet mar, beobactstete er, wie

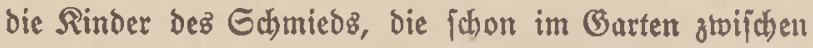
Den noch blattlofen und troctenen Beerenbüfchen liefen, fich zu einem Epiel aufriefen, indem fie zuetranber fagten: "Rommt! ... wir wollen Eggert Den Pfeifer fpielen?" Ott fahraf zufammen und fah bin und fah, twie bas eine ber Rinder (iid) binter eintem $\mathfrak{B} u[$ j) ver= ftectte uno da leife priff, uno bie andern ez baum mit Sallo entbecten und herborzerrten.

(Er fam völlig verftiört nadh Saufe. Was jein $\mathfrak{B e r}=$

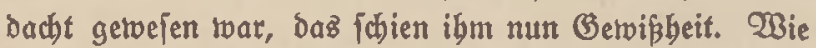
lounte er noch ztweifeln? Bolfez Gtimme... Gottes Gtimme. $\mathfrak{E r}$ war verzweifelt in ber num ficheren $E r=$ fenntniz, dás jein eigenes Rind ibm und den Geinen diez unjagbare Böje getan, biefe offenfundige $\sigma_{\text {djande }}$ und biejen $G_{d j a b e n}$ ant unjduldigen Rind; und baz allez,

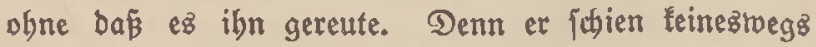
bedrüutt. (Er ging feiner 21rbeit nach wie getwöbnlid, und priff wohl gar leije bazu. (Ez war ber vornebmen

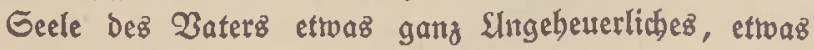
(Braufigez; $e^{2}$ ging feinem foheuen, gütigen (Gemüt über

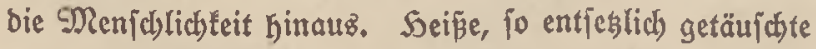
Rebbe, beimlich beifer, nun jo zerbrochener Gtolz woüblte in jeiner Seele und gierte nach einem 2 (uşbruct) und einer 
Qofung. Er trug einen Bram im (Befidt, der fein Weib crichütterte und feine Rinder eridjrecte. Ex jagte aber niemanden, was ihn quälte. (Er boffte noch, feine Not in fich zufammenprefien und nieberbalten zu tömnen, io jebr fie auch berausjatieien wollte.

Zm Mittag aber, alb fie alle um ben gropen runben Sijch jaßjen - auch Sarm, ber Simmermann twar, ba es Eonntag toar, nach feiner (betwohnbeit auz der Gtabt nad) Sauje gefommen - und er bie Befidjter alfer feiner Rinder fab und wie rein und harmloz fie waren, tontute er es nicht länger ertragen, fuchte einen $\mathfrak{B e q}$ für fein (d)reetlich) fdwweres Slnternebmen uno griff in feiner jeelifhen Slngeididflichfeit falj(h), und fing an, bie Rinber eingeln nach biefem unb jenem zu fragen, fragte erit Sarm mach feiner 2 trbeit auf bem 3immer.

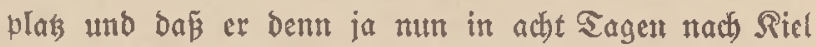
ginge, um feine 3eit bei ber Marine abzubienen, fragte Den Reimer, weldjez 3 uch er jest leje unt feberzte jogar, indem er ifn ben Profeffor nannte, und fragte dann Emma, ob fie beute nachmittag 3 ejuch von einer Freunbin befäme, und fo alfe Sinber ber פieibe nach, und fah jedez an und werjuchte fogar zu jojerzen. 2lber jeine 2ugen raren blind und jein Gdherz ungeldictet, und ez zerrí ibnen bab Serz. Sulezt fonnte bie Mutter es nicht länger ertragetr, dá ex Eggert weder anredete noch) anjah, und jagte, von grober übertommender 2lingit getrieben, mit ranfender Etimme: "Eggert bat beut morgen in aller Frübe das Foblen fobon traben laffen; er lagt, es bat einen guten Gang."

Da brach es mit jobrectlicher Bitterfeit auz bem 
Bater beraus. "Der?" lagte ex, "mit bem tann ich boch nicht reden?! Nit bem, ber unjer ganzes Saus in Slnebre gebradjt bat unb feine Heine Edwefter auf

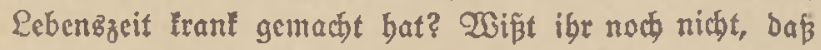
e: im ganzen Rirchjpiel Eggert Det Dfeifer beißt?"

Die Nutter war aufgeiprungen und jhrie in beller Bergweiflung: "Yater, verfünoige bich nidt... mein Sind!... mein Sind!... Er gebt roeg von nir!“ Die andern idfrien alle und bielten bie Sänbe gegen ibn und vor ben 3 ruder, um abzumebren, was gegen ibnt anidlug. Die אleinen toeinfen laut auf. 2ber ber Zater ließs fich nidit beirten: "Ift er nidjt immer bei ben berDorbenen Qubwigz gewejen? Sot er nicht vor Weibnachten mit Den roben Qeuten von ber bollandjach Tjall bas ganze Saus Durdjitobert? Gpielt und pfeift er nidt fein? Sft er nicht twiberieglich, vom Morgen bis 21bent, und will vom Soaure tweg? Ta bat er unz eftrab borgepfiffen... beil er unв verachtete und von unz fort roolte".

Der $\mathfrak{B e}$ (h)uldigte war fhon längft an ber Sür, bie magern Gdultern biz an bie Obren bod)gezogen. "Sch... (d)?" fabrie er rajend -, bollig von Ginnen - er trollte trobl fagen: , Ich, ber id für euch alle in fiebert. fachen Tob ginge?"

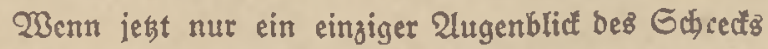
oder ber Qual ourch jeine Eeele gejagt twäre und fich in feinem bageren (Beficht unter feinem rotblonden Soant gezeigt bätte, fo wäre es vielleict) nod gut ges gangen; aber er war fogleid, im felben 2ugenblid,

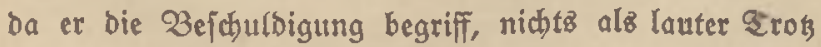
uno lauter namenlojer, eistalter Sodmut. Fr warf 
bie wifben, falten 2lugen auf ben Antläget und fagte

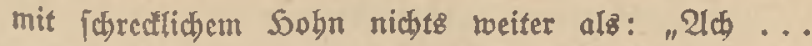
bu!!"... und fab noch einmal um ben इific alle an, fo als wenn er jagen trollte: ,Oa feib ibr alle ... Jum lestenmal ...' Dann wandte er ficd, und ging binats.

Wäbrend die Mutter bald in verztweifeltem 2 einen zufammenbrach, bald ben $3 a t e r$ bejdrwor, Dem Rnaben

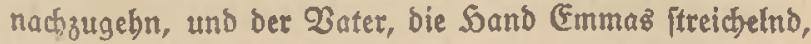
bie bitterlich weinte, ftumm und fill bor fich binftarte, billig im 23ann jeines (B) laubens, roaren Sarm uno Reimer Dem Sruber, ber nadh feiner Rammer zuftrebte, nach= gefprungen. Silz er vor jeiner Sammertür ftano, fehrte er fich um und fdrie: "Was fommt igr unir tad)? (Gebt

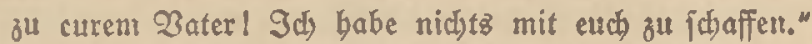
Soarm bielt aber bie $S u ̈ r$ fejt und jagte in jeiner 20 cife, Die immer rubiget wurbe, je ftürmijळer ber altgenblict war: "Rebe nicht fo, Bruber! Es glaubt ja tein cinziget bon uns, twas ber ßater fagt. ßerubige dich"!

Qber er toarf Den Ropf milo berum und jibrie: "Rann ich es euch anjeln, ob ibr ez glaubt ober nicht? Un' went ibres beute nidjt glaubt, glaubt ibres morgen aud nidht?

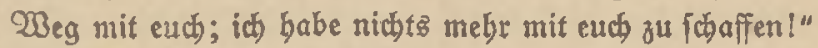
(Er tniridgte mit ben 3äbren unb jagte mit rajenben 2lugen: "Sebt zu bem Mann ba brinnen, und rebet tweiter bot Eggert bem PFeifer! Macht, baß ibr toeg= tommt! Sub wenn id nad fünfaig Sabren einmal twieber-

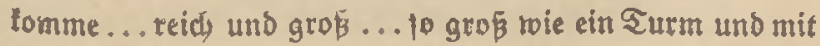

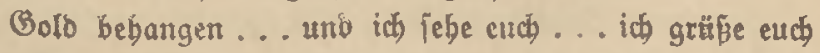

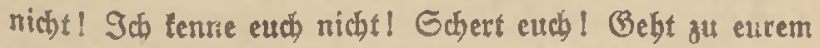

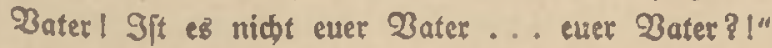


Sarm lagte rubig: "2lber wit haben boch eine Mutter gemeinfam, 3ruber Eggert."

Uber ar börte nicht. Er batte eitt gropęes rotbuntes Fajchentud aus ber Lade geriffen und auf ben Sifd) getworfen unb twar babei, feine alte Rleidung und etroas

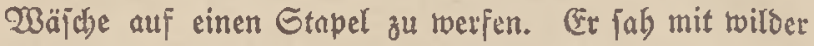
Bebärde auf und fagle: "Eine Mutter? 230 Dem? Gtebt fie bier neben mir? Echnirt fie ibr Bündel, toic in tu? Sie bleibt, wo fie ift, und ich geb' allein. 9d geb' ganz alleit?... ich bin idson jezt ganz allein. उch

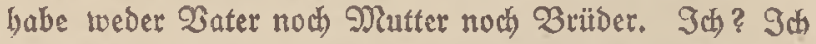
bin viel zu jtolo, nod) irgendeinen Renichen bejizen z̆u rollen . . . bier int diejer begent . . . wo ith für möglich

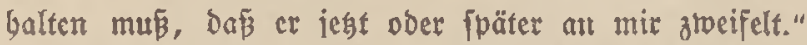

"Wir ztweifeln nicht an bir, 2 ruber," ingte Soarm... "wir werben ez aud) nientals tum!"

aber er börte nicht. "Meinen alten Gtallanzug nebme id mit. Der glaubt an mich. Slno meine Pumb= barmonita... bie glaubt aud) an mid); und wenn fie es nidjt tut, zertrete ich fie. Dieje beiben Dinger gebören mix und gebören zu mix. Bon allem amoent twill ich

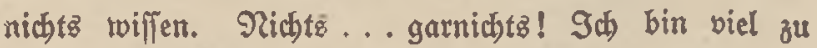
jtorz Dazu. OSiel zu ftolz! Ich bin fo ftolz, fo jauber, fo bod wie Die Eonne am falten Wintertag! $\Im a$, jo bin ich! Eo fern bin id euch."

"Slno bift Dod) unfer Bruber," jagte Sarm mieder.

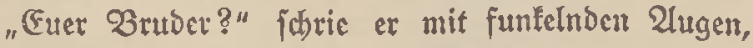

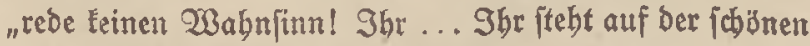
jauberen Eteinbrïcte, die zweimal in ber Wodje gefegt mird, Damit igr reine Füpe babt, wenn ibr Darüber 
gebt... ich abet... mich bat mein Water vou Der Eteinbrüfe berab in bie Diingergrube geftopen! Goll ich mit euth leben uno rcben biz zum balben Qeib im

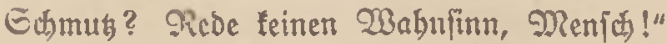

(Ta Drängte fich Der licine Reimer vor, ber bizber, Die Soänoe ringeno, cin Bild ratlojen Entfesens, in ber Rammertür geftanden batte. (Er warf fict) vor bem 3ruber auf bie Rnie und umlammte ibn und bat ibn: "Slaube Doch an unz! Glaube wenigitens an Mutfer uno an uns beibe! Wir wiffen, dafi du ez nicht getan hajt. Ou bift ebenjo gut wie twir, ja, but bijt beffer als uir, benn bu bift wabrer als wir. Já) ... ich tam fo etwas im Epiclen ausobenten, fo etroas 23 bję und 23 unter: liches. . . aber du. . . du tannjt es nid)t mal im Epielen Denten. Sch bitte bid) ... wenn bu audj toeggehit jegt ... glaube ... glaube ... an uns! $\mathcal{O}$, ich bitte bich vom Simmel zur Erbe... glaube an uns! WGie willit tu leben, reen bu nidbt an uns glaubje! !! “

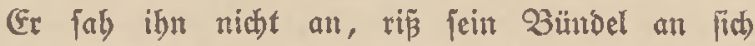

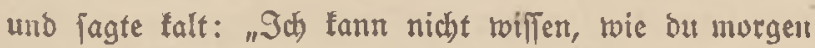

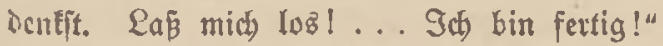

(Er rande fich our Sür und wollte geben. Sa fitmo bie Mutter ba an Der Sür uno bielt fich am Dfolten und fab ibn aus todbla fem (Geficht an uno fagte: "(Ez ijt red)t, Daß bu jetzt gebjt ... bisz er fein Sinrecht cinfielyt und es dir fidreibt. (E\& wiro nicht lange dauern. Uno bann mupt ou wicberfommen."

Er bäumte fich auf: "Der Seufel foll mich bolen, menn ich jemals bieje Begend wieberjebe, und werve ick แtunzig Salir alt!" 
Gie ftobnte und fagte: "Orbenn ou io gebft und nidjt triederfommft . . . bas ertrage id sidjt."

"Warum baft ou bir eirnen Mann genonmen, Der Feine Simber in bie Dingergrube ftöft?"

Gie fubr in wilbem Sorn auf, währent thre Sand mit einer jäben Wervegung über bas Soar fufr: "Wenn mir bie Rleinen nicht an ber Gdüurge bingen, glaubft

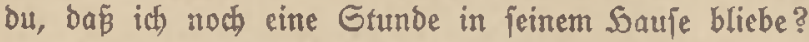
aber id bin bier angebunden." Ulno fie weinte laut auf. "श̂u aljo," fagte er, "fola la mich! So weiß ich, daß ich einmal eine gute rechte Putter batte, und ou, Dap ou ein rewtes Rind battelt! Denn ich toäre auth mit bir gegangen, went er bit fo etwas angetan bätte .. . bis anz Ende Der Welt!" Slno er tí fie an fich uno berzte fie und jólutuzte trild auf. "Go!", jagte cr, "num mach) Wlak! WBeg in bie Woelt!" Ulno er ging butch) Die Diele aus bem Saure.

Die beiben 23 rüber folgten ibm in einiger f Entfernung. Sarm, der erfannte, Dap in biejer Etunde nichtz bon ifgm ofu erreichen war, fagte in gewiffen

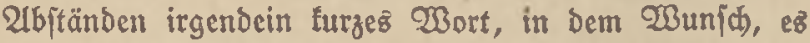
mächte fich als bas leste, toas von feinem Elternbaus in jein $O b r$ georungen war, in ciner päteren rubigeren 3eif und berftänoigen \$abren in jeinem Bemüt erbalten. Der fleine Reimet, in bolliger Raflofigleit und $\mathcal{Z} \mathrm{er}=$

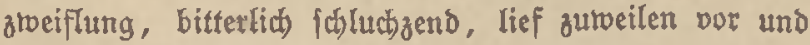
frreichelte ifm über ben 2̈̈rmel. Er batte alle feine

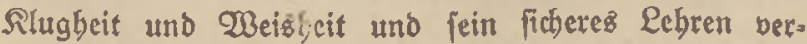
loren, auf baz er fo fols twar; er bat nur immer wieber: "(Blaub" uns Dosb!" 
aber ex achtete gar nicht auf fie und bärte fie nicht. (Er ging mit rafchem, fotwerem Altem fieinen $\mathscr{B}_{\mathrm{eg}}$, bie 2lugen auf ben Deich gerichtet, Dem er zujtrebte. Er baute immer böber an bcm Surm jeincs Gtolzes, immer bobber... bis zur Gonne binauf, die mit blaffem Gefid)t fdräg über ifm am frifchen, wolfigen Grüblingsbimmel bing. Go tamen fie biz zu ber Gtelle, wo er mart) feiner Berwobnbeit, fo im Gteben, bie Etiefel abzog, um barfuß quer über bie Gelber meiter zu laufer. Ul' er fich nun in biejem 2ugenblict bistte, fab und bebactse er ex[t, Daj er feinen Gonntagzanzug trug, den feirt Bater exft neulich für ifn bezablt batte. Er bätte ihn ia böllig als fein figentum anjeben łbnnen, mit 2lrbeit auf Dem Sof vom früben 2 Norgen biz zum 2lbend reolich ertworben, aber er bad)te ja an nidjtz toeiter, alz wie ex feinen Soodmut zeigen uno ben Water fränfen fönnte, uno badte, wie er es anftellen follte, uno fnirjite mif ben 3äbnen und háliff am bärtejten Gedanfen.

Tun lag ba an biejer Etelle am $\mathfrak{W e g}_{\mathrm{e}}$, nicht rocit mebr von ber Landitrape, ein groper Bauernbof, uno ber baumreidhe alte Garten dez Saufes fitié an ben Weg. Es wohnte aber auf Dem .5of eine Witwe, eine freundidie, fhon alte Grau, und ibre इobter. Diefe Sochter, mit Ramen Söbfe Gubl, war gerabe getwad) [en, vielleid)t ein trenig zu lang, und batte ein edlez gutes und reines (Beficht und bellblondes Saar, bas fie ichlid)t und $\lceil\not b ̋ n$ in eirtem einfachen Snoten trug. Gie war fo um vierundzranzig $\ a b r$ alt und war nod ledig. Wenn fie arm getwejen wäre, bätte fie wobl fobon einen Mann gebabt, ba fie aber Crbin bez fattliduen Sofez 
war, bielten fich manche aur 3 ornebmbeit zurüct. 2lnbere fürdjteten ifhre Rlugbeit und Gelebrjamteit; Demn es war befannt, baß fie in ber Gejhidhte ber Qanbidjaft uno ifrer (Gejdledter und Familien jebr betwandert twar, und es ging daz Gerede, dnép fie gern las und nicht immer lcichte 2 üidjer. Inbere fürchteten ibre Epottjucht. Denn obgleich fie jelbjt ein ungejdidtez Wefen batte, fo fpottete fie bod) gern über anderer Qeute פ̧e bäufig ift, nicht aus lieblofcm, fondern im Gegenteil aนs einem menfdocnfreundlidyen und gütigen Bemüt.

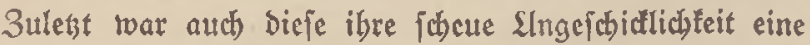
Urfache ibres Qedigfeinz. Denn wenn es einem Mäbstien auch unmöglich ift, fich gerabeswegs angubieten, fo twei eine Gejchicte, cine Gedenfundige, inre 3uneigung robl anzudeuten, ofne fich in geringften etwas zit vergeben; bie Sngefficte aber bleibt ftumm und bält igre (Befühle in ibrem Innern veriळlofien, ja zeigt vidleidst im rechten, twid)tigen 2ugenbliaf das vertebrtefte Befidt. Da fie uxn alfo obne Gefdwifter und obne Mann und Rinder war uno boch etwaz baben muste, bas fie lieben uno Daren fie ifren Epott anbringen fonnte, fo hatten ibre Nutter und ibr alter Tagelobner Peter von Norgen

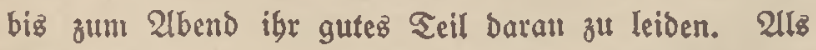
oritter aber mufte ibr Eggert bienen, der fajt jeden 2bend, wenn fie fich nach ibrer (3etwohngeit unter ben Bartenbäumen erging und, indem fie bie (Bejdichte ber Landichaft bedađte, übers tweite Land ipäbte, bes $\mathscr{W}_{\text {egs }}$ fam uno am Weg, auf Der anderen Geite bez Grabens,

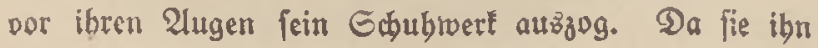


von feiner Rindbeit an fannte unb iiberaus gern batte, fo breitete fie ibr ganzes Snneres in Mätterlichfeit, Gchelten und Gpottluít immer mebr über ifn aus und es gab feit Sabren mand) gute SInterbaltung für fie über Den Graben bin. (Er aber ließs ez fid Durchaus gefallen; ja, ibm bebagte eż, wie einem jungen Rater Das Rrauein; er war zutraulich und von freilich ettpaz fnurriger Bemuttlicbleit. $\mathscr{W} a s$ fie eigentlich beibe im tiefiten (Grund aneinanber modten, war, bak fie einer am andern füblten, Daß́ er ein ganz natürliçer uno ganz trabrbafter Menj h toäre und ben andern, obgleid, er ibn für ein toenig quer bielt, bennodi) in biejem feinen Wejen laffen und nicht aus feinter Saut jagen rollte. 2ber baz twar ibnten nicht tweiter betwuḱt.

Diefe Söble Gubl ftand ba nun auch beute, nadh

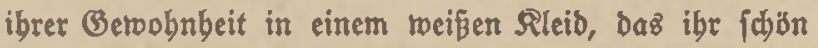
um ben langen, fdlanfen Qeib ftand, fab bie brei berantommen, fab das feltiame Bebaren, uno als fie das bittere Weinen uno Bitten Reimerz bïrte, fragte fie

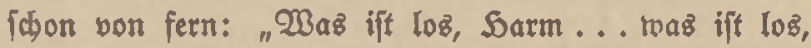
Eggert?... Whas willit ou, Sunge?" und trarf ibre graublauen \&ugen, bie ibr fchion unb flug im Ropf jaßen, auf ibren Grabenfreund, ber nad jeiner Gewobnbeit an Diejer Gtelle feine Gtiefel bon Den Gü̈en ríp.

Er, von feinem 3orn völig befeffen, tümmerte fich nicht um fie, fnurte nut etwas, und gog an feinem Stiefel.

Gtatt feiner fagte tb̆r Sarm, roas gefdyeben war: Dap ber Bater ibn bejhuldigt, und nun toolle er roeg ... roobl nach Samburg.

frenfien, Die Beliber. 
"शnch Samburg?" 低rie er, "zu ben Bofvluben!... 子น Den Geurerländern!"

Reimer, ber Hleine Belebrte, erjaraf. (Er Dahte: "Welch ein Wirtrarr! ,Wie untwiffend geht er in bie Welt !' und tweinte laut auf.

Das Mäbゆen twar aufs beftigite bejtürzt über Das grope Slnglüd, und twußte in ifrer Bertvirtung - po wie ein Menich, wenn fein Saus ploglich in Flammen fteht - nicht, trobin fie greifen und wie fie belfen pollte. Sie jagte voll berzlicher Tot, Bedauern und Ditleib: "2ldh, Bott ... tweldh ein Srrtum! Weld ein Irrtum! Sätte ich e\& boch getbort! Soätte ich boch mit ibm gejprochen (fie meinte ben $2 a t e r)$ ! Weldh ein Irrtum! 2l山, Sunge... lieber Iunge ... ach! ..." Und plisglid wubte fie, was fie tun tonnte. "2la Eggert . . . böre . . . Sung' . . tomm zut mir! Sh bitte bich, fomm zu mir! Sch freu' midh ja, wenn bu bei mir bift!... fomm ber und bleib' fo lange bei mir, bis alles mieder in Oronung ift."

(Fr rí feine Gquthe und Gtrümpfe von der Froe auf und ichrie: "Zifit bu verrüctt? In bie reite $\mathscr{B}_{\text {elt }}$ will ic)! Wenn bu waz für mich tun willft, fo gib Dem Mann da ... auf bem Sof da ... Dem Ott . . . Die achtundoierzig Narf, bie biejer 2inzug foftet! Sch mill nidts bon ibm gejwentt baben ... von bem Menjhen ... Dem Gdünder. Sch will es dir in einem Sabr wieberichidfen, fo trahr ein Bott im Soimmel ift!"

"Sunge," fagte fie zornig, mit bleid)em (Beficht, "Dut bijt ja twirt im Ropf! Slm jolch einen Quart bemühit

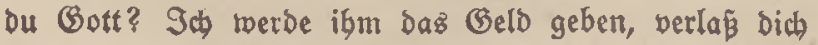


Darauf! Gei verninfitig, Eggert ... Eggert ... bör' noch, bleibe noch...."

Er jprang, Die Echube in Der Sallo, übern Braben. "Das ift nett bon bir", fagte er, "aber id) babe ez auch) nicht ander von bir gebad)t!" und lief übers Geld, Daz feiflich Dez (Grabens nach bem (Deich) zu lief.

Gie war von ber Begebentheit, bie ift fo plizglich über ben tweiß̄en Salz licf, völlig vertwirtt, füblte aber,

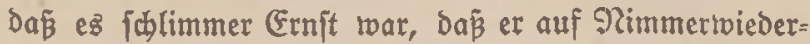
tebren bavonginge. Die Not ber Geinen uno jeine eigene brannten ifyr im Soerzen; fie füblte auch, roievicl fie felbit an ibm verlor; fie batte ja aufer ifm nie= manben, mit bem fie ein wenig ernftlic) bantieren uno fpielen fonnte. Wie cine Senne, bie ifre Entlein reg= fohrimmen fiebt, trat fie Dicht an Den Grabenrand und rief, Not und 2lngit in ibrem weípen Geficht: "Fggert, Du weift, wie lieb ich bich bab' ... fafreibe mir ... babrit du? two bu aud bift! ... du follft mir fdreiben!!"

Er wanbte fich auf ben Sacten um, fab fie groß an,

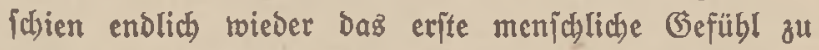
baben und rief, wie ivenn ex fich befänne: "Sa, bu . . . Du glaubjt an mich! Du und meine Mutter! $\mathfrak{U}_{\mathfrak{n} \delta}$ id) twill bir fdrciben! . . . Sa . . . unb du gibit es Mutter." Und bamit rannte er bavon.

Der fleine Reimer wollte hinfer ibm ber über Den Graben. 2lber Soarm bielt ibn zurüc." "Ė bat feinen 3roed," jagte er. "Er ifit jest ganz won $\mathfrak{B e r j t a n o . ~ E s ~}$ ift Da nichts zu machen."

"Sक fürchte auch," fagte Subble Gubl. "(Er iff jest 


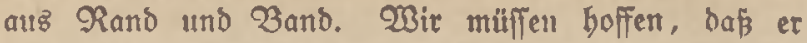
allmäblic) zu Berjtand fommt."

Gie ftamben alle brei und faben ibm nach. Soarm mit rubigeren 2lugen, mit jeinen $\mathfrak{b e b a n f e n ~ u n d ~ G o r g e n ~}$ mehr zu Sauje bei Dem 3urtand Der Gittern als bei

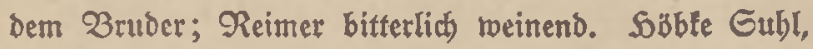
Die bübiden flugen 2lugen nahe beieinander, idutttelte Den Ropf fowohl über ibn und fein Bejebid wie über fich felbjt; Denn fie füblte beutlich, Daß ba ein eigen

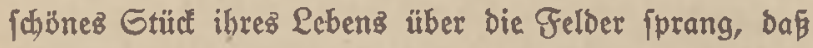
bie früblingżnaffe Erbe ihm um bie Ohren flog, uno immer fleiner rurbe. Nun erreidfte er Den Deidh uno prang im Lauf forräg binan, nun ftand er einen 2ugen. blic, bie Gtiefel in Der Sand, gegen ben Simmer... शun twar er weg.

Die Drei ftanden atemlos und ftarten auf bie Gtelle. Dann wandte Sarm fich um und jagte zu feinem Sruber: „शun tomm ... nun müifen wir zu berren im Soure."

Souble Gubl mollte noch etwas tröiten und raten. Aber nun, da ifr alter Betannter fort raar, mit bem fie fich in Bebanten und Son eingelebt, fam roieder ibre alte Slnfitherbeit über fie. Gie fieß und murmelte ein paar gleichgültige Worte berbor, rourbe über bicje ifte SIngeichictlichleit noch verlegener, füblte, Daß fie barüber rot wurbe, unb randte fid) $a b$, igrem Soaje zu.

alz bie beiben Brüber nach Saufe tamen, batte bie Mutter bie Rleinen in bie Rammer ber Magd

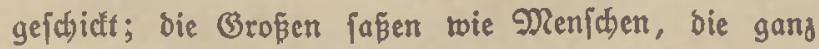
gegen ibre Natur unb Betwobnbeit ein wüites Belage 
gemact und mun voller Ctel find unb vergebens berjuchen, fich wieber ins (Beoronote uno Reinliche binein= zufinden, mit verfiörten (Gefichtern bier uno ba in Dent beiden Gtuben. Der Zater jaß am Genjter und farrte in ben sben Barten binaus; bie Mutter bodte auf bem niebrigen tleinen Gtubl am Ofen, ber nod bon ben Brobeltern beritammte. Sie trat fonft fo grop und (tattlich und auch f(bön, und trar bas aud jest noch,

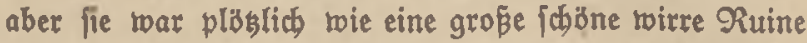
geworben. Emma batte fid inz 2 ett gelegt, batte fict) sur Wand getpendet und weinte beftig.

Die beiben Brüber famen berein und jaben Die Shren in biejem 3ujtand und traten ftumm und troftloz an bas Fenjter und ftarten binaus. So blieben fie roobl eine Stunde. Dann fing Sarm an, quer burd Die Gtube zu geben. Er trollte etroas jagen und zum Buten reben, empfanb aber immer wieder, twenn er ben शlund bffnen

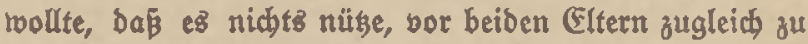
ppredoen, ba fie eine entgegenge [ezte Gtellung zu bem Fall batten. (Er überbachte aber in jeiner Weife bie ganze Gade langiam uno grünblia, uno ertwog, wie er nad) ber jedem für fich zu Silfe fpringen wollte, Der 2 Rutter, inbem et

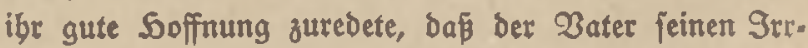
tum erfennen würde und daß Eggert nidjt für immer verloten wäre, bem ßater, indem er iłn leife und vor= fidtig 子u überzeugen fuchte, Daß er fith geirtt. Er jab wobl ein, baj bieje Slberzengung bem 2 ater febr lang.

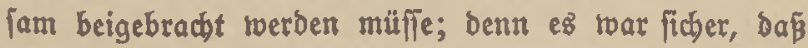
er nach jeiner Ratur iblwerer noch als an einem mis̄. ratenen Gobn, an dem gropen Slnredtit leiben ruirbe, 
Daz er einem gufen uno berfannten angetan bätte. $\mathfrak{E r}$ erfannte, wie fhiver alles itand und lag, und war aufz beftigite beorüct, und fein fonjt io frober, frifcher Mut war zum eriftenmal in feinem Leben aufs ärgite

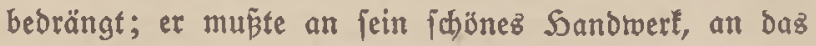
muntere belle Saus feincs Onfels und Qebrberrn und an fein blikendes Fabrrad denten, um fich aufrecht und jauber zu erfalten. Der fleine Reimer batte jein Geo jangbuch) gebolt, batte fich auf den Bettrano neben leine Gatweiter gejest, und las unter bem Borivand, baj er priffen twolle, ob ex fie noch austwendig twiffe - in Wirtlichteit fühlte er trok feiner Sugend, daß̄ Dieje Gtunde für baz Bemüt bez Zaterz eine furchtbare Befahr roärc und rollte ibm belfen - mit leifer Gtimme, ooch jo, oas fie ez in ber ganzen Gtube bürten, die alten Bejänge. (Fine ganze Weile, fait eine ganze Etunde lang, Hlangen bic gropen, ernjten, vertrauenden 230 orte burd bie beiben nieberen Räume bicjez nieder[äd)fif hen Saufez, in dem bic bitterfte Qual wobnte. Dann wurbe bie Rrante mübe und idlief ein, wie fie lag, ben idmalen, feinen, im Weinen gebeugten Rücten zur $\mathfrak{B a n d}$ bin. Der Rnabe

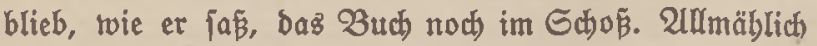
fant ibm der Ropf auf die $3 \mathrm{ruft}$ und er jas jo in Ginnen, unbetweglich, bie fharfen Wlugen an ber Froe. Gein etroas langes Beficht mar noch länger als fonjt, fo, als wenn das Leib es gezogen bätte; das bunkel= blonde Saar, bas im Nacten biż an ben Rocttragen bing, ftand im Gcheitel faft aufrecht, als befne und fträube ez fich von ratlojer Bergroeiflung im wirren Soinund Serjagen naథ Plänen unठ Sooffnung. 
Go verbradten fie ben Sag, biz ber 2lbend tam.

2ls es abent twar, gingen fie auseinander in ibre Gd)lafituben. 2lక Reimer por feine Rammertür fam, Die er mit bem Gortgelaufemen geteilt batte, baf er jeinen Bruber, noch einen 2lugenblict mit bineingu= fommen, fing an zu weinen unb llagte, dá⿱㇒㠯 fie ben Bruber to bätten fortgeben laffen; fie bätten noch weiter mit ibm geben follen. (er jetste fich auf Den Gtubl am Genfter, rang bie Soänbe ztwijhen ben Rnien uno jagte: "Er roirb mit ben Rubrvigs nach Samburg geben;

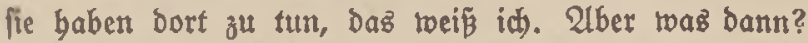

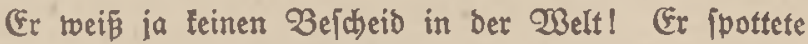
immer über mein Büberlejen, und wenn ich ign bes lebren wollte, fagte er, was id aus ben Büdern ber: ausläje, das ftünde für, ihn auf ber Sanbfläche; er brauche fie blop vor fich bingubalten, fo wiliste er $\mathfrak{B e}=$ icheib."

Sarm juchte ihn zu berubigen: "Ith glaube, er bat rect), mein Sunge. Die meiften Menjoben finden von felbjt in ber $\mathfrak{B}$ elt zurecht; und po einer ift er. Er wirb in irgendein Lant geben unb da auf einem Sof 2rbeit juchen."

„Эa ... aber weldes Land bat guten Boben, gute Soisfe, gute Menfduen? $\mathfrak{O o n}$ all bem bat er teine 2lbnung! WBenn et nun ... idi) reif nictit roobin reift ... und tommt da um?! ... Sund dann -" er iकludbste beftig auf - "Dann möd)te id aud bas andere mit ifm bereben! Gieh, wenn er fo im 3orn bleibt gegen den Bater... wie idredtich ifjt baz für ign! Snd renn er nie wieder zurüctfommt, wenn 
bie Cltern ibn nic wieber febn, menn et gang verloten ifi, ganz beimatloz ... Das ifi ja nicht zu ertragen! Das erträgt bie Mutter nicht. . . Gie toürbe ja au币 Dem Bater gram bleiben! Slnb Bater . . . wenn Bater nun zน yer Extenntniz tommt... unb bas twird ficher

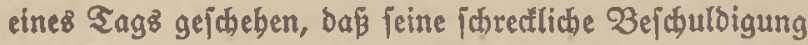
ein Srrtum war, und Eggert ift bann weg, verjdiwunben in ber roeiten $\mathscr{W}$ elt . . . Das twiro graufig für Water; benn er bat ein empiñolidjez Betwiffen. 2luz eincm überempfindlichen und überreinen Getwifien bat er Eggert von fich gejtopen; et wollte mit feinem Schelmen unter einem Dad) leben, unb er ptiés ibn weg, obgleidh ez pein Gobu ror. Wie wito fein Berwiffen erft leiben, wie wiro es fich qualvoll aufbäumen, wenn er erfennen wito, baj er, inbent er robr und flar zu fein glaubte, einen 10 idgredtlicjen Srrtum beging und eine foldbe Not itber reinen unichuldigen Gobn uno über fein ganzes Sauz bract)te! Er twiro fid felbit nicht meht ertragen tömen unb twirb fict aus ber Welt roegidhleiden. (fi bat Diefelbe Ratur wie feir Onlel batte. Du erinnerft bick bod ber Bejdidte?! Der nabm fich das Leben, tweil ein cinziger Nenid, ber nod) bazu eitten idledbten Ruf

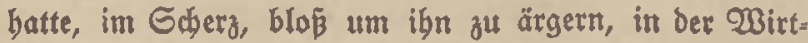
jajaft bebauptet batte, er bätte vor ztwanjig Sabren feine Gd)eune angezündet! Gieb ... jo ftebt e8 ...

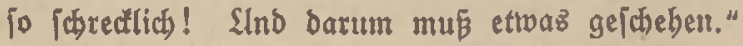

Sarm gab bem 3 ruber in alfem recht, toas er jagte, rouste aber feinen Rat. "Was follen twir tun?" jagte er. "Er ift ja von CEis. Er ift ja blind und taub, und fiebt uno biort auf nidtz ... auf niemanden." 
Der Rnabe fagte: "2luf bich bät er nicht. 2uf Pajtor Boblen... twenn wir ben bäten, ibm nactjureifen ... wiro er aud) nicht bören. Wir riffen ja audb nicht, ob Paftor Boblen gerabe frei ift... id meine, innerlid ... ex bat ja immer feine Not und jeine 2rbeit ... Rein ... e. tann niemand richtig mit ifm reben, als allein id). Wenn ich ihm allez ... alles fage ... rasz id bier ... bier... in ber 3ruft babe

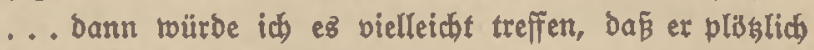

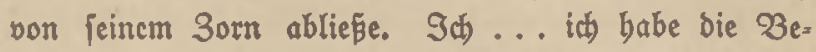
gabung, bie feiner bat... i i fann mit einem Men[chen burch feine gange Geele gebn und ibm allez zeigen,

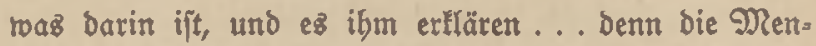
(đ)en fennen ithre eigne Geele nicht... und fann mit ibm an baž Genfter treten ... iđ meine der Geele... und ibm ganz beutlich der andern Geele zeigen ... ibre ganze 2lut... Baters Geele ... Sa, Das tann id ! Sa

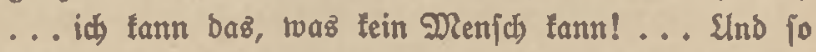

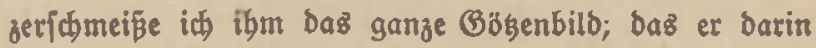

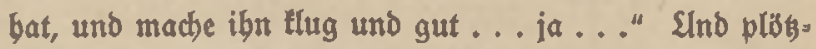
lich richtete er fich auf und fagte frober und mit bellerer Etimme: "2lber nun geb, es ijt ífjon fpät uno bu mǘt morgen febr früb wieder fort."

Da ging fein Bruber binaus, vertwundert über feine $\mathfrak{W}$ orte, fo in bem unbetousten, untlaren Bebanten: , Eggert, in Der Frembe, wirb es nicht leic)t im Reben Gaben ... aber biejer da in ber Rammer... Der wird ez noch jhyerer baben." Uno ging in feine Rammer und legte fich bin. 


\section{Rapitel \\ Bruber Reimer}

Q1: ber Bruder gegangen war, fuchte der Inabe 21 einen Saufen Büber zujammen, band fie in ein gropes buntes Saj(bentuch und machte fich über bie groß̉e Diele beimlid aus Dem Saute. (Fr lief nach Dem Deid zu und fam an bas Rubwigfhe Sauts uno

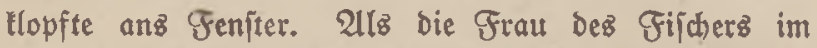
Semb am Genjter erjofien, fragte er fie, ob jein 3 ruber noch bier wäre. Die Frau jagte ibm, Dá er mit bem lekten $3 u g$, vor zroei Gtunden, mit ibren Eobnen nach Soinburg gefabren räre.

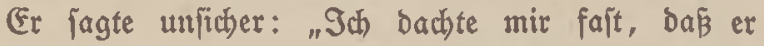
f(t)on fort twäre und nad) Samburg. Sd) möbte ibn io getn noch mal fpredsen und igm bies geben."

Die Frau, die ourchaus guten Willens war und bie Not ber Mutter utio ber Rinder begriff, meinte, er bätte 2luftrag von ber Mutter, und fagte: "Dann fabr boch bin, Reimer; es ijt ja 'n Rabenfprung! Du fäbrjt morgen frith $u m$ vier $\mathfrak{a b}$ und bift um fieben ba," und fie nannte ibm die Udreffe ber Wirtichaft in Samburg.

Er merfte fich bie 2loreffe und machte fich rieber auf ben Seimtweg. $\mathscr{A}$ lz er fich aber bem $\mathfrak{D o r f}$ und Dem Sof twieder näberte, beforgte er, Daß

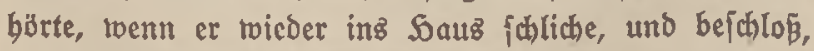
in ber Weife feinez 2llterz, fich bie Nacht brautent zu vertreiben. 2llfo feste ex fich zuerft auf einez ber Secf̈z am $\mathscr{W}_{e g}$ und badite über bie Not im Sauje nach und 
ging im Geijt balb zum Zater, balb zu Eggert, uno trat in jebez Geele rie in ein roblbefanntes Sauz und wušte genau, wie cinem jeben zumute twar, und fprach mit ifm, mit ben einzig richtigen (Gedanten und Worten, beuteno, enträtjelno, erfläreno, taịteno, borchend, feurig benegt, verjhicbeno, gütig, mit freundlichen Worten zurechtftellent, und ging erfit wieber, wenn er aus bem wirren Sauje ein fdün georonetes und reines uno frohes geid)affen batte. Befonders ging er dem Beflobenen nach. Er fab itn in der $23 i r t j \omega a f t$ im grop̃en Sam= burg físen. Er jaß̃ ganz allein bei einem Błaje Bier, won bem er teinen Sropfen getrunten, in einer Efte, nit bem bageren, rotblonden, finfteren und bijen Ges: ficht. Er fegte fich ibm gegenüber und fprach mit ibm. (Fr hordyte jeinem Gdjulterwerfen und bojen Worten, brang won neuem auf ibn ein, vorfichtig, mit langfam bebächtigen, ztweifelnden Worten, mit rubiger, langjamer Gtimme... genau, wie man cin unberfänoigez, ftürri¡山es Sier treibt, baz in ben Gtall foll ober burch cin Secf. Slno zulegt, vorfichtig erflärend, borcheno, wieder ertlärend, gütig, beiß werbeno, Gott uno bie Mutter ins Feuer fübrend, gerwann er ifn.

Go já̉ er wobl cine Gfunde. Da wurden diefe Gedanten mübe, verbla ǰten und vergingen, und ex ges

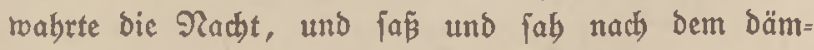
mernoen Dorf, und glitt mit ben 2lugen die lange, bunfle Baummaffe entlang und fan biz zu ber Grelle, too um Rirche und Pajtorat bie 3 äume am bicfiten uno böbjten ragten. Da glitt er unberwust vom Soet berunter und ging langiam in Ginnen quer ïberz Gelo, 
iprang über einige (3)ăben uno fom bis bor bas ftattliche Sauz neben bem Pajtorat, baz früber bie $\mathfrak{W B}_{0}$ = nung bez $2 \mathfrak{l n g}_{\text {fez }}$ gewejen, nun aber von einem Samburger Raufmann betoobnt wurbe, ber jeiner Befundbeit roegen bier mit jeinen Rindern lebte. Fr Hletterte über bas Gtafet in ben Garten and ftand und $\{a b$ binauf und fab beutlich bie Genfter, wie fie mit blinden 2lugen

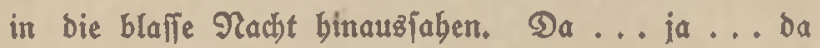
war bie Diele ... und da die Rühte und ... da war bie Gd)lafitube der Sobter. And nun waren feine Gebanfen bei dem blonden Rinde, weldjes das fob̈nile, bornebmite und reinjte Wejen toar, das es auf ber weiten Welt gab. Slnd er ... ex batte bas unjagbare Brlüd: er prach fait täglid mit ibr! WBent er bor bem Pajtorat auf ber Etrape ftand, am Eingangżtor jum Barten, feine Bücher unterm 2lrm, und rartete, bis̄ bie Turmubr fhlug, fam fie immer aus ibrem Barten und fagte biejes und jenez, und erzäblte ifm vom Garten, von ibren (Befhiniftern, ibrer Qebrerin. Slnd allez, twas fie jagte, war thug und toundergut, und trie fie es fagte, war un. jagbar fein und vornebm! 2d, wie twar fie fobön! Wie war fie reinen Serzens! 2(d), fie war viel zu

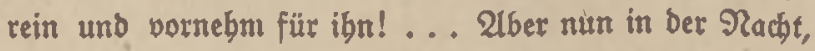
Da ex fo ba ftand, ein Nenjक gand allein, in feinem eigenen Menichentum, und wüte, baß fie follief und twebrlos balag, - ibre Waffen waren gar zu berrlich und funfelnd und macten ifn unfidfer und bange - umipielten feine Bedarten ungebinderter, mutiger ihr zierlic) jü 3 es æejen. (Ér rebete fie an; er börte ibre Antworten; er wurbe rebjelig ... er plauderte f́bön ... er gefiel ibr ... 
ex Iachte leife und fah, baß̧ jein Lachen ibr tooblgefiel, uno war ftolz und eitel Darob, und ftand ba mit fprübenden 2ugen im jungen Ilaren (Befid)t, belwegungšlos und bie Geele voll vom beroegteften Reber. Da fam vom Rirchlof ber irgendein Laut eines fidlafenden ober ichleidenden Tieres. Da wurbe er wieber bie Racht getwabr und twie er bier [tanb, bem Fenfter jeiner Heinen Qiebjten gegenüber und bachte: ,Gerabe wie einer' - er batte es mal irgendro gelefen - "ber feiner Riebifen ein Rachtitändchen bringt," uno fuchte jogleid, läh)elno uno wieber ben eitlen Gdein im Befid)t - er badfe: , So fdön wie ich, tann es Eeiner' - in feiner Geele, tras er thr fingen toütbe, und billete an grofen Gefüblen und Worten, unb uma gab das fleine zrodlfjäbrige Wejen mit bobem, fanftem,

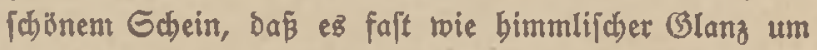
ibr lurgtleibiges Figürden ftanb, und feine frif̧en Lippen bogen und bildeten in idjiner Oronung an ibren Worten, unb feine laren 2lugen frablten bon ber Güpigfeit jeiner Befüble.

Enolic batte ex feiner Qiebe und all feinem Befübl genuggetan und ging langiam aus bem Barten uno in Den Edatten Der alten $\mathfrak{Z a ̈ u m e , ~ b i e ~ b i e r ~ b i c h t ~ u n o ~}$ mächtig itanben, am Rirchbof entlang, ïberfab die Frorm ber Rirche und blieb am bunfelften ßaum im pilligen Gd)atten ber शadbt jteben, ben Rüden gegen Den rauben, rifigen Etamm, bie 2ugen noch immer auf Die Rircbe geridtet, bie gröber, rubiger und ernjter, als er fie fonjt fab, in all bem Dunfel ftand. Die 2lngit, bie jeine grofe Phantaje fonft wohl fannte, war bier nicht bei ibm, Da ber Rircbof bell genug lag, fo Daj er jedes 
Der menigen Rreuze erfennen founte, uno bie Etrá̧e mit ibren Säujern, falls fich boch Gdrectliches begeben follte, mit einigen groß̄en Gprüngen zu erreichen war. (Fr (a) mit rubigen, träumenden 2ugen nach) Den Fenjtern und fuchte $D a s$, bas neben der Ranzel twar. Geine Eltern und Daz ganze Dorf muipten nicht anders, als Daß̄ er Lebrer werben follte und wollte. Er jelbịt aber frug heimlid im Serzen ben feiten Glauben, Daß̄ er eimmal über biez 2 mt binaus als Qebrer ober Prediger ober twas fonit... das wuste er nicht ... vor vielen

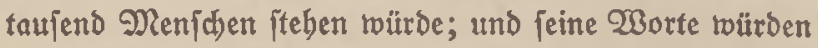

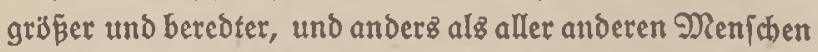
Worte jein, felbft Der Gelebrteften im Land, Darum, weil er wie feiner wušte, waş in ber Geele ber Men.

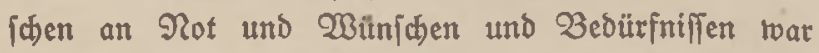
.... feiner!... Slno jeine Pbantapie, im Nebel der Sugend tajtend und greifend, nod unfäbig, den (befüblen eigene Gründung und eigene frorm zu geben, erging fich in ben alten bergebrachten $\mathscr{W B}_{0}$ rten ... Greibeit ... Gitte ... alle Brüber ... Glantez, freies, frobes Leben . . nirgends. Sa $\tilde{\beta}$. . . nirgends Feindidaft,

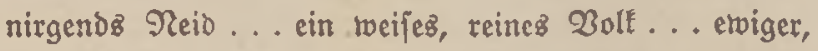
fđb̈ner Friebe... Rinder Bottę ... Wie in einem ungebeuren Beficht, in einem ungebcuren-frrablenten Getooge fab er eine neue Menfhbeit, ftant er bor jener Erjdeinung, bor Der unjere ganze edle Sugeno jtebt, und twar nicht melyr in fict. Ein Erwachjener, in bem Ulter uno ber Rleidung von Pajtor Boblen, Den er beimlich aufs beiß̄efte vereb̧rte, in einem einfacten, bäus rijchen, aber ängftlich) fauberen Rocf, ein Nann bez 
Bolfes, fein Prabler, fein Driefter, fein Gelebrter, tein Reidter, ftant cr mit einem idslidsten (Befidst, oljne allen Gdhmuct und (Bebärben, und pprad fo zu ben Taujen= Den, bie bis über bie Ränder dezి Rirchbofz und orïben now auf ber breiten Gtrape ftanden. Geine Eltern, beibe mit weí̄em Saar, faß̄en ganz weit zurül, auch fie mit ftillen, feierlicten (Gefidtern feinen 2 orten Iau[d)end. So feierte er im veridjwiegenen eine Borfeier, ein Gejt feines zutünftigen Qebenz.

Da trähte in einem fernen 5 of ein $\mathfrak{S a h m}$ auf und ein tübler Puftzug fubr Durch Die Bäume. Da jhüttelte er feinen Sraım $a b$ und gedactie ber fwheren 2lufgabe biejez Tagez und ging in biejen Gedanfen unter ben Bäumen bin uno ber, bis im Often und feitwärtz ber Rirche ein fhwacher Echein bes Norgens erfhien und im bidbjten Baum mit lärmendem Glügelflatid)en eine Rräbe aufflog. Da ging er in ber Morgendämmerung nach bem Babngof.

Die Vieb̧ändler und Rotjen, die um ifn jaßen ... Befannte waren nicht unter ifnen... fragten ifn, ba er fo etwaz überwaht und berloren bajafi, twaz er benn in Somburg rolle, und fherzten, er rolle sod) woll nicht auf abenteuer aus? (Er verftand fie nidt, fah fie mit feinen offenen 2 ugen an und jagte: er toolle feinen 3 ruber befuchen. Uls fie ibn fragten, twas Der Bruber benn wäre, merlten fie an Dem bilflofen, unficheren 2lusbrud in feinem Beficht, Daßj Da eine Rot wäre, liefen ibn und bergafen ibn fajt. Nur einer lah ihn bann und wann an,

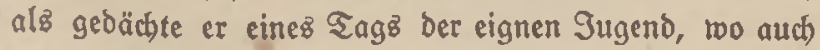
er eine 2lufgabe Latte, bie über bie Rraft feiner Sabre ging. 
(Fe war noch nie in einer grofen Stadt getwefen, magte fich nidjt auf eine Grapenbabn, fondern mactete fich bu Gup auf ben 2 eg und ging und ging, fo twie bie Reute ibn wiejen, und redete in Gedanlen eifrig auf feinen 2 ruber ein, und fam uber fein bisigez KReden in immer bisigeres Qaufen; er fürchtete audd, ben 3 ruber nicht mebr angutreffen, und lief fich aus 2ltem unb Rraft. Er war in Den Sabren, wo ber Rostper lang

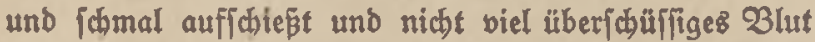
bat; und er batte geftern abend nictis gegeffen und raar bie $\Re$ (acht Durch auf ben Beinen getwejen. So rourbe er müber uno müber. (Endlich fam er an bie Reeperbabn, und die Qeute jagten ibm, Daß ez nicht meb̆r weit wäre. 2ber nun trar er auch am Ende jeiner Rraft. (Er ängltigte fid entieglid), Daß ibm die Reute unb bie Säufer vor Den 2lugen verfbrwanden und baß er bald niederfallen würbe, aber mebr noch, tras es

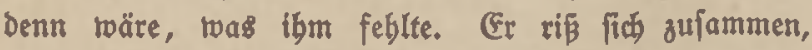
warf bie Gïbe fraffer bor fich uno berfuchte zu fingen, und fo ging eв cine Weile befler. Ulళ et bann aber cinen Meniden fragte, two bie Wirtidaft toäre, und ber (Befragte nach einem Sauje fajräg über bie Eträe beutete, berfotwano bie Etimme uno ber Mann in ganz merf= müroiger Weife vor feiten 2 ugen und Obren. "Sch fall' um," fagte er. Da prang ber Mann binzu unb fübrte ibn an bie Saustur und in bie Gtube.

Die fleine lümmerlid)e Frau, bie ba in bem Etüb. chen am Genfter fáp, ertannte gleich, baß er vom Lande fam und aนz gutem Soaufe unb baß̄ er verbungert răre, [tand auf und bumpelte uber ben Bang nat Der Wirts. 
Ttube und rief nach 3 rot und 2 ein und fimmerte fich borläufig nicht Darum, Daß̄ biefer pl'sgliche neue $\mathfrak{B a j t}$ mit einer (htwaden (Gebärbe und Bitte auf Den Wacten Deutete, Der nun, wie er jegt wieber jah, bor ibm auf bem

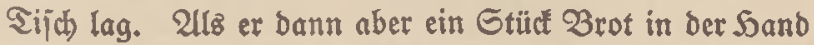
batte, nabm fie ben Pacten und jah nichts als einen Saufen zerlejener 23 üb)er und oben barauf eine fleine 3abl Lichtbilder. Gie bejah bie Bilder uno wunderte (ich) und jagte: "Bott bewahre . . twas für eine groß̉e Gamilie! Shr jeid ja toobl mebr als zebn Rinder. Эa... und ber $\delta a \ldots$... das bijt bu! Sawobl ... aba ... und da ifit ja ber, ber beute nacht mit den Rubrigis getommen ift...

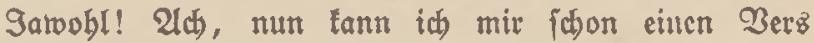

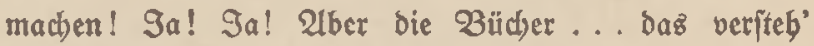
id) nidft!"

Fr fonnte ifre Eprache nun jøon veriteben und jah auch ibre gebücte Figur und baß fie rie ein rechte

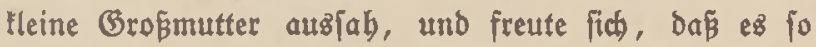
etwas in Samburg unb gar in ciner Wirtjhaft gäbe; er batte gemeint, ganz Samburg twäre nidts als bobe Soäujer, fhtweres Wagengeraffel unb grope lärmende Menjien . . .; aber er tonnte now fein W̧ort fagen. Uljo faß er und fab fie an, wie fie ber Reibe nach bie Bücer aufidlug uno bie Titel vor fich hinjagte: "Die (Boldfelder 2ujtralienz ... Niebubrs Treife Durch) 21ra=

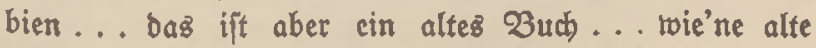
Bibel ... mein Sott, wie altmodifh! Was rollte ber Mann benn in Arabien; ich babe noch niemals gebört, Daß̧ einer nach 2lrabien ging... Die 3ufunft der Levante . . Amerifa, Das Lano Der unbegrenzten Nïg. 
lidfeiten ... wumberlide Sitel... na, meinetwegen!

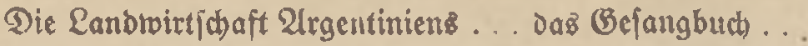
dab Reue Teftament . . Gdhiller Gebidte . . Balladeu won Slbland... Was foll er aber bamit ... mit Be= bidsten ... uno dann nod von einem Slblano! . . SAnd bie andern Büdser? . . "Gie fdhittelte ben alten reipen Siopf.

"Ia," fagte er ... "bamit er tweif, wie ez da ift." Slnb mit beller 2lngit in Gejidst: "Er fann boch nicht aufs Beratewobl in bic $23 e l t$ laufen!"

"2ld," lagte Die 2llte, "marum nicht?" und idütteltc lvebmitig ben Sopf, "laß ign laufen! (Er fommt wieier oder er fommt nicht wieder!"

"Er muß aber roicberlomurn!" lagte er uno Tränen ftürzten ibm aus ben 2lugen.

"शlun, nun?" fagte bie Alte, "Du baft ia nod (B)eidwifter genug."

(Ex weinte auf: "Das twobl," fagte er, "aber toir ... wir balten to fdrectlid viel voneinander . . . vir balten sujammen twie Pech uno Seer!"

"Go!" . . fagte die alte Frau mit fitillen, nactbent. lichen 2lugen: „einige 10, anbere anders. Dein Mann ift über alle Berge... unb meine Rinder lommen nicht unebr gu mir ... id gab ífuen nidst Beld getug. Эa ... ja! fo was gibt es allez im Qeben! ... Nun

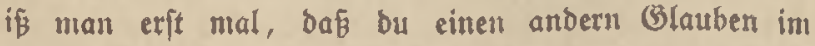

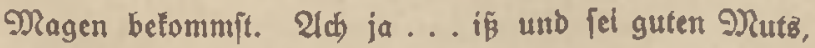

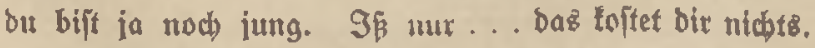
Peinen Bruber follit Du aub feben."

Êr af unt fammelte feine Gebantell uno börte mun 
aud) von jenfeitz bes (Banges Qärm uno Radien uno Mufit, unb badbte voller Mitleib: , Der arme Denich . . . Figt ba mit feiner Rot allein in feitter Ecte und muß diefe Ruftigteit anjchn!' Er ftand anf und fah bie alte Grau bittend an.

Sie erbob fid langfan ant ging mübjant thber bic Diele und trat an bie Sur, fijob Den Zorbang, Der bor Dem Ileinen Genjter in ber Sür war, zuriud, jab binein uno fagte: "sutu, ba ift cr."

Er fab binein umb fab da acht oder zebn Dlann,

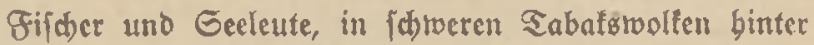
Daunfenden Groggläjern um einen rumben Sij fĭsen, mitten unter ibnen feinen Bruber Ëggert und bie beiden Qubwigz. Cinige unterbielten fich lactent mit einter

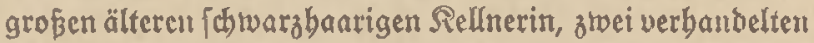
mit grobem Gifer und Lärm eine Ertreitfrage, einige fangen mit guter Etimme arweiftimmig ein Seimmeblieb, 23ruber Eggert aber fa ber unter ber offenen, fdumtigen Sadte ein breites rotes (क)leierartiges Tut) un ben Leib trug, auf bem Sofa. Gie faßen Edulter an Gaulter, jeder feine Daultrommel in ber Soanb und fitritten fid mit 3eichen, Gingen, TrommeIn unb Radien über ibre Sunjt. Ser Dulatte fpielte eine Weije, bic twie baz Gtibnen einer Goub. larte llang, und war offenbar entzüft babon; Brutber Eggert aber fकlug vor Zergnügen über bie verrüdte Dufit auf feinen Gdbentel unb auf ben Sifch, baß es tradjte.

"Gichft bu," fagte bic 2llte, "Da ifit er! Gie geben in cince Gtunbe an Borb und feicrn 2abjhieb. Dut 
fiebft, er ift gat nidjt in Not. Sobiel ich von bet $\mathfrak{B}$ elt

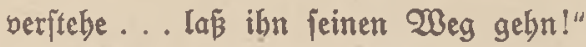

"Tein," fagte er jäh, voll brentendem jab̉enen (Eifer: "Sch) will mit inm reden. Nun erit rect)!"

Die afte Grau bffnete bie Sür und rief: "Du da im Gofa ... id meine niळt Den Gelben ... Du! Deiu Bruber ifit hier unb will mit bir reben."

Eggert war im felben 2ligenblict, ba er că hörte, wieder

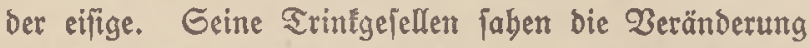
uno bie meilten fdrbiegen. (Er richtete fich fteil im Rücten uno fagte läfifg tno gleidjgültig von oben herab: "शng er berfonmen."

Gein Bruber lam beran unb jeste fid) neben ifn und legte auf ben $S i j($, toas er mitgebracht batte, und fagte: "Sier find Bilder, Eggert . . . die follit bu gern mitnelymen ... unb bier fino einige 3itd)er."

(Fr fag mit fojiefen 2lugen auf bie Bilder und idhob fie bem Zruber rvieder zu. "Sth rill nichts bavon," fagte er. Er fah bie 3 ücher, Eannte fie und fagte ber=

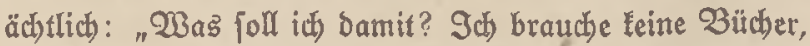

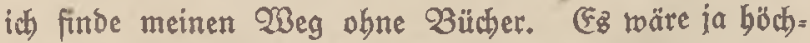
ftenz daz Neue Teftament . . roegen Der (Sejhichte vom veriotenen Gohn. Dešnegen baben fie bid) wohl binter mir berlaufen laffen. Geh mit Dem ganzen Rram!"

Ta itand einer ber Rubroige auf, lam um ben Sijh berum, berübrte ben Rnaben am 2̈̈rmet und jagte freundlidi) mit rubiger Stimme: "Eg nüpt bir nichtz, Reimer, bu

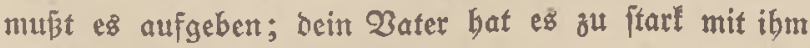
verdorben. $\Im$ hr müßt mun abroarten, ob bie 3utunft es wieder in Oronung bringt." (Er toollte nod) mebr 
lagen, da fwrie Eggert, treiberweip in (Fefidt: "Gag” Deinem Bater, ich bätte es wirtlich getan! Sh twäre ber Pfeifer! Эd) bätte vom Sauss tweg wollen, ich bätte ben muffigen (Geruch zu Saufe nicht mebr ertragen fömnen, Darum bätte ich ez getan! Dak er ftolz ift! Dap er red)t gebabt hat, uno als ein roabrbafter Mann in die (Grube fäbrt!"

Ter Rnabe riditete fich auf und fagte, inbem ein fhönes Qeuchten über fein Gefítht ging: "Bruber... unjer Bater bat fich geirrt... jeber Nenjid tann irren... Bebente ..." Eein Bejicht trat voller 3uttauen und Ruit, zu trerben, zu geminnen, des Brubers Geele zu erobern. Er raa Daran, fum exftenmal in feinem Leben, einen Meniden zu bilden, eine Geele zu überivinden.

2ber ber Ginnlofe fprang auf und ftand mit rajenber Bebärde vor ihm und bob die Saand, ihn zu ihlagen. 2ls ber Snabe aber fteben blieb und ifn mit biejent reinen guten 2lugen anjab, als rollte er jagen: , $u^{\prime}$ es, Bruber! Bielleicht bilft es bir und lbit Deinen 3orn!"

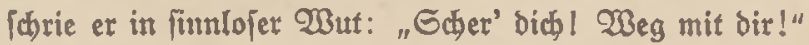
uno roiez nach ber Titr.

Da fübrte Der junge Qudwig den 2ufroeinenden auz Der Gtube wieber fut ber Ulten, verfuchte ibn zu tröjten unb jagte freumblich: "Du muft es nicjt glauben, was er jagt... er berifellt fic jegt in allem, toas er tut uno rebet. Gag' beiner Nutter, Daß́ toiz allez̉ getan baben und noch in biejer Gtunde tun, Daß er uns ppäter mal jabreibt. Wir maఓjen das jo in unjerer Weije, fo von achtern, obne da euci) twill er nun vorläufig nid)ts twiffen... (Beb nur 


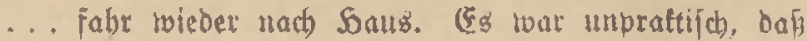
bu tamit. 2luf bieje Weife wirb es̊ unt immer fojlimmer. (Beb nut . . Dein Patet bring' ich bir wieder mit."

Die alte Grau fab ibn mit ftillen, rubigen 2 ugen an ... "Du mupt ibn reijen lajīen," fagte fie. "Das Reifen, das æBeiffortlaufen . . e einerlei, wobin ... das ift nun das bejte fuir ign. Rennft bu bas nicht auch ein renig? 2 iff bu nicht aud fo aufz (Beratetwobl von Srauje roeg gegangen ... i id fenne boch Deine (Begend ... nad ber Beeft binauf . . und bartn immer fo beiter ... uno bu warit toll bon Ertwartung, ob ba nun ein 3 erg bon (Glas täme oder ein Poil in ber (Frbe mit einer biclen siröte, bie wabrjagen fonmte?"

"Эa," jagte er alttlug, mit bocbmütiger Gicherbeit: "2lls ich cin Rind war, ba bachte ich fo!"

"Sa," jagte fie, "viele bleiben biz zu fünfundjtwangig, und viele bleiben zeitlebents Stinder. Smmer brauf loz ... obne Gebanfen ... obne nach einem Wegtveiler ju jeben! $\mathrm{Q}_{\tilde{B}}$ ibn reifen! . . ou bältift ibn nicht auf .. und toein' nicht fo."

Sie wollte ibn gutücthalten, baj̃ er nods rubte unb ¿̈в. Fr aber bachte nun, da er mit feiner 2ufgabe biet zu Ende war, an bie Gorge, bie fie zu Saufe um ibn batter. (Er banfte ber alten Grau und lief nach Dem 3abngof zurüct.

Unterdes roar baheim auf bem Jof am Deich grope Surub um ifn. Sarm ber Simmermann toar am Motgen in feine Rammer gefommen, batte zu feinem Gdject fein Bett unberübrt gefunden, toar fofort auf ben $\mathfrak{B}_{\mathrm{e}}$ danten getommen, daß̄ er binter bem Beflobenen ber 
rodre, war du den Lubrvigs unb bon ba tad Dell Babnbof gegangen, uno batte fo exfabren, da $\bar{\beta}$ es roar, wie er fib's gedant batte.

A18 er nad $5 a 4 z$ zuridfam uno in Die Pücbe trat, fand er feine Putter vor bem Serd jebend, betr Ropf 3twifden ben Sönben. (E\& twar noch gand früh am Sag uno in ber gropen, niebrigen Rübe nod fajt buntel. Das Feuer warf ben Gdhatten ifrer grop̃en Geltalt, die in Reiten utute, gegen die dunflen 2 alfen. Sie lab ibn mit verzrocifelten 2lugen an und fagte: "Э\$ toeí̈ fकon: Der eine ift über alle Berge und ber andere

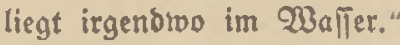

"21ф, PRutter!!" jagte er, "rebe boch nicht fo toas! Deine Rinber geben nidgt ins Wafler... fie baben alle guviel von beiner 2 rt. \$a ... Water ... Der tönnte eB tun ... aber wir, beine Rinoer, nidht. Eggert, ftatt insె $\mathscr{W}$ affer ju geben, ift unterwegs, un auf Den bijchften Berg au llettern uno den Boloflampen berunter au bolen, ber ba liegen foll, und Dann nah Sabren, binten und vorn vergoldet, wieder zu formen und vor feinem 2 ater unb jeinem ganzen Rirchpiel zu prablen: ,febt, roas id flur ein Menjob bin!' Slno Reimer ift nach Samburg gejabren, um feinen 3 ruber nod) einmal ins Serz bu reden uno ibm 23 über au bringen, aus benen er bie Welt tennen lernen foll. Denn er fennt die Welt und tenut die Seelen, fagt er! Cor tann bamit machen, was er toill, fagt er! 2indere, fagt er, fenner fie nidbt, et allein Eennt fie! Bielleicht macht er nachber noch einen abftecher nach Zerlin, um zu verfucten, ob et bem Sraifer eine 3ate bon feiner firone abjobivagen tann. 
Denn er tann alles und zwar beffer als andere Reute ... Ulnd daz bat er bon bir."

Da trurbe fie filller und ging ơ Emma, bie in ber Milchtammer arbeitete, und auth zu ifrem Mann, ber im Etall war, uno jagte ibnen, wo Reimter toäre. Dann gingen fie alle ibrer Sagezarbeit nach. Sie toaren aber alle in groperer 2lngit um den Rnaben. Die Mutter fand am Fenfter in ber Rüche und fpähte nach dem \$eg, Der zu dem Hleinen Babngof fübrte, und nact) Der Gtrafe binaus, Die von ber Gtadt fam; uno wenn fie binaustrat, um deuflidger zu fehen, jah fie igren Mann an Der Ecfe bez Sofz fteben und it diefelbe Ridtung ftarten. Er ftanb ba obne Mäke, obne die et fonft nie das Saus verlié; ;er Wind fpielte mit feinem dünnen ergrauten Saar. Sie ftand lange und fab nach ifm biniber, in ibren grauen Augen ein

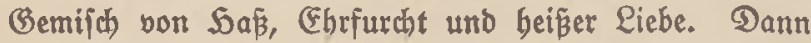
ging fie rieber an ben Serb. Sarm war in bie Stabt uno zur 2rbeit gefabren. 2bends lam er rwieber.

Balb nach ibm fam aud Reimer. (fr ging nidbt in bie Stube, tro ber Bater uns Emma twaren, fondern ging in bie Rüche, wo jeine Nutter uno Sarm traren, unb fegte fich mübe tmb bedrült auf bie 2 afferbant unb erzäblte, wie er ibn getroffen und was er gejagt batte. Geine Niederlage verfdiwieg ar - ez twar ibm zu befdämeno, fie zu gejteben -; ar tat 10 , als twenn Eggert ihn thberhaupt nidft batte zu Wort tommen lafien. 2lis er fertig twar, lethnte er ben Ropf auf ben Sifch und reinte.

Die Dutter, ba fie ben auf Der Wafferbant in 
Gidherbeit mupte, war mit all ibren Gedanten bei dem andern und fab ith fo ... fo zornig und finnlos in bie $\mathscr{W}$ elt laufen, und 3orn und Rummer folugen über ibr zujammen und fie jagte jäh, mit bojjem (Beficht: "Euter Bater bat nir meinen Sungen ganz verrült gemacht. . . und er ... er felbft ..." und fie wollte ein argez Wort

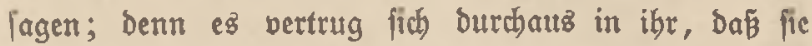
ibren Mann über allez liebte und igm Danach zumeilen bitterlich gram twar. Shre Riebe war bie bes Blutes unb nicht Des Beifter. Begen feiren Geift batte fie oft gebabert.

Uber Sarm fam ifr zunor und fagte flar mo bart: "Gtill, Mutter! Wenn du fo etroas fagen mupt, fo lage ez vor bir allein und nicht bor ben Obren beiner Rinder! ... Slno nun will idu eud beiben mal etraz jagen ... mas ich mir beute bei ber 2rbeit und auf bem Weeg fo ausigebacht habe . . Sört mich an! . . Waas ift unz in biejem Winter paffert? Da ift zuerjt bas Pfeifen! Wir wiffen nicht, twas es getwe [en ift... Ein Tier ... ein Windftop ? Raum möglid ... Eggert? Tein ... ex fann robl Garen machen und ift ein Shelm... aber feblt ifm das Rajhe und bic Şlăue, bie zu foldhem Gtüct gebört; aud bätte er finh, nachben (Emma babon zujammenbrach, ganz anderz be: nommen ... Die Qubrwigs oder fonft jemand vom Dorf? Uber twie follten bie fo flint und ungefehen über bas leete Geld furüdfommen und twarum follten fie es tun? Das

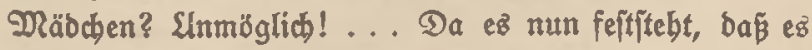
irgendwie und zwar natürlich zugegangen ift . . Denn an Seren glauben wir nicht... fo bleibt ber Rnedt. S屯 
lage, ber Rinedht bat es getan! 2lber warum bat er

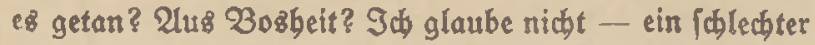
Denfid) war er nicht. 2lus purer Quit am Slnfugmadien?

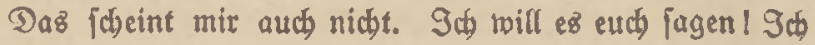
will jagen: es lonnte ifn irgent etroas in unjerem Soufe geärgert oder gereizt baben ... irgent etwaz ... uno bas fönnte ihn bagu getrieben haben. Slno toaz wadre bas? Waż fonnte biejen fremben Menisen tränfen und reizen, Daßs er bies Gtüct auffübrte, baz num als Elend über unz

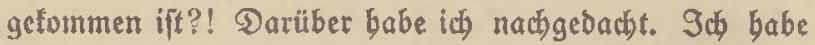
beute zum erfentual in meinem Qeben berjuctit, unjer S.üz unb unz alle mit den Augen eincs fremben Menjwen, der von brauben Gereintommt, anzufebn. Was fonnte ibn ärgern, und zrwar mit Recht? ... Sund ba will id euth nun dies lagen: Gebt, da ift Der Bater: lvie ift

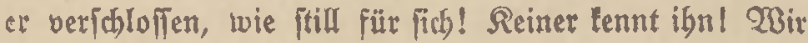
Sinbet... toir abnen ibn mur. Ou jelbit, Dlutfer... ich febe es oft an bem 2 lict, mit Dem ou ibn anjiebit: Dus fragit immer nod, an ibm und rätjelft. Reben,

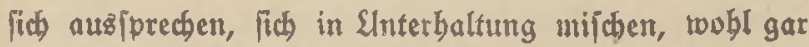
lebbaft werben: bas if für $i \overline{\text { n, }}$, was für einent unge-

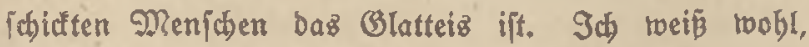
daj ex im ganzen uno groben unjubulbig an biejem feinem $\mathfrak{B e}$ een ift. Geine Borfabren baben alle auf einfamen Sobfen gearbeitet uno ein jeber ging eirjan

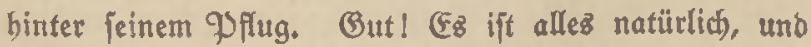
es ifit allez fo rabr. 2lber weldsen (Findruct bat ein Frember bavon?! Ciner, ber aus einem lebbajteren Wolf fommt und felbit ein beiterer, gedanten= unb redes

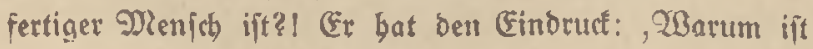




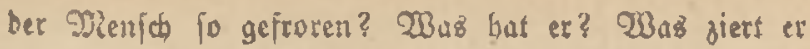
ficb? Waz ftellt er fich an? Sit er bodmütig? Sift er itolg? Eint bie Menid)en nicht gut genug für ibu?: Gieh, fo mudte Der Rnedt mobl benfen! Suto weiter: Da bift du ... Du! du bift eine gute Frau uno Putter; ou bifi fogar febr gut! 2aber bu bijt at ftoly auf Maun und Slinder. Obgleid) du zuweilen

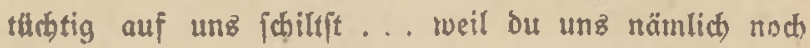
länger, nod ftolzer, noch flüger roünfchit ... bu bift Doch überzeugt, Daß teine Grau einen fold)en gropen, rubigen und ernften Raun bat uno fo fluge unb tüd)tige Sinder, twie bu. Den Orbert anderer Familien, anderer SPinder fiebit bu nicht; bein Slrteil ift rafd), und meifit ift es bodfabrig, und oft ift es bart. Dieje beine 2let fab ber Rnecbt und Dachte: Thas föllt der Grau ein? Waz bat fie? Dieint fie, Dai anbere Mütter nicht aud) wacfere, Huge Rinder baben? $23 a z$ fällt ilyr ein? Sit

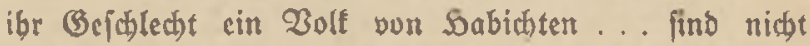
auc Gperlinge barunter, find fie nidjt vielleidht alle Sperlinge?" Weiter . . . da fino twir Rinber! Wie bod) benten toir son biejem Sof, wour diefem Sausz, von unjeren Eltern, von unferen Gejchififern! Frembe SDenfhen? Die brauden wir nicht! Wir gebn uidt zu ibnen; fie mögen zu unz lommen! Wenn wir aber mal mit ibnen 3ujammentommen, fo baben twir Gorge ... bejonders ou, Nutter ... ob twir auch mit reinen Ellbogen nad Soaufe tommen ... Sieh, to ift es! So ift unjere 2let! Und baz fonnte ein Eluger Frember 1 obl bald ertennen, unb es tonnte ign roobl reigen, uns eitur Sort anju-

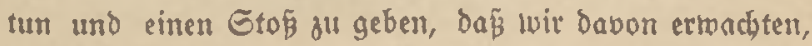




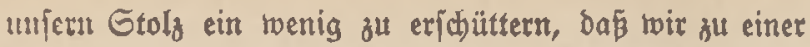
neuen Erfenntnis fämen. Slno fo glaube ich Dern, daß Der Rnecht Der Preifer getwejen ijt. Daß̄ jein tleiner Stoß fich jo idylimm, fo beftig, ja jo verberblich aus. rirten twürbe, jo twie ein Gteintwurf inz Waffer Welle auf Welle fortwirft: Emma bauernb frant, Eggert befdulbigt und in ber weiten Welt, unfere ganze Familie berftört ... Da ba bat der Lump, ber lecfe Sanz= twurit, nidjt bedacht und nidjt getwollt ... Wir aber, Mutter, wir muiffen, waz er $b \bar{b}\lceil e$ gemad)t bat, zum Guten renden! S(b) fage euch): roir müffen banach

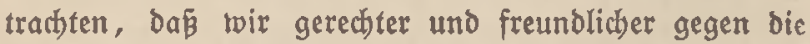
Menichen fint, auth mitteilfamer! Bring' Bater unter

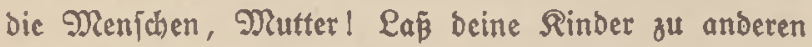
Sinbern laufen alż zu iŁrez gleid)en! Greif nidjt gleid) an bein rotblonbes Soaar, als wenn bu es raufen willit, wenn fie mal einen unfeinen 2uв̈bruct ober gar ein

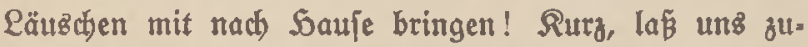
traulidher, freundicher, mitteilfamer, neugieriger, rejpcttvolfer zu anderer Menjben Qeben uno Weije merden!"

Go rebete ex. Es fommt für einen jeben SMenfden, ber fich voll ausiwächit, ber Tag, wo er ben (Eltern gleich wirb, und banach ber, too er ibr Gührer twirb und

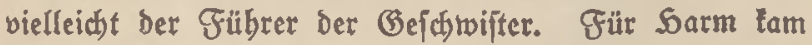

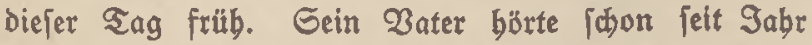
uno Tag auf ihn; ez roar ihm ein angenebmes (Befübl, eine (Empfinbung von leifer Gicherbeit, wenn er ihm zus Görte. Geine grope Nutter geriet an biefem Sag unter

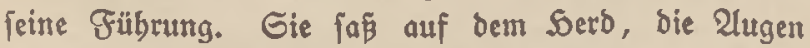
fragend auf feinem Beficht, bielt bie Sämbe im $\sigma_{\text {cho }}$ 
und fagte fein 20 ort. Eein Bruber Feimer jab mit thugen, emften 2lugen zu ibm auf. Ulnter feinen $\mathfrak{G}_{\mathfrak{e}}=$

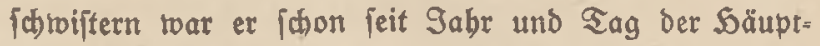
ling gerwejen.

Gie jaßjen noch lange beicinander und beredetent noch, Daßs fie unter fich nun bicjen (Blauben baben wollten, bak der Rnectit ez getan; und fie roolten es auch den Rleinen wenigftens andeuten, bamit fie benn aljo ficher rären, baß bie unbeimliche ßegebenbeit fich nicht twieber= bolen würbe. 2utb Dem Bater roollen fie ibren Blauben mitteilen, aber mit bejonberer 2 orfictst und nur alz eine unfichere Meinung; Denn bem Zater ruitrbe bie flare (Ertenntnis, baß̧ er feinen Eobn falich bejhuldigt bätte, faft zur $\mathfrak{B}$ erzweiflung bringen. Emma aber wollten fie nichts jagen und auth den andern verbieten, eż ibr z"I jagen. Sie betrachtete und itrcidjelte mit 2lugen uno SJänden Das̄ fleine goldene Sorz, das ber Rnecht ily: gejchentt, und biefer Glaube und bieje Freutde jollte Der fo Gtillen unb Staurigen nidjt beritönt twetben.

Ulz ez शachtgeit twar und fie auszinander gingen, fagte Sarm in ber Rammer zu Reimer: "Sh gebe ja nun in acht Sagen nach Riel und fann aljo nicht mebr widdentlich nad) Soauje tommen und nach ben Rechten Feben, und Eggert ift roeg. Eo gebt es nun nicht an,

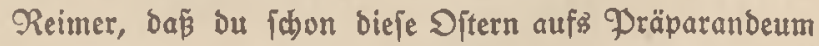
gebft. (Es gebt nicht anders: bu muß̈t noch ein $\$ a h r$ beim Sauje bleiben, bamit Zater, nadjbem Eggert tweg iijt, boch eine fleine Silfe an bir bat, nicht allein bei Der 2lrbeit, fondern auch, um feine 2 lot mit zu tragen unb ibn zu ermuntern. Denn toenn er trübfinnig witto 
oder in Betzmsiflung fiele, baz wäre itber bie Mlaß̧ farrectlich. Es mus auct) jemand bier fein, ber nir orbentlich Rachridt fduidt, trie es mif jebem einzelnen uno mit allen gebt uno ftebt; benn mit Mutter Briefen if

Der kleine Reimer fab ibn mit feinen bübjchen, thugen 2ugen ftill an uno lagte: "Das babe id mir alles genau fo gebacht ... mertwübig... gennu fo, wie bu ez fagft! Sch bachte mir, baßs du genau fo benfen uno zu mir fagen roürbeft. Nertrürbig, wie genau th immer weiह̈, twie es in einem anberen Denfकen ausfiebt!" 


\section{Rnpitel \\ (T) $\mathfrak{g}$ äbnlein}

Q1 cht Sage ipäter fuhr Sorm Dtt nad Riel und 2twurbe bei ber erfen Matrofendivifion eingetleidet

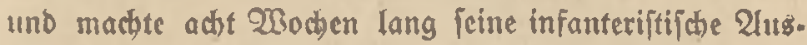
lilloung burch. 2llz bieje beendet war, fragte ibn ber Sapitänleutnant, bem ja twobl peine belle frielifiche (Er.

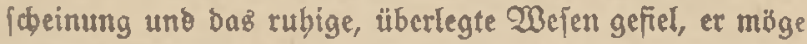

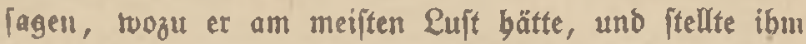
Guntentelegrapbie oder Gignalweien oder Beidüts zur 2ustwabl. Er batte fid bie berjdjebenen Tätigleiten, aud) bie Räume, in benen fie augigefïbngt wurnen, angeieben, und entichlop fich fürz Befdurï, meil ba eine tüdtige Sechnif babei toar, uno man boch wenigftens einen Heinen 2 lid ins Greie batte, ja auf einem tleinen Preuzer fogar ganz in freier Quft ftand.

Er tam auf ben fteinen Sreuzer, Frauenbant" unt lourbe exft britter Danm am Befoüh. Fs ging ibm

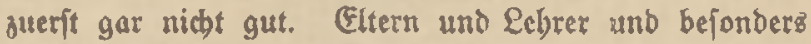
Der Onfel un Eebrmeifter, Der voller Edjelmerei $\mathfrak{a}_{\bar{\beta}}$, waren allzu roichtig uno gütig mit ibm gewefen uno batten tbu gern reben und bandeln laffen, ba fie feine Berftänoigleit uno Rube erfannten; und fo war er ctwas au üppig ins Rraut gefकoffen unt mit 230 tten und 2lnfictst ou raich bei ber Sand. Und es zeigte fí, baß bie Rebte, bie ber Rnecht nach feiner Meinung peiner Gamilie gegeben batte, juerit für ibn felbji zur Intwertung tan.

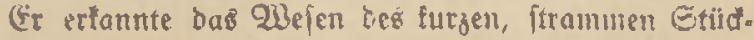


meifters trobl; aber ertannte es nidgt vollig. Der Gtildmeifter bielt fie alle, fo twie fie ba waren, gute unb

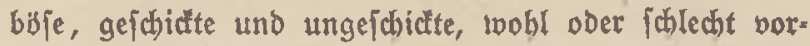
bereitete, nicht allein in ber Befdübbebienung, fondern liberbaupt in ibrem ganzen Menfchentum für 2lnfänger; er bebandelte und unterrichtete fie als wenn fie lauter erfte Menjuen, Iauter 2lbamz wären, bie er in biefe Beit und ibre Begriffe und (Bejhäfte, Rünfte und 2lnfid)ten einführen müpte. (Es twäre noch angegangen, wenn er fie für 2loans vor bem fall genommen uno

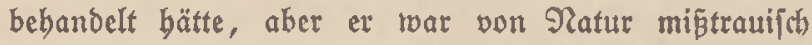
und permutete leidjt böjen Willen. SRurz, er baute fie nicht aus Borbanbenem, er baute fic aus bem शichts heraus auf, und Soarm Dtt batte, gerabe tweil er ber verftänbigite und überlegenfte toar, feine Not mit ibm.

Dagu fam in ber britten Woche ein belonders un= glüfliches (Ereignis. Sie fubren nah) einter S̈bung auf Dev Reede von Selgolanto mit Rurz nach Wilbelms = bafen und freusten beim oritten Feueridiffi die Elbe; und Soarm Oft ftand fo um ziwei Slbr nachmittags in feinen gropen, fanweren Geejtiefeln - benn eż war Wind und Regentwetter - an ber Reling, da lan ein Frachtbampfer von etwa fünftaufeno Tons bie Elbe berauf und fubr nicht mehr als zrocibundert Neter an ibnen vorbei. 2llz ber Sanipfer in geraber Rinie neben Der, Frauendant' twar, $\{a b$ er, dáp es einer yon ber

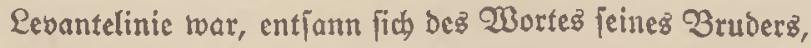
Daß̃ Eggert Freube an einem Rebantebuch gebabt bätte, fab im jelben Sugenblict eine Figur am Sect fteben, bie am Enbe fein 3 ruber fein fonnte, verlor in auf. 
wallender, heiper Liebe uns Gorge alle lliberlegung, unb vergá das Verbot, um diefe Etunbe über tie Ganange zu gehn, weil ber Rapitän in jeiner Rajüte jeine Nittag. rube bielt, trampelte mit jeinen grōen Gtiefelı über

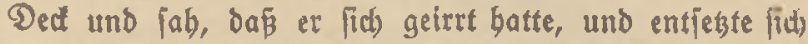
jugleidh, oas er jenez Berbot libertreten batte. 2118 et fich wieber umbrebte, erichien aubl idjon ber furge uno grobe Gtüdmeifter und fdrie ibn an; und ex mufte sum Rapităn binunter. Er Dadyte, ber roittbe ifm ben Ropf abreipen, benn er war ein eftwaz eiliger un jüber SRam. Und er faudfe aud twie ein Siger. 218 er aber banu Den groben Eag fagte: "Slno das tut io einer ... io einer ... Det ausifiebt wie'n Denids!..." uno Der

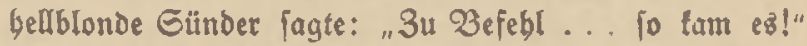
fitoctte ber 2 interid) und rourbe rubiger, uno fragte, toas benn los getwejen träre. Da berichtete er turz bon feinem 3ruber. Da wurbe ocr Rapitän yang rubig, ricf den Stüdmeifter und iagte: "Fs ift in Orbnung," uno warf von ba sutweilen 2lugen auf ibn, bie nicht unfreundlich waren. 2lber ber Gtüdmeifter bebauptete, wäre von

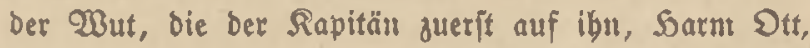
geworfen und bann wieber bon ibnt abgetworfent bätte, ein Gtüd auf ibn, ben Gtülmeifter, gefallen ... bas twäre inmer $10 .$. das twäre baz Gdidjal beret, bie

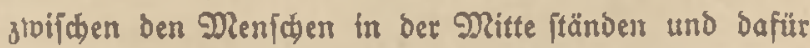
ju forgen bätten, baß̧ bie ganje Rifte richtig gepactt toürbe. Slnb er blieb Som Ott gram und madjte ibus Daz Qeben jauer.

(Fi wurbe trogbem gegen Ende Deb erfen Sabres Obermatrofe uno macte im Frubjabr ote Reife nach Grentien. Die Brather. 
Den $\mathfrak{A}_{z \text { oren }}$ mit, roorauf fich bie ganze Mannj daft fithon das ganze $\$ a h r$ binourch unjagbar gefreut batte. (Er freute fid an allem, was er fab: an Der langen Reibe ber machtwollen englijchen Rriegsidifife, an benen fie bor Queenstown borbeifubren, an ben frembartigen Gijcher= fabrzeugen an ber panijhen Rüfte mit ibren Männern und Gegeln - wie leicht fie waren und in ben $23 e l l e n$ tanzten! - uno an Dem blendenden Błanz dez Lichtz, Das nom Simmel berabbrach uno bie reite tiefblaue

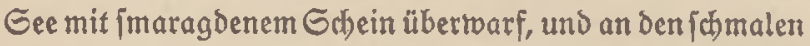
Straben in Fundual, beren Quft in Gonnenglut bebit.

In Fundal lagen fie brei Sage auf Der Recoe tuld fie waren ztweinal in ber Etaot, Hletterten in Saufen unb Säuflcin in die Weinberge Ginauf, rutichten auf ben Ochjenjalitten mieber berunter, frricben burch bie engen, bolprigen, jhmubsigen Gtraßen, ftanden bor ben Qäben mit ifrem Gđjund uno Tano, uno fǟen zulez̧t, jects ober fieben, alle fo jweiundzronajg $9 a b x$ alt uno Obermatrojen, uno barin gleid), Dafi fie alle empte Seute waren uno auf jich bielten, unter einem gelben Gomnenjegel an Den fleinen Rarmurtijhen und nippten an jüpen panijhen 2 ein uno blinzelten in bie golbene Glut, bie in bie Gtraje hinunterprallte. Gie batten ph( fo gejest, daßj fie fern auf der Reede ibr Gdiffi leben tonnten, das ihnen, feit fie auf frembem Dreere trieben, nod) viel mebr als babeim, Scimat, Gtolz und Qiebe เvar. Berlumpte शlänner gingen vorïber, barfū Tücber um Salż unb Reib, bas pechid)warze kaufe Saar tief in bie Gtirn binab, bic 3igarette läifig im Numb, Frauen mit ftumpfen fătoarzen Augen in bunten Ropf* 


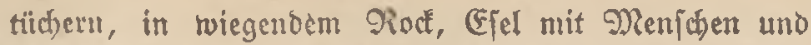
Grüd)ten belaben; eine feingefleidete Frau mit ichwargent Epikentud um ben Ropf jकritt rajळ vorüber. $\mathscr{D} a 8$ PFlafter war famusig, ilberfät bom Mijt ber Tiere, won 2lpfelfinenid)alen und Bigarettenenden; ein toter Sund lag im Rinnjtein.

Gie japen ba ziemlich lange und faben auf bas bunte, frembe $\mathfrak{B i l b}$ und famen in ihren Gebanten bon felbjt auf bie Scimat und ibre Menjaten, wie fie jo anders wäre, und faben fie im Geift, und kamen zulest jeoer auf jein eigenes Qeben: roie ez benn nun getommen

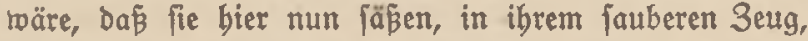
Natrofen, Obermatrofen, weld) einen Weg fie gegangen wären. Slnd fie überbachten $e^{8}$ und fubjten bie einzelnen Gtationen zu erfennen, io mie man auf einen $B$ ergroeg zurüffiebt, Der balb jchon im Siébel berjanf. Gie twarent alle ftrebig und ein roenig ftolg barauf. Qangiam, ruct: reife, ihnen jelbit unberwust, bom Sage das Geine nebmend, waren fie zu flarerer Ertenntniz, zu belleren 2lugen, zu itrafferem Willen, zu rajcherem Gdyrung,

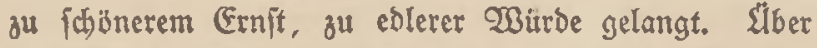
bies allez bachten fie nach; und es bauerte nicht lange, fo rebeten fie hieriber. Sie fpratien Darïber: ob und Durd meldbe Begebenbeiten, vielleidit gar burch welche cinzelnen, ganz beitimmten, ein Nenj(h) ein Qid)t betäme,

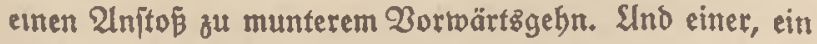
Dunfeľblonder Württemberger von breiter Gigur uno

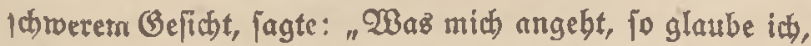
Oaßetn ganz bejonderes (Erlebniz, nämlich) cine Slnterbaltuna, Die id eimmal batte, mir eine grope Silfe getwefen iff." 
Da fagten fie: "Erzăble!"

"Sa," fagte ber Gdwabe... "the ribït, on vor vierzig Sabren viele nach 2lmerifa aużwanderten, weil es bier im Lanbe noch alles bedriidt und ent war. Dlan arbeitete bier now nidbt bell uno frifh brauflos, uno man lachte auch nod) nidht auz freiem Serzen. Nun, ba wanderte aud ber Gobn umerz Rabbarn aus, fiebzebn Sabre alt, ganz arm, Rino eintes Sagelishner8. (Durch vierzig Jabre börte man wenig oder gat nichts bon ibm und man hatte ibn fait gatt vetgeffen; nur feine Equlfameraben und Sugendgenoffen, Die Sagelöhner bez Dorfez, fpradien noch jutweilen bon il) $m$, weil fie ibn germe gemodt; benn er twar ein

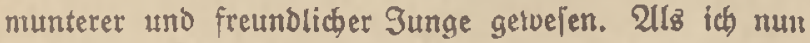
wor einigen Sabren - id batte meitte Qebrzeit binter mir uno war achtzebn, und roar mädstig gierig auf ein

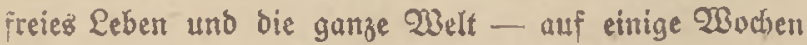
nach Souje fam, toat er, zum eritenmal nach vierzig Sabren, wieber nad) Deutichland gefommen und twar in jeinen Seimatsoorf. Es toar Gommer uns am Sag bes Rinderfeftes und er nahm baran teil; und autb alle feine Sdulfameraben maren augegen; bent biez Gejt ijt in unferm Dorf ein groper Sag für alle, weil bie Rinber ja uts allen gebỉren. SUno ba waren bent nut ant

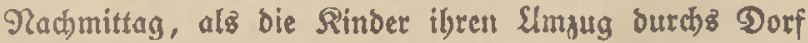
beenbet batten, alle, bie von feinen Sugenogenoffen noch rebten, un ibn verjammelt unb er ftand unter ibnen unb plauberte mit ibnen, gand in alter 2 beife, von vergangener 3eiten. Und febt... ba mar nun bet Unterfaied! Die offteren Sduffameraben uno Sugenbfrentno, bie in Der 
Seimat unb im Torf geblieben, bie waren geblieben, boas fie bamals getwefen, uni ftanben ba: berfnotrt, gebeugt, unficher, arm, fo redht twie fotefe, alte Weibenbäume an Dürren Slfer; er aber war, obrwobl man aud ibm anjab,

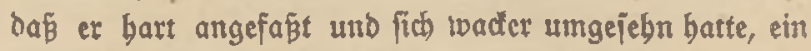
Mann geblieben, wic bie शatur in ibm getwout batte: 'Ttattlich und grabe, mit bebenden 2ugen, mit rubigen, fobjonen Bewegungen und fid)eren frifhen Worten; unto er fprach ou ibnen bon $\mathfrak{W e l t}$ und Men. fden, bavon fie nicbts gefeben, bavon fie fich nicht eir = mal ein Bito machent tornten. Slno renn er aud wobl bon Beburt tïchtiger nar, als bie meiften, bie ba um ibn ftanben: er trar bod alfu boch iiber fie auftuärts gefitiegen. Scht: biejer Unterichieb fiel mir jungen Edjelmen auf und mactite mir fajwere Bebanten, fo bafi ich Den ganzen Sag ftumm umberging. Slno als er am 2benb barauf bei meinen Eltern zum Befuch toar und

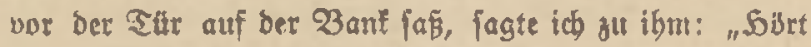

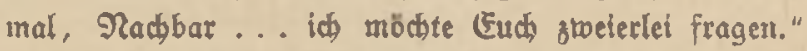

"Ex toarf ben Ropi fll mir unb fagte in jeiner leb. baften 2lrt - id glaube, ex roar in feinem Gtaat ba nrtiben fo roaz wie 2lbgeorbneter uno war gewohnt, fith bie Dinge in Sopf au oronen --: "Slberlege bir gut unb fonm in ber richtigen Reibenfolge."

"Ia," fagte id, "bie Reibenfolge ijt faton ba: erft"

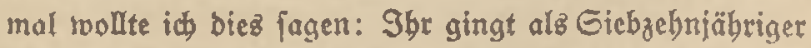

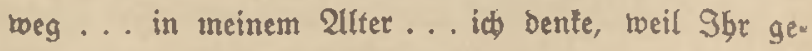
bört hattet, daß man bort weiter fäme. (Slaubt 3 br nun, bas $96 r$, indem $9 \not b r$ auf biefen Gedanten fant und ign auci ausfübrtet, eure Sugenogenoffen, bie ba 
geftern mit (Eud) auf bem Platy itanden, an Beift unb Willen überragtet... ober bat bas Land ba brüben (Eud) po weit gebracht?"

"(Erjt Dad)te er ein wenig nach, Dann jagte er: "Beibez! Ich war wacher und rajher als bie andern. SUnd Dann: das Leben bot Dort mebr Möglichteiten ... 2 Aber nun iit ja auch in Deutichland Leben und Wandel genug, und twer fann und roill, wirb auch bier twas erreichen. Run Das 3weite."

"Эa," fagte id ... "Daum wollte id nod wiffen:

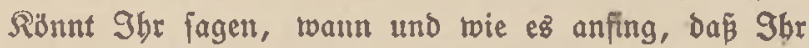
in wirtichaftlichen Dingen vor vielen anderen vormärţ tamt?"

"O ja," fagte er, "Dab tann ich auf Tag unb

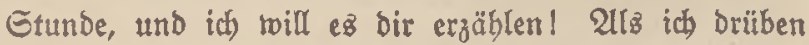
brei Sabre bei cincm englifden Garmer, nicht weit von ciner fleinen Gtadt in wiatonjin, gedient und Eprache, Ranb und Qeute fentuen gelernt batte, zog id in eine andere, etwas entferutere Gtabt biefez Gtaates. $9_{\phi}$ zog Dabin, weil id gebort batte und aud jelbit erfannte, Das fie, jest noch flein, wachfen wïrde. Sch war ba erit ein balbes \$abr lang 21rbeiter... fo bier und ba .... : $\mathbf{m}$ zu jehen, wo fĭh eine Belegenbeit böte. Ulz ich bann exfannt hatte, wie alles lag und ftand, machte id mit Dem verbienten und exiparten Gelo an ber Gtraß̉e, die nad) ber beften Farmergegend fübrte, einen Heinen Qaben auf unb verbäferte und verjchidte Waren an fie. $\mathscr{D a}$ id) nun forwobl wach twie ebrlich war, ging basె (Gefchäft ganz gut; tmo mand)er - nun böre zu - toäre zufrieben gewejen und bätte Dollar auf Dollar 
gelegt, gang langfam, immer beibe Augen auf ben bertlichen $\mathbf{S} a g$ geridjtet, wo er als ein Kleiner Rentner twïrbe leben tounen, weil er icton jest nidht red)t mebr arbeiten, benten und rachen moshte, furz, tweil er fojon íçt nicht mebr leben modjte. Denn ift bas Reben: im ielben Bebarren immer auf biefelbe Etelle treten?! Эab rar einez Sagelöhners Rind aus biejem itillen Dorf; id fam aus grober Siefe und Gtille. Sch batte von meiner armen, engen Sugend ber nod) idtwere (Erbe an

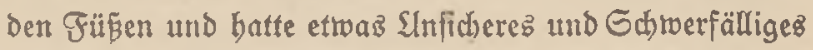
an mir, ober vielmebr in mir... genug, ids trat auch), twie jene Qangreiligen, eine 3eitlang, cin \$abr lang, auf diefelbe Etelle. Aber Dann ging ez porruärtz. Und den Tag und dic Gtunde tann ich netmen. cincz Bormittagz dabei tvar, für meine Runden, Die Farmer, Riffen uno sibrbe zu paden, und bie zweite uno oritte ... Damn bie fiebente und adte ftopfte, pacte und nagelte, fam mir plosklich ber Bebanfe ... mundere bich nidht,

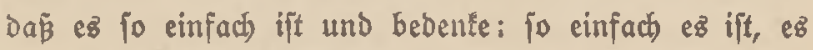
entbält, glaube ich, alles Bortoärtżfommens Brumb uno Slrjache jotwobl ber cinzelnen Menjळen wie ber ganzen Bülfer . . . iđ bachte: Das, was bu bier fult, wabrbaftig ... Das tönnte ein anberer tun: ein Süngeter, ober ein G(hwäderer, oder ein Slnbegabterer, oder ein Gdläfrigerer! Er fönnte es cbenfo gut toie bu und fönnte fich Dabei trohl. befinden. (Du aber follteit Echwererez, Neuerez, Yornebmeres tun! Eo bachte id) und riditete mich auf, uno trat

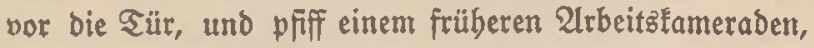
der ba über ben Plaßs ging. Sieh, von ber Stunde an bin

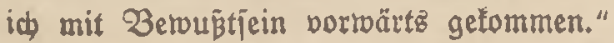


Gie niden alle tumb lagten: "Sa ... ja . . bo b Iif $e$ ! !

(D) beugte fich Soarm Ott var und fagte, ein wenig verlegen: "9a ... ba bel dir bar es alfo ein Menifo!

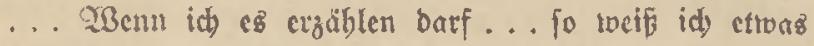
anderez zu beridyen."

"Er子äbl"!" fagten fie.

"Ia," fagte Sorm Ott ... "th ... th tom fo um lechzebu, fiebzebn und in oer Lebre, und wurbe onn meinen (Eltern uno bem Qebrbern ein bißshell zu weid behandelt... da geriet ich in eine Bejedfdyaft von jungen Wenjiłen, bie mir loobl fürz ganze Leben băttc werberblich werden tostmen. WBir Latten allejamt Ratber und machten damit gemeinjame Fabrten, und bemtsten fie bejonder fonntäglich, und ztwar zu dem Stoect, uns recht weit von unferem Soimatşbezinf ju entfernen. Dort, einige Meilen in ber Grembe unt in einigev Sidarbeit vor Befannten, tricbell wir uns bann balbe Tage untber, prablten in den $2 B i t t j$ aften, rebeten ältere Seute mif alfflugen, prosigen Worten ober toobl gat mit Tlectereien an, beläpitigten uno ftäntten junge

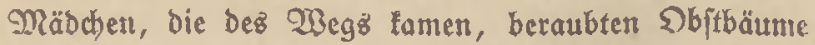
ibrer Frübte, uns entgingen wallig unverbienter $2 B e i[c$ Der Tractit Ptügel, bic wir auf jeber biejer Fabtten von feiten Der Finwohner, bcjonders ber jungen Burfben Dez Orteź, reichlid uno unverlürzt veroient bätten. Dies Treiben Dauerte fo einen gangen Eommer bindurch und bis in ben Soerbjit binein; und ich reiß, ras mich angeht, weiter nichtz Yerjtändiges ober gar (Erfreuliches Darüber

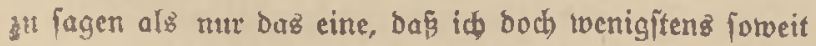


anftünbig blieb, bas ich mein Rao, bas mein Ontel und Qebrber mir geichentt batte, in einem netten unb fautbern 3 uitand erbiclt.

"Cines Eonntags nun, als wir wieser au unferm törichten unt licberlid)en Sreiben ausgogen, batte id, eitel unb fpielig roie if bar, um mein $\Re a b$ ju gieren, uuf Der Renffitange cin hübfchez Gäbnlein in den Landesfarben angebrad)t, fo grof roic eine Sinberband. 23 äbreno mu unjere Eleine (Bejellidlaft unter allerbant Iofen, leeren, unb prabligen SInterbaltungen babinfubr, fal id wieder uno wicber nach meinem Fäbnlein, und zuerit glwar mit

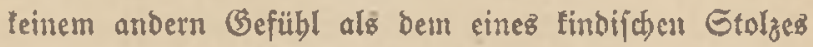
über bie Eleine luftigflatternde 3ier, bic nur ich allein auf meinem ghabe trug. Aber balb, ba iक immer twicber babin fab, twar mir fo, als twenn daz fleine Ting-in einer gwar fitummen, aber febr cifrigen $23 e i j e$ redete: "Wie id luptig flattre! Woie fteil iá) ftebe! \$d bin nur tcin ... aber twaz für ein tüd)tigez 20 efen ich bin! Smmer grabe! Summer tätig! 9đb feire nidjt

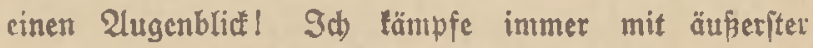

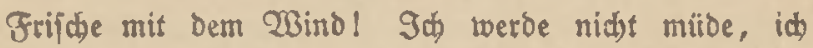
falle nicht um!" uîtw. S\$ nabm broar immer noch an ber Slnterbaltung meiner Epiésgejellen teil, àber ict) börte nicht rebt mebr bin, uno allmäblich wurbe id fill uno börte immer mebr bie Rebe, bie ber fleine hunte, fteile 3rwerg mit feinem flatternben 2̈rmchen immerfort bielt. Und am Ende fam id gar potweit, daß ith es bem tleinen Ding nachmadte, und fiteil und grabe auf bem Rabe jaß́ und ein ernfteś (Beficht machte. Slno allmäblicb, Da twir auf ber graben, cinfamen Gtrape 
weiter fubren, glid) ich fo renig bem, der fonjt mit

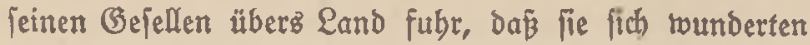
uno mich fragten, waz ez bem mit mit wäre. Sd) aber war verfunten in Bettachtungen wie die: ob mein bisberiges Peben nidjt eine einzige toridjte und zroectloje Summelei und Spiclerei getwejen twäre, ob nicht andere meines alters ... Der, und Der, und Der ... mir an Ermit, an guten Erfolgen, an Soffnumgen für bic 3ulunft tweit vorauts rören, ob es̄ nicht an Der 3eit toüre, mid wöllig uno tråftig zu ändern. Bentg, es genügte biefer cine $\mathfrak{T} a g$ und bies fleine Ding von eincm Flatterfälynlein, mich auf einen andern $233 \mathrm{eg}$ zu loden. Эc) fubr ztwar mit meinen (5enofTen biz zum 3iel, bas twir unz für ben $\mathfrak{S} n g$ vorgenommen batten; Dort aber mušte id mich oon ifnen zu trentuen und fubr allein

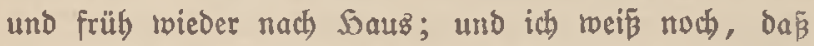
(i) auf biefem Scimtueg melyr als cinmal freichelno uno (a)meia elno mit meiner Sand über bas Gäbnlein fubr und ibm fofurt half, wenn es nicht austwebte, fo als madte id ifm eine Greube banit. $\mathfrak{B o n}$ biefer 3eit an bin id Dann erniter getworden und habe mir 3iele gejest und bin darin nicht mutlos geworden. Sth badjte immer an bas fiteile, grade, unerniidofiche Fähn= lein. Wenn ich einmal $\mathfrak{A}$ nglüat batte voer es mir nicht nath Wunich ging voer Gorgen mich bedrüctten, die nicht lvegzulकaffen waren, fo beghielt ich boch guten Mut; id) badjte fo in meinem Einn:, Wenn nur bas Fäbnlein flattert! Slnd fo twurbe dies fleine Ding und

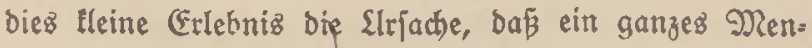
fhenleben auf eitten anderen $2 B e g$ tam." 
Go erzäblte er, ftulz, boch ein menig $\mathfrak{B e r l e g e n t y e i t}$ in Gefidt, und fdtwieg.

Die andern nictten und fagten: "Эa, ja ... jo ift eş! 23enn man darüber nachbentt, ijt ba meiftens irgendein Errlebnis, fei ez ein DRenjh ober ein $\mathfrak{B}$ uch, cine Reife ober eine geringere Begebenbeit, oder fo etroas ... bie geben einem ben Rud." Dann jprangen

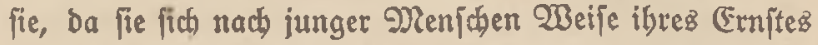

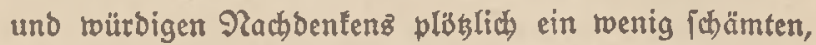
von biejer Gache $a b$, und macten fich roieder auf bie Erjcheinungen ber Gtrape aufmertan, und waren nun twieber grope, neugierige Rnaben.

In filllen Gtunden aber auf biejer ganzen Reife, nacbittags an Ded und abenos in Der Sängematte und two fie fonjt ein wenig 3eit hatten, fitllen Bebanfen nachubuängen, erwogen fie bie gebb̈rten (Bejdidten. Für Sarm Ott aber toutbe jette Gtunde unter bem $($ f)musig gelben Gonneniegel in ber engen Gtrap̃e won Gunchal von bejonberer Bebeutung. Was er bort als fein Cirlebniz von fich felbft erzäblt hatte, twas toobl in ber Sauptjache die lautere Wabrbeit getwejen; aber es war ibin bizber in feiner Zedeutfamleit nicht betrupt ge= wejen. Erjt bieje Daritellung des Erlekniffes, bie jene Gtunde gebractst hatte, ftellte es ifm in feinem Wert beutlich uno flar vor 2lugen. (erft won jest an ge= bachte ex b̈ter, und immer mit einem Qütheln, Das rajch über fein Geficht flog und wieder verīblwand, Dez guten tapfern Fähnleinz, Diefes fleinen, fteilen Bernegroßj von einem Selfer, ber ihm damals in ben Sagen feituer Sugend eritanben war. Wollte Wiübigfeit ober gleid). 
gưltige Qáffigtett 2 efith oon ibm netgmen, ober rollte

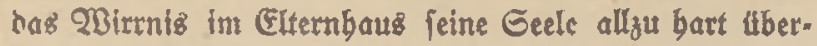
fallen uno fie niederbrüden, fo fab er im Beift bas Fälyntein an feinem Rad, lädjelte unb ermunterte fich, uno fagte leife bor fid bin: "Wenn nur bas Gäbnlein flattert!"

Und er wurbe ficterer in feinem eigenen 23 ejen, und feine 2lugen wurben flarer; unb es erichien rubige, ftarte Männliớteit in igrer Siefe.

Gie batten eine minbige, fait ftittmifabe, bods belle beimfahț unt Englanb berum, unb erreidten am zebnten Sag die Recbe von Echillingebjon. 


\section{Rapitel \\ Solgen}

Q1) Sage ipater befam er Sitraub unb fuly: auf adbt Sage nach) Sams. (Fr batte bie Geinen über ein Sabr lang nicht gejelgn uno wupte renig, wie ez Dort ftano; Denn Das Brieff dreibent uno Berid)terftatten Der Plutter war nicht von ber beften 2lrt. $O b$ es ibr am Willen feblte ober an Begabung, fie batte bie 2 irt

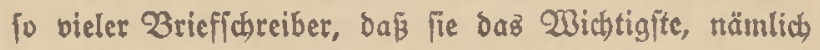
bie feelijøen Dinge, in verfhiwommenen, untlaren 23 ortel! nur andeutete, aber baš Sistperliche genau bejtyrieb. q3ie ber Bater fein Reib trug, ob Eggent irgendcin, wenn auch nod io leifes und fernes Qebensigeidjen gegeben batte, twie es mit Emmas Gemuit ftand, wic Der tleine Reimer fich zrwijhen feinen geliebten Büchern

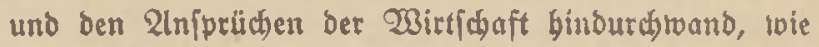
fie felbft in Scio uno 3orn und 2abeit ibre tapfere Geele betwabrte: das alles ftand in ibren Briefen fern tm Sintergrund, in Dumit und Rebel, währeno bas gegen bie Rübe und Ralber, bie Gulveine uno Sühbner uno bie lurzen, träftigen Figuren ber Feinen Bejdyifter in Borbergrund und beutlic greifbar berumprangen.

Da ibm ber Ginn fo ftanb - er roollte fïb in feiner ifbmuten SUniform ber Reibe nach ber ganzen Familie zeigen -- ftieg et eirte Station früber aus, ım feinen Bruber Rlaus aufzujuchen, ber eine Stunde ßegs vom Elternhaus unterm abbang ber Beejt auf geringem Rand einen einjamen Noorbof batte, auf besn er mun fळon gegen zebn Sabre mit jeiner fleinen 
und feinen Rindern lebte. (Er batte fid) während feiner ganzen Rindbeit mit Der Mutter uidjt gut geftanden. Gie jobalt immer an ibin berum, baj er zut toeidblich uno zu [d) laff wäre; und in ber Tat war er bas inz

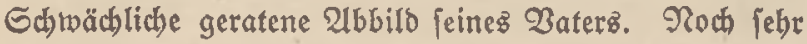
jung, faum ztreiunbztranzigjäbrig, ein langer, bünner Menjih) von (h)led)tet, läffiger Saltung, fleipig, aber obne rediten Willen, batte er fich in leiner Gebnlucht nach einem weichlichen uno bequemen Slmgang und 2 nbang mit bem erften beịten Mäbdhen verlobt, Das ibu gefallen batte uno bas ibm entgegengeiommen war, eimem gütigen, roeichen Wejen, bas aber nicht in einer gejundent Soaut ftal. Gein Bater hatte inm bei feinen viclen Rinbern unb eigener Edulbenlaft nur foviel Beld mit=

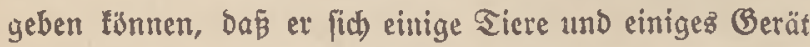
batte faufen tönnen; im übrigen war Sattz uno Lano

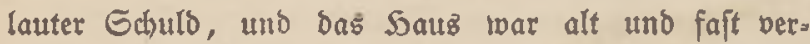
fallen unb ber Boben nicht ertragreid. Plber ba er ganz bejheiden und ftill lebte und immer fleiṕig war uno fein ganzes Ginnen und Denten immer um bie Geinen und um feine Gelder fpielte, und ex feine Sofftelle nur bann berliep, wenn es Durchaus nötig roar, Gielt er fich in feinem $\mathfrak{B e f i t s}$ und Gtand, mo fonnte fogar boffen, Daß́ ibm in älteren Tagen bet lleine Sof twirtlich gebisren würde, ber jegt (Eigentum Der Gpartafie und ber Bant rar.

Die Hleine Frau fab bent Edbivager pon fern tomment und trat mit ibren fleinen Rinbern ... es waren idton fünf $\mathrm{Da}$... Dor bie alte fdiefe sür unb erwiberte jein Müzefdbenten. Da bie Ermiberung aber now 
matter als gewöbullich war, fiel ibm fchon bie Gorge

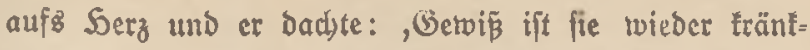
liđ̄.6 Gie war mit ibren breiṕig Sabren, wie man bas bei roenig lebenzlräftigen Frauen, die viel arbeiten uno forgen müffen, fo bäufig bat, fdion febre verfallen. 2Als er berantam und fie und bie Rinder ibm bie Sant (W) üttelten, fagte fie mit ihrer langgezogenen, Hagenden Etinme: "Du fommit an leinem guten Tag, Sarm. Rlauz bat fein beftes Pferb, bie bratme Grtte, verloren; fie ift beim Goblen eingegangen und das Foblen ift aud tot. Esz ift ein grojer Berluit. Romm mit, er fitst in oer Gdyeune auf ber Gdhrotlifte und ift poller Drügjal. Romm nur mit!"

(Er ging mit ber Edblougcrin unb ben Rinbern, bie binterberliefen, nach ber Edoune binüber uno fano Bruder Slaus ba auf bex niebrigen Edrottifte fiken.

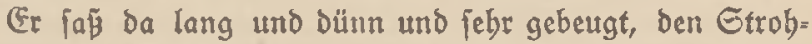
(wij), mit dem er bas Froblen abgerieben batte, nod in ber Sand, futbr fich mit ber andern über Den idon Eablwerbenden Gababl unb fah mit befümmerten \&ugen auf bie toten Siere; ein alter $\Re$ achbar, ber zur Silfe herbeigetommen war, werliés eben bie Soffitlle. (Er jal) auf, erfannte ben $\mathfrak{B r u b e r}$ und fagte: "(Ein idjlechter Sag, Bruber Soarm. Gie war erft zeln Sabre alt und follte mir nod) viele Foblen bringen, und mit ben Fohlen rollte ich bie Bantzinjen bezablen. Nun ift bie ganje Rechung entzwei; ez gebt mir immer alles ichief." Geine Frau fhüttelte Den Ropf und fagte mit ibrer langgezogenen, Hlagenden Etimme: "Alles ... Slaus? Wie tannit ou baz jagen, Rlatz?! Du barfit uns 
nicht vergeffen, Slaus! (Er bat es fo an fíd), Sarm, Daßj er mich und die Rinoer immer vergiß̈t!"

"Nein," jagte Bruber Rlaus und rafite iidb auf, unto ein 3ug won gutem Nut, ja von Gtoly tam in

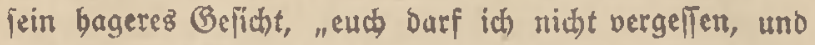
tu' es auch nicht! Rommt, fegt euch bierber, bier neben mid, ibr Heinen Rrabaten alle miteinanber! Ees' bu bich auf ben Sraublod, Sbarm." (Ex hob die Rleinen, bie bieje $21 n t$ tannten, neben fich auf bie Qabe, io ba bem er fein Reib ein wenig verga Qeute um fich batte: "\$a ... To ift esิ, Bruber Sarm! (Da mübe id) mich um Den tummerlichen, fleinen Sram, Daß̄ alles feine redite Ordnung bat . . . ich babe nicht Sonntag und nid)t Feiertag, uno verbe fünf Sabre früber in bie Grube fabren, blop weil id auf einem sof leben und fterben middte ... unb babe folches Pech! 2(ber id bin immer ein red)ter Soblpel getwefen. SAnfer $\mathfrak{Z}$ ater fab mich immer fbief an; ich erinnere mich noch feiner 2lugen; e\& ftond immer barin: ber wiro uirbt vier Blüct im Qeben Gaben... und unjere Dlutter... na, bu fennit fie ... Die fajalt mit mir, two idh ging und jtand."

Geine theine Grau fab ihn mit ibren gropent flagen-

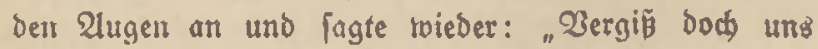

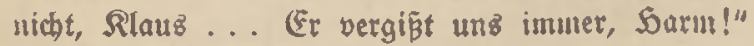

"Oh," lagte et mit weid)em, gütigem Stolz unb, inden ein teifer, inniges Reuchten über fein fonn. แno winbverwittertes (Beficht fubr: „Shr! ... TRein, eud) Darf ith nicht oergeffen!" Er jog Die Steimen, fotoeit 
er fie erreichen fonnte, näber an fich, indem er beide 2lrme ausbreitete. "Weiß̧t bu, Bruder Sarm, toenn ez mir mal idjlecht geht ... und ez geht mir recht oft verquer; Der Rloggen bat auch nidht gegeben, twaz er bätte bergeben follen ... Dann jebe ich mich nach bem Nittageffen für eine Biertelftunde aufz Sofa . . länger babe ich nicht Beit... oder bier auf bie Gchrottifte ... bie leiber oft leer ift... und denfe $\mathfrak{u}$ ber meine Not nach ... Alber twas meinjt bu? Size idh ba länger allein alsె eine Ninute, ja, alв eine Gefunde? Ġleich) jeben mich die Rrabaten, Diefe Heinen Puppen, und fesen fich neben mich ober auf midh. Slno bann be= reden wir, wie fie mir belfen rollen, twenn fie groß fino, uno waz ez dann für ein Leben auf'm Soof merben foll. $\mathscr{W a z}$ meinjt bu robl, raz biejer fleine Rerl von neun Sabren fobon allez kann und rwill? Der hat im vorigen Sommer idhon zmildengefabren, jage ich bir! SUnd ber ba ... ex ift freben ... Der fagte beute morgen: Du, Bater, id will bie ichiefe Mauer von ber

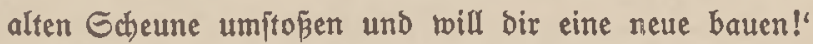
Die Dauer ijt nämlid roirtlich jebr ichief, aber idh batte bisker weder Geld nod 3eit, fie neu zu machen. Nun babe ich fie erit mal mit bem (Gid)enpfahl geftüßst."

Geine Grau jab ifm, wenn ex fprach, unberveglid, und unentregt mit ibren groß̈en, Hlagenden 2ugen auf ben Nuno, alz lomme bas Evangelium Daber: "Du prichit immer nur von ben beiden Ültejten," fagte fie, "Du vergiṕt immer uns andern."

"2luch Solden!" fagte Bruder Silauz, "alle Solden, powie ibr bier figt! ... 2lber mun lage mal, Bruder

frenfren, פte $2 x u b e r$. 
Sarm, was ou mitbringft aus ber Welt! Du bift in Der gropen Stadt getwejen; Du bift jogar über bie weite Gee gefabren. Du bajt mebr gejehen und reiät mebr alz ber \$aftor, ja, als ber Landrat, ber hier geftern mit feinen alten Sengiten vorbeifubr. Eag' mir mal: nas ift bas mit bem (Serebe bom Sirieg? Geit 'n paar Saliren grimmelt ez balo bier, balo oa in einer Simmelô. ecte, bas mant bahin fiebt und bentt: num fommt ein tühtiges Betwitter! Die Verjammlung da ... weip̌t ou ... in ber fleinen Gtabt in Gpanien .... da mar fein guter Beijt Darin, Bruber Saarm! SIno feitbem grollt und grummelt to meifer."

Uber fein 2 ruber fdüttelte ben Ropf uno jagte:

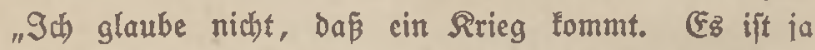
zu ungeheuerlich, Rlaus! Du folltejt unjere (Beichüse fehn! Sch lage bir: ein Gdup bavon in bein Sants, und Daz ganze Sous zerbricht, und aus den Trümmern, bie auf ber Erbe liegen, fhlagen bie rilden Flammen. Nein, eB ift ummöglich!"

"Eo," jagte Bruber Rlaus ... "alfo ou meimit nicbt? $\mathfrak{U l m}_{\mathfrak{m}}$ fo befier! Wenn id daran benle, Daj

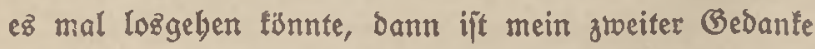
immer: Gott fei Danf, daß̄ ich nicht mit gineinfomme! Wenn ith mir benfe, dáz ich fort jollte, in bie Frembe, unter bie Maflen frember SMenfiden, uno müpte Dann da braupen Poften ftehen, uno da vorne .... im Felde bor mir ... ba wären Denid)en, bie mich töten roollten und die idh töten follte ... und mein Sof und meine Qeute wären weit ... weit weg... ich twübte nicht mal bie Shimmelarichtung, wo fie wären ..." 
"Iđb) bitte bich, Rlaus," fagte feine Grau uno fab ibn flebeno an: "Bergís uns nichtl Giebft hu, Soarm, wie er unz ganz und gar vergiñt!"

"शein," fagte Bruber Rlaus und wachte auf, "ich vergeffe euch nicht! Nein! ... mas, Marie? ... wenn ich euch berlaffen follte? ... in bie roeite Grembe ...

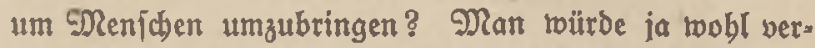

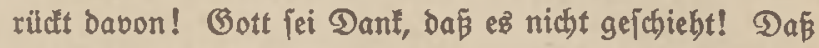

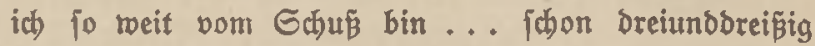
und fein Golbat getwejen und fein ftarter Mení)...

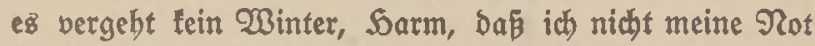
mit ber $\mathfrak{B r u f t}$ habe ... nein . . . Dein Bater mú bier bei bir bleiben, waz,, Đeter ... Damit bu Daz Bauerfpielen lernft ... maz? Slnd bie Hleine Margret und 21nnemarie ... was? \$hr mübt boch immer binter eurem $\mathfrak{B a t e r}$ ftehn, wenn ar bie Gdhweine füttert ... maz?" . . Ex bolte boch 21tem: "Das mit ber Gtute ift

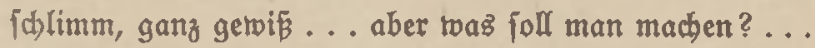

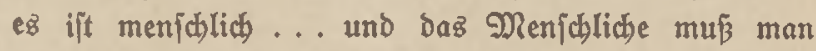
crtragen. Uber in Den Sirieg zieben ... das iff un. menfchlid! . . 2 Uber num fomm binein und trinfe eine Taffe Raffee mit uns; und bann lannft bu weiter zu Den Ulten gebn."

Sie gingen alle nad) Dem Sauż binüber und jaßen nod) eine Etunde um ben Eofatifh. Bruber Rlaus batte immer brei Rinder auf den Rnien, bie anderen beiben jaßjen bicht an ibn geprept; und alfe batten bic großen ftummen 2ugen auf bie blanten Rnopfe uno Das (Beficht Des Onfels geridhtet. Tann machte er fich wieber auf ben $\mathfrak{W}$ eg. 
In fitlen Bebanten ïber feinen Bruber twanderte er ben breiten, fandigen $W_{e g}$ entlang, ber unter ber Geeft entlang gebt, und bog bann in ben Feldweg ein, ber in bie Maríh binabfübrt, und fam fo gegen 2 beno an Das Elternbauz, und machte lange 2lugen, $\mathrm{ob}$ und wer trobl zuerft Qärm jhlagen twürbe. 2lber ez zeigte fich feiner. 2l(z er fich aber ber offenen Tür näberte, börte er eine Stimme laut und Deutlich prablen, als twenn fie z̆u einer $\mathfrak{B e r j a m m l u n g ~ f p r a ̈ d ) e . ~ ( F r ~ f a m ~ n a ̈ h e r ~}$ uno horchte; und da mertte $e x, ~ d a \tilde{B} e s$ bie männlich ge= worbene Gtimme von 3 ruber Reimer rar, ber über die Diele priejterte; und er berftand auch, maz fie fagte: "Damals wobnten bie Bermanen zur Sauptjache, außer in Glandinavien, daz fie gand betoobnten, zmifthen Flandern und ben Bogeien im Wejten, ber Ober im Oiten, und ber Donau und ben Ulpen im Gïden. Sie waren aber noch nidbt böllig le Bébaft, fondern zogen in biejem Raum bin und ber. Slno es war unrubig barin wie in einer Mild)jatte, an bie man mit bem Fur itögt."

ఇun fam vom Ende ber Diele Emmas Gtimme, ein wenig mübe und langgezogen: "Der lezte Gag ftebt da nicht. Du reiß́t ez allez ganz richtig uno läßst aucb nichts aus; aber bu féscit immer etwas binzu, uno das barfft Du nid)t. Denn warum bat ber Mann, Der bies Buch) gef(hrieben Gat, nur bies gefagt und nichts meiter?" "Weil er keine Rraft uno keine ordentlichen 2usz= Drüdfe im Leibe bat, Emma ... Darum! Wenn id) eifrig werbe, fommen mir inmer folche Worte, twie Dieje, und bie find gut. Man fieht die Dinge Dann 
orbentlich, berfebjt bu? Wenn andre Nenichen folche Woorte nicht haben ... i id babe fie; und will und tann fie nicht aufgeben. Sth fann mir boch bie 3unge nidht abbeiß̈en?"

Bruber Sarm ftand in ber Tür und jab bie beiben in ber blizenden 2lbendjonne. Reimer, größ̈er und breiter getworben, war mit boctgetrempelten थ̈!rmeln beim Reinigen unb Echmieren einez Wagens. CEmma faß auf ber langen Rijte vorm Pferbejtall, bas $\mathfrak{B} u(h)$ auf Dem Gdop. Gie faß nodh gebeugt; aber fie batte $\mathfrak{B u d}$ unb Bruber villig vergefien und jah mit farweren, traurigen 2 ugen vor fith auf bie Diele.

"Guten Tag," jagte cr, "alle beibe!"

Sie fubren auf und faben ifn mit großien 2ugen an und famen ibm bann freubig entgegen und gaben ibm bie Sand, und roolten gleich mit ibm über bie Diele nach Den Etuben gebn. 2lకె fie aber jagten, baß̃ bie Mutter ganz allein in ber Rüche wäre, wollte er bieje feltene Belegenbeit benusen, und bat fie, auf ber Diele bei ibrer Urbeit zu bleiben.

Gie fam grabe aus bem Milchteller und machte bie Sür binter fich ou und fab ibn baftebn, und verlor bie Rraft in Den Rnien und fegte fich auf bie Bant neben Der Tür.

(Er fegte fid) neben fie und fagte lactend: "Da fint ou! Run, wie gebt es̉ euch allen?"

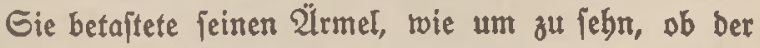
großje (d)mudfe Men(ch) Wirtlichfeit wäre, und fagte: "Sunge ... r roie fein ift das 3eug! Dafür bajt bu viel Geld ausigegeben. Uber baran fenne ich bid." 
Dann bejann fie fich böllig und fagte: "I屯 fab bich etit nicht beutlich ... ober tras es fonft raar ... i id bachte erft an Eggert. Reing meiner Rinder tif fo lange son mir fort getwejen twie bu und Eggert, und

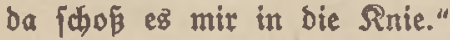

(Er fragte gleich: ."Sabt ibr won Eggert gebört?" Gie fchüttelte traurig den Ropf.

"Slnd Der Pfeifer?"

"Der ift nidbt twieber exphienen."

"2)

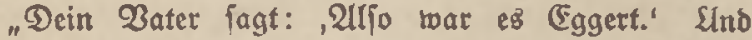
im Dorf fagt man es auth. Ulno Das ..." und fie meinte auf ... "bas ijt furchtbar. Sch babe tein Rino geboren, bas idlecht iit, leitnen Verbrecher oder Epätter oder Eduelmen."

"Sabt ibr nad) Dem Rnedt gejucht?"

"Der Rirchjpieljhreiber bat binter ibm bergefdrieben und nach ifhm gefucht; aber er ijt nicht gu fimben. (Fr meint, er ift trobl inz 2lusland gegangen, vielleidht in Die Edureiz; Die ift ia in ber शäbe jeiner Seimat."

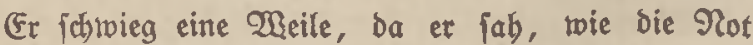
noch immer gleich groj und gletch troftloz toar. Dann lagte er: "Wenn Eggert noch nidt an Söbfe Subl geidurieben bat, fo bat et bas (Gelb nod) nicht zu=

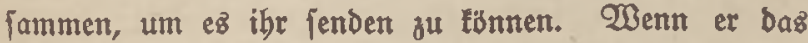
Geld zulammen bat, wird er es ibr fenden und ibr \{hreiben; Denn jein Wort wird er balten." Dann fübrte

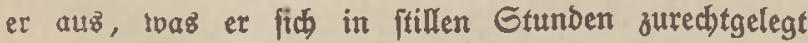
batte, เoaš er ber Mutter fagen wollte. "Du mußst es nun tragen, Mutter," jagte er. "Wodurd iit Eggert 
In jenen Berbadit getommen? Brabe burd jein $\mathfrak{B e j t e z : ~}$

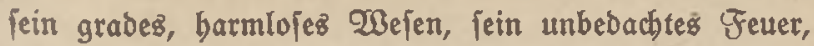
feine Runft. (Brabe daburth), Durch diez Fein Bejtez! (Daburd) fiel er erft ben Menichen auf, erwectte bann ibren Zerbacht, wurbe Dann von ibnen angeflagt, und verîtand Dann in feiner bölligen SMrchuld nicht jeine Vierteibigung. $\mathfrak{D u}$ bait einen guten, wenn aud) allzu feurigen und irrenben Gobn in ber Frembe; und er Dentt mit großjer Liebe an bich. Ulfo jei mun feinet. twegen nidjt allzu traurig ... Edhwerer ift bie Gadje mit $\mathfrak{B a t e r .}$ Du bift boch freunolid gegen Bater?"

Gie fकluchzte auf. "Wie tonnte ich bart gegen ifn fein! Geine Rot ift ja nod taufenbmal fotwerer als

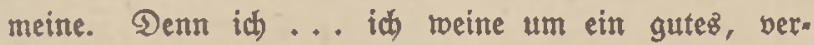
lorenes Rind; er aber glaubt an jebem Sag, vom früben

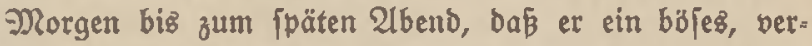
Dorbenes uno verifoctez bat. Tas aber ift bas Gdjlimmite auf ber Welt. Sutto Dazu noch diez, Sarm . . .: wenn cinmal ber Sag fommt ... und er fann boch fommen ...

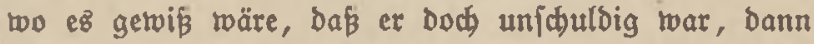
toird feine Not nicht beffer, fondern nur größer werben; denn bann muß er fich fagen: T) bajt nicht an bein Rino geglaubt; ous bajt es zum Edselmen gemacht uno

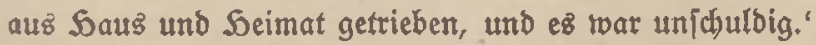
Gieb), Daz erträgt er nicht." Gie jenlte ben Ropf auf bie

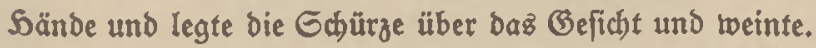

Er warf einen ideuen 3 lict auf bas Shaar ber Mutter, baš im lekten Sabr beller und grauer getworden toar. 2luch er wü̈te nidjt $\mathscr{W}_{e g}$ noch Gtege. (Fz mar alles 10, wie fie lagte. 2Aber lange tonnte er nidjt 
(4)weigen; ex batte etroaz in fich, einen Willen, eine Gtimme, die von ibm forderte ... das Leib modhte nod) fo fđwarz fein ...: , (Blaube an bas Qidht! Er breitete bie Sände aus und fagte: "Mutter, ich)

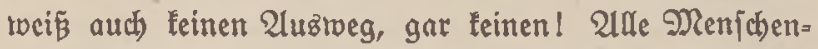
traft ift bier o $^{\text {u }}$ Ende! (Ez bleibt nichtz übrig, als bieje Gache Gott und allen guten Beiftern vor bie Füpe zu werfen uno fu jagen: Wִ Wenn ibr ksonnt, Dann belft!

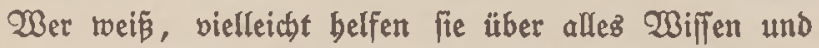
Berfteben !"

Die Mutter nictte unter Sränen. "Man muß́ immer boffen," lagte fie; "aber fd)wer ift ez, Soarm." Dann wiez fie nach ber Tür uno lagte leife: "Die Rleinen fommen."

Da ging er nach ber Sür und (trid) Den brei Rleinen, bie vom Rabbar famen, über die Rispfe, und fragte jeden nach den Epielgefäbrten und nach ber Gajule uno nach bem netren Ralb, das fie befehn hatten. Danadh fam auch ber $\mathfrak{Z}$ ater von ber Müble zurücf. Grof uno getwidhtig ... er mupte fich bücfen, ba er burdh bie Sür trat ... fam er in bie Rüche. Der Gohn rounderte (ich), oa er ibn wieberjah, roie groß̈ feine (Erjoheinung war. Er batte in bem ganzen $\Im a b r$ in ber Frembe leinen foldten Mann gefebn, von fo ebrwüroiger Er (d)einung, feinen, ber in bober, fdherer, etroas zur (Erbe neigender Figur jo Das Wort predigte: wie berrlict ift ber Menji) und wie mübjelig! 2ự̆ er war grau ge= roorden; und feine 2lugen, bie immer fhon icheu auf bie Menjwen gejebn, waren nun flüctig in Not uno Gd)am. 


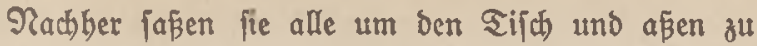
Ubend; und Der Sreimgetebrte erzählte von allem, was er gejebn und erlebt batte, bejonders bon Der Reife, bie er hinter fich batte, die das grope Erlebniz feines jungen Qebenz war. Der Bater jagte fcin Wort; er börte bald zu, bald wieber tweg; Dann waren feine $\mathfrak{B e}=$ banfen bei feinem Leib. Wuth die Mutter war nidht immer bei feiner Frgäblung. Reimer aber rar lauter

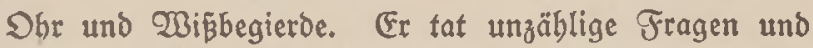
ließ feine Kube, biz er ein beutlichez Bitb von allem batte. Emma batte erjt eine $\mathfrak{B}$ eile zugebört, wäbreno fie am Rleid ber Süngften näbte. Danad ja je fie mit gebeugtem Ropf über einem diden, altmodij(hen Buth uno laz Geite nach Geite, und fah und börte nichtz anderes. Der Seimgetebrte modhte nidt fragen, ras für ein 3 uch es roäre. Dann wurbe ez Shlafenżzeit, und fie gingen auzeinander.

Ulక ex mit jeinem $\mathfrak{B r u b e r}$ Reimer in Der Rammer rar uno fie fich entfleibeten, fragte er: "Waz war bas für ein Bud), in bem (Emma lą̧?"

"Эa," fagte Der, "bas war ein frommes $\mathfrak{B}$ uch; ich glaube, es fino Predigten."

Er fahüttelte Den Ropf: "Waß ift denn mit ibr gex worben, Dáp Der Rirdgang ibr nicht genug ift?"

Bruder Reimer batte fid fobon bingelegt, ftübte Den Ropf auf ben 2lrm uno fagte eifrig: "Weipst bu, es breht fich allez um ben Rnedt. Du erinnerft bich Doch Der (Beffichte, wie fie Den Grofch an bie Wand warf, Dá̧ er ein Prinz würbe? Na, fiebjt bu: uno nun ifft ibr STlaube, baj ber Rnecht, tweipt' Dut, Der 
Rnectit ... To einer getwejen ift ... To ein berfappter Prinz. Iđ rebme an, Dá fie fich mebrfach mit ibm unterbalten bat und er ibr fo biez und daz aus feinem Leben erzablt hat; aber fie fpricht nie babon; genug, fie ift überzeugt, Daß er beimlich grobes Slnglüct in fich trägt, গot vom Elternlyauz ober oon feiner Rinobeit, ober vielleid)t eine alte 5 dhuld ober twas es ift, uno dás Gott ihn bierber auf unjern Soof gejandt batte,

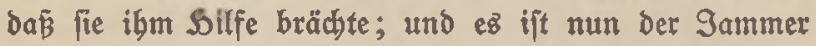
und die Plot ibres Lebenz, baß pie Das in ifrer Träg. beit oder Blinbbeit ober Ġlaubenzarmut nidit erfannt bat, und daß er nun aljo bilfloz in feiner alten, jchlimmen शlot Durch Die TBelt läuft."

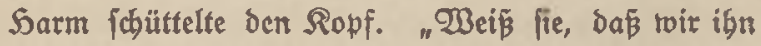
beichuldigen, daß

"Nein, das weis fie nicht. Tas ragen wir ibr nicht zu fagen; es würbe fie auch nur in ihrem (Blauben an ign bejtärfen."

"Wer mar Denn nach ibrer Meinung ber Pfeifer?"

„Der Pfeifer? \$a, vielleidt war ez Eggert... mabricheinlich aber irgendein andrer, Beift ober böper Menjh), ber nach (Bottes Willen Den Rnecht berfolgt und beuntubigt; aber wir veritanden ez eben nicjt; wir waren nidbt fromm genug. Bor allem war fie

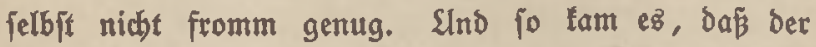
Rned)t rublos weitermanderte und bás fie felbit trant

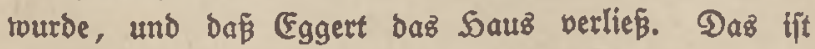

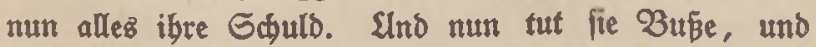
bittet Bott um Bergebung, und bittet wobl vergeblid und toeint." 
Sarm batte fich auth bingelegt, atmete fibroer und fagte: "Slnd was benfift bu, toas twirb nun Daraus?"

2ruber Reimer richtete fich auf und fagte eifrig: "Erjtenz gebt fie alle Eonntag abeno zu Swujter Eblerz, Den fie ben Soiligen nennen; da betet und fingt fie. Und twenn fie von ba zurialtommt, ift fie inmer etwas froberen Mutes. Slno zweitens belfe id ibr. Sh ver-

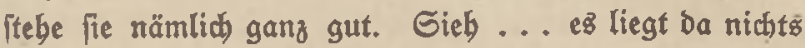
anderez vor, alz ein überzartez Beiviffer, und ihr fehlt

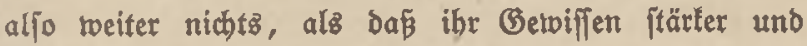
fejter mird."

"Wie machit bu bas benn?"

„Du hajt ez ja geiebn, wie bu anfamit! Sch) tue, alb trenn ez gut für mid) ift, wenn fie mir bie 2 elfgeididfte uno alle meine anbern Gahen verbört. In Wirflic). leit, toeíft Du, ift es Durchaus nicht notig; ich babe allez, waz i屯 will, im Sopf, wenn i屯 ez ztweimal mit

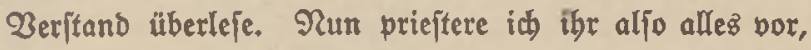
toas mir gut für fie ít)eint, um ibr (Betvifien zu bärten. Yor allem Weltge[dichte! Damit fie erfäbrt, wie ez trirtlich in Der Welt bergegangen ift uno noch bergebt! Du follft jebn, fie wirb badurch allmählich wieder gejünoerl"

Sarm Ott fibwieg eine Beile uno badte über bie

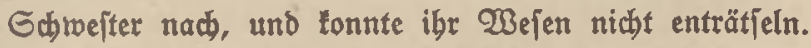
Dann famen feine Gebanfen mit faum geringerer Gorge zum Bruber unb er jagte: "Slnd toas treibjt du Gonntags??" Er badte an jene ibblen Rabfabrten, die er in biejem Ulter gemacht batte, die ibn bejhämten, fo oft er iḅrer gebachite. 


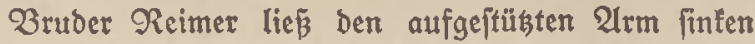
und jagte mit unficherer Gtimme: "Ia, wenn Emma bei Edufter Eblers ift, bann bin ich meiftenz mit ben Rindern won dem Samburger Raufmann zujammen, ben beiben Süngiten... Du Eennit Doch Daš Mäbchen und ben Sungen?"

"Эa ... Die Dunfle," fagte jein 3 ruber, "bie einen immer fo vertoundert anfiebt. Gie bat jo bübiche, erforrodene, veriounderte 2lugen ... fie mag jekt jo um fünfzebn fein."

"Sa, bie ift es! Mit den beiben bin ich zujammen ... wir brei baben einen Oerein gegründet." "Einen Berein ... Shr drei?"

"Sa, wir roollen bie Natur entbecten... bejonbers die Natur im Nenichen! 3uerit rollen rwir, baß bie

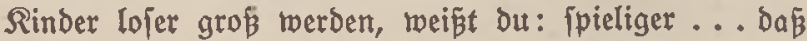
fich) ibre Ratur ausbreitet und zutage fommt, ras in ibnen ift. SUno banach wollen wir allen Rinbern be= fondere 2lufgaben allerart ftellen, um ibre Grund= begabung zu finden, wollen ibnen auch alle zwei Sabre allerlei Runit und Sanbroerte vorfübren, und ibnen Dann felbjt bic Entjheibung ihres ßerufz vollig allein überlaffen. Dabei foll auf bejonders eigenartige Merf= male: Gduablelbildung, tiefe 2lugen, bejonders finnige Untworten und bergleid)en Bebacht genommen twerben. Unz faheint, bies fei ber richtige und einzige 2 nfang, bas ein $\mathfrak{B}_{\mathrm{olf}}$ und ein Qano bohtommt. Sa, man wirb fogar groß̉e Wunder erleben! $\mathscr{W} a \mathfrak{s}$ twerden da für Nenichen, roaz für Begabungen aufbligen! Slno in reldjen Mengen! Waв für Gebanfen toerden fie benten! 
Wenn id auf bem Geminat bin, will ich biejen Plan tweiter ausbenfen, immer weiter!"

Es war buntel in ber Rammer getworben und Sarm fab nichts weiter von feinem 3 ruder alz bie längliche Form bes Ropfes mit bem Saar, bas ein wenig zu lang war; aber er hörte an Der Gtimme, Dáp feine Alugen von fommender Frtwartung brannten.

"शun," fagte er, "... und beine beiben Benofien find ganz mit bir einveritanden?"

"Sa," jagte Bruber Reimer. "Waa Den Sungen angebt, fo benlt ber ja zur Sauptjache immer an jeinen eigenen Fall. Er fdhimpft auf bie Gdule, und ba í fein Sater immer nod) nicht erlaubt, סaß́ er zur Gee

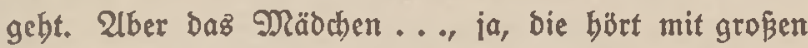
2lugen zu, twenn id ez auseinanderjese. Mit jebr gropen, jage ich bir!"

"Die bat bich robl gern?"

"Эa," jagte er in angenommenem, gleidmütigem Son. "So twie bie Mäbd)en Find."

Dann fdtwieg er, und lag noch eine 2 eile fo wach und unbetweglid), fa/t atemlos, bie 2lugen in bie weite Gerne. Dann fagte er in ber präd)tigen, fïhern und jelbjtbetwupten 2lrt, bie er in biejer 3eit an fich batte:

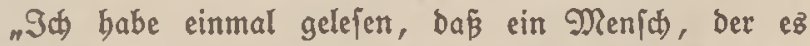
nachber reit gebracht bat, feine rwidtigften (Bebanten jhon in jeiner Rinobeit und Sugend gebabt hat. Die Bcoanten, bie er nad) z'twanzig odcr breipig Sabren aus= fübrte, hatte er fđbon alş Sungel Wer weí̈, vielleicht ift es mit mir ebenfol"

Dann fhrwieg er, und jojien bald darauf zu fdlafen. 
Sorm Ott aber lag nod) lange Seit road, bie Sönde unter bem Rovf verjđränfl, erfüllt von all bem, twa\& biejer Sag ibm gebrad)t batte. (Fr fab noch einmal jeben ber Geinen bor fin, wie er ihn im Laufe bes

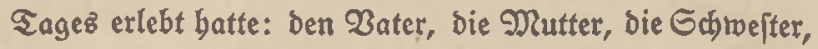
ben Zruder Rlaus uno ben $\mathfrak{B r u b e r ~ R e i m e r . ~ 3 u l e s t ~}$ bachte er aud an ben 9 ruber in ber Frembe, und endlich an fich felbit uno feine Soffinung auf ein tüchtigez und angefebnes Reben unter ben Menja)en. (Fr ließj fie alle nod) einmal an fich vorübergebn und rounderte fich, uno Dacble fajt erichroden: ,Welch eine bunte (Bejellichaft, und alle aus bemielben Souje! Wie follen fie alle ibren Weg finden?" Und eg wollte find rwieber eine Lajt auf feine Gecle legen. Qhber Dann rubte er in jeiner $23 e i f e$ nicht eher, als biz er an jeder Gtelle, wo Tunfel war, einen Edjimmer von Qid)t fah, und too Trauer und Gorge war, einen Ghein won Soffnung, und too Wege und Gtege für Menjळenaugen und Memidenjorgen aufbötten, Slauben und 3utrauen zu Bott twie cin ftures, fleines Fäbnlein aufgeri屯tet trar, baş por ihm Dabinflatterte. 


\section{Rapitel \\ Der $\mathfrak{B}$ efuch}

Q1 $m$ anbern Bormittag ftand er überall in Saug und Gelto umber und befab fich alles und rebete mit allen, und wuß̈te mit ben langen Gtunden nichtz Rechtez anzufangen.

Ulm Nachmittag aber mactite er fich nach इifid zu

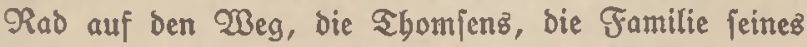
Berwanbten und Rehrberrn, zu bejuchen und fids bort in feinem Blanz zu zeigen; befonders aber bie Todter Qizbeth mieber zu jeben, mit ber er eine leibige und müb[ame Soerzenz̄jache batte.

Qllz er fịth bem Soaufe näberte und es̃ baliegen fah, furz yor ber Gtabt an ber breiten Etrap̃e, nod) neu, boch, mit breiten, bellen Genjtern, an Der einen Geite einen weiten Gemüfegarten, an Der anbern einen groß̋en Simmerplak, Der bizz zur 2 lu binunterging, und an bie munteren, lebensfroben Menichen dachte, bie biez groß̧e,

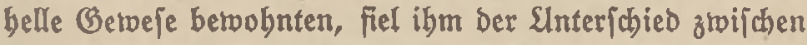
feinem elterlicten Sauje und biejem fehr auf, und er Dactste bei fich jelleft, Dás er alles und alles tun müîfe, Daß́ auch feine Leute roieder munter würben., Denn

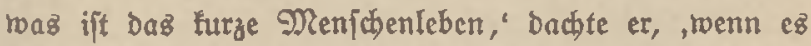
immer in Nebel geht!"

Er ging ins Soaub binein und bärte von dem $\mathfrak{\text { Räb. }}$ d)en, bá̈ bie Elttern über Land, bie Rleinen in ber Gchule, bie Groben aber auf Dem 3immerplaţ wären, ging bindurd und fudfte fie. Die beiden Sungen, jeine früberen 2rbeitżgenofien, freuten fị berglich, als fie 
ibn faben, richteten fich auf, warfen bie Deefels über bie Edulter und fragten nach allem. 2luch Qisbeth, bie bei ibnen jtand und foftwagte - eigentlich follte fie in Der Süche ftebn und Ruchen anrübren - verga ja ganz und gar, baß er ibr neulich in einem furz gefaßsten zornigen Brief verboten batte, ibm roeiterbin fo Dumme Unfichtzfarten an Bord zu ichreiben, und freute fich, Daß fie inn wiederjah. Sie ftellte fich wie von ungefälyr jo - et merfte es aber bodh - daj er ibr gegen. überftand, und fab ibn mit rubigen, foridenden 2lugen an. Sie war etwas älter als (Emma, fo um achtzebn, und in allen Dingen ifr Gegenteil: ganz bell von Saar und Saut, von langen, gropen Gliebern, unb pon ber unbekümmerten Rebenðluit ibrez Zaterళ.

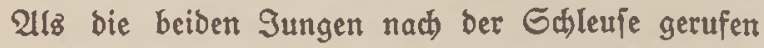
wurden, um da Solz abzulaben, und er mit Qiöbeth über Den ganzen Plaḱs bis an die 2u Ginab langlam binunter= ging, unter bem Borwano, zu jehen, toas fie auf Rager bätten und twas fich etwa verändert bätte, und fie zrwifchen bobe Gtapel Beridjalbold famen, jegte er fich auf einen niebrigen Gtapel, to alb wenn er fich bier etwas um= Feben wollte, und fagte gleichmütig: „Gek' bich und erzäbl' mir twas!" und bachte, bier an biejer Gtelle, mo niemano fie feben tönnte, freundlich mit ibr zu fein, Fein Woort von Den Dummen Rarten $z u$ fagen und fie fo vielleicht $z$ u einem hüb/hen Eleinen Enfgegenfommen zu verfübren. Denn renn er fich über ibr mutrilliges und widerbaariges Weien, wie zulebt über jene Rarten, autch noch jo oft geärgert batte, er batte fie boch immer und über alle Naß̧en lieb. Wenn er an fie badbte und nun gar, tvenn er 
fie fab, Eam er immer wieber in einen Raufd bon

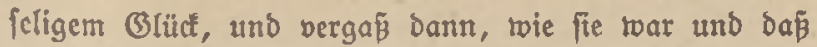
er fich fo vft an ibt ärgerte. Eic itand bann in einem fabanen Gabein und Blang vor ibm, und er bachte nidt anders, als baß biejer grofe, mutwillige, belle Gatan Der reine Engel wäre.

Er feste fid aljo auf ben niebrigen Etapel $B_{e}=$

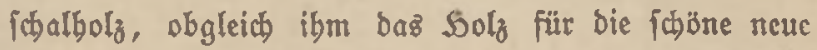
Sofe eigentlich nicht rein genug war, unl fragte fie, bie vor ihm ftehen blieb, nad) ibrem Berfebr und was fie ben Tag über triebe - obgleid) er es ganz genatt wußß̄te - und ppürte nach einer Belegenlyeit, wo er fo vorfichtig uno langlam ibr Serz beichleidyen fonnte. Slno zuerit ging ez auch ganz gut. Gie erzählte ibm biezs und bas von ben Sbren, von ibrem Slmgang, aus ber Gtadt; jwar etwas übermütig, aber er füblte boch mit feligent Sorgllopfen, wie fie fein guter Freund roar und

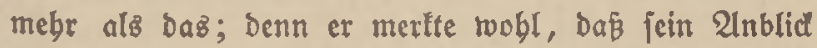
ity gefiel; Denn fie bejah mit 20 bhlgefallen, mit rafchen, rubebollen 2ugen alles, was an ibm war: 2ugen und Muns, Nüвs uno Sade, uno bie Etiefel an jeinen Füpen. Sund er war bidbt babei, bittend und febr bringend วu fagen: Wie fdjön und lieb bift bu!

Uber da - fie jah wohl an feinen 2lugen, dá̉ eź fo mit ibm ftand, und meinte wohl, fie bätte bes Guten zuviel getan, ober bätte zuviel ihr Serz gezeigt, ober verlangte nad) einem andern Rieb ober waz ez war fie fing plobslich oon ben bummen Rarten an und jagte: "Die letste Rarte, bie ich bir gelandt babe, twar trok Deines Ulrteilz bübi๘), mein Bejter! Deinen zornigen Brief Exenten, Die 92riber. 
Darüber hätteft bu bir twirflich fparen fönnen! Mber benle mur ja nicht, baj ich Diejen Brief etroa verjtedt babe, o nein ... ben babe idh ber ganzen Familie gezeigt und babe ibn jebt in meiner Rammer an ben Epiegel geftedt und freue mich noch täglich Daran; denn ich babe ja genau das erreicht, was ich geroollt habe: Dich mal grünolich ges ärgert ... Gag' mal, baben beine Rameraben bich zum beften gebabt? Das follte midh freuen! Bilde bir bod

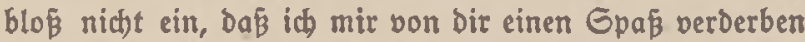
laffe! Du bift robl gropartig getoorben?! Daju bajt bu aber ganz und gar leine Urjache. Nein! $21 m$ roenig. ften mir gegenüber; Denn grofartiges Weien ift mir von allem, roas es gibt, Das ärgerlichite. Du braudit Dir auch nidht einzubilden, Daß̧ Dir Die Slniform befonders gut ftebt! Mand)em andern trürde fie viel be ler ftebn, uno toenn meine Brüber bei ber Marime wären, fo twürben bie fich befler barin maden. $3 o r$ allem bie Dlüße ftcht bir nicht gut, Deine Gtirn ift zu boch baju, ober bie Mä̧⿻ lift nicht gerabe genug ober toas es ift." So redete fie und fab ibn luftig und berausfordernd an, uno um fo Iujtiger, je blafier er rourbe.

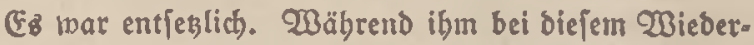
feben vor Quft und Freube das Soer tlopfte, Daß es ibn fchmergte, bielt fie ibm bieje Redel Er füblte ober abnte wobl, Daß in all biejem Lawen und 2lngriff im Brunbe irgendrwie Liebe rebete und lachte; aber er modte und

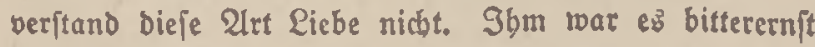
damit. Man ladbt uno pottet nicht, roenn man an einem fdönen reinen Gonntagmorgen Durch Den $23 a l b$ geht, uno auch nicht, wenn man vor einem altar ftebs 
(Er war febr årgerlich und unglüdlid). 21ber was tut cin therer Mann?! - Wenn fie ez fo liebte uno wenn man fie nod leiolid) traltabel etbalten toollte... er toollte es boch nid)t mit ibr verberben ... fo mupte er auf ibren Son eingebn. Fr bebauptete lädbelno: "Die Düßse ftebt mir bejonbers gut; Daż baben mir nodh unterwegs im 3 ug zrei fdjöne Näbdhen gejagtl“ unb er nabm fie vom Sopf und ftrich Das 2 and glaft, und gab fie ibr, und bat fie, fie mal aufoufegen.

Gie ferte fich neben ibn und tat $e$, fegte fie aber vertebrt auf und liéв fíd) baв Zand vor ber Naje baumeln und puftete bagegen; und war nun wieber anders,

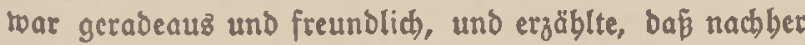
eine Freundin tommen rürbe, um beim Ruđbenanrübren zu belfen. Slno et bliebe Dow den ganzen Sag? So plauderte fie und faß vallig unbetümmert neben ibm.

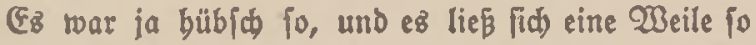
ettragen. 2lber am Ende ... ein junger Menjh will bod mebr, als zivifhen Solzitapeln fïgen uno mit feiner Liebften nichtz als plaubern. (Ex lonnte ez nicht länger

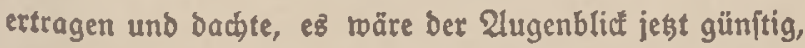
einen Eleinen 2lngriff zu wagen. 2lz fie aber mertte, twas er vorbatte, langte fie idjnell nach bem böberent Bretteritapel über fich und jagte, fie roürbe obne Befinnen ben ganzen Soaufen zum Slmfallen bringen, wenn er fich noch einmal rübrte, und liés ihn bedentlic) f(jwanten, To oft er nad ibr langen roolte. Gie roolte fid balbtot lachen bor lauter Qlbernbeit.

Ex war im Soerzen febr untwillig unb twïnjldte ibr alles mäglidje an ben weífen Sals; tat aber leicht und 
gropartig, und laciste auch felbit, fo als wenn auch er nur geichergt und geipielt bätte; und ftand auf und ging mit ibr nach Dem Sallie; und fie war guter Dinge.

2lв fie bie grop̉e helle 230 onjtube betraten, brachte fie ifm freundlia) eine Sigarre, ja rauthte fie jogar jelbft an und frecte fie ifm in ben Mund -, fo dap ibm wieder gant wunderlich tourbe und bas Serz ifm bis fum Solz fallug uno er nod) einmal wieber auf eine Heine bejondere Greundlichleit und Ergößung boffte. Uber da fam bie Greundin; und fie fingen jogleich an,

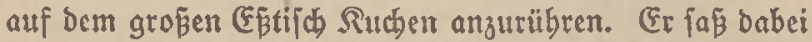
und jab ibnen zu, twie fie ab und zu nah ber Rübe

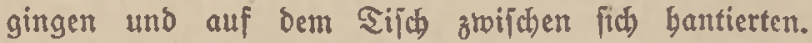
Sic ladten und atbeiteten, fohoben fich gegenfeitig falid)e Süten zu, und erzäblten uno malten fid) aus, wie beim Oertauj山 Der Süfen biejer uno jener Seig mífrafen, und was für Slnformen von Ruchen zuftande fommen

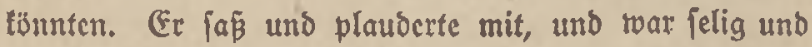
unjelig in ifrem 2lnblict, twie fie ibre grope fdobne Figur betregte und ibr Lachen aus gejunder Brujt tam, und lauter Blü: und llbermut aus ibren blauen frifden 2ugen fubr. Er trarf feine beimlichen Wümíte, bie ex monatelang gebegt batte, und feinen 2 irger bon bors bin von fich. (Er bachte: , Sie ift nodh zu jung, um ernjt zu fein; fie ift noch fo zwifjen Rnabe uno Mäb. chen uno nods lein 2 eib. Wie runderbar wirb fie feir, wenn fie ein 2 eib fein wirb!"

Gie batten ben Seig fertig unt probierten ilgn und gaben auch ifur bavon, und famen barauf ô ipred)en,

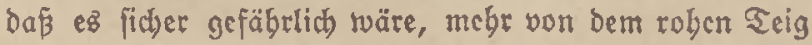


gu clien, ba er ja aufginge; und fingen an, einen fold Fall augzumalen, faben fich an und rourden eir roenig rot, und tonnten boch von ber Gache nidjt lafien und twollten fich unter ben Silich lachen. (Er, ein ziemliches Etüđ Seig in Der Soano, fo alz wenn er ez jelbit nebmen twollte, fprang auf fie zut und verfuchte, eह ibr in ben Nuno zu ftopfer. (Ex brachte ez aber nicht fertig, da fie fich mit Soänden und Jü̈en trebrte; aber er erreichte num 10 , worum $i$ bm zu tun toar, nämlich, Daß́ er Das föbne, geliebte Frauentwejen in ben $21 \mathrm{rm}$ belam. Slno da fein 2lrm um ibre Gdulter lag uno er merlte, Daßj ez ibr nicht unangenebm twar, bafte er alles erreidjt, was er fid in bielen fitfen Gtunden gea bünjht batte, und toar jelig.

Uber aud fie war fid bewufit, was geidehen twar: Daß fie ibm Licbe gezeigt Gatte, und war in ibrem Näbdjenftolz verlegt; und ba man fich nidht gern felbjt fraft, meinte fie boh, fie mü̈̈te ihn ftrafen. Slno fie fing an, im Verein mit ibrer Greundin mit veritellter, getragener Etimme einige Säke berzulagen, teren Ginn und Bebeutung er nidjt verftand unb audi nidjt ver= fteben follte, bie aber boch für ibn bejtimmt roaren; denn inden fie einander gegenüber faß̄en und Mandeln

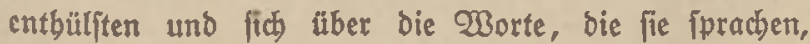
roeglachten, twarfen fie ibm Blicte' zu, und lacten Dann, offenbar über fein rätifelndes Geficht, noch mebr. Go lagten fie mit boblem, mattem Ton: "Sö̈tte id bich zur rechten Seit erfannt und bätte bir gebolfen!“... ODer: "Denfe immer Daran, baß́ ich ganz feft an bich glaube,

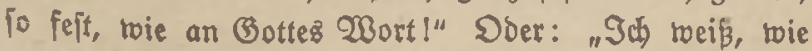


umfdulbig but biftl" Doer: "2ldh, tönnte id bir in Deiner Sot belfen! Der barmberzige Bott wirb meine Bitte erboren uno nicht zula rublos burch die $23 e l t$ wanbern mußit!"

Bei biejem lebten Gag rurbe ibm plöglidi) flar, dap fie oon feiner Gdinefter prachen. Er tourde von fdhtwerem Sorn befallen, Daj fie fo twar, twie fie fid bier zeigte, ftand jäb auf und lagte emit und lalt: "Iegt fagit bu mir fofort, was es mit biejer Gache ift. Wie fommit bu zu Briefen meiner Edrefter? Seraus Damit! Gonft fag' ich es beinen Eltern."

Eie war blaṕ getworben und bís die Lippen uno wollte fich beflagen, da er jagte: "Die Gadje ift allerbings ernit; benn meine Gdwefter ift ebenfoviel wert uno vielleicht mebr, als ifr, bic igr obne Ernft jeib. Slnd fie ift ourd jere

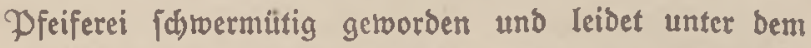

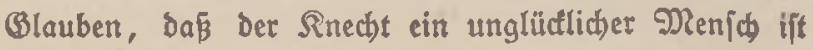
und baß fie ibm bätte belfen tonnen uno follen."

"2lber fie fojreibt ihm, als wenn fie in ifn ver. liebt ift."

"Wą gebt euch Daz an," jagte er, "twenn ezి fo ift? Sind nut fag' mir fofort, wie bu zu biejem 3 rief getommen bift!"

Sie war ziemlich gedemütigt und bebrüctt, Das et jo batt wax und wobl auch ein Recht bazu batte; ez wat aber nod lein Renich fo mit ibr gervejen, benn fie rourbe immer mit Sandichuhet angefát. Gie be. fand fich ia ploglid oor cinem orbentlichen Beridbt! Die 2lugen ftanden ibr voller Tränen und fie fagte: 
"Sie gab mir inn beimlich, als tił bas Iekte mal bei ibr war; ich follte ibn bier in ben Raften ftecten. Er twar nicht orbentlich berfchloffen und ba las ich ibn." "Slno auch beine Freundin las ihn; und ibe beibe mahtet aus ber Not einez tranten Neniben ein albernez, Dummes Belähter. Gtand in Dem Brief ein einzigez Wort, Das ebrlog ift?"

"Ė ftand nid)ts barin, alß allcin bie brei ober vier Säge, bie id berfagte."

Er wandte fich fur Tür und fagte zornig und folf: "Du weipt toobl, twie id fut bir ftebe... uno id lage Dir: ich treíß auch, twie bu zu mir ftebjt! 2lber einft=

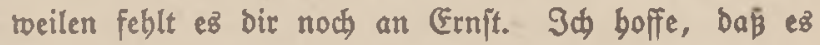
anderż twirb, twenn bu älter bift. ..."

Damit ging er zornig binaus, und ging nach ber Gdleufe, uno war ba bei ben 3 rübern uno balf ibnen beim Berzeidjnen ber $\mathfrak{Z}$ alfen.

218 er gegen Geierabent mit ben 2 tübern wieber nad) Saufe tam, twaren Die Eltern angetommen und fie faß̄en alle vergnügt und in lebhafter Slnterbaltung um Den gropen (Ebtifh. Qizbeth roar offenbar noch iebe bebrüctt und sornig, verbarg ez aber gut und war nur ftiller als fonft und zumeilen in Bebanten.

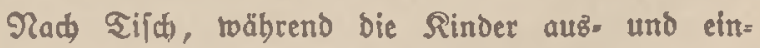
gingen, fingen bie Cltern an, mit ibm über ben 3ujtand in feinem Elternbaus ơ reben; er aber ftand gern

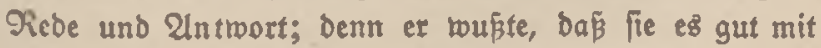
ibm meinten.

थlв Tie von jebem eingelnen gejprodien batten und es alles bin und bex berebet batten, fobroiegen fie eine 
Weile, alles im fitlen überbenlenb; baun fagte ber Yater: "Id) glaube, Sarm, Dá ibr ba auf bem Sof ben einen Sauptfebler habt: Shr tlebt alle zu febr an Sauie und ancinander... Shr feid barin fajt fo iblimm, wie die Rinder von bem alten Matzen."

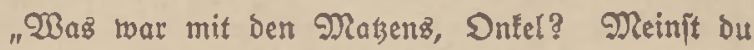
Die Weberfamilie?"

"Sa, bic!... Gie firib eine alte, alte Weberfamilie, fo roie ibr cine alte Bauernfamilie jeí. 2lı ев nun, fo wor vierzig, fünfzig Sabren mit Dem Weben immer (chlechter ging, faß̧te ber alte Mazen ben groben (Ent-

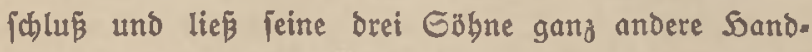
werfe lernen, damit fie bor ber Weberei gand ficher bewabnt blieben und auf burchattz anderen 23 egen und Weije in ber Welt vortwärţ̇tämen. Der eine twurbe Naurer, ber andere Lanomann, Der britte Rüfer. Ev gingen fie in bie $\mathfrak{B e l t}$ unb lernten jeber fein $\mathfrak{G}_{e}$ fhäft; und ber alte forgte bafür, Daßi fie immer etwas fern won biejer Stadt waren, und daj fie, twenn fie cinmal bier im Elternbaus zum 2 ejuch waren, bie Wertftatt faum zu jeben befamen, und fie famen über die Dreiß̈ig.

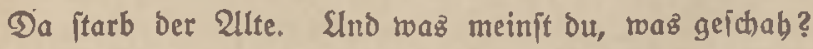
Es vergingen teine drei Sabre, ba faßen alle brei Brüber

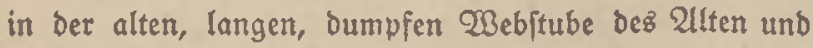

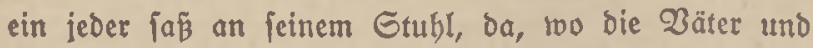
Borbäter gefefien batten, und fie flappten mit Den alten Geftellen, Daßj ez tnallte. Go if́t ez mit cuc)! Shr klebt, innendig, itm Socrzen, zu bicht zuโammen - Sbr feib inmendig zu eng miteinander verbunben. $\dddot{W} a z$ ift $b a z$ für ein Mitleiben miteinanber! $\mathfrak{B a s}$ für eine Not Durd)= 
cinanber uno fẗreinanber! $\mathcal{C a g}^{\prime}$ boch blofi mal, was foll z. B. aus bir werden, wenn bu hier im Qanbe bleibjt? Wie wirb es twerben? Du rirft immer benfen: , Mein Bruber! DNeine Echtwejter! Neine Neifgeno|Ten!' Slno bald twirft bu um biejen forgen und balo für jenen laufen, bald für ben britten bürgen, bald beine eriparten Faler zu bem vierfen bringen. Was aber erreichit bu Damit? (Bar nichts! Sa, weniger als gar nidts! Dat fhabejt ignen! Du fdäbigit nicht allein bich, jonbern auth fie. Denn mit ben meiffen Menfchen ift $e \vec{b}$ fo: wenn fie rwifien, Dap ba irgendwo binter ifnen eine Silfe fteht, fehn fie nicht um fid), fitrengen fich nicht an, ftraffen fich nicht. Mein Bater fagte, als id fünfuno= zwanzig war und beiraten wollte: ,Sier baft bu brei= taujeno Narf, bas ift alles, was id bir geloe, folange

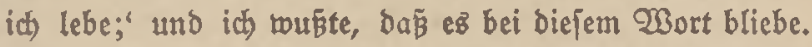
Giebft Du, baz twar recht! Rurz ... Du nufit bich inrwendig von beinen Reuten mebr trennen, ein शenjळ für dich allein fein. Wialit bu (Butes tun, fo juch) bir einen einzigen

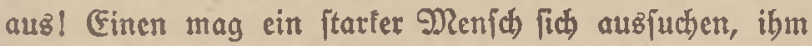
子ँ belfen! Ttimm ben Reimer! Cinjtweilen ifit er ja fo'n bif̧ben ein Tarr; aber bu jollit fegn: Der wird noch gut! ... 2lber nein, bu fannit einen andern nebmen. Dem Reimer fannjt bu fagen, daß̄ ich ihm helfen twill, daß er iक力on biefe Ditern auf Das Geminar fommt."

Sarm Ott ftrablte überz ganze (Beficht uno lachte. "Silfit bu aud nur immer eintem, Onfel, nur biejem?"

Der 3immermann lachte auch). "Go ungefäbr!" lagte er. "I

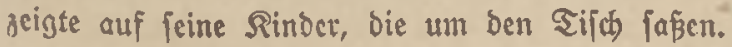


Run fprachen fie von Den anderen: bon Rlaus uno Eggert und von ben Rleinen, und am meiften von (Fmma uno ibrer Gdtwermut, bie ifnen ein Rätfel trar; Denn ber 3 immermann und bie Geinen waren muntere, tag frobe ERenfid)en, und ibre frömmigteit trar auch fo; und Bott twar ibnen ein roadrer, muntrer Wertmann, frob wie fie felbit über feine Sage und über bas feiner Sände.

Ulntertwegs auf feinem f(h)mucten $R$ abe, aโs er burd) ben bellen Grüblingsabend beimfubr, tamen feine $\mathfrak{B}^{\mathrm{e}}=$ Danfen gleids mieder zu feiner Riebiten, $u m$ bie fie auch twäbrend ber ganzen Abendunterbaltung gefpielt batten. (Er war glüctlich, Daß̧ fie räbrend bes ganzen 2lbendz, obgleich immer nur bon feiner Familie gerebet rurbe, im 3immer geblieben and ernft und ftill, ein wenig im Sintergruno, am Sij内) geieffen batte. (Er batte ichon wieder vallig vergefien uno vergeben, daß fie ibn fo geärgert batte, unb fab fie nur immer, twie fie ba

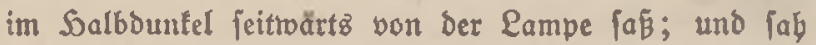
igr leuchtendes (Beficht, das fich zutweilen zu ihm wanbte und ign mit langem, rubigem 3 lidf anjab, und twie fie rot rourde und fich tief auf ihre 21rbeit beugte, als er bon ber Not feiner Sdwejter prach und es ibnen et= tärte. Er twar jelig, Dabihre ihöne, ftarfe, liebe Geele boch Feue empfunden batte; und roar gand betäubt von Der Güß̈igkeit ibrer Erjaheinung, bie, wäbreno er fo

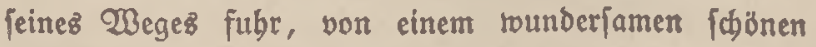
Gd)ein umfloflen, bor ibm Dahinid)webte.

Den andern Sag werbrachte er wieber im Sourfe und juchte Dabei eine Belegenbeit, mit leiner Gebrefter 
allein zu iprecten. $\mathfrak{F}_{3}$ wollte ifm aber lange nict) ge= lingen, Da ex, wo er ging und ftand, won Den Rleinen begleitet murbe, bie i won in aller Grübe an Der Ram= mertür geftanden und auf ihn getwartel batten. (Endlid) um die Nittagitunde itanden fie beibe allein im Barten, in bem fie das erjte Früblingzbeet zurechtmadte. Da erzäblte er ibr, Dafi Lizbeth इbomien ibren Zrief geIejen und ibren Gpott damit getrieben bätte.

Gie blieb bölig barmloz und meinte, baß Lisbeth Sbomien ben Brief ja gern bätte lejen tünnen.

Fr fragte: "Shalt bu eine 21ntmort befommen?"

"शein," fagte fie traurig, roäbrend ihr Sränen bie 23angen berunterliefen: "Er ift $\delta a$ in jeinem Beburt8̊ort nicht angelommen und ber Brief ift wieber zu mir zurülts= getommen. ${ }^{\prime \prime}$

Er fragte: "Was wollteft bu Denn mit bem $\mathfrak{T r i e f}$ erreichen: Daßj er bir roieber fdreibt ober dą́ er biers ber tommt?

Gie weinte beftiger, aber fie fagte flar und ficher:

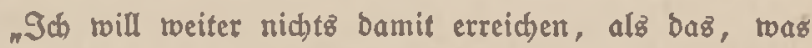
brinjtebt: Daß er rubig tvirb und ben OBlauben nicht verliert."

"Wober roeíst bu Denn, Daßs et unglüatid ift?"

"Das tweí ich," lagte fie idlid)t. "Das tonnte (t) ja iebn ... und dann daz Pfeifen."

"Waz bat das Preifen damit zu tun?" jagte er. "Sa," lagte fie, "daz Dfeifen ... bas ift ber böje Geift, ber ibn verfolgt. Das ift an einer anderen Gtelle, wo er gebient bat, aud ichon bagetwe en."

(Er borchte auf: "2ln einer anderen Etelle, wo er 


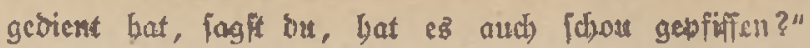
... "Gepfiffen nidbt..." [agte fie, "aber fo toas äbnt= lidies. Er ift eben von Dem Böjen verfolgt, Der ftebt ibm nach ber Eeele ... und ..." fie weinte bitterlich "... id bätte ibm belfen tönnen und babe es nid)t ges talt. Slno nun weip id nicht, wo er ift."

"Womit bätteit bu ibm benn belfen tönnen?"

"Sd) bätte mit ibm und für ibn gebetef... aber id) war ein unnüger $\Omega$ ned t, ich verftand unb nun ift es zu fpät und er bleibt weiter im Slnglüa und in ber Berfolgung, und wandert immer weiter von Gtelle zu Gtelle; und immer ift ber $3 a j e$ ba und jteht ibm nach ber Geele."

"Slnd nun gebjt ou jeden Gonntagabend zu Gaujter (Eblerz und betelt Da mit Den andern? $23 a$ fino bas für Reute, die ba fommen?"

Eie nannte die Namen ... E. twaren alle fille Reute und alle von gutem Ruf.

"Slm was betet ibr Detrn Da?"

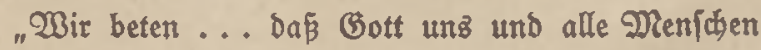
vom $\mathfrak{B b i e n ~ e x l i s f e . " ~}$

"Slno bann benlft bu an ben Rnecht?"

${ }_{n} \Im a$, bejonders an ibn ... reil er fo unjagbar unglüutlid) und verfolgt ift... und burch meine Eduuld; benn ficher bat der liebe Bott ifn in unjer Saus ges jandt, Damit id ifm belfen pollte. Slno nun tweip ich nidit, Bruber Sarm, warum ich auf ber Welt bin! Das einzige, waz ich in ber Welt bुätte tun tönnen, babe id) verfäumt."

Er ftand eine Weile neben ibr. Geine Gebanten 
liefen bin und ber und fuctsten irgendwo eitren $\mathscr{W} e g$, ben er ibr zeigen fönnte, um aus biejem Eleno herauš = zutommen. Es roar aber nicht leidht, ba feine cigne Natur fo pollig anders twar. Endich begann er vor= fichtig und langjam: "Ich will bir jagen, Echivefter, wie ich mir alles benfe. Sör' mich an: Du bift vom Bater ber fabreemütiger Nafur; von der Mutter ber aber bifit ou munbergläubig. Nun fam ber Rnedst und war ein freundlicher und feltfamer und bielleicht unglüate licher Nenjw. Slnd da, fiebjt bu, ba hatte beine ganze Natur, beine ganze Gcele Gefallen an ibm. Er erzäblte bir bies und bas; er reizte Deine Phantafie. Dann fam Das Pfeifen und Dann ging er fort. Slnd ba gerieteft bu nun in biejen Blauben. Gtatt jtebrzubleiben, ro Du ftandeit, tro Gott bich hingejtellt, als ein gejunder

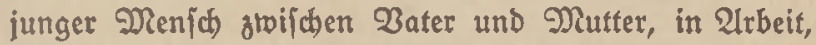
Wind und Sonne, liefit ou in eine fdroermütige, Duntle Wunoerlid)teit binein, in einen finftern Irrweg, io als bätte ber Rnecht eine unerträgliche Rot auf fich und werbe vom bifen Geift verfolgt uno nun bättejt aud Du Günde auf dich gelaben. If) glaube: Die $23 i r t=$ lidkeit und $\mathfrak{B a b r b e i t}_{\text {ift }}$ ganz anders. Du jagteft vorbin: es twäre ichon an einer andern Gtelle, two er gebient, fo ras gewejen: ein Pfeifen ober jonjt ein Epul. Weipt bu, traz idj benfe, twas twir alle benfen: Daß er jelbft ber Pjeifer war! Berfteb', nicht im $3 B$ ben! Tu Eannit gern mit guten Bedanten an ifn benten! (Er ift ein Ed)elm, cin 2 underling! (Er roolte uns und auch Dich aus einer gewiffen Dompfbeit und einer getwiffen Gd)roerfäligteit beraus̄nötigen! Slno fieb, als er fab, 
waz ex angerichtet batte, ba lief er in $\mathfrak{B e t z}$ treiflung Davon. Denn et batte unz gern, bejonders did)."

Gie fah zu ibm auf pöllig verwirrt. Damm jagte Fie langiam uno unifcher: "2lber bu glaubit nicht, bak er böje war, bu meinft, er tat ez allez aus Licbe?" "\$a," jagte er, "Das meine ich. Slnd vielleidt tommt er cinmal wieder, Emma, uno erzäblt ez̉ bir, wie es roirflich getoefen ift, fo roie id es̃ mir bente."

Er $\{a b, \delta a \tilde{B}$ fie in ein ftilles Ginnen verfunlen war, unb biclt ez für ridjtig, mun nidbs mebr zu fagen. 2llo ging ex jobroeigend neben ibr nach dem Sauje zu, bon wo Die Sileinen zum Mittageffen riefer. Ex iprach Dann nicht mebr mit ibr Darüber.

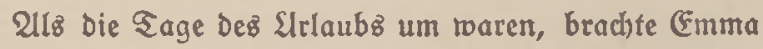
Die beiDen $\mathfrak{B}$ rüber mit Der llapprigen alten (Sig nad)

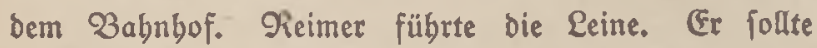
jebt gleich mit nach Riel uno follte nun bort bie Qebrer

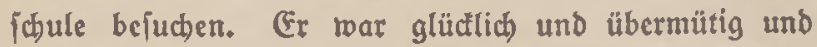
wollte die Edweiter erbeitern, uno verjubte zum erftenmal Das Englifde, das er beim Paitor gelernt batte, an ben Mann zu bringen. Er redete grope Dinge: wie $e^{\mathfrak{s}}$ ihy ba in Riel trobl gefallen würbe und reld)e 2ltt Menjuen ex ba robl vorfinden twürde und ob et ba

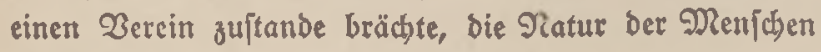
วu erforjchen.

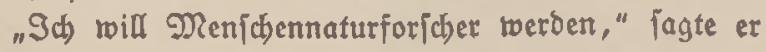
prablig, „ich tweiß wie tciner, wie im Menjhen ausfiebt.

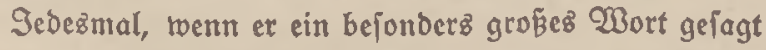
batte, das ibm felbft gefiel, uno er Dann fein Befidt 
Ju feinem 23 ruber toandte und ifn mit feinen ftrahlenden, gläubigen 2lugen aniah, gutte es ihm in ber Sano, und Dann bielt ber groß̉e 3 raune plöglich und ungejchict an, unb fant fo ftarl auf bie Sointerbeine, $D a \beta$ er fí fajt auf Daz Beftell bez Wagenz ferte. Dann beendete er erit feine Rebe; uno bann fubren fie weiter. Die Gdroefter börte ibn ftill an, einen rubigen finnigen 3 ug in tbrem reinen Gefid)t. Sie war beute muntrer als feit langem.

Da wurbe alth Sarm guter Dinge. Geine GeDanten wanden fich ber naben und fernen 3ulunft zu. Er jah Das iđmucte Gøiff und bie guten, munteren Rameraben, zu Denen er zurücffehrte, und Dabinter jein blantez

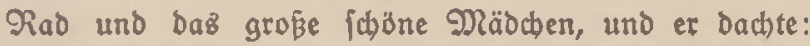
,Ez tommt noch alles, allez in gute Oronung." $E r$ läd)elte über ben Bruber, und fitié bie Echwefter an uno fagte mit frobem Spott: "Was find wir für eine großßartige Framilie, Emma, was? Salt' beine Eleinen Obren fteif, Deern! (Fs roirb noch allez gut! (Fine foldhe Eamilie!? Go zablreid und fo klug?!" 


\section{Rapitel \\ Die englifhe Mannj chaft}

Q1 hit Tage fpäter... e ez war gerabe an bem un= jeligen Sag des Mordes von Gerajerwo ... murde er in Sofen won Ricl bei einer S̈lbung, beim 3ootaug= fitwingen, von einem eifernen $\mathfrak{B o l}_{z}$ en beftig am Snie getroffen und mußste auf fajt brei Wrochen inz Lazarett. Er twutbe ztwar wieder walltig get)eilf; $b a$ aber $b a ß$ Rnie

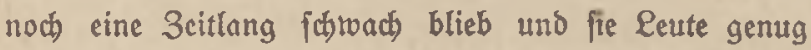
batten, entließ̄en fie ign.

(Ex batte alfo jeine Dienjitzeít nun plöglid binter fich. 2llz er aus Dem 3 B̈̈ro herauztrat, wo er jein Dienftbuch empfangen hatte, und in baz ßü binein=

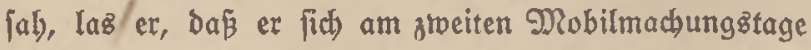
in WBilfelmshaven, im Soof Der groß̈en Rajerne, zu ftellen hatte. Es flog ibm fo burch Den Ginn:, So ... alfo am zweiten Mobilmadjungztag!' ... unb fab fich im Beift in Sof ber Rajerne, bie fie bie Taujendo mannstajerne nennen, aber gleid) verfdhand biefer $\mathfrak{G}_{e}=$ Dante wieder und das Bild, und er actetete ez nictt. Wer in Deutfdirand Dactite an einen Rrieg?!

(Er ging, nicht unfrob, baß bie ganze Gache io $a b=$ gelaufen twäre und er nun wieber in feinen Beruf und

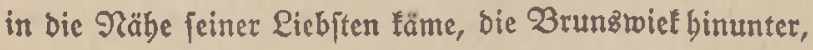
Da begegnete ibm ein Gteuermannzmaat, den er faton von ber Scimat ber fannte. Der erzäblte ibm, Daß er beute morgen einen alten englifhen Freund und Fabreng. genofien gettroffen batte, ber man Bootzmannzmaat auf einem englifden Rrexter war, ber jeit brei Tagen bier 
tm Safen lăge. SInd nun bätten fie für beute nach) mittag ein Ilcineß Weftrubern veranftaltet und twollten

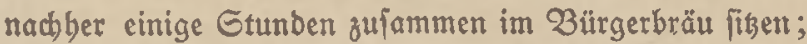
und toenn er Rujt bätte, follte ex mit bintommen uno an bem abend teilnelymen.

Er war ftolz Darauf, daß ber Maat, ein ernjter und tüd)tiger Mann, und bebeutend älter alß ex, iłn zu ber fleinen Geftlicjteit einluo, und fagte mit 2 ergnügen zu. Ulz ex Dann allein reiterging, eilten feine Bedanten nach feiner Weife jofort nach Sauje, und er freute fids, Daßß er ifnen im näb)iten Brief idreiben fönnte, wie er bics erlebt bätte; und gleich fiel ifm ein, dá̉ er Bruber Reimer einen Winf geben wollte, Daj ex fich bie Gacbe beute abend anfäbe, menn er 3eit dazu bätte. Ulio fandte er ifm rajh Nachridt, er möge fich um fieben Slbr im Bürgerbräu einfinden. Dann verbrachte er ben Rejt bes ఇachmittagz, indem er in ber Familie, bei ber er feine Gachen und aud feine 21njorift batte und bei ber er auch bie Racht (chlafen rollte, feine Gadjen sufammenjuchte und pacte. Dann machte er Fich nach ber Wirtichaft auf ben Weg.

(Fr traf ba aud fhon ben Steuermannzinaat uno einige andere. Dann famen auch, felbftbewust tnd fidber, fid) gleidmütig umiebend, belocglich und frifd, Dic Engländer; unb balb fa ja da eine vertrauliche Echar, robl ztwanzig oder fünfundztoanzig Nann, Deutide und Engländer Durcheinander, an bem langen Tifh. Die Engländer erzadlten in frober Bebaglichteit, twas fie in ber Gtabt gejeben hatten, zcigten, twas fie in ber Solften= ftrape getauft batten, uno idrieben 2nfichtstarten in Erenffen, Die Briber. 


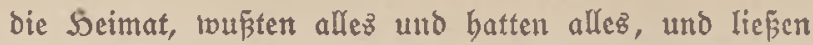
mebr als beichlofien war, zum Srinten berbeibringen uno liefen baz Gelo jpringen. Tach einer Weile faut Bruber Reimer hercin, fab fich vermirrt unt - er war, feit er in Riel war, fitifler und unfict)erer getworben und juchte ez zu verbergen, inbem er über ocn Bruber

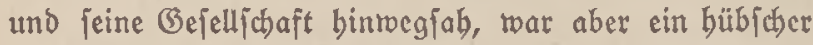
und ftattlicter Sunge in feinem neuen Dunfelblauen Inzug. Sorm ftand auf und begrïßste ign und fübrte inn an cinen Play, wo er nicht zu fern twar uno fegte fich) vieder, und grüp̈te zuweifen ou ifm bintüber, und boffte, ihn einfdmuggeln zu lönnen, wenn ez ctwaz

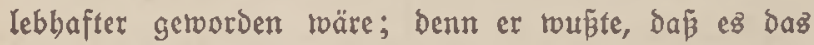
größ̄te Erlebniz auf ber $\mathscr{W e l t}$ für ín fein wärbe, wenn er lebendige Menichen eines fremben $\mathfrak{B}$ olfez, und nutn gar Engländer, tennen lernen fümnte. Da jaß Bruder Reimer nun und jab jobeinbar in eine 3eitfdrift, bie Da lag, fah aber in Wirtlichleit Darüber bin und bejab fich) unauffällig allez, roaz in bem großzen Raume vor fich ging, und jah, fo oft ez anging, nad) bem Sif Der Engländer, bord)te aufz [chärffte, ob er etmas von igrer SUnterbaltung veriteben Hömme, uno war voller Bెenug. tuung, wenn ex cinen Gał begriffen batte. Die Engs

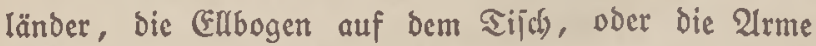
läffig um einige Gubllebnen gelegt, einige die Müze im Pacfen, waren fichere und gemütliche Qeute.

Die Snterbaltung tam balb auf das Wettrubern, Das fie binter fich batten. (Es war ein barter Rampf getweien und bie Deutichen waren bicht babei getweien zu fiegen; aber ba war ein mumberlichez פríggejdict 
geidseben, Die Deutfden batten ifr Boot bormittagz aufz peinlichjte gefäubert und aufz bejte in Oronung gebract)t und batten ez, ba ez cin bibiger Iug war, noch biz zulest unter ber Periennig gelafien. Nun batten fie einen fleinen weípen Röter an 3orb, Der ibnen lieb war, weil er immer gleichermajen freundlich und gefällig war. Diefer fleite Sund toar bon dem, Der zulegt, furz vor dem Gtart, Das Boot betreten batte, um S̈lmäntel zu verftauen, und es Dann wegen einer plöblichen 3 be fluchtartig verlaffen hatte, mit inz Boot genommen und bort bergefîen roorden. (Fr hatte fic) vor dem Platregen unters Sect verfrochen, batte Da ein Pläthben gefunden, das ibm zujagte, uno war da in Echlaf geformmen uno vergefTen. 2llz fie nun im bejten Rubern waren uno eine gute 2usficht batten, Die Englänber zu fchlagen, mußte einer von ínen mit Dem Gü ausgleiten und Den Sund treffen, Der aus feinem Pras beraugigefonmen twar, um fich bie $\mathfrak{B}_{e}=$ gebenbeit zu bejeben. Das lleine Ding beulte laut auf, und baz genügte, um bie ganze (Bejellichaft unficher zu machen, da jeber bejorgte, ibm web zu tun. Slno fo verloren bie Deutjhen Daz Epiel und hatten nod) Epntt bon ben Rameraben uno eine getwaltige giede pom erjten Offizier Dazu anzubören.

2ber fo wic ber Deutfhe nun cinmal ift, fo ijt er rounderliderweife fajt ein wenig unfidier, ja, ein roenig bedrült, wenn er bei folchem Epiel ber Gieger ift. In ernften Dingen will er gern Der Gieger fein, aber beim Epiel denft er: Eđabe, daßj ber anbere nun leinen Gpás von ber Gache bat und traurig ift; es 
wäre mir wabrbaftig lieber gewelen, wenn ber anbere gefiegt bätte! Warum nicht? Bin ich Darum weniger cin titd)tiger Mann? Sch günn's ifm! (Fin andermal fiege ich!" Der Deutfche ift beim Epiel gern ber

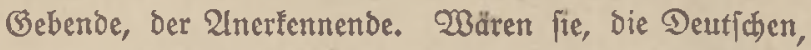
bie Sieger getvejen, fo bätten fie nicht jo gemütlich, fo froh, fo volllig übermittig an ber langen Safel gefeffen, wie fie jest bafaß̧en, da fie bie (Bejd)lagenen waren. Freilich, fie fhimpften über ibr Slngemad) uno gaben dem Sound jeden Gdimpfnamen, den fie fanden, und Das twaren nicht twenige, zumal fie auch bes (Englifhen mäd)tig waren und bie meiften bon ifnen eimmal auf englifchen Echiffen gefabren batten. 2ber obgleich fie behaupteten, Den Sund mitgebracht zu haben, Damit ex feine Gdhande biz auf ben (Grund tofte, raar ez boch Hlar, dá fie ibn nod) mebr liebten alz bişber. Sedenfallz jaßs ex ztwijhen ben Biergläjern und Godaftaichen auf bem Sifd, eine lleine englifhe Mü̈se auf bem Ropf, Da fie bebaupteten, er fei von Den Engländern bejtochen morben; und wurbe auf'z lebbaftefte von ibnen genect.

Da Sorm feintem Bruber einige Male zugenidłt hatte, twar es bem Soäuptling Der Engländer, einem

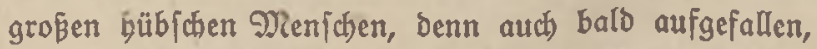
und er fragte $i b n$, ob ez fein Bruber twäre. Slnd als Sarm niclte, rief or in guter Raune binüber: „Are we down-hearted?" und al\& Reimer bas Wort nicht gleid) ridtig verftano, rief er: "నommt boch) ber mit Curen fiefen Augen, uno feib mit uns," uno machte ibm Plats an feiner Geite.

2lls Reimer mun, rot bor Freude, neben ibm fä, 


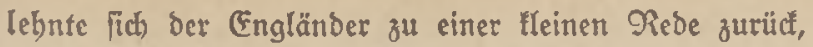
indem er Den Q1rm um Teimers Gtubllebne legte, uno fagte: „(Ez ift ficher, baj alle meine Rameraden, ja bie ganze englif che Glotte, Darin einig ift, Daß twir bie beutichen Geeleute jebr gern baben. Die Franjojen und Staliener baben in ibrem 2 cjen etwaz, baz gegen unjern (3)= fđdmact ift, und find unz fremb; aber bie Deutfchen

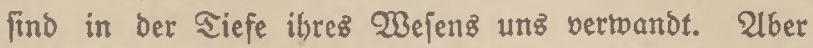
mand)es" ...er lächelte - "tönnen bir - meine Sameraben rocrben mir zuftimmen - an ben Deut= ichen nicht verjteben und lieben, fo z. 2 . Dicje Begebenbeit mit bem Suuno. Rein! Êritens wäre ể uns nie und nimmer wiberfabren, ba wejen wäre. Slno twenn ez junge Raken geregnet bätte! Es ijt eine Unorbnung, ein Mangel an Gachlichleit, Silarbeit und Bereitjめaft. 3tocitenz, wenn roir ibn bennod im $2300 t$ gefunben bätten... mitten im Lauf ... To bätten mir łeine Rüdfict)t auf ihn genommen! Tein, biejer Sunb, io gut und nett er iit, trirflid... ein brolliger, bübiher fleiner Rerl, obgleidh nicht ganz reinraffig ... ex bätte bran glauben müffen! Ein guter Fußtritt und er wäre ftill gewejen!" Ułz er baz ges fagt batte, fité er ben jungen Reimer freundichaftlich in bie Rippen und fagte leije mit jofelmifdoem 2lugen* 3roinfern: "2lber ez ift unz recht, bafi ibr folthe Qeute feib. Es gibt unz Englänbern eine gute 24usficht." Reimer Ott toujte nid)t recht, toas er $\triangleright a z u$ jagen follte. (Ex batte aud nicht ben SRut, fid in feine erfte englifise Rebe zu ftürzen; er lädjelte ben Engländer freunblid) an und nictte mit bem Ropf: "E⿱乛龰 if [o, wie $9 b r$ fagt." 
Der Englänber murbe ein wenig vertwint, Daß̄ ber junge Deutiche, in beffen 2ugen foviel Siefe uno Rlug= beit ftano, Das jo binnahm, mahte fich noch bequemer auf feinem Etubl, juchte mit ben Fü̈en bobluer zu fommen, und legte, alz ihn bas nicht gelang, bie 2lrme noch) rociter um bie Stubllebnen. "Sh) Dachte," fagte er wieder nectifh mit ben Qutgen zminterno, "ibr Deutîtbe bättet fo ben (Bebanten, wenn fich eine $\mathfrak{B}_{\mathrm{e}}=$ legenbeit bìte, fo ein gut Stûct Weit an euch zu reiß̄en."

Reimer Ott fah fich am Sijh um und fah, ba隹 fie alle anderweitig bejhäftigt waren. Da rurbe er etwas ficher; ja er wurbe jebr ficher. (Er fagte langfam, mit febe ernftem und flugem (Geficht: "O nein, Daran benfen roir Deutfden nidst. Wir find froh mit bem, wie es jest ift. Wir arbeiten, foridhen, treiben Rumit, reijen; uno find in vielen Dingen bic Lebrer und Fübrer anderer Bölfer."

Der Engländer nahm die Snterbaltung mit dem balben Sungen nicht ganz ernft, batte aber einen ebr. lichen Epás an jeinen leuthtenden, toderniten 2lugen und nicfe (d)elmifd): "2lber ing werbet bei eurem Gtubicren und Reijen, Arbeiten und Sandeln fo verbammt reid); uno bas grïßtenteilz auf umfere Roften!"

Reimer Ott, in Beift und all feinem Denlen fiton gand 2 ebrer, fagte eifrig: "Ja, wir werden aud teicher, mentigftens" - er twurde rot, benn er bachte, daj fie Da in feinem verfdulbeten Elternbauz am Deid) von biejem Tieicherwerben noch nichts gejpürt batten "henigftens fagt man fo. 2(ber das ift nicht der 3roeff 
bon all bem regen Qeben und Gireben in unferm Dolt. Reider werden? (Das bat nod) feinen Menichen und fein

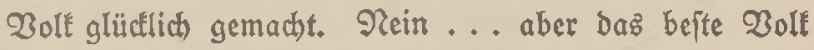
werden wollen, bas gefundefte, reinfte, bas vorbildliche, das Hoinnte uns trobl betwegen. Wir Teutfhen," fagte ex mit einem eifernden 2 luzbruct in feinem (5eficht, "roir Deutiden Denten immer gang untwiffürlich - wir fönnen gar nidjt anders, es fommt aus unferer Natur — an bie ganze Nenjabeit. Wir lieben fie; fie find unjere Menjめenbrüber, alle unter Dem[clben Gtern, unter bemielben Tob. Wir möshten ifnen allen belfen, trir möcten ..." und eine neue Welle Rot ging über fein Geficht ... "ifhen in biefem gern vorangebn."

Der Engländer fah iłn mit feinen großen 2lugen an, inmer nod) mit ben freundidsen Gdjelmenaugen, uno bachte wobl:, Ser fpricht ja wie ein alter Franzole!

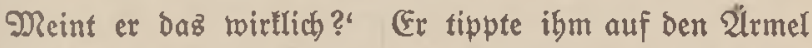
und jagte: "Sh) will nun aber mal jagen ... annebmen ... ę täme plöblich ein Rrieg uno bernidytete all eure ¡abönen Gedanfen!" und er machte eine furze abjaneidende Bewegung mit peiner flachen, magern Sand.

2lber Reimer Ott tat wie ein fleiner Prophet daz Innerfte feines Serzens auf und fagte mit gemichtigen, fitrablenden 2lugen: "Rrieg? . . Rrieg?“. . . jagte er, "Das ift ja ganz ummöglich! Denn mit eud) find wir vertoandt und befreundet! 2lio zrwijhen uns uno euch ift ein Rrieg unmöglich. Wer folfte ez dann aber noch wagen, unz anjugreifen? Es twagt feiner."

Der Engländer machte fich an feiner Pfeife zu ibaffen, brebte und pubte baran berum und war aus 
Feiner Behaglichleit berauzgeriffen. (Er toollte getn mit Dem lebhaften, eifrigen, zierlichen Sungen treiter fohelmen; aber ez ging nicht, tweil er ibn nicht berftand. (fr war Darüber ganz unglüclich; ja, er twurbe verlegen. Er jagte unficher, bie 2lugen auf bem Sijd): "Wer bat Denn foldhe 2Inficht bariuber . . . idh meine, Daß überlyaupt fein Rrieg fein fann, unb erft recht nicht ztwifめen unz ... Soabt ibr fie allein?"

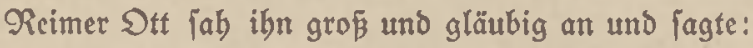
"Fieir ... id glaube .. Die bat gamz Deutidlanb."

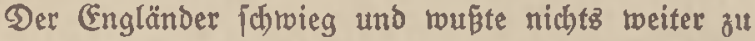
fagen. (Ex fah mit getrauften Brauen auf ben Tijh und Dachte wobl: ,Sätte ich bod) lieber mit $i \mathfrak{m}$ über

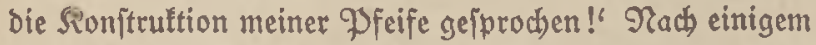
Nachbenten fam er auf Die Gdule zu ipredjen, und es gab eine gute Unterbaltung über ben Begenftand, Die Der junge Deufjhe mit flammenden Augen, ber Eng= länder rubig uno bebödhtig vortrug. Danach, alş fie diefen Begenftano genitgend berebet batten, jaß̉en fie beide ftumm und etras ermübet nebeneinander, beibe zurüffgelehnt und die (sejellichaft bevbachtend, Reimer Ott ftolz und gliutclich, baj er freundlid) gegen ben Engländer getwejen war und ifm Rede und 2intwort geftanden und lauter gute und von Sorzen fommende Gachen gejagt hatte und daṕ bics alles die bejte Gtelle im Serzen bes Englänber gefunben batte; Der Engs länber in rubiger Feifftellung ber Tatjache, wie ver=

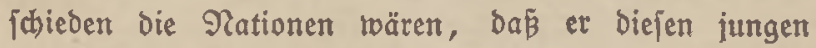
Deutichen, Der eine Erficheinung mar, Daß́ cr Durchauz für einen Engländer aus guter Gamilie gelten tonnte, 
überbaupt nicht werfteben fonnte. , Menn er dinelifd geiprodhen bătte, bachte er, , fo bätte idh ebemiobiel bon bem begriffen, was er in feinem runberlichen Ginn bat! Surely... die Rationen veritebn einanber nidst, nicht mal fo nab Zertwante! Gelbit unter ben roichtigiten Worten, wie Ireue, Ebre, Berechtigfeit, Freibeit verjtehn fie verjdiedenes. Slno fo reden fie benn aneinander vorüber; und es entijtebn bie größ̄ten פriß̄= verftänoniffe!"

Ulz die (Bejelf Brüber nebeneinander nach Saufe gingen, twar Reimer noch Geuer und Glamme, unb redete in einem fort,

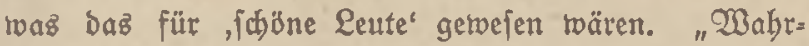
baftig... fieben ober acht bon ihnen..., Sarm, alz wenn fie Soliteiner wären! Die übrigen waren nicbt fo gut ... nein ... bie batten etwas im (Beficht ... etivas, das man wobl in Deutichland nicht jo bäufig fiebt ... To ctipas Sortez pder Leeres in ben 2ugen. Ia, Das batten fie."

Gein groper 2 ruber börte faum bin. Er Dachte an Die nächite 3ufunft, an ieine Reije nach Şauje, fein Wiederieben mit Liäbeth. (Ei, wie war jein $\mathscr{B}_{\mathrm{eg}}$ mun tlar, fhỏn und rein! Er wollte nun einige Salyre in einer größ̈eren Gtabt ber Drovinz auf cinem grȫen Simmer. plaz arbeifen; dann wollte er wieder in bas Symieniche (Bejc)äft zurüdfebren, wo er jederzeit willfommen war. Und Dann ... und dann ... a a ! waz wollte er nicht alles! Und er fab gleich wieber bas Sild feiner Licbften und bachte trieder und trieber: "פ, Das runderichöne,

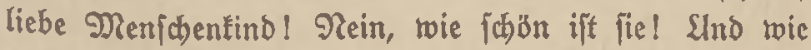


fdisn und lieb wird fie expt fein, wenn fie alter und ernjter getworden iff! Welch ein Leben! Säglich ibs Begleiter, igr Serr und Fïhrer, und ibr Liebjter fein!" 2118 fie oben in bem 3immer antamen, too die Nutter bez Rameraben ibm ein Lager bereitef batte, und Reimer, nach allem Denjullichen immer neugierig, (ich) gleich) an bie $\mathfrak{B i l d e r ~ b e r a n m a c h t e , ~ b i e ~ a n ~ b e n ~} 2$ änden bingen, fab Saarm zu feiner Yerwunberung, baß da zlwei Zriefe von zu Saule lagen, beibe von ber Mutter Sand. Er war jebr beunrubigt, offnete ben einen und Iaz̉ binter den Rüben, Rälbern und Gđreinen, die wie immer Den Zorbergrund Dez Briefez füllten, bie Pach)=

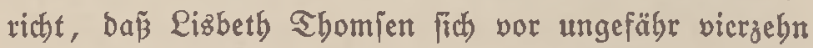
Sagen, vorläufig noc) beimlid), aber boch im (Finver= ftänoniš mit den Eltern, mit einem jungen Lanomann werlobt bätte. Gie war vorgeitern auf ben Sof zum ३ejuch getommen und batte (Emma die Neuigheit er zäblt, ber Nutter aber fein Wort bavon gejagt.

Go! Das war ein Ekhlag! Die ganze Gtube brebte fich um und bie $23 e l t$ ftürzte zujammen! $G_{0}$ ... po... aljo einen andern genommen! Ulno er ... und ex ... er war ganz allein. Weg twar fie! Cines andern! Gab cinen andern an ... mit biejen Uugen! ... Dit toas für 2ugen! 2d) ... und ließ fid von ifm Eüfien! 2luf ibre Augen, auf ibr Soar, auf ibren

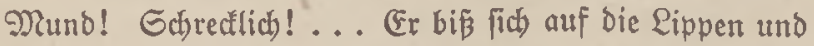
atmete Icije und fdwer, daß́ ber 2 ruber nichtz merfte.

Dann offnete er ben andern Brief, wobei ím eine Ieife, verrüdte Soffinung Durch) den Ropf zudfe, Daß́ Diejer Brief melden twürbe: ,es ift nicht wabr; ez war nur 
einer iffer Dummen Grberze ... Tie toolfte nur mal hbern, toie bu ez aufnelymen lvürocft!' ఇun lyatte er ben Bricf geöfnet. Wieder bie febr orbentlid)e, fteife Gdfrift ber Diutter, bie jo gar nicht zu ifrem Wejen paß̈te. 2lber Dics̄mal, obne Rübe und Rülber, flipp und Klar gleid) auf bie Gache losgebend: dap eben Sobfe Gubl ba=

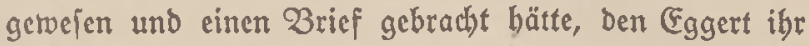

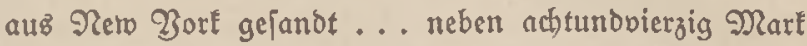
... Ficton vor fects $\mathfrak{B}_{0}$ chen. Gie batte ibn bizher verheimlicht, in ber Soffnumg, auf ihre Alutwort, bie fie fofort gejdrieben uno abgejandt lyatte, trieber eine 21nt= mort zu befommen uno näbere शachrid)t über ibn bringen zu tönnen; aber bis jęt twar biefe erwartete 21ntwort ausgeblieben. Der Brief, ben bie Mutter nicht aus ber Sand batte geben wollen, lautete in abidurift fo: ,2in Söble Gubl, Saroffertoog bei altenfiel.

Sier erbältit Dut achtundvierzig Marf. Gib baz Beld an Den Ranbmann Peter Reimer Ott in 2llten= fiel und fhide mir alßbald bie Beftätigung. Sch wobne bei Rebefta Pcin, Netw 3 orf 136, Grreet Nr. 42.

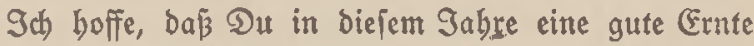
befomm[t, und Daßj auch ber Birnbaum trägt, bon bem (D) mir mand)mal ganze Sände voll über ben Oraben gejd)miffen bajt'.

Sum Gduluß farieb die Nutter: ,Söbfe und id find in Gorge, Sharm, wie er ba robl mohnen mag! Waz Reimer bamalz pon ber WBirtichaft auf Et. Pauli erzäblte, Daß̧ er ba neben cincm Mulatten im Gofa ge= feffen bat... Edulter an Ed)ulter, fagte Reimer ... bas war febr bedentlich. Wber unjere Soffunng ift ber 
Name Rebefta Pein. Wुir bilfen nur nic̣t, ras für eine es fein mag; ez gibt fo viele Peins. Sooffentlid teine von den Gübertoogern, bie find alle fdeinig und uned)t; Die von Et. Margarethen fino beffer."

(Fr itand noch und fab auf bie Worte, billig im Bann allez beffen, twas auf ilyn einftürmte, ba jagte Reimer, Der plöglid) neben ifm fand und auch gelefen

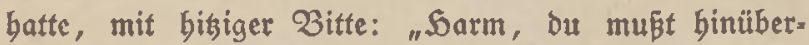
fabren und mit ihm reben! Bitte, Soarm! Ez ift ja ganz natürlich, Daß̧ Du es tujt! Wie trird bie Mutter glüctlich fein, rwenn fie ez bört! (Ez ift ja ein Raken= jprung! Du verbingit bich alz Simmermann! Wiel= leidbt befommt io alle unjere idlimme Tot ein Ende!"

Sorm Otf überlegte nidht lange; er rusiste gleidy,

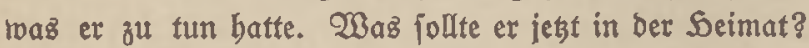
Er founte bas Thomjenjhe Satts unmöglich vermeiden. Diejez vertuchte Mäbdjen aber nieberjebn, und ibr Liebiter ftand neben ihr?! . . "Natürlich!" jagte er jäb. "Э屯h fahr' binüber! \$đ fabre morgen früb nach Samburg ... Saft bu ben andern Brief fdon gelefen? Was rar

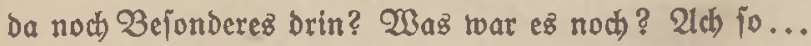
Lizbeth sbomien bat fid werlobt. Gie bat es felyt eilig! Sie ift noch nicht neunzebn."

Reimer dachte nur an Bruber Eggert und toollte nod), wer weiß toas, bereden; aber ber 2 ruber batte genug won Menichen. "Nach", daß ou fortfommit!" jagte er, und idhicte ibn weg.

Ulz ex allein twar, fam ein 21nfall bon Wut uber ibn. Er feste fich aufs 3 ett, tnirichte mit den 3äbnen und foimpfte auf bas Näbden, und war mit bem 
ganzen Qeben fertig. (Ë iff nicht leidht, ben Menichen, mit bem immer alle lieben Bebanten gejpielt baben, nun mit billig andern, fremben 2lugen anzu[ebn. (5z ift, alz wenn allez $\mathfrak{B l u t}$ aแz bem Serzen tweggebt und man leer und bohl zurüctbleibt und nur noch cin toter Ed)ein von eincm Nenidhen ijt. Sa, es ijt ebenjo

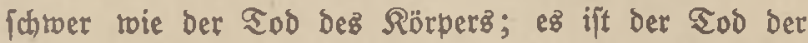
Gecle. Dagu fam nod das. ... und das nurmte und fräntte ibn fait am meiften, $\delta a \bar{\beta}$ fie ibm nidjt ein cin=

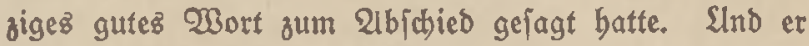
twïtete nid)t allein gegen fie, fondern gegen alle Men= fhen, bie ez ja, wie ibm fchien, alle und immer fo machten. Waas fie einamber antun, ift an fich nicht bas Gdylimmite; benn e马 fann ja obne Bertwirrung nicht abgehn uno bie Eđuld baran trägt mebr Gott alz bie Menichen. 2lber bie Form, in ber fie ez̊ fich antun, ift to fdlimm. Baben fie ibrem Sun nux immer cine fab̆le uno gerechte Form, fo wäre nur Der balbe Rummer unter Den Menichen. $\mathfrak{W a z}_{a}$ fornte bicjes TRäbchen am Ende bafür, wenn igr wirres Şerz fich einem andern zuneigte, zumal er in ber Ferne mar?! Oerb ..., mag fie laufen, toobin ez fie gelüjtet! Mber, Dá̉ fie es ifm nicht in einem langen, guten Brief mit Ent;chulbigungen mitteilte, das war fo un[agbar fräntend. Aber Das begriff fie in ibrer Berftoctheit unb $D u m m b e i t$ nicht. Sum Donnertwetter! Sie twar bod) feine Licbite getrejenl Wenn fie auch nic ein tLarez Wort liber ibre Liebe zueinander gefprochen batten, io wujte fie boch, wie beiß er fie liebte! Slno aud) ibre Alugen batten befannt, neulich nod zwijhen Den Solgjtapeln, 
wie ez um fie itand! Nein, es twar cin unentjdullo. barcz Benebmen!

Go grïbelte er eine ganze Efunde lang und fränfte (id); und tauthte bie Riebite immer roieder und rieder in fcinen Sorn binein, bis fie, fo blond und weişbäutig fie war, ganz fiblwary war, und ber ärmite 3 urfhe, ber hungrig und frierend feines $\mathscr{2} \mathrm{eg} g \bar{s}$ zog und an threm hellen Satte vorüberfam uno cintrat, feinen Biflen 23rot von ihe genomnen hätte. Slnd ez balf ihm fürz̄

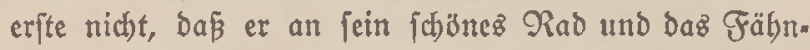
Iein benten roolte. E⿺s war ihm allez, daz ganze Reben, zerjalagen mis zerichmiffen. 


\section{Rapitel \\ Nerw Zorf}

Cr fubr am andern Morgen nach Samburg, fragte fich 2 am Soafen zurectit uno ließ̈ fich auf Der "Rauenburg", einem fleineren Dampfer ber Sopag, ncunzebn Mann unter ber 2 act, mit Etüdfgut nach Nem 9 ort, alB 3immermann anmujtern, und idwamm am vierten Sage nach Weften unb erreid)te am vicrzebnten Sage New 3 orf. (Ex batte Dem Rapitän, Der ein verftändiger Mann war, gejagt, was er Befonderes borbatte, und befam gleich Lanourlaub und madte fid auf ben Weg. (Es rar ein beifer, blendend fonniger Sag.

(Er fubr nad) bem New 3 orker Pier binüber und tam gleich in ber erfiten Girape in onz Gerwirr ber Nenifhen und bog in ben 3roadway ein unb ging langlam, mit Elopfendem Serzen, bie ganze Geele in ben 2ugen, burch das getwaltige Soben bez Lebenz. Gđräg über ibm, in ber Nitte Der mädtigen Etrape, auf machtwollem Eifengerïit, jagten Donnernd die 3üge Dabin, unten auf Der Etrape fauften ratternd und ftoßßend in vier biz jechż Reiben bie Gtraß̧enbahnen, bielten iäb, uno fhofien mieber weiter, in vier bis jeds Re Reiben fholfen 2lutos neben ibnen babin. 2ln ben riefigen bunten Läben entlang brängte fid ber breite Gtrom ber Menj屯en, bie Männer obne Sut, bie Sacke am 21m, einen fchlic)ten (Bürtel um ben Leib, glattrajerte, fübne Befichter mit gejtugten Echnurrbärten, mit ben icharfen Linien zu beiben Eeiten bes Mundes, ra|d) fïh $\mathfrak{B a b n}$ bred)end, gleichmütig, um nichtz fich fümmerno, nur 
tweiter, weiter! Sunge Mäbøen, follant, fein, frei . . roie fie gebn! ... wie fein ibre Röde ... twie ornelym ihr Sdhubzeug! 2lber oa . . ein Neger . . e eine Negerin ... fomija) fonntäglich gefleibet . . da . . e ein Staliencr ein Indier, ein Sube, wieder StaYiener ... ein ganzer Saufe mächtiger, breitjchultriger Reger, mit graumeipem Gtrub bedectt, von einem Neubau fommend. . . da ein Gdukz mann, ben weißjen Gtab in ber Soand ... ein idjuucter, ftolzer Menjh ... 3eitungzijungen fpringen rufend und

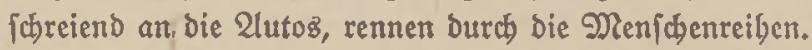
Da . . e ein totes Pferb ... Da now eins, noch in jeinem

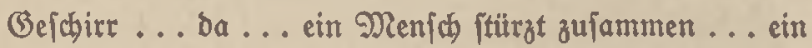
gellender Pfiff . . e ein Wagen jagt berbei, eine Babre erfd)eint ... weg. Da ... cin 2luto bängt plöslich fdief; bart itibät es gegen die Borblwand. Die Menichen fpringen zur Geite, Grauen farreien auf; auz ber Eleft. trifळen tönt lautez Rufen uno Qacher. Shre Wagen? find gand überfüllt; bie Nenjळen fteben in ben Süren, bängen feitwärts an ben Wagen, obne Sut, mit ge* offnetem Semo. Gie genieben auf und abfabrent, immerzu, ftundenlang, ben Luftzug des Fabrens. Da ... e in Deutfder ... ficher, ein Deuticher! Vielleid gar ein Solfteiner! Dann twieber bie glattrafierten (Bejichter mit ben fdyarfen Linien zu beiden Geiten bes Mundes. In Grlyaren, in Gtïben ichiebt es fich Dafin.

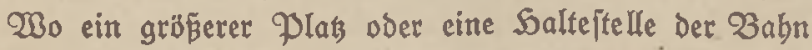

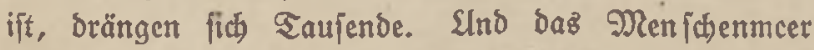

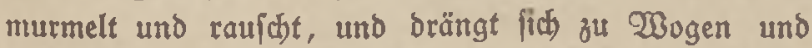
flutet babin.

Da war bie Nummer der Nebeniftrấc, bie er jutchte. 
Cr blieb ftebn und fab fich um, und jab bie ungebeure Etraße, bie er gefommen war, die fanft vom Safen binauffübrte, binab. Welche Saujende oon Denjden! Wie fie rogen und raujwen, trie Wafjerfluten! Wie bie Babnen vorwärtz fhießen, plöklich itehen fie. Wie bie Wagen bin und rieber zutfen, wie taujend $\mathfrak{W e b e r}=$ fhifflein! Wie ragen bie Säuler, bidht aneinander, Gdjulter an Edulter, madtooll, ein (bejhled)t von

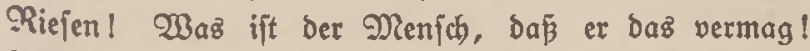

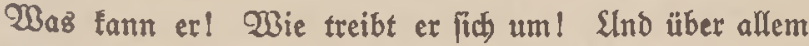
Die rajende Gonne, die unbarmberzige! Wie fie brennt! Sief binein, tief in bie Gteine und Mauern binein!

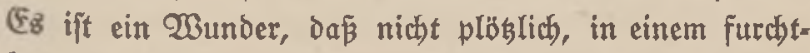
baren 3utfen, all bieje faujenden Wagen und $23 a \mathfrak{b} n$, all bieje gewaltigen Säujer, all biefe hunbertfaujeno

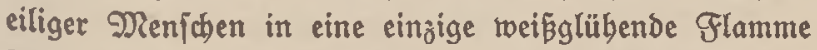
fï roandeln, die bis zur Gonne binauffhlägt.

In Der Yebenitraß̧e war ez etwas rubiger. Epreng. twagen giebn porüber; Rinber in leichter Qeinentleibung twerfen fich zur Rüblung Darunter. 2uf Dem Mflajter bocten und liegen in Soufen Staliener, beffern Daran, Elopfen, jhlafen Darauf; einige ibrer Frauten in bunten Ropftüchern fis

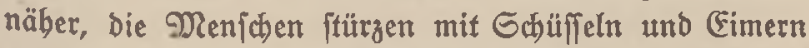
berbei, der Ruticher ftöpt fie roh zurüc; fie laffen ez fich gefallen. Drei Glandinavier, bohe fiböne Geitalten

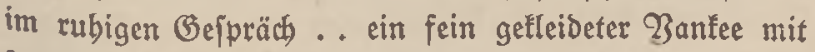
ieiner Dame; fie adten nicht, was um fie ber vorgebt. 2luf Den Baffonen toerben Qager für bie Racht bereitet; Rinderdaen jtebn ichon im Rabhthemb am Gitter.

Frenffen, ote Bruber. 
Er fand bas Saus und ftand eine Weile fid befinnend. Weld ein frembez Leben! Wie getwaltig! Sier in biejem Leben jollte jein $\mathfrak{B r u b e r}$ haujen? (Fr fitieg binauf, und fand am Ende eines dunflen Banges an ciner idjicfbängenden Tür den Tamen Rebefta Pein und flingelte. Das Serz Hlopfte $i b m$; er meinte die Nähe bes 2 ruders zu fpüren. 2lber bie alte freund. liche Frau, bie ifm iffnete, fagte: „D, Gie find fein Bruber? Sa ...ja, i山 jehe es! Rommen Gie berein! Shr Bruber ift leiber reggefabren, oor zroei Tagen. In eine Hleinte Etadt; er meint, er tönte da in einer

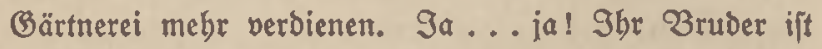
binter bem Gelde ber wie Der 20 je hinter einer armen Geele." Gie fübrte inn in bie Gtube und war eine Weile veribnunden.

(Ex fah fich in Dem tleinen Raum langiam um, uno twar gleid beimild, benn er war genau fo eingerih)tet wie bie fleinen Gtuben ber Säuler, bie in ber Seimat im Gduns der Deidje ftebn: Die Mrobel von braun. blantem $\mathfrak{S o l}_{z}$, Daraư bie weí̈en gebäfelten Decten, an Den $\mathscr{B}$ änden und auf Den Rommoben bie viel zu vielen Bilder von Zermandten und Befannten; allez Elein, alles übervoll, alles [auber. (fz war ibm, als toenn er plöslich in der Soeimat in irgendeiner Gtube bei 2 runsz: büttel ober baberum ftände, nicht taulend Meilen fern in bem riejengropen twilben शetw 3 ort. (Er trat an bie Wano und befab die Bilder, und fah lauter Belicter, bie ibm befannt und bertraut waren.

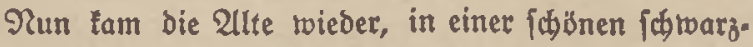

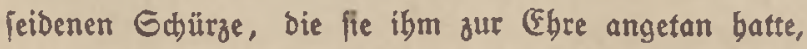


genau twie bie Grauen in ber Seimat ez tun. Gie lächelte, ba fie ibn bor Den Yildern ftebn jab, uno fagte: "Ia, die finb Shnen alle belannt, alle aus bem Rirchpiel Gt. Rargaretben; aber faft alle fhon im Grab. Sđ) bin vor fectjig Sabren als jungez Ding nach New 3 orf getommen. Sa, ja! \cb begegnete ibrem Bruber ... e es ifit gut ein $9 a b r$ ber... bier unten in Der Gtrape, alßz er bie Säu[er binaufftarte und fich ein Gtübdhen juchte. Sक jab ibm an, wober er war, uno nabm ihn mit, uno feitbem baujt er bei mir. In ipäteftens brei Sagen lommt er wieber. Cr ift aufz Qano gefabren zu einem Soamburger, ber eire Gärtnerei Gat."

Der junge Soarm Ott war febr glüatlid, Daß er feinen Zruber bei diejer alten Grau fand. Er jebte fich in ben gropien Gtubl am Genjter und jagte: "\$क bin frob barüber, bá mein Bruber fo orbentlid lebt!" "OO, " jagte bie alte Frau, "er ijt fajt allzu orbent. lic)! (Ex arbeitet tagüüber in einer (Bärtnerei und abenos bilft er nod) beim 2lufräumen in einer gropen Werťs ftatt. Slno in ber übrigen 3eif treibt er, two er gebt und fiteht, englifh, fogar bes 2lbendz mit mir. Slnd er geizt mif jedem Penny, und fagt, er muÉ ber reidjte Mann in ganz Deutjhland werben."

Fr fagte bertwirt: "Eo, Dab jagt er? $\Xi_{0} \ldots$ in Deutjaland! Warum Denn twobl?"

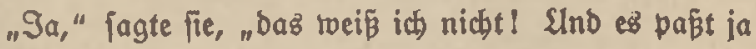

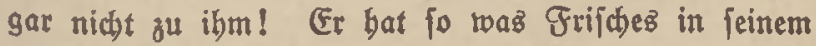
(Beficht, fo etras, bas in ben Sag bineinleben mobte; und er ift ja noch fo jung, nod teine zroanzig. 2aber er fagt, er will reid werben ... zum Berrüdtwerben 
reich, fagt er ... und zwar bald. SAnd fo gibt ex mir benn auch teine Miete."

"(Er trobnt umfonft bier?"

Gie lächelte: "Nicht umponjt. Er fagte einez Tagz zu mir: Mutter Pein, Gie baben Shre lleine Rente, mit der Gie bas Sagr bindurch gut 'rumfommen fönnen; und ben Dlats in ber (Ecfe, in ber id) fallafe, den brauctent Gie audh nicht, wenn ids nicht da bin; alfo wozu gebe id Shnen (Beld? Rann ich es nicht mit etraz anderm gutmachen?" Sie läめelte wieber: "Wir, id) unb mein Mann, find feine Amerifaner gemorben. Nein, wir find leine 2lmerifaner getworben! Geben Gie, id) mochte ibn leiben, und jo jagte id): Iđ) börte bich neulich am Gonntag abeno ein Lied fingen. Wenn bu mebr folcher Qieder fannit, fo fís' den Gonntag bei mir uno finge mir vor. Wegen meiner alten 2lugen tann ich nicht mebr lefen; und ich babe es mein Qeben lang entbebrt, Daß ich nidjt fingen tann.6

"Эa," fagte 3 ruber Sarm, "fingen und pfeifen, Dab fant er."

${ }_{n} \Im a \ldots$. und num fiken wir benn jeben Gonntag abend beieinander: Da, wo Gie figen, fist $\mathrm{er}$; und idh ba auf bem Gofa; und bann fagt er: , Nun wollen wir eins fingen, Mutter Pein.6 Sno twenn mir dant über die alten Licber und daz Scimtwel und bie Be. banfen an all bie Soten an ben. Wänden bie 2lugen äberlaufen, bann ftebt er auf und fingt und flbtef gegen bie Wand an und weint aud ... Denn er bat auth Seimtweb; und tut bann, alв befälye er bie Bilfoer, Billo nach $\mathfrak{B i l d . " ~}$ 
Sarm Ott jaß̧ eine Weile verifummt uno traurig. (Er wufte nicht re⿻t, ob er ibr lagen burfte, warum ber Bruber fo jung in die Frembe gezogen wäre.

Uber ba jagte fie jhon: "Sh habe mir viele Be= Danten Darüber gemacht; ich babe in meinem Ulter ja nichts anberes mebr ou tun, alz mir Bebanten ju maden... trarum ex fo gern und gierig reich werden will, obgleich es eigentlid) von Ratur nicht in ifm [tectt, und wartm et fo leere 2lugen mahte, rent id ibn im Ulnfang nach feinem Elternbaus und Der Seimat fragte... nawber liés ich es ... aber feit einer Stunde fann ich e8 mir zufammenreimen. Sieb, er bat biejen Brief bier liegen laffen, ben er bor viet 230 den betommen bat. Lejen Gie ibn!"

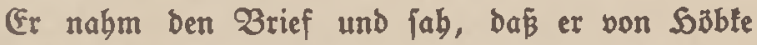
Gubl toar und laš:

\section{Qieber Eggert Ott!}

Э屯 bejtätige Dir bie 21nfunft von achtunbbiergig Dart, Die id nicht Dem Serrn Deter Reimer Ott, Ranomann in Altenfiel, fondern Deiner lieben guten Mutter gegeben babe, bie fie für Did aufbemabrt. Wenn Du zu Sarm und Reimer in Deinem 3orn ge-

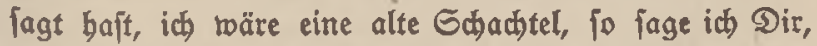
Du bift ein junger Efel. Denn alz man Dir an bie Ebre ging, muśtc|t Du da nicht grade bier bleiben, um für fie zu forgen? Wer foll fonjt für Deine Eggre bier jorgen? 9 ch tu' ez freilid, ich trete für meinen junger Nadbarn ein, too id fann, und viele glauben meinen Worten. 2uch Deine Bejhrwijter treten für Dich ein und mein alter Peter audb. Uber Das Bejte räre, 
Du wärft felbit bier, und follüglt jedem tng (5e/icht, der

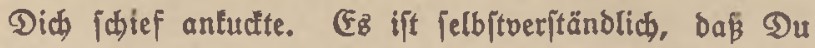
nicht bei Deinen Eltern tobnen tönnteft; aber was ift im Wege, baß Du bei mir roobnit? Du fannjt bas ganze $9 a b r$ bei mir pflügen, jäen und füttern. 21ber

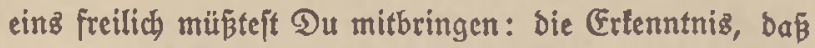
(Du auch nidbt obne Echuld bif̣t. Tein, mein lieber Eggett, das bijt $D$ u nicht! Du warit unfreundlid und oft runberlict. Aber twas mich angebt, fo mag id Dich num mal fo, wie Du bijt. Romm wieber ber, Tunge, und jei bei mir! Wir trollen bie beften Freunde fein und unz um bie Nenjhen nicht tümmern.

Deine Raఢbarin und Greundin Söble Gubl.

Er liés ben Brief finten, und erzäblte der alten Graut furz die ganze Beichichte.

Die fah ibn eine Weile ftumm an und nidte nad Der $23 e i f e$ bez Alterz, fo alz roenn fie Dad)te: , Эa ... ia ... ichwer ... idwer! . . w wirr, ... wirr! ... wie allez Lebenl" Dann jagte fie: "Warum trill ex benn fo raid) uno gierig reid) twerben?"

Bruber Sarm lagte zornig: "Weil er cines Tagez, und zivar recht bald, fo auf einige Gtunden, im belten 2lngug, mit blendendweifem Rragen uno golbener Slbrtette, und romolich im Extramagen von Samburg ber ... in Der Seimat ericheinen will und allen Reuten, bie ibm begegnen, frech ins (Beficht ftarren und went fie ibn grüfen unb lagen: ,Gish ba, Eggert Dtt!' fo tun will, als wenn fie शiondtälber find, und dann wieber bavongebn! So möchte ex alle fünf Sabre machen ... immer 
reicher, immer tătter .... immer bođmütiger! $\Im_{a}$, jo ift er! (Fine einfache Gache ift das nicht, Grau Pein. Er ift berrüdt bor 3orn und S̈berbebung."

"Er ift ein lieber guter Sunge," jagte bie Frau.

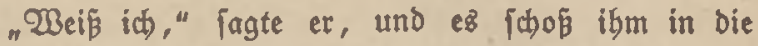
2ugen. "Das ift ja grade bas Slnglüd, ba i er beibes ift: verrüctt und gut. Go maz haben wir băufig bei uns."

"Sa, ja," fagte fie. "Go ift $e^{8} \ldots$ fo ift es immer: ... baz Gchicfjal rubt nicht eher, alz biz es uns grwifhen ztwei Gteinen hat; Dazwifhen werben wir Dann gerieben, bis wir mürbe fino.... Bleibt $\$$ bre Gdiff bier brei Sage? ... In brei Sagen mollte er wieberfommen ..."

"Getwí," fagte er. "WOir bleiben. 9क fomme übermorgen roieder, nach ibm zu feben. Bielleidft fommt er ja auch eber twieber, alz er angenommen bat. $9 \phi$ tomme eines abends fo gegen neun $\mathfrak{A l b r}$, da ou Sauje finde. 2lber fagen Gie ibm nidht, baj ich bier bin und fomme." Damit ging er.

(Er war febr aufrieden mit feinem $B$ ejud und ging nidit twenig folz, Daß er biefe groß̄e Tieife, biez groß̈e Wagniz, unternommen batte, feinez 23 egeż. ,Gie toerben mich zu Sauje febr bewundern, bad)te er. "Slnd im

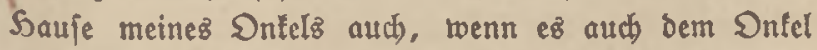

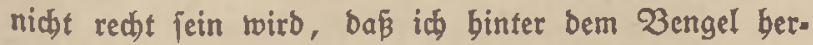
gelaufen bin. Aber im Scrzen wirb ez ignen bod) ge=

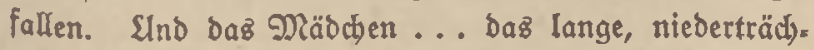
tige... wirb auch benten: (Er tut, was er will!" In folchen gropen uno fhönen Gebanten ging ex bahin und actitete nicbt biel auf bas, twas borging, und fam 
wieber auf ben Broabrany in bas ungebente Bewoge. Ohne Dämmerung uno Dämmeriftunde war es plöglich abend und Nacht geworden, und was noch bor einer Gtunde in roeikem Gonnenglang gelegen, lag nun unter bunfelblauer Siefe. 2lber aus ben riefigen Sö̈ujern, aus unendlichen Fenfterreiben, auz ungebeuren Läben, auz zabllojen $\mathfrak{Z a b n e n , ~ v o n ~ b o b e n ~ R a n d e l a b e r n ~ h e r u n t e r ~}$

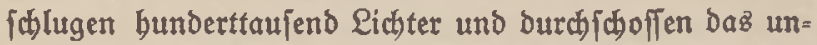
gebeure Sreiben, Beifteriput, Dabinglitt und braufte. Er ging langfam feineż Wegzz, mit 2lugen und Obren bei Dem Bilde, aber mit ber Geele bei fidh und Den Geinen.

Da fab er robl taufend Meter vor fid ein bejonders bid)tez und unrubigez (Betroge von Menichen und ein wilbes Cilen und Sagen Dabin, und wurbe belltwad und netgierig, und ging eiliger, um bie Gebenztwïrbig. feit, bie ba etwa bes befommen, ebe fie Davonliefe. Zlber als er bie Etelle erreidte und fidh nun iaton mitten in Dem eilig Dabin. flutenden Gtrom ber Menidhen befanb, fab er vor fich... Die Gtrape fentt fich nach Dem Safen binunter ... Die ganze getwaltige, breite Etraß̄e, mit all ibren Babnen und Wagen, yollgepfropft von taujenben und aber taujenden

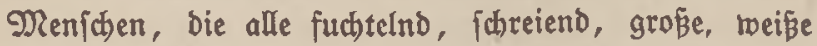
Papierblätter (d)twingend, nad) Der boben Wand cines Saujez binaufitarten, auf ber in riefigen, flammenden Budjitaben etwas geidrieben ftand; ein rildes, joweres (Bebrobn wie aus ungebeurem Raum, wie bon Donner, ber aus ber Frde fam, füllte ben ganzen weiten Plas. (ir bad)te, ez räre etrba bie Anzeige von einem Eifen- 
babn= ober Gdiffisunglüd, irgendwo im Innern beš

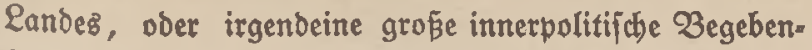
beit; Denn er batte irgendwo mal gebört ober gelejen, Daß̄ in ben Bereinigten Gtaaten ganz anderz alz in Deutichland, Die Maffe Der 2 ürger bie Politil macht und fich täglich Darüber aufs Qlukerite erregt. $\Im n$ bem Uugenblid - er wat noch feine Minute in bem Gtrom ber laufenden und eifenden Raffe - börte er bas Woort: "Rrieg! ... Rrieg in Europa! ... Deutic. lanb!" $\mathfrak{E s}$ irrte Durch feine veritörte Geele: ,Rrieg? ... Wer? . . . mit tweld $\mathrm{em}$ Bolf? . . Öfterreid? . . . Der Mord pon Gerajetro? Rußland? $\mathfrak{E r}$ biß bie 3äbne zu[ammen und fdüttelte in forefflicher शot und Gorge immerfort beftig ben Ropf. $\mathscr{D a}$ war er fijon näber getommen und laş an ber $\mathscr{W a n d}$ bie glübenden Worte: "Gam Europa vorm Rrieg! Deutichlanb von

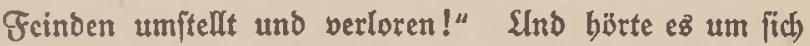
rogen und fajreien: "Die verbammten Deutichen! Na. türlich) ... Die Rubejtörer! ... शatürlich ... Sbr Raijer! ... Nun befommen fie ihre Zezablung!" (Ein Saufe von jungen Leuten, gut gefleibet, aber in ibrem Benehmen bon Berberbtbeif zeugend, in einer $W_{0}$ olfe bon jüflichem 3igarettendunit, ichlug fich auf bie Rnie

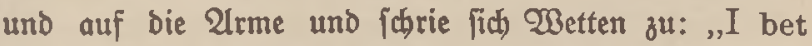
you, I bet you!" (Er wuste nicht, wie ibm loar. (Fz war ibm, alz wenn bie Welt und fein eignez Leben ploghlid) alle Oronung verloren bätte. Alక mübte er bier nun fitebn bleiben ober, twenn er fortginge, toäre es einerlei, robin er ginge; benn bie ganze Welt hatte weder शoro noch Gäb, weder Seimat nod) Frembe, weder Ginn nod) 


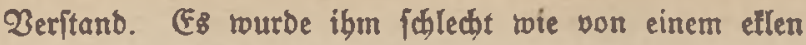
Gejdmact; und er muste ichluofer.

Ulz er nod) jo ftanb, vällig betäubt, unb ein Saufe von Reuten, Granzofen und Staliener, auf bic Deutiden und ben beutfhen Raifer fhimpften und fकrien: "Eng. land gebt audh mit gegen fie! ... Gicher! .. Dann gehn fie zu Grus und Nus ... So bo ... Natür(id) gebt England mitl . . 2 2lber felbftwerftändlicb!" und mit roildem Belädhter: "Ea twirb fich Dow ben fetten Bifien nicht entgebn lajien!?"... ba börte er binter fich eine rubige Stimme auf plattbeutid) Inurren: "Na, lat bi man Sib!"... er trandte fich um und fab einige beutifbe Datroien binter fich ftebn uno zog fich unauffällig fo weit zurüct, Daß er zroifden ibnen ftand; und war plös. lid), obne ein Wort, nur ba fie fid arjaben, einer ber ibren. Bleid barauf jagte einer won ibnen: "Rommt nach unjeren Gdiffen! Wer tweiß, was noch geichiebt!" SInd fie brängten fich zurü und gingen bie Etrake rieber binunter, tamen an ben Pier unb fegten über. Gie pradhen auf bem ganzen $\mathscr{W}_{\mathrm{eg}}$ tein 20 ort mitein= ander, gingen bleidh und fill babin, fauten an ben Qippen, rouften nicht wobin mit ibren 21rmen und Sänben, atmeten idwer uno ftöhnend, und bachten nad) Saufe; und batten eine ungebeure 2lnglt um etroas, bas fie vorber eigenttich nicht getannt, obgleich es immer

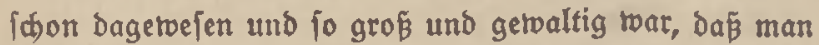
es robl jehn unb erfennen fonnte; aber fie batten ez bod nidht gejebn und nidht getwuft: Deutichland, Das Baterland! Was ibnen bisber fait ein leerer ßegriff gemeien war, ein WBort, ein 2lusbrud, eine Bleich. 


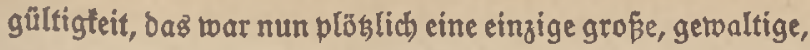
suctende Geele. Unb bieje Geele mar bie ifre. Gie roußten mit einemmal, baß fie ein Zaterlanb hatten unb eine Seimat; unb Das Serz ftocte ifnen in Ungit und Liebe barum.

$21 m$ folgenden Sage icjon - Starm Ott lonnte

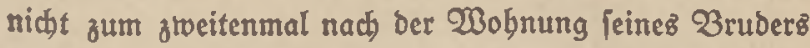
gebn ... er fanbte ibm nur einen Brief - fubren fie auf Orber, bie von Samburg getommen war, won New Zorf ab. Gie waren, trom ber Orber, rubiger getoorden, und waren guter Soffnung, ba im 2lugenblia ibrer Ubfabrt noch twieder friedlicjere Nacbridhten getommen roaren. Gie fpradsen aber natürlich bon nichts anderm, als vom Rrieg. 3twei vber orei Der Süngften freuten (iid) auf Den Rrieg; ez Ieud)teten ibnen bie 2ugen, wenn fie baran Dachten; aber bie andern alle toollten ben Rrieg nid)t. Gie batten ein Deutlic)es (Befübl für feinen Sammer, feine Gchrecten unb Bertwülfungen, und fie hatten alle

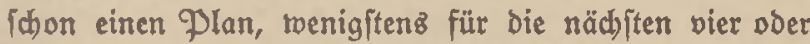
fünf Sabre, unb in bieje Đläne papte ein Rrieg nicht binein. Sie roollten ibren ftillen, rubigen, ernften Qebenstweg gebn; fie wollten erft baž, bann baz, bann Daz. Go baben Millionen von Teutjhen gedacht: von Sütland biz an bie Ulpen, ach, viele, viele Millionen auf ber gangen Groe ... und baben von ibren \länen laffen müfîen.

2ber am fiebenten Sage, gegen Nitternacht Sorm Ott batte bie Wache auf ber Bat - über= bolte fie ein grober 3 remer Perfonendampfer; er fubr abgeblendet und in rafender Fabrt Deutichland zu; fie laben in ber bellen Gommernacht, wie ber bobe Bifcht 
vor jeinem $\mathfrak{B u g}$ fi் bäumte und überftürzte, und rie eine lange, jhimmernde $\mathfrak{2}$ elle bell beleuchtet bas Shiff entlanglief. Die ßrüte rar voll von Nenjchen, uno aud) in Den Raufgängen ftanden tros Der Nacht unzäblige Menfidhen. Bon jeiner bohen Brüté famen Morjeseicjen zu ihnen berüber. Sarm Ott fragte ben Dritten Offizier, Der berantrat, und erfubr: Rrieg mit Ruß̧land und Frantreich .... ! uno fie follten toad fein und cilen, fo fehr fie lönnten.

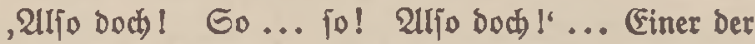
Süngeren, ber Rod, war wie bejeffen bor Greude. "Waz ift bas Leben," fagte er, "wenn man nicht mal einen Rrieg mitgemadbt bat? $\Im_{\text {ch }}$ melbe mid bei ben (Einundbreipigern in 2ltona. 3u Gdiff mag id) nidht. 3ur Gee wirb ja nicht viel geidebn!"

(58 raren mun auch unter ben Q̈ltern einige, bie Fich freuten, ja logar unter ben Berbeirateten. "Es ijt

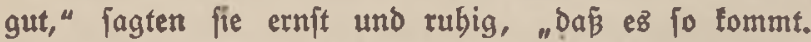

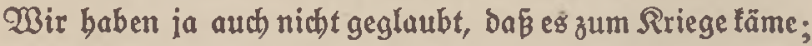
aber ba ex num ba ift, fo ift es wohl gut. Die Ruft in Curopa war ftictig geworben. Ulno am Enbe: man erlebt mal roas ßejonderes!"

Sarm Ott fonnte fid nicht freuen. Bielleicht fam ez Daber, Daß̧ er tros jeiner eifernden Dutter fein

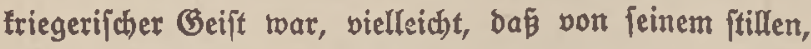
fhrwermütigen $\mathfrak{B a t e r}$ ber eine natürliche 2Inlage in ibm mar, bas Sraurige, bas Sdrectlidje zu ieben: Den bunderttaujendfachen Sob ber Bejten, die Qual und bie Tränen von Millionen. Bielleicht batte ez jein guter Rebrer in ibn gelegt oder bow in ibm gepflegt, bas ber Menid, zuerft ber Menf́bbeit gedenfen foll, Dann Desి $\mathfrak{Z a t e r -}$ 
landez, danach feiner felbjt. Go ptand er benn in biejem Gefübl die brei Sage, bie fie nod) fubren, auf ber 3rücte; benn ba er belonbers gute 2lugen batte, rourbe er beftellt, 2uzgute zu halten. 2lm Sage in ber Gonne, bei Nacht im bunfelblauen Gdhein Der Eommernächte, bachte er bald an all bie Saufende, bie fich mun gegenfeitig

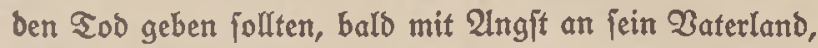
ob es auch mit innern Rräften und mit $\mathfrak{Z a f f e n ~ g e r i u j t e t ~}$

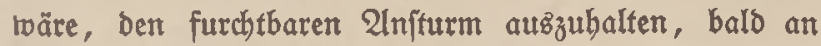

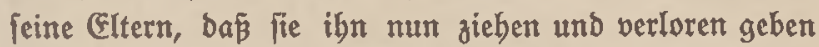
müüten, balo an fich felbjt, Dá er tapfer jeinen Mann ftebn und fein Baterland verteidigen wolle. Slno ez

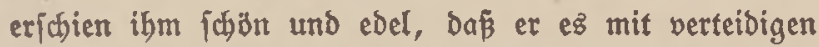
Follte, Darum, weil er wupte, baß es eine reinlid)e Eache Gatte; uno er fnirldhte mit den 3äbnett, da er an bie bacte, bie fein Land in ben Rrieg gefübrt, an die, bie ibm und feinem $\mathfrak{B}$ olf biefe Not angetan hatten, an bieje Gropen in Ruß̧land und bieje Fülyrer bez fran=

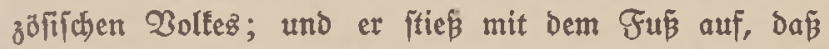
Der Rapitän ibn von ber Seite anjah.

Um eriten Sag, nachdem fie bie शachricht betommen batten, faben fie tros Des flaren Wetterz wenig Grtiffe. Gie batten Weijung befommen, mit notbojftichem Rurs bie Gübjpige von Norwegen anzufteuern. Begen גbend begegnete ibnen ein Hleiner, englifher Rreuzer, ber bon Often Lam. (Fr beleuchtete fie mit feinem Gd)eintwerfer und fubr vorüber. Çäbreno er fo in ungefäbr vier Rilometer Entfermung vorüberglitt, iprachen fie roieder auf ber Brüde über Das Shema, Daz ben ganzen Tag

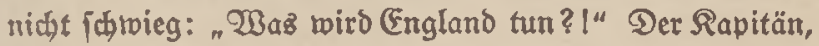


ein älterer Mann und in feiner Sugend viel auf eng. lifchen Gdiffen befabren, zog wieder bie Gdultern boch und bielt für möglich, Daß England gegen uns ginge. Er twar aber ber einzige an Borb, Der fo bachte. Der z'weite Offizier, ein Flenzburger Lebrers] gedulbig: "Raptän, toie lönnen Gie nur po etıas für möglich balten! (Englano müBte Dod einen Bruno baben! Saben wir Englano je etroas 230 jes angetan?

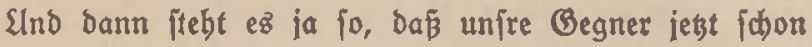
ftärfer find als tvir. Bedenfen Gie: bas ungebeure Rupland! $\mathscr{D a}$ follte England (id) auch nod auf uns werfen? Zerzeiben Gie ... aber da Denten Gie ju gering von England; zum Donnerwetter, roenn fie aud ¡đjarf aufz Beld find ... ez find bod bornebme Qeute!" So fagte er; und Sarm Ott jtimmte ibm zu, ober befier gejagt, gab ibm idjon recht, ebe er geiprochen batte.

Gie jagten Nortwegen zu die Racht bindurd und den Tag und wieder bie Nacht und trafen weiter nichts

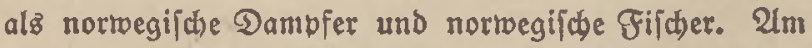
britten Sag gegen Nittag jaben fie fern im grauen Nebel bie lable, fteile Rüfte, und nahmen fübliçen Rutz, und faben gegen Abend in ber Abendionne bie Dünen von Gnlt. ,Seimat! Scimat! W3ie mod)te es ba aus. jefn in jebem Sauje! In jedem Serzen! 2bjabied ... 2lbichied! . . Qualen namenlos! . . Rein Sauż, tein Serz, won Sütland bis in bie boben גlpen, bas nicht in Not und Qual rar!" Slnd rwieder endeten feine Gedanfen bamit, daß́ ein wilber Bram und 3orn jein ganzes Soerz erfüllte. Gie follten füblen, twas bas beutiche Bolf vermodbte, wenn es einig twar!, Mit 
Sffterreid zuโammen ... über bunbert Millionen Men. fhen! Xh! Gie follten ihren Lobn baben!' Dann gingen bie Bedanten rieber naw) bem Saus binterm Deich. , शutter bentt in biejem 2ugenblict an mid ... lie bentt in jebem 2ugenblid an midh, Sag und Radbt. Denn ich bin basjenige von ibren Rindern, das jest fhbon in (Befabr ift und bas mit in ben Rrieg ziebn

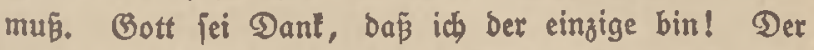
Bater bentt auth an mid, immer in feiner ftillen Weije, bei feiner Arbeit in Feld und Gtall! Slno Reimer bentt an mich über all feinen $\mathfrak{B}$ üc)ern! Wie er wobl verftzort ift! Ex, mit feinem etrigen Frieden! ... Die Mäbdhen, bie twiflen nid)t reht, twas Rrieg ift ... (Gut,

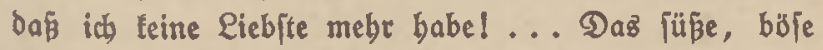
Mäbden ... Soerrgott, wie lieb id fie babe... beute nod)!'... Go fann er, und war traurig um fich uno bie Eeinen; und poll 3orn gegen bie, welde fein Lano nicht in Rube liepen und ibm ben ftillen Lebenstweg zeritörten und bie Seinen in Leib brachten.

Begen Dlorgen erreidten fie glüclid) Die Ellbe unb fubren binter einem groß̈en Soapagdampfer ber, ber von England tam und bis an bie Soppen voll bon Rejerviften war. Die Ulfer bei Blantente waren ein ein. siges Beflatter bon weipen Südern.

Begen abeno um fünf Ubr madyten fie am Peterfen. lat fejt. 


\section{Rapitel \\ $\mathfrak{S a m b} \mathbf{u} \mathfrak{g}$}

(5)er glweite Offizier meinte, er follte bie Radit an Bord bleiben, da er beute bod nicht mebr nats WBilfelmshaven fommen fünne, und morgen mit Dem frübejten naw Dem Babnbof gebn. Da bie Raileute

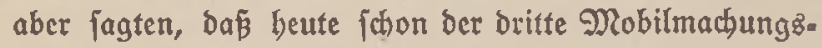
tag wäre uno er alfo geftern ¡đjon in Wilhelmzbaven fich bätte ftellen follen, liés es ibm feine Rube. (Fr ließ̧ fich vom Rapitän einen Gchein geben, Daß er beute erît ange= fommen wäre, raarf feinen Gađ über die Gchulter uno ging in bie Gtabt und nad) bem 2 ahnhof; elf Mann, lauter junge Rerle, bie wie er gleid eintreten follten bie meiften in Riel - gingen mit ihm. Sie gingen

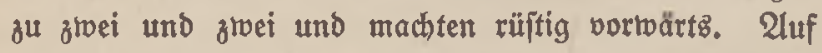
Dem Wege fagte ber eine oder andere mindeitenz orei= mal: "Qaß̧t unż Doch langjamer gebn, Rinber... Der Srieg läuft unz ja nicht treg!" U(ber immer famen fie wieber in rajheren Gdbritt. Ess brannte ibnen bas Sorz, zu erfabren, wie eż in Deutfhland ftünde, und fobald wie möglid) an ber Gtelle zu fein, wo fie bin= gebörten, two fie nötig waren. Gie hatten alle das Gefübl... faben alle irgendro im Beift... auf dem Sof einer Rajerne ... eine Lüdfe in einer langen Reibe, wo gerade fie ftehen follten. Went fie nicht an bie Shren dachten, fahen, fie cine blaujhtwarze Pinie in einem Rajernenbof ftebn und faber einen Offizier fich fragend umichn, und fabn fich und biele andre binlaufen, um fich in bie Reibe zu ftellen, daß fie voll toürbe. 
Borm Sauptbabnbof roimmelte es und ftaute es fich bon Menichen. WBie an einem ungebeuren Bienenjtod

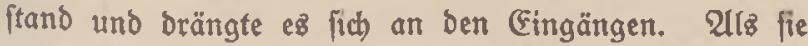
mit ibren Gäcten berantamen, famen zugleich in grop̃en Gdaren andere Eeeleute uno Rejerviften auz den Grraken vom Soafen ber. 2lus Den Sotels unb Raffeebäulern am Gloctengieß̄erwall fam es in langen 3ügen, wobl bie Reute, die vor ciner Gtunde auz England angeformen twaren. Daztrifhen ftanden und gingen andre Menjchen, in jebem Alter, viele in mitts leren Sabren, die in biefer Gtunde nicht ahnten, Daß̈ Fie im nächiten Sabr jelber ben grauen Rouf anzieben müp̈ten ... Die grüßten und nicten und riefen ignen

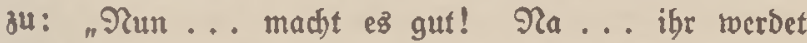
fun, twas ibr tönnt!" Slno fie antworteten: "Reine Bange! Wir ldaffen ez! Daz alte beutiche $\mathfrak{B}$ lut ijt

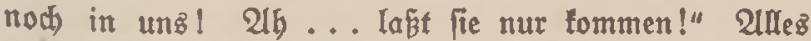
gritiste und freute fich an ibnen. (Ein bübjches, junges Blut, bas nid)t weit von Soarm Ott ging unb ibm im Bebränge nicht näber fommen fonnte und fich badurd) wobl ficher füblte, nictte ibm immer freundlich zu. (Fs wurbe ihm rarm ums Serz, und er bachte: , Die tönnte ich) fo nebmen, wie fie ba geht und ftebt, und ans Serz

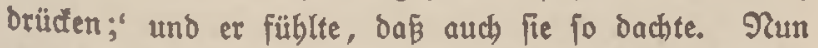
war fie nidjt mehr ba. Uud bie Rameraben waren von ifm abgetommen, und cr ftand alfein in bem un= gebeuren Srubel uno muste lange fo ftehn. Zon ber Gtrape ber flang eine feierlict)e vaterländifdue Weife von vielen, vielen Menjhenjtimmen. Didbt neben ífm flagte ein Gchüler um feinen 2 ruber, her Raufmann märe uno Grenffen, Die Briber. 
gerabe eine Reife in Rupland mahte: "WBenn ber bie Brenze nicht erreicht und bie ganze 3eit in (Befangenichaft fitsen muBs, itirbt er. Er ift mit Leib und Geele Goldat." 2urf ber andern Geite jtand ein junges Paar und rebete leife mifeinander. Er twar now febr jung; aber ez war ein fo tiefer, lichtlofer Ernft in feinem Geficht, DaB ez Sarm Ott jäh Durdbfubr: , Der twirb fallen!" (Fin älterer Mann ... ez fhien cin gutgeftellter Raufmann ou fein ... der wegen Soarm Ottz Gadt auf ber Gdhulter Den Ropf johicf balten muste, nicfte ibm zu und jagte: "Na, Geemann? Soffentlich brauchen Sie nicht auf

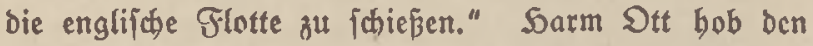
Ropf und fagte: "O nein, bas wirb nicht gefhebn," uno auch andre, bic umberftanden, fagten: "Slnmögs lid)!" Slnb einer, ber wobl cin Lebrer war, fagte: "Das ift fdhon wegen ber (Bejdjidjte, bie binter unjern beiben $\mathfrak{B b l t e r n ~ l i e g t , ~ u n m o ̈ g l i c h . " ~ a t h e , ~ b i e ~ i b n ~ b u ̈ r t e n , ~}$ nictten.

Rađ einiger 3 eit trurbe bon Goldaten mit Selmen tmo weiper Binde um Den $2 \mathrm{rm}$ Plas gemadt, und er tam biz an ben Echalter, und crfulbr, baß́ er am beften am andern Morgen in aller Grübe fübre.

(2) nabm er Feber und Papier aus bem Gad und gab ibn $a b$, unb brängte fich eine 3eitlang burch bie Menge uno (ab) fid um, ob er nicht bas (Blüd bätte, auf irgendeinen aus jeiner Begeno ou foßfen. Er fand aber lange niemand. 2llz er aber bann in ben Wartefaal gebn wollte, um zu fatreiben, da ftand plög. lich bie vor ibm, bie er auf ber ganzen Welt am allerroenigiten febn wollte! $\Im_{a} \ldots$ da ftand fie! .. und ez 


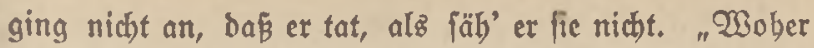
tommit beun bu?" fagte er tithl.

Gie war febr perlegen, fah an ibm norbei über bie Renge und [agte: "Yater batte bier zu tum und bat anid) mitgenommen ... wir trobnen im Soljteinjhen Sof in Altona unb nun juchte id) einen Befannten, mit bem ich ein $\mathscr{B}$ ort rcoen lann." Go waren fie alle untertoegz und \{uchten alle Menidjen, un alle bie Gragen in fie binein zu fahütten, bie im übervollen Serzen brannten. Denn fie twußten ja alle nidt, twas Sirieg wäre. Daas Wort Srieg war ibnen ein graujezి uno graues Närchen aus alten Beiten geworben, und fie batten fo menig geglaubt,

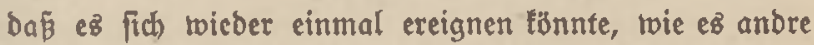
Märchen tur. Gie plauberte lebbaft und eintönig, uno tat, als wenn fie Nachbarßfinder wären ober entfernte Bertwandte, bie fich nie nabe geftanben; aber fie roar

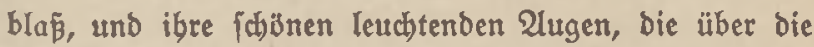
Menja)nmenge binjaben, waren unrubig uno verlegen.

Sarm Ott raar gequält unb zornig; er bätte $i b r$ am liebjten gelagt:, Beb weg von mir! Was willit bu grabe neben mir gebn? (Beb taujend Meilen weg! Quäl' mid. nicht. Sळh bin nicht barthergig mie ou; ic) fann nicht mit bir reben, alz lvärft Du eine Frembe! Weg mit biejen 2ugen! Mit bicjem Sraar! Mit Deinen Edultern! $\mathscr{W e g}$, weg von mir! S4) geh' jegt

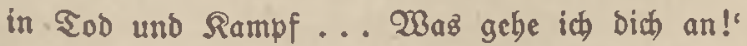

Gie plauberte unrubig loeiter und fragte: "Wืas glaubit bu ... wie viele fallen werben? Wie viele meinft bu, Dấ auz bem Rirchppiel 2lttenfiel nicht wiedertommen werden? Einer ober ztwei? Tas märe 
ja fdrectlich! Rann es nicht gefdchn, dẩ fie alle riederfommen? (Fz fand ja einmal in ber 3eitung, Dá̉ die Rriege immer ungefälyrlicher twerden. Slıd England wiro unz ja beifteben; ez ift ja mit uns ver wandt und wir find ja unfluuldig. Slno twas meinft but,

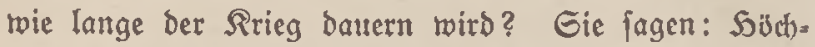
ftenz fünf Monate." Slno bann erzäblte fie, tważ "ein

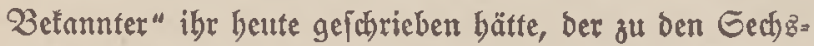
undachtzigern nact) Flenzburg gegangen war uno idjon in Reib und Blied jand.

,Diejer , Befannte i iłt natürlich ibr Berlobter", Dachte er bittcr.

Gie rebcte lebhaft und lachte in ibrer 2 erlegenbeit über cinen Gak in bem Brief bez "Befannten" und betrachtete dabei eine $\sigma_{\text {dar }}$ Gdüller, die mit Sungen vom Safen $21 \mathrm{rm}$ in 2 rm burch bie toeit pffne Sür zogen, robei fie ben Zorübergebenden zuriefen: "Sdh gebe morgen zu Den Fünfundfiebzigern!" "S屯 nach Kendsburg!" "Sch ơu Den Sägern nach Rakeburg!" und "Эd) nad) Mürtwict zur Marine!" Gie gingen binter Der Gdjar her auz ber Salle.

Gie waren aber eben auz ber Babnbofslyalle beraus: gefommen und gingen in der Menge, die ben ganzen breifen Plas vollgeftopft füllte, auf ben Glocfengießer-

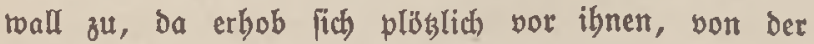
2liper ber, ein Soben und Tojen, und bald tam bier und da ein Gdarei: England! England! England bat uns ben Sirieg ertlärt! Slno gleich barauf twar es bicht um fie ein Soben, Edreien, Eridhrecten, Entiegen: „England . . . Tein! . . Slmmoglid!!! . . Dod ! . . 


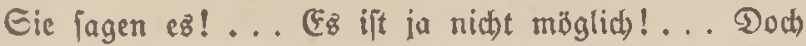
... शatürlich!... Dic Sarmich= Dampfer, bic aus $8=$ fubren, find beute zurüdfefommen! .. Serrgoit! ... England!!" ...

Gic fah ibn an und jah, Dap bie Nachricht ilgn bolltig verltörte, dẩ er mit all feinen Gedanfen bei diejem Ereignis war und feine Geele mebr für fie batte. Gie gab ifm ploshlich bie Sand und fagte mit

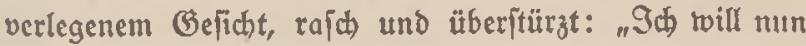
wieber zu meinem Zater."

(Er bejann fid jhitwer: "(Beb," jagte er lalt.

Gie wollte noch etras fagen, ibm Gutez toünjhen, fand aber nicht bas Wort und murmelte, baj fie den Geimen jagen toolle, daß fie ibn getroffen bätte. SIno wande fidh $\mathfrak{a} \mathfrak{b}$.

Err wollte fein Serz gleich von ibr lozreifen, hordhte auf bie Worte, bie um ibn gerufen rurben, und fuct)te zu einem Saufen zu gelangen, Der fich um ein Ertrablatt brängte. 2aer das großje blonbe Menjuentino nit ben fabjnen fliegenden 2ugen, bie mit einem feltfamen 2lusoruct bie jeinen gejucht, (क力ob fich beifhend, forderno und zugleid bittend bazrvijchen. (Fr machte Orei lange Garitte zur nädajten Saustreppe, unঠ nabm die Stufen, und fpähte über bie Menjhenmenge, ob er fie noch einmal fäbe. (Erjt fand ex fie nid)t; aber bann, plöslich, fab er fie, twie fie brüben an bem gropen Randelaber ftand, genau wie er, und ibn judbte und ibn erft nicbt $\{a h$, und ibn bann, eine vällig veränderte, mit vielem ఇiułen bes Ropfes grüß̈te, innig, fitll, beitig. Es twar die erjte Lieblojung, ja bic erfte Riebcsäuperung, 


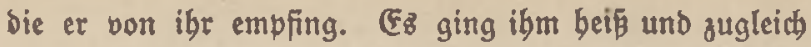
bitter burch so Serz. Er nictte ifr langjam zu, mit finftern 2lugen. Nun war fie in Der Nenge verjhrwunden.

Da ftürgte mit erneuter $23 u d t$ bie neue Begebenbeit auf ibn ein. (58 rar ibm, als wenn bie gange Welt über jeinem Baterlande jujammenjtürjte, ja, alళ wenn Gott felbit vom Soimmel fiele. Gein ganzez Denten, bon jeiner Rinbbeit an, bas immer, roenn auth obne Worte und ofne Formel, in feinem Serzen lebte, Da亩 ein Serrgott im Simmel lebte, twar ifm bertwirt und veritört. Esz roügte ibn twie einen Neniकen, ber auB Trümmern und Rauch nach freier Quft ringt, und es fatrie in jeiner Geele zu Gott: , Sage mir, toas

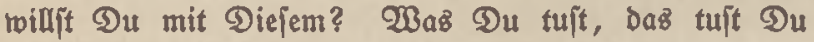
boch zum Woble ber Menjhbeit?! Rrieg . . . Rrieg . . . cin frifher, wilder Rrieg mag nötig fein, bie Menichen ju

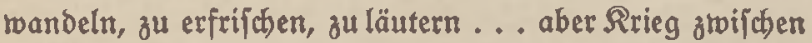
germanif̧ch Brübern?! Der Bruber fällt über ben fhon bart genug beorängten Bruber ber?! Willit bu

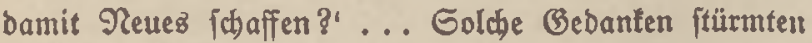
mirrend Durch jein Serz, wäbrend er von ber Menge, bie ibn umbrängte, reeitergetrieben rourbe; und er veritummte por Braujen por Bottes Tun, roäbrend die Menichen um ibn idfrien und aus ber Gerne ber feierlicte (Bejang bon Saujenden berüber brang.

(Ex war zur Sür eines Raffeebaules georängt, in Dem mobl nach Der Neinung ber Nenichen neue Nachrid)ten zu erfabren twaren, und befant fidt, ebe er'z fith betwuft wurbe, in bem grofen Raum. Reben ibm fagte ein einfacher Mam in unendichem Eritaunen vor 
fich bin: "Wie ift bas möglids? Gie baben ja boch blondez Shaar und blaue 2lugen bie bir?!“ Fin andrer fagte: "Slnd wir baben ifnen nichts getan, nichtz," und laut fagte ex, alz wenn er ez belräftigen müfie, Daß́ lie es ibm glaubten: "Sch fenne die ganze englifabe (Befojichte, es ift tatjächlid) fo; - wir baben ifnen nie

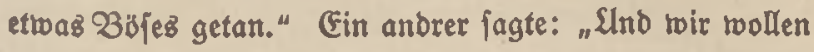
aud jest nichtz von ibnen! Gie follten nur rubig zus jebn, wie wir biejen icheren Rampf bejtünden." Bleiф Darauf ftellte fich ein älterer Mann auf einen Gtubl ... twie es fobien, ein Najhinift ober Wertmeifter ...

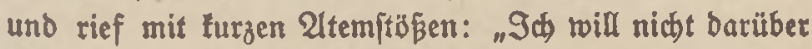
reden, roarum Englano als unjer Geinb auftritt! Sक roill nur jagen: ez wirb ein ungebeurer Rampf werben! Bejonders Englano ift getwaltig an Mitteln und Rräften! Srobbem werben wir fiegen; Denn es ijt nötig, Da je wir fiegen! Denn wenn wir unterliegen, werben fie นnz ১aв Gell über Die Ohren zieben! Gowobl ßiz.

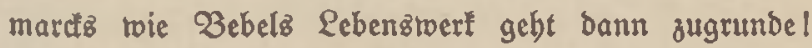
Wlyo müfien bie Sungen im Geloe von $\mathfrak{A n f a n g}$ an ibre Pflicht tun und bie Geinbe jo rerfen, daßj fie um Grieben bitten. Das wollen wir von ibnen exboffen, uno Bott fei Tant: wir Dürfen es boffen!" Gr wollte noch mebr lagen, aber ba fprang ein junger Mann mit einem geiftoollen Beficht und langem bellen Saar, bielleid)t ein (Belebrter, auf einen Sijh) uno fagte mit

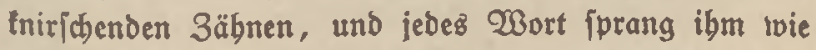
ein Galfe vom Munde: „Reutel Mein Yorreoner bat recht: es werben jhbere Tage unb Monde jein ... bie, bie twir jest baben rerben. (9ab ganze Curopa gegen 
uns! 2ber die 3abl unjerer Feinde ... fo groß fie ift ... fie macht uns nichts! Eebt, wir baben breierlei, toas unfre Geinde nid)t baben: wir baben eritens: ein gutez Betwiffen. Reute! Wir baben biejen Rrieg nicht gewollt! Weder unier Oolf, nod) unjre Regierung! Wenn wir unjrer Regierung einen Z3orwurf madien tönnen... Das twiffen wir alle... po ijt ez nicht ber Dez Rriegez, fondern Der deż übergroß̄en Freundlichjeinz,

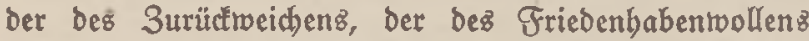
um bohen Preiz! 3tweitenz haben twir Finigteit! Gie follen febn und follen fich entietsen! Deutichland in Not? Deutjdbland cinig bis zum legten Nann! Orittens: twir baben cinen $30 \mathrm{rn}$, einen $\mathrm{Sa} a \tilde{\beta}$ ! Qeute! Wie grof́ baben roir, von unjerm Raijer bis zum ein= fachften Mann, von Englano gedacht! Wir meinten, fic rwären unfre Greunde, bon vornebmer, coler Gejinnung, ja unjre Brüber um ibrez Sertommens willen! Ober liegt es an unz? Saben roir unz gegen England ver= fündigt? $\mathfrak{I m}$ Begenteil: rair find feine Solfer gewejen in mebr als einer शot! Ober roollten wir uns in 3ulunft an England verfünoigen? Tas ift ein unfinniger Gebanle fuir beutiche 21rt! Woir, twir Deutjche ... wir leber und laffen leben! Reute! Warum rill Eng: land denn fommen und Deutiflands Rinber töten? Warum? 230 ift jeine Rot? 230 ift bie unendlicbe Qual, bie allein ein redlides Zolf in ben Sammer bez Rrieges jagt? Qente! England ijt cin anores $\mathfrak{B}_{0}$ lt, als

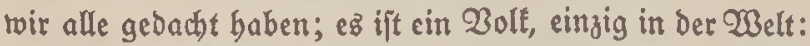
es ift Daz Bolf, baz Siriege anzettelt uno führt, wenn irgenorno auf ber Croe cin anorez Bolf aufiteigt, Daz 


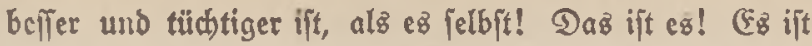
Das $\mathfrak{B}_{\mathrm{Dlf}}$, bas vom Söten bes Buten lebt! Es ift Der

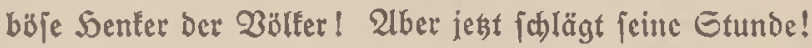
Sekt ihlägt Gottez Etunde! Diejer Sirieg wirb neben viclem andern, bas alt und morjh ift uno bas er weg=

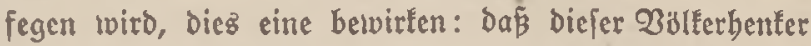

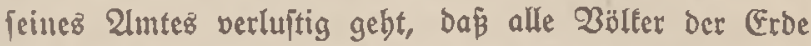
frei und gleichberechtigt nebeneinander|tehn, bis cinjt in fernen 3eiten der Sag fommt, da fie alle einander 2 rüber

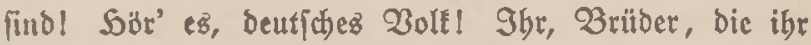
binauzziebt zum Rampf ... Shr fämpft nicht allein für Deutjdlano! Shr tämpft: Den Shron Des frommen Welt=

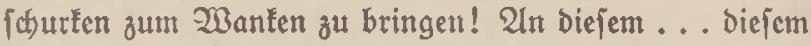
Niebertreter ber Bälfer, bie in allem Guten roachlen toollen ... Diejem Entmanner ber Tationen, daz Bottez = geridt zu balten!" Die ganze EDenjh)enmenge, bie Den Raum füllte und in Den offnen Süren und Genjtern ftano und braußen, rief laut und wild immer wieder: "Richtig! Das ift es!" Cin junger Eduüler, ber mit funfelnden 2 ugen nicht tweit von Dem Rebner geftanden, fprang auf einen Giufl und ricf: "Sört mich . . . I Sa) ... id bin nicht breit"... er follug immerfort gegen feine 3 ruft ... "ich bin erft fiebjebn . . aber id ... mit biejen bier"... er zeigte auf feine Benoffen, bie binter ibm ftanden... "twir find heute abend fdyon im grauen Rod. Waß rollen toir? Wir rollen unjer bei geliebtez Bateriand, feine idjöne Eroe, jeine Frauen uno Rinder verteibigen gegen Franzojen und Gerben, Neger und Rofafen, gegen allen Gdymus in der Welt. SInd rollen ibm (Ebre uno Quft fdhaffen in ber Welt! 3ulebt 
aber, renn bie anbern am Boden liegen, rollen roir bem Bruber an bie Burgel, Dem Edjurten, ber feine Seimat und fein 2 lut vertaten bat ... ber, grop̉e unb fromme Worte im Munঠ, นทళ überfällt, uns ... Die wir ihn liebten uno ebrten. Wazs rebet auz unzె, Brüber? Wober unfer rafender 3orn? ... Weil wir ibn liebten ... weil wir ftolz auf ibn waren ... ibn... von unferm Blut ... a a unjerm Land bier getommen!" (Er fohlucte uno fämpfte mit Sränen. (Er wollte nod) meiter fprect)en, Da fam von ber Straje ber ber rau= fđende anjwwellende Bejang von mäd)tigen jugenoliden Gtimmen: , Fin fefte Burg ift unjer Bott ... Slnd wenn die 2Belt voll Seufel wär . . . fo fürdten rir unz nicht fo febr ... Edjüler zogen in Soaufen vorüber, taufende junger Mannja)aft. Die Menjdhen ftanden mit abge. zogenen Süten und lauf f)ten oder fangen mit; viele tweinten.

Banz betäubt von Dem, twas er erlebt batte, ganz erfiullt oon all Den Gebanfen, bie es ibm neu gegeben batte, ging er fitll für fich Durch bie Menge, bie bie Gtraßen füllte, und gelangte trieder nach bem Babnbof.

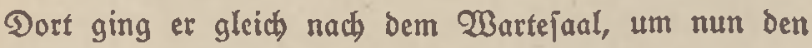
Brief an bie Elltern zu ihreiben. (Ez gelang ibm, burd, all bie Menj(hen bindurd)zulommen und in einer Ecfe ein Pläßchen zu finden. Rechtz pon ibm laß ein Saufen junger Rerle, gelbe Pappidjadteln vor ober neben fich, Rejervijten, bie zu ibren Regimentern roolten. Gie redeten, mübe Der Rriegzunterbaltung, rubig von babeim, von Cltern und Pferden, Sdwejtern und Rame. raben; fie jabienen aus benactbarten Dörfern zu itammen. Rints von ibm jaßen gauz junge Befellen, die Röpfe 
auf ben Pappichachteln und (h)liefen, Freirvillige, bie morgen früb weiter roollten, um in Zerlin und baberum ifr Seil zu verfuchen. Ourch bie Gänge bes gropent

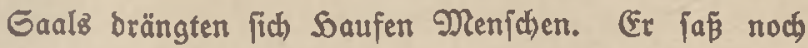
eine $\mathscr{B}_{\text {eile }} \mathrm{ba}$, in Gebanten an bie Szene, bie er eben erlebt batte und an baz fo bebrängte Waterland; bann fing er an zu idreiben:

\section{Riebe (Eltern und Befditwi|ter!}

9c) babe in New 3 ort Bruber Eggert nicht ge:

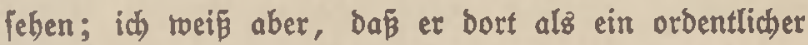
Menich lebt. Rebelta Pein ift eine alte Frau unb gebört zu Denen von ber Gorte von Gt. Margaretben. Wir find febr rajh nach Deutichland zutrüfgefabren mit cinem Bogen nach ber norwegifhen Rüjte ou, und find beute abend bier in Samburg angetommen.

Liebe Eltern! Run gebt ja auch England gegen unz; Der Seufel weiß̈ warum; Gott und anttänbige Men[d)en riffen es nidht. Qiebe Eltern unb Geidwifiter, c8 ift nun robl möglich, bás ich nidht wieberfomme. Sd) tröfte mich aber Damit, baß ich bann für eine ge" rechte und reine Gache falle, und bamit müpt Shr (Euch) auch) tröften; benn einen anbern Sroft gibt ez nicht. Ulfo trauert Dann nicht um midf; fondern babt guten Mut Darum! Gagt Den Gefchtwiftern, Daß̧ fie nicht fo aneinanber Heben, fonbern bell in bie Welt fethen und fich jeber feinen eignen $\mathfrak{B e g}_{\mathrm{e}}$ fuchen follen. Sie müffen immer benten: Went nur bas Fähnlein flattert! Taz babe id mandimal im Gpap zu ibnen gefagt, reenn fie fid über mein Rab luftig mact)ten; id meinte es aber im Ernjt. Grü̈t ben Bruder Eggert von mir, uno er 
foll ins Elternbaus zurülelebren, wenn id) nidht wiebers fomme. Bater aber foll an ifn glauben; glauben ift das bejte im Reben. Bruber Reimer twirb robl ein gelebrter Mann werben; ber tann Dann alle Bejhwijter zufammenbalten, foviel ez gut uno möglich ijt.

Mein Rad foll 3ruder Reimer baben.

Euer treuer Gohn und Bruder Sarm Ott.

Go fabrieb er rubig und in furzen, flaren Eäken,

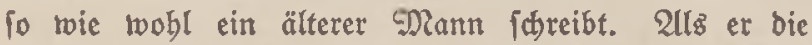
Feber binlegte, batte er aud) jelbft bas (Gefübl.

Et machte ben Brief fut und ging binaus in bie Salle, um ign bort in den Siaften zu ftecten. Slls er (iich) Durcl) Menjidyen Durchbrängte und bie Salle erreicht Gatte, und mit jeinen Gedanten toer weís wo mat und über bie Menge Ginjah, fam inm ber Gedante an feinen 3 ruber Reimer. Es rourbe ihm aber nidjt llar, robber ber Gedante Füme; und er verlor ibn twieder. Uber gleid darauf war er wieder da, tuth da . . fieb ... Da ftand cin junger Menja), Deffen etwaz langes Saar und bobe Galäfen grabe wie Reimers twaten ... und da ... ... da jaben fie fich beide und crtannten fich!

Die 2ugen von Bruber Reimer leuthteten und eв flog ber fwönfte Gdjein über fein Beficht: "Da bift

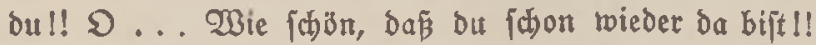

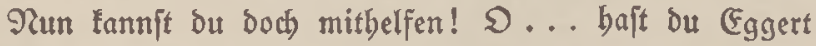
getroffen?! Saft bu ibn gejprocten, und twas jagt er?"

Sarm fhüttelte ben Ropf por Bertwunderung, Daß́ et ben $3 r u b e r$ bier fab. "Sch babe (Eggert nicht getroffen,

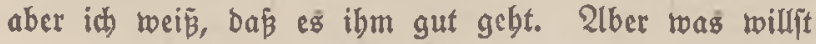


Du bier?... Sunge! ... Su willft bod nicht ...?! Waz foll ber Rioffer?"

Bruber Reimer richtete fich boch auf unb jagte ver=

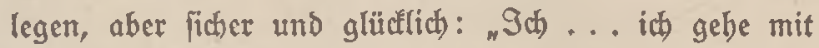
... mas dentit du?"

Gein Bruber erforal aufz beftigite. "Du?!" jagte er, "fo mitten aus beiner Urbeit?! Soerr Bott, ich bachte vorber now) an bich, als ich fo viele Freitwillige (ah); aber id) tröftete mich, baß ou ja to beftig gegen ben Rrieg rebeteft, fo als wenn bu nie mitgelyn würbejt, toenn Du nicht müßteft."

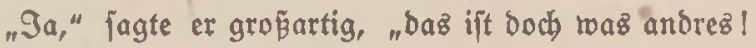
Sch bin Durchaus gegen ben Rrieg ... verjtebit bu ... io als menfchliche (Ericheinung; er twirb ficther über wunben werben! 21ber wenn mein 2 olf angegriffen wirb, muß ich bow) belfen . . . Daz ift boch jelbítberftändlich!" "Inb Nutter?" lagte ber 3ruber.

"Эa . . M Mutter" ... jagte er ... "ez tut mir ja leib um fie; aber mas foll ich machen? Sd fagte: , Nutter, wenn ou mich nicht gehn läpt, wirb mir ber ganze Reft meines Lebenz nidbt ichmeden." Da jagte fie fein Wort mebr."

"Du rarft bei Den Elfern? 2Bann bift Du Denn bon Riel gefommen? Scute?"

"Nein, gejtern vormittag. 2lદ bie Rriegzertlärung gegen Granfreich und Rußland ba war ... bas war vorgeifern ... oder wann war es. ... ich weís mebr... da wollen wir gleich mit; aber einige Qebrer bielten uns noch zurüct und jagten, England roürbe uns

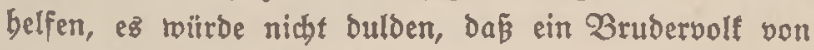


zroei fo mähtigen Gegnern überivăltigt twürbe. 21ร e\& Dann aber geftern abend bieß̄, Daß́ (Englano unz nid)t belfen tonne ... ich reís nicht warum ... Da brach es Lo8. Da war fein Salten mebr. Dent' Dir: wir allein mit S̈fterreic) gegen Franfreic) uno bas ungebeure Rußlano."

"Ia," jagte ber $\mathfrak{B}$ ruber bitter, "menn es bamit

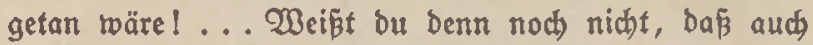
England gegen uns geht?"

Bruber Reimer ftarte ifn an, totenblap. "Eng= lano!? ? rief er entfebt, "England ... gegen unz?" Fz flog eine tiefe Rüte ber Gatam über ' feir junges (Be-

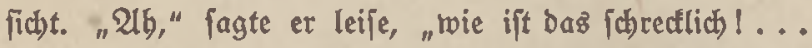
Das gebt ja gar nid)t ... toir tönnen bod nidht 3 ruber auf Bruber fhiepen?! . . Sarm ... roir baben ibnen nichts getan, tmo fino von fo gropenen Mächten über= fallen! $\mathcal{O}$, ein Bruberbolf! ... O nein! ... nein ... Ou, Sarm ... To etwas ijt noch niemals geid)ebn, folange bie Welt fteht! Davon wirb man nad taujend Jabren nod) reden!"

Gie batten fich roieber in ben Gaal gedrängt und

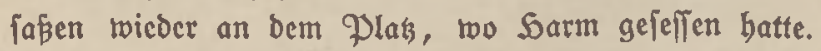
Gie batten eine Weile geidrwiegen. Da jagte Bruber Reimer: "शun muß ich mit gegen England, Sarm ... Du mußt mir belfen, Soarm! S(h) gebe Dir nicht bon Der Geite!... Id) roill mit gegen (England! Эd) will!" Gein 3 ruber fdüttelte beftig ben Ropf und jagte: "Wenn es fein mús, wenn dit bein Leben fonft nicht fdimecten wirb, fo magit bu mit in ben Rrieg gebn, aber nic)t jur Gee! Sa) belfe bir nicht und nebme bich nicht mit!

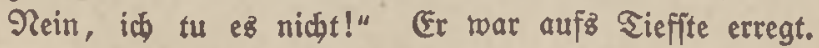


Er hatte jest Das Befübl, Daß nun, Da England mit* ging, ber Soof am Deich jeinen Seil an biejem Srieg rürbe zablen müffen, und fo genügte $e z$, baßz allein er ez twäre. "Bebenfe," lagte er und jab ben Bruder mit 2ugen an, bie mit ben Leben fertig waren, "wab es für ein Rampf werben miro: ibre Flotten find brei. mal grofer alz unfre! (Ez gebt nicht an, ba von unz beiben wiedertommt."

"Sazి träre freilich fhlimm," fagte Reimer; "aber es

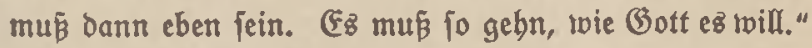
"Ob es noch einen Gott gibt!" fagte ber Bruder bitter. Dann idbiegen fie wieber.

Rad) einer Beile fing Reimer an, ihn nach feiner Reife zu fragen; und er erzäblte es íbm. Go fpracten fie eine 3eitlang. Dann fhlwieg er lange, unv jein 3ruber, ber ibn von ber Geite anjah, fah, wie bie (GeDanfen in ihm arbeiteten, und jab, wie fie erft mübjam bin und herliefen; aber allmäblich fab er einen rubigen,

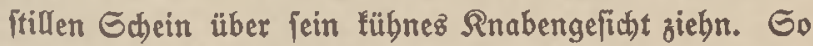
berbarte er lange. Dann lagte er: "Zruber Sarm, es ift alfo abgemadbt: id gebe mit bir, ober ich gebe allein nach Wrilhelmş̧aven. Rede nicht bagegen ... es muß fein! Falle ich, po ift es gut; tomme ich) zu= rüct, fo werbe ich mein Leben lang itoly fein, bá ic id mit gegen England gelämpft uno damit bas Sbeiligfte in meinem ganzen Qeben getan babe. Denn es ift nicht 10, wie bu jagteft: (Bibt nod einen Gott? Grabe biefe Tat Englands wirb beweifen, daß es einen Gott gibt. Du wirft feln, wie England es twiro bitien

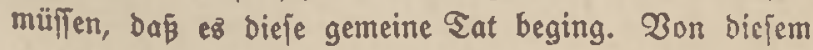


Tag an twito man ben Nichergang Englantz rect)nen. Denn ez ijt fo mit Bott... er tann nidht anbers.... er futbet bie WBelt und die Nenjabbeit weiter, inden er ben Bujegetwordenen, den er verberben will, zu furd)tbarer Gier und zu Ulngeredhtigteiten verleitet und ben andern, ben Rleinern uno Beffern zrvingt, gegen ibn zu Eämpfen uno ibn endlich niederzuiflagen. SAnd babci will ich belfen! Эa, bas will ich uno mü ich; fonft mag ich nicht mebr leben!"

Dann fás or wieber ftill und fab mit gropen 2lugen in das Betriebe um ihn ber. Gein 3 ruber jaß neben ibm und jab zumeilen nach ibm bin und jab, roie grope, reine Bedanten burch jeine Geele rogten: (Teutichland ... altes Zaterland ... in groperer, fchwerer Etunde ... in Not ... in farectlicher Gorge ... in beiper Berteibigung ... o o! Deutílblano! . . tapfrez, emites Bolf! Diç ift deine grope Etunde ... Gott verläpt Dich nidht darin!... 2us tiefer शిot ichrei' id ơ bir ... Gie gedachten ez bojfe zu machen, (Bott aber ge= Dachte ez gut zu machen... Du wirit fiegen!... Du wirft ber Menjubeit belfen, bie in Gold und Rüge vers fomnen wollte! Deuticland, Deuticland über alles, über alles in ber Welt' . . Goldje Bebanten, jah fein Bruber - benn er fanute ihn von jeiner Rindbeit an - betwegten feine reine Geele, wäbrend feine tiefen

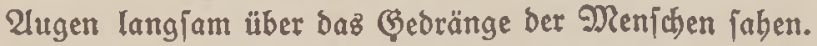
Uber allmäblich wurben ibm bie 2lugen mübe. (Ex jab Bruber Sarm an und jagte: "Ih babe in ber vorigen Nacht nicht geichlafen; idh will ben Ropf auf ben Silch legen uno bie 2lugen zumachen." 
Gein 23ruber, der 3immermann, Га⿰三丨 no屯 eine Weile uno fab mit rubigen 2ugen über baz Bebränge, Das bieje ganze Rad)t nicht nadblię. Dann twurbe auch er mübe. Er hatte von Der Gabjpike Nortwegens biz nach Samburg, im ganzen breifig Gtunben, geraatt und gejpäht, bie Geele immer boll von allem Graujen und allen Wundern biejer Sage. Der Ropf fant ibm naw vorn; er börte nod) wie ein Srupp Rejervijten, leife, um fie nicht ofu ftören, an ibnen vorüberging. Dann fiel fein Ropf auf ben 2 rm und er fdlief ein.

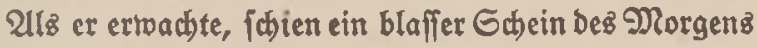
burd bie boben, bunten Geniter. Da rectte er ben Bruber, und fie tranten eine Taffe beipen Raffee und nabmen ibre Gachen; und gingen binunter, um nach Wilbelmşbaven zu fabren.

Die tocite Salle mar boll von Rejerviften, bie fich an ben Gperren zu ibren Babnjteigen jammelten. $\mathfrak{B}$ on unten berauf Donnerten bie 3üge und bie taujendfachen Rufe ber \&użziebenden. 


\section{Rapitel

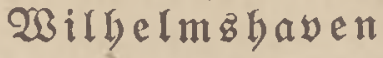

(9) 3 ug war unendlich lang und icton ziemlict mit Rejerviften und Greimilligen bejest. Frokdem bielt er auf allen Gtationen und nabm überall Rejerviften und Freiwillige mit. 2 n einigen Gtellen be. gegneten fie andern 3ügen, die ba bielten und warteten. S̈berall, auf allen Babngb̈fen, fah man auf Den erften Blid, was vor fich ging: in ben 3ügen und nad) ben Sügen fich drängend bie junge Mannidaft zu Sumberten uno aber Sounderten, und in ben Ģärten und Bängen bie bidte Nenge ber Renjwen, die Daheimblieben. Sund bie, welche in Den Rrieg, in Rot und Tob zogen,

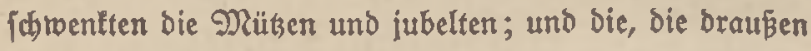
ftanden und 2tbifhied von ibnen nabmen, verfucthen zu lächeln; aber in ihren 2lugen ftand ber Sammer; und manibem, ber fidh, zurüübielt im Edjatten, liefen bie Tränen über bie $23 a n g e n$.

2lls fie in 3 temen bielten, zogen wobl grweitaujeno Mann ben Babnfteig entlang, noch uneingefleibet, aber fchon in Reī und Glied geordnet. Gie fragten fie aus ben Genftern, wolin fie fübren. Sie antworteten "Barbe !.. Berlin! ... Potždam 1... Gpandaus:

(5\& waren lauter niederiädjificde Leute, und famen, wie

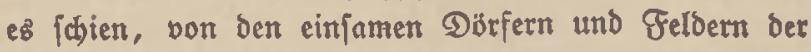
Slmgegend. Gie batten ibr Qeben in gleidbmäß̈iger $\Re u b e$ werbractit und mancher bon ibnen ging auch jegt noch

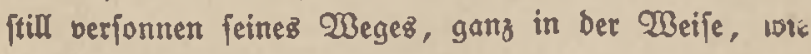
er binter bem Dfug bergegangen war; aber bie meiften 
waren bon bem ungebeuren \&eben auf bem großen Babnbof und von dem berwegten Empfang, den man thren bereitete, erregt, und es glimmte etwas wie feuer in vielen 2lugen. Fin ditterer Mann, moblgetleibet, ftand zur Geite, too fie vorbeigogen, und fotwie fie vor. übergingen, griff er in feine Rocttajhe, und wäbrend er mit Sränen tämpfte, fagte er: "Sch babe feine Rinder ... ich fann euch nichts andres geben als biez ... madyt euch eine Greube bamit," und ex gab ibnen (Bolds. uno Gilberfücte. Sie nabmen fie mit idlictem Dant gleid)mütig an. Nidbt weit bon ifm warf ein frilchez Mäbden Blumen in bie Reiben. 2ls bieje an ibrem Wagen vorüber raten, fam eine anbre Gळar, bie no屯 bon ben Shren begleitet twar, toobl Reute aus Bremen felber. Gie twaren filll; ja mandier war biz inz $\mathfrak{I n}^{n}$ nerfte in Not. WBie fejt bie Sänbe ber jungen Elye. leute inteinanber lagen! Wie lie einanber in bie 2 lugen faben! Unb immer roieber, wenn ber 3ug fich ftaute, börten fie aus bem Nunde Der Nänner biefelben BeDanten: "Du fiebjit ez ein, Dá̉ es nötig ift... Das Befte ift, Dá̃ wir wiffen: unjer Saijer und unjre Re* grerung baben es nicht angefangen. Slage nicht... Grage nidft .... Es ift Edbichal! ... Es gebt über

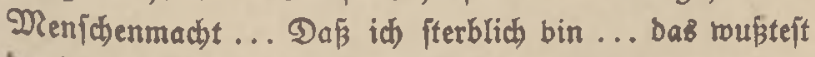

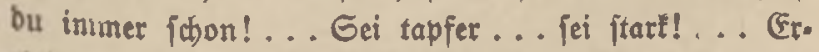
jied, bas Rind recht unb gut l" Das börten fie immer wieber. Die stüber modten eş zulebt niळt mebr bören, fie Jogcis fid in ibr 2lbteil zurübt und faßen ba in fitllen Bedanten ... Stach langer Fabrf famen fie um Mittag in willyelmos baben an. 
Gie wurben fhon am $23 a b n h o f$ von Offizieren und Quten empfangen. Die Brüber mußten fich trennen: Reimer zog mit einem gró̃en Srupp noch böllig un= georoneter Freinilliger babon, um in irgendeiner Rajerne jein Seil zu verjudben; Sarm marjhierte in bie Gtabt. Gie füllten bie ganze Breite der Grraje. 2uf den Bürgerfteigen, an Den Fenitern, auf ben Pläken, an der Rirche brängte fich die Nenge Der (Finwohner, uno rinfte ibnen zu und grüp̃te mit Mund und Sänden; in ifren Befichtern ftand lauter Fifer, Freude, Ebre, Gtolz, und fie gingen aufrehter, da fie vorübergingen.

Untertweg fragten lie bie sorübergebenden Geeleute: "Wißít ifre etwas von braupen?" ... "Eind bie Engländer fhon ba?" ... "Shaben rir ichon Gdiffe berloren?" Slno fie glaubten ibnen nicht, als fie fagten, baß von den Engländern weber etrwaz zu febn noch zu bören twäre. Sie meinten, fie wütß̄ten es nicht anbers, und bie Wabrbeit würbe ignen werbeimlicht. Denn fie dachten alle nicht anderz, alz baß England, roenn ez benn ein= mal gegen unz ginge, glcid in ben exiten Tagen mit feiner ungebeuren Macht auf unz loşbrechen würde, unt unz mit einem Gdhlag zu vernichten. Da ç nun noch nich) erfidjienen war uno alle başfelbe jagten: "Nein, fie fund nod) nidgt bal" ... oder: "Nichtb von ibnen zu febn!" . . fam ez Sarm Ott in ben Sinn, wäbreno

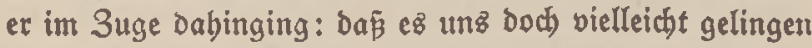
tönnte, jogar auch zur Gee, leiblich bavon zufommen. Slnd er ermunterte fid und jagte einiges von dem, was er fo Dachte, feinen beiden Rebenleuten; und or mertte, báp auch fie guten Nutz waren. 
Su bem gropen Sof Der Saujenimannfajerne roar es idwarz von Menjujen. Rejervijten ftanden und oroneten fich; (Eintoobner gingen mit Mild) uno 3 rot unb Obft Durd fie bindurch und baten, zu nehmen uno

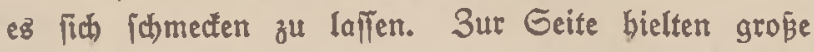
Möbeltwagen, auż beren Sicfe in mädtigen Pacten Uniformen uno Näntel famen. SUnteroffiziere riefen mit lauten Gtimmen Raiz, Divifionen, Ediffznamen in die Nenge. Nad) einer balben Gtunde Wartens tamen fie, ungefäbr bunbert Mann, in eincn groß̉en Gaal, wo Die Rifte werlejen, Slnteroffiziere zugetcilt, Nummern für jeden cingelnen gegeben wurben. Sie iabliefen diefe Tladt auf bartem Solz in Gälen uno SGängen. Gic lagen ba z̆ Taujenden, Nann an Manu gedrängt. Um andern Morgen entpfingen fie bie neuc Sleibung und zogen fie gleid) an. In einer Ecfe bez Sofez be= tamen fie Gewebr und Entermeffer. SIm vier Slbr gingen lie Durch bie betwegten mit Menfd)en gefüllten Gtraß̄en in Reih und Blied nach bem Rai.

Untertwegz fragte er ben Unteroffizier, auf loelchez

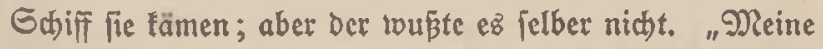
Befannten," jagte er, "baben ichon ihre Beftimmung und baben es alle gut getroffen; fie find teils auf groß̧e Edbiffe, teils auf Minenfdiffe getommen. Wobin wir

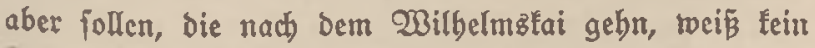
Senfib. Finer fagte mir was von Fif d) bampfern; aber Daz ijt ja bummes 3eug. Fijhbampfer!? Sollen wir auf Giichbampfern gegen England fämpfen?"

Uls fie fich Dem Rai näberten und eine Gtoctung eintrat, uno ein andrer Befannter bez SInteroffizierz des 
Weges fam, lachte ber und ricf: "Wahrbaftig, ich lïge nicht: Ibr tommt auf'n Gifdbampfer. Soundert Gijd: Dampfer follen braußen Wache fabren, immer fo ..." uno er madbte etnen langen Rtingel mit bet Sand in ber Ruft.

Bald Darauf ftanben fie, ibre Gäfe vor ibren Gǘnen, in Reib und Blied, die Interoffiziere vor ber Gront. Fin Obermaat zăblte fie $a b$, uno ftand Dann wieber und fab nach bem Offizier aus. Der tam benn aud bald in jiemlichem Edritt von eirem Dampfboot ber, bas twie ein großjez Berfehrzboot ausfah. (Er war ein f山lanfer, feiner Mann. Die eine Sölfte feines tübnen, bageren Gefichts wurbe alle Augenblid, bejonders went

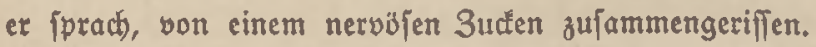

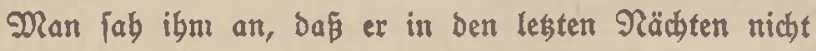

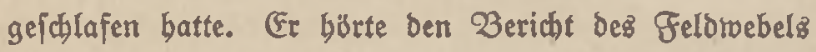
an, jab prüfend über fie bin, trat zurüct und fagte Dann turs, freundlich und frif(h), mit einer idmetternden Etimme: "Qcute! Sbr míst es alle: wir find von jwei mädtigen Büleern überfallen, bie uns berauben rollen. Slno als̈ Englano das jab, meinte ez, ez müpte Seilbaber jein

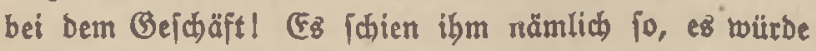

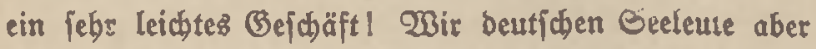

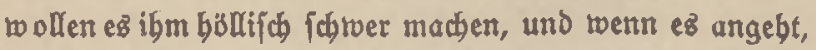
wollen wir ihm vollig verjalzen!. . Keute! (EB

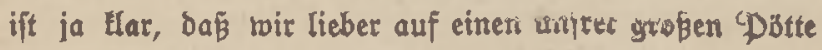
gegangen wären! Sol will euch ebrlich lagen: sat yobe

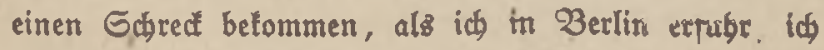
jolle Chef einer Glotte bon Fijdoamptem wetbes. Ylber

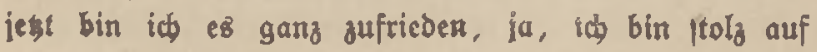


mein Sommando! Sक benfe, ifr werbet es audi werden! Saben rwir nicht bie 2lufgabe, bie Nächjten am Feino au fein?! Werben wir es nicht jein, bie ben Rameraben melben: , fr tommt! Gr fommt Geib wadb!?" ... Rameraden! Wir wollen Dem Raijer, unierm Fübrer, geloben, ibm wertwoll zu lein in unjerm fhlichten Dienjt! Geine Majeftät, Raijer Willbelm, er lebe ... bod)!"

Gie waren alle fortgerififen won feinen flaren, rajhen Worten und fitmmten freubig ein in ben Ruf; er batte tbnen ganz und gar auz bem Sorgen gepprochen. Dann prach er noch biez und bas mit bem Obermaaten, unb nerabjhiedete fid) Dann von ifnen, indem er an jeine Bruft jahlug uno mit jeiner (d)metfernden Etimme jagte: "Sh) werbe über bundert Boote unter mir baben ...

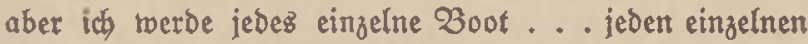
Nann bier in ber 3rujt tragen!" Ulıo er bligte fie an uno forberte Blauben an jeine Worte.

Gie glaubten es igm alle. Slno ezs ging ignen allen

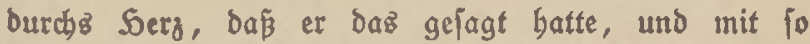
idmetternder, fharfer Gtimme und brennenden 2ugen. Er wollte fie alle in feiner 2 rult tragen! ... Sa ... bas batte er gejagt!

Gie murben nun verteilt auf bie eingelnen Gifd, Dampfer: je einige ztranzig शann $\mathfrak{B}$ faßgung für jeden. Rapitän war ein Eteuermann ber Fejęroe, meijt ein Mann aus ber Danbelzmarine. 2 n ber Epize Der Bejakung, 6u ber Sarm Ott geborte ging ein Hleiner, Dunller Dann mit einer ftattlidfeil Sabichtżnaje, Gteuermann bei ber Lebantelinie. Er roar in einer fünftägigen Reife 
von Bentedig ber burch D̈|terreich und gand Deutichland geftern in Wilbelmb̧baven angetommen. In jeinem Ropf fpuften noch) bie begeifterten (Empfänge, bie Reden uno

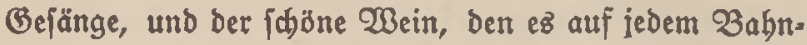
bof burch das ganze, weite S̈fterreich gegeben batte, und das etwige Gerummel und Bejtó bez 3uges. Vor Mübigfeit mantend, fich bei jedem britten Garitt jäh aufraffend, ging er vor feinem 3ug her. Die Reute berebeten, nachbem bie Crregung, bie von Der 2Injprache ausgegangen twar, fich gelegt batte, nit fitllen 2lugen

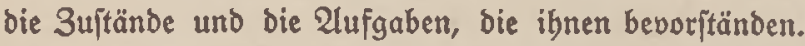
Ein junger vierkantiger Fijher von Emben fagte verjonnen uno vertwunbert: "Pat wär' aljo unj” 2lomiral!" uno meinte bann: "Das bätte idh mir nicht träumen

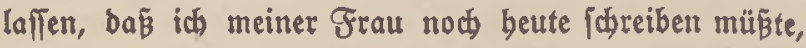
id) Pei auf einen Fifchbampfer gefommen, genau babin, two id bertomme!" Ein Mann von Büjum, Dem man an ben rafchen Betwegungen und an ben etwas rub= lojen 2ugen amjab, baj̃ er nidht immer zur Gee gefabre! batte, fonbern erft nach vielen, nicht geglüdten Ber[uchen an Lano auf bas Meer geraten war er fijwte jebt Rrabben in der Giblerpiep - jagte: "Rinder und Reute, ein gróerer Panzer wäre mir lieber getwejen! (58 wird verdammt langtweilig werben! W3ie es wohl mit ber Berbindung nach bem Land jtebn

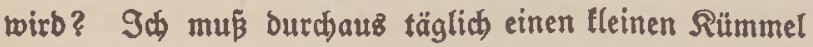
baben." Die andern lädjelten und jaben bei ber Be" legenbeit jeber in baz Gefiळt bez Nebenmannz, wes Beiftes Rinb er wobl twäre, mit bem er nun vielleidft Donate im gleiden Raum und in gleicher Befabr 
baujen pollte. Cin andrer, roie es fáten ein Safenarbeiter, breitfdultrig und fchwer, fhon älter, ging mit niebergeid)lagenen 2lugen vor (ith) bin und bact)te nact); Dann fhlug er bie 2lugen auf, fah Sarm Ott ant unb fagte langfam: "Wenn bie Engländer tommen ... und natürlich tommen fie ... vielleicht Sorpeboboote oder U- Boote voran ... vielleiळt auch gleich mit ibren 2 llmäcbtigen ... baun follen wir natürlid) auళืbüren. (Da wir aber nur höch ften's acht Dleilen laufen, wirb unz Das nidht gelingen. Uber bas ift ja auch nidbt nötig; benn twir find ja nidjt biel rert: ein fleiner Fif d) Dampfer mit ztwanzig Mann ... tras ijt has für ein Hleiner $\mathfrak{B e r l u f t ! ? ~ U l f o ~ f d i d t e n ~ m i r ~}$ nod) raid) uniern Funffprud) an ben abmiral: , Sie fommen ... mit to und fo viel Gabiffen ... und bann gebn wir in bie Siefe." Er batte po rubig uno laut gejagt, daj fie ez alle gebört Gatten. Soarm Ott war ber crite, ber nach ber Gtille, bie nawh jeinen Worten cirtrat, etwas roie cime 2lntwort gab; er fab feinen Nebenmann an uno fagte: "Waz ift zu tun, Ramerab?! Der cine bat biez, ber andre jenez Echict= ial ... und nirgends bunter alz im Rrieg."

Go tamen lie an Den Sai und lletterten über zrwei

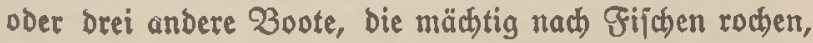
uno fitolperten auf ibr $30 o t$, legten die Gäcfe vorläufig uri bie çani ber Rombüje und nabmen erftmal bas כ̌diff in Lૈugenlchein, bejaben, twas ben meijten neu an is einem Gifdherboot war, und beredeten Die bejondere Uusrüjtung: Den Gdeinmerfer unb bas Bejchüs und Fie roobl noch mebr befämen, und ftanden bann ein roenig umber und warteten auf ben Gteuermatn, Der abgebogen 
uno auf einen Nufterbampfer gegangen roar, um fich die Beränderungen anzufehn, die nötig waren. Balb Darauf erídien er rieder und rief: "Sier mal ber! Sier im Gifchraum baz $S_{0}$ olz beraus! . . E Es ift ganz bermulmt und riecht unerträglich. Sịt ba ein Sifhlec unter euch ... ein 3immermann "Soarm Ott melbete fich. "Echön, bierber! Fünf Mann belfen Sbnen: baż Solz wegreí̄en, neue Ratten anbringen, Rojen einrichten ... fo und fo ... Solen für die Sängematten cinfchlagen," uno er gab baz Weitere an, wie er ez̉ auf bem fhon eingerichteten Rachbarbampfer gejebn batte, uno ging, um nach bem ïbrigen zu jebn.

Gie madten fich mit (Fifer an die Mrbeit, wobet fie Fin in ibrer langiamen, rubigen 2 rt unterbielten. 2umäblich aber zeriplitterte fich bie SInterbaltung, indem

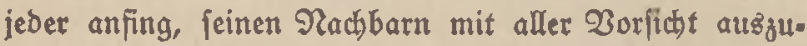
fragen, wober er täme, weldjer 2lrt jein Beruf wäre und ob er verbeiratet wäre und dergleichen, wobei immer ein Räfifger mit eirem Rajheren zujammengetommen zu fein fhien, unb ber $\Re$ ajhere aud ungefragt über jeinen eigenen 3uftand 2uskunft gab. 2(tz fie fo forich toeg arbeiteten unb nach all bem unendliben, mäd)tigen Sreiben unb ben 2lufregungen ber Reife bie alte, langjame Fube über fie fam, wurbe von oben ber wieber nad einem Sijchler gerufen. Gie fagten alle: "(Geb) num twie machen es fchon allein!" uno einer fagte: "Tlu fiel, Du bift ein begebrter Dann!"

(Ex gab noch anweifungen, toeldbes Sold fie bolen follten, und ftolperte die Reiter binauf uno ging mit ber Orounnand an Land und nad bem $\mathfrak{B}$ erlebrs. 


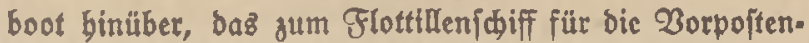
flottille beftellt twar, und wurde in einen gropien, wobns liden Raum an Dect gefübrt, tro ein Dffizier ifm auftrug, aus verifliebenen Solzplatten einen gropenen Rartentifक zujammenzu[dlagen uno aufzultellen. Fin Matrofe war ihm als Solfer gegeben. Fs twar ba ein immertwäbrenbes Rommen und Bebn, und bie Offiziere wubten oft nidbt, auf weldhe Oroonnang fie zuerfit bören uno tweld)en Mann fie zuerit abfertigen follten. Er madte fid in all Dem Wirrwarr gleid an bie 2rbeit, ging $a b$ und zu, bolte fich Solz und Sanbrwertzzeug berbei, und freute fid, für einige Gtumben in feintm Beruf, Den er fo liebte, tätig ơ jein.

Ul'z ex nac) einigen Gtunden - ez̉ ging gegen 2benb - bie 21beit getan batte und mit $\mathcal{Q}_{0}$ ent= Iaffen wurbe und burdh ein Getwirr von Meniduen und Wagen jeinem Boot wieber zujtrebte, rief ifn ein Cutrbabener Bootsmann und Gifher an, den er einmal lennen gelernt batte. $\mathcal{F}_{t}$ ftand im Cingang eines Gduppens unter roobl bunbert andern Nännern, bie

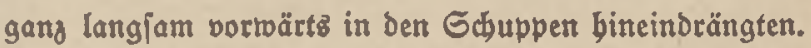
Er fragte ben $\mathfrak{B}$ efonntent neugierig: "Waas willit benn Du bier? Du bift ja boch bei beinem 2llter now lange nicht verpflidtet, bid ju itellen?"

Der Mann bob die mäbtigen Saultern und jagte: "Sa fiebit bu... ba England nun aud getommen ift uno ein 2ufruf nach Greiwilligen erlafien iift, fo bachte id, ich trollte benn gleich mifgebn." Und alz twenn er meinte, er müfie diefen Gdritt nod befonders entjduldigen ober erflären, fügte er binzu: „\$థ 
und meine Rachbarn bachten: wenn wir möglidyft viele uno gleich mitgebn, ift ber Rrieg aud) um fo eber porbei." Slnd um noch ein übriges zu tun, fagte er: "S屯) babe übrigenz, Da id mit zebn Sabren angefangen Gabe, jest fwon fünfundztoanzig Sabre gefifht und babe uun mal Qujt, toas andres zu tun." Das allez jagte er auperorbentlich langlam und roüroig; nut zulestst, als er Daz von ben fünfundzivanzig Sabren jagte, lächelte er ein wenig über fich jelbit.

Sarm Oft meinte, eż ginge uur langfam vortwärtş mit Der Slnterfudjung uno er müffe nodh lange warten.

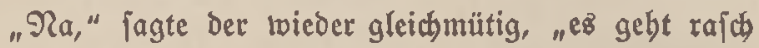
genug. Der Doftor, Der ba orinnen unterjucht, mact)t ez ganz prattifh, uno tut itberbaupt alles, twas er fann, bejonders renn man bedentt, baß̈ er grade einen (Bid)tanfall bat. $\mathfrak{B a z ̧}^{\mathrm{daz}}$ zu bedeuten bat, weís ich. Meine Mutter bat über zrwanzig Sabre baran gelitten. Bom Marjhtwajer, jagt ber Doltor." (Er wandte fid nach bem Genfter um, bas binter ibm twar, legte bie Sand über bie 2lugen und jagte: "Situt mal binein."

Sarm mahte eB toie fein Befannter, legte die Sand über bie Augen und fab inz Geniter. Sn einter 5ängematte, bie unter Ded aufgebängt rar, Iag ber $\mathfrak{U}_{\mathfrak{z}} \mathfrak{t}_{\text {, }}$ ein langer, bagerer Mann in mittleren Sabren mit einem nod) jungen, aber jebr verwitterten (Gefict)t, Das Dann und wann bon Gdhmerz werzerrt wurbe, unter einer Molldecfe im Nachthemb, aber bie Dienjtmütge auf Deur Ropf. 3roei mächtige Rerle, braun vou Eeewafjer und Eomne, traten grabe neu vor ibn bir. Ex tar etnige Fragen, fab fie icharf an und ihrie: "Üngenommen!" 
Die Gdyreiber an ben Rebentipien fatreben ez nieder. "Sit bas nidat gropartig?" meinte ber Curlyabener. "Rurg und praftif́ch!"

Da batte ber 21; bemerft, baß d Fenfter be= ichattet twurbe und daßs ex nicht mebr fo gut jah. (Er bob fich jäb in ber Soängematte nach bem Genjter zu

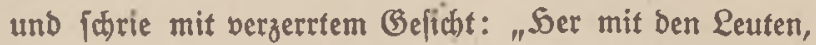

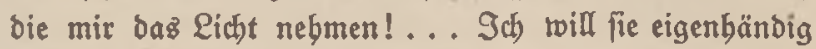
nieberjhlagen!"

Der Curbavener fam ziemlich ifnell nom Fenjter weg, ftectte Die Sände in bie Tajdjen feiner Sojen uno fagte gemütlich uno beifällig: "Wrir beibe fino es natürlid nidjt getvejen! ... 2lber toar bas nid)t

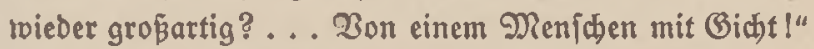
Slno er roollte wieber irgendeine (Bejdid)te bon jeiner Nutter erzäblen; aber $\mathfrak{S a r m}$ Ott hielt eş für rictiger, fid aus bem Gtaube zu machen.

Er fehrte trieder zu feinem Gifdbampfer zurüd, two fie fich zroijt)en ibren neugegimmerten Rojen uno an bem neuen Sijळ grabe zum 2lbendbrot binjester. Gie erzäblten iøm in einiger (Erregung ... jo alßె roenn fie nađträgliథ jeine 3uftimmung baben rollten, ba er Doch Dagugebïrte ... Daß fie mit bem Rod) Etreit be= tommen, reil er ibnen bie Brattartoffeln böllig trocten vorgejegt babe; und ba er noch bazu funoborige 2unt. worten gegeben, bätten fie ihn verprügelt. Sie warer. offenbar etwaz bedrültt; Denn ber Rod) war von Bord gelaufen, um fich zu bejdweren; uno fie fürchteten, oẩ Der Eteuermann nun über jie berfabren rouroc. "Wir Gaben abgemadit," fagten fie, "wor rollen Eurz lagei, 
Daß́ twir burch ben ganzen Wirtwarr nerbös toăren und auperbem bätten trir ibn für einen englijchen Spion gebalten." Fin Rurzer, Diđer, ein $\mathscr{W}_{\mathrm{e}}$ [tpreupe, Der bizber nod) faum ein $\mathscr{W}$ ort gejagt batte, murmelte, pollig im Bilbe: "Wenn ith einen $\mathfrak{D e n i c h e n ~ f u ̈ r ~ e i n e n ~}$ englijden Gpion balte, ben barf id bod perbrejめen?" Rachbem fie ibm bas ergäblt batten, riefen fie ibm pon mebreren Gtellen 311, fo eng ber Raum auch mar, er jolle find bier und bier binjegen. Er jegte fith zroifhen ben Slnteroffizier und Den bicten Wejtpreußen, und es

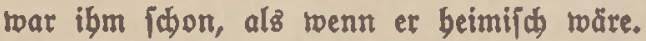

Ulm abenb (d)rieb er nod eilig eine Rarte nad) Saus, auf ber er melbete, too er benn nun untergetommen toäre, uno jhlief bann in einer rajめ) aufgebängten Sängematte, Da bie Sojen noch nidht alle bergeftellt toaren, tief und feit, in feinem Sraum immer roieber in einem Eleinen Gijdlaben in ber Sauptiftape Feiner Seimatitabt. 2lis fie ertoad)ten, riffen fie fofort bie Qute auf; es toar noф ein unerträglicher Fijd. geruch) im Raum, ber Durdh Das Naळtquartier von ztrolf Mann niळt fめb̈ner getoorben war.

Ex ging an Dect und roufd fid); und fie gingen mieber an ibs Sagetwerf, Das $23 b$ ot für feinen neuen 3 redf braubbar zu machen. Go arbeiteten fie ben ganzen Sag mit (Fifer, ja mit Leibenidaft. Der Gdweí rann ihnen von ber Gtirn, ibr 2ltem ging fdutwer; und mandser tat zuviel unb mußste eine Weile innebalten, weil ibm ber 2ltem augiging. 2lm folgenben Sag nabmen fie Roblen ein. Slno am 2lbenb, nadbem fie vter Gtumben lang Daran gejфeuert und gejфrubbt, twat das Boot tlar. 
Da ging er mit Arlaub bon grvei Gtumben an Lanb, um fich ein renig allein zu exgebn. Denn es ror ibm Doch läjtig getworden, fo Gtunde für Gtunde, nun fめon zroei Sage, immer unter Nenichen zu fein. (Er ging über ben Rai und Lagerplas, und tam an Den Teid

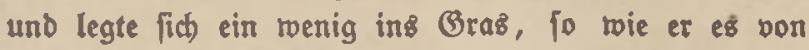
Der Seimat ber getwobnt toar, too an Sommerabenden oft ganze Reiben ben Deich entlang nad Feierabend in ber Gonne liegen: junge Leute und $\mathfrak{N a b \omega e n , ~ u n d ~}$ fich unterbalten. Er lag da zwei Gtunden lang unb bing feinen B̉ebanten nad. (Fr twüte, in reldhe Gefabr er ging, und meinte, Daß ba niabt viel 2ub̄jicht twäre, Daß er mit bem Leben Dabon tam. (FB roar bie Gtimmung, Die zu 2lnfang bez Rrieges in allen war, bie in bie Gee gingen. Eie bachten alle, Englands ungebeure Slbermadt toürbe fie jerjhmettern, und fie roürben nicht mebr Erfolg baben, alz baß̧ aud bie englifdje Madbt fdwer bertwundet werben würbe. Slno nun ging er morgen auf einen tleinten Rabn, ber weiter łeine $W_{\text {affe }}$

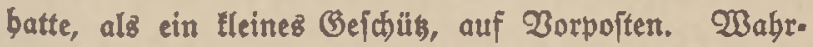
baftig, ba war nidbt biel Soffinung! Er wurbe wieder

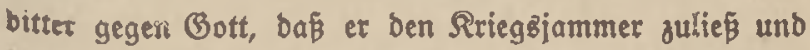
igir auf biejen Poiften gejtellt, und báp er nun roobl trub fterben müfie: roeg bom Leben, bas in fo fchöner Gonne uub Ruft bor ifm gelegen, weg bon Den Geinen! (Fin Rätfel twar Bott! (Ez war nich)t jo einfach, was er in Der Gchule gelernt hatte: Bott if bie Liebe! , Daßj ez alles einen gaten, rechten Ginn bat, babei roill id bleiben:, Dacbte et, aud im Iebten 2ugenblict, aud wenn id verfinie! aber Liebe? Serb und duntel!" 
... Go rătfelte et an bem Betraltigen, $b_{a} s$ ibn in feinen Gtrubel rí, und war traurig um fid und um feine Gltern und um bie ganze Menjwbeit.

Geinen Bruber Reimer ab er nidt wieber. (Fr erfubr erjt brei $\mathscr{B}$ ochen (päter ourd) einen Brief ber Mutter, $\delta a \tilde{B}$ es $i$ ijm geglüutt toäre, angenommen $\delta^{u}$ werben. Er batte gefagt, er ftamme aus einer uralten Sdifferfamilie; und ba batten fie ifhn genommen. Er boffte, auf ein Sorpedoboot zut tommen; denn bie, Gatte er gefdrieben, würben vorangeben, wenn es gegen Eng. land ginge.

Denn England, fo fagten fie alle, bie jungen und alten Freitwilligen, uno eben jo baz ganze Seer, wäre ber eigentlide Feino, nicht allein Teutfilands, fonbern Der ganzen Menfwheif.

In Der Jreiten Sälfte ber Nacht warf bie "Ulte Liebe" - Daż war ber Rame ifrez Bootz - von Lano und fubr nach Gdbilling Reede und feeträrtz, und erreichte um Mittag jübrejtlich pon Solgolano bie offene Eee. Finige Gtunben ipăter rief ber Gteuermann bon ber Brüde berab: "פlajbine... Iangjam!" Gie waren auf ibrem Poften. EB webte ein frifser Güb. meit- $\mathscr{W i n d}$. 


\section{Rapitel \\ Der Etropp}

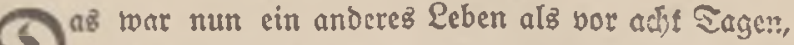
2 ba er auf ber "Qauenburg" "Bftlich von Selgoland in voller Fabrt nach Der Ellbmïnoung geftrebt batte! Nun fubren fie bier als Zorpoiten auf Gee ibren Sörn, 10 ungefäht zebn Meilen auf und $a b$, und biclten Wache, Tag und Nadht, Daf fie meldeten, toenn bie Engländer fämen, oder mit ibren 2llmächtigen. 3wei Mann itanden Tag

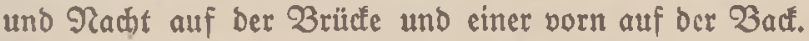
2ber in biejen erfen $W_{0}$ ohen wadjten fie fajt alle mit, von einer fकrectlichen Anrube wachgerufen, immer wieber geztrungen, mit brennenden 2lugen bas nabe und ferne Waffer abz̧ufuchen, babei immer und immer, die ganzen vierundzwanzig Gtunden des Tages und der Racht, ben fajt fichern Sob vor 2lugen. Denn es war ja ibrer aller Meinung, twie bie bon ganz Deutid)land und der ganzen 2Belt, und bor allem auch bie offen ausge. iprochene 26fïcht ber Engländer, baß̄ bie ungeheure englifche Flotte, alle beimlichen Liften voran, in bie Deutiche 2 utcht einbrechen toürbe. Slno bann waren fie die erften. Rein Nenfw, fein Gdhiff balf ibnen; und leiner rürbe ibrer an bem fd)rectlichen, großen Tag aud nur mit einem Wort erwähnen ober auch nur mit einem Ramen fie nennen! Es würbe furg heiß̈en: , Rachbem bie Borpoftenboote überrannt waren u[w., unb toeiter nichtoి! Gie meinten, ibr Wolten räre ber i hrerite, ber aller-

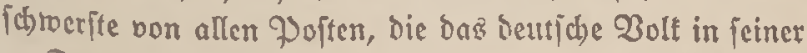
Frenffen, Die Britier. 
graufigen Rot mun zu beffellen hatte! 2th, Die Deutfhen follten nur fehu, trie fie bier in Den 20 ogen ber Porbjee berumgemorfen twïrden uno twie toeit Der Simmel und bie wilde Gee! Wic waren fie verlaffen! Wie raren fie cinjam! Gedisunojtwanzig Nann allein in ber 2 elt! (Ez trat nur gut, Dấ Deutfdhland an fie Dachte! $\Im a$, Das füblten fie alle beutlid, Daß Seutidhland an fie Dachte! Sa, ganz Deutichland [af nach ibnen! Gtand am Etrand, auf Den Dünen und Deiden! Slno in Soamburg auf ben शauern unb Säufern, und im ganzen (Deutf(). land auf ben Sibhen und Sebirgen! Slnd fab nach ibnen, unb twie ez ifnen ginge! Slno rounderte fich mit ihnen, Daß̧ Dic (Engländer immer noch) nid)t berangejagt tamen,

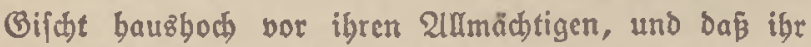
tleiner Rabn immer uno immer nod fhiwamm.

(Es war eigentlid) immer 2llarm, und bie Freiract)e flog nut io aus ben Sängematten und ben 2 rettertojen. Bei Tage twar eş bald ein Rauct) am Sorizont ... fie redcten ftundenlang barüber, ob es ein Rriegzichif fein lönnte ...; und fie achteten genau bararif, und frritten Darüber, ob bie einzelne Raucbfabne auf $\mathfrak{B}$ crbänbe bindeutete ober nidbt. Zald war eż ein Gdiff, Daş fic) ỉnren näberte, cin Deutjhes, bas Den Englänbern entging und bic Seimat erreicte. 21m fiebenten Sag, nachmittags, in fabuluten Eonnenglang twie in blanle Watte gebüllt, Lam eine fleine Dreimaftbar, cine breite Deutiche Flagge an Sct, auf fie zus. Die Brjagung, zebn ober elf Mann, ftanben alle an Dect, bie Sönbe in ben Sofentafjen, ftanden und jaben lange zu ibnen binuber, redeten miteinanber, und aben roieber nach 
ibnen binüber. Der Gteuermann fragte mit bem Megas phon binüber: "20ober?"

"Die Elabcth pon Samburg ... mit Solz yon Ranaba." Dann fragte ber Rapitän brüben reiter: "W3as in aller $23 e l t$ macht ibr benn auf bem \&ifa. Dampfer, Raptän?"

"Wir balten Wabe! Wißjt ibr Denn nichts vom Rrieg? Deutid)land im Rrieg mit England, Frantreid) uno Ruß̧tand!"

Der Rapitän brïben falug bie Sand gegen bie Gtirn, als bätte ihn ein Gdhlag mit ber 21țt getroffen, und ricf etwas, was fie nid)t verftanben. Geine Qeute aber ... e cz twar mertrürbig zu jegn ... ftanben jofort, in eirem 2lizgenblict, in zroei Saufen. Die Heinere Säffe blieb lofe ftebn, twie fie ftanb, einer bon ibnen, ein Narr, lachte laut auf; einige (prachen twild burch= einander. Die andere Sälfte aber, die gröbere, ftant erit flarr unb nicte nun langfan mit bem Ropf, wie

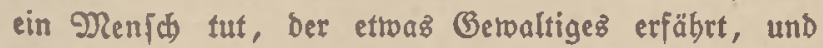
fofort und jogleict bie WBitlung trobl abnt, aber no(i) sicht enträtjeln fann. Das waren die Deutidjen. Das Gurpojtenbo ot brebte twieber ab und lief von ibnen fort. Aber fie faben nod lange zu ibnen binüber uno redeten von ibnen.

Der Sauptgedante und ibre Sauptiorge waten bie U. Boote. Eie batten fich in ben Ropf gejetst, da bie Engländer fie mit Sorpedo. und U. Booten aufz lürzeite erlebigen twürben uno bann, nadbem auf bieje Weife eine Rülie in bie Reibe gemadt, burdh bieje Rüde eine brecten sultrben. Allo ftanden fie wie bie Säger, die 
cine gropse tndo weite Gelomark mit einem Riefer nach irgendeinem $23 i t d$ obcr einer $2 B$ ilbipur abjuchen, uno fuchten mit ihren Gläpern bie ganze ungeheure Waflerfläche $a b$, jeoen Wellenberg, ber fich böber nlz bie übrigen zu er= beben fchien ... i i t ez ein Bontzrücten? ... jeben Dunklen Etrich, Der fich bcim Sinauf= und Sinabivogen jäbling bildete ... ift es cin Gebrobr? ... jeden Gijcht auf den Söben ... ift es ein Sarpedo? ...

$W_{\mathfrak{c} n n}$ es bämmerig wurbe und die Racht herantam, traren fie erit recht nichts alsె 2hıgen. Wenn Sarm Ott ơltweilen, wonn er nicht fiblafen tonnte, in Der Nacht berauffam, fah er immer basfelbe Bild - und baz wiro einz ber Bilocr fein, die er nie bergeffen miro

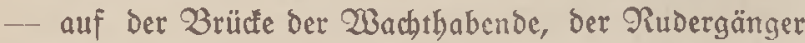
neben ifm, vorn im Ninntel ber Slużgut, baż Doppelglaz auf ber Butut, und bier uno ba an ber Reling einer oder ber andre, Den bie Erregung, die Errwartung, die Slnmbe nicht johlafen ließ̧, und rund um baz lleine babin= ziehende Ding bas ungeheure rogende Meer in ber Gommernacht, bald im Grernenjuein, balo unter wolten= verbangenem Situmel, buntel und farblos. Einmal fand er um Ditternad)t, alz auch er berauffam, die balbe Žcjałung oben; und ez war nichtz tweiter zu fehn, alz

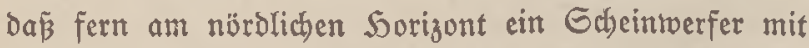
langlamem ungebeuten (Bleifen baş weite raujd)ende Pleer beitrich. 3twei Gtunden ftanden fie ba in ber graus blauen Nad)t und ftarrten bintiber, und bann vieder biet und ba bin auf jede Gtelle bez unendlidben Gefichtzs.

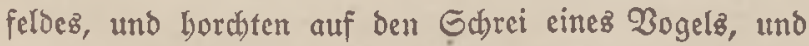

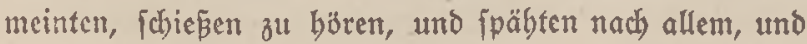




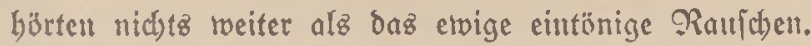
Smmer, Sag unt Nacht, waren fie gerwärtig, ja fajt

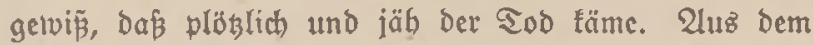
Deer wärbe er plöglich auftaud)en, uno fie zerfanmettern uno in bie Siefe reiß̄en.

Das ervige 2ufpaffen uno 2uffordhen erregte fie, da fie ja fajt alle ans einem ftiflen und langiamen Lande uno Qeben famen und 3 rïber von Regent und 2 Bind, Gonne unb $\mathfrak{W}$ ogen waren, bie nach igrem 23 ejen langfam fino. Slno fie wurben alle mager und bobläugig, und einige rourben unrubig. Dazu litten viele unter ber Gees frantheit. Daż Hleine Ding von $\mathfrak{B}$ oot war ja beftändig in trilder $\mathfrak{B}$ elvegung, bie nodh Dazu immer veriditeden swar, benn fie fubren bald mit dem Wind und ben 23ellen, balo, indem fie tebrtmachten, dagegen an. Dehr alz einer brach fich fajt bie Geele auz dem Reibe. 3wei von ibnen mubten daz Gaiff verlafien, da fic böllig entträftet traren.

Wenn fie einige Sage fo verbracht batten, fam bic Ublöjung, und fie fubren nach Wilfhelmsbaven und Foblten ... Tachmittagß gab ez dann Lattourlaub. Dann machten fic fid fidmud, rafierten fich, zogen ibr Gountagsjeug an und wanderten burch Dic Grraß̄en ber

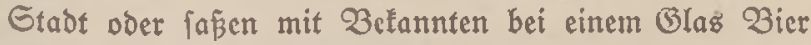
oder liefen ins నino, und jebnten fich nach Sauje. 2un Dritten Sag fubren fie bann twieder binaus auf ibren Dojten.

Das $\mathfrak{B e r b a ̈ l t n i s ~ u n t e r ~ b e n ~ R a m e r a b e n ~ t o a r ~ g u t . ~}$ In ben erften Wodben waren bie Bemïter fo erregt,

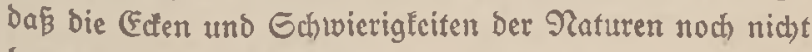
bervortraten. Man ipradh vom Nargen bis zum 2bent 


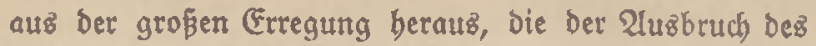
Rrieges in jebes Serz getworfen batte, immer über bie= felben Dinge: Daß England fauld wäre an biefem Rrieg, unb warum in aller $23 e l t$ fie nidbt tämen! Gie batten bow fo unjagbar gebishnt uno geprablt! Ino Dann bie ßegebenbeiten an ben Ranbfronten! Rüttid. . . . toeld nunberbare S̈berrajdung! Welch auffliegender Subel! Unfere Seerfübrer baben einen Plan, und cinen gewaltigen, einen ftürmenden! Ulno bann Sannenberg! Und Dann Untwerpen! Fz twar tlar ... ja, foviel war flar: man batte ba oben rabrbaftig ben Ropf nidjt verloren, trog bes plisgliden und ungebeuerlid)en Überfalls! Nein, man war ba oben febr flar! Man fübrte bie getwaltigen

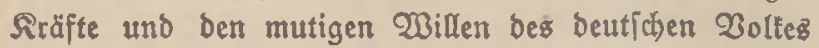
auf Den rect)ten 2 eg! Silber bieje gropen Dinge fpractien fie vom Morgen bisz zum 2lbent.

Uber allmäblich, to in ber fünften $23 \circ d)$... als die Engländer immer nod nidt famen. und Gtunde io an Etunbe fí reibte, unb bas Boot immer nod nictjt

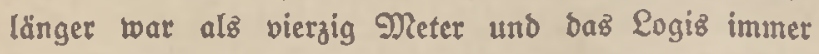
nod ber fleine fdumale Sijdtaften, und bie Freitracte immer nod nidht grober als feds Nann, ba tam auds bas zutage, waš jeber zu Sauje zuriidgelaffen batte. Banz foübtern erfit und langlam fhoben fich die tleinen, müb= famen Dinge deş einzelnen ftärler grwijhen bie groß̄en,

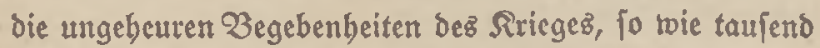
fleine Rrabben neben einem Walfif dabintreiben, immer in Befabr, alle miteinander, in einem 3uge, von ibm veridbludt zu werden. Scoer hatte jeinten tleinen, aber runden Sicis von Dingen, die ibin gehörten, zu Denen jeine Gecle 
tmmer wieber aurïdlebrte, twenn fie bon Glanbern obet

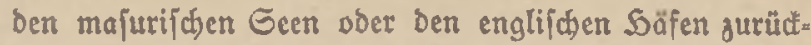
famen ... bie fie mit ganzer Gecle immer bieber burd)= lebten. Nlancher batte viel Gutez zu etzäblen, jebr viel: er (prach) won einem lieben, orbentlichen Intreicn, voll Lobesె von einem Weibe ... "io recht ein Ramerao, weipt bu!" ... bon netten, gejunden Rindern, und $80 \mathrm{~g}$ mit vielen Slmitänden ein 3 illodben aus ber Brujttajche Der Sadfe, bolte fich Sammer und Tägel und folug es

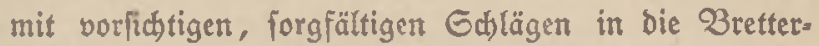
wand über ber Roje, tno eräblte von fhönen Lebensa plänen und litt bis zur Zerzweiflung unter den Qualen:

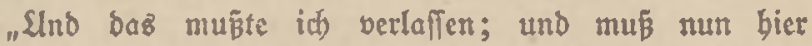
am Sor bes Sobcz Wache ftén! " aber andre batten mebr non Gorgen zu erzäblen. 2lch, einige von uner= träglichen Gorgen! 24h, twenn Der Sirieg ibre eingige Rot getwejen wäre! Wie furdbtbat war ber Rrieg!

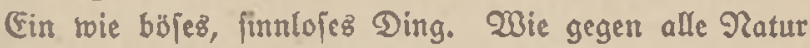
und wie gegen alle Bernunft! 2ber ber Rrieg, fo febr er fie bier brauken auf ber Norbjee in feinen Slauen batte, er war boch nicht bic größte Not! Der eine batte fकtwere Gdulben, ber anbre ein idweres Betwilien, Der britte ein tranfes Rinbden und ber vierte ein (क)lechtez Weib. Slno bieje lekten maren, bejonders unter vier 2lugen, bie Redieligften. Sie wurben all: mäblich eine Not, eine Bebrüdung. Mit ben meifiten bon biefen batten fie Mitleib, faßen neben ihnen auf ber Eectif̧te, ober liepen fie bei Der 2lrbeif neben fich ftebn uno börten alleż rubig an uno gaben verițänoniz. bolle 21ntroort, bie biejen beorücten Serzen wobl gut 
fun fonte. 2lber einem, ber immerfort über feine Frau klagte, daßj fie fo gar nid)t wirtid)aftlich toäre, daß́ fie ifn wohl aud) mit einem andern betrüge, fagte der Slnteroffizier Sagedorn, ber immer etwas furz, factlich und geradcaus war, ba er er ju weit ginge; er jöge fie ja aus yor ihren 2lugen; bas müffe er nictt fun. Da id)roieg er traurig. Fin andrer, ein Seizer aus ber Begeno bon Emoen, langweilte fie Damit, Daß er in einer wunterlid ftarren und fiteren Weife immer wieder erroog und erorterte, two robl biejer und jener feiner Dorfgenolien infolge ber Nobilmad)ung bingeraten fein tönnte. (Er failderte jeden einzelnen nad) Wejen, Sauz und Gamilie genau und wie bie Nobilmachung grade auf feine Geele getwirtt baben modbte, und trieb bieie (5r=

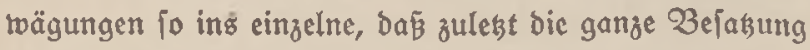
jeben einzelnen jeiner Dorfgenofien genau tannte. 2udh biefer ging ibnen za weit und fie mubten igm fagen, er tönne nicht verlangen, Daß fie alle für fein Dorf Dabjelbe Intereffe bätten roie er; er müffe ez bei feinen vier

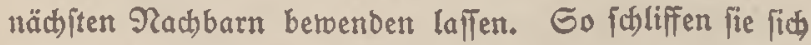
aneinander $\mathfrak{a b}$ und waren und blieben ein Soerz und eine Geele, alle eins in bem Gefübl, barüber fie aber weiter tein Wort jagten, Daß fie bier ehrlid ibren Nann itteben unઠ ausbalten, uno den Engländer erwarten follten,

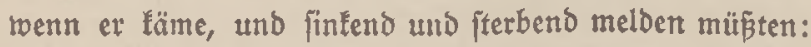
"शun fommen fie! . . . nun fommen fie! . . nun twach, Selgoland! nun toad), Deutichlands Glotte! Pun, Deutich= land, fei auf beiner Sut!" Denn bas twar ifyrer aller Blaube: Der ba über bie $\mathfrak{O}$ ogen beran anfam, Der roollte fie an Bolf und Baterland, Ebre, Recht und Figentum 


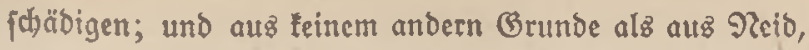
Geiz und Gier.

Im Laufe dez Oftobers wurben fie etraz fić)erer, Da fie trog Englanos ungebeurer Flotten, U. Booten uno Sinen immer nod fdrammen uno lebten. Sie mutben ein wenig munterer und freier. Die Epan= nung lisfe fich. Gie batten einen guten Sarmonifa= fpieler an Bord, einen furzen, grob́töpfigen Wommer, ber in Den erjen vier Wochen ichloeigiam und bumpf unter ibnent bingelebt batte, fo als fönte er nicht fprecten uno noch reniger lachen. Dant ftellte ez (iic) aber beraus, Dá̧ ibm tur ber Rrieg und baz frembe Qeben und bie fremben Menjuen aufz Serz geitopien waren, fo da meint batte, im Rriege madje man feine Mufit, uno

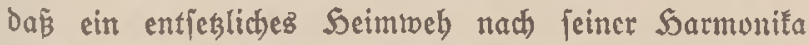
und überhaupt nach ber Mufik ibn beinabe um den

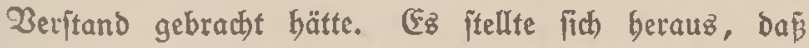
er, oblowhl er wenig von ber Welt gejebn, fondern fein ganzez Leben - et war nicht mebr jung - ba an feiner ftillen Rülte zugebradt batte, alle Bolfz= uno Geemannstieder fannte, von benen, die flingen wie ber

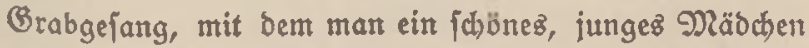

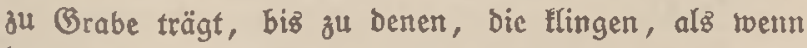

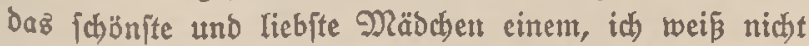
twas, verjpridtt. WBenn er auf feiner Rifte vor feiner Roje jaß uno, leidt fich wiegent, bie balbgeidjlofienen 2lugen vor fich auf bem Boden, jpielte, waren fie alle obne Betwegung uno Gedanten. Go fhberfällig fie alle an Geele waren und obgleich fie alle die gropen, 
falweren Sranftiefel anbatten, tortben fie bow aufgeboben, tnd fiswangen fich fanft und ichis, je nadoem, toas er ipielte, balb fröblid) uno munter, bald tieftraurig, ja fo traurig twie ein Brab, in Dem eine Soluter mit ibrem Rindchen liegt, und glitten zulegt janft wieder zur Eroe, twenn et aufbörte. Er jpielte alles, waz fie ifm leife und unjicher borjangen. Gelbit bas Licb, Das Der Dicte, iheue Wejtpreuße im Soerzen trug, bas ex aber nidft fingen fonnte, ba er feinen Son in ber Reble batte, enträticlte er. Er nabm ibn eincz Norgens, oa er beim Dectidyeuern war, binter dem Gchurnftein beifeite und lié $e^{3}$ fîh von anbetten, und ben Satt, ben er auf leine Weife ber. außbringen fonnte, Durch Galäge mit ber Pfeife gegen den Gdyornftein marfieren. 21m andern Tag fpielte er cB ibm vor, nachbem er vorher, twie immer, gejagt batte, was er fpielen twürbe: Seoje’z Lieblingslieo!' Oie bjöten twie immer, andädtig zu, Der $\mathfrak{B}_{e}$ ftpreuße überrof por Gdjam, Freube und $2 \mathfrak{l n g}$ f und was man fonjt in foldjen Lugenbliden empfindet; unb er war Durd und burd glüllich, als fie es lobten uno jagten: "Wrirllich, Tebje ... Das ift trabr, das ift ein gutez Lieb!"

Sa, dicfer Mrann mit feiner Sarmonila twar ifnen unendid biel wert! $\Im a$, man tonnte rubig bon ibm behaupten, Daj er bem hagern und binterfinnigen Weter Gobt von $B u ̈ j u m$ bas Leben gerettet babe. EB tat ibmen alfen leib, Dá̧ Der Gteuermann ihm das Gijhen verbot, roozu er unjagbare Lujt batte. Aber ber Gteuermann fagte, eв̉ gehöre nicht zu einem Rriegs[chiff, Dấ man ein Gchlepp= nes binterberziche, uno wenn $\mathfrak{e r}$ esె noch cinmal fälye, 
roctbe et bas Ding tappen. So ftand et benn in ber

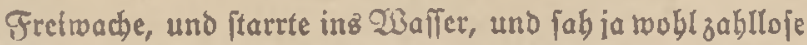
Gijace, und biß an feiner Pfeife und jann, weiß (Bott twas für ve'ztreifelte Dinge. Went cr aber Plufif börte,

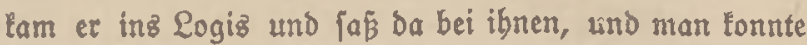
febn, wie fein (Befid)t fich lojte uno ber Blang feiner 2 ugen, ber bart und fdbarf getwejen war, fich milderte. Sa, biejer bicle, gropltoppige Pommer mit feiner Sormonifa, ber fonit eigentlich roenig bebeutete, war roirtlich unbezablbar!

reben ifm fam lein anberer in Frage. (Fs war ba freilid) nods einer, ber ignen viel Freube mad)te, aber träbrend fie fid flar betwust roaren, Daß fie Dem Dufiter bantbar fein müteten, und jeine Sarmonita, toenn fie in ibre Päbye tamen, wie ein fleines Rino arjaben und vorilatig anfapten, batten fie gegen ben fommeriprolifigen Selegraphiften nicht bas geringite Be= füb/ bez Dankez, obgleich Der Kleine Denfकh mit jeinem turgen, roten Epigbart jeben 2beno etroas angugeben wußfte, trorüber fie mit lautem Qärmen Iachen mub̆ten. (Er batte jeine Rinobeit alz Gobn cines beutityen Siell= ners in Fiotterbam verbracht unb abmte ben bicfen Wirt aus ber Wiffemstabe nach, bei bem er in fdhlimmen, jungen Sabren Licblind getwejen tvar, mit all feinen Gebärben, mit ber balbbeutichen Gpradje und mit ben fetten und fidjeren 21nfid)ten, bie bicier Eেyrenmann gebabt batte; aber fie chrten ibn barmm nicht, wie fie ben Dufifer ebrten. Der Rünftler ift ber Nenicjen Freude uno शrotwendigfeit; Der Rritifer nur igre bittre Rotwendigleit.

Uuch) Sarm Otf bedeutete nidjtg 3 ejonderes unter 
ibnen, fabon toeil et eitter ber Süngften toar. Da fie aber mertten, dá⿱㇒㠯 er mebr gelernt batte als fie und mebr nact)= gedact)t, und eine aufred)te, vornebme Natur abnten, und er fich in feinem Gtüct über fie erbob, bebandelten fie ibn miteiner Ant leifen 2 latung. (Fr aber füblte fich wobl unter ibnen;

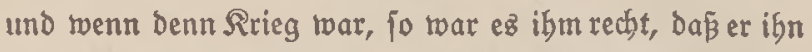
10 verbringen muste, bier auf ber WBacht gegen Eng= land, unter bielen julichten, wactern Gejellen. Gdlimm

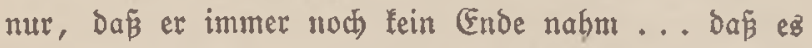
nun Winter murde, und ber Rrieg nun fhon bald ein balbes \abr Dauerte, und daß fie fo gar nichtz erlebten! Nein ... rein gar nichts! Wुar Rrieg in Deutichland? Эa, im ganzen (Europa? ... Eie merften nichtz davon! 2lm Weibnachtżabend bingen vier (Bänje, bie fie Durch ben Slnteroffizier Deter Sagedorn batten bejorgen laffen, an einer Reine, bie vom Mait nach dem Etcren fübrte, im Winbe. Sie modten Peter Sagedorn fonft eigentlich) nid)t gern, tweil er to waz Snfreundida ez, Buffigez batte und jeine Worte beraus̄tię, als renu er ihnen fahon gram raar, ebe er fie gefagt batte; aber cr batte eine lleine Fifflyandlung in Lltona und war ber roeltgetwanosfe unter ibnen, und toar, toas in biefem Fall auch in Betracht tam, eine burch und burch) ebrliche Saut; und batte bann auch) einen guten Sandel zultande ge= bracht. Den PReujabrzabent verbrachten fie bei Punich uno \afeten von zu Saufe in groper (Bemütlichteit. Slno als ber Zergnügtefte und Redjeligfte unter ihnen, Der Samburger Ewerfübrer, fthon Nitte ber Dreißig, eine Rede bielt und, won feinen WBorten now hinge= rifīen, die ar Dem großjen Waterland getviomet hatte, 
auf bie Gefellfhaft im Qogis ber "2llten Qiebe" überging und behauptete, Daßz ibre Rru bie befte raäre, nicht allein auf ber 9 lorbjee, fonbern itberbaupt auf ber ganzen WBelt .... "foweit Winde welyn und Eterne fdeinen" ... nictten fie ibm alle zu uno gaben ibm völig recht. Am erften $\mathfrak{S a g}$ im neuen $\Im a b r$ fubren fie roieder twie jeben vierten Tag zur 2blöung nach W3ilbelmşbaven. Sebesinal, wenn Sarm Ott nad) Wilbelmsbaben fam ... es waren nun jhon viele Rale... war jein erjer (Gang nad) Der Rajerne, jeinen Bruber Reimer zu fefrn. Er traf ibn immer guter Dinge. Er lobte allcz, twas ex jab uno bjorte: wie fie alle freundich) und nett rären, Sffiziere roie Xannldhaften, uno wie fie fich alle bemübten, bas Pätige müglidb) tafd zu er= lernen, um möglichit balo nach Flandern an bie Front ober aufz Ghiff zu fommen. 2lz er vier Wobhen da war, crzäblte er, Daß cr jđjon ziwei Gleichgenofien ge= troffen bätte: einen Lehrers̄john aus Seffen und einen Raufmann auz Soanburg. Gie fitimmten in allem über. ein und er roäre fict)er, $\mathrm{D} \alpha \tilde{\beta}$ er in biejen beiben für alle Rebenzzeit treue Freunde gefunden bätte.

Slngefäbr vier Wocten ppäter, alz er bie Rajerne verlaffen und auf ein Sorpeboboot getommen war, war er in grofer 2lufregung. Nit ftrablenden 2ugen erzäblte

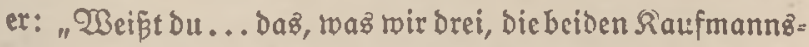
finder und $i \pitchfork$, da an Deich neben Gdhäfer Sarbers

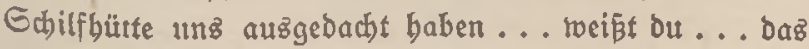
über Gott, Bolf und 3utunft: Das haben fhon viele $\ldots$ andre junge Qeute, roobl hunderttaujeno in Deutichland, fich ausgebaht! (58 gibt ifjon viele Bereine burch) 
gang Deuffchland ... befonders die 23andervögel ... bie diefen boben, reinen und feinen Blauben baben... tocipit Du: Daz von Bott, ... Dapi er mebr in Der शatur

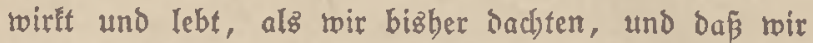
melyr auf Natur felnn und pon ibr lermen müflen, fo mie (Goetbe ez aud gemact)t und in peiner Sugeno befannt bat ... und daß wir forgen müfien, daßj unjer ganzez

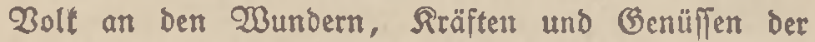
Ratur teilbaben foll! Und fie find aud) gand mit meiner bejondern 21nficht einberftanden ... exinnerit bu bich? ... Daß man ben Rindergeift unterjuchen muf̧, mit be"

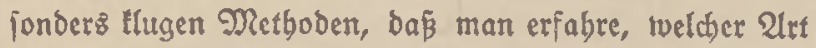
grade bieje lleine Pflange ift und fie in ben richtigen Boben fest und richtig vertrendet. Wenn ber Rrieg 3u Ende ift... im näd)iten Frübjabr ..., roill ich jo: fort einen fold)en $\mathfrak{Y e r e i n}$ gründen! Wer reiß ...

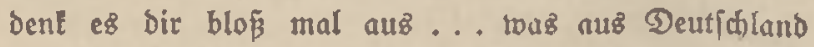
noch cinmal werden wird, wenn wir, biefe bunberttaujend, nachyer älter geworben find und alfes durchiesen tönnen, was wir uns ausgebacht baben!" Eo fagte er mit ftrablenden 2ugen und lief inz Pogiz und bolte ben jungent Samburger unb ben Lebrerşโohn, Damit fein Bruber fie tennen iernte. Slnb fie gingen zujammen Durch ben frijd)en Serbjtwins; und ex bỉrte ftill an, waz bie jungen Propbeten jagten, bie fich wor bem 3immergefellen nicht genicrten, da fie ibm an $W_{i f f e n}$ überlegen twaren.

Dunach, wenn bieje gropenen Dinge genug beredet waren, fam ex auf bas (Elternl)aus zu fprecben; uno bann wurbe feine Gtimme fachter und unficher. $O b$ robl die Mutter ben Ropf immer tapfer oben bieltl? "2luf 
Die Piutter tommt ez an, Sarm, bie bält Den gangen Rram zulammen! Die foll es mad)en! (Eggert hat aljo immer nod) nicht gefdrtieben! Was meinft bu?

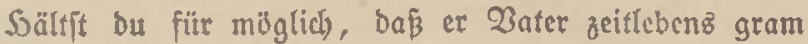
bleibt uno nie roicberfoumt? Sarm, ez fann ja nidjt fein! Denl nur ... Der Rrieg! Wie er wobl an uns benft! Er Dentt Tag uns शacht an uns!" 3 uweilen fing er an - Der 2ldstzebnjäbrige lebnte fich jehr nach Sauje - auszumalen, tons grabe in biejer Gtunde im Saufe vor fíh ginge: Bater tut biez und Daz, und शutter bies und $D_{a z} \ldots$; und fie firitten fitc Darum. Slno Rcimer rubte nidht, bizer recht bebalten batte. Denn ex twat ein Fiferer twie jeine Nutter. Wber Fifern unb Redithaben gebört ja aud gu einem guten Propbeten. Im Legten Brief ber Nutter war binter Stüben, Rälbern und Nildbeimern und ben blonden Röpfen ber tleinen $\mathfrak{B} e=$

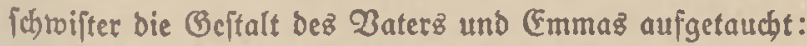
„ Эc) und (Fmma find jebr gut mit igm; aber to as bilft e8? ... (E) glaubt $j a$ immer nod), daß $\mathrm{B}$ er ein verlorenes und verDorbencs Sind bat; und das ift Das entfeglichfte auf Erden.

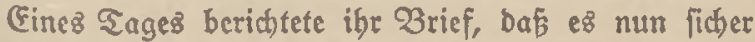
twäre, Daß ber Berlobte bon Lizbeth \$bomlen gefallen roäre. Er wäre in ber Marnejhlacht geblieben, unter ben biclen Saufenden.

Soarm Ott vernabm es und toar traurig ibretrocgen. 2(n fich jelbit Duchte er nidjt. (ES war ihm jo, als toenn fie jenem, bem fie im Leben gebört, auth nad bem Sobe nocb angebiorte.

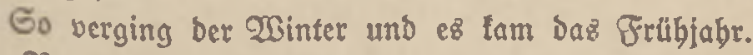
D) 3rüber an Qano tämpften bei Digmuiben ... o, 
die Sungen, tapfern, tobesmutigen! und in Gturn und Gchnectweben in Majuren ... o, dic treuen Pämner, manche fabon in grauen Saar, bis an bie Rnöd)el im Gdinee, ftöbnend unter ber Laft Der Tornifter! Sund bie Brüber zur Gee fhlugen fich an Der SRülte Gübamerifas und in ber Norojee; fie gingen Der englifhen S̈bermacht gegen bie 3äbne, uno rourben zermalmt und ftarben. (Dentichland bielt ber getwaltigen S̈lbermad)t noch immer ftand! Deutichland ftand feft! Sa, Deutjoland fiegte! Эa, ez fiegte! 2aber fonnte nicht durchftegen! Wie lange foll Der Rrieg noch Dauern? WBic lange follten fie noch bier in ber Pordjec bin und berjhauteln, und auf bie engliichen 214mächtigen twarten uno auf Den Sod?

211mmäblid), ba baz Leben Wodhe auf 230 dee, Nonat auf Dlonat fo tweiter ging, ben ganzen Winter bin: burch, bildeten fich), obrwobl fie alle untereinander gute Rameraben blieben, fo zwei, brei Saufen unter ibnen. Die Seizer waren fowiejo mebr für fich. 2lber auct) Die übrigen teilten fich etwaz, nicht in ber Ramerad= ichaft, nicht in ber Sreuc, aber im Serfehr, im ver= trauten Slmgange. Slno bie $\mathbf{B a f f b o r b w a t h e ~ u n t e r ~ i h r e n ~}$ Säuptlingen, Dem Sluteroffizier Peter Sageoorn uno 5arm Ott, zut Dem ber Fifher Gäht, ber lleine, Dunfle Weftpreúze, Der Sräumer, uno Der Dommer, ber Mufiffant, gebörten, Dazu noch der Rübecfer uno Der (Frorfübrer und Peter Simblen, ber Sagelöbner, bielten am treuften zulammen. 


\section{Rapitel \\ () ex: $\Re a r i$}

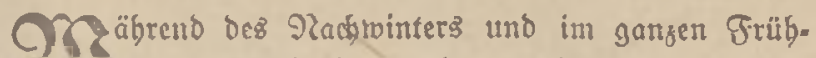

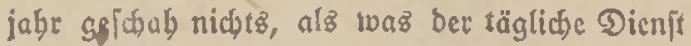
bratite. Drei Tage lang ber Gtropp auf unb ab, in frifdyen, bellem Ditrind, in ftürzendem Regen, in cifigem Edhreemind, in twütendem Gturm ... Ö $\mathfrak{l}_{3}$ eug und Ecejtiefeln biz liber bie Süften, 20 ge über 2̧oge über Dect... und bie Iangen 2lbenbe bei Rarten= ipiel, Gejang unb Erzäblungen uno Slnterbaltung ïber ben Sirieg! Sa, ber Sirieg! Der Ruffe war ja nun auf ber ganzen Linie im Riuckug. 2lber wie lange lonnte man now binter ibm berlaufen, bis̄ man iḅ in die Enge belam!? Man lonnte bod nicht binter ifm berlaufen, biz man ifn gegen ben Slral prellen fonnte?! Uno im $2 B e f t e n$ ftano die Front bie cine Eteinmauter uno wollte nid)t wortwärtz. Sino Stalien batte Den Sirieg erllär!! 2ber trobsom war alfgemein bie Neimung unb

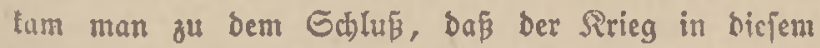
Gommer zu Ende geben twürbe. Sidjer! Sn biefun Gommer nod)! Wabricheinlich in 2lugujt! Denn Dann batte er ein ganzes langes $9 a b r$ gedauert, unb länger als ein Satr lang tonnte er nicht bauern!

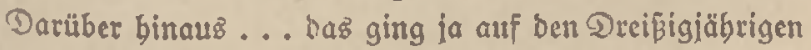
Rricg โos!

Cinmal, um Nitte Nai berum, gab eह̉ cine flcine 26twedilung: fie retfeter ein Flugjerg aus Ecenot. (9) batte ben Sag über gebriefelt uno twar gegen 2benb billig mushelig geworben unb the fprachen bavon, sab

Everiffen, Die ßrüber. 
es Gdinnee geben Hounte. Slno ber Büjumer, ber wieber trüb/innig war, fagte: "Warum nicht Gdhnee im Nai? Sft Die ganje Nenjabeit verrïdt, warum folf bie Natur

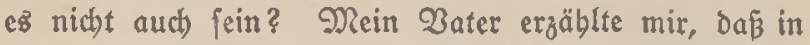
cinem verrüdten $3 a b r$ feine Sub - er batte nur bie eine - einmal an cinem bellen Morgen, to Ende Nai, bis zu ben Rnien im Edynee geftanoen bat." Die Eid)t, bie tagelang febr gut gerwejen war, ging faft ganz verloren; fie faben feine vier Ediffalängen mebr. Begen 2lbend wurbe in Rorbweften geidoflen und pie fubren vorfintig in biefe Richtung. Sie bielten alles Dentbare für möglich und waren auf bas Gurd)t= barfte gefapit. Seber ftand auf feinem Dojten. Dann fichrien fie alle plistlich auf: fie faben teine zroeibundert Meter vor fid) einen merfivürdigen (Begenftand auf dem

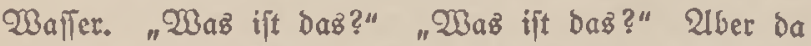
ertannten fie es pröblic). "Ein Flugzeug!" "Eint Flug* zeug! " Gie twaren auß̉er fī por Intereffe und Gpannung uno Silfsbereitfchaft. WBie mertrütroig ez auf bem Wafler

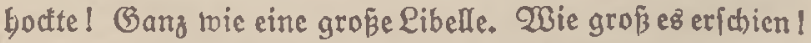
Wie ez von Wind und Wellen bin und ber geftoken rourbe! Ter cine bet beiben $G$ drwimmläpten trar zerbrod)en uno fo bing ber $\mathscr{B}$ ogel idjief, uno bas falte 2 affer fwlug über bie beiben jungen Xienfwen toeg, die aufrecht in bem Heinen Raum ftanden. (Fr rourbe ibnen nicjt gleich flar, ob Deutiche ober Engländer raren; ja fie glaubten wobl untwilltürlich, baß es (Englänoer twären, weil fie es in Norbmeften fonden. 2lber Das trar ja vorläufig ganz gleid)gültig; es waren $M \mathrm{Nen}$. ichen in Not; und fie überitürbten fich, Saue und Fangs 
Ieinen zu balten. Gleich Darauf faben fie bie Eifernen Sircuze an ben frügeln. Gie marfen cine Reine bits tiber uno fogen fie Dann zu fidh beran tmo brad)ten Die beiden Qcute an Tect. Ez raten zrwei blutjunge Rerle, ganz in Leder, Sandtücher um Den Salz, todblab vor Rälte; der cine, Der Fübrer, fonnte fich nid)t mebr in ben Rnicn balten uno war robl nicht gang mebr bei Ginnen. Nit legter Rraft verjuchte er, fich auf= red)tzuljalten und etwas rie eine Meloung zu maden, in Dem mirren Glauben, er ftände vor einem Gbef. Er fagte: "Notordefeft, muß̈te 'runter... Dann im W3afier ber linfle Raften zerbroci)en." Der Eteuermann licß ibn austreben, fafite ifn bann aber an und zog ifyn unter Deff. Injtwifhen war Das शadjbarboot herangetommen und machte fich Daran, das Flugzeug zit Kergen. 2ltz Der zweite ber Flieger, Der now oben raar, $\mathrm{D} a z$ jab, lief er zu jeinem Fübrer in Dic Rajüte, ber jogleith erjhien, obglcich or taum ftebn fonnte. Eie fagten, fie roolten bei ibrer Najdine bleiben. Da bractsen fie bie beiben nach Dem andern $\mathfrak{B o o t}$ hinüber.

Das rar ein gropez (Erlebniz getwejen. Sie jprad)en

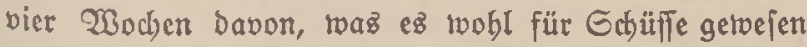
toären, bie fie gebart batten, uno auf bie fie losgefabren toaren. ob da irgendwelche bibbere Nacht bie Sand im Spicl gebabt bätte. Slnd fic erzäblten (Befdidjten von wunder: baren $\mathfrak{B}$ egebenteifen. Slno ber Ewerfübrer, Der eine febr toumberbare (Geibichte von einer Sotenmarnung erzäblte, Die man ifm nidjt redst glauben fonnte, idjricb loegen

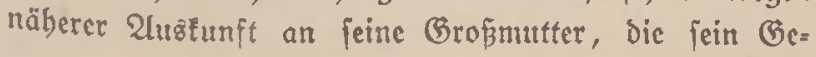




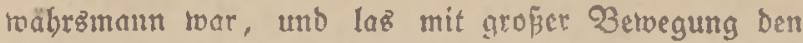
Zrief vor, in bem fie Durchaus beftätigte, was er erzäblt batte; und er feicrte cincn groken Triumph.

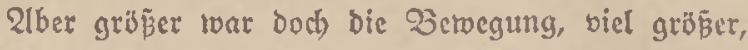
als num Sarm Ott, Der über einem 3ant शaturfunie

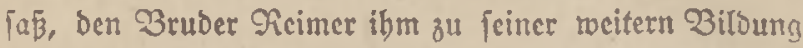
gegeben hatte, Die Bejchichte vom Pfeifer erjäblte! (Er hatte ben Rameraden bisber wenig ober nichts oon zu Sau[c erzäblt. Gie wußsten weiter nichtz von ifyn als Gtand und Saus, und viele Geffinijter, und dic eine Gdhivefter fräntlich, uno feinen ßeruf. Er twar ju fueu und zu ftoly, ihnen mit feinen Gorgen zu tnmmen, mit biefer $3 e g e b e n b e i t$ vom Pfeifer oder gar mit Dem Rummer um Die Liebife. Q⿹er frun trug er cz boch oor! Ez paffe ja fo genau in bie Sunterbaltung! Es twar ibm auch eine (Erleid)terung, endidl) cinmal mit andern Men[C)en über bas zu reden, twas ihn immer betwegte. 2lijo beridhtete er bon bem rätjelbaften Pfiff, bon ben Sausgenoflen und Sachbarn, unb von Den beiden Berdädbtigten: Eggert und Dem Rnedjt, und von Dem Gshictial Gggertz und ber Gdhtwefter, und Der

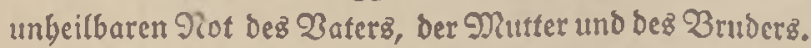

Wer fonnte ba cinen $\mathfrak{B e g}_{\mathrm{e}}$ finden?! Eie lourben

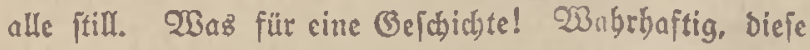
(Sejdichte twar ilynen eime 3eitlang cbenjo widhtig, cbenfo bebeutend, ja fie twar ibnen bebeufender alz ber Serieg! Welch ein tounderlid)ez Rätjel! Welch cine Wetwitrung! 2Beld) eine Not! Sie fprachen immer wiever bavon; und to $50 \mathrm{rm}$ Ott fiand, traten - fie an thn beran unb fragten ibn nach biefem und jenem und gaben 
$16 \mathrm{~m}$ irgendeinen Rot. Det eine meints, er folfs eine Bctamntmaking binter bem Menjaen, Dem Rnecht, berlaffen, vielleicht, baí er Tieue empland uno betannte; uno einige entwarfen den ₹Bortlaut Der 21nzeige, wie

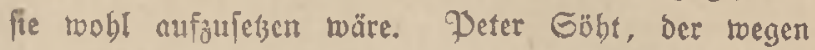

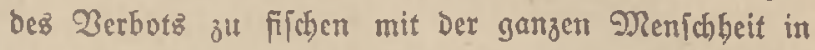
beimlichenr Streit lag, fólug mit berbem (Geficht por, ez follte ein Bcheimpolizift in 2rbeit gejert toerden; uno er verjenlte Fich aufz tieffe in Diefe 2ufgabe, fo

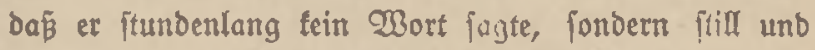
unbetweglich bajaß́, mit 2lugen, wie ein Suno vor cinen Maufclod. Der tleime Dumlle Weftpreupe aber baçte Darüber nact), mie es zu madjen fei, oaj biejer (Fggert Ott wieder mit jeinem Sater auzgejobnt whitre. Ob er unfer Ded im Logis faf, ober ob er auf Ded facuerte, puste oder TBade ftano: immer fann er Darüber nach.

Uber fohliçlid) batten fie die (Bejhichte zu Ende gerebct. Nachbem .5arm Ott unzäblige Nale, erfit im aLgemeinen, und banm nod) jebem einzelnen bie Gathe batte erzäblen müffen uno ben Priff unzäblige Male Gatte bormachen mülifen, uno biejer Eggert Ott, ben feiner je gejeln batte, bic berübmfefte Perjünlidhfeit an Boro getworbent war, ließ̄ bie 2ufregung über ign nach,

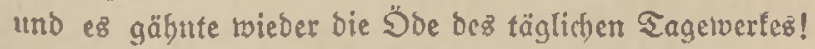
Ein Iabr faft fubren fie nun fo ... auf und ab ... auf und $a b !$ Wenn boch etwas geịjäbe!? Jrgenb etroas! 2umäblich märe es ihnen reci)t uno rillfommen

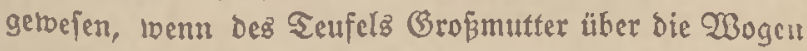
gefommen träre, um einen 2lbeno lang mif ibnen Rarten zu fpielen, obgleid) fie, wie ber Pommer fagte, 
io ficher wie waz, all ibr Beld babei zufeken twüroct. Ober wenn die Engländer grade bei ihnen borgeîtopen twären! Wer fonnte es wifīen?! Wielfeict)t bargen fie Doch Das Leben! 2luf irgendeine WBcije ... obgleich

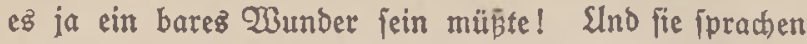
Dabon und fabn fich fdjon im Glottenbericht: "Esz war Daz ßorpoftenboot "Zlte Riebe", Das die erjte Meldung brachte. Das tleine $200 t$ ujw. ..." Gie japen lange ftumm und malten fich ben (Bebanten aus. Der fleine Duntle Weftpreupe lächelte glütflich verjonnen vor fich Gin, indem er bachte, wie jeine Trau ibn anjeben toürbe, toenn er jo wiedertäme. Der bagere und trübjelige Gibgt, Der Gildier, Dacbte an eine Feftlidłteit, eine üppige $\mathfrak{B} \varepsilon=$ toirtung und tat im Beift einen gropen Gchluct; und ber Erwerfübrer ftand im Beift vor Raijer $23 i l b e l m$ und ftano Rede und 21ntwort, und griff nad dem Rragen, ob cr

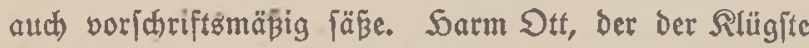
von ibnen twar und bie beịten 2lugen batte, fab ez und lächelte.

Eo verging Der Sommer uno ber Soerbit fam beran und brad)te die erften Etürme. Uno da gab eв roieder ein Crlebniz, und zwar einz, daż dann cine grobe Gache für fie twurbe.

So gegen Rachmittag war ez biefiges Wetter ge* worden, unt es war Gturm gemeldet: won Solgoland, Windftärte 10, won 21mrum 9. Sarm Ott ftand in

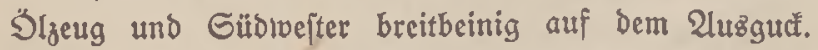
Gie fubren fteif gegen Den Norotweft an, ber zutweilen abflaute, Dann plumpen Tegen anjo Deff jdmis uno Dann plibzlich beftig aufwelte. Die Eprizer flogen fo 
boch, oaf or gemug zu fulaffen batte, bie lligen aufo zubalten. 2llz er eine balbe Stunde jo gejtanden batte, fab er Durd ben Regen, twie grabe por ibnen in fict berambälzenden Wogen unt Nebel irgeno etwaz heran. trieb... irgend etroas ..., und plisklich fuien ez ifm nichtz andres zu fein, als cine Dine ... nicht eine ... mebrere! bie Saare ftanden ifm zu ßerge. Er fđrie: "Ninten! Ninen!“; uno bachte, Dá̃ es num völlig auz twäre mit ibnen. aber ba fárie Der Obermaat von ber 23rücle berunter: "פaz fino ja S̋lfäffer,

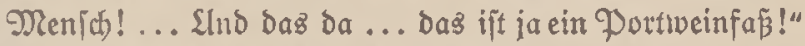

Śno nun fingen fie in 2lbendbämmern an, ben

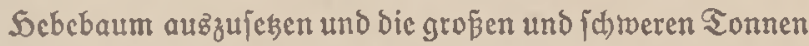
an Dect zu hebert. Gie trieben mit ben Wellen, und bie Gee ging in fdhtweren Xaffen über Das ganze 1 dhter= Dect, und fie batten feinen troctnen Fetsen mebr am Reibe, benn fie batten pich nicht alfe 3eit gelaffen, Fich in S̈lzeug z̆ werfen. Sie fhimpften uno jagten, bie

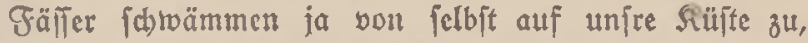
warum fie fiech damit quälen follten. 2lber ber Eteuers mann, ber wobl ein Wort bavon börte, jagte in jeiner

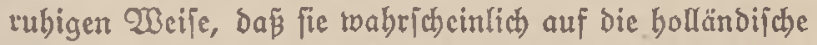

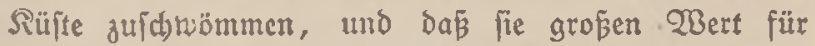
Deutidhland bätten. Da arbeiteten fie, als menn fie fich Die Geligteit verbienen follten.

Ulz fie noch fo mitten in beifer 2 ltbeit waren, bie Sälfte an ber Feling, um zu faffen, bie andere unfer Ded, um zu verifauten, faben zrei, bie öäblen wollten, twicoicl ba nod trieben, faum zebn Pefer vom Boot, eine Tonne treiben, bie feine ridtige Tonne war. $\mathfrak{I n}$ 
bem 2lugenblid fing bet $23 i n d$, der nach Vorboft übergegangen war, at, Edinee ơ treiben. Srotsdem batten fie erfannt, baf́ es tcine Öltunne, jonbern cine Nine war. Gie zeigten mit entjetsten Befichtern uno aubigercaften Sönben bahin. (Es twar ein furchtbarer 2lugenblid. Es loar bem Eteuermann, ber jelbjt ans $\Re$ Rab iprang, tros allen Gteucinz nicht möglid), fie son bem Slngebeuer megzubringen. Sie ftonden alle roie verfiteint, bie 2lugen alle auf bas graufige Ding ge beftet, bas bie näbjfte Welle gegen bie Borbwand twerfen muß̈te. 2lber bamt, fo plöblich die Befahr ge= conmen, fo plöblich war fie vorüber. Gie trieb, ja fie jagte von ibnen weg, won eirter langen, gropen Welle fortgetragen. Sie atmeten alfe bow auf. "2lb!" ... fagten fie; und rannten wie verrïlt an ibre Cemelyre. 2lber ehe lie foreit tamen, jhlug die Mine mit inrem ganzen (Bewicht gegen eine S̈ltonne und explobierte unit ungebeurem Rrach. Saushober (sifbt flog in ben rebel. ג'z fie fich bann wieber ben Ölfäffern ऊua soenden roolften, twaren feine mebr zu feben. Go Eebrten fie benn um unb fubren wieber ijre alte Strecfe.

Der Wind loar ftärfer geworben unb gegen Nitter. nacht batten fie Eturm mif Gance. (EB twar eine furdbtbare Radjt. DaB Boot war ia gut; aber baß Ehlimmfte maren bie Sonnen, bie fie gar zu gern bebalten wollten, ba fie fo wertwoll fïr Deutidland waren. Gie verjuchten erfit, fie an Dect fejtzuzurren, aber fie batten nidbt Retten genurg; 3mei gingen über Borb. Da veriuditen fie, eire nach ber andern in ben Roum binabzubeben, bas mollte aber aud nidjt mebr 
gelingen. 3weimal fotrie ber Eteuermann: "Wenn ibr

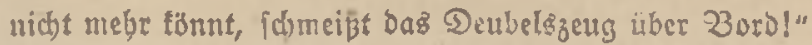
2ber fie fchültelten bie Röpfe; fie maren twie verieffen, fie zu retten. Eв wat ibnen allen zumute, als täten Tie ihrem 20 ll mit bicjer Irbeit eine bejondere Qiebe

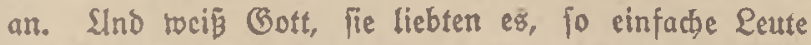

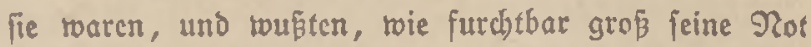
twar. Der Telegraphift batte ibnent aud) nod gefagt, ¿aßi Dortmein fo gut für Wertwunbete toäre, baj fie wieber ga Rräften tämen! Gie arbeifeten über ibre Rräfte. Cs twar ifnest allen twieder, als twenn bas

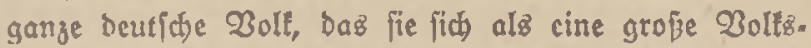
menge vorftellten, am Gtrand ftände, auf ben Deid, auf Den Sautzö̈bern, auf ben Werften uno auf ben boben Säu[ern von Samburg, ja auf dem Plidaclis. firdyturm, und ibnen zujah, wic fie fich auf bem maffer= überraufhten Decf in fteter Lebenżgcfabr mit ben Sెl= tonnen uno ben riefigen Đortweinfäfern abquälten, unb jebcōmal mit ben fïppen nicten, wenn fie einz fict)er geborgen batten.

So verging bic Nacht unb bieje Gadue.

21m Norgen ... ez war nod dämmarig . . . fichtete ber Unterofrizier Weter Sageborn von Der 3 tülfe berab - Der 2üguctmann, ber Durd) Den Nebel, Rigett und Eddnce nidhts gefebn batte, befam mächtige Sajimpfe - in Norbweiten einen Gegenlitand, den lie erft für Den Turm eineş U-Boots, Dann für cine Mine, Dann für ein grȫes Gaß bielten, biz fie endlich Darauf $z^{u}=$

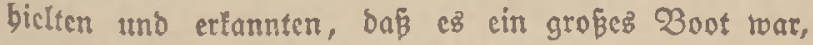
bas jo altmodijch, bick unb wurdtig war, baj es aller- 
Dingz eber eiurem Tấ3 alz cinem Boot glich. Gie liefen vorfid)tig näher, und balo fabu fie, Dá ç bejebt war, uno twie bie Infaffen mit Sühern und Mürsen winten und fdyrien. Dann börten fie eine belle Grinme auf englifa) prablen und fichimpfen, bie bon mun an

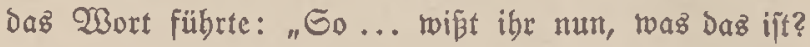
Rennt ibr Den Lappen? ... 20nz? . . Nun fommt i(j) auf ein Deurfibes Gdiff; und in einer balben Gtunde feib ifgr geidlachtet, gejalzen und gepofelt!"

Die andern im Boot,... ez waren etwa achtzehn Nenichen, alle beruntergetommen getleibet ... twaren fitil. Einige Enieten, bie meiften lagen, mehrere fdhienen tot. "Mebr Reine, Rapitän!" juric die belle Etimme auf beutfh. "Binige wollen nicht herauf; andre töunen nicht, weil fie balbtot find! ... Sorjicht, Rapitän, Gie baben nicht biele Nann an Borb! Wer tweíß, ob bie Sdurten nidyt an einen Slberfall Denten, fobald fie wieder feften 30 cen unter Den Güßen baben!"

Der Wind batte nachgelaffen; Der Simmel fah in Weften gelbounfitig auz und im Often twurbe cz beller. Gie jabn num deutlich, dap es Menjichen in joblimmer Rot waren. Sie griffen zu, two fie fonuten. Es war eine bunte Bejellị)aft: Epaniolen, Engländer, Norweger, Brafilliniter. Einige fanfen lautloz an Dect zulammen, andre fnieten rieber uno beteten fie alt, trobl toeil fie nach) ben 3eitungen bie Deuffhen für Möbrber bielten.

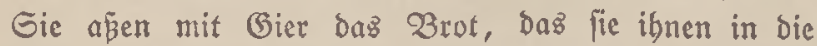
Soand brïtten, und ftecten ibre Roppe trie Dferde in Den fleinen Waffereimer. $\mathfrak{A}$ lz lette band ber mit ber bellen Gtimme die beiden Gterbenden oder Soten in bie 
Ecine. Eic legten fie an Dect nicber, ba wo fie fie aufgeljiewt hatten; ez waren ztwci älterc Mlänncr, einer von germanifher, ber andre von itibifcher Rafle; fie waren ber Sälte uno ben Entbelyrungen erlegen, und Silfe nüzte nichtz mebr. 2lls lebter fam ber junge Nenjd) mit ber bellen Gtimme berauf, etroas über zwanzig Sabre, in werifjmustem, abgeriffenem 2lnzug, in läfifger Soltung, aber in feinem Wejen frei uno munter, fo alz wenn er von einem Ball fäme uno nicht ftundenlang bicht an jeinen Snien Menichen batte iterben febn. (Fz f(bien ibn aud) nicht zu frieren, obgleich er in jeiner bünnen, vertommenen, völig durchnäp̃ten Rleioung ba im falten Wind ftand. Er batte ein nicht unedlcs, freimütigez Geficht, wie er da fo ftand, abgeiondert von Der elenden Befellifhaft, bie fich in einem Rlumpen zus fammendrängte, und Deutjch und berfommenes (Englij) wie Rraut und Rüben burcteinander raarf: "Wir find auf einem Dampfer von शeroport abgefabren ... mit Munition für England, und baben $e B$ alle getwupt. 2luch ich batte mich antwerben lafien, um auf bieje 23eife nach England und von ba nad) Deutichland zu fommen, um für mein Baterlano zu tämpfen. O̧⿻it von bier... Dort binüber... ift das Gdiffi in Der vorigen Ract) auf eine Mine gelaufen und gejunten. Daßj Der Dampfer Munition gelaben batte, fann id bezergen, benn idh babe die Gdiffzpapicre, bie bem Rapitän beim Gturz pon der Brücte entfallen twaren, bei mir. So ift es benn nun ficher, daṕ dieje ganze Bejellichaft an ben Galgen tommt."

Der Gteuermann hörte den jungen Mann mit gea 
rumbelter Stiru an. (er toar unfidter, was er mit ibun machen follte, uno fing an, Die übrigen auszufragin, bie mit ftarren 21 ugen Den 23 orten igres Benolfen $z^{\text {u- }}$ gebört batten. Gie gaben zu, daß ex jo wäre, rie iener gejagt hatte, und wollten Entjhuldigungen ver. bringen: fie wären afle arme Sierle uno bie bobe Seuct b̧ätte lie gereizt. Sie meinten, ez räre fo, twie Dur junge Damn fagte, Daß̧ fie ibr Leben verwirtt bätten.

Der Gteuermant berufigte fie. "Das ift ja Sln[tun," jagte er, "ibr werbet interniert und toeiter trird eud nid)tz geidebn," uno ex befabl ibnen, aufs 2 Bort ju geborchen, und lié, fie unter Dect fubren.

Sluterdes batte bie Rannichaft angefangen, bie beiben Soten notsürftig in Leinen einzutoiceln uno einju= ¡̈nüren. Damn legten fie bic beiben auf ein Breft uno boben fie auf bic Reling. Gie fitanden mit $\mathrm{ab}=$ gezogenen Dä̈sen; auch von ben Gdiffbrübigen famen einige beran, grabe, ernjte 2ugen auf bie Soten geridtet; Datn rutjhten bie beifen ichmalen 3 ündel, bon benen bie Sau=Enden in Winbe flatterten, inz $\mathfrak{W a f f e r . ~ T a u n ~}$ gingen fie ibrer 2lrbeit wieder nach).

(Bleid) darauf fam bie 2blöfung; unb fie fubren mit ibrex boppelten Laft und gegen ben Wind, Der fich mely uno melyr biflid georebt hatte, nad) TBithelmz. baven zu. Dee junge Deutjhe fitand bier und da berum unb plauberte mit ber Mannidaft, po, alg toenn ex fie alle fibon lange tannte, fragte, erzäblte, prabltc, uto lief aud) auf bie Brüce, und fragte den Gteucrmann nach biefem und jenem. (fr erzäblte, er wäre dec Gobn eines Samburger Recbers uno Rejerbeoffijic: 
tnit nannte aud bas Regiment. (E) bätte fid ein ganjes Sabr lang als einfacber अrbeiter in Pew Mort

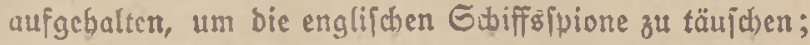
uber es röre ifm nicht gelungen, fich zu verbergen, ba fein 2ater Da Drüben gar zut betannt toäre. Da wärc cr auf Den Bebanten getonuru, mit biejem Gojiff menig. ftens bis England zu geben; fo wäre et dod Dentich. lano fobon näber.

Gie waren allc, vom Gtenermann bis zu bem breit= töpfigen Pommer, obtwobl cinige bon ibnet fhon runo um Die Erbe gefabren waren, feinetwegen unficber. Daf er fich tallog benabm, füblten alle; Denn fie batten ein gutez Empfinden für vornebm uno unedel. 2lber fie reduneten es igm an, bas cr fuwere Sciten binter fich batte, die ibn aus der Gorm gebracht, unt baj ber Gdiffbruch, Dic Befabr und Dic Entbebrung ign erregt

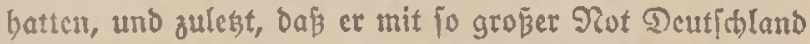
batte auffuchen wollen. Denu auch bas glaubten fie ilgm. Gie batten iberbaupt ben beißín 23 unfh, ibm alles zu glauben, ibst ou beritebn und zu entichuldigen, um bod nur ja feine Ebre zut retten. Dent ber Gebanfe, ber ibnen aufiteigen wolte, Daj er cin Gduwäker, Qügner unb Socblapler fein fonnte, soar ibnen furchtbar. Gie verid)loffen ibn im innerjen Serzen. Der We[tpreube fam, in feiner 2rot und 2ingit um ifn, un ibn liber allen Derbacht zu erbeben, auf ben Gebanteit, baf er biellcicht ein Dring toäre; benn man börte bamals fdoon von vielen Offzicren, Daruntet aud, Wrinzen unb Güriten, bie ftch beimlich in 2 crtleibutg nach Deutichland foliden, um ibrem Eande du belfen. Denn brannte fa alfen, 
was beutfches 3 lut in ben 2loern batte, bas ifre zu tun; und bie 20 rnebmften fheuten nicht ben grüsten Gdymus uno daz̧ fdwerfte Reben, um nach ber Seimat

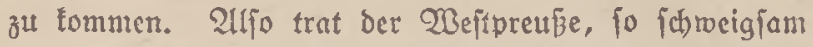
ex fonjt war, an bicjen und jenen feiner Rameraben beran, io, alz wenn er ba ein twenig itebn und ins Weite febn toollte, und fagte leife und mit zuโammen=

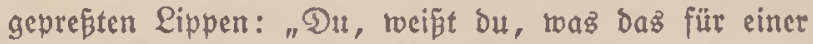
ift? ... Das ift cin Prinz ... vielleicht ein Gohnt vom Raijer. Der bat ja jo viele ... ba ift vielleidst einter im 2lušlano getrejen!" 2ln biefe Piöglichleit glaubten fie ja nun natürlich nicht; aber fie twaren boch alle überzeugt, $j a$, bas rwaren fie, Dá er ein Sunge auz gutem Sauje roäre. Sn biefen Gebanten biffen fie fith orbentlich bincin; benn ber anore, baß̉ er ein winbiger Patron uno Sodj) ftapler wäre, war ibnen fo peinlids, baß fie fhon in voraus, im Gebanten an bie Möglichleit, fich) in feincm Ramen ibämten und einer nach bem andern im voraus rot wurbe. Nein, fo ettas toollten fie nicht erleben! Rein! Sie tamen beute abeno nach Whlbelms = baven ... ba modte denn fein Gdhidfal ifn ereilen. Da, wo es Qeute gab, bie fefter zugriffen! Dazu batten Fie lcine Begabung! ... Rein!

Gie waren alle erregt uno won Arbeit und $\mathfrak{\text { Wache }}$ übermüde. Es twar ein wunderlicher, faft unmirtlid)er 3uitand.

Gegen 2lbend jtand Sarm Dit an ber Reling, ba trat Der frembe auf ibn zu und fing in peiner Wocife aud) mit igm an; und erzäblte ibm unter anderm, baß er auch Tiew Y̧ort gut fenne. Da jagte Sarm Dit, 
um etwas zu fagen - Detn auch er wollte in ber Wornebmbeit feiner Gecle gar ou gern an ihn glauben und freunblich und biflich gegen ifn fein - unb tweil er nac) ber geringften Soffnung griff, etros bon feinem 3ruber zu erfabren, Daj̃ er Dort einen Bruber bätte.

Da fing ber junge Grembe an, fich ơ erinnern:

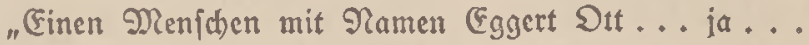
babe idh den nicht mal fennen gelernt?!... Sat er nicht blondes Saar und ift ein bejonders bübjeber junget Rerl?! Go toas Finfteres in Befid)t?... Sa! Namen crinnere id) richt mebr; aber ben mü id fernen!... Gut logar! Sa ... id babe mit ith gearbcitet! Sa= toobl, ja ... twir babent in einer Wirtichaft zufammen Seller gerwafden, ja! . . U Und er hat mir audb erzäblt, Dấ er einen 23ruber in Der Deutichen Marine bätte."

Sarm Dtt wollte fich ein roenig toundern, Daf̈ 23ruber Eggert seller getwajden baben follte. Eber tat er jebe andere Arbeit und wenn $e^{z}$ bie fdwerfte twar! Q Aber er twar zu glüclich, Daß̉ er von feinem geliebten $3 r u b c t$ börte, uno ftrablte über Das ganze Befict. Welch ein tounberbarer 3 ufall! (Fr fragte und fragte, "und Der Grembe ftand Rede uno 2lntwort. Slnd ging, um mit einem andern zu plaubern.

So ging er von einem zum anbern burchs ganze Gaiff und redete jeben an und twar freundich, und batte Dabei fo etwas Serablaffender; tund fie waren alle umficher, uno füblten fich ungemütlic). Uber fie wufsten nichts bagegen zu machen. Gie raren alle überbiblich und febr freundid) gegen ibn ... Sa Der lange, bagere Gibt, Der Fifither, verjuchte, alz ber Grembe ibn etwas 


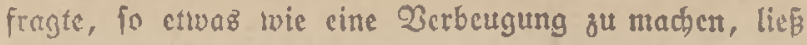

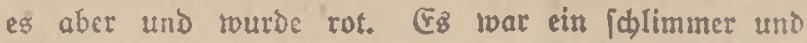
peinlicher 3 uftans. Wemn ex fid bods fo benommen bätte, fo bap fie ibm von ganzen Serzen geglaubt bätten! Dit vie freubigem Serzen bätten fie ibn bebanoclt! WBic frei bätten fie ihn angejebn! Woie neugierig uno rbieviel ift gefragt! Wie ftolz rären fie auf ibu gewelen! Welde Liebe bätten fie ibm erriefen. Denn ibr Sorz brannte ja banaw, einem SRentben auf ber DEelt Liebe zu ertweijen! Die Gdiffibuthigen japen bn unten zulammengepfercbt in ifren Rejerbelleibern, bic fie an Borb hatten; einige batten ibnen bas beite 3 ung gegeben, Daz fic befaßjen. Wie bätten fie exit Diejem Fremben Gutez getan, diejem tapiren Lands. mann und feinen, freundiduen Stungen, bet fo verfrocen unb berbungert auşโab! $20 \mathrm{enn}$ fie ibm nut von ganzem Scrzen geglaubt bätten! Wacum in aller Welt forgte ex nicht bafür, baj fie ifm von gangem Serzen glauben founten, fo wie eB in Der Bibel fteht: glauben von ganzem Serzen, won ganzer Geele und von gonzem Bemüt?! Ein Nenic muß glauben ober nict glauben; Der 3rvilichenzuftand, ber 3weifel, if fürchterlich. (E⿱ toar

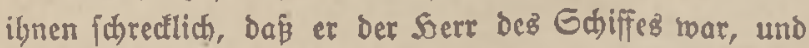
Der Serr von ibnen allen ... ja, bas twar er !. . und fie nicht an ibn glauben lonnten!

थ!8 Sarm Ott nach Dem Ellen mit einigen von

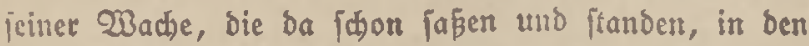

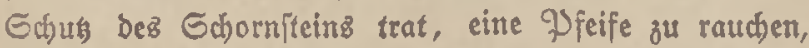
tam ber frembe vieder beran und ergäblte, er jei in bie Welt gelaufen, um in Den Wälithern Ranabas Welztiere 
zu jagen. Slnd er erzăblte ihnen bon Ranada! Rannda im Eommer . . W Wälber jo groj wie Europa. Weijen= felder to grop wie Deutichland! Slno Raitada im Winter: Edjnceberge wie Die Alpen, und Pel $b_{1}$ tiere ... ganze 3elte voll! 2lber er fei aller biefer Dinge mübe!

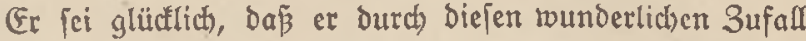
auf ein beutfeches Gdiff gefommen; und mun tolle er feinem Greuno Willyclm belfen.

Sie ftanden um ihn und fefämten fich jeiner ichr und fahen an ihm borbei. Zejonocr gefiel ihnen bas ewige Drablen nicht, und gar Der Uusoruct, ben er

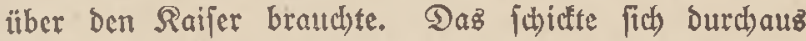
nicht! Raijer raar Raijer, und war kein Freund, am wenigften für fo cin jungez, leichtfinniges Reichemanns: fino! Denn winoig war et auf jeden Fall; das twar ifnen tlar!

Slm die Zerlegenbeit abgulenten ... Da fciner ein Wort Der Erwiberung fand -, Der Slnterdfizier Peter Sagedorn fnurrte vor fich hin und bi - fagte Sarm Ott: "Soaft bu fdjon geljöt, Sage= Dorn? (Fr bat meinen Bruber in शeto 3 or fennengelernt unb hat mir von ibm erzäblt!"

Da legte Deter Sageborn feine Dfeife auf bie Reling uno jagte mit einem fdweren Gtöbnen: "פu, Dommer! WBas baft du bem Nann vorbin erzäblt, als Du da neben ifym ftandejt? Du erzäblteft fo twichtig und eifrig. Serauż Damit, Dommer!“

Der Dommer fah aufs Wafler und jagte: "Sh babe ibm Die Gejhichte von Eggert Ott erjählt."

"Na, aljo, Rinderl" fagte Deter Sagedorn, "Denn Ercuffen, Die Brüber. 
ift es nun genug! Shr alle miteinanber, von bem 2llten auf ber Brülde biz zu bem elenden Pommer, ber mid' nicht anjebn mag, fondern aufs Waffer ftart ... ibs feid alfe mitcinanber Feiglinge!" Slno plöglich fürie et mit wildem (Geficht nach der Rufe himüber, roo Der Ewerfübrer ftand: "Erverfübrer, zrwei Berwebte!" Der lief mit verwirrten, entiegten 2lugen und fam mit zroci Getwebren und warf fie Deter Sagedorn in ben 2lum. 2ไв Peter Sagedorn bie Betwebre in Der Sand batte, tourbe fein (Befict)t nod) wilber. (Er jah aus, als wäre cr ein Feind ber ganzen Nenjobeit. Er rarf bas eine Berwebr bem Gremben in ben 2 rm, rí jich auf und idjrie: "snothen zufammen, ou elender Bengel!"

Der war blaßj gelworden, batte das Bewelje in ber

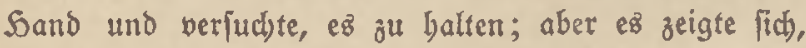
Daß́ er nie eins in Der Sand gehabt batte.

"Etramm geftanden!" fajrie Deter Sagedorn, "ftranm, lage id bir! Wer bift bu, Du clender Sound?"

Der Grembe zucfe mit ben Gdjultern: "Ein Reliner! (Ein beutidber Rellner."

"(Fin verlogener Deutfher, beiát ez," ichrie $\mathrm{cl}$.

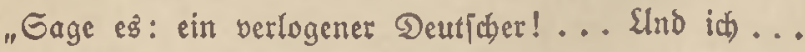
ich will bir auf bie Beine belfen! Du mutit boch ein

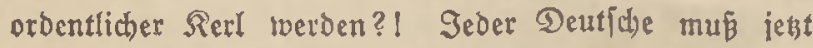

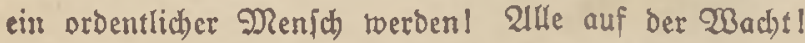
Reiner eine Sd)lafmüвe, uno teiner ein Tarr! Soer bie 2lugen, (D) Qump! Dräjentier'!" 


\section{Rapitel}

Der abfall von ber "Alten Liebe" (5) gingen lie alle zut Geite, der eine bierbin, bet anbere dabin, alle moglichit tweit fort oon ber Gzene. Peter Gobt und fein guter Freund, Der Ent= bener, gingen ins Logis und ftelleen fich vor ibr Gpind und griffen barin berum, als fuchten fie etras. Der Dommer nabm jeine Sarmonita beraus und fummelte baran und fah nicht auf; über fein breitez, bicfez Geficht flog ein Rot naळ Dem andern. Der 2 ejtpreupe troch in ben 2 cridslag unter ber $\mathfrak{B a d}$ und blieb eine gange Weile verichrounden. Gelbft ber Etcuermann, ber von Der 3 rücte bie gange Gache ge= feben batte, fab fidb nidst um; er ftand da wie feite genagelt und fab oor fich übers $\mathscr{W a f f e r . ~ D i e ~ S e i z e r , ~}$ Die ichon bei Den Rarter boctten, tamen, oon Dem Rärm aufgeftört, berauf, faben bas Inglitef, ftanden einen 2lugenblid und berichwanben twieder. Diejer grobe, tnurrige Peter Sagedorn! (Er jollte fich nur nidt einbilloen, Daß̄ er da ein Soldoenftül pollbracht batte! $\mathfrak{W a z}$ toar bas für ein Runftifücl, ben armen Teufel zu enta larben!? O nein! Gie freuten fich, Dás fie bieje 21rbeit, Diez Senferamt, nicht berrichtet batten!

Weter Sageborn ftand mit milden 2lugen brei Gctritt bor bem Günder und machte ibm bie Sandgriffe bor und fajrie die Rommandoz und fnurrte bagrifaten:

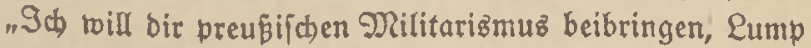
Du!... Das beift: ich rill bich zu einem orbentlicben Men= (d)en machen! Iat mill bich zu einem Deutichen macten, 
Du Lump! WBeift Du, toas beutid) ift? Deutich ift Har unb rabr fein! Gtramm, Sund! uno fut* mir in Geficht!" Eein 2ltem ging fhtwer, uno der arme Günder

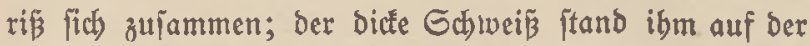
Etirn. Gdyreatlid), Dahin zu febn!

2llz fie bie Gdillling= Rieede erreidjt batten, fprad) 「hon einer bavon, daß er doch eigentlich Quít bätte, etwaz andres ơ verfud)en, bevor der Rrieg ou Ënde ginge. Smmer auf biejem Boot . . Den ganzen Rrieg bindurd)? SAnd Dann, wenn er zu Ende ift, nichtz tociter erlebt baben, als biejez Boot? Rein, er wollte einen 2intrag ftellen, $o b$ er nicht auf einen Minen. jucher ober fo ettraz fäme! Slnd ichon gegen 2lbeno waren ba mebrere, bie fo bachten. Gie meinten, man folle mal traz andrez verjucten! Der cine twollte auf einen Struzer, ber anore auf eil Sorpeboboot, ber oritte wollte nach Flandern an bie Gront, fo fdher es ba träre. Die "Allte Riebe", ihr Gtolz uno ifre Seimat, war ibnen burch dieje lezte 3 egebenfeit verleidet. Fz mar ifnen, als renn Daz 2Boot fdhushig oder boch freubloz geworben wäre, und als wenn fie, dic dicz erlebt batten, Dieje Täujhung uno bieje Nieberlage einez Menichen, ez nicht rieber reinmachen fönnten, und als wenn fie auch niemalz roieder ben rechten 3 th= fammentlang, die rechte Sormlopigfeit würden finden fönnen. Nein, es roar ilunen num plöblich allez verDorben! Diefe einzige böfe ßegebenbeit batte mitfamt bem Bild den Rabmen zerid)lagen; es mar allez Gplitter uno Serwüffung getworden.

Gie famen gegen Mittag in WBilbelmbaven an, 
lieferten bie Gdjiffbrüd)igen $a b$ und reinigten ibr 2 oot. Gie reinigten es von ben fh)mukigen S̈lfäfīern uno von Den ichmugigen Gdjiffbrüdigen; aber mebr noch won Dem (Frlebniz mit Dem Gremben. aber obgleid) fie fünf Gtunden lang goflen und farubbten, wobei fie wenig ober gar nidt fpracten und es bermieden, fich an= zufebn, wurde es boch nicht rein. Dann gingen fie an Land. aber wäbrend fie fonjt hödjitens in brei Saufen geteilt waren und fo die Etadt genoffen batten, bes baupteten fie mun, biez ober bas bejorgen zu müjīen, uno gingen faft jeber für fich.

Als Sarm Dit - audh er allein, uno auch er in jebr bebriidter uno unglüdticher Etimmung - die Soaupt=

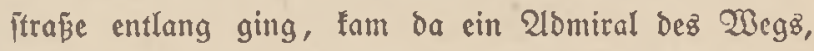
und neben ibm ging ein Rechtzantwalt, Den Sonrm Ott aus jeiner Gtabt ber und von Dem Sbomjenfich Sonufe, two er verfebrte, recht gut faumte, fo gut, Daßj er ifn wobl anreben Durfte. Er ging Den beiben nach, bis Der 2lomiral in ein Saus trat; bann redete er Den $\mathfrak{B} e=$ tannten an. Der, cin mitteiljamer, freunolicher Mann, fdhien (iid) zu freuen, cinen Seimatgenoffen zu jebn, erzäblte ifm, daf er von Selgolano täme, und bat ihn, ein Gtülä $\mathfrak{B e g}_{\mathrm{s}}$ mit ibm zu gebn; und fragte nach bem Shomienfiden Sauje. Sarm Ott erzälite ifjm, foviel er wuste, und fragte ibn dann, ras ihm eben Das Serz bervegt batte: was er wobl meine, wann ber Rrieg zu Ende ginge. Das war ja bie fiälloige Frage aller Menfchen.

Da fagte ber Rechtzanmalt, er bätte eben Denjelben Begenftand mit bem 2lomiral verbandelt, fhwieg cinen Augenblid und fagte Damu: "Sie find ja ein verjtän= 
Diger und rubiger Nenj(h, Ott. Gebn Gie, nad) meiner Meinung fteht es fo: Englant bat Der Reibe nach mit Denjenigen Mächten, bic ifm gefäbrlid twaren ober tourben, Rrieg angefangen und fie niedergeworfen. Go bat $e^{8}$ ber Reibe nach erit Epanien, Dann Sollant,

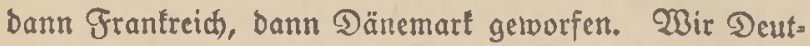
fichen, wir baben ja Dariu eine gand anbre शatur; wir

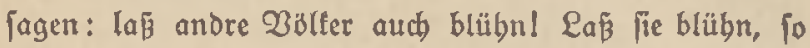
f(b) ön fie tönnen, wenn wir nur auch unjer Seil Quft uno Gonne baben! 2lber bie Engländer find anderz; fie rodllen alles für fich allein baben; fie wollen ber Serr ber (Erbe

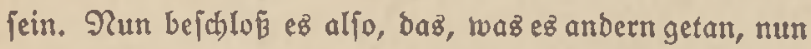
auch mit Deutichland zu machen; benn Deutichland mar nun an Der Reibe; Denn ez rar in Den lez̧ten Dreiß̧ig Sabren fein gefürchtefffer Ronkurrent getoorben. Slm nun viele Selfer zu baben, uno um ez böllig zu erniebrigen und unfdäblid) machen zu fönnen, fammelte es fid) Bunbes. genoffen, wo immer es möglid twar, und erdachte und verbreitete fhon Sabre vorber ungebeuerlide Lügen; und bann ging es los, mit allen Soänden, bie es in ber ganzen Welt batte befommen tönnen! (Es bachte, es pollte mun eine leichte Gadje merben; 10 in zwei, brei Nonaten, meinte ez, follte ber Norb gejtheben jein! Nun aber

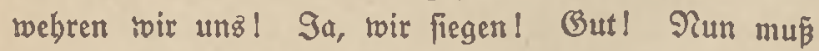
man aber nicht benten, daß England ben Rampf nun aufgeben toiro, oaß 3 Englano nun fagt: , Faliळ fpctuliert! Ein andres Bej̄äft! Nein, ganz uno gar nicht! England ift foldhe anfänglichen Nieberlagen und ift lange Rriege getwöbnt. (Es fann fie auch viel leid)ter und viel

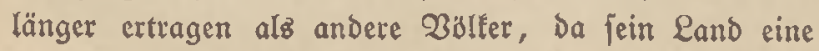


Snfel ift und aljo beridbont bleibt. Sange Siriege find England burdhnus nid)t unangenebm. Rein, indem $e \mathbb{8}$ immer bebarrlich und zäb blieb, fiegte es zulegt um fo

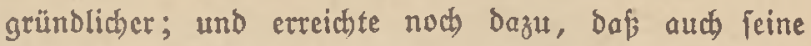
Bunbeżgenoffen febr geíchwächt twurben. Gehen Gie, und fo banbelt ez auch jebt! CEg riro immer weiter fämpfen, jabrelang. Denn je länger es bauert, um io fdbrächer und mürber twerden alle andern, Freunde twie Geinde; felbjt aber bebält ez feine Edbiffe, feine Rolo= nien und fcine ungcheuren Mcere, und darf boffen, Daß ez endlid) fiege, und zroar wie es immer fiegte: über Freund uno Feino."

Sarm Ott ftand bas Serz ftill und er jagte: „Eo

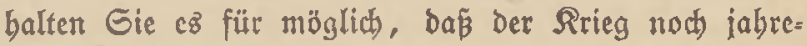
lang bauert?"

Der Rectizanmalt fagte: "פa, ez ift jutrectlich ... aber ez ift burchauz müglich."

Dann prach er noch trieber von gemeinjamen 2e= fannten in ber Seimat, und bann ging er.

Sarm Dit glaubte, daß ez fo fein würde, toie bex ältere und Fluge Mann gejagt batte. (Ez jab ia aud ganz banach) aus. Der Rrieg bauerte num fibon andert* balb Эabr, und man fab nod lein Ende. Serraott... jabrelang nods diejer 3ujtand!? Diejes Menjchentmorden!? Diefe Angft in Millionen Serzen im Lanol? Sabrelang noch jollte er fern von ber lieben Seimat fein, fern onn friedlicher, fhöner Eätigfeit!? Das Seimmeb, das̊ ibn vorber (d)on gefapt lyatte, wacte ilyn nun mit furchtbarer Betralt; $c$ fprang ibm wie ein twilbez Sier gegen die 3 rujt, uno er ftöbnte; und aus 
ihm frbbnte bas ganze Qano uno all die Millionen Menichen. Wie fï Wie fchb̈n war bie Scimat im Gommer! Wie ihbun

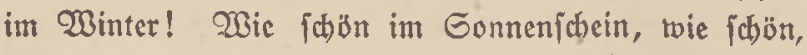
ach twie idbön in jhroerem Regentwetter! Wie ichön bas CElternbaus mit all feiner Gorge uno Freube! Wic fchön ber Friebe! O, Fricbe! ... Friedel ... Uber wenn die Feinde ben Frieden nicht geben wollten? Wenn fie

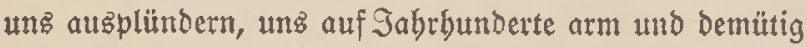
madyen rollen?! Tein, daz gebt aud nid)t! Rein, das ift unerträglich! Tein, wenn id) das abtwebren fann ... mit meinem Lebent... fo toollte id mids bierber legen, bier, wo id geb' uno iteh', und wollte bier, auf biejer Etelle, fterben! Das barf nicht fein! Was ift mein Qeben, twenn mein Rano und Bolf feine Fbre uno feine 3utunft mebr bat?! Tein, Daun fdmect' bas Reben bitter ... Dann licber weg danit! 24ro unz mebren! Rämpfen, bizz fie Den Fricden geben! Fin andrez gibt

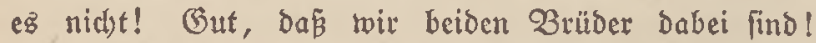
Eine gute Gorte! Slno wenn ber britte nidbt in ber Ferne wäre? ... Waas der wobl dentt... da brüben! Wie er robl trok jeines 3ornes und Saffes an daz Elternhaus und an bie Seimat Dentt! Denn im Brund feiner Geele bängt er ja unjagbar an ben Geinen und an ber Scimat. Tarum ift ja fein 3orn uno Bram fo gró getworden! Ob er robl verjuctst, wie jo viele, berïberzulommen und mitzubelfen? Gider roiro er ez

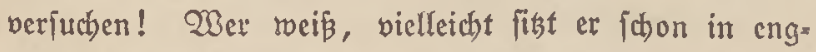
lifher Gefangenfchaft; vielleicht liegt er fabon auf bem 3oden bes Mecres; vielleicht täntpit er filon an irgend= 
einer Front, ober liegt fohon anbetannt unter ben Sun= Derttaujenden, die namenlos gefallen find! Pum gut! Qeben ift recht und gut; aber zumeilen ift Gterben nötiger!" Go ftand er lange und bachte nact, uno fud)te fich bas Sorz Elarzumachen uno den Nut zu berabren: ,Toch jabrelang!? (Fz muß mir recht fein!"

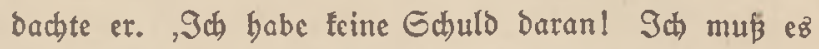
tragen und meine Pflict)t tun!... Fertig!'

(Er atmete tief und richtete fich auf, und ging in id) weren Ginnen nach feinem $300 t$ zurïlf, fente fid) in eine Cefe, und las unter Dem Gercbe Der Rameraben

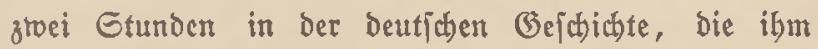
Bruber Reimer gegeben batte. Er โas̉ an Dem 2lbeno

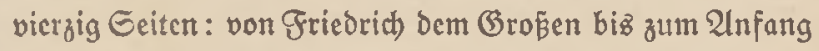
ber Befreiungstriege, uno rurbe Darüber rubiger.

In der গacht, als er lange nid)t fchlafen lonnte, überlegte er fich, das auch er, wie bie andern, verjuchen wolle, ob er nidft vom 3 orpojtenboot negfommen tönne. 2luch) ibn bebrüctte, mas fie da erlebt batten. CEs quälte und befdämte ibn, daß er bem Gremben fo obne reiterc fein Qügen geglaubt batte. Fr batte immer gemeint, DaF er gerwikigt, weltflug und überlegt genug twäre, bie Dinge um fich genau zu beiebn tno fich nicht irrefübren zu lafien; und nun toar igm biez wiber= fabren! Es war ihm bitter. Go lieb ifm bie Rame= raden waren, jeber in jeiner $\mathfrak{B e i f e , ~ a m ~ l i e b f t e n ~ w a ̈ r e ~}$ er faton jegt fortgegangen, jest fofort; und am liebjten toürbe er keinen von ihnen wicberfebn. Sein, ex toolfte loeg, es jei nad) Glandern an bie Front ober auf einen

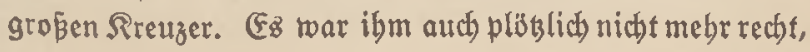


Daß́ ex auf bem lleinen Ediff entlbeder zugrumbe gebn ober tweglaufen follte, wenn ber Engländer faml $\mathrm{Ob}$.

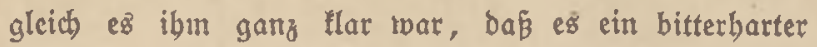
und tapfrer $\Theta_{\text {tand }}$ trar, vielleidgt ber bärtefte und tapferite an allen Gronten: auf fold)em Hleinen Gdiff vor Eng= lanbz 3äbnen auf Wacht ju itebn. Nein, er roollte mun boch lieber babin, two man mit $\mathfrak{B}$ ut und 3äbne. fuirfhen ifm an bie Bruft fprang, ifm, der bas arbeitjame Deutid)e Bolt nicht lcben laffen wollte, dent Welträuber, Denr Entmanner und Entehrer ber $\mathfrak{B a l l e r !}$

Erft am Gpätnadmittag fam er Dazu, feinen Bruber aufauiuchen.

2lz er aber nach Dem Torpeboboutbafen tam uno nach ihm fragte, exfubr er, Daß̧ er Urlaub bctommen bätte und nach Şaufe gereift twäre.

$2 \mathfrak{m}$ andern Norgen jtad)en fie mieder in Eee, und waren gegen Mittag auf bem Doften. (Es webte ein febe falter, fanarfer Norbweftrind. 


\section{Rapitel \\ Paftor $\mathfrak{B}$ oblen}

S(nterbeffen war Reimer auf Ullaub nad) ber Seimat gefabren. Er fand bie Eltern itill und bebrüdt. Eie prachen feltener miteinander als̈ früber. Der $\mathfrak{B a t e r}$ war ja immer ichweigjam gewejen; aber nun roar auch bie Dutter beritummt, bie früber allez, toas ibr Gorge machte und ibr burch Den Ginn fubr, in ben Yater bineingerebet batte. Soatte er auch) nidht viel geant= wortet, fo batte es bod, ibre Geele befriedigt. Wie ztwei Sirten immer wieber, immer twicder um ibre Serde gebn, bie ibnen beiden gebört, fo twaren fie inmer nebeneinander um die fleine Serbe ibrer Rinder gegangen. 2lber jegt ging jeber für fich. Segt fab jeder ein jebes Rind nut mit feinen eignen 2lugen an; und ibre 2lugen swaren febr veridfieben voneinander. Die Mutter tounderte fids über ibre Rinber und fhalt fie, war aber für alle guter Soffnung. Der Zater liebte fie; aber twat in Rot um fie. 21m meiften waren bie fillorborborgenen Bebanten um Den Geflobnen bejchäftigt; und auch bier war Der (Begenjaz: Die Nutter Hagte um ein ungereht befchuldigtes und unglüdliches Rinb, ber Bater war zertifTen um ein ver= Dorbenez. Emma ging immer nod zu Gd)ufter Eblerz, aber roar llar, Dá fie jest mit rubigerer Geele bon ta zurültam. Gie hatte fich in biefem innigen neuen (Blauben jebt surechtgefunben und eingelebt, und batte mun Gtärtung Darin. Dagu ging fie aud) nod fonns täglich in bie Rirche und börte Paftor Bobleng Pre.

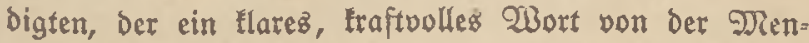


fdicn Gände (prach, abcr ein fräftigeres nod) von Gottce (Bnabe. 2luch daz tat ibr gut. Altz ber Rrieg auzigebrochen rar, war fie zuerit febr ftill getwejen, und bie Eltern batten fhon gefürchtet, $D_{n \bar{\beta}}$ es folimmer mit ifr

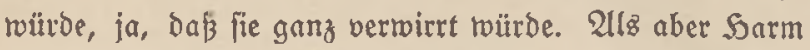
uno Reimer in Den Siricg gezogen waren, und bier und Da cin Betannter fiel, und fie bie berzzerreipende 2lngft ber Mutter jab, ba fan im Begenteil eime Siraft über fic. Gie ftellte fich bicht an bie Mutter, wie wenn es die bebrobte Gtelle wäre, half ihr vom Morgen bis Abend, und veriuctete jogar, in unbebolfenen Worten ibr Mut einzureden. Slno 10 , indem ibr Glaube ibr nun balf ... Dá̧ ber liebe Gott über ben Seufel, trob) all jeiner behenden 2lusflüchte bei bebarrlichem $3 e t e n$ und Gingen die Oberband behielte ... unt fie fräftig mit= arbeitete, unb bie tapfre 21tt ber Nutter wicber mebr (Finflús auf fie getwann, twurbe fie törpcrlich) fräftiger uno blübte auf, und ibre 2lnfälle rourben feltener, und bie Nutter lié̃ fie ungệtört, ja börte ez nicht ungern, toenn fie in Der Sücbe, im Garten ober unter ber Rub, mit rübreno gottegfürdbtiger Etimme ein geiftlich Zerzlein von unires Seilands Sod und Gottes (Er. barmen fang. Freilid) das licbe Lachen, bas ibrem emften gotifden Prinzeffinnengeficht fo twunderbar guf geftanden, weil ibr Beficht eigentlich ou ernit zu irgend. einem Lachen twar, bas war verjhbunden. Slber den Rnecht, über Den fie fonit mit jeocrmann geiproctien batte, und zwar billig barmlos, fprad) fie nun, feit fie geiundete, nicht mehr. Die Mutter meinte erit, fie bätte ibren Slauben an ibn aufgegeben und bies 
wäre nun abgetan. 2llz pie aber einez Togez ibrerfeitz bon ibm anfing, Da tourde ibr Rind rot und warf einen ichenen Blict auf bie Mutter. Slnd da fah bie Mutter,

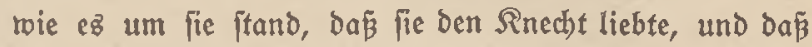
fie fidh ibrer Liebe jebt betwufit twar. Da erjerat fie erit fehr. Nachber aber, da fie barüber nawbachte, fichen ez ibr in ibrem tapfern reiblidyen Sinn, $D a \tilde{\beta}$ fie fich faft barüber freuen fänne: fo war ifr Rind bod in Diefem auf bem $\mathfrak{B e g}$ ber शatur und Gejundbcit, baß fie liebte, toie andre $\mathfrak{B e i b e r ;}$ und fie junmte an biejent Sag ein wenig bei ibrer 2lrbeit, waz fie lange nicht getan batte.

Dies alles und waz fonit geidjelyn war, erzäblte fie ibrem jungen Gohne Reimer, der in feiner bübidsen Uniform, mit jeiner noch etwaz fwmalen, fnabenbaften Figur mit kurzgejdnittenem Saar ibr gegenüberjá. TBie war Der Sunge gerwachfen! Slnd twas war er veritändig getworben, und roas batte er für ichmucfe, feurige 2lugen! Nein, wie felig fie war! Eo cinen idyucfen Sungen gaF ez weit und breit nicht! (Es war eine Deränoc= rung zum Eritaunen! Was wobl noch aus ibm werben miirbe! Gie war fo poll von Zerwundcrung, da jie fie unter Dcm Yorwande, fie bätte noch im Gtall zu tun, fonme aber gleich roieder, nach Dem Gtall ging und zum erftenmal nad) langer 3 eit bieder in ibrer frifden, forbernoen Art zu ibrem Nann fagte: "Waz jagft du nun วน Rcimer?!"

(2) jab gedanfenverloren auf, berftand fie aber pos gleid) uno fagte, ein wenig ermuntert von ibren Alugen: "Ia, weun er glüdlich ourd den Rrieg fonmt..." 
Gie batte fo die Anftht bom Rrieg, Daß man Den meiften Rugeln entgeben tönne, wenn mant fich raich Dreimal umbrebte, und Daßi man überbaupt burch) Silug* beit und Getwandtbeit ziemlich ficher wäre. Und wer toar flüger, als er? "O," fagte fie, "warum nicht? Der roird fich fiton burchldlagen!" Slno fie fab that in ber alten, lieben, ermunternden Weife an, die ibm bas Serz bewegt batte, als er zreiundzwanzig war uno um lie gefreit batte.

"Sa, bu!" fagte er in demielbert Son, in bem er ibre Ermunterungen Damals ermidert batte. Mebre bractite et in feiner Weife nidht über bie Lippen; und bas Lächeln, $b a z$ er verjuchte, twar traurig.

Da tam fie roicder nad) ber Rüche und fprach mit ibrem Sungen und freute fict an ben zarten, fdomucten शannzbild; benn obgleich fie' über fünfzig raar, trar fie noch ein völlig frifches Weib. "Weist bu," jagte iie, "waz bie grōée Beränderung an bir ift?"

"Nun?" fagte er und jab fie neugierig an; Denn er iprach nidht allein gern über andre Menichenieclen, am liebjten iprach) er über fich felbjt.

"Ou bijt nidht mebr fo ficher und po prablig," pagte fie nectent.

Er exfannte es felbit, da fie ez fagte, twurbe ein wenig rot uno lächelte: "\$a . . D Dutter," fagte er, "all Die vielen, neucn פlenfhen, uno barunter fo viele ältere, bie man fennen lernt, und bann bie Offiziere, unter benen mander mädbtig llug ift! slno man toird ja auch) älter, CMutter!" Slno bann rourbe er fehr ernjt

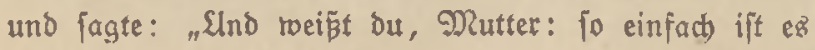




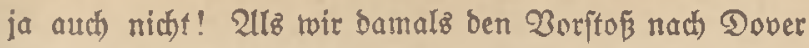

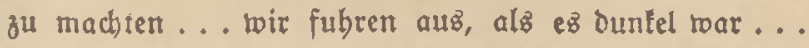
ich war munter und guter Dinge... twat nichts als Neugierde. Go um brei Slbr nachts famen wir in bie Begeno, wo die Engländer ein Minenfelo gelegt batten und Reke und Retten. Gie lonnten auch jeden 2lugen. blicf́ auz bem Duntel auftauben... jeben 2ugenblict. Sch ftand am Sorpedorobr; das twar mein Plats. Wir waren ganz allein ... Das fleine, fhrwarze Boot und bie neunzig Nann auf Dem weiten, mächtigen, nacht= Duntlen Neer! Da fab iđ plöblich, wie Der Obermaat ... er ift ein verbeirateter, etniter, fdobner DRann ... feine Nüke in Der Soand batte... nur einen 2lugenblidf lang... und mit gebeugtem SRopf ftand; fieb, ba mertte ich exit, twas mit uns war... Daß ez auch anders tommen fonnte ... Dá ich da in ber nächiten Dimute treiben fonnte, ba auf ber Welle ober auf jencer anbern, cin ftiller Foter. Davon wird man älter, Dlutter."

Gie erichraf und fdrwieg und war cine Weile nach ibrer 2 rt ganz auz $\delta \mathrm{em}$ Weg getworfen. Dann ichüttelte fie ben Ropf, als renn fie foldhe Gedanten von fid) fíç̄e, und jagte mit groṕem 2lufatmen: "Wenn ou To etroas jagit, fann id) bid) nicht braudhen! (Beb ... iđ Imuß in ben Gtall, und babe teine 3eit mebr für bich."

In ben erften vierundzrangig Gtunden ftand er fo im Sauje und Sof und Barten umber und fragte mit groper Teugierde nach allem und jebem. Slno ging in bie Rücbe zur SRutter und befchtwerte fich mit grofen

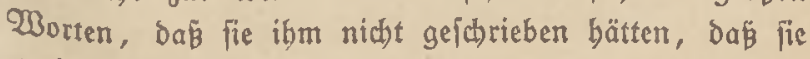
ztoei neue Obftbäume gepflanzt batten und Daß Nachbar 
Sabn bie Wand peiner Gdieune batte flicfen Iaflen. Er fagte, fie müв̈ten ibm alles und jedes fidreiben. Wie er fich fonft ein Bilo madjen tönne?! Wie er jonft mit ifnen leben fämne?! Denn ob in WBilbelmş̧aven oder bier unter thnen: er lebe immer mit und unter ignen. Ex ging um alle Ecten und ab in alle Wintel und fuctefte jeben an, als wenn er ím Durchs Serz feben rollte, und fragte fo viel, $\delta a \tilde{\beta}$ daz Mäbd)en abentoz ganz ärgerlic) fagte, fie babe iłm erzäblen mü|îen, twas fie bisber nod feinem Mienjuen erzäblt, wonad) aud lein Menich fie gefrngt bätte; aber fie bätte es tun mitilfen; er bätte cine 21 tt 3 fragen: er frage bas Ralb aนz Der Rub.

Uber nit Dem Wrablen war es in ber Sat nicht mebr 10. Go ein Rann=21lez, $\mathscr{W}$ ei mebr. Er war nachbentlicter uno bedentlicher geworben und war ins Etugen uno Scrivundern getommen, und ftand nach jeinem Gragen oft in Ginnen und Gatweigen, einen überernften 2luzbrut in bem jungen (Befidst. Daz

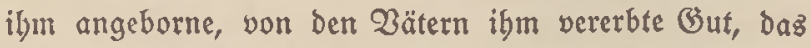
ifn fo reich und gró gemadht hatte, twurbe nun vom $\mathrm{Qcb}$ en und von ber $\mathscr{B}$ elt bejtürmt, und geriet inz $\mathscr{2 B n f e n , ~ u n d ~}$

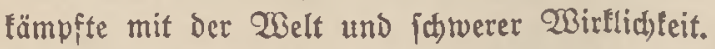

Als er alles bejebn und genau burchforicht batte, ging er ins Dorf, um Daftor Boblen zu befuchen, Der ifn in Den legten Sabren in Deutfid), Befchichte und Englifa) unterrichtet batte. (Danach) wollte er zu feiner Liebiten gebn.

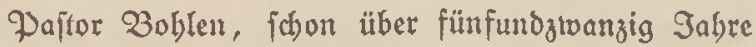
in ber Gemeinde, ftammte aus dem Radjbartirch)piel 
und toar ber Gobn eines armen Mäbdens; und war im Sauje jeines Brobuaters, eines Wattarbeiters,, Gifchers und Gtrandläufers, jehr arm und fütnimerlich großj geworben. (Et batte mit biefem Groppater, Der ein rauber, rücfíchtzlojer und leibenichaftricher Saenich war, bon Hein auf ins Watt uno ins 2 oot gemuet, oft dürftig gefleidet, immer id)lecht genäbrt; und roenn ber Grop̧oater fich Dann, tras bäufig am Sag gejdjab, einen Golud aus ber 3 ranntweinflafdhe gegönnt hatte, batte er fie auch feinem Enfel gereicht. Der Rnabe toar febr begabt getwejen, to febr, dan man in den Dörfern ber Slmgegend von ibm als von einem Wunder= Inaben (prad), und fo maren fid denn fect) ober fieben Lanbleute einig getoorben und batten ifn auf bie Rateinjuule gefdicft. Dort war es noch gut gegangen; er batte auch ein gutes 2bgangsieramen gemact). Dann aber, als er Gtubent toar und fich jelbjt überlaflen er toar bon breitem, mächtigem Rìtper uno groß̄er, ur. vüchfiger Rraft — war die baltlole, unordentliche शatur feines Gropoaters in ibm bervorgebroden und er toat in ein zeitlofes, nachtwanolerifdes Leben bineingeraten uno leiber aud) ins Trinten, ullo war fpät zum Examen getommen. Dann, im Amt und weiterbin ledig, ganz fein eigner Sert, war es eine 3citlang (h)limm getworben. Er lief bei Tag und Radt, wie Gbbe oder Flut esి ifm beftimmte, die eine Getwalt über ibnt su baben foienen, viel in Dem Vorland uno im Watt umber und twurbe zwar ein febr guter Renner Deś ganzen Gtranblebents uno ein geifhäbter Ratgeber ber Deichbebörden und ber befte Greund aller $\mathscr{W}_{\text {att }}$ Frenfien, Dle Büber. 
arbeiter, Gtrandläufer und Soirten; aber er betrant fich oft auf biejen weiten, naffen und falten $\mathscr{W e g e n}_{\text {, indem }}$ er bald allzulang in einer jener etwas unorbentlichen

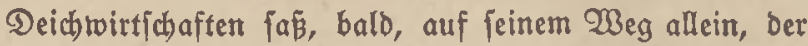
mitgenommenen Flajđhe jo zufprach, Daß̧ er nächtlicherreile taumeInd inz Dorf beimfebrte. 2llmäblich aber, fo mit Den Sabren, gelang ez ihm, eine 2 ltt Oronung in feine Qeibenjwaft ou bringen, fie in eine 2lrt Form zu gieß̄en, Derart, Da fein 2lmt nicht ganz Darüber in bie 3rüche gingen. Er

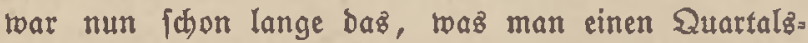
trinter nennt. Go etra nach einem Bierteljabr, in bem er fich) pïlig nübtern bielt, überfiel ibn tagelang bie (Bier, und er trant fich im perichroiegenen Sauje toll und voll. 2lm briften Sag börte er bamit auf uno geriet jogleich, nachbem er ausgejhlafen batte, in eine bittre Reue hinein, und laż, noch in unorbentlichem Saar

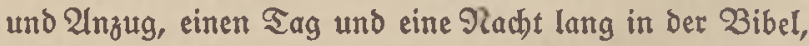
uno zwar bie alleridylimmiten Etellen, bie es ba gibt, und po,

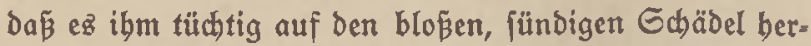
abbagelte. 21m andern Sag aber, gegen 2lbend, erbolte er fich) allmäblich und fand fich twieder alb शen[ch. Slnd

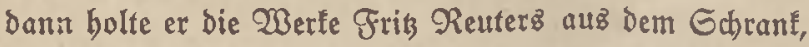
und fand fich an bem Sumor biefes edlen Menichen, Dex basjelbe Leiben twie ex batte burchs Leben fd)leppen

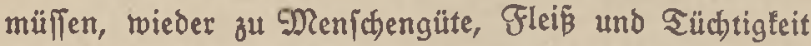

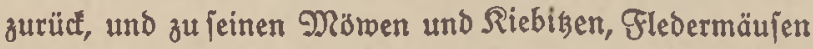
und allem Rachtgetier, bas er liebte uno bas er in feinct bumpfen, untubigen Geele aufjuchte. Die Bes meinde ertrug ibn, und nibjt nur Das: fie liebte ibn 
und bielt auf inn. Gie bahte über fein (Bebredjen menjchlich und nannte ez , peine Rrantfeit'. Gie ers

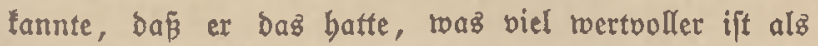
Berechtigfeit und fanurgrades Leben: Das beipe und bilfreiche, tapfere und tüdtige Soerz. CF twar twie ein Übercinfommen in ber ganzen Gemeinde, Daß́ man ber=

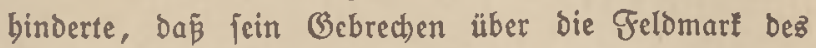
Rirchipiels binauz berebet uno beurteilt wurde. Manches Rino bez Rirchipielz, baz ami Gonntagabend, Daz 3 ündel

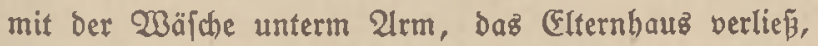
erbielt noch an ber Sür bie Weifung: "Slno bann ergähl" nicht, ba的 Paftor Boblen wicber frant getwejen ift. Daz gebt bie andern Reute nichtz an!" Er twar nun fकon an үed)zig Sahre, ein gropier, breitjultriger, bagerer Pann von gebeugter, ichled)ter Saltung, mit grofiem, bartlojem Geficht, in Dem gütige 2lugen llug und tief flimmerten. Gein Soaar, in bünnem Rranz rund um bie fable Gtirn, twar ihon graus.

(Das Daftorat war noch) ein altez Gtrobdad), und Da Paftor $\mathfrak{B}$ blen auf $\mathfrak{B}$ (1)erungen nid)t brängte uno bas Rirchipicl gerne Gell parte, etwas verfallen. Die alte brcite Doppeltür bing ftart fatief, uno bie Glocte bimmelte flapprig, und febte, nabdem fie fibon eine 3eitlang gejd)riegen, aus irgendeiner Sirfache mit nod) flapprigerem Son wieber von neuem ein. Mitten in der Pcbmbiele mar ein Qoch, baß́ man barüber ơ Fall tommen fonnte.

Die Souzbälterin, eine ältere, gutmütige uno einfache Grau, ließ fonft niemano zu Paftor Boblen, menn er feinen folimmen 3 jutand batte. Gie fagte bann ben 
Befuchern: "Er ij̃t franfl," ober "er ift noch frant," ober "er ift nod nidte wieder fo reit; aber morgen fannft bu fommen," obcr "gel nut binein ... er ift wieder bübich, und liejt in Dem Reuterbuch." $\mathscr{D a}$ fie (ich) aber beute morgen etwaz mit ibm gezantt batte, muste fie fich rächen - wie der Menfich daz fo an fich bat - und fagte: "Geb du nut binein; er ift ja toobl fo tweit! SAnd fonft fhadet es aud nichts ... weder bir noch $i \mathfrak{g m}$... Shr jeid ja auch) alte Belannte."

(Fs war Dem febr ordentlichen und ftarl gerectiten Reimer $\mathcal{O t t}_{\text {tt }}$ in feiner fdönen, blanten Slniform ein wenig ungemütlich; aber er war zu unfither, um bie 2ufforberung abzulebnen uno fortzugeben. 2llo ging er mit feinen jungen, federnden Gd)ritten über bie balb= bunfle Diele um bas wohlbefannte Lodh berum uno flopfte an und ging binein.

Ëz war eine grop̈e Gtube oder fajt ein Gaal mit niebriger, Dunfler Decfe; rumb berum an Den Wänben ftanden Gdhränfe mit allerlei auşgeftopftem Etranogetier und igren Fiern unb andere Gammlungen; an ber einen Mand jtand auf dünnen $\mathfrak{B e i n e n}$ ein eijerner fogenanter Beilegeofen. Sn ber Mitte ftand Der großje an Dem er jo mandie Gtunde mit Paftor $\mathfrak{B}$ oblen ge= jeflen uno Weltweisbeit mander 2lrt genoffen batte. Ez raar won den Linden, die bicht bor bem niedrigen Fenfter ftanden, in bem niedrigen, tiefen Raum balb: Dunfel.

Paftor Boblen fá⿱㇒㠯 groß̉ und breit und hager, mit noch twïitem Soar und trübe ichimmernoen 2lugen, vor

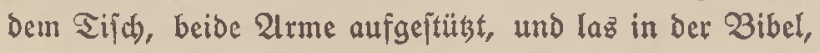


und twüblte und orbnete baztwifdhen in einer 9 Renge alten Gold = unঠ Gilbergerătz und Gd)muctz, baş auf Der Sijcbplatte lag, bas ihm bie Gemeinde gebracht batte, um ez ber Reicjsbant fur Berfügung zu ftellen. Darunter war ein großer alter Srintbecher, ben bie Branogilbe bergegeben batte. Das alte, goldene Berät leuchtete feltfam fheu in Dem Edhein ber Ubendionne, die bünn und jpärlich in ben Kaum brang und mit ibrem lesten Finger noch eben feinen $\Re$ and erreichte.

(Fr fabral zujammen, als bie sür ging, und er feinen Echüler fab. (Er fdüttelte ben Ropf und fagte be= Drücft: "So fieb)it ou mich, mein Sunge..."

Reimer Ott lagte rajd und betreten: "Goll id wieber geben, Serr Paitor $\mathfrak{B o b l e n ? " ~}$

Paftor Boblen ihüttelte wieber ben Ropf: "Nein," fagte er, "bleibe nur! Geţ" bid ... ba ... auf bie

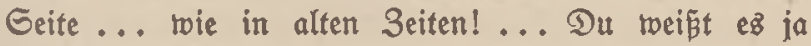
boch fchon lange... fie trifien es ja alle...“ Er ber= fuchte fein Saar glatt zu freichen und fog jeinen Rodf zurecht, und ftarte vor fich bin. "Эफ) fann nichts ba= gegen machen," jagte er. "Es fommt bas Gröjteln über mich, Das id) bamals als Rint im 2 att hatte, wenn mein (Broşbater midh ftundenlang auf bem Rü̈fen ober an jeiner Soufte trug, und bann ift es ba."

Reimer Ott bachte: ,Wenn ein Nenjक nur mill, mú er miberitebn tönnen," uno fagte verlegen: "Sch weí̄, Serr Pajtor Boblen."

2ber Pajtor $30 b$ len war nod in feinem Gtand Der Reue und ber (Bewifîenzిqual. "Sa, du jagit: ,ich

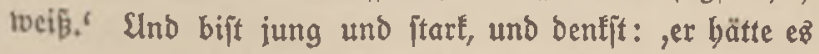




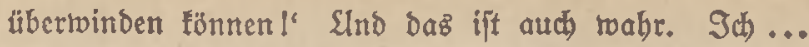
mit meinen breiten G(h)ultern unb meinen jtarfen Sänben ... fieb boch, traz für 2rme ich babe! शein, nein ... Gott bat mich robl in ber Siefe aufroachfen Ialfen, aber er bat mir bieje 2lrme gegeben ... ich follte mir felbjt berausbelfen. 2lber ich bin träge ge= reien; ein fauler Rnebt bin id getweien!" Uno indem er jein Saar mis̄bandelte und mit ben 3äbnen fnirjhte,

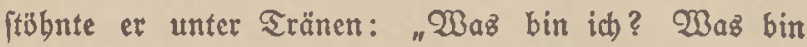
ic) meinem $\mathfrak{B o l t}$ in biejen Sabren feiner Socimfuchung? Snjere Sugend liegt in Not und Gdumus, uno fällt und ftirbt. Slnjere Frauen weinen; unjere Rinder leben

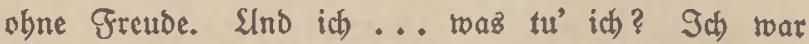
vor einem Sabr beim Propiten und fagte, er folle mich gebn la lien in Den Rrieg ... fo tönnte idh nod etrwas tun für mein Bolf . . a aber ber Proplt [agte, ich twöre zu alt ... id follte bleiben und meines 2lmtez roalten"

Reiner Ott lagte mit berzlid) betwegter Gtimme, in gró̈em heroorbrechenden Mitleid: "Qieber Serr Pajtor

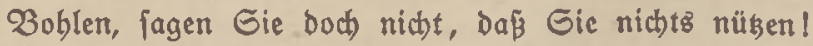
Gie belfen jo vielen in biejer gropen Bemeinde mit Shren Wrebigten ... nun gar in biejer idbreren 3eit... unt noch) mebr mit Shrem täglichen 3ufpruch! Denten Gie

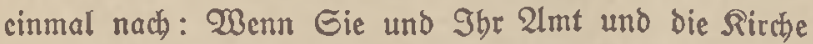
in ber Mitte besz Dorfeż nidłt ba twären ... triebiel roürbe fehlen! Bar nidbt au reden von bem, was Gie fo vielen einzelnen find, mit jebem tlugen, freundliden 20 ort, Das Gie ibnen fagen! $\mathscr{Z} a z$ baben Sic allein fhon an meiner Edmefter Emma und an mir getan? Wenn Gie nid)t

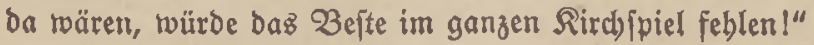


2ber Waftor Boblen wollte nichtż bavon bören; er faßs noch in ber 2liche, und es trar ihm innere Qujt uno (Bier, fie fich noch bicter aufz Soupt zu werfen. Er füüttelte ben Ropf und ftähnte: "Uch) rebe nicht

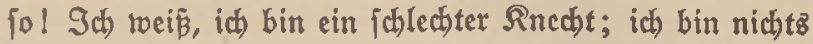
... gar nichtż" Er vergrub fein Geficht in feine Sände. "Dent bod nach... vieviel verjäume id allein faton burch meine Rranfbeit! 2lls ber Sunge pom Briefträger unter ben Wagen fam and ftarb und bie arme Mutter laut tweinend Durcbs Dorf ging und andere Qeute fie zu tröften verjuchten ... to twar ba Pajtor Boblen? Der lag da in feiner Gtube auf ber $\mathfrak{B a n t}$ und trant...

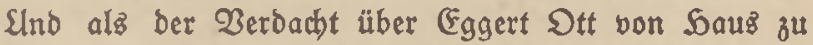
Souts lief und dieje fajrectliche (Befabr und शot über eurcm Saus ftand und jedermann bätte binzupringen müffen zu belfen, wor allem ich, ber 'Daftor, too roar Da Pajtor Boblen? (Ex lag und trant. Und nun verfolgen mich bieje Begebenbeiten, biejer tote Snabe und Dein 2 ruber Eggert, Der Durch bie $23 e l t$ irrt, bei Tag und Racht, und quälen mich. Rein, ich bin nichts wert... gar nichtz! Sch jollte dicjen Becher, ben ber bumme Ș̈njes Arpz mir brachte, obgleich er an meinen 2lugen $\{a b$, Daß meine Notzeit mal roieber ba war, und ber mit jeinem (Gleißen mich) verfübrte, daß ich) ibn gleid), wie er fort twar, biz zum Rano futllte und binuntergo $\beta$... ich jollte mir bie Stirn bamit einjhlagen ... ja, bas jollte ich! 2lber bas ijt ja nod) grobere Eünde... fo dabonlaufen! Slnd fo fige inf nun bier und laffe mir bas Serz zerreizen bon bem fabredt= lichen Wort Gottez!! " Slnb er nabm Den goldenen Bedjer 
in feine mähtige Fauft und falug bamit auf Die $\mathfrak{B i b c l}$ bå die ganze Gtube bebte. "Wenn die Engländer in Sütland lanoen uno bringen in Gchlesimig ein, bält midh fein Propft uno fein $3 i j h o f$, dann nebme id mein Getwebr ... meinen Eeehunder ... und geh mit. Dann

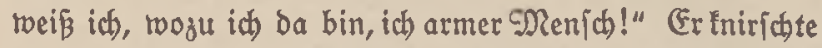
mit Den 3äbnen und die Tränen ftrömten über fein (Befid)t.

Reimer Ott trar blä́ getworben und bebte über ben ganzen Rörper. Diefe Reue uno Qual eines Menjchen mit grauem Saar, Dazu bieje fonberbaren eigenen 2 užbrüche einer inneren Nafur, waren ihm etwaz Neuez, etwas Furdutbarez. (E⿱ mit feiner tübnen, ernften Geele nad) ben (oründen, nad) irgendeiner (Erfenntnis, nach) irgendeiner (Ertlärung, nach einem Glauben. Slno ploshlich jagte er mit berzlidber Gtimme: "Sorr Paitor Boblen, ich babe es niemals fo erfannt ... i id babe ez bielleicht überbaupt noch nidht gejeben ... aber jest febe ich ez, nämlich, Da Gie als ganze Derfönlichleit und in jeder einzelnen 2̈̈ußerung ein Menich mit einem großen (chrectlichen Erbe find! (Es ift wirllic) eine Stanfbeit, Serr Paitor, und nichts weiter... ein Erbe ... und Shre eigente

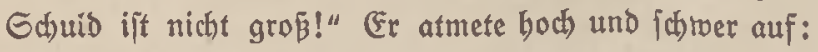
"Эक) bitte Gie, -jeien Gie gut gegen fich jelbjt!"

"Ia," jagte Paftor $30 b l e n$ und feine Soaltung und Gtimme twurden eftwas rubiger: "Ih) babe eir fobweres Erbe. $9 a$, id) tweís. Bielleid)t, twenn id in meiner Rindbeit in gute Sönde getommen räre, fo hätte id baz alte (Erbe unterbrücten tönnen. Wenn ich aud) immer

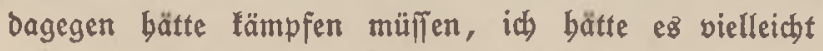


Bffer unb befier befiegt. 2aber mun raar ich, bas frierende und bungernde Rind, bem fdlimmiten Qebensfübrer überlaflen. Wenn du ein Mann wirft, mein Эunge, Dann

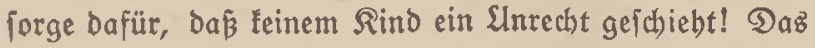
tann eine Nenjchenjeele in einem ernjten, tüd)tigen $\mathfrak{B o l f}$ twobl verlangen, Dá fie in Der Rinobeit wobl bebütet uno gezogen wiro! Sa, Daz jollte daz erjte bez Gtaatez fein. Wozu baben wir ifn fonft? ?ֶ."

Reimer Ottz 2lugen leuchteten von einem fäb̈nen Qicht: "Gerade daż will ich tun, Serr Pajtor, wenn ić) älter geworben bin! Slnd ich danfe Gott für biejen 2lugenblicf... benn 50 , jo in ber Siefe, batte id es noch nicht gejebn, wie idh es jest febe! Suno nun... roenn ez jo ift, Serr Pajtor Boblen, wenn es cine Rot ift, bie mit Sbnen geboren ift, und viel mebr Günde an Shnen begangen ijt, alb das Gie fie felbit begingen, fo follten Gie fich ermuntern."

Uber Pajtor Boblen ibüttelte traurig Den gropen grauten Ropf. "2lch, Reimer, mein Sunge," jagte er, "ich bin ein armer binfälliger Menj(d, ich bin in allem binfällig und unorbentlic) .... in allem!“ Slno mit Sränen in ben 2lugen fagte er: "Gich ... ich twill es Dir befennen! (Berabe bir ... was id) nod) feinem Penichen gejagt babel gerade dir, ifrem Gobn... Gieb, als ich noch jünger twar, zu ber 3eit, alz bu uno Emma, bie 3willinge, geboren traren, ba war beine Mutter frant gewejen ... bei Der Beburt ... und feitoen

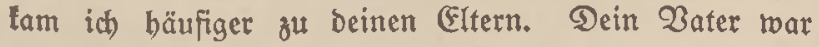
auf bem Gelde, uno id fás bei beiner Mutter uno euch) Rindern. Deine Nutter meinte, ich fäme euretrogen 
10 oft ... und roohl batte id) Freube, befonbers an eud beiden; benn ibr tratt ein paar brollige Rinber. lber i ftecte, weber vor mir now vor Gott... báp ich bamals beiner Mufter wegen zu euch tam. Эah babe jonit lein Weib geliebt; aber fie batte id lieb. Gie bat es nicht gemerft ... Bott fei Danfl Uber fieb ... mit mir ... mit mir ftand es jo!"

Da richtete fich Reimer Ott auf und jagte eilig uno freubig: „Da irten Gic Fich, Pajtor Boblen! Meine Nutter hat $e^{8}$ wohl gemerft, uno bat $\mathrm{ez}$ in igrer 2 eife mit mir bercbet, unb zroar vor einem $3 a b r$, in ber Rüche. Sie bejpricht

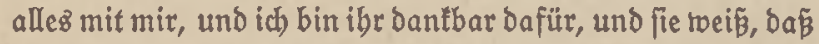
ich mit andern nicht barüber rebe. Sie jagte: , In ben Tagen, als bu uno Emma flein waret, da tam Pajtor Boblen

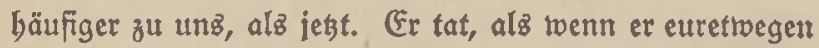
täme, aber ich mertte wohl, Das er meinetruegen fam! Uno id) jage dir, mein Gobn Rcimer, Darauf bilbe id mir toas ein! Denn Paftor Boblen ift Doch, gand abgeieben bon bem, toaz er für ein 2lmt hat uno tras er auf ber bohen Gdule gelernt bat, ber vornebmfte Nenid) im Dorf, euer Bafer natürlich außgenommen, uno waz̄ feine Rranfbeit angebt: ift Da einer im ganzen Rirchipiel, ber ohre Günde ift?! ... Wुeí̈t bu, twas Paftor Boblenz einziger Gebler ijt? I Nicht, baß er alle Biertel= jabr fich) mal jatt trinft, fonbern $D a \beta$ er fich von biejer feiner Not und Rrantheit auth nadber, twenn ber 2ungriff vorüber ift, fo niederbalten läßt! $\mathscr{B}$ enn er getrunfen bat, fo foll cr fich mit Reue und Qual nicht aufs balten, fonbern mit beiden Fü̈̈en trieder inž Leben 
und in feine 2trbeit bincinjpringen! TBieviel verfäumt er benn Durd feine Rrantheit? (Es find im ganzen Sabr vier $W_{\circ}$ elf Monate ift er treu bei feiner 2lrbeit; rie leiner fonjt! Waz tun Denn bie Bauen bier ben ganzen Winter lang?! Sie ftebn und fingen umber, und fotwaken ober machen fich unnübe Gedanten!' Go jagte meine

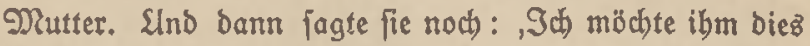
allez mal fagen, aber ich fomm' nicht bazu, tweil ich

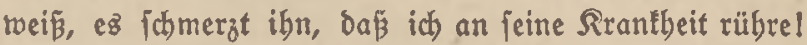
Sör': Du bijt ja jo'n bellijder Rerl und tannjt Geelen bebandeln ... wic bu fagit ... jag' bu es ihm! Ulno wenn es wirflid) Dazu fommt, baßi bu ez ihm fagft und idh bann vielleidst nicht mebr bin, bann lag' ibm aud

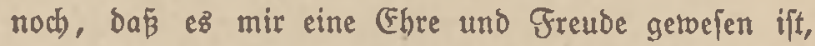
bas er mich einmal gern gebabt bat vor allen anderen Frauen im Rirchipiel, und bap er fich gut gegen mich benommen bat! Sa, bas jag' ihm!"

Pajtor Boblen batte Den Ropf in bie Sand gelegt unb treinte.

"Eie follten bann und ram fu ibr gefn, Serr Paitor," Fagte Reimer Ott feurig. "Wenn ein Wenich bem anberen belfen tann, bann tann meine Dhutter eв! " Eeine Qugen frablten von Liebe und Gtol auf jeine Nutter.

Paitor Bohlen liés bie Sönde von ben Gdläfen finten und jagte mit rubigerer Gtimme - ez mar, wie benn ein Gturm auzgerait bätte: "Sch Danfe bir, mein Sunge... bu baft mir robl getan ... ich danfe bir! Ulnd nun geb! Sör', warit ou fhon bei Deiner fleinen Freundin im Nachbarbauz?! . . U. Slnd lettere boch mal 
in ben Dachreiter Der Sirche und fieh nach, ob bu bie Worte Iejen fannit, bie auf ber alten Rlingelglocfe ftebn, fein Menfa fann fie enträtfeln ... Sh) will bier noch ein wenig fo ftilfiken uno nacbdenfen . . . du fannft mir noch den Band Reuter geben, bu weißjt ja, wo er ftebt ... gib mir den britten Band ... ich will ein wenig in Der ,Gtrontid" 【elen."

Reimer Ott gab ibm baz Buth uno ging aus der Gtube.

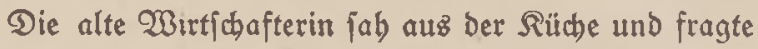
- Fie hatte robl ein falledtez Benifien -: "Wie war er? Sit er toieder bübjd?"

"Err macht fich jekt bübjoh," iagte er, nicfte ibr zu, uno ging mit feinen jungen federnden $\sigma_{\text {d) }}$ ritten an bem Qoch in ber Diele vorbei uno auz bem Siauje.

Drausen itand er eine Weile an ber Gartenpforte, ganz benommen von Dem, was er erlebt hatte. Es war das eritemal, Dafi er ein ganzes Menjobenleben überiebn batte, uno ez fhien $i b m$, er bätte erfabren, daß baz Menjchenleben immer, immer unfertig bleibt, und räbrt ez auch neunzig Sabre. Dagu hatte itn aud) ber Sammer und bie Not aufz tiefite betwegt, ibr 2lušbruch) nach auß̃en bin ibn erregt. $\mathscr{D} a z$ allez bedrücté ifn und twüblte in feiner Geele. SIno in bem Gefübl, dấ er bież alles noch lange nid)t böllig begriffen bätte, jagte er leife bei fid) felbit: "Sch mur über bies alles nod) viel nachoenten."

Ulno fhon in biejem Rachbenten ging er bie fleine Gtrecte Der Dorfitraße entlang and fam zu Der Pforte Des Tachbarbaufez. Da erit ridtete er fich auf und fpannte Den Beift auf biez pöllig andere: feine Heine Qieblite zu feben. 


\section{Rapitel \\ $\mathfrak{D e x} \mathfrak{R} \mathfrak{r a n z}$}

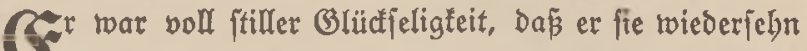
twürbe, und zwar alz einer, ber freimillig in ben Rrieg gegangen war, und daj er eine fo fdhmude Slni= form trug und größ̄er und viel crfabrener und flüger getworben twar. (Ex muste auch ohne ber Mutter 2ugen

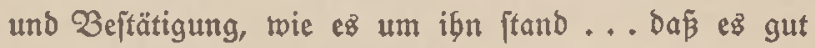
um ihn ftand.

Shre Eltern empfingen ihn freundlit) läfirig und ¡hidften ihn, ba fie zu einer Unterbaltung mit bem 2 dht= zebnjäbrigen weber Begabung noch Reigung batten, gleich zu ifrem Rind in ben Barten.

Sie fá an biefem lebten uno warmen Oftobertag

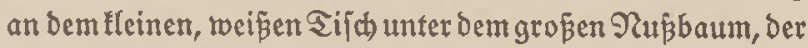
als ber Rönig unter Den Bäumen mitten im Garten ftand -

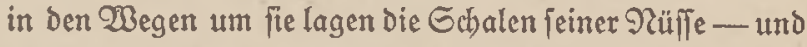

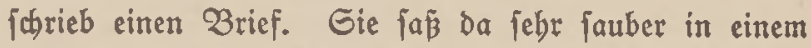
Galblangen Rleib, Daz loje, bunfle Saar, Das immer bei jedem Edyritt, ben fie tat, jo zierlich aufroble, von cinem roten Band umithlungen, und tauchte bie Feder mit einer langfamen, vorfichtigen, reinlichen Art ins Sintenfaßa, fah finnend ins weite Geld, und beugte fid) bann rwieber auf ibreri Bogen und fhrieb mit unendlich vorfichtiger Sanofübrung; benn auf jeber Ecfe bez̧ nur

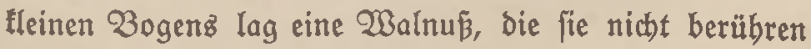
und von igrer Etelle fhieben Durfte und bie fie fich Dann für bie Yolfendung des Briefes zugeiprochen batte. Deun fic twar nod) balb ein Rino unb muste noch zu 
jebem Ernit ein Epiel fügen, damit fie bei ber Gtange bliebe. Er fah gleich, Daßj fie größ̈er gemorben twar unb baß ein neuer, weidher Gdhein um fie lag, und füblte, Das er nicht mebr fo frei beraus und ficher mit ibr reben tönne twie früber, da er mit ibe und ibrem $3 r u d e r$ am Deich in ber Gdhilfbütte von Gdäafer Sarber ge= feffen hatte. Er bachte, Du muß̉t febr vorfichtig mit ibr reden: etroa bon ben fibjnen, anmutigen Rinbern cinez 21 domirals, bie bu mal gejehen, oder bon fän̈nem, bellen Gommertwetter und Epaziergängen, ober bon ben böchiten Bebanlen, bie je in Menfd)entöpfe gelommen fino. Yor allem fein 20 ort von Rrieg vor ibren 2lugen und Ohren!

Gie furie auf, als er ibren Ramen rief; Denn fie batte now nicht erfabren, Daß er auf Surlaub auf bem Sofe rar, und fchrieb gerade an ihn. Slnd jah ihn gerabe im Bcifte auf einer jđönen, glängenben Fabrt auf ber Torblee. Denn fie fab nod das ganze Qeben und bie ganze Welt, und felbit Den Rrieg, in einem janften rofigen Lichte ... W3ie wurbe fie froh, baß cr ba twar! Slno war jo biel größer gelvorden ... und

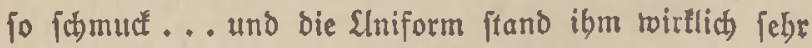
gut ... fegr gut! Gie war jebr glüdtich, Daf igr und ifres Brubcrs alter Epielfamerab uno Plänemaher da

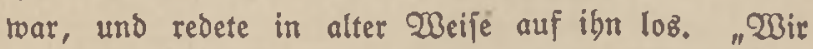
bleibent bier unterm 3 aum . . . auf alle Fällel Sier find wir allein! Slno ou erzäblit mir tras!"

2lber twas jollte er ibr erjäblen, wenn nidjt pom Sriege, wenn er benn bon fid) felbit erzäblen roollte? ! Slno won fich fclbit muste er Dod) cräallen; Deun bon ibm 
wollte fie boch hären!? Geinen Beift, feine Gedanten fein Leben roulte fie boch fennen?! $E_{r}$ abet fam mitten aus bem Rriege, bradte feine Tage ïber Sor" pedorohren zu, und lag nachts feinen Meter meit von Der blizenden Saut dez Sorpebos. Fr fragte fie nach ifrem Bruder und ibrer älteren Echlweiter, und machte fie auf eine Golbammer und auf bie Mismen aufmert. fam, Die vor ben Dunfelgrauen $\mathfrak{W}$ often vorüberflogen, ibre Flügel flammten vor bem Grau ber Wolfen, wie weipes Geuter. 2lber es rar nicht daz Rechtel War bas eine Unterbaltung, bie ibr gefallen tonnte?! Sln=

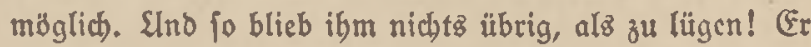
muß̈te ibr eben Den Rrieg fo fchildern, Daß er ibr ge. fiell Obgleid ez ber erfte und twidtigfte Brund jats feines 2ebenz twar, in allem rabrbaftig zu jein, bier muß̧te er lügen. Obgleich er von allem, von ben Rarpa= then und von Glandern, von ben Torpedobooten in ber Racht gegen England, bon ben $U=2300 t e n$, von Den Rezen im Ranal und von Der Brandung vor den Geilly. injelit, und von ben 3eppelinen und Qufifabrzeugen über Lonbon Daz richtige, barte, graulige 23 ild bor ber Eeele batte, erzäblte er ibr fdöne, vorncbme Dinge: von Ieuchtenden Gabrten burd bie blaue शacht, von fdbüner braujender Gabrt burd) bie ichimmernden 230 gen, von leichtem, lachendem 3 ing an boben goldfarbenen $W_{\text {olfen }}$ vorïber, bie ba ftanden toie bimmlifwe seerficharen

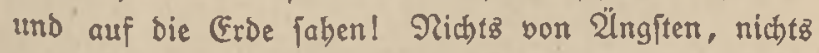
bon Rlagen und Antlagen, die gen Simmel fdreien, nichts von jähem $G_{t u r z}$ uno bittren $\sigma_{\text {d) }}$ merzen, nichtz von Seintoch und von leţten Grüṕen, bie nidst antommen 
fonnten, nid)tż von f(htwerem Sterben. Sie hörte ifm mit weichen, fchönen 2lugen zu und atmete langlam, und gab ibm jedeşmal, roenn er ein bejonders fäb̈nez

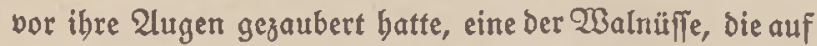

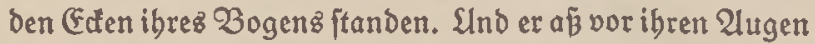
und crzäblte weiter, und war um ibrer 2lugen rwillen ein Tarr uno ein f́böner Pfau, wie vor zroei Эabren, als er fechzelyn war und die Rätjel ber Welt vor ihr gelöft batte. "Wie fatrade," fagte fie, "baß bu jelbitt noch nicht jo was Serrliches und Großjez erlebt bajt! Diejer Yor= ftó in Der Nacht gegen England ... bübld if er ja ... aber id toolle, bu fämit mal in eine grof̧e, getwal= tige E(hlacht binein und erlebtejt 20 underbarez."

Da fiel er von feinen goldenen Wolfen berunter und fab) fie an, baßj fie jurwieg. "Wुenn id) aber fiele," fagte er unficher, "und nicht roiederfäme?"

Sie fab finnend über den Garten. Sie dachte fich auc) basz Gterben f(hön, und nur fđjän ... ein plägs= lichez 2lužgebn cinez Qid)tez in einem beftigen, jäben

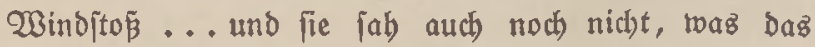
rechte, zu Ende gelebte Leben an tapferen Saten, an mutigen Müben, an bildenden Nïten, an ber 2luzein= anderjesung mit bem langiam nabenden Sode für Werte hat und bildet; und ibren Ginnen feblte nod) bie Quft an ber (Exideinung uno शäbe Deş Beliebten. Darum fagte fie langlam mit leifer, wel)mütiger Gtimme, obne groben Gamerz, ja mit einer ihb̈nen, finnigen Greude: " $\mathscr{B} \mathrm{cm}$ das gefdiebt... Dann will ich bier... unter

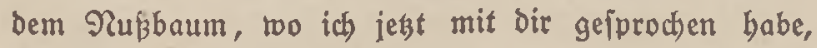
fiken und an bich benfen, und twill bich nie vergeflen!" 


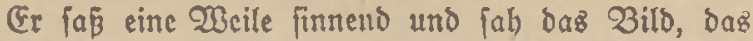
fie ibm malte; uno auch er war mebmütig glüclich Darüber. Dann aber jagte er leife: "(E⿱ märe boci) ( all bie fijonen Pläne, bie ich habe!" sind er fing an, von einigen Rameraben von ber Rieler Gdule und von feinen beiben tretten Freunden in Wilbelmşaven zu erzäblen, welche boben Dinge er mit ibnen beredcte;

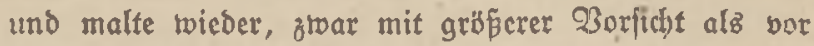
z'wei Sabren, aber mit Demielben Geuer, ein Bilb ber 3 ulunft einez reinen und freien 20 olfes und einer boben

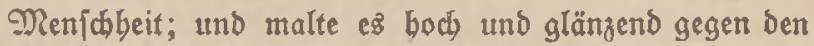
weiten, weiten Simmel.

Slno Da, als er fo redete und alle Edjeu vergá und nichts wollte, als feinen beift ibr mitteilen, uno Fich porbeugte, und nit blisenden 2lugen und fä̈n be. wegtem Mund iprach, da warbe ibr munderbar tweid)

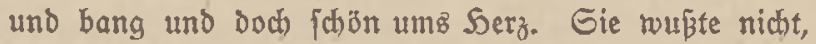
twie ibr gefdah. Sic wollte fich zuriatefiegen, baß er ihr nicht to nabe twar; aber fie fat ez boch nicht. Sie blieb in berielben Soaltung und dachte mit jtarfem Socrz= tlopfen: ,Was bat or für fob̉ne 2lugen! Wie fanner futfen!' Er fpringt ja mit jeinen 2lugen in meine Ginein! Slno fie füblte, Daß̧ fie langlam rot nurbe, und ftand rajक auf.

Er batte gejebn, baj fie rot und verlegen wurbe, und twurbe es auch), und trat ein wenig von ibr zurülf und folwieg. 2lber als cin rechter Mann uno alfer Goldat murbe er balb wieder ficher und fagte, um bon andern Dingen u reben: "Waz meinjt du, wollen wir mal nach bem Surm binaufgehn? Pajtor Boblen lagt, Erenffen, Die grttber. 


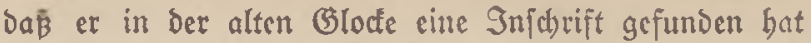
und fie nidht enträtjeln fann... toollen wir mal gebu und fie anjebn?"

Gie faste fith roieder, erbob fich und ging mit ifm nach der Rirche, und erzäblte ifm, nun wieber ganz ficter, baz Heine bejondere Erlebniz: "Ia," fagte fie, "Dente Dir, alż \$ajtor Boblen neulict bie Fledermäuje, bie oben im Surm twobnen, bejebn twollte, entoecte

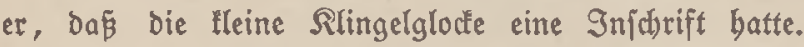
Er rief mir vom Sutm berunter, id, möbte mit Waller uno Feudel binauffommen; und da baben wir fie gereinigt, und nun ftebt bie Injujrift ganz beutlich ba. 2lber was meinfit du: wir tönnen fie nicht enträtfeln! $\mathfrak{D a b}_{\mathrm{a}}$ gange Dorf ift fchon oben getweien unb hat ez berjucht! Nun . . . Daß̄ Daz Dorf eż nidjt fann, ift ja begreiflid); Denn

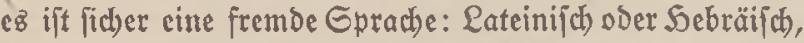

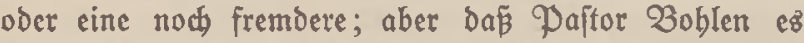
nicht fann, ift boch ftarf, und bas babe ich ifm auch gejagt. Sch babe ifm gejagt, er jolfe ooch lieber feine alten gelebrten Bücher twieder vornebmen, ftatt bei Tag und Sad)t im Watt und auf ber Seibe und im Eidjen. fratt berumzulaufen uno bie Siere zu belauern."

Gie twaren burch bic Bartenpforte auf ben alten Rirwbof getommen, betraten bic Rirche und fitiegen bie Treppe von altem, ausgebórrtem (Fichenlyoly binauf. (Fz war gerabe Plag für zrwei nebeneinanter ju gehn; Die Gtufen waren febr bo() und ausigetreten, und fie mus̄ten tüchtige Sdbritte macten und bie Rnie beben. Es

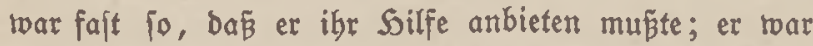
auch immer nab Daran, baß er fie berübrte. 2lber er 
fonnte zum Blü beibez vermeiten, unb jab gar nicht nach ihr bin, wäbrend fie idweigend Etufe auf Gtufe nabm.

Sa, und ba hing bie Gloctee, bic er ja bon feinter Rnabenzeit ber fannte! Uno in Der Tat waren ba mun runbberum um ibren Rano, da, too früber in Roít und Vogelichmus nichts als undeutlict)e (Erbebungen gewefen waren, die man für ein 3iermufter gebalten batte, Bud). itaben, undeutliche freilich; uno zur Eeite auf bem Balten lag ein 2boruct Davon, eine jogenannte Pauje, aużgebreitet. (5z rar eine Reibe von ctwa viergig undeutlich getrorbenen 3 uchjtaben febr alter frorm; Davon maren fünf ober fect) o vällig verwittert. Die Gchwierigkeit ber $\mathcal{Q}$ jung aber lourbe bejonders gró

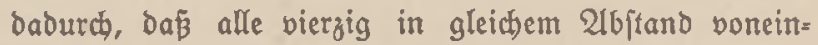
ander ftanden, fo das Anfang und Ende ber WB̈rter in feiner Weije audi) nut angebeutet war.

"Sieh," fagte fie eifrig, "Da ifit eś! (Ez liegt aud) untell in ber Wirtfhaft aus und wenigftens fünfbunDert Meniden baben fchon werjucht, es zu lejen, utno tönnen ez nicht, Darunter fünf oder (cch) 叉a Sie beugte fich Daritber und glitt mit bem Finger über Die Rcibe.

Er ftand binter ibr und twar etroaz ungejdict, wie er es ordentlich überfeben follte, wenn fie nicht etwas zur Geite widhe. Ta fie aber fo blieb, beugte er fich bicht neben fie und überfah bie Buchitabenreihe, die ungefäbr to aubjab - mobei baz 3eichen $x$ bie $\mathfrak{u n}=$ beutlicf) gewordenen bezeichnen foll - h. e. x. n. x. p. i. e. v. x. k. e. h. e. f. t. m. x. g. e. g. x. t. e. n. 
g. a. x. e. h. e. 1. x. d. e. e. m. 1514. (Gr überflog eв̊ no屯) cinmal. Dann lachte er turz auf uno lagte: "Das ift ja plattbeutfch uno beipt: Soeini Diefefe beft mi gegaten. Sade - bas ift Gott - belpde em. 1514."

\$ly ftand Der Utem vor Berwunderung fitll, Da es plattbeutfh) rar, und twas es bié; aber noch viel

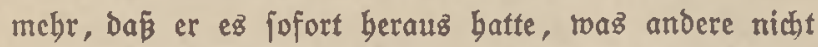
getonnt ... Gie bachte, wäbrend ibr baz Serz rieder jäb Hlopfte: ,Wie ift er eigentümlich rafd ... er ift über* baupt fo raidh ... fo jeltjam darin... und wie cr mir fo nabe ift uno mich anfuct'! Slnd trifft mich gerabe ins Soerz. 2ld Gott... wie ijt er rajh) und jo lieb! Und wäbreno fie vorber geztweifelt batte, was f(b) iner wäre, $o b$ er roiederfäme ober ob fie da unfer bem Nuß̈baum in Garten zeitlebenz an iăn denten follte als an ibren guten Freuno und Solben: mun plöglich, indem fie nicht twußste, wie ibr geidab, ftürzten ibr Tränen aus den 2lugen und inbem fie den Sopf aut

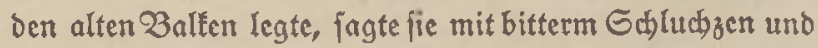
zudfenden Gdultern: "Du folft miebertommen! Du folfit twicberfommen!"

Er twar erît pällig vermirrt, Daj ber alte Soeini Piefele mit diejem Eprudy diejen Erfolg batte; aber er berftand fie boch bald. Er blieb aufrect neben ibr itebn und fah über fie reg überz weite Lano nach Wejten $z^{u}$, two baz Land uno dabinter baz Meer im Abendichein lag; und bas Serz rar ihm plöglich feir id)roce. Er fabrieg eine ganze Weile, wäbrend fie \{hluchzte. Dann fagte er unficher, wic ein Den[ch, Der fich im Dunfeln vormärts tajtet: "Daß̉ Gott mir 
bilft, twie er bcm alten Seini Piefefe gebolfen bat bei

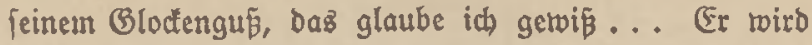

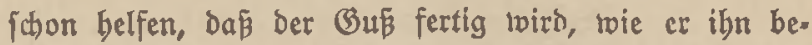

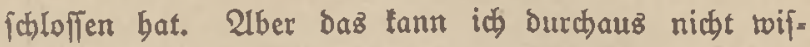

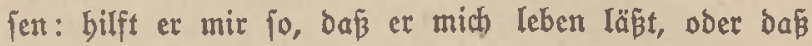
cr mich fallen läpst... und mich anderziwo vermendet ... benn er bat ja 2rbeit genug."

Gie weinte und fobric beiß auf: "Nein!" fagte fie, "bu folfit micbertommen! Du jollit wieberfommen!"

"Romm," fagte er leife; "wir wollen uns ein wenig binfegen und übers Land febn; Davon wirb man rubig." (Er feste fich auf bie fleine Banf, bie da ftand; und fic fá neben ibm. Slnd er begebrte, etwas von ibr zu berübren, zu baben, und fab ibre Sand, bie in ibrem Gdop̃ lag, und fagte: "Deine Sand ijt nod) immer dicjelbe geblieben."

Ta legte fie, nod immer treinenb, die Sond auf fein Rnie, unb er ftrcichelte fie; Dann bielt er fie fejt und fie faßren Sand in Soand.

Wie felig das nun war in allem Reio! Wie rounderbar! Sie waren beibe binweggeboben, wumichloz, ereignislog, unjagbar traurig, uno boch felig. Eo jaßen fie ba uno fatmecten die Güpigfeit der Liebe, bie um fo ftärter roar, als fie now obne Begebren war, und faben über Das Lano, das im Grieden Des Gpätherbjtez zu ihren Güßen lag.

Ullz fie aber lange fo jaß̧en, famen die Bebanten zuleģt bow wieber auf ben Rrieg als auf Den Boruno uno 2 nfang ifrer Sraurigteit, und fie legte Den Ropf in bie Sand, die fie frei batte, und weinte bitterliф. 
(Ta tourbe aud ifm bas Sacr wicder fotwer, ullo fo idhiber, wie cz noch nie gerwe fon roar. Slnd cr lämpfte einen barten und fdweren Rampf zivi ichen Iugend und Tob, und wurbe Durd) bas ichivere 3 lut von feinem Bater ber uno ein buntlez Befübl in ihm getrieben, daß er fid) ergab, Daß̧ er fein Leben Dabinten liej und ez als gewejen [ah. Slnd es fam ber Wunfh alles Lebens über ibn, bier unten auf ber (Erbe nitht vergeffen zu fein. Slnd indom er wie träuneno noch einmal alles überfab, was er bier geliebt batte, und in cinem ans. gemeingefübl ber Menichenfeele weniger an bie einzelnen Renjchen Dachte, bie er laffen müffe, als an bieje Lano= jhaft, bieje Natur, bieje Erbe, bieje Nenichenerde, Davon cr ein Rino raar, fagte er mit zögernder, unjicherev Gtimme: "Weenn idh nicht wiederfomme, dann möcbte ich, Daß̧ Du ... weißßt bu ... wenn du vom Norben her Den $W_{e g}$ nach dem $W_{0}$ bansberg hinaufgebit. . . fo ift da cine grope Mulde ... die ift mit Garnen beftanden ... uno rundberum, zu beiben Geiten, auf bem Rand, ftebn Heine, ftämmige (Fichen, bie werben nidht geidlagen. Dut fennft boch Die Mulde? Es ift fehr fän ba und fitill und man fiebt von ilyrem Ranb tweit übers Land unb fiebt auch tie Norojee; und id denfe mir ... nein, ez iff ficber ... daß da, in der Nulde und auf ibren Rändern, taujend Iubre lang unjere Zorfabren angebetet baben ... Wenn id denn falle ... po müd)te ich, daß̧ du da an Der gröbten Eiche... menn man binauffommt rechts oberbalb, nicht tweit von ber Sobke . . e einen Rrang für mich auflyänglt, ber ba immer, imuter bängt zum $\mathfrak{G} e=$ Däc)tnis an mich. Ėz foll feir Tame babei ftebn... 
id) babe baun feinen Namen mebre, ober ich babe einen anbern शamen. 2lber ber Rranz . . S Snd jo lange bu bier bift, wiro es mir licb fein, da官 du ibn beforgft, uno baj bu, folange du lebjt, bann und wann beż Weges fommit und eine Gtunde bort auf ber jhb̈nen Söbe verweilft. Willit du daz?"

Gie nictte unter Sränen; ipreden fonnte fie nicht.

(Dann, als twenn er num allez beroerffitelligt bätte ... fo wunichloz und gró̄ war er in feinem Gemüt und vor bem Sobe ... ftand er auf; und fie gingen bie fteile Sreppe trieber binab unb aนริ ber Rirche.

Gie batte fich berubigt und ging ftill neben ibm. An ber Grafie gaben fie fich bie Sand und gingen voneinander.

Am andern Bormittag ftand er rwieder in Saus und (Barten unter feinen Reuten umber und (prach mit

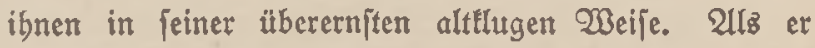
am zroeiten Nachmittag feine fleine Greundin roieder auffuchen roollte, erfubr er, bás fie plöglich zu einer erfranften $\mathfrak{B e r w a n d t e n}$ ins Bjtliche Solftein gefabren fei und nicht ba wäre.

Da ging ex, räbrend er an Den Bormittagen ou Sauje war, an ben शachmittagen in bie Seide binauf unb raanderte ba umber, ober faj $\delta a$, unb fah übers Rano, und genoj bie Einjamteit und die Seimat= landiđaft; uno erging fị in unzäbligen groben $\mathfrak{B}_{e}=$ Danten, bic twie $20 ̈ g e l$ im Nebel, bie man nidbt fiebt ... aber man bört fie ziehn... vor ihm vorüberflogen, ohne Ende, ohne Ende, alzె 1wenn Leben und 2lrbeit noc) envig bauerten. Geine Tobesgebanfen batte er nun 
ballig vergeffen uno fajt aud ben Rrieg. W3as twar ber Rrieg vor joldjen Gedanken? Fine lurze Gtrecte Slntub. Die ging vorüber, twar balo nidst mebr in Wege, und toar faum getwejen.

IIm neunten Tag feincs Slrlaubs, am Gountag Morgen, fam eine Botichaft inż Soüz, Daß̄ Bruber Rlauz auf Slrlaub ba wäre. (Er toar nodh Retrut, und feine Garnifon toar nicht fern; und er tonnte alfe vier Wocben zu einem breibigitünoigen Slrlaub nach Souje tommen und bort nach bem Rechten febn.

Da ging er burch Dent falten, frifhen Oftobertag Der Gecft zu; und fam in Gedanfen, er wup̃te nidat roic, auf Die Soffitelle Dez Zrubers.

(Es jah auf der Soffitelle nods etwas unordentlicher und

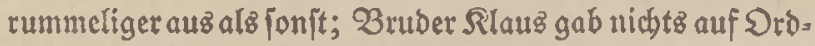

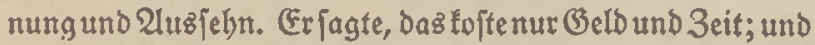
Der Soof läge ja einjam; fein Menich (d)iere fich darum, tvie es darauf auzjebe. Slnd jeine Frau batte nie 3eit, etraz bafür zu tun. Gie bätte ja aud), twenn da Oronung getweien wäre, einen (Bruno weniger zum Rlagen gebabt.

Fr ging Durchs ganze Saub, in bem alle Füren offen fitanden, und tam in Den Barten, um inz Gelo zu Febn. SAnd auch ba fab er fie erit nidjt; dod börte er ibre Gtimmen. Endich fand er fie auf bem Rartoffelfeld binter bem Garten. Sie jaß̧en ba alle am Wुall, von oben biż unten nichtz als ftaubiggraue Erbe, richtige Wüblmäufe, und aß̉en

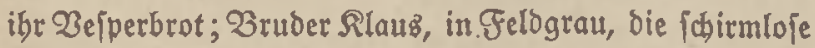
Mübe tweit zurüctgeiळoben, Die Binde im Racten tweit aus bem Rottragen berausrageno, in ibrer Mitte. Sie freuten fich berglich, Daß̧ er fam. Bruber Rlaus 
fland jogar auf, fo fteif er bon der arbeit toat. Der Ültejte muBte Iaufen eine Taffe bolen, Damit ber 3 ruber cinen Gdhluc Raffee befäme. "Sa," jagte Bruder Rlauz,, "mun bir id auch Golbat! Wer mir baż vor ztwei Sabren gejagt bütfe! Sa, noch oor eincm Sabr!" Slno er wies mit der graü̈berftaubten Sand nach ben fleinen Söfen, Die verjtreut in Der Räbe lagen, unঠ erzäblte lang und breit, two ber und ber शachbar twäre unt twie ez ifnnen ginge. Finer roar in Dftibirien in Befangentidaft. "20az der roobl für 2lugen mađt, Reimer! (Er ijt nie über bie Lanbichaft binauzgetommen. Slno jegt ift er $\mathrm{Da}, "$ und er zeigte mit Dem ausgerecten Finger bicht oor fich auf bie graue fandige (Erbe ... " "auf ber andern Eeite ber Erde! ... Und ber da ift gefallen ... an der Gomme... und der da ... Der ift mit mir in einer Rompagnie... WSie esి mir geht? Tun

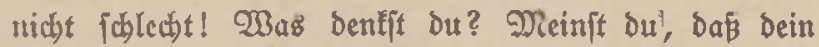
Sruber Slaus fich da blamiert? Daz Ejfen fönnte natürlich befier jein; aber in übrigen ... nut, wie es eben gebt! Den Tag über bat man feinen Dienft ... Du fannit eż dir ja alles denfen ... uno nad)tż (c)läft man."

"Er vergī̈t uns mieber ganz, Reimer," Hagte bie Flcine Grau.

"Sch vergefle euch nicht!" jagte Zruber Rlaus. "Wie folf ich) euch vergefien? Shr arbeitet und quält euch) bier ab für unjern Sram, il)r fleinen Gtactelż, und ich jollte eurb vergeffen?! Эa) jage dir, Reimer, fie fino Selden, bieje fects bier! Go wie fie bier am Wall fitsen: jeder ein Selo! Der ba, der Eleine Mrabat 
... fieben Sabre alt; aber id fage bir, er faumelt die Rartoffeln, wie 'ne (Elfter golbene Ringe. Sफ) babc mal fo was gelejen."

"Ich habe viel an bich gedacht," fagte Reimer. "Dit warit in beinem Qeben nie auz biejer Gegend fort; Dein roeitejter $\mathscr{W}_{e g}$ ift rabarbaftig biz zul Dem Rirchturm ba getwejen. Uno Mutter jagte mal fo twas, fo als wenn bu leicht Seimmeb befämit."

Bruber Rlauz runzelte bie Gtirn uno fah ein wenig unficher in bie Gerne. Er war einmal, alz Gechzebn, jäbriger, von feinem $\mathfrak{B a t e r}$ zu cinem 2 auern gegeben worben, Der z'wei Gtumben Wegz entfernt rohnte, Damit er Sunterichied lernte. 2lber er toar nod) am jelben Sag, jpät abenos, wieder vor ber Rüchentür Dez Celternbaules erfachienen und hatte befannt, er tönne bas Qeben "in Der Frembe" nicht ertragen. Er fürchtete, Daß̧ 3 ruber Reimer bieje Bejhichte lannte, obgleich Davon, als von einer Ileinen Gamilienfdymad), im Saufe nie bie Rebe war. „\$ch, Seimtweb?" jagte er grobartig. SUnd im alten Flü, ficher und feft, mit Dem tiefen, vollen 2 ruftton, in Dem er immer zu feiner fleinen Serbe fprach, fagte er: "Weipt bu, es gibt welche da, die Seimweh baben; uno roovon fommt baz? Teil die Seimat zu nah ijt! Eie gebn jeben Eonntag nachmittag auf bie Soshen, bie ba find, und reden dann bavon, twas rundberum in ber Ferme für Gtäbte und Dörfer find, und ftehn ba uno ftarren ba binübel, uno machen fid ... im Geift, veritebit bu ... auf ben Weg; und dann ijt Daż Ulnglül $D a !$ Dann find fie fitiller alz fonjt, weil fie immer ba binüberbenten; und, firisen länger auf 
ibrem Gtrob[acf; und Fỉmen baun auch nidit idslafen. aber ids? ... Seimbeh? ... Nein, dab iff nicht Der Fall!"

Die tleine Frau batte ifn betwundernd angefebn, wäbrend er fo groß̃ redcte, und jagte mit leudtenden 2ugen und Klagenber Gtimnre: "Waß bie Männer boch für Reute find, Reimer! Rein, glaubjt ou, Daß er an unz denlt?! Slno iff jonjt Dod) fo'n guter Mann!"

"Эath Dente an euch," fagte Bruber Rlaus voll guten Getwiffenz. "Wie follte ich nicht an cuch benfen! Eold)e fixen Qeute vergeffen ... was bentft Du?!" und cr zeigte auf zmei ber Rleinen, bie fo um brei 马abre alt waren. "Dieje beiben Rreinen ... was meinft du ... find neulich binter ber ßub hergelaufen, bie auf bem TBeg roar, und baben fie richtig rieber burchs Sect und auf bie Weide gebracht . . mit einer Galaubeit . . mit einer Echlaubeit... Tage idh bir! ... Nein, eв tut mir

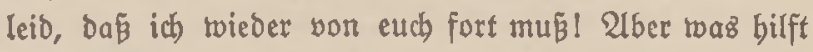

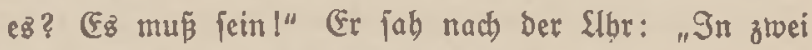
Gtunden muв ich von Sauje fort."

rach Dem 2lbendbrot gïrtete Bruter Rlaus fein Soppel um, tüßjte Die Sileincn, bie ichon im Bett lagen, und ging Dann, fein Weib am $2 \mathrm{rm}$, die brei Bropen an Der Sand, Bruder Reimer an linten Flügel ... Der alte fandige Seerweg twar breit gentig und vom Regen feít ... nach bem Babntof.

Die Frau flagte, was fie alles für Lajt baben würbe von diefer $\Re$ ub und von jenem $\Re a l b$, von jenem Sinztag uno von diejem Söndler, Der fïcber tommen twürde, ifretrwas abzuictrasen. Bruber Slaus redete grope Worte, fie 
folle es rubig anjeḅn und anjtebn laffen, bis er wieberräme - er täme ja balo wieder! - und ruß̧te für allez Rat, war leichten Serzenz uוઠ groß̄en Wortez. 21m Rreuztoeg lefrten feine Grau und Die Rinder um; uno nur Bruber Reimer ging nod eine Strecte mit ihm. Zruber Raus fab fich wieder und wieder nach feinen Reuten um, obgleich nicht gut möglich twar, Daß ex fie noch febn fonnte, ba fie binter einem Soügelrücten pet(c) wunben waren. Sjatte er fid) Dann vergebeng umgelebn, bob er bie Echultern und ging tweiter. (Fr twar plöglich ganz ifweigiam getworben, fab vor fid auf bie Erbe und zucte die Gdultern. "Wुeipt Du," Fagte er mit veränderter, miß̄mutiger Etimme, "meine Grau klagt zu viel! Gie madt einem reinweg das Serz fdwer." (Er ftand wieber ftill und fab nach ber Kichtung Des Saufes. Gein Bruder fab ibn von Der Geite an und madhte Fid an biefem $\mathfrak{S a g}$ zum erfenmal Gebanten iuber ihn, (ab) ibn zum erjtennal als 2 ejen für fich, in feinem (Fignen lebeno, und wunderfe fich und Dachte: ,Wie tann man boch nux fo fpielig fein, fo in Gedanten und Worten bin. unb bergleiten, wie Der Wintbauch webt! Wie ift biejer mein 3 ruber verjhieben von mir!' SIno

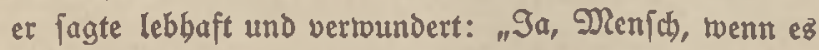
dir unangenegm ift: warum befärtfit bu fie Denn Darin, indem Du ben Gtarten fpielit und Den groben Selfer?"

Bruder Rlaus fab ibn von ber Geite an, fo als toenn er jagen twollte: , So'n junges 2 lut will mix raten!' und lädbelte tlug, glüdlid und ftolz, uno jagte: „2aber ift es nid)t bübid, wenn fie fo alfe auf mich jebn uno tnich mit ibten groß̧en 2lugen antudten, und alle 2lugen 
fagen: Tu bergift unz bod) nid)t, Bater? Rein, unjer

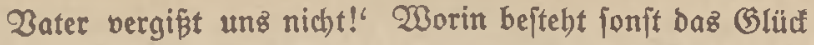

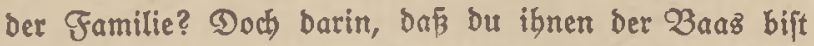
und fie alles von bir ermarten? Uber daz ift roabr:

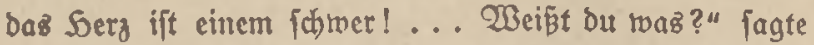

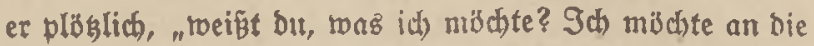
Front! Damit bicier nerbammte 2ufenthalt ba in Rends= burg unb biefe Befuche zu Saule atfbören! Weg mit Diejer Grat ... und ben Rindern und Den Tieren und ben Felbern! Entweder bier im Sauje tagtäglich feir uno ben $2 a a z$ fpielen, ober Goldat irgendwo in fremben Land, taujend Meilen von zu Sauje, wo die Woblfe (iid) gute Nacht jagen! Dieje (Sarnifon iff zut nab! Nan benlt uno fiebt immer wicher baz Soats mit allem Drum uno Dran! Saft bu gejebn, Daß̧ sie Wand Der Gcheune ichief gefactit ijt uno $\delta a \tilde{B}$ ich fie mit Dem alten

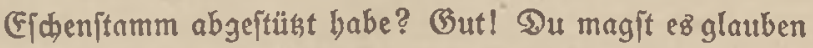
oder nicht: bieje fdriefe Wand mit bem Ejchenjtamm febe ich, wo ich gebe uno itebe! Sch jebe fie bei Sag auf bem Rajernenbof und nachtz auf bem Gtrobjact ... ja, ich) febe fie im Geficht bes Felowebcla und in Der Êrbjen: juppe! Benug, id babe mich an bie Front gemelbet! Rieber Fetrer uno Echrofel nom Simmel, als biefe Exijteng! aber ber Souuptmann will mich noch nicht loslaffen. (Er fagt, ich bin nicft recht ftarf. Er fagt, id bin tein ftarter Menjh. Slnd das ift ja alth wahr.

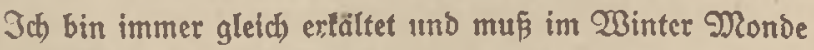
lang buften." Eo rebete er mit grofem Eifer, 3orn und faft 2lufregung, fo Daß Bruber Reimer gar nicht vor lbm antommen tonnte, feine $\mathfrak{B b e i z b e i t ~ l e u c h t e n ~ z u ~ l a f f e n . ~}$ 
- Eo tamen fie bis zut ber Etclle, wo Brtuder Raus abbiegen mupte, um auf der Scibeipur, bie ben $\mathscr{W} \mathrm{cg}$ febr abtitzte, nach dem Babnhof zu fommen. Da gabett Fie firth bie Sand, und 3 ruber RTats trabte allein weiter. 3u Sauje erzäblte Reimer Der Mutter, wie ber Bejuch abgelaufen wäre, tnd in jeiner 23 eije allez, twaz er erlebt batte. Slm feine Gedanten gu flären und in einen Ertwerb für fich zu verivandeln, jagte er: "Bruber Rlaus ift getwís wunderlich ... ja, man tann wobl fagen, $D a \beta$ er fajt immer und in alfem eine idjiefe

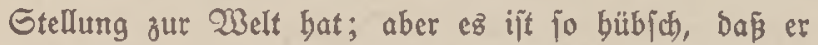
in biefem rounderlicten $W_{\text {ejen }}$ fo ficher Iebt."

Eeine Mutter mupte mit biefem großßen Gab nidit recht twas anzufangen und jagte: "Da a er wunderlich

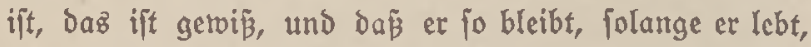
ift auch) geiví; ficher ift, weís ich nicht und glaube id nicjt und babe meine Grtinde Dafür; uno tweiter fage ich nichts über ibn! . . S Sno nun erzäble mir mal ordentlid, wie rat ez Denn neulich bei ben Sambutgern? $23 i f t$ bu nod immer jo gut Frentud mit Der flcinen Deern?"

Gie redete ibren Rindern nid)t in ihre Qiebesan= gelegenbeiten; aber fie fonnte es bei ihrer fräftigen Ratur nicht !aाjen, allez freunbidaftlich mit ibnen zı erörtern, und im Geift mit ifnen auf die Freite zu gebn. 


\section{Rapitcl \\ Die Mutter}

Q1 $m$ vorlekten Tag wurbe ber idjöne Griede feineż

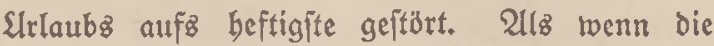

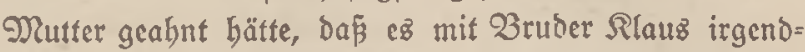
wie nicft in Oronung wäre! Radbmittags, fo um vier Slbr, faben bie Nutter uno Reimer, bie in der Rüche ftanden, bie Frau von Rlaus vom Geldweg ber auf bas Saus zutommen, und fahen fijon von weitem,

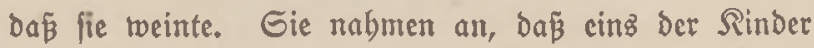
frant wäre, uno traten binatız ibr entgegen. 2llz fie bann näber tam, erzäblte fie, dá⿱ geftern mittag cin Telegramm aus Renožburg getommen wäre, Daß ibr Mann oon feinem Slrlatb nidft in bie Garnijon zurürđgeftchrt wäre; und beute morgen war Der W3acht= meifter getommen, und batte fie lang und breit autzge= fragt, wann uno wie er von Soalie fortgegangen roäre

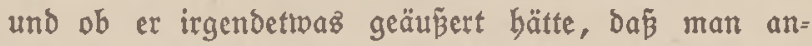
nebmen tünne, er bätte an Fludt)t gedad)t. (Dann war

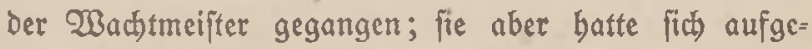
madjt und war bic einfame Epur über sie Soeide ge= gangen, ob er da vielleicht läge, franl ober tot. Eic hatte binter jeben 2 all und jeden Baum gejefn, und batte mit jachter Etimme feinen Namen gerufen; aber fie batte nidts gefunben. Slno nun twar fie bierber gelaufen; benn bic Nutter war ia biejenige, bie nod) auf= rechtifände, wenn alfez umficle. Go erzäblte bie łleine träntlid)e Grau. Die Saare ftanden ight zienlich trirr um ben Ropf, und bie 2lugen barin waren noch wirrer. 
Dasิ war nun wieber eirte Gadje! Weldh eine Not! Welche Slngerwipheit! Weld Gerede! Welde Ghande! (3lüdtidhertweije twar niemand fonft in der Rüc)e als Die brei, und börte ben Sammer. Gie jaß̄en ftumm Da. Die beiben Frauen reinten; Reimer ftand an die Tür gelebnt und ftarte in bie buntelite (Ecte am Serd. Er nabm obne reiteres an, $\delta a \beta s ~ b a$ wieder irgendeine , [diefe Stellung zur Welt' vorläge, und war zornig auf ben 3 ruber und beradjtete ibn.

Die Mutter, im Shiglitef fdon erfabren, befann fict zuerit. Gie ridjtete fid auf und fagte: "Wir roolletr ez noch teinem Menfकhen erzäblen, auch $\mathfrak{B a f e r}$ nicht, unb wollen uns zugleich aufmachen und zu bir gehn,

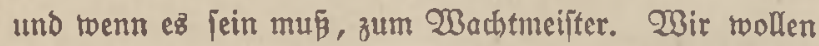
bier jagen, Dấ einz deiner Rinder trant märe." Gic ging in bie Gdhlafitube, legte mit fliegender (Eile ibr Gonntagzlleio an, lam roieber, rief Emma aus bem

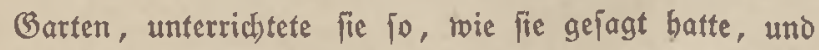
roar zum 2ufbruch bereit.

Sie madten fich auf ben $\mathfrak{B e g}$ und berebeten unterwegz, was geidhehen fein mödjte. Die Fraut meinte, er bätte irgendwo den 3 ttg verpast, fich Dann zu Fup nufgemad und wäre auf bem Wege frant getworben uno geftorben, uno läge ba nun irgendwo in einer Sleibe. mulde tot, und fie jammerte in fich binein'. Die Mutter redete von Seimmel). Gie meinte, er tönne aus Seim. weh irgenteinen Dummen Fluchtoeriuch gemadht baben.

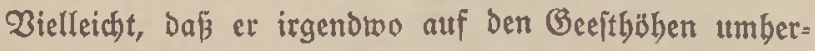
ranberte, wo man bas Saus nod) febn oder renigitens abnen fönnte. Gie überbacbte fein Leben und feine 
Tatur und roas fie ichon mit ibm erlebt hatte. ,Fin Prabler," Dachte fie; aber inmendig fein Solb." Shr Eobn Reimer fagte tein Woot. Er war voll 3orn, uno fand es burchats untwirbig, bof er biejen Weg maden muste. Eelbjt feine Slniform war ily zu gut Dazu und fat ihm leid; tno als bie Bänder jeiner Nü̈se, vom Torbmeitwind gejagt, nach vorn flatterten, warf er Fie ärgerlich binter fich.

Uls fie den Sof erreicht batten und fich gerabe

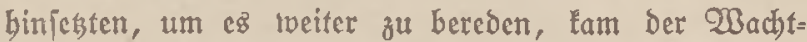

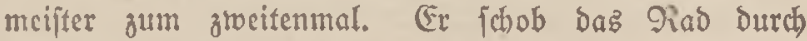

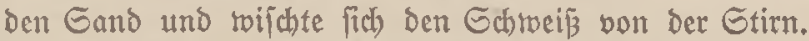
(Fr war won älteren Sabren und jdjon lange im 2lmt uno allen twoblbefannt. Gie traten beraus und ibm

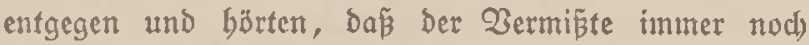
nicht ba wäre. "Sdh treiß ja, Frau Ott," jagte er, "Dan Shre ganze Fanilie orbentliche Reute Finb, und Daß eire Dejertation natürlid) nicht borliegt; unt po habe id) benn bistber audh gegen jedermann gejdtwiegen. Zlber morgen frül mứ ich ez befannt machen, Damit nach ibm gefudit wird. Sch roar beute bormittag nad) Dem Babnhof, wo man fich aber nidht erinnert, ibn gejebn zu baben; Danach bin ich brei Gntuben weit in Der Ridtung nach Renosburg gefabren und babe mich ülberall nach einem Goldaten umgebört, babe aber nichtz in Erfabrung gebrad)t. (58 muß bod) irgendroie eine Ertlärung vorliegen ... zum Donnertwetter! ... aber id) zerbreche mir vergebenz ben Ropf." (Ex jab Mutter Ott fragend an.

Mutter Ott fubr mit ber Sano über ibre ergraufe Frenifen, Die grtiber. 
Erläfe und fagte: „2luch rir brei baben bis jest zul anberen $M(e n j$ h) wir zerbrechen unz ben Ropf, twaz ez fein fann uno waz wir benn unternebmen tsuncn. Da auch nach unjerer Reinung bon Dejertation nicht bie Rebe fein tann - et läuft boch nicht für etwig von $\mathfrak{W e i b}$ und Rino - fo bleibt roobl nur übrig, bá er fich in irgend. cinem sinfall zu $\mathscr{F}$ ü nach Rendzburg auf Den $23 \mathrm{eg}$ gemad)t und ba auf irgenbeinem ber einjamen $\mathfrak{W e g e}$ ober in irgenbeinem einfamen Sauje trant liegt. 2Inores tann if mir nidjt benten." Slno da fie in biejem 2lugenblict das bachte, mas fie fagte, liefen ibr bie beflen Stänen über bie gefurchten Wangen. "Er i i t tot ober irr," jagte fie, "Shr roerbet ez fpätejtens morgen erfabren; bis babin gebuldot (Fuch noch!"

Der Wadjtmeifter fdüttelte ben grauen Ropf, von berzlictem Mitleid ergriffen, twandte fein Rab und ging jeines 2 Beges.

Die Heine Frau ging treinend $a b$, um bie Rübe zu melfen, bie treitab in ben Wiejen gingen. Die Rinder gingen mit, alle ftill, ba fie bie Mutter treinen faben, alle bicht um fie berum, zwei, brei brauben an ben (Fimern, Die Sändchen am Griff, Die itbrigen beim

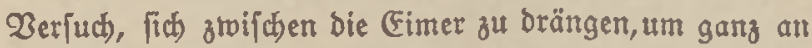
fie beranzutommen und fich an bie Echürze zu bängen. Wic eine rid)tige Blucte! 2/d), und toas für cine

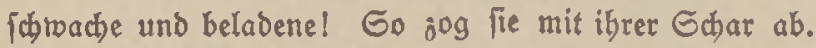
Nutter Ott uno ifr Gohn Reimer blieben vor ber Sür itehn, und fingen bann an, bor bem Sourfe auf und $a \mathfrak{b}$ zu gebn, roobet fie immer grübelten, toab benn 
nun twohl gefdeben twäte, wo er benn toanderte, fäpe Doer läge, und waz fie benn tun tönnten. 2lb ung z̆ boben fie bie 2lugen und faben nach ber Gtabt, ob von bort irgendeine Zotichaft fäme. Eo tamen fie allinähs lid, obne eg zu riffen, in ben Garten, uno fajen auf Der Solzbant am niebrigen $W_{a}$ all unter bem bürren Eliederftrauch und fagten tein Wort, und faben beibe im Geift bas̄elbe Bild : cinen Eoldaten irgendivo auf einem fernen Beeftrand ftelyn, oder auf einem einjamen Scibe= roeg taumelno, binfallend... frant ober fterbend. Ta teine Rachricht von ifm ba war, reder bier nodh in Renbsburg, war faum anzuncbmen, baj er noch lebte. (Ez war ja nutn ber britte Sag, daß er verichroumben war.

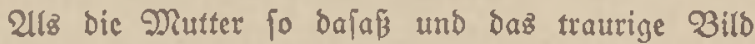
ihre Gecle zerriß, ftand allmählich irgendein Wiberiprud) bagegen auf in iff. Shre Geele rurbe wieder wadher, uno fie ridjtete fich auf und fagte mit fraujer Gtirn: "Du erinuerft bich) boch, twie er bamals, als er fo fech. debn war, von Sauje fort follte und es auch toollte, und ber 2 ater ihn binbracte und troblgemut 2 abjoied von ifm nabm; und et noch am felben 2bend rieder vor meiner Siüchentür ftano und barmte... Slnd idh erinnere midh aud einer anderen (Gefhichte, bie nod reiter zurüdlliegt. $\Im_{a} \ldots$ ba ging id mit ibm fur Sebamme ..."

"Wann war రaż, Mutter?" fagfe Reimer.

"Ia," fagte fie, "wann war bas? Daz rar, glaube ich, als id) mit Deter ging, Der nir balb nach ber (Geburt ftarb." Gie rechnete alles nach Den Zegebenbeiten beż Saufes: "in bem 
Rub verloren," Docr, "alz Zater bie Rungenentzïnbung batte ..." "WBir battem aljo Damalz eine neute Scbamme belummen und ich rollte ifr ein gutes 230 ort geben;

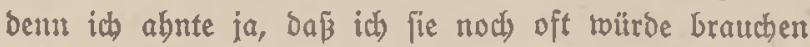
müfen. Slnd ba nabm ids ibn mit. Er toar fo ein Hliner Bengel von vier over fünf Jabren. 2llz mir nun bie Sobanme ibren Birnbaum zeigte und id) midh nad) bem Sungen umiehe, war er weg. Denf' dir...

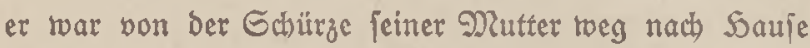
gelaufen! 2on feiner Nutter Echürze! E\& gibt Menjhen, weipt bu, bie an Den Menjđjen bängen . . . bie meiften tun ez. (5z gibt aber auth Dentichen, dic, wie bie Raken, an ben Säufern bängen. Sch tweî́

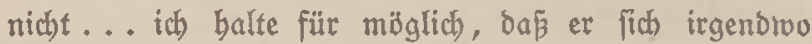
bier in ber ఇäbe berumtreiben tönnte."

Shr Golnn Reimer fohtwieg. Er hatte ber Bejchichte Der Nutter nicht recht augehört. Er batte eine (Exholung von den traurigen (Gedanten gejucht und batte fich oll jeiner Liebifen begeben, und fah fie im Beift, wie er aut Sag bez Friebenz mit ihr burd' Den Barten

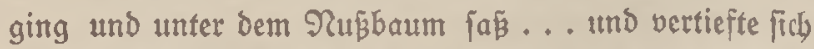
weiter in Das Billo.

Indes glitten die 2lugen der Miutter griubelnd, fin= nent und forgend, und bods zugleich flbarf urteileno über die gange Sofitelle. Man fal ben Garten ganz, uno bie halbbohen Sllmen vorm Sautz, uno vom Soaufe felbjit bie ettwas verjafte Mauer, und feittbärtz Davon, oben, einen Seil bez Gtroboachs Der alten bau= fälligen Gdieune. Nitt ibren forglichen 2ugen jab fie, Dá̧ Der legte Wejfturm ganz oben an Der Epize, über 
Dem runden Slblenloch, bie Rappe ocz Tachez abgeriffen battc. Daz Gtrob batte fich aufgeifträubt, und bie Semmllau mit Den beiben fächlijhen Pferbefïpfen ritt fchief anf Der Girft. Gie jah noch babin, fo in Dem

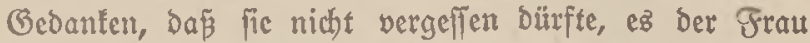
zu fagen ... Da weiteten fich plöglich igre Augen ... und fie fagte in einem Son unendlicten fraulichen $\mathfrak{E r}_{\mathrm{r}}=$ barmenß, mit bent Son, mit Dem bie junge Mutter zum erfenmal in all jeiner Silfäbedirftigteit igr Erfts gebornes piebt: "2l(h) (Gott!" ...

Ticimer richtete fich) aus feinen Sräumen auf und pogte: "2ßaz ift, Mutter?"

"2ldh," fagte fie mittcibig, "rübr' bich) nicht. . Da Da cr uns nicht fieft!... Gís" ganz ftill! Gieh... Da ... da oben am $\mathfrak{L}$ blelenloch)!"

2ld) Bott... da fucte er mit jeinem langen, magern Salz und feinem vorn jळon fablen Ropf aus bem SlbIenlod, wande ibn nads allen Geiten und verrenfte fich faft ben Salb, um im Dämmern, wo er fid fict)er glaubte, now dic 2lugen mit ben Serrlichteifen jeiner unorbentlichen Soffitelle und jeiner Felder zu füllen! "Ed)rectlid)," jagte Pieinter leije, "ganz vertütt!" "Berrüclt? " lagte Mutter Ott leije, "verrüctit ift er

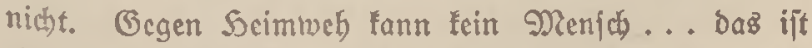
cine Rrantlbeit wie andre... 2la Gott, ber arme Tunge!... Siomm mit!"

Gie gingen binter ben Flieder unb bie Obftbäune uno fichlidhen fich über ben Wal, uno famen fo, binter Der Secfe entlang gebeno, an Die Wand Der Gabcurte beran, offneten Ieije bie Eleine Geitentür, tajteten fid in 
bem großen, balbsunflen Raun nach Der Peifer, unb fitiegen binauf unb Eamen auf ben Boben. Da Enacte bie Reiter. Gie bielten an uno ftanden unbelocglich. Es war allez totenftill; $e^{8}$ war, als wenn bie ganze alte Gdeune, ftarr über Dies Gonderbarjte, das fie in biejen lebten orei Sagen und mun jeß̧t in Dicjent Alugen. blict erlebte, ben \&tem anbiclt. Dann jagte bie Nitter beutlich und fanft: "Silaus, fomm herunter, mein Sunge ... ich bin bier... Deine Mutter! . . E E weí fein Renich als ich und Reimer, baßz bu ba vben bijt... "ein Men/ch auf Der weiten $23 \mathrm{clt}$, auch beine Grau nid)t!"

Finen 2lugenblict war ez noch ftil. Dann famen jögernde Gdiritte burch baz Gtroh, unb bann fam ez langjam, langiam bie kurge Leiter lycrab, bie auf ben Boden Ginunterfïbrte. Slnten angefommen, feste Silaus Ott fich ins Sou; feine Mutter faß da fdon; es wat ibr bod) in bie Rnie gefabrell. Die groß̉en Begeben. beiten ibres Lebenz fhoffen ifgr immer in bie Rnie.

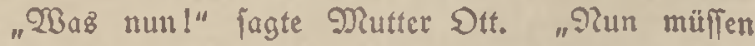

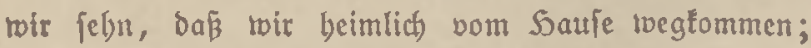
uno bam mülfen wir bie Racht burd) nach Rendzburg gebn; uno wir milifen แnz beeilen, benn tvir müfîen in aller Grübe ba jein." Gic jtand mit einem Ruct auf uno ftieg bie Reiter binab. "פu gebit nach Sautz zu Bater," fagte fie zu Reinex, "unD fagft, baj baz Rino

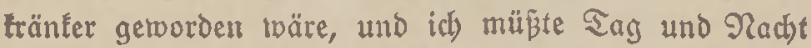
bier bleiben."

Uber Keimer war fo ïberwältigt burch bie $B_{e}$. gebenbeit, Daßj er immer noch nicht glaubte, baß 3 rutoer Silaus nur Seimmeb und einen wunderlichen (Einfall 
gebabt; er meinte immer noch, er wäre toirt im Ropf, und trollte feine Mutter nidft allein mit ibm zieben laffen. Sino wenn das nicht war, fo toollte ct jeinem Bruber Rlaus zeigen, Daß er ibm nicht traute, Daj er nun wirtlich in die Rajerne ginge; und twollte ifm in

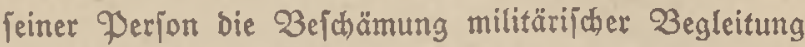
bereiten. "Nein, Mutter, “ jagte er entichieben, "ich gebe mit bir; ich verlajle bich nicht."

"Nun ... Dann geh uno bole cin Brot ans ber Rühe, und eine Flajhe mit $\mathfrak{Z a f f e r}$, und idjreibe einen 3ettel für Narie, Daß wir jest trü̈sten, wo er wäre. (Er wäre frant, aber in ber $2 c \mid$ erung; und wäre morgen früh in Tiendsburg. Das folle fie bem 2 achtmeifter lagen, เvenn ex tvicoerfäme, uno fonjt nichtz und zu niemandem." Slno ba er ttod) twas fagen wollte, fagte fie fo lurz, als wenn er neun Safire alt wäre: "Beb, uno tu, twas id jage!"

(Er ging und fam roieder; und fie gittgen burch bie Dämmerung, bie injtwifhen grauer geworben war, einer binter bem andern am bujchbejtandenen Wall entlang, tamen barn in Den niebrigen Baungang, unb von ba auf bie böbere Beejt. Dann gingen fie in ber Riditung auf Renosburg in einjame Wege binein, bie fie noch meilentreit lannten.

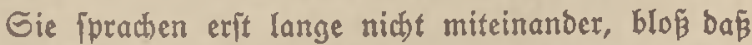
bie Mutter bann uno wann mit einem treichen Son Des Mitleios lagte: "Du armer Sunge!" . . oder "Eei nur guten Muts! Rein Nenidh weiß Davon, auch beine Grau nicht ... und feiner wirb es erfabren...," oder

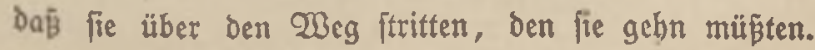


(Ez war eine belle Serbitnadyt, aber in ber Sicfe lag Tebel und Daf. T2orbmeftrino webte bon Gtunde zu Gtunde fd)ärfer binter ibnen ber.

alb fie gut zwei Gtunden fo gegangen waren, meinte Bruder Reimer, daß bie Geelen nun foroeit zur Rube

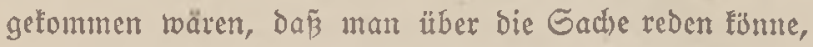
und er fagte zornig: "Gag" mir blop, wie mar bas möglich!"

Bruber Rauz ftoblute und foüttelte ben Ropf: "W̉enr ich fagen foll, wie es̉ gelvejen ift," fagte er, ... „ez lvarcn meine Qeute, Die Grau und die Rinder .... und bann twaren es bie beiben ztreijälyrigen Odfent, Da unten in der Wifch, bie fich in ber letsten 3eit fo gut gemadht baben; uno bann war ez bie alte Safel= twanl im Subftall, gegen die idi) Den (Fichenpfabl gejtellt batte. Snumer fab idh Den alten, trummen Efchenpfabl!...

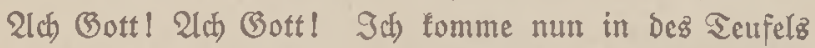
Sïche!“ Er jeufste tief auf und riß an ber Salzbinde, bie ibm hinten, weit uno fern, auz dem Rocttragen berooritano. "\$ch tollte erjit nur einen einzigen Sag blciben, 3 ruber Reimer; Dann roollte idh midh auf= madben. S(h) wollte fagett, ich wäre auf ber Reife frant getworben unb bätte dann ben 3 ug verpapt. 2lber num twurben ç brei Tage, ehe ich wegtam. 2lber beute

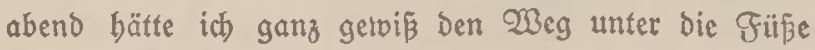
genommen."

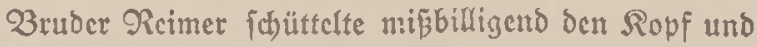
roole fagen: ,Zeritebe ich nicht! Er toollte noch melor, noch Gdylimmeres jagen, uno bas füblte 23ruber Rauż. "Du muj̈t nidyt benten," jagfe er, "Daß̄ ich feige 
Bin, Daß ich nicht in Den Rrieg und nicht an bie Front will. Sch bin fein Sold; aber wenn id an ber Front wäre, toürbe ich meinen Mann ftehn, fo gut twie bie andern. 2lber biez Renbsburg, fo bicht bei ber Seimat, und alle brei Wodjen bei meinen Reuten ... Das fann id) nicht ertragen. Wenn idh in Franfreich over in

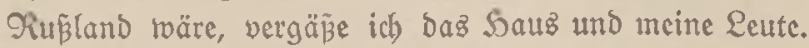
Ia, obgleid) ich immer fage: T(ein, id, vergeffe euth nidjt $t^{2}$. . Dod ... Dann würde id fie vergeffen. Gie wärocn mit verijhtwunden fein wie unter ber Erde. Es würde mir fein, als wenn fie irgendwo unter einem Secibebügel fäpen twie bie Cromänner und von ver= goldeten Edjuifleln äßen. Sch babe mich) fchon breimal beim Gtabsarzt gemelbet; ich jagte, idh wollte gern an die Gront. 2tह er mid) fragte, warum benn, prablte id) und fagte: id wollte was erleben. Drahlen mur id) mun mal, Reimer! Wrablen tu' ict immer! 2lber Du meinjt, binter dem Prablen jtect Geigheit; aber daz ift nicht wabr! Rein, ich twürbe ebenjogut meinen Mann ftebn, twie bie andern! Slnd es toürbe mir ja auch ge= fallen, wenn ich Iebendig wieberkäme, Reimer, meinen Qcuten allez zu erzäblen, waz̈ idh erlebt bätte! Sa, das babe id) mir fidjon oft auggebad)t!" Er fenfzte wicder trautig uno rí̄ roieber an Der Salsbinde. "2Aber Der Etabsarzt fagte, id wäre nicht ftarf gentg, und da ift auch $23 a b r e s$ bran: ich bujte ben halben WSinter lang."

Bruber Reimer rourbe ftill uno ging eine $\mathfrak{B}_{\text {eile }}$ fdhtreigend, bann fagte er freundlidyer und mit milderer Etimme: "Go ... jo ... ou bajt bich alpo roirflich an Dic Front gemeldet!" 
"शlicht cinmal ... breimal," fagte 23ruber Rlats. "Go," fagte fein Bruber, "Danm bifit bu boch nidht feige. aber wumberlich bift bu . . verqrebt . . . fothief gerwicfelt!"

Qena Ott ging in tiefen Gedanlen bor thren Sinbern ber. Gie war bie Gührerin und muß̈te auf ben $23 \mathrm{eg}$

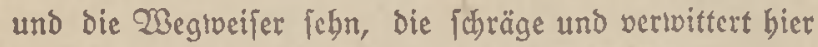
unb ba an Den Eeiten ftanden. Eie batte aud fonjt genug zu bedenfer.

2lz fie orei ober vier Etumben fo forfdrweg getwandert waren and bie zrocite Sobke ber Becft erreicht batten, fucte bie Mutter fidh cine bequente Gtalle am Wall,

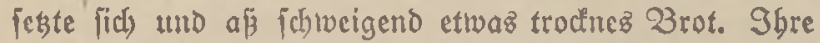
Goblne fázen nebcr ibr. 2liz fie fertig war, glättete fie basz Gtüat Dapirr auf ibrem Gchob, faltete cz jorglich zujammen und fagte in ifrer frifhen, fapfren 2lat:

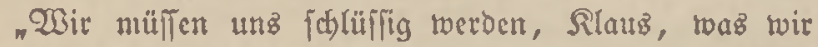
lagen wollen, wenn wir bei beinem Sauptmann finb. Ulno ich babe mir bas fo gebacht: ich twill fagen, ou bättejt von fino an baun und wann wunderliche Ein. fälle gehabt. Go twärit bu 3. 2. einmal auf Dem Gelo, als id) Garben band, verfditpunden getwejen, und id bätte bid) überall gerufen und gejucht: auf bem Feloe, in Sauje und bei Den शachbarn, und bätte bich nidbt gefunden. 2lber endlid), gegen 2lbeno, bätten wir bich in einer Sodfe fitsello gefunden, wie bu bor bich bin auf bie Erbe geftart bätteft, ganz und gar in irgend= einem Bebanten getwiffermajen erfturnt. (O) erftarrtejt jutreilen in Bedanten, werde ich jagen. Go wie Men= fden forperlich erfrieren, fo erfrierft und erjtarrit bu in 
GedanEen, fint ba und rübrft bich nicht. (Cimmal wärft bu fo fünf Etunden lang in Gebanten erjtarnt getwejen." "Ia, Niutter," fagte Rlaus unficher, "aber in was für Gcoanten?"

"Was für Secbanfen?!" jagte Mutter Ott. „Эa ...

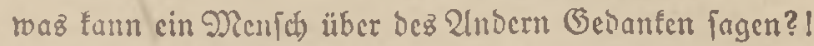
Da joll bein Sauptmann wohl ftillitebn! Srgenduclche Gedanten!! Was für Gedanfen ez finb, bratuch it du ja nicbt zu fagen... W Wenn fie bich fragen, fagit bu eben,

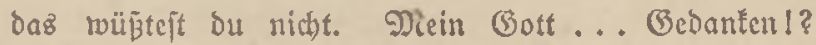
Bedanten!? Die tann man boch nicht febn und nidt richlen! Die bat man, und Damit gut!"

"Zlber die ganze (Bejajichte ijt ja nicht wabr, Nutter!" jagte Reimer.

Rena Ott wandte fich mit blisenden 2agen - er fab fie beutlich im Dunfeln blisen - uns mit einer

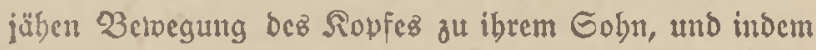
fie fich rajめ) über bie grauen Edbläfen fitrich, jagte fie: "Wabr? Waahr? Waz gebt mich Die Wabrbeit an?!" Sa, Daz fagte fie! Gie wollte binzufügen: ,wenn ez (iic) um bie (Egre meinez Rinbez handolt; aber fie vergaß

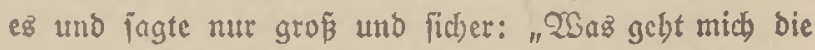
Wabrbeit an?!" aber ibre Eiblue verftanden fie aud) fo.

"Slnt fo werbe id nod) einige andere (Befdidsten eröäblen," fagte bie Nuttcr, "ich tocrbe fagen ... ich merbe jagen ... ou wärft frant geloejen, werbe id jagen, und bättejt einen geidtrollenen Ropf gcbabt . . Du battejt eiumal einen geichrollenen Ropf."

"Sa," fagte Slaus bedentlich uno unficber, "bas Foblen batte mix einz gegeben." 
"Ia ... tmb da wäre id allein mit bir zu Sauz getwejen... fie wären alle in ber Rirche getrejen, uno ba wärit bu im Sento mit beinem verbumbenen Sopf aus Dem Fenfter geftiegen; und ich) bätte burchs Rüb)en= fenfiter gefelnn, wie ou mit metfwutroigen Gdritten, mit

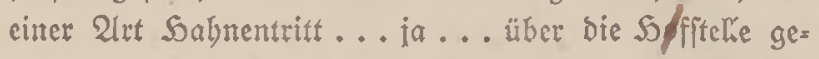
gangen wärit.... ja .... und ba bätte ich dich jäb aufgegrifen und wieder ins ßett gebract); und da wärjt bu Denn alfmäblich wieder gu 2 crnunft getommen, grabe fo wie ein Xenich, ber vom Boden gefallen ift... unfer Rnecht ficl eimmal bom 3oden ... Das war aber, als noch fciner won euch da roar ... Sa, bieje (Ge= (d)ichten loerbe idy erzäblent. SIno roenn ber Sautptmann nod) mefor bavon will, loerbe id ibm banit bienen. Drei werbe id ibm fofort erzäblen, daz ijt bie bejite 3abl; und ich werde ibm gleich fagen, oaß ez ein $3 u=$

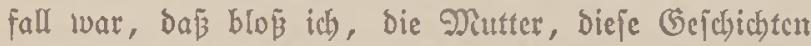
wiipte, denn nur idh bätte fie erlebt und gejebn, die

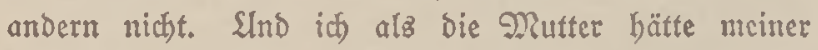
Elye wegen mit niemanto barüber gejpructen."

"Ia ... Nutter," fagte Silatis, "went bu man Damit Durchtomnit! Der Sattptmann ifit cin ziemlich icharfer Serr; und wenn Du gar an Den Najor Lommitt, Der frift bas Eifen glüheno."

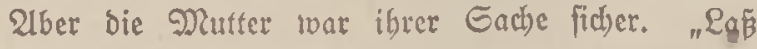
mich nur!" fagte fie: "Wुer will gegen das anjtreiten uno baz aนz der 2 Belt reden, waz eine Mutter mit ifrem Rino ertebt bat?! Slnd aljo will ich fortfabren: rwie bcine Frau zu mir getommen wäre, ba bätte idh gleid)

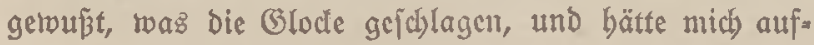


gemadjt, unb bätte bich auf Dem Weg über bie Seibe gejud); aber nicht blö am Weg, wo deine Frau fhont vergebens gefud)t bätte, fonbern abjeits vom $2 B e g$, uno zivar nad) dem Moor zu, da too wir unfer Surflano baben; unt ba, in ber fleinen Nulde, bätte ich bich richtig gefunden, wie bu, den Ropf zrī̄ॅen ben Rnien, ges feffen bättejt und unz roie ein netgebornez Ralb angeftarrt bätteit. $\Im a$, daz twerbe id jagen, ober richtiger ... ich tocrbe fagen, ich wäre allein nach bem Noor binuntergegangen. Sa ... Dann bleibt Tieimer aus Dem Gpiel ... Der ift zu fein Dazu!“ fagte fie bog̈haft.

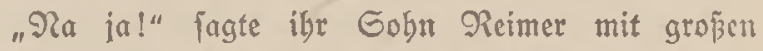
2ugen uno groß̄em 2ltembolen, "סas iǰt ja alles recht fabön uno gut ... ijt aber leioer allez Lïge ..."

"2lch) ... Lüge bin, Lüge ber!" jagte Lena Ott, "idi) muß́ wiffen, twaz ich als Mutter zu tun babe! Rede mir nicht bazroijuen! Waas ich tu', ift gut und

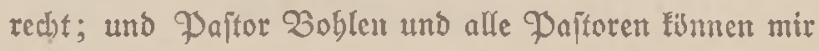
im Nondichein begegnen."

Shre beiben Göbne wü̈ten, Daß̧ fie eine rectutiche Grau twar und baß fie ihre Sinder aufz jorgfältigfte zur $23 a b r b e i t$ angebalten und fie ftreng beitraft batte, wenn fie von Der Wabrbeit abroidhen. Stno nun fá fie $\delta a$, breit unb grop, am $2 B a l l$, tnd erfand Litgen; uno nicht nur baz̃, fie bebauptete auch noch, Daß̧ ibre Qügen gut und recht wären! Aber roaz follte ibr fluger,

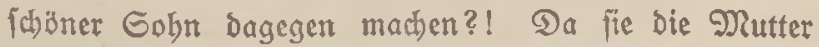
war und immer jefre bündig mit ben $2 B o r t e n$, fonit in ber 2 abjbeit, jegt in ber Lüge, und für Eintvendungen 
taub rar, fo mufite er es beim Vertwundern betwenden la Ten, unb munte ichtweigen.

Sm Norgengrauen, alz fie fieben Stunden getwandert twaren, ftieß̄en fie auf bie fleine $B a b n$, bie nach Renoga burg fubr unb exfubren von einem ber[d)lafenen, tworts fargen Sungen, ber Pferbe bon ber Weibe bolte, Daß bald ein 3 ug nawh Rendzburg fübre. Da twarteten fie und ftiegen Dann ein, und erreidten bie Gtadt, als bie Gonne aufging, fragten nach ber Wobnung dezి Saupt. manns, und fanden fie. Da twintte die Putter, Daß̧ bie beiben unten an ber Treppe fteben blieben und ging binauf, und ftié auf eine ältere Grau uno fagte, fie müfe notwendig ben Serrn Sauptmann prechen, uno zwar unter vier 2lugen. Die Grau batte eine jolche 2ldtung vor Dem gropen, jtattlicten 2 Beibe, bem bie Rachtranderung und fonjt noch mandjes in ben 2lugen ftano, Daß̄ fie fogleid) bie Tür aufmachte uno fie eintreten liç三 und bann bie silt binter ibr zuz machte.

Der Saupfmaun fǟ im offnen Rod, bie lurze Pfeife quer im Nund, und las die 3eitung; und tar in bie Tinge bes 2 aterlanbz verfunfen, uno bachte nidbt andersิ, aโร bậ jeine Wirtin bereingefommen toäre, und las iveiter, und las gerabe einen 2lrtifel, Der (d)arf gegen England ging. "Brobartig!" fagte er. "Diefe verfluchte Räuberbande! Dicje Welthalunten! ... Diefen Urtitel miilen Gie lejen! Lejen Gie ibn gleid) jekt!"

Rena Dtt batte unbetweglich an ber Sür geftanden, bie Sand nod nicht vom Drü̈ter, und batte ibn auf" merfjam uno mit fo fdarfen Sinnen beobachtet, twie fre 


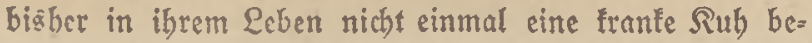
trachtet batte.

"Soerr Soauptmann," jagte fie, "ich babe jeft feine Bedanten für fo etwaš; mir ift Englano uno das̆ ganze Zaterlano gleidgültig. Shb bin bie Mutter von bem Goldaten Ott, ber Shnen verloren gegangen ift."

Der Sauptmann roar febr verwundert; war aber alsbals im Bitbe und jagte: "Geben Gie fich, Grau Ott, und reden Gie! $\mathfrak{W}_{0}$ ift er... der Sal... lury, toaz ift mit ifm!!"... Slno er legte bie lurze Pfeife auf ben Sijh.

"Ia," jagte Mutter Ott langjam und nachbentlich, benn fte twar burd) brcisig Sabre gewobnt, fich unter einem langjamen (Bejchlecht (Bebjur und Beritänoniz zu berid)affen ... "iebn Gie ... id ... id babe ibm unb feinem 3ruber vorgclogen, id twollte Slynen eine lange Beidhichte erzäblen: ex wäre ein tranter Nienia ... er bătte 2lnfälle unb bätte in einem foldben Gablaf. zujtand - id babe cinmal fo twas gelejen - irgend. two in ber Sreide gejeffen; ich roolte nänlich igm und feinem Bruber, ber ein jebr ftolzer und najetweifer Sunge ift, bie Sdymach eriparen, baj ich einem britten Renichen in ber $\mathfrak{B}$ elt bie Gchande erzäblte. Nämlich ... geiund und ganz Hlar im Ropf wie aubre Menichen ift ex roobl nidbt... aber ber Raijer braucht ja jest

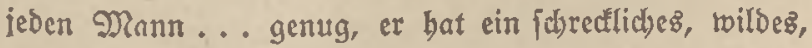
ganz verrüđtéz Soimtvel) belommen, fo Daß er fich ricoer in fein Soaus zurücfgefchlichen hat; uno hat brei Sage lang oben unterm Girit feines alten Etrobbaches gefeffen, unterm slblenloch, unb bat fich oon trodnem Brot 
und einem $\mathrm{Ei}$, bas eine barmberzige Sente bahin trug, genäbrt... ganz twie Ellaz feine Rräbe... Ia jah ifn ba und rief ifrn, und ba ging ex gleid) mit. $\Im$ dh

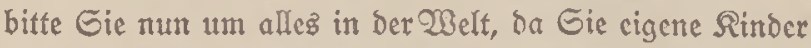
haben: blamieren Gie Den गlann nicht für fein ganzes Reben. Gagen Gie feinem Denfichen unt aud ibm nicht, waz idy Slunen gcjagt babe. Gagen Sie, er wäre brei Sage fopftrank und binteritunig gewefen uno bätte fich herumgetrieben; er bütte $\partial a z$ io an fid $-j e b n$ Gie: ich babe Slunen ben Nann felbit wiebergebracht, fobald id) ibn fand ... a auf meinen eignen Fü̈̈en - wir find bie ganje Siacht durch getwandert! . . U Und Dann, Darum bitte id Gie, tum Gie, roorum ex fhon Drcintal gebeten bat: fchicten Gie ibn an Die Front! Ob er nun

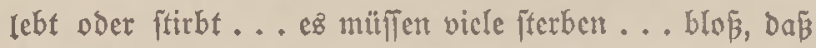
er auz biejer Gegeno bier fortfommt, bie ífu aufz Gemüt gefallen ift!"

Der Sauptmann foüttelte lange ben Ropf. Dann

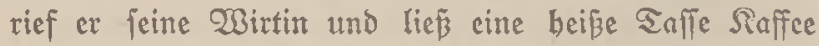
hereinbringen. Sunterdes ließ́ er die beiden Eäne die Sreppe berauffommen, tmo berbandelte Drauß̄en auf bem Borplas mit ifnen. Dann zogen fie alle brei $a b$, Bruber Rlaus mit fteifen Fingern einen 3ettel balteno, ben $i$ mm Der Sauptmann für ben Gelorwebel gegeben batte. $21 m$ Tor Der Raferne nabmen fie $21 b$ chied pon ibm.

Gie gingen nach bem 3 abnlyof uno fragten nach bem

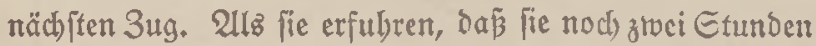
warten müß̄ten, toollte Sena Ott im Babnhof nicht bleiben, tweil ba fut viel Menidjen wären, unb toeil fie meinte, dá fie da etwas verzelyren müíte, waz fie fparen 
toืnte. Sie ging aljo bie Gtrapie binunter und fette

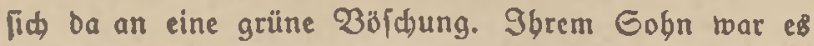
lange nid)t gut genug, in feiner föbnen (Extrajacte mit ben vielen blanten Snopfen unb mit all feiner beimlidben Würbe fpätcrer grojer Taten und Dinge, fich fo am Weg ins Bras zu feken. 2lber er wagte nicht, ju woiberfprechen, rouste aud, baß er nur Epott von ige ernten rürde; denn fie batte immer Rinder in eine folde Lage zu bringen, bie ilgnen unan- . genebm toar. Gie brcitcte ibr Rleio forgfältig und breit um fich, uno raar nun fo tweit, Daß fie iare Geele lölen uno mit ibrem Eoún Reimer ein W3ort fprechen tonnte.

Ziz Dabin, folange ber Bruber und Srrmeger bel Ibnen gerweien war, war fie lauter Mitlcio uno Erbarmen getoefen; nun aber trelgte Norbwind. Nun er fort roar, Fing fie an, über ibn zu lahelten. „WBas i ît Das für ein Erlcbnis mit biejem Sungen!" fagte Fie; "ich muB mich ja in ber Geele (d)ämen! (Fz feblt nidht viel, fo ift fein Soaar grau: und er madt foldhe Sadjen! 2ber roooon tonmt bas? $\mathscr{D} a z$ ift bas Erbe bon feinem Vater! Der ift audb fo fill und binterbältig! Slud warum ftill und binterbältig? 2luz lauter 2 ngft, bem Ding an bie Reble zu gebn. Ricber inz slblentoch! Was ic von Baters 21rt ber für 21ngit und 92ot im Seben gebabt babe und babe ausfteben mülTen, Das ifit nicht zu fagen! 2uber bieje Bejwidbte ift fajt bie idlimmite! Rein, toaz lift bas für eine Gamilie... und Davon babe ich nun elfl Denn ibr ieio idblieşlich alle gleid!!

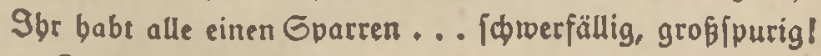
grenffen, Die goriber. 
Der Soarm tann mit mir reben, alš wenn er mein Ulrabn ift! Zon bir uno Emma gar nidit zu fprechen!"

Shr Gobn Reimer empörte fich, baj ber Zater und feine 2lrt fo von ibr gerichtet und geidjolten wurbe. Er lagte mit feiner boben, fliegenden Gtimme: ${ }^{\mathfrak{S}}$ lno Eggert, Mutter? Wo bat der Denn feine 2 int ber? Wo bat ber feine Willbeit uno feinen Säbzorn ber? Ober find bas fdüne (Figenjhaften?"

"2lch) Bottl" fagte Fie, "Das ipt eine andre Gadje!"

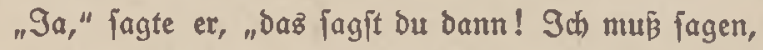
bas ift eine bübiche Antwort: cine andre Sache! Du meinft: meine Gache! Sno Deine Gadje, meinft Du, ift gut! Es ift rabr: Rlaus hat viel vom Bater; aber ez ift aud) wahr: (Eggert hat viel von bir! Slnd was ijt noch idhlimmer: er, Der twie verrücț auz bem Sauje pprang und in bie tweite 20 elt lief, voer ber hier im Ublenloch? SAnd id) ... id habe aud) von beiner Ratur, von beinem Übereifer... febr viel fogar! Эch fliege aud leidt in Feuter auf ... in meinen Be= Danfen! Ulber id rill bir twas fagen: iđ glaube nicht, Daß̧ Du in beinen Rindern etwas Befonderez bajt... folc)e Rinder, wie bu baft, haben Millionen Mütter. Ic) glaube, du bilbejt bir ba was ein. Denn es ift fo mit bir: twenn bu fdiltft, willit bu blok eine Yerteibigung beffen bören, was bu bej屯iltit, uno aus ber Yerteibigung bir ein Qob faugen. Sch tenne bich ganz genau!"

Mutter Ott runderte fich), baj ber Sunge fo alt= flug redete, und fhrwieg vor Erftaunen, zumal fie ifm ziemlid) red)t geben muf̧te. Sie begann mit rubiger Grimme von ibren anderen Rindern zu jprechen, lobte 
und tabelte fie ... tabelte viel... und war rieder berubigter uno in alter Gleidhe. Dann und twann fah fie mit Gtoly won ber Geite auf ben, der neben ibr fá̉. Sie fä̧en noch fo und bie MRutter rebete noch, da famen einige Snaben vorbei, uno ber eine fagte etwas̄, indem er nach ber 23 ; / thung und sach) Der groben Grau in ibrem ausెgebreiteten Sleibe blicte, worauf feine Rameraben auflacten.

"Waz fagte der Bengel?" jagte fie miptrauija. "Ex jagte boch nichts über mich?"

"Doch, über bich," fagte Reimer. "Er jagte: Ta fist Nutter Bermania." Er bat wobl mal fo'n Billo geleben: Germania mit einem Matrofen."

"Go'n Bengel!" jagte fie zornig, und fubr mit ber

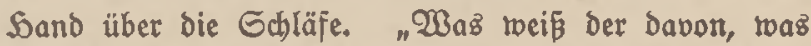
ich) für Plage babe."

2Ulmäblich, alż fie fo rubig fäpen, wurbe ber lang= aufgejhoffene, noch immer etwas fdymale Sunge, Der bie

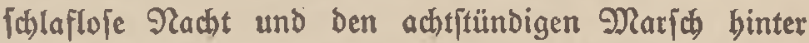
(iid) batte, mübe, ex ftübte fich auf ben (Ellbogen, uno lag bald banach auf Dem $\mathfrak{A} r m$ und fdlief bann ein. Sm Echlaf und gleidh im Sraum... nadjem er eine Silbung am Sorpedo mitgemacht und bann ben 2uftrag befommen batte, den Sorpedo abzureiben, fah ex in bem fpiegelblanten (Fijen fich felbit und feine lleine bunfle Liebjte... pie gingen burch bie beimatlid)e Seibe... Die treite Fläche war nod) wie tot vom Winter ber, aber der Binjter roollte fdjon blüben ... bronzefarben lag es wie alte Echilde bier und ba auf ben Soügeln und an Den Söngen... und ein berber Offtrind fubr 
barifber bin. Ulnb er ergäblte ibr... er fab es an feinen Sandberwegungen ... mit begeifterten Worten und glänjenden 2lugen, toaz er allez im Eeben tun und erreid)en rollte, grofic, bertliche, reine Dinge, Dinge bon lauter Büte und reiner Größ̈e... Die ftanden por ibm auf ber Soeide wie lid)te Monumente, burd bie ein idb̈ner $\mathfrak{W} \mathrm{cg}$ nach fernen Sobben fübrte, bie in zartem blauen Dunfit lagen. Sie aber ging in ber Beftalt, in ber er fie gulegt gefebn batte, in ibrem balblangen ountlen

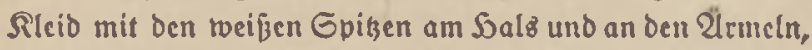
und mit ibrem roippenden Bang neben ibm, Sand in Sand. Go gingen fie auf eine bobe (Fid)e gu, bie ftart und mäcbtig am Ende beż boben $\mathscr{W}_{\mathrm{eg} z}$ aufragte. Slno an ibrem Gtamm, oben unter ber Rrone, bing ein Rranz. Fin Rame ftand nidjt Darunter; aber er roußste, Dafi ber STrang für ibn Dabing. Go genó er das Reben uno feine Liebe in bem reinen Sraum dcz Sünglingz und fam zu Dem Geinen. Denn ez ijt ja nicht ganz fider, tras rirtlider ift: ein Traum oder ein Qeben. Fr lebte, twas er aud ougleid lab, und füblte mit aller reinen Geligleit, die bas wirflidye Reben nidgt gibt, toas er im Sraum erfubr.

Die Dutter aber jaß breit uno itattlid mit ausgebreitetem Rleio neben ibm und $a \hat{B}$ oon cinem Gtüd Papier, Das fie auf ibrem Gdoó ausgebreitet batte, von bem mitgebradten 3 rot, und dadte über ibre Rinber naक, uno vergás teinz; und blieb zuleßst mit ibren Gedanten bei bem einen, ber fich ibren 2lugen und ibrer Geele entzogen batte, ibrem twilden Gebnerzling, ber num idon brei Sabre fort toar und nun fhon 
groet Sabre, folange ber Sricg bauerte, nicht gefdrieben batte. Gie fab ibn in Not und 21rmut, in $\mathfrak{B}$ cbräng. nis und maj̄lofem Scimwel in Der Ferne, fand ibn ba nicht und fuchte ibn, und ging irre über Meer und Land. Gie batte in ben lezten Monaten gelejen, da viele junge Deutfhe fich auf allen $23 e g e n$, Die Dentbar roaren, und rären ez bie gefäbrlidjiten, nach Soauje fdhliden, um Der Scimat in ibrer ichrectlichen Not ju belfen, unb füblte, Daßj auch er bas unternebmen toürbe, und rouste nicht, two lie ibn fuchen follte.

Go bad)te fie über all ibre Rinber nad, und fáb da neben bem Galafenden, breit, fid)er, rubig; einer Erntes arbeiterin gleid, bie neben der lesten Garbe fitst uno mit frillen 2lugen bas Gelo überfiebt, uno fiebt: es mar biel Nübe und 21rbeit, aber . . . es mag nun werben wie Der Soerr Der Frnte es will. . . es roar robblgetan. 


\section{Rapitel \\ Die gute Prife}

Q1m felben $\mathfrak{T a g} \ldots$ am $\mathfrak{A b e n d}$ in ber Dämmerung tamzte bie, 2llte Qiebe' auf dent bunflen 20 ogen Der Norbjee in bem fteifen Rorboftrind, Der am 2bend vorber eingejest batte, feinte Gtrecle auf und ab.

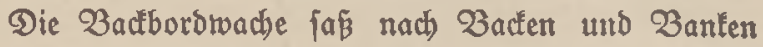
in bem Logiz beim Rartenfpiel. CEz ging aber etwaß träge babei ber, ganz ohne Lärm und Qachen, wie denn überhaupt bie ganze Gtimmung nidjt bie richtige war. Bon ber Begebenbeit mit Den Gdiffbrübjigen und ibrer Nieberlage mit bem Narren ipracten fie fein Wort. Gie (chämten fich nod) fo febr, forwobl feiner, weil et den Feinen und Yornebmen geppielt batte und Keiner gewejen war, als auth ibrer felbjt wegen, bap fie es igm geglaubt Gatten und fo fकredtlich getäuld)t worben

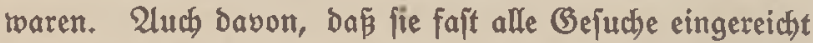
batten, um von bem Boot fortzutommen, fpractien fie nidft; ez war ibnen ein ž traurigez Rapitel. Sie fprachen nur bavon, , bá̄ fie nun noch mal' - bas follte beip̃en: ehe fie auseinander gingen: eine gute Orije baben mächten ... Das follte beícen: im Gegenjats zu Der (a)lectsen Prife, ba fie ben Rarren und feine (Be $=$ jellidaft fingen. Sie waren zurünthaltender gegenein= ander, fo als wenn fie fid fajon etwas fremder geworben

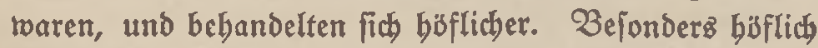
bebandelten fie Peter Sagedorn, Den Unteroffizier. Zon Der Stunde an, da er Den Narren entlarbt und ber Masterade ein Ende gemadt, batten fie ibn alle, obne 


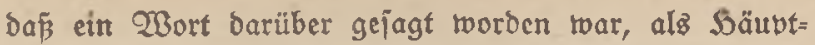
ling anertannt. Sie folgten ibm roillenloz, fragten ibn zuerit um feine Neinung, und jaben ifn fragend an, menn irgend etraz शeute auf fie zutrat. Sa, ber Sachie, Der auf einem gró̧en Rittergut ßnecht getweien war, liéz 旸 auf Den Bängen und Der Treppe Den Bortritt, felb/t wenn ex bie Raffectajpe für ben Steuermann in Der Sand batte. Nicht, Daj fie Peter Sagedorn be= fonderz gern batten! O nein! Uber ez war flar: er fab tiefer, und war auch tapferer als fie. Sie alle, fie waren Feiglinge. Nicht gegen bie (Engländer, natürlich) nicht! Serrgott ... Die Engländer ... Die follten fommen! Slnd twenu einez Morgens aus Dem Serbitnebel Geraus einer ibrer allmäd)tigen bervortreten roübe: fie mürben, ibr Befdüglein am $\mathfrak{B u g}$, auf ibn logfabren und ifn befdiefen, folange fie fotwämmen! aber in ben Geelen, ba waren fie feige getwefen.

Ul\& fie fo in Der Dämmerung ibren Sörn babint fubren ... das Boot ftampfte unb rollte in ben fuberen Regenbisen gegen Wind und Wogen nach Rorben zu ... fie waren alle ettoas mübe, benn fie hatten ichon Drei Tage und Näcbte, da Wino und Gturm fie abwechielnd in Surub gebalten batten, feinen rechten Ed)laf gebabt ... ba wurbe alarm berabgerufen, und fie ftürzten an $\mathfrak{D e c}$. Da faben fie in ungefägr zroeitaujend Neter Entfernung bie undeutlichen Slmriffe eines giemlich großzen Dampferz mit einer grofen Lajt von Sols und Riften an Decf. Gie fonnten es im Dämmerjobein nidbt Deutlich auszmact)en, zumal er mit Gübofturz gefabren roar und mun grabe dabei war, Gübrwefturz zu nebnen. 
Gie fandten ibm baz Gignal, ju ftoppen, und fubren vorfichtig in grobem Bogen an ibn beran, jeber Mann auf feiner (Befechtz) fation, Sarm Ott als ztweiter Mann am (Geichüßs. Gie lonnten fich nidht ertlären, wie ein fremder Dampfer dazu tam, in unjre Eperre zu laufen, und bachten, es fünne irgendeine Falle fein. Als fie

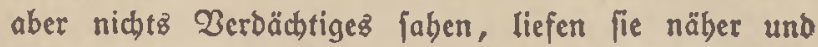
liȩ́en daş ßoot zu Waffer. In bem 2lugenblid börten

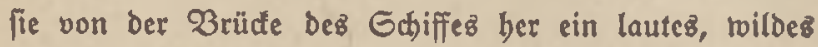
Gdreien und faben im felben 2ugenblid cinen ftarten, roie es faien bellyaarigen Menjchen unter ben andern berworragen und gleid barauf ein Ringen und Gdhlagen,

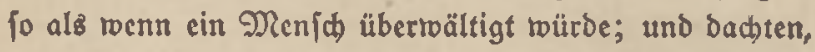
es wäre da irgendein Gtreit entfanden. Indefien tam bas $\mathfrak{B}$ oot zu Waffer uno Peter Sageborn fubr mit vier Mann binüber. Nach einer Weile Fam bas $\mathfrak{B o o t}$ zurüd und bracte bie Papiere. Der Gteuermann jah bincin,

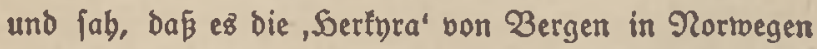
toar, mit Gtüdgut, Darunter Plunition und anderes Rriegsmaterial, bon Bojton nach Rotterbam beítimmt. "Der Sapitän fagte mir, fie bätten falfdb navigiert," berictetefe Peter Sagedorn.

Der Gteuermann.fagte: "Nlar und gut, cine Prife l* und ju Peter Sagedorn: "Wir werben ja beute abend abgeloft; aljo tönnen wir felbit die Gadje maden. Gie uno vier Mann, bie Gie fich ausfud)en tionnen, als Prifenmannidaft tlargemacht! Die Papiere nebmen Gie mit. Gie bringen das Gdiff nad) Curbaven. Gunler!*

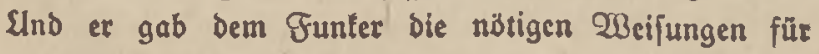
bie Gtatior. 


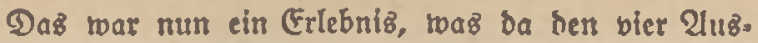
erroäblten bevoritand! Erft in Das ßoor gebn, Dann baz frembe Gdiff betreten, bie fremben Matrojen befebn, als Prijenmannfalift ftolz auf bem feindicben Dect bin und ber gebn, und bann in Curbaven an Lano gebn! Ulnd am andern Sag ftand ez in Der 3eitung! 2lber nur fünf bon ibnen follten ezs erleben! C58 raar ein febr id)limmer und barter Alugenblid! Gie blieben alle an ber Gtelle, an ber fie ftanden, fitll und ftumm ftebn und faben bier und ba bin, nur nidat auf Peter Sagedorn. Daßj er bod ja nidjt badjte, fie wollten werben obet betteln, daß er gerabe fie ausroäblte! 2lber aud für Peter Sageborn rar biejer \&ugenblid fdwer. (Er fnurte etras mit feiner buffigen Gtimme, und mufite nidht, mas er fagen follte. Da fam Sarm Dtt, Der feine Not fab, zur Silfe und fagte mit leifer Gtimme: "Nimm bie Berbeirateten uno थ̈lteiten."

Gie waren alle twie erlojt. Iatwobl, bie Berbeirateten! Gie gönnten den ßerbeirateten, bie wegen bez Scimwebs nach Grau und Rindern bejonders litten, bielez Crlebnis, und daß Fie, indem fie an Land fubren, nach Curbaven, Den Shren näber twaren, und auch, daß pie für einige Tage aus ber Gefabr raren. Slnb fo fabien bieje Gadbe glatt ab̆zulaufen.

Uber ba trat ber 2 eftpreube, ber mit zu ben 2lusertuäblten gebörte und jchon an ber Sreppe ftand, um binter ben andern bergufpringen, twieber zurücf, mandte ben runden Ropf zu Peter Sageborn, fab ibn an und muste nicht, wie er fagen follte, twaz er fich bachte. (Er Dachte fich nämliç in feinem phantajtijaben, dicten 
Ropf - als̄ wenn jo etroas möglich), ja alż wenn ez wahricheinlich twäre! - రaß̄ ber Bruber yon Sarm Ott grabe auf biejem Edhiff fein tönnte. Esz fam ja boch bon 2merifa, aljo war ez ja boch möglich! Sa, bas war es bod)?! Warum nicht?! (Geichaben nidht bie jeltjamiten Dinge und Begegnungen, und nun gar im Sirieg? Satte nidjt Walter Rebendahl, fein Dorfgenolle yon Rlingbüll, in einer verräucherten fleinen Wirtzftube in Flanbern feinen 3 ruber getroffen, Der nad) feiner Meinung in Ralifornien auf einer Garm Üpfel pflütte, und Den er zebn Sabre lang nidjt geiebn batte? Uber wie jollte er fagen, was er bachte? I Er tonnte es bod) unmöglid fo ausiprechen! Obgleich fie fich geröbnt batten, febr

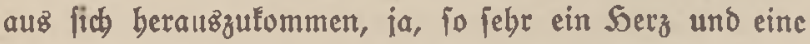
Geele twaren, twie jonft auf kinem Ediff in ber ganzen Welt: jo war biez bow ein zu großjez Wort! Rein, in roelcher 2ufregung und शlot er ba an ber Sreppe

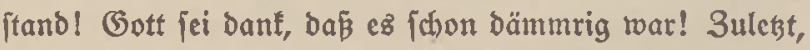
Da er fid nidjt belfen fonnte und bỉshjte Eile not tat, fagte er bas allerbertebrteite uno Ginnlojejte; er lagte ifoctig und mit verfniffnen 2 ugen: "Эat) will nicht! Shr fönnt mich vierteilen... ich gebe nicht! Sarm Ott foll mit! Er ift nach Peter Sageburn unjer Befter."

(cr atmete boch auf, Denn er meinte, et bätte ez fo richtig gemacht und zugleid feine Gebanten aufz tiefíte verborgen. Aber fie lächelten alle gutmütig und ver=

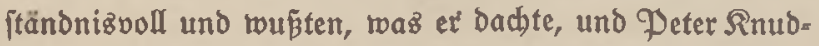
ien, ber Tagelöbner, ber eigentlich auz $\mathfrak{B e r f e h n ~ a n ~}$ Bord und zur Gee war, prach igrer aller Meinung aus, alz er langiam uno bebächtig fagte: "Das ift nett von bir, 
Dider! Snmer famerabid)aftlich! Patürtlich ... S Sarm Ott mús mit!"

$21 b e r$ bann bielt bet Gteuermann ez für richtig, da fie fects Nann ftart binübergingen; und fo fam ber Weftpreube audy noch mit.

Die 2uB̈erwäblten waren überglïctlich. Wie bie Wilben fprangen fie dic Qeiter binunter, riffen ibre Gäde auf, warfen bincin, twas fie brauchten, nabmen cine Rifte Sanogranaten uno für ieden Mann cinen Pievolver, und fletterten über Bord. Der Wind fing an, ftärter zu werben; das Boot fchlug gewaltig auf und nieber; aber fie famen boch gut und rafh binein, und zu Den andern binüber und flefterten an Bord.

Der Rapitän ftand an ber Reling und empfing Fie. 3wei ober brei Deffsleute itanden bier und da zerftreut berum und fdienen bumpf neugierig zu befebn, was vorging. Es war eine jtwar fiternlofe aber helle Tacht, fo Dấ man bie Figuren recht Deutlid) febn lonnte; aber bie Gefichter jab man nur, wenn man in einer (Entfernung von zwei oder brei Netern vor ibnen jtand.

Peter Sageborn fragte Den Rapitän, einen langen uno breiten Menichen mit bartlofem (Geficht, wieviel Qeute auper Den Majdiniften an $\mathfrak{B o r b}_{\text {wären. }}$

Der Rapitän muíte fich erjt befinnen, Dann nannte er aufer ben Majdinenleuten vierzebn Mann.

"Die fint nicht bier," lagte Peter Sageborn, "two find fie? "

"Sier unb da bei der 2lrbeit. Die Dectslabung muß befier verftaut werden."

Peter Sageborn ging mit ben Rapitän uno cinem 
ber Reute nah ber Brü̃fe binauf; bie anbern madbten (ich) unter Gübrung Soarm Otts auf, bas Ediff zu Durchiuchen, wie fie vorber verabredet batten.

Er ging zuerft in bie Mafbine binunter und befabl bem erjten Majhiniften, einem furzen, biden Menjden,

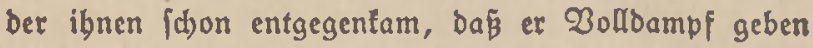
jolle, und baß er fofort gegen ibn borgebn roürbe, wenn bie Mapdine aud mur ein reenig nadblieje. Der Najめinift, fhwer betrunten, nictte mit Ropf unb Sänoen, bie ibm beibe gleich icher waren. 2lls ber शann bann aber noch cinmal bie Augen bis zum Beficht von Sarm Ott erbob, rí er fie rocit auf und (d)rie: „Germun! German!" und lad)te, und berfuchte, fich auf bie G(hentel ou ichlagen; und fagte etroaz zu feinen Leuten, twaz Soarm Ott nicht veritand. (Fr bachte, es ginge ibn weiter nichts an, und fitieg rieder binauf. Er batte aber ein unangenebmez Gefübl, fo als twenn da etroaz nicht in Oronung wäre, als wenn fie betrogen wïrben. Er lonnte (ic) aber burchaus nidjt benfen, twas da vorliegen tïnnte. Dabei fuhr iğm fo ourch den Ginn, ras bas roobl für ein Gdbrei gemefen wäre, ben fie vorbin, ebe fie bas Gabiff betreten batten, von ber 3 rüde berab gebört batten. Er roollte danach fragen, vergá̄ ez aber roieder.

Ulz er an Deff fam, wunberte er fíd) roieder, baß ba fo trenig Leute auf bem Gctiff maren. 2ls er aljo roieder in Eicht ber Brücte war und - rieber unter feinen Qeuten ftand, rief er einen ber Mannidjaft berbei, einen langen Menichen mit groß̧em (क)musigen (Befid)t, uno fragte ibn zuerit auf Deutjw, Dann auf englijch, wie ftarl bie Mannịd)aft bes Gdiffes räre. Uber ber 
Dann berftand ibn nich ober tat menigftens fo. Er batte biflich und fidnell ben Ropf geichüttelt und tar

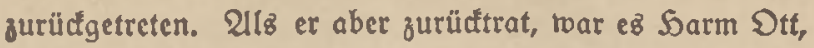
als trenn er gu feinen Sameraden binüberjab, bie id)räg binter ibm ftanden, und alz toenn ein babnijhbes Qädbeln

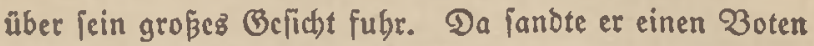
ou ber Brüle binauf und liér Pcter Sageborn fagen, baji ibm bie Gache bedenflich vorfäme, fo als roenn da Leute auf bem Gaiff werftectt wären; er möge boch ben Rapitän banach fragen uno auf jeben Gall einen Mann an ben 2lufgang zur Brüde ftellen, bamit er rüđtıärts gefichert wäre; inbes twolle er baz Gchiff tweiter burchfutcen. Der Mann tam zurüd uno meldete, סaß́ ber Rapitän geleugnet bätte, baß̈ noch عeute an 23oro wären. Soarm Ott batte nun nod drei Mann. Mit benen machte er lï) nun rociter an bie Durdf fucbung bez Gdiffez. Er Bffnete alle Türen und fab in alle Rammern und Nellen uno in baz tleinfte Gelaß̄; aber er fano nidhtz. Die Racht und Der Gturm und bie Dectslaft, Die überall umberlag uno bier und ba nicht ficher befeftigt war unb bin uno ber id)lug, binberten lie febr. Daz ganze Gdjif

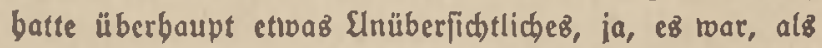
wenn es lïh fortwäbreno veränderte. Er - und ber cine Ramerad waren nidbt bon Sint an Gceleute getrefen, und ber andre war von ber Slurub uno 2lrbeit Der legten ftürmifden Tage fo totmübe, Daß̃ er ftolperte; und fo machten fie es trobl nid)t gans ridtig. Benug, er glaubte föter, Daßj er die eine Reibe Ramnern zreimal geôffnet batte unb eine anore gar nid)t, ia bielleicht Den Bang überbaupt niфt betreten batte. Ulio 
fanden fie nichts und ließ̄en Davon ab. Sarm Ott.

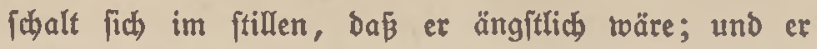
[pottete über fich, Daß biez eben jein er[ter richtiger Rriegstag twäre und $D a \hat{B}$ er baher übereifrig träre.

Der Gturm roar ftärfer getworben und immer mebr nac) Siten gegangen. Das Gdbif bielt nod) Rurz nach Güboften, aber er merfte wobl, Daß fie nicht vortwärts famen, ja baß fie vielleid)t abtrieben und immer mebr auf englifhes Bebiet gerieten, und am Morgen verloren wären. Dabei wunderte er fíh, రaḱ das Gdhiff to (d)wächlich gegen ben Wind lief, fo als wenn es feine Rraft bätte; und bald barauf mertte er, Dap̃ das Gdiff aนв bem Gtcuer lief.

$\mathfrak{I n}$ bem 2ugenblicf tam ber Mann von ber 3 rücle beruntergeiprungen und jagte, baj ber Majdinift melde, Daß̄ bie Majdhine jtoppen müffe; es wäre eine Eleine Reparatur nötig. Soarm Ott möge nadjebn.

Sorm Ott nabm feine beiben Mann mit und fprang die Sreppe zur Majchine binunter. Ulnten jaßj ber erjte Majhinift eingeidlafen auf einer Rifte, neben ibm bie umgefallene Wiăfnbubdel. Der zreite ftand, bie Sände in Den Sojentafden, an bie $\mathfrak{W}$ and gelebnt uno lah die Sommenden veritocft an; man jab ibm ordentlich an,

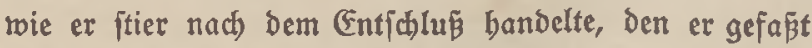
batte. Sarm Ott bactete: , Mach's raich und turg,' nabm ifn beim Rragen und warf ifn ben Rameraben zu und fagte: "Eperrt ihn ein!" Die Soizer, Die im Sinter= grund ftauden, fitwanften einen 2ugenblid, ob fie fich auf fie ftürzen follten; aus ben beiben Qöd)ern, die zu

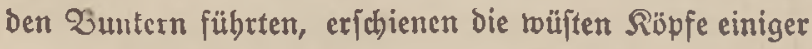


Srimmer; aber ebe fic fich befannen, rief Soarm Ott mit rajwer, beller Gtimme, englijh) und plattbeutid Durd. einander: "Geibibrbez Seufels?! Quid, quid! ... Geib ibr verrült? ? Wir 【aufen ja auf bas englijhe Minenfelb! ... Dampf! ... Dampfl... Wer ijt der Seadman? Der ba? Mach' Dampf, Mann, oder ihr jeib tote Peute! Now zebn Minuten und wir fiken brin! Etellt Die Najdine an!"

Der Oberheizer, ein junger Menjh mit frifhem, tübnem $\mathfrak{G e f i c h t , ~ g r i f f ~ a n ~ b e n ~ S o e b e l ~ u n d ~ l i e ß ̧ ~ b i e ~ M a f d h i n e ~}$ anjpringen. Die andern glaubten ober glaubten es nicht ... Fie fanden es auch roobl praftijळer, tweifergufabren, alz auf Gee zu treiben; fie roandten fich von ibm ab und fingen an, erft wiberwillig, twie wenn fie fich fdcömten, Dann rajher, Dann zulegt im alten Edrwung, Roblen

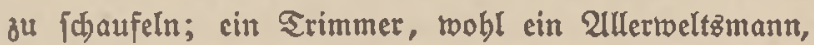
tam aus feinem Loch beraus, tippte fich auf bie Gtirn und rief feinen Rameraden zu: "Wie fönnt $i \mathfrak{l} r$ folche शarren fein unb für England auf Die Minen laufen Doet von Den Deutiben eine Rugel vor ben Ropf zu betommen? Geib boch neutral, Rinber! Neutral! $\mathscr{W e r}$ hat bie Gewalt über das Gdbiff uns über uns? Der da an ber Sreppe und feine Reute! Deutjdye! 2lljo gebordt! Reutral! Reutral! Daz ijt jegt alles!"

Da mertte Sarm Ott, Dá̉ Diejer bier geniigte, und ging mieber nach oben. Slno füblte, swie unter feinen Fü̈en die Majdbine mit neuer Macht arbeitete.

Bleich Darauf meldete ifm der Weftpreuße, Daß̄ einige grofe Riften an ber Dectlabung fich gelofit bätten. Da rief er fie alle berbei, auch die Rannjabaft, bie ba 
berumitand, und arbeitete, wäbrend bas Gđiff mäctitig gegen Den Wind itampfte, mit aller ERacht an Der Dectladung. Fine ber ungebeuren Siften, toabricheinlich eine Majकine, tonnten fie nicht balten; fie zerichlug bie Reling uno ging über Borb. 2aber bas andre tonnten fie ficher vertauten und retten. Eo vergingen mebrere Etunden; e8 modhte nid)t lange mebr Dauern, Daß́ ber Morgen fam. Geine Reute toaren übermübe. $\xi_{8}$ rar bie britte Racht, dak fie teinen orbentlichen Gdjlaf mebr batten. Der Samburger, Der Emerfübrer, ber fich einen 2lugenblid an bie Sreppe lebnte, ftolperte, als er auв Beríbn angefto Ben trurbe; er batte im Eteben geidlafen und wäre beinab umgefallen. Esz twar aber an Gdylaf nidjt zu benfen, folange fie nod bier brauben berumtrieben.

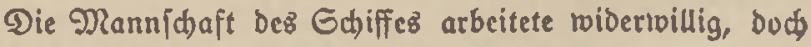
batte er teinen rechten (Brunb, eingufdreiten.

2llz fie nun fo... ez modte gegen vier subr pein und bas Wetter trurbe eftwas tlarer, und man tonnte bie Gefichter beutlid ertennen ... Dic Erregung ber erften Gtunden lié̉ aud, nad, ... bei ber Urbeit ftanden, uno er felbft mit zugriff, fiel ibm mieber auf, bap bie Mannjajaft dezs Gchiffeż jedesిmal, wenn fie bei ber Irbeit fich ibnen näberten, fich von ibnen zurüdjog, io als menn fie, bie Deutfden, die 'Peft bärten. Er tonnte es fich nid)t ertlären und grübclte Darüber nad, тав ев fein möchte. Fr fab nun aud)... ba er nun rvicder unrubig getrorben war und feine Gedanten nun roieder auf jenen Edbrei und Rampf auf ber 2 rücte uno auf bie Gpur bes शipintrauens getommen waren, uno e\& auc beller wurbe ... Dáb die Lcute fich immer wieder 
umfahn, fo als ermarteten fie irgend etwas Plöbliches. Da ichictte er ben Klemen Edbifījungen, einen bübichen, lebendigen Hleinen Rerl, ber aber auch jitheu unb verbajit berumitand und lief, nach Der Rombüie, um ibm

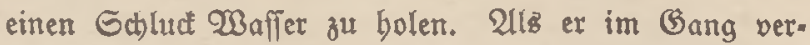
ichrounden war, ging er wie von ungefäbr binter ibm ber, faşte ibn, als er allein mit ibm mar, bart an, Deutete über bas Edhiff uno fragte auf englifh und Deutich: "Wo? . . W Wer? . .."

Der Reine fah mit entjesten, gropen 2lugen zu ibm auf und jagte leife: "English seamen on board." "Wicviel?" „Eight men!" uno tweinte und fchüttelte verztweifelt Den Ropf.

Da ließ er ibn, ftrid ibm zur Berubigung über Das Sbaar und ging zurïct und trat zu feiren Qeuten und jagte leife uno feit: "Es fino englifhe Gecleute an Borb veriftectt; vielleidyt eine englijue Drijenmannid)aft! ... Die Waffen bereit ... roir müffen fie unjdäblich machen." Damit trat er auf ben gröb̆ten ber Mann= fchaft ză, hob feinen Revolver, Deutete überz Gdhiff und fagte: „English seamen. $\mathscr{W}_{0}$ ?... Vortwärtz! Uber leipe! (Fin Ton ... uno id jübęe!"

Der zudte zufanunen, ließ̧ bie Epeiche, bie er in ber Sand batte, fallen uno madjte fid millig, ja, wie es idhien, von einer Sorge befreit, auf ben $\mathfrak{3 e g}$, Sarm Ott, Dic Qaterne an Der Bruft, binter ibm her. Er fiibrte fie in ben (Bang nach ber Rombüje und Dort an eine Sür tmo in einen Eleinen Raum, in Dem allerlei Sintfäffer ftanoen, uno beutete auf eine grweite Sür uno trat zuriic. In Demjelben 2lugenbliat fam ein rilder Erenfien, Die Brtider. 
Edhrei von Derielben Gtimme, die fre vorbin von der Brücle gebört batten, aus bem Riaum: "Deutiche! Deutiche! Borficht!" Slno ein Gtoß̄en uno Ringen uno Gdilagen, tno mieder der wilde Gdyrei.

Da fdirie Sorm Dtt: „Here German seamen! 3molf Mann! Open the door!"6

Drinnen war $e^{b}$ rubig getworben. Er börte nun cin leiiez, rubigez Reben und 21ntmorten, und daz 2luf=

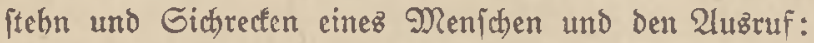
"Oba ... Oba!" und ein langes "Sonnerwetter!" Daz bauerte cinte ziemliche Weile. Dann rief biejelbe Etimme mit noch mithjamem 2ltem: "Sier ift cin englifaches Prifentommando: ein Dffizier utnd acht Mann. Slno Dann ift bier ein Deuticher, einer bon ber $\mathfrak{B}_{c}=$ fakung bez Tampfers, ben fie gefangen genommen und gebunden bielten tno mit fich in biefe Rammer gefdleppt baben, damit er fie nicht verriete. Aber jetst babe ict) mich frei gemactit; und fie baben mir auch alle ibre 20 affen gegeben und geben fich euch gefangen. Uno nun в̈ffue ich, Der Deutíche, Die Sür." (3leich Darauf ging Die Tür auf, uno ber Deutfche, ein groper, junger Denf(h) in fdymariger uno bertommener Siteidung, fam beraus, mit bohen Gdyultern. Sointer ibm tamen Dic englijuen Matrojen, breite Reute, bie Müzen tief in der Stirn. Bulebt fam einer, Der wie ein Offizier ausz= fab; doch toar ez ein einfacher Menich. (Er grübte und bielt in guter Soaltung eine fleine Rede: "Wir batten Den Dampfer, Der nach Sollano jollte, als Prifen= fommando bejegt. WBir müffen aber burch ben Gturm und f(c)lechteż Navigieren von unierm $\mathfrak{W e g}$ abgetommen jeir, 
benn wir liefen Shrem Wactstichiff in Den Radben. Da beic)loffen wir, uns zu verbergen, um, wenn angängig, Gie in Der Nacht zu überfallen uno zu übertbältigen. Ulङ wir mun noch) nit Dem Rapitän und den Reuten verbandelten und fie uns veriprachen, Daß̄ fie fich an nichts febren wollten, fabrie biejer Matrvje, Der am

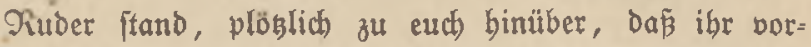
fichtig jein follet. Ta mufiten wir ibn nieberreipen und ibn Enebeln und mit in unjer $\mathfrak{B e r f e d}$ nebment. Wir baben ibm aber nict) mebr angetan, als für unfere Gidberbcit Durchaus nostig mar."

Der junge Deutfiche, die Santo an eignen Sals, lachte turz auf: "(Ez ift fo, twic ber Mann fagt. Sá) tocrbe vier 230 d)en lang einen biffen Salz baben, uno toeiter nicht8."

Soarm Ott wunderte fich, wie rubig, fozufagen: wie gerecht er bas fagte, uno auch wohl über bie Stimme; aber es verflog ibm twieder. Er lię̧ die Engländer nach vorn unter die Bact fïlyren, fhlós den Raum binter ibnen $3 u$, ftellte eine Waache Davor und ging $b^{u}$ Deter Sageborn birtauf und fagte ifm, was gejchehen war, fam Dann roieder binunter und fielle fich mit feinen Reuten an bie Reling uno wollte io Den Mlorgen ermarten. Die Mannichaft dez Édiffes jás uno lag in Lee ocs Gdhornjteinz und fdhliē.

Plach einer Weile fiel ibm auf, daß̧ er ben Deut= fden nicht fab, war auch neugierig von ifm zu biben, Dachte auch, es fömute ifm gut tun, fich ein wenig zu unterfyalten, da ex bart mit Mübigłeit zu tämpfen hatte. 2llo ging er bin, ibn zu juchen. 
(Ex ging burch ben Bang und fand ibn nicht, uns fuctse ifn in ber Rombuife und fand inn ba auth nicht. 3ulezt fab ex ifn einfam am Ende bez Banges finend, die Gchulter in ciner mertmüroig Yeidenifhaftlid) bingetworfenen 2lrt gegen die 23and gelehnt. Ez war da Dunfel.

(Fr achtete erft nicht brauf, Daß jemano fid) ibm näberte. Er fuhr fort an jeinem Salz zu reiben. Dann aber bürte er Damit auf uno jagte miibjam: "Gie haben mich boch mächtig hart angefapt! Mir tviro bunfel vor ben Ulugen," uno er griff nach Sarm Ottz $\mathfrak{A}$ rm.

Ta griff Sarm Ott zu und balf ibm bow und fübrte ibn zu ben andern an bie frifhe, falte Macbt= luft am Ende des Bangeb, tund ließ́ ithn dort auf eine Rifte niedergleiten, und befabl Dem Eleinen Sungen, ber (iid) num zutraulich und $\sigma$ chus fuchend in feiner Nähe bielt, Raffee uno 3 rot zu bolen, uno befabl ibm, audh für alle andern (Effen und Srinten berbeizuja)affen; und ftand fo neben bem Fremben und falb auf ibn berab, und machte fich nach feiner Woife (Bedanten über ibn. So dunfel es twar, fo extannte er jegt beutlicher, da feine Rleibung bülig heruntergetommen bar, aber nicht feenännif̧), fondern jo, alż twenn ein Qanomann ber= unterfonmt. Er batte grobe Stiefel an und dicfe, ftarfe Sojen, bie mit Fett und Gdmuk wie eingerieben maren, eine Sacke vom felben Stoff uno Gamus und eine ent feslich verfommene Tuthmüke, die früber mal blau ges wejen twar. Daz (Geficht fah er nicht, zumal jener fá und ez nur ein wenig bob, wenn er langfam jprach. Dabei madhte er fid) immer an feinem Solb unb शacten zit forffen, fo als ob er nactjebn trollte, ob atch bie 
einzelnen Wirbel noch an ibrem rechten Dlał fäßen und beil rären; uno trenn er bei feinem Effen uno Srinten iablucte, bob er bic Echultern und preste ez hinab.

Als er fertig gegeffen uno gctrunten batte, wurbe er etroas munterer, fing von fid) aนs an, zu ergäblen, unb jagte: "Gie baben bie ganze Racht beraten, ob fie es wagen follten, fich berauszufchleichen unb euch zu überfallen; aber fie batten nicht ben Dlut bazu; fie batten immer irgendweldye neuen Bedenten. Sch bachte, räbrend fie beriefen: ,Pluı follte ich bier figen mit meinen beiben Brübern uno einigen Tachbarjungen! Wie bätte ich euch fangen wollen!" (er lachte fitll vor (ich) bin.

"Wie lange bift bu fort bon Sauz?" fragte Sarm Ott. "Zon Sourfe? ... Oh ... jo gegen brei Sabre." "Go ... S S nno mun machjt du benn einen furzen 3efuch bei denen ba zu Sauje . . und bann wieder fort und in Den Rricg!"

"Sh twill nicht etrt nach Sauz," lagte er rubig. "Da, too ich an Lano fomme, will ich mich gleich melden." Soarm Ott fagte: "Das ifit nicht rech)t... (Erit nach Saus zu Dlutter, und Dann in ben Rrieg. Der Frieg ift eine bitter etnite Gadbe."

Der Frembe bob mit feiner rajofen, ftarten $\mathfrak{B} e=$ lvegung bie ichlanten, breiten Gdjultern und meinte gleich)mütig: "Sch bin ja nicht wegen ber Familie ge=

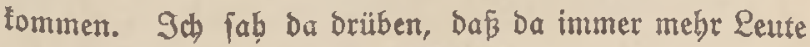
über Deutid)land berficlen, und da meinte id), id) twäre bier nötig. Darum bin id) gefonmen, bod nid)t regen Der Familie!" 
Sarm Dit futbr es fo Durch ben Ginn, dak er jemand fannte, ber in bojen Gtunden, befonder in ocr lebten bisfeiten, die Gatulter genau jo bob rwie biejer; aber er Dachte: (Der Wejtpreube ift verrüft und bat bich aud) verrïat gentacts." (Er ftarrte auf Den Fremben berab uno fagte bei fich lelbit: , Der ift ja viel gröper uno breiter als Eggert; auch) ifit feine Eprache anders." "WBie ift ez dir benn gegangen . . orïben," fragte er ... "ichledtt?"

Der Frembe fulgr auf und fogte verlegt und falt:

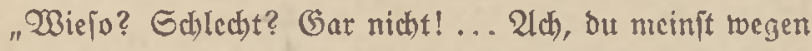
nciner Reibung? ! O, nein, ich babe meine gute Reibung in

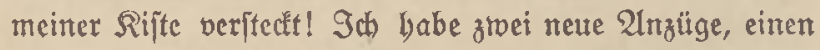
für Gonntagz̃ und einen für ßeit, uno Beld babe ich auch in eimen Beutel um ben Reib ... bier!" Er griff iid) mit einer ftarfen Bewegung ber 2lrme an bie Süfte.

Sarm Ott zucte zujammen, als cr bieje Berwegung fah) uno die Wcndung hörte "und einen für 3 eft". Eagte man fo aujerbalb der Seimat? (Fr borte ein (Geräufich binter fich uno wandte fich um.

(Da ftanden die vier slann von Der "Zllten Qiebe" binter ibm. Gie ftmbent ba fahon sinige 3eit. Ez ftand ihnen ber 2ltem, fitll.

Der lange Gobt von $\mathfrak{B u ̈ j u m , ~ b e r ~ i m m e r ~ g e r n ~ f i d ) e r ~}$ tmo feit auftrat ... weil er im Grunbe cin etwas balt. lojer Menich war . . tonnie es nicht länger ertragen. Er fagte: "Frag” ihn, Soarm Ott! Frag' ihn frijhrog! Ift er ez̊ oder nicht? !"

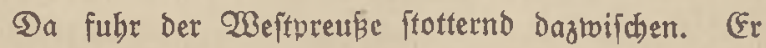
war feiner Eache ja fider. (Er batte es̉ ja getrupt. 


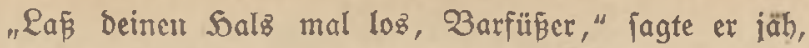
"Euct" bich mal um!"

Der Frembe ließ̄ von jeinem Reiben ab und jah langiam auf. Dabei fam fein (Beficht in den grauen Morgenichein.

"Eggert!" jagte fein 3 ruder, "hier treffen wiz 1เท8!"

Eggert Ott blieb fingen und ftarrfe neben feinem Bruber über bie Gee und lagte falt und buctig: "Эक erfannte dich eben fhon an ber Gtimme... idh bin nicht zu meiner Familie gefommen."

Uber ba hatte er eine böllig falfde Rechmung gemad)t. Eie fprachen alle burcheinander: "शee ... bisr' mal! ... Du! ... Das gibt es denn Dod nidbt! Ree! . . bitte... mein Sunge... das geht Denn Doch über Daş Nenfiliche! Nee ... Das gibt es nicht! Ser mit ber Sand! . . Wir hier fino alle Zeugen, Die ganze Zact. bordwade, ja bie ganze Nannichaft von ber "Ulten Qiebe", 26 शann, Daß bein Bruber immer für bich eingetreten ift! Er jagt, ber Rnedht bat es getan ... fein andrer als ber Sinecht! (Diefer bein 2 ruder ift bein wabrer Bruber und treuer Freund I Tein ... nein ... beide. . .

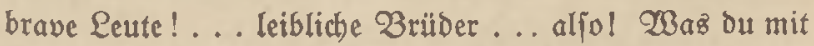
bcinem Alten haft, Da rollen wir nidht hineinteden : aber bu und bein 3 ruder ... nichtz . . gar nichtz zrif (j)en euch! ... Blïtlid, twer cinen guten, treuen 3 ruber hat! Nein, gib ibm die Shand ... 10 ... Gib fie ibm, Eggett!“ Satm Ott liefen die Tränen über bie Wangen. "Bib mir bie Sondo! Dent an bie Mutter, mie fie fich) freuen würbe!" 
Ez rurbe Eggert Ott, Der jof̣ort bei ibren Worten uno dem S̈berfall aufgeftanden war, unjagbar ichtoer. (Es jah erfit aus, als ob er bie Sand nidyt heben wollte, um fie bem 23ruber zu geben, fondern um fie alle nieber.

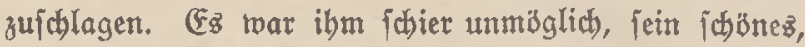
berrlidjes $230 r t$, Daj er feiner Familie bis in den Soo gram fein twollte, feinen berrlicten, golbenen Sa官, feine ftrablende groß̧mächtige (Finfamfeit aufzugeben; aber bie von ber "2llten Qiebc", alle fleiner als er, ftanden Da, breit mie Umboffe, bereit ben Eळlag zu empfangen; fie umftanden ign uno blisten ign fo gornig und oringend an, und waren fo mutig, ia tolltübn und fiegeş/ict)er, uno bebrängten ihn fo mit ihren [türmiןchen, beißen Geelen, Daß̄ er übertounden twurbe, fo mädtig und ftart auth jein Serz war. - Er twarf feine Soand boch und feft in bie Sand des Brubers, und fagte wie eriojit, — Denn ibre Sorzen batten geradezu wie Gteine auf feinem Serzen gelegen und es batte fait itillgeitanden vor bem Druct, Den jie barauf madhten -: „Na . . Dann aljo. (Es ift gut, Bruber Sarm... Wern Du auf meiner Eeite geftanden haft ... 2 Uber nur mit bir! ... Die andern" ... er meinte ben Bater uno die Qeute aus bem Rirchipiel ... "Niemals!" Er fकnitt mit Der Sand Durd) bie Ruft.

Da griffen alle nadb feiner Sand und auch nach feincz 3 ruders Sand; und ez gab ein beftiges und

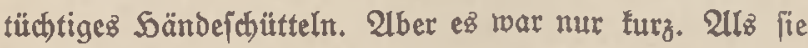
füblten, daß es genug war, traten fie alle won ben beiben roeg unb ftellten fich abjeits gegen bie Reling und iprachen laut uno ganz gegen ihre $\mathfrak{A}$ rt fait lärmento 
über bies und Das: über das Gchif und feine Labung,

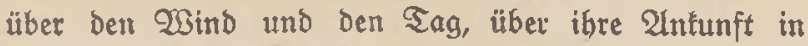
Wilbelmshaven - benn fie bielten nun Rurs auf $\mathfrak{B i l =}$ belmshaven - und gingen in biejem (Beipräch, fo ganz allmählich, twie trenn $e z$ fid) fo gand natürlich madjte, nact) ber andern Geite binüber. Slnd fanden erjt ibr natürlicjes, langโamez und rubiges fie bie beiben 3 rüber ganz allein an ber andern Reling fteben faben.

Go ftanden bie beiben Brüber nebeneinander. Der ältere, mit noch inmer flopfendem Soerzen, vorfictitig in Worten, Daß̉ ex ben andern nicht verießse, und vorfict)= tig mit ben $\mathfrak{A} u g e n$, von ber Geite ihn anjehend; Der

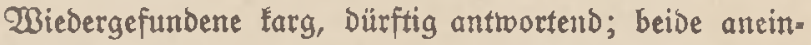
ander vorüberjebent. So ftanden fie bis ber Morgen fam.

2llz Der Morgen wöllig ba war, eill grauer nebliger Sjerbitmorgen, fubren fie burth bie Gd)leuje von $23 i l=$ belmbhaben und melbeten ibre Drife an.

Der Rorbettentapitän, ibr Chef, tam an Borb, fab Das Rommando von (ec)s Rann, Das in Reih und (Blied [tand, und babinter, in einem Rlumpen, bie MRannidhaft, und zur Geite für fich einen langen, gropen, rotblonden Menjhen in beruntergetommener Rleibung und einer bäp̄licten Suchmütse; und bärte den furzen Beridt, ben ¥ater ذjagcdorn herauż|tiés: „Ein Ulnteroffizier und fünf Mann von Der "Ulten Liebe", Drijenmannfchaft auf Dem norwegijacn Dampfer Sertyra, mit Gtüchut von Mon= treal nad Lonbon. Soier... Ediffipapicre... Dort Sapitän."

Peter Sageborn madte eine Pauje. 
Der Sbef fagte: "Ėz ift gut, Slnteroffizier. Gut. Shr Rommando ift beendet! " und roollte fich zu Dem frem= den Rapitän wenden.

Aber Die fünf von ber "Ulten Liebe" faben ibm fo forich, fo kübn, fo erzähleno in bie 2lugen, daf cr unrubig routbe, und fein tühnes, jđharfez, lebenbiges (Beficht einen ricbtigen Tanz auffüt)rte. (Ex rutbe butch biefe 2ugen gez̆lvungen, daß̄ er Peter Sagedorn wieder anjah, und iagte mit fnatternber Gtimme: "Noch maz??"

"3u Befebll" fagte Petcr Sageborn. "Llno eine englifthe Prifenmannicbaft von einem Offizier uno fieben Nann, bie fichon im Schiff roaren und fich verjtectt batten. Wir baben fie entraffnet und gefangengenommen. Sic fino unten in ber Bact."

Der Chef ladite furz auf und fein Geficht tanzte. "But!" fagte er, "gut! Sch will fie fogleich verbdren," und er fah nach der Badf. "Zringen Gie fie ber, Ulnter" offizier!"

Aber alz er baż fagte, fah er, baß die Qeute vou ber "2liten Qiebe" nicht Damit einberjtanden maren. Sic batten noch immer bieje bligenden und raja) uno beif ergäb= lenden 2ugen, und er fitugte zum ztweitenmal und fagte, ein roenig ungeduldig... er war ja ber Bater von bunbert und zwanzig foldhen Booten, und twenn er aud) feft beripprodben batte, Daf er jeoez einzelne Zoot bier ... in feiner 3 rujt . . tragen wollte, er fonnte fich

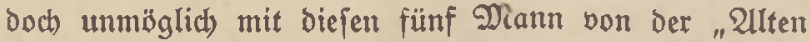
Liebe" folange aufbalten! (Er tonnte es unmöglid); Denn bie anderen $20 o t e$ riffen ja fortwährend an jeiner Geele. Geine Geele roar zroar ftart... das jab man ibm fofort 
an, fo twie er hucte und fommantierte und bie Seele ifm im ganzen Beficht fof und prang. 2lber er war ঠod) nur ein Menfi ... "Noch mebr?" jagte er furz. "Befebll" iagte, Peter Soageborn. "Diejer bier" - er zeigte auf Den Wiedergefunbenen, Der ben Chef balb neugierig, balb trokig betrachtete - "gebörte z"

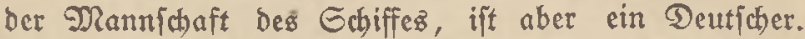
(Er madte zrocimal mit Lebenżgefahr ben Berfuth, uns zu warnen ... als roir an 3orb lamen, unb als wit an Bord waren . . . und bat ung, ba er unz burch fein Bejdyrei unrubig madhte, vor S̈berfall gerettet."

Der Chef nicte Peter Sageborn a unt lagte: "Zrav! ... Bran! . . ." uno trat auf Eggert Ott zu und gab ifm bie Sand und jagte wieder: "Brab!" Dantl mandte er fich wieder fu Peter Sageborn unt jagte: "Sie und der Obermatrofe . . und Sie" - er minfte Fggert Ott - "fommen mit, wir wollen bie Gadje zu Drotofoll nebmen," uno inoem ez jäh in jeinen Uutgen von jenem Fener blizte, oas in tübnen Soerzen glübt, lagte er furz und fait barid): "(E⿱ cinige Eijerne Rrellze geben."

Die andern vier von Der "2llten Riebe" marteten nun auf

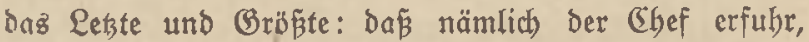
Dafs unt toie bie beiden Brüber fidh gefunden batten! Denn bas trar ja noch taujendmal wumberbarer alz afle andern Begebenbeiten! Sind fie faben den Chef fo an,

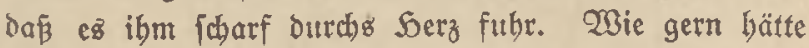
jeder von ibnen ibm dicje (Befohid)te ergällt und jein

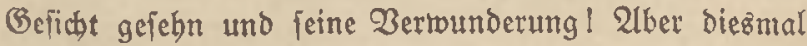
berifond er ibre 2lugen nicht. (Fr meinte, es wäre 
wegen der Eijernen Rteuge, bie er in 2lusilidst gejtellt bätte. Suno fo nicțe er înen zu, fohmetterte fein: "(Buten Morgen, Reute" uno ging mit Den dreien von 3 ord.

Tacheiner Hleinen balben Gtunde gingen die 3 rüber mit einem Gdreiben, das der Cbef Eggert gegeben hatte, nach) Der Rajerne, wo (Eggert Ott fid) alz Refrut mel= bete und angenommen murbe. Gie boten ifm vierzebn Tage

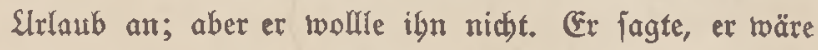
berüber gefommen, um mitzubelfen, nicht um Slrlaub

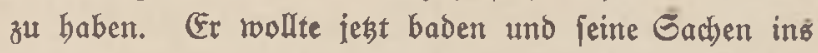
Wirtşbus bringen, und motgen um fieben $\mathfrak{U}$ br antreten.

2lв fie das extedigt batten und orauben auf ber Gtrabe ftanden, fagte Sarm bittend uno vorjichtig: "Wu, Eggert, la $a \tilde{\beta}$ uns fébn, ob wir Bruber Reimer jegt treffen tönmen. (Fr bat Slrlaub gebabt und tommt entweber mit Dem nächiten 3ug oder mit Dem 2lbend=

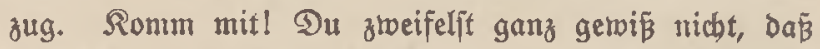
er immer zu bir gehalten hat, ganz wie ich. 2ǘerbent ... ex ift num mal bier in $\dddot{3}$ illbelmśbaven, wo bu nun bift. $\$ b r$ fönnt bod nidut fremb aneinander vorübergebn!"

Der Seimgefebrte bärte ibn mit gleidggültigem, fal. tem Beficht an, die $2 \mathfrak{u g e n}$ in bic Weite. 2lber ittwen=

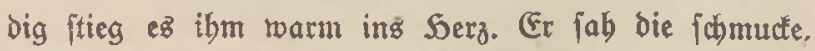
betwegte Geftalt Des Brubers und die ounteln, gläubigen 2ugen, und fab ibn im Geift, wie ei bamals nach) Samburg fubr und mit feimem 3 ücherpatet in Der Wirtsitube in Gt. Pauli itand und bitterlich um ifn reinte; er empfand fohon lange, Daß̃ er Dicjem unrecht getan, und liebte ibn twie immer; abez ax tounte es

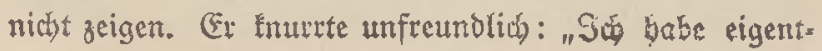


lich genug . . . aber went es nötig ij̈... Slnd nun jage mir, wo id mir neue Sleibung fanfen faun. Id fann ia an meine fifite nicht berantommen und id mag biefen 2bend nidit fo herumlaufen."

Da tauften fie neue Reibung und gingen Dann nach dem Zabnbof.

Bruber Reimer fam, bienfteifrig unb getwiffenhaft toie er wax, wirflich ichon mit bem erfiten 3 ttg. Ex fah jeinest Bruber Soarm da ftehn und wintte ibm fojon von ferte zu; uno fam burch Das Beoränge beran und gab ibm bie Soand. Ta erft fab er ben Menfiden an, ber neben thm ftand. Er glaubte mohl erft, das Beipenjt feines Brubers zu [ebn, ben Geijt, ber ja, twie cinige meinen, van Reibe (ied) trennen und jeine bejondere Ericheinung baben fann. (Fr tonnte bor $G$ dbred uno Vertwuberung nidbt (prechen. Uber plöglich $\{a \mathfrak{b}$ er binter ben berben, überitolzeu 2lugen einen leijen Ghein brüberlicher Liebe, uno jayrie auf uno umfäte feine Gdjultern. Qiber gleidh bedad)te und empfand er, baß bes 2 rubers (Bemüt noch rutno wäre,

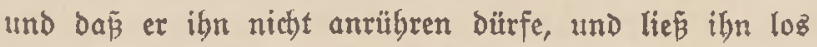
und trat zur Geite neben ibn, und ging rubig neben ibmen ber, obgleich feine Geele in beiper Erregung, in rafender $\Im a g \delta$, wom fernen 2merifa bis auf ben Soof am Deich uno pon ba an bie $\mathfrak{B r u f t}$ des Brubers forang.

Dann gingen fie neben einander, in unnthiger, zers fester Slnterbaltung; uno famen aus ber Stabt, uno zum Banter Bürgergarten. Da gingen fie hitein und iesten fich in Den Zorbau, ber in Den Barten blictt. Da erfit tam ez zu ciner ordentlichen Unterbaltung. Der Süngite fübrte baz $\mathscr{W}$ ort. Erft als Grager. Er weigerte 
fitch, Bruber Sarm, Der ił̆n bedrängte, aud) mur ein ein=

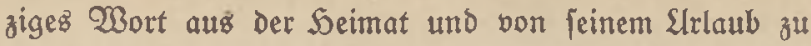
craäblen; er vollte erft bören, wie bie 2 rüber fich gefunben batten. Wie genau er fragte! Wie er nicht cher rubte, alz̈ bis̄ er bie (Bejdidfte von Der guten Prife burch und burch

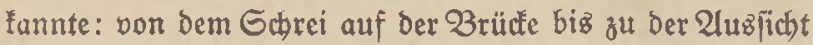
auf bie Eifernen Rreuze, pom (Beficht des betrunfenen Majuiniften uno bez Gajiffziungen bis zum Beridjt von Defer Soageborn! (Er rubte nidjt, biz er alleg Deutlich vor feiren 2ugen fab. Danach fam fein eigner Bericht! Wie gut und wie tlug war e8, báp er gleith zu 2lnfang fagte, da í die Gache gut abgelaufen twäre! Wie gut, ఏaß̄ er baż gleid, [agte! Nicht allein wegen Zruber Sarm, Der fonft die gange 3eit, wäbrend beß ganzen langen Berichtz, tobunglüdlich getwejen twäre, ncin, auch) wegen Bruber Eggert! Denn obgleid) (Fgs gert mit gleichgültigem (Gefichte daja von beliebigen fremben Meni币en erzäblen börte: eine

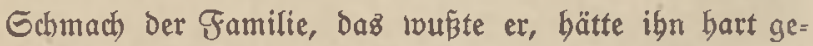
troffen. War nidjt fein 3orn, der Damals über ihn fam, fo farectfich und rajent, zuerit, weil bie Familie

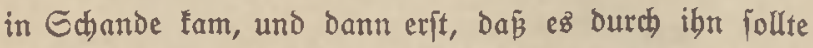
getommen fein?! 2lfo erzählte er bie Begebenbeit von Bruber Rlauz, die er eben binter fich hatte! Denn die Nutter batte gejagt: "Du muß̄t ez Sarm erzählen.

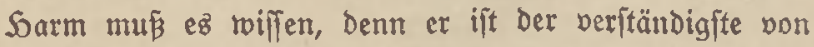
cuch), obgleich ex nicht ber flügite ift, bamit er rocí, toas für einen 2 ruber er bat, und ibn bebüten tann, wenn mir Eltern nidst mebr find." Nein, roie flug er erzäblte! WGic er won ber ganzen übrigen Gamilie fein 
Wort jagte, fonbern mur bieje Bejchidte oon Bruber Rlaus und ber Nutter erzäblte! O, er bütete fich roobl, daß́ er ibm nicht das wunde Serz verlegte! Und wie lebendig uno berzlich er es vorftelfte! Sund wie man mertte, $\delta a \bar{B}$ er jelbjt woll von Etaunen warl Tein, Diejer $\mathfrak{B r u b e r}$ Rlauż! Wie er mit feinem langen $\mathfrak{5 a l}$ uno vorn an ber Stirn forn tabl, uno bie Saare an ben Sd)läfen fdyon grau, auš bem Slblenlod) (päbte! Wie er bann, fo gegen Morgen, bei feiner Raft am Wall, ingendwo bei Bendorf, ôu jeinen beiben Begleitern gejagt batte: "Wenn ich an Der Gront bin, werbe id meinen Qeuten natürlich immer ichreiben, ich bätte fie nicht vergeffen! Das muß idh ifnen fdreiben, Denn fonjt find fie traurig. 2ber in Wirflichfeit roerde id fie vergeffen haben. Sie werden mir fein wie (Frb= mäuner, bie in einem Scibebügel von goldenen Sellern effen; benn ich fann nicht in bie Ferne benten. Nein, Das fann ich nicht." Sa, fo batte er nod) geprablt in Diejer Gtunbe am $23 a l l$ bei Bendorf, unter mütterlicther Fübrung auf bem Wege nach Rendsburg! SAnd wie bie Mutter einen rajhen Blict auf ihn, Reimer, gemorfen büste, aber bann ibren थ̈lteiten freundlich angejebn und gejagt hatte: "Das ift recht, mein Sunge, ftell" fie bir bor im Sreibegügel; ba figen fie roarm unb trocten, bis Du wiebertommit! Und nun bol' beine Pfeife heraus und raud” mal!" SInD wie 3ruber Rlaug̈ bann noch) eine Weile am $\mathscr{W a}$ gefeffen unb rubevoll geraucht bätte... an Der Miutter Schürze! $\Im a$, uno wie er Dann neben ibm auf ber Treppe vor bem Sauptmann gejtanden bätte: in Feiner unmilitärifゆen Soaltung ... die Soalsbinde 
binten weif berauz unb toeit, weit entrernt vom Roc. fragen!' Ex machte ez faft ein bif́chen folimm, wie cr die Bilder vor ihren immern 2lugen malte, einz umz andere, und feine Qujt bran batte, und einige Male

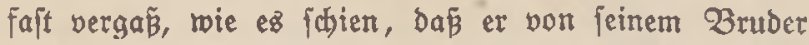
fpract). Slno Der. Seimgetebrte fah ihn einmal, alz er

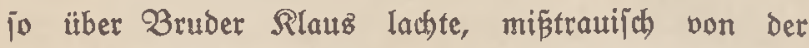
Geite an. Aber $b a$ fab er in ben 2 ugen bes jungen Brubers bie Eeligfeit, Daß̄ er jeinen 2 ruber Eggert twieber batte; und füblte, daßs die CFreude Darüber mit ihm Durchging, uno baß er mit feiner lebbaften, jäben, erregten Grzäblung nach feiner Geele griff, ign für fïb unb Daż CEtternbauz rwieder zu getwinnen. 


\section{Rapitel}

\section{Lobrede auf G. D2. G.,Below"}

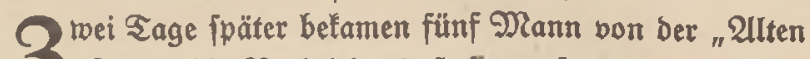
Siebe" bie Nactjricht, Daß fie periegt wären, unter ihnen Sarm Dtt. Er tam auf Den gró̧en Sreuzer, Below", ber zur 2 ufflärungsflotte gehörte. Einige ber ßejałung maren fihon von Borb gegangen, threr Beftimmung zu; andere batten Lanburlaub. So ftanden nur pier ber alten an ber Reling, als er bei frtrömendent Regen, den Gadt auf bem Rüuden, won $30 r b$ ging, um auf den Sireuzer überzufiedeln.

(Er war nod niemals auf einem großen Sireuzer

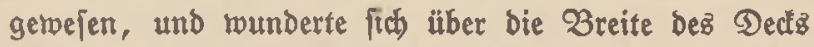
und bie getwaltigen $\mathfrak{B e r b a ̈ l t n i f f e ~ b e r ~ T u ̈ r m e ~ u n d ~ b e r ~}$ Brüđte. WBą twar bą̧ für eine Treppe vom Delf́ binauf zur Brütée! Eo bod), wie von Der (Erbe biz zur

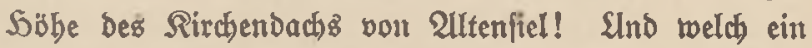
großę Gewirr im Innern dez Edjiffez: von Steppen unঠ Bängen, Rammern und Räumen, Robrteitungen und Dräbten, Majdinen und Renidjen! (Fr fah nach bierzebn Tagen nod) Befichter, bie er bisher nidbt gejebn batte, uno er brautchte bier 230 djen, bis er bon felbjt und in Gedanten Den $23 e g$ fand, den er zu mad)en batte. (Er twurbe ber mittteren 2lrtillerie zugeteilt, zmeite Raje= matte an $\mathfrak{B a f f b o r b}$.

Dort, in Der Rajematte, bie fo gró und fo bod twar wie eine mittlere niebere Bauernitube, übten fie täglich) an Dem Beffüüs, Daz in Der Mitte ftand und

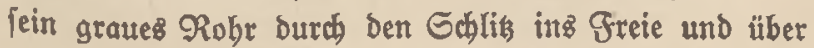

Grenfien, Die Brüber. 
bie Wellen frrecte. Dref 230 d)en lang toar et viester Dlann, bann rourbe er britter. Dort in Der Sajematte Itellten fie nach bem Exergieren am Bejeing auch bie Bact auf unb apen ba, vierzebn Nann, am langen Si fie Da auth bie Sängematten und jhliefen ba. Er bachte

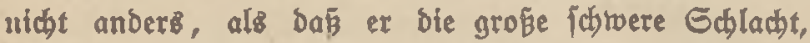
Die fie erroarteten, aud in biefem Raum erleben würbe. Wenn es gejheben twäre, fo wäre ex nicht mit bem Leben bavon gefommen; Dern in bieje Rajematte iolug

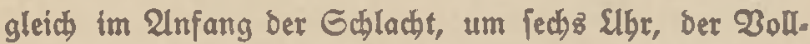
treffer und totete alle, bie batin twaren.

Gie fajen meijteng aud in ben Geierftunden in biejem Raum. (Ex war ja freilich niebrig, und bie

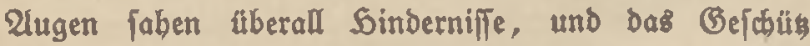
zerrís ibn falt bis zur Mitte in zwei Seile; aber wenn in biejen 2 Binterabenden die elettrifa) $\mathfrak{B i m e}$ fo von oben berabichien und fie in ifrem blauen 3eug Darunter[apen, die einen bei Rartenjpiel, Die andern bei Salma, bie britten beim 2 riefichreiben ober Rejen, anbere in gemüt. lidber SInterbaltung, taäbreno bier unb ba einer an ber Wand oder am verblutten (Befdüh Iebnte und mit rooble toollenden 2lugen auf fie bercb fab: Dann toat ez Dod frieblid und traulich und aud nicht unjwön. Ober twenn es gu einem allgemeinen Gefprd̄ं tam,

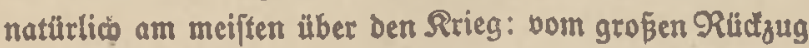
Der Ruffer, bum Sampf um Zerbun; ober toenn fie auf England fu fprechen tamen: wie fie ba unire guten

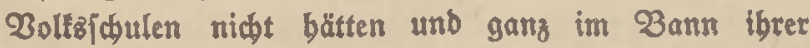
Seiturigen träzen und in bielen Dingen altmobijक, 


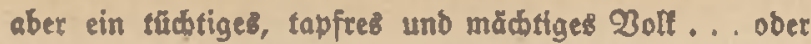
wenn, nadidem fie fich itber ben Lauf ber Welt matibe

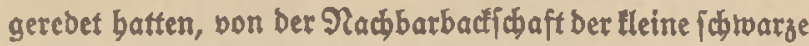
Gdloffer aus Erantfurt am Main, Bejめüsmann unb Ruttergajt, und ber büblche grope 3 reslauer, ber Gignal= gaft, bom Beruf Spolierer, bereinfamen, und ber Schloffer auf feiner Sandbarmonifa - Gtablitimmen und D. Dur - fpielte und ber Spolierer Den Sriangel bagu Elingeln liés .... alle bie alten Gdullieber - am liebjten oon allem fangen und börten fie bie em[ten Gaullieber und fie alle leife mit jangen, bamit ber Sriangel ju jeinem Recbt täme... und wenn fie bie Rajematte verließ̄en und biejen und jenen Rameraben in feiner $B$ ad bejudten, Dber wenn fie zwanzig, ja sft bunbert, ja ztweibundert Nann ftart im Rantinendect auf ben Sonnen boer 23 änten berumjapen ober ftanden - Det ganze Raum fummte von brem Geplauder und ber Raud ftand in Gdwaben liber ibnen - Dber wenn fie bei bellem 20 etter zu zrelen Dber breien auf bem Dittelbed ppazierten und, bie Augen 4hber bie frifdtoogenden Wellen, bertrauter als unten, bon allem practen, toas das serz betwegte... ober wenn fie einmal wieber, waz bann und wann gefdab, binauвffubren, über Solgolanb binaus, bie Englänber zu treffen, unb ber 21 tem Der freien Gee fie umbebte ... Doer wenn fie an Lanb gingen, jeben gtweiten Sag, und efwa eine fuptour madten nach Yarel gu ober nach SeverIanb binein, unb über Sirieg unb Grieben, Beruf und Mäbchen redeten unb Danach ein menig burch Die Gtrajen bummelten uno einige frifhe Mäbden gebn jabn uno Dann in irgenbeirem Rino ober bei einem Balaje Bier 
japen ... ober wenn fie Gonntags nadimittags anf einem Durfīpaziergang, jo ganz zufällig' - es mar verboten - ein Dubend Mäbd)en beifammen fanden und fie to ein befonders jauberes und fretndicties Ding berumidnentten, bis fie bod)aufatment um eine Pauje bat und fagte, fo fchön bätte fie nod nie ge= tant: toabybaftig, bann fonnte man es rovbl einige 3eit ertragen, ja, went e马 fein mušte, ein $9 a b r$ lang, ja, wenn es benn burchaus fein muste, auch zivei. Freilich, an bie alte, gemütlid)e Rüche im Elternhaus mit Der Mutter am Serd uno an Das helle 3immer Shounjens, Durch bas Lizbeth mit flatternden Rleibern gegangen war ... Die Sreulofe! ... Durfte Sarm Ott nidht benten, uno aud) nicht an fein jijünes buntes Sands. berf und ben 3immerplał, ber fabräg berauf zur $\mathscr{2} u$ lag. Nein, baran butrfte ex nicht Denfen. Es war Srieg! Rrieg! Ulnd in biejem Rrieg, Den bas unjululbig bedrängte Baterland fübrte, hatte et feine Gtelle: eben Diefe: Bactboro zreite Rajematte, unb jeinen Woiten. Wie Unterftände einer ungebeuren 3 atterie, f(d)ien es ibu, Dehnten fïch bie zabllojen Bänge, Rammet" uno Riäume bis in bie tiefíten Siefen. Slno überall, in jebem Raum, ftand uno lag, gejammelt und bereit, bie Siraft und Rlutgeit und ber Put bez Zaterlandez für den groben jळrectlichen Tag. WBie Bergleute faß̄en fie ba uno warteten auf ben Befebl von oben, um bie 2lrme zu rübren, uno die glübende Rraft ber Siefe auf Den Geino zu werfen, bet Das Baterland nidit leben laffen wollte. SUnb er war einer biejer Bergleute, und mušte anbre Gebanten fabren lafjen. 
(Fs datrerte geraume $3 \mathrm{cit}$, bis er fich unter bem Gemimmel zurechtiand. Wodhenlang war ez ifm ein (Getrirt bon Nenichen, bie fich mur burdh ibre Saltung, Saarfarbe und ifren Gtimmtlang unterfdieden. 2lber im Laufe ber Wodhen teilte fich bas Getwirr etrbas; tnd Die Rameraben ber Zactichaft utnd zivanzig oder vierzig anbre, twie ßerkebr, Näbe, 2lrbeit voer Neigung fie zufammenfübrte, wurben befanntere Qeute.

Ulnd ba fand er benn alz exjtez, baß bieje (Bejellichaft eine febr, jebr andre war, alz bie von ber "Alten Riebe". Ille WBetter! ... Dieß hier waren feine Sräumer und $2 B$ under linge! Nein! Nicht einer lwar wie bie pon ber "2lten

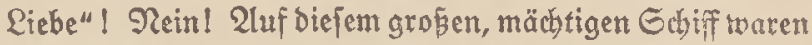
fie alle, alle belle, rafde Ropfe, vom Rapitän an, Der quicf war wie ein Fäbnridy, biz zum jüngften jeinter Fäbnridhe, bon dem alten Gtürtmeifter aus Sönning, ber wic eit 3auter auş|ab und genau wie ein Bauer feine Gadje tat, bis̈ zu Dem Hleinen Seizer, ben Berliner, ber ber Germaniaberft fison zwei Erfmbungen angeboten batte, Die freilich worläufig abgelebnt waren. Gie waren alle, vom 2lomiral, ber unter ber Edjanze feine beiben Räume batte, biв zu bem fleinen Seizer, von dem einige jagten, Daj er idjief getwachjen wäre, wäbrend andre es bejtritten, ein wenig abenteurer. Gelbitwerfitändlich! Wie wären fie fonit auf bie Gee geraten?! Ez twar bod Plak genug auf der gropen, baumtragenden Erde! 2lber fie hatten die Gee getwählt, bie weite, wegs und ftegelofe,

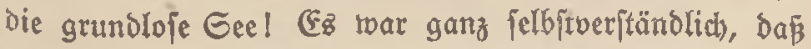
fie wachere, bellere Qeufe waren als bie auf bem Rande!

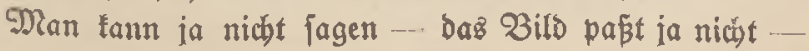




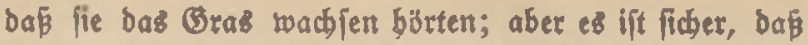
fie ibre Majdinen und Befbüze prablen, tbre Geuer reben, ben Wind fauden und die Geele des Gdiffes

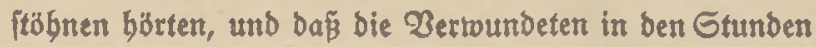
Der Morgendämmerung Des erften Suni das Gdiff im Sode rödeln bïrten. Diejer Admiral, ber da in ben abmiralstammern gaujte, Der ja roobl balber funfaig alt war ... twie er bet grauten Ropf brebte, twie bell uno fröblid, feine 2lugen bligten! Diefe jungen Männer Des Gtabez, nicht toie bet ben Englänbern (3efidter von nur Saut und Rnodien ... nein, roblgerundete, feine, thuge Befichter voll Blut und Reben! Diejer lange, bellblonbe 2lrtillericoffizier, bem man fichon von beitem amjah, baß er ein Grieje twar, mit nachläfíger Saltung, mit treubergigen blauen 2lugen, aber babinter To tluge Gedanten, wie nod tein Menjw gebacht, foviel veridblofiene Geele, daß jelbjt ein Wreib fie nicht begreift! Diefer erfte Offizier aus altem Reiter- und Rittergejdlecht und nun ebenjo frijh, fकlicht und felbitverftänblich arwijhen Eifen und Gtabl! Diejer erjte Ingenieur mit ben freunblichen, guten 2ugen, ber roobl immer, wenn es fein 2lmt erlaubte, an bie Geinen bachte und an feinem fdomalen Stebpult fo ficher und

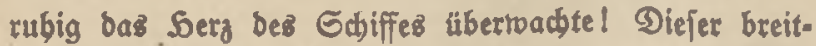

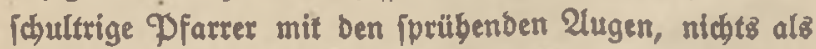
Denid und Denfdiengüte, ber fich am Tag von Glagerrat das Giferne Rreuz erfter Rlafie bolte! Dieje Gtüdmeifter an ben Ranonen, Sorten Der Robre unb ber Menfien! Diefe Obermaaten und Naaten, alle voll Ebrgeis... mands einer wollte an Land nodh gropie 
Dinge tun! Diefe jungen Obermatrofen, bie von tüdtigen Qebenzplänen förmlid Ptarten; bieje Natro|en uno Seizer, bie liefen und forangen, Rebe ftanden und fangent, Dáb bas Gaif davon erbebte! Dieje Eleltriler, Funter uno Gignalgäjte, die mit ben Soänben börten unb ppracten und mit den Obren rebeten ... ober twie nun ift ... alle bieje leute, frob und ftoly auf ibren Beruf, boll Imerer Würbe, daß fie biejen idweren Etand batten: gegen bie vornebmite und gröste aller irbijwen Betwalten und Näd)te in ibren Sagen, gegen Englandz Flotte, su ftebn, voll innerer Gidjerbeit, daß̄ fie ebentfobiel wert feien alz biefer getwaltige Geinb, alle einez einzigen guten Willemb, alle boll brennender, flammender Erwartung: twie biefer gröpte und fofrectlich) fte Sng, ben lbt Qeben baben wuirde... und roürden fie neunzig Sabre alt ... fich entrollen roïrbe! शein!: Sräumer unb Ginnierer... die batten auf Diejem bellen, groben Ecbifi, das von Reben und Etreben zitterte, das von fünfzebnhundert beipen, wacten, neugierigen beut/fhen Serzen pochte, leinen Plas! Nein, auf diejem Gdhif, in biejer bellen Bejelfhaft, fonnten Reute ric bie auf ber "Alten Riebe" nidbt eriiftieren! Es toar einfach lein Raum für fie, feine Quft für fie, feine Belegenbeit für fie! Und Sorm Dtt twar bas recht jo. Denn toenn er auch) etwas von ber $\sigma$ dheubeit und (Finjamteitŝneigung bes Baters batte unb fich unter ben langlament, raadren unb tobesimutigen, lieben Befellen jebr bebaglic uno bequen gefüblt batte: er roar bow mebr ein Rinb feiner Nutter. Nein ... e rar gut, baj er mun rach fein

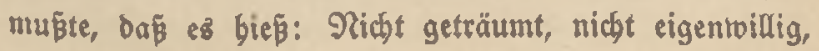




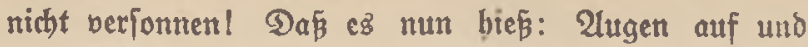
aufgepafit!

2lber es war mumberlich: als er fo bier biz fechs Wodhen auf bem Edhiff getwejent mar, ba fah cr, DaB́ ex fich boch etraz geirrt batte. Da merfte ex mit feiner immer forjhenden, binter ben 2lugen fuhenben Geele, baß aud bier, auf ber frifhen, bellen, mädytigen, Below", Qeute bon ber $\mathfrak{a t}$ ber "Ulten Qiebe" waren. Cinige waren auf bem ganzen Gøiff befannt, ba fie aus ibrer Ecele teinen Sebl machen tonnten uno wollten; andre, ficheu und bang vor Gpott, umficher im Bemuit, fanden nur in fitller Etunde den Mut und bie Rraft, fich einem Berftändigen zu offenbaren. Da fie mertten, bá Sorm Ott binter Feiner frijhen (Erjheinung uno jeinen thugen, männlichen 2ugen ein ver[tändiges, teilnebmendes Gemüt bejá, ergablten fie ibm, mit foridjenden 2lugen ihn anjebens ... wb da nidft bod ein Gpott aufblizte ... ibre bejonderen Anjichten, Gorgen, Greuden und Pläne. Da war einer an Borb, ein Seizer, feinez ßerufz ein Rlempner, ber war immer berfitimmt und traurig. (Fr batte nicht bie geringfte Freube am Qeben, bas iln umgab; und das Rriegzleben wat ihm ein (Greut. 2(4), ez war bas alte Lied: eine unendlich grop̉e, etwas meichliche Liebe

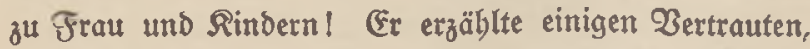
mic er fie fennen gelernt, und die 21rt jedes Sindes.

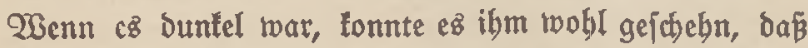
fict) feine 2ugen, indem or an fie bachte, mit Sränen füllten. Er war ein bübfher Nenfch; und er erzäblte gut. Went fie an Qand mit ihm gingen, auf bem Deich nact Barel gu, fitumbenlang, war er wie vertwandelt. 
Esz war ibm bann twohl, als wenn ex feinen geliebten Menfchen năher wäre, ba er nun boch mit ihnen auf berjelben Erbe ftand. Ex fam bann aus fich beraus; jeine Geele löfte fich und prach. Eie gingen alle rund um ihn und bingen an feinem Mund, und went er geendet batte, faben fie einanber an, als roären fie fich fremb. Ein anberer, ein theiner Dunfler, unicheinbarer Nen[d, von Beruf Rlavierbauter, an Bord Eleftrifer, tat ibnen zumeilen etroas zugute, indem er in einer eigentümlich zierlichen uno edlen Weife auf Det Flöte cine leife Dufif vorttug. Es war aber immer fromme und traurige Nufif; und einige fhalten ihn beswegen und verlangten ctwas Quftiges. Aber er tat ibnen nicht

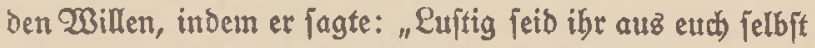
genutg, Da braudbe ich) uichtz binzuzutun; aber an (Ernjt - er lagte nich)t Frömmigleit - fonntet ibr wohl zunehmen." Er gebörte, wie es fchien, einer Eeffe an, batte aber nicht ben Nut, fich offen baģu zu befenten, wurbe aber won feinem Setwiffen geztrungen, diejes fromme Epiel, Dicjen Lippendienjt zu tun fïr die Gad)e, die ifm beilig war. SUnd Dann war da einer, feines Berufz ein Soatzinnedit in einem Sotel, ein Nenj(d) von einer getwals tigen, geübten Rorpertraft; aber er prablte nicht Damit. Gein Zater trar, wie er einmal einem Betannten erzäblt batte - Fie roujten nun alle; aber feiner redete bavon - ein Srinfer getwejen; und er batte eine traurige Sugent gebabt. (Er felb/t aber war ein nüb)terner, ziel=

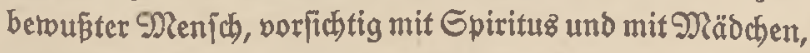
arbeitete für Drei, ftant jedermann bei; und balf mebr als eiuem aus mit jeiner Leibeżtraft und jeinem rubigen, 


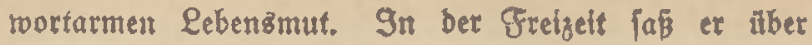
einer Solgifhnigerei, arbeitenb und raucbend, ließ aber jutueilen bas Meffer finfen und fap bann 10 , oḅne zu arbeiten, wobl eine balbe Gtunde und Darüber, und fann; und man mertte, baß ex nidts Erauriges und 2 itteres \{ab, nidjt feinen Vater, ben Stuntenbold, nidt jeine weinenbe Putter, nid)t jeine unglüalidie Sugend, ponbern [chöne, rubige Bilder. Er fab trobl bie 3eit bez Griebenz und ber rubigen 2lrbeit, ein eigenes Slnternebmen, ein gejundes, fittiges 2 Beib, gute Rinber. Finer Hagte feinen vertrauten Greunden, daßj er immer mit fdjmubigen Bebanten zu lampfen bätte. Gobald ex allein toäre, gerieten jeine Gebanten in Gdimus, tmb ergingen fitt

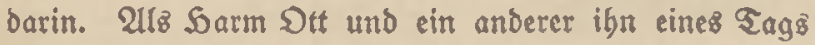
in bie Ecte nalymen uno ighn brängten, er mỏdte ignen boch cinmal fagen, roas für Bilber er fäbe, um ibm ju belfen, wenn es möglid wäre, toar es nidit jo fablimm, toie fie gefürdytet batten; und fie trojiteten ibn, inbem fie ifm lagten, doß er gang gejund werben twilloe,

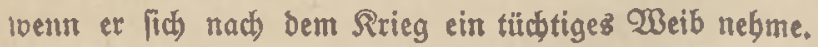
Biele litten unter ber Satjatie bez Sirieges; fie batten Den Glauben an Den Ginn ber Welt verloren. Wie ichỏn trar ibnen bie $\mathfrak{B}$ elt erichienen, wie aller Garben voll und frob bas Reben ... aber nun?! Die Welt trar nichts andrez als eine Sinnlofigfeit; Das Leben nidis andres als 3erftörung und Sob! Bott? Bott ift nicht mebr; ober trenn er ift, ifit er ein Engländer, o. b. gierig, friedenvernichteno! UnD es balf nidt viel, Daß̈ man ibnen शut zuredete, Daj man ignen auf bie Gdulter tlopfte unb fagte: "Nut! Mut! ez 
tommen twieder bellere 3eiten!", oder baß ber Pfarrer, ber wobl abnte, twie bei einigen ftand, firr bas (56riftentum zeugte. (Fr iprach mit itarten 20 orten und blisenden 2lugett. Gir jagte, toeld ein Slnfinn es fei, zu jagen, Daß̧ Das Cbriftentum und ber Glaube Bantroft gemađt bätten. Cbriftentum unb SIlaube wären ewige Dinge, mit Bott, mit ber ganzen Gdjöpfung unb mit ber Бळäpfung ber Nenfchenjeele gejest uno gegründet, nicbt ander wie bas Ridht, nicht anders twie bie Frende. CGriptentum ... ber Blaube an bas Bute ... twirde now ba fein und über bie Gabpfung itrablen, twenn

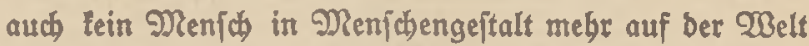
twäre. Cbriftentum ... ber (Slaube an bas Bute, Reine

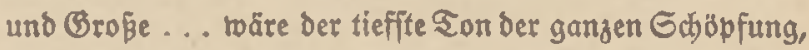
ibr groper Slang, ibr innerftes uno mädtigites Wejen! Oiele, ja bie meiften, waren ibm bantbar, und batten Erbabung, Rlärung und Gtärtung Davon; aber bie nun einmal beritörter Geelen twaren, blieben ez fajt alle.

Bebentlidie, ja idjlectste Naturen, waren nur zrwei auf bem ganzen Gchiff. Gie verfuditen alle, fie zu guten Menjकen zu erziebn ... Gie gaben fíd tattboll unb unauffălig alle Dlübe, alle miteinander. 2Aber es

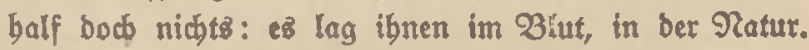
Nicht einmal ber Wille zum Guten war ba. Der eine, mit

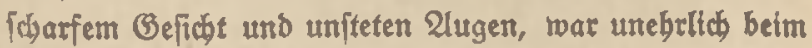
Rartenjpiel. Ralt bebanbelt, ja zurüdgetbiejen, tam er, obne (Ebrgefübl, bow mieber. $\mathfrak{A m}$ Sage Der $\sigma_{d}$ ladt verjagte er. 218 ein Sreffer gefommen twar - er jtand im Bang am Siantinended - pprang er ztranzig Meter zur Geite... fie fagten, weil er ein idjledtes Bewiffen 
bätte und ben Sod fürchtete. (Er machte fid fpäter,

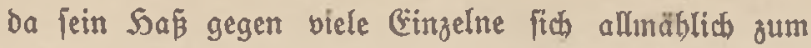

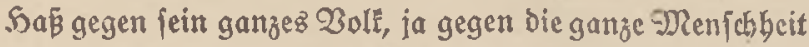
verwandelte, vollig ungluctlid). Der andere, aus einem tleinen Dorf Gübbannobers, war nachläfifing im Dienjt, fo als wenn er, trog einigen guten Willens, fich nicht

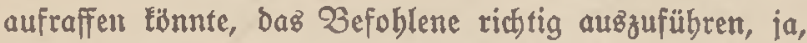
als tvenn irgendein $2 B i b c r f p r u d t$ in ifm wäre, ber ihn grwänge, Daz Gegenteil zu tun. Ulno fo twar es auch mit feinen Worten. Es f fien zutweilen, als roenn er nur austwendig Das (Bute unb Drbentliche rebete, als wenn plïslich auz Dem Snnern, wie burch Epalten bindurch, $\partial a b^{3}$ Bufe binburdigleifte. Er machte fich in ber Ed) (acht - er war beim Lectitommanob, -- ganz ordentlich. Mit flacternden 2lugen bin= und berjeheno, idhien er zu beobachten, wic bie andern fich mactenten. 2lber auf bem ichlimmen शachtmarich, als fie bic Soten zufammentrugen, baben fich bie lekten oon ibm abgeivandt. Es war, alz wenn bie Erregung bez Tages das Befüge feiner Secle geloctert batte; und twas da Durd die Gpalten fidtbar lourbe, Das war fhlimm.

Im übrigen aber twaren fie alle Deutjode, uno im groben uno ganzen cinander gleidh: taltooll gegenein= ander, in allem guten $\mathscr{W}$ illenв, tapfer und wadt; und alle gläubig zu ibrem Zaterland: סав ez einen $\mathfrak{B e r}=$ teibigungåfrieg fübrte, und z'war einen gered)ten; $D a \tilde{\beta}$ Der ganzen Nenjabeit, bie burw) Lïgen verfübrt war,

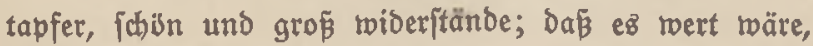

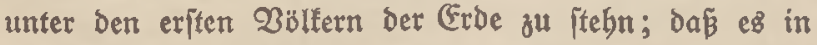
Diefern Rampf fiegen toerbe und $\mathfrak{c}^{3}$ aud berbient bätte. 
So waren fie: Ulno es twar eine jeden eingelnen und auch Sarm Ottz fitller Gtolz, Daßj er fich unter innen berwährte.

Ia, Soarm Stt betam jogar eine 24uzzzeid)nung! . . Denn als ber Divifionzopffizier eines Sages vom Rapitän gefragt worden toar, ob er wohl einen ordentlicken, tüdtigen und bebenben Mann empfeblen Hisnnte, der als Räufer beim 2lbmiral gebraucht werben tonnte, batte er Sarm Ott empfoblen. Der Divifionzoffizier batte īn nämlich einez Sagez über einem 2 uch) gefunden, Daz dic Bejofichte Ed)lestvig=Solfteins behandelte, und hatte itm gejagt, er müffe fich nicht alfzulange Dabei aufbalten; benn $e^{2}$ täme babei, wie bei ber (Befchichte aller Grenzlänber, nid)t viel beraus; er müffe bie (befchichte des ganzen Deutfchlands lefen, fo wie fich ber Mrittelpunft allmäblich veridboben bätte: erît Granten, Dann Şüringer, Dann Gachjen, Dann Sabsburger, Dann Preußen, und nun, erit in biejem Rrieg ex[d)einenb, bas ganze Deutichland: ein Serz uno eine Geele. Sno ba bafte er gemerlt, bá̉ Sarm Ott bies Gtubium idjon mit (Enjt betrieben batte

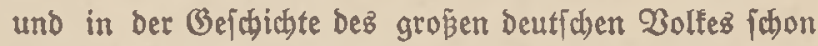

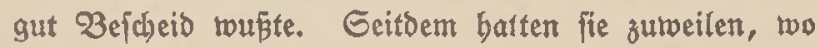
fich die Gelegenbeit bot, ein $W_{0}$ ort miteinander gerebet. Der batte alfo Sarm Ott empfohlen.

Slnd fo rutrbe er Qüufer beim 2lomiral und feinem

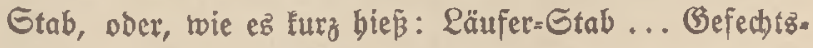
ftation: in Lee bez fommandoturmz. 


\section{Rapitel \\ Feuerbrand}

ie batten, alle an Borb, jeber शann, einen 2 ulen. freunb, einen, mit bem bie Geele übereinftinmte, vor Dem fie teine Bebeimnife batte, bem fie bie Note Der Rinbbeit, bas Slrteil über bie Cltern und bie Näte mit ibnetr, bie 3wetfel liber ben Beruf, unb von thren Grauen ober ibren Däbchen, uno gulest auto von thren religiojen unb fittlichen Bedanten uno Bebenten erjäblten.

Diejer $\mathfrak{B}$ ufenfreund tann niemalళ der 2 ruber fein; benn zwifhen Befdyiftern ift, in iüngeren Sabren wenigitens, oon ber Ratur cine Gdranfe gejest, baj fie id)eu gegencinanber find, und jeber feinen eignen Weg gebe. Denn, mag das Serz eź lieben, Daß̈ 3 rüber einträchtig beieinander roobnen, bie शatur, bie fich um bas Bebagen ber Sorzen nicht tümmert, bat biel eber Reigung, fie auseinanter zu fdidfen.

Slnb to batte Sarm Ott nicjt feinen Bruber Gggett zum Bujenfreunb, obgleid) [ein 2 ruber Eggert jest aud auf bet , Below' war.

Bruber Eggett batte nac feiner infanteriftifden

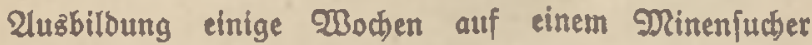
Dienlt getan; aber ba byatte es ibm nidbt gefallen. Das Bopt war ibm für feine freie Ratur ou eng; er batte auch Gtreit mit bem Gteuetmann betommen, ber ein allgemein gerechter Mann war und nicht veritand, bie Menichen veridieden zu nebmen. Slnd jo twaten bie 3rüber in biejen Donaten in gropien Gorgen um ilyn 
getwefen, Daß ex bel feiner jüben, ffolzen Patur eines Tagy in ichlimme Gdbierigfeiten geriete. Aljo batte Soam ibm fein Leben auf ber, Below' gelobt und ibn

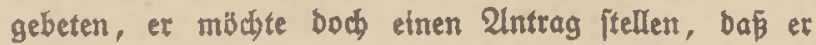
Dabin läme. Golde (sefuche, mit einem Bruder vereint zu werben, rourben, weun es irgend anging, ge* nebmigt. Soarm Dahte, er tönte ba über ign wacten, uno wenn es nötig twäre, zum Buten reben und wenden. Ex aber wollte lange nidjt. (Ex bielt fich febr bon ben Brübern zurlid unb lam nux felten unb mit berfकlofienem (Befictit zu ben $3 u$ ammentünften, bie fie mit einigen Qands. leuten unb $\mathfrak{B}$ efanten bier uno ba in Den $\mathscr{W}$ irtfdaften batten. 2luf Epaziergănge mit ben 2 riabern allein, bie ou eirem prillern Gejpräđ Belegenbeit gaben, ließ er fich nicht cin. Wenn fie ibn baten, jagte er mit tnurrigen Worten: er bätte jwon grabe Familie genug bier. (Fr bebauptete, er bätte Greunde gefunden; und bas war roobl aud fo. 2Aber es toar ben Bribern traurig, Daß er anbre ĭnen vorzog, unb und Rälte bebarrte.

Da Fdrieb Reimer, ber mit brennender Geele allen Wegen feinez Brubers nachlief, ber 2 utter, fie jolle cinen Brief fhreiben, und fatrieb ibr ben ganzen 2 rief vor, fo wie fie ibn obne ibre leibige Bewobnbeit, Rübe und Rălber voranzutreiben, lurg und bünbig und ins Serz treffend abfaffen follte. Denn ex war ja ber Rentner Der Geulen, Der Ranig Der Soerzen!

"Du fatreibjt ibn gand genau fo ab, wie er bier ftebt!" ichrieb er. "Denn id babe midh gand uno gar an Deine Gtelle verfegt, fo Daż bet Brief in Snbalt 
und Form gewiflermapen Deiner ift. Edreibe ibn aljo genau, mit jedem einzelnen Woott, mit jebem eitzelnen 2ušruf; und fareibe nichts dazmifhen ... Gomft webe Dir!"

Ia, fo batte er gejdrieben! Go lange die Rinder thein raren, war fie furz und flar mit ibnen, froblich in ibrem mütterlichen Regiment über bie fleinen Wejen. Wenn fie aber größer wurben, berlor fie allmäblid bie Soerrichaft ober ridiger, gab fie auf unb geriet mit ibnen in eine freundliche Necterei uno genop nun in anderer Form und aufs neue, Nenfक unter SDenid, meift fiegend, zuweilen unterliegend, das Blïct ibrer breiten, ftarten Natur.

Gie batte Emma und ben Q̈ltejten won den Rleinen - fie mußste fïr alleb, was fie tat und jagte, 2/n=

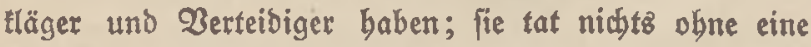
ordentliche (Gerichtsjigung - am Serd zujammengerufen und (ich) über bie 3umutung jebr bertwundert: "Nun left bodh blö mal, toie ber Sunge an mich (d)reibt! Was benft ex fich?! Sals bin bei Rechenmeifter Sanjen in bie Sdulle gegangen, vier Sabre auf der linfen, ber Sinterjeite, und ebenjo lange auf ber rechten, Der Oberfeite. Sa babe freilich bie lesten vier Sabre bas Uln. glüct gebabt, binter bem breiten Rücten bon Sbees Rlaupen zu físen, ber aud fonft noch unangenebme (Figenjibaften hatte, und babe aljo nidbt allez febn tönnen, mas ber Rechenmeifter an ber Safel Demonjtrierte. 2ber ba iø einen offenen Ropf babe... ja, Daż funn iđ twohl jagen ... ber Bemeiz bafür find meine Rinder, (Bott fei Dant! . . babe ich bod mein gut Seil ges 
lernt. $\mathfrak{B}_{a z}$ bic Sungen immer flagen ... baz mit ben Süben und Rătbern... fo babe ich ja unter biejen mein Leben, unb gebe aljo in meinen Zriefen von benen

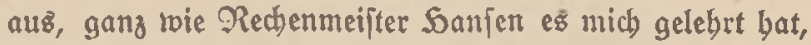
wie man 2uffäke uno Briefe ichreiben mús: vom Raben zum Entfernteren, vom Gichtbarcn zum Slnfid)t= baren, vom Naultourf ou Bott empor.' Eo fagte er. 2lfo, waż twollen bie bummen Sungż?" Go rebete fie, mit der Geuerzange inz Feuer ftoß̄end. 2lls fie aber Ғah, Daßs ber Brief bei der jäben Betwegung in Gefabr geriet, inz Feuer zu fommen, legte fie ibn zujammen, ftrich ibn glatt, fab ihn an und fagte befcheiden: "Ia, freilich... fo fdön wie Reimer fann id es nicht! Эa ... cs ift wirffich cin fdjöner Brief, uno wenn ber Sunge ... idh meine - her andre ... ein Soer im Reibe bat ... und das hat er trog alfer Wildbeit: dam

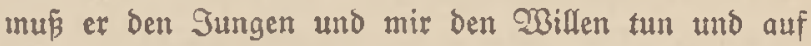
Das Gdiff Beloro gebn. $9 a \ldots$ Der Brief ifit gut. 2lber bas will ic nur jagen, Daß ibr ench über eure Dutter nicht erbebt: twenn idh fo lange zur Echule

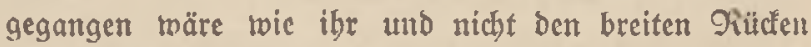
von Shees Raupen zlwijhen mir und dem Rechen= meiffer gebabt bätte, bann bätte id es meiter gebracht, als ibr alle zufammen l"

"Эa, Mutter," jagte Emma, mit ibrem exniten, langen (Geficht und ifrer etwag langfamen Eprache, "mir fcheint ... nun fohreibit bu ben Brief genau fo, twie Reimer ibn aufgefdrieben bat."

"Fängft bu aud fhon an, twie bie Gropen?!" fagte

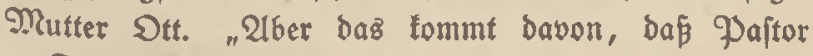
Erenifen, Dle છrüber. 
Boblen ben Sut bor bit abnimmt und fagt, bu labelt aus bie eine gotifde Pringeffin, obgleid bu weiter nichto bift als (Emma Ott! Beb bin und tübr' ben Rälbern Das Futter an!"

Radbem fie fid aubgerebet batte unb ben RTeinen beim Geuer angeftellt, ging fie in bie Gube und jurieb Den Brief, Den ibr tlügiter und wadffter Gobn aus innerfter Geele gefdrieben batte. Banz obne Einfügung und Sujüze ging eह aber Dod nicht $a b$; aber jum

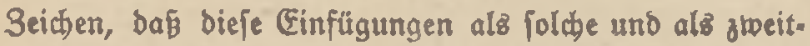
tlaifig zu jügugen waxen, Hammerte fie fie eir.

\section{Rieber Eggert!}

Sch bin ja bod Deine Mutter. Sф) babe Dich mit Gimerzen geboren und babe viele Sabre lang vom Morgen bis zum 2bend und, alร פu Den Edarlach batte[t, viergebn Sage lang bei Dir getwacht (bazu batte id bamals fieben Rübe im Gtall, rooon vier talbten ober eben getalbt batten. Es twaren jabje Rube; aber Bott vergebe mir, ich babe mich in biejen Sagen atber bie ganze Nith nidht gefreut. Die sälber batte id auch noch auf bem Solie). Seben Tag, fiebzebn Sabre lang, bift $\mathscr{D}$ u meine Liebe uno meine Gorge gewejen, fo baß̧, wenn mein Seer tlopfte, id nicht wuBte, ob esur Did ober für mid flopfte. Dann, an bem fdrtweriten Sag meines Lebenz, bin id für Dich eingetreten und wäre gern mit Dir gelaufen, wie id mit Deinem Oruber Rlaus gelaufen bin (über Sodhborn und Sale . . So Sale ift idon allein biber ein und cine balbe Gtunde lang. (E) foll bas längfte פorf in Solftein fein ... bis nach Renbsburg, too rir eim grob́es (Slüd mit bem Soupt* 
mann batten. $202 a b$ muß man both an jeinen Ritioern erfeben! 2lber ber Sauptmann batte aud Sinber; Int Das war gut, lieber Eggertl). Denn twie tann eine Mutter ibres Rinbes vergeffen? S屯 babe immer an Dich geglaubt, mein lieber, lieber Sunge, mein guter, lieber Eggert! So bitte ich Did mu, mein lieber Sunge, tu Deiner Nutter bie Liebe und geb ju Sarm auf bas (d)iff Below und rei auds gut mit ibnt Siel), ex ift fo ein elurlicher, redtlidjer Denjob, mein Eggert, uno ex bnt aud immer an Dich geglaubt unb Reimer au由) (bloß Bater nidt, aber ber baut mandimal ebenjo vorbei toie Pajtor Boblen. Paftor Boblen bat äbrigenz wieder mal getrunten. Sage es aber um Soimmelz

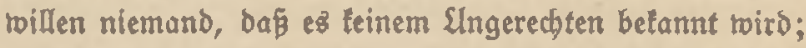
Denn ex ift ja ein guter Denich unb auds tücbtig ... und aud Emma nidit, aber bie lift offenbar in ben Rnecht perliebt, und verliebte Reute find blind trie Soühner). Mein lieber Eggert! Das Saar Deiner Nutter ift in biefem Sabr grau gelvorben und twer reißj, ob es nid t bald roíp wirb. Denn im Rriege lann tein Menjw jagen, toas tommen toirb. Scb bitte Did, erbarme Dids Deiner lieben Dlutter.

Renchen Ott.

Diejer Brief rourbe abgefandt, lam an und rirlte aud. Er twirtte, obgleid Eggert beutlich extannte, Daß er zum Seil beffelfte 21rbeit toar. 2lber fo berfteint er gegen ben Bafer rar, und fo vertrobt gegen Daz Rird). fpiel .... , शot und Sob über fiel" er triridte mit ben 3äbnen, wenn ex an fie badte... feine Nutter batte an ibn geglaubt, obne Wanten. Fs tat, aud 
obyne $\delta a \tilde{B}$ eż ibm felber tlar wurbe, feiner überftolgen, franten Geele gut, daßj fie ordentlid ein Gchaufpiel aufgefülyt batten, um zu erreid)en, daß er auf bie , Belulv' ging.

Aljo erjhien ex eineş Tageš mit einigen anbern Reulingen an ber Reling und ging groß uno breits beinig, won Diejem 2lugenblict an ber ftattlidjfe und gewandtefte an Bord, in feine Rajematte ... er war Gefchübmann und Ruttergaft... und war furz und bündig mit Worten, aber nicht unfreundlid); und gefiel gleid allen mit feinen auffliegenden 2lugen uno ben rajd)en, lebenbig itbönen Betwegungen feiner Schultern und bem ichmudten rötlichen Ropf. SAnd als Bruber Soarm Da* für forgte, bá bie Rajematte erfubr, twie bie (Beichichte ber Prife von ber "Zltten Qiebe" getwejen twar, wie fein Bruber in bie Sände der Engländer gefallen und wieder ber: ausigefommen war, wat er ein geadteter Mann. 2ll

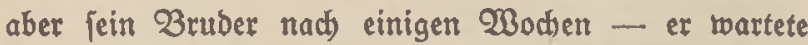
folange bamit - in ber Rafematte jo beiläufig fragte, ba bon Nufif dic Rede roar, ob fein $\mathfrak{B r u d e r}$ denn auch fpicle, und bie Rameraben ifn zur Rede ftellten unb er jeine Munb harmonifa berborzog und Dufit mad)te und er nach Dem Epiel bie Wiederbolung mit iajöner Etimme jang oder pfiff und jein Gpiel entichieben bejier war alz $\mathrm{Daz}$ ber Rajematte z'wei Eteuerborb, bie eine febr gute Mufif batte: ba wax er ein angefebner Mam. Er twurbe ez aber noch mebr, ja, er rourbe eine $\mathfrak{B e}_{\mathrm{e}}$ rübmtbeit an Borb, unter den ganzen fünfzebnhundert Mann, alż er und ber Rlavierbauter, ber Geftenmann von ber शadbartajematte, fiø fennen lernten und mit ibrer 
Pulit zufammentamen. Belch $_{\text {cin }}$ Bilo, allein, eq anzufebn! Diejer lleine, ftäbtif che Württemberger mit bem fümmerlichen Sörper, und dem fleinen, frommen (Befitht, und ber breite, groß̉e, rotblonbe Frieje mit ben gropen, berrifकen Betwegungen! Slno mas̄ war bas für eine Mufif! Wie fanft roiegte ber fleine Geftenmann den Ropf, wic berionnen und wohl taujend Meilen fern war feine Geele; und wie jharf und tlar, toach unb feurig waren bie Augen bez Friejen! शein, wie fie fpielten! Niemals hat man fo etroas gebört! TBenn Fie fpielten: ,Willtommen, o jeliger 2 bend, voer: ,Grei= beit, bie id meine', ober: ,Nach ber Seimat will id) eilen, will bei meiner Qiebjten weilen', oder: (Fin' felte Zurg ift unjer Gott" ... ez erfichien innen unbegreiflid, tvie bie beiben Geelen, bicjer fleine, muttrige Wütttem= berger, Der feine Fliege fdjief anjebn fonnte, und biejer rifloe Rote mit ber fü̈nen, Hlingenden Stimme und ben berrlichen, lebensodllen Betwegungen zufammen= ftimmen fonnten! Sedcr, ber bie beiben jah und bies 3ujammenipiel börte, muşte benten unb bachte ez auch): ,Wie mertwürbig ift bas SMenichenberz! Tichts iff

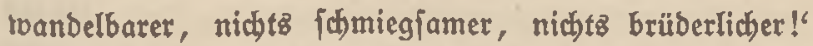
Richt allein, bá̃ die Rajematte voll von (Säjten twat,

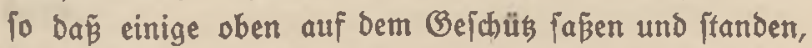

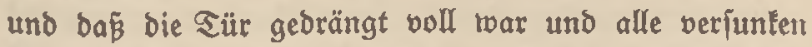
und verfonnen in jeligen Träumen ftanden und nur bann unb wann bie 2lugen auf bie beiden Epieler randten, bie da in ber Ecte faß̃en... nein, der ganze Bang fand voll, und manctier Offizier blieb ftebn und börte zu. Эa, es mar großartig mit Eggert Ott! Slno 
wie tüdtig er im Dienlt toar! Wer war bet torperlich Betwandtejte? Wer begriff alles ipielend? Wer war ber Bebendefte in ber 9nftruftion? WBer trat immer idfidt, natürlich, freundlid, gefäfig? $9 a .$. er war sa Eggert Ott! Fr war ber Riefling aller, bie mit ibm zu tun batten! Der Ileine, fortoarze Gtüctmeifter, ein Berliner, ber fकtwierige Büळer Ias und gern ins इbeater ging und fich toas Darauf jugute tat, batte ibn , Qorb Geurer brand gettant; bas nabmen fie auf, und namten ifn fury, Guerbrand'; und fpraden ibn getn an, nur um

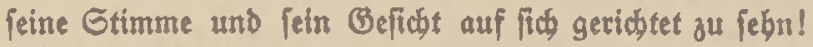
Sa, es war großjartig mit ibm! Eggert Ott, Der auf bem Sof feines ஜaters nicht zu bändigen getvejen raar, ber battloz bie gebabnten Wege gemieden batte, jeigte nun bier, an Borb ber , Below', alles, toas er an Baben batte, lię̧ allez funteln und glăngen, was er an Cober. ftein in feinem Gdilbe batte! Sa! So war es! 2lber warum twar ez fo? Warum tat er bas? 2lub Riebe jus

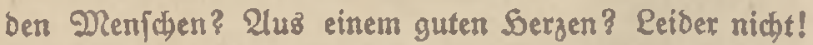

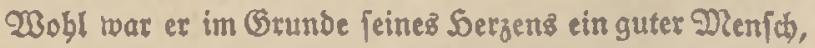

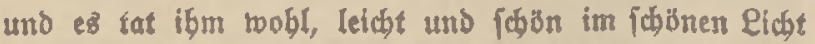
gu ipielen, anjtatt bumpf und wilb ourch bie Finiternis des Froges du jtolpern; aber bä er bier in biejen Plonaten auf ber Beloto bieje Finjterniz, bie in ibm toar, zurüdjtieß und in bet innerften Sammer jeines Serzens verbarg unb

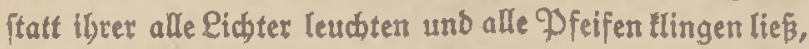
Das war Darum, Daj 3ruder Sarm naw Sauje fariebe: Sbre glaubt nicht, wie beliebt ber Eggert ift! Wie fein unb ordentlict jeine Rleibungl Wie begebrt fein Slm. gang! Wie befiebt jeine Mufit ... bis in ben Bang 
ftebn fie unt bören zu! Slno wie tuthtig im Dienit! Sbr glaubt nicht, wie fionn ex ift, twie breit, wie wact, wie Ptrablenb! Daß̧ fein Yater unb Emma unb bas Rirchipiel, bas verfluctete, erfübren, was fie vermorfen bätten, uno twas ba nun bodimütig, [trablenb und lađbent an ibnen voruberfubr! ...

Tein, Bruber Eggert war als Bujenfreund für Soarm Ott nicht ju gebrausden, erftens, tweil er eben ber Bruber trar, unb zrweitens, weil er ein jolch trosiger und berftodter Bruber roar!

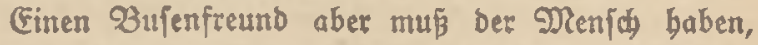
ber vom andern Bejhlecht noch feine Lebenġgefäbrtin bat. Unb gulegt fand er ibn autb; und einen, an ben er nidjt gebacbt batte. (Es roar da eini hurzer, breitक人ultriger, bunfelblonber Samerå, viel älter als er,

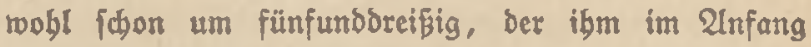
gand und gar nicht gefallen batte, ba er eine gerriffe breite unb felbftoer[tändliche 21nt bez 2luftretenz batte, bie gand und gat gegent bie Ottide 21t roar. Sorm Ott meinte, wäre ein oberfläcbliches (B̉etu, bas aus einem lecten Sergen täme, fo twie eine bide, leete Sonne, gegen bie man ihlägt, 100bl einen ftarfen und breiten Son gibt. 2lls ber Mann Befalten an ibm fanb und ibn zutpeilen anfprach, antroortete er baber nur tübl und fpärlic, worauf Dann bet Nann feinerfeitz ben Sorm Ott nidit mebr anjprad und für Qlugen und 2lnrebe andre Selfer judte. almäblich aber mertte Sorm Ott, bá̧ e8 Dod twaz $23 e$ jondere mit dem Manne war. (fr war broar ein einfader Beift und batte aud feine be-

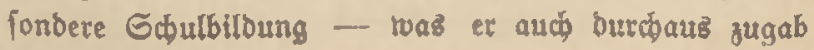


- aber fein Geift fpielte aus einter gejunben, ftarlen uno gütigen Natur beraus fidjer uno frijdstoeg, gleich einem Fifh) im llaren Strom, in bem Sreiben bes Lebenz; und was er ba jab unb börte, beurtcilte er mit ebenderfelben Gicherbeit und Grifde. Slnd fo war er ein geborner Plauberer, und zroar ein rubiger, guter, uno ein joldber, ber am Wlaubern jełbjt, alz an einem ichönen Spiel bez Geiftez, jeine Sreube batte, gleich, gültig, roas ber Begenftand rwar, wenn er mur einez ernften Beiftes würoig twar. 2 on feinen Eltern und von jeiner Rindbeit jprach er twenig oder gar nidjt; ez lag ba irgend etroas Slnerfreulid)es vor, wobl bie

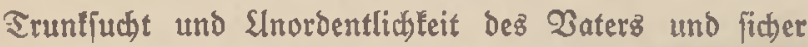
bie furchtbare Not einer guten Nutter. (Er mod)te wobl bie Mutter nidjt loben, ba er es nicjt lonnte, obne ben Bater zu tabeln, und daż roollte er nidjt; ex batte aber ein Billochen der Mutter in jeiner Brief. tajche auf ber 3rult. Er batte nach aljo bedrängter Rindheit zuerit als Gchiffzzimmermann gearbeitet uno batte feiner Nutter und feinen Ileinen (Befdrtwiftern ges bolfen. Sn diefen Sabren batte er and feine erjte Qiebjte gebabt und hatte ficher unendlich viel von ibr gebalten. Da er aber viel batte arbeiten unb porgen mitfen, batte er fie aus ben 2lugen verloren. Tas batte ibn gequält; und oa bie Mutter gejtorben war uno bie Befdyrijter fich entweder von ifin abgelwand oder fich jelbft batten bel. fen tönnell, war er einjam geworben und trar zur Gee ge= gangent. Slnd ztwar war er wie teiner auf allen Meeren uno auf ben Gdjiffen aller Nationen getbejen. Finige von biejen Sabren batte er auf eiuem Woermannichen Rüftenllepper 
an ber afritanifdsen Rüjte Jugebracht unb wat auf einem Marfd, Der monatelang gedauert, tief ins Snnere 2 frifas gefommer. SUno fo twar er ein rechter Weltfahrer ge= wejen. 2lber obgleich ifm jo ztweimal, uno ztwar in einer fajt finnlojen, ja unbeimlichen art, zuterit bie gute Mutter Durd) die Gdull dez Baterz, Dann bie Hleine Liebjte, die er an einer Gtraṕenteffe Samburgz zum lestenmal gejehn, zulest auth nodh die (Bejchroifter genommen waren und er fo einjam burch bie Welt futr, toar er boch nidf verbitfert, fondern blieb boch, lraft feiner menjobenfreundichen und mittelljamen Geele, als ein freunblicher Mitjpicler bez Lebenz auf dem Plaze. (Ex freute fich) mit und lachte mit, und fïmmerte fid) mit; und tat bas noch) mebr alz andre, und ficherer als andre, und ruhiger als andre, Darum, tweil er Nahes und (Eigenes nidbt batte. Aber es twar in Der Siefe

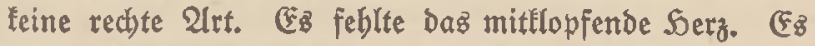
roar ibm ums Epiel felbft zu tum, nidbt um das, was ifm zugrumbe lag. (Fr Gatte bie 2 beife, daz Leben felbit zur Debatte zu fitellen, und den Berlauf biejer Debatte rubig und freutnolich anzubbren, gleichgültig roie fie liefe.

Sarm Ott batte wenig von ber Welt gefehn; er war trob jeiner Gahrten nach Seneriffa und Nem ein Seimatżmenji); Diejer aber war in Den Etraßjen Des gropen Shamburg aufgetwathfen und batte nachber alle Gtrá̧en Der Welt befabren. Sarm Ott war inner= (id) nod) nicht ficher, fo fübn auch feill (beficht war und To bell aud feine 2ugen blizten; biefer aber fpielte mit bem Reben und mit ben Dingen, wie ein Rind mit 
emften, befinnliकber 2lugen mit bürten Blättern fpielt. Die Simmerei, bie fie beibe als Sandreet batten, gab bie exfe Unterbaltung, bie gut zujammen|timmte. 2alb banach börte er thn follidit unb gut über einen Rame. raben fprechen. Danach fpradyen fie einmal über ridbtige uno unriळtige Leb̆berren; und bann, alz fie eines 2lbends turz vor, Pfeifen uno Qunten aub' im exifen milben Erübjabrstrind uber Dect ipazierten, uber Siebe und Seirat, inbem fie eine Slnterbaltung fortfesten, bie in Der Rajematte bon andern angefangen war.

Der 3immermann - fo nannten fie ibn - jagte in feiner erniten, fpielenden, alles trägenden und gerech). ten Weife: "\$a, wenn man ez po anbört, wie die ein. zelnen ber Fieibe nach Darüber reben und ibre (Bejwichten bebon erzäblen, fo mus man robl fagen: Seiraten if gut... nidht Soeiraten ift auch gut. $9 a \ldots$... ja!... und bod fiebt man, wie bie meiften früber ober fpäter in bie Ebe gelin, aljo zu ber Entidueibung lommen: Soeiraten ift beffer. (Es muß bod irgenbroie bie Ratur Fein unb ibr Wille, ber bie Menichen bincinfühtt."

Sarm Ott jagte: ${ }_{n}$ Ratitrlid mü man beiraten! Sa, id jage jogar - von einer villig ungliudliden Ebe abgejebn - jelbit eine Ebe, bie nidit glüdlí ift, ijt beffer als teine! Was ift ein Leben obne Yerantwortung um Geelen, obne tiefe Riebe, Nübe und Nöte um anore... fobmal, bürr, biuftig, obne ein volles Denfchenjobidfal, uno oft, ja meiftenz, irgenbeiner Wunberlidleit, wenn nid)t Gdlimmerem bingegeben!? Sa, ich jage: ein Mann, der ther bie Sabre binaus lebig ift, ift mir mebr ober seniger bebentlich, um 
nidit zu fagen zumiber. Эक Dente inmer: wet tweiß, toas ber treibt! Die lebigen Grauen... freilich, Das tif eine andre Gache! Die find meiftens fhuldolos ... fie finb eben bie bebauternstwerten Opfer fener mănn. 【icben Verbrecber am Menjøentum."

Der 3immermann bachte eine Weile nac; bann

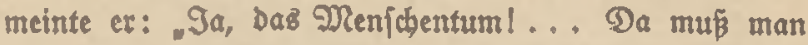
nun tiefer graben unb fragen: lif das gejunbe, gütige, tapfere Renfc)entum, bas bu meinit, tif bas irgendric Sottes Bebot und Wille? Darauf lommt es an! Oft icheint es, als twenn biejenigen recht baben, bie fagen, baß alles 3ufalf, Blita, Belb, Befunbbeit ijt, uno reiter

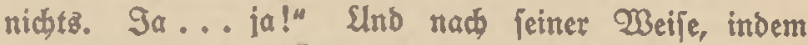

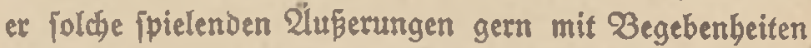
erläuterte und beleudtete, ergäblte er cine (Befdich)te aus feitem Reben.

Sarm börte nur mit balbem Obr zu. (Er twar mit feinen Bebarten bei ben exiten Worten feines Beglei= ter ftebn geblieben und bachte über fein eigenes Leben und über feine Familie unb Die Briber nad, unb Dacte befonbers an bie Ratur feines 2rubers Reimer und fagte, als bet 3immermann feine Bejwichte beendet batte, aนs ber Siefe feiner Bebanfen beraus mit fकlichtem,

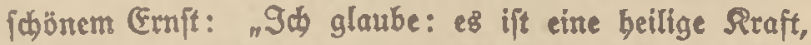

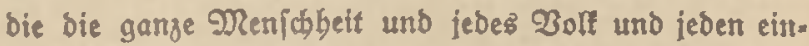
selnen Denichen und auch mich burch bas Reben fübrt."

(Ex batte es obne alle abficht ber Wirtung gefagt, viel mebr für fic jelbit, als für feinen Begleiter; und mertte baber aud nicht, soie ber Simmermann aufbordbte, ia betroffen und fitil wurbe. 
Bon biejer abendftunbe an Dect an fuctete ber Simmermann bann und toann mit Soarm Ott aflein zu fein, und (prach) bann weniger ipielig, weniger gleid)= mütig; und mühte (ïh), zutraulid) zu werden und getwiffer= map̃en perjönlid) zu fein. Da er aber feit jener fernen Gtunde, ba er in irgendeinem Glect Samburgs rein Mütterchen uno an irgendeiner Gtraß̄enede Samburgs jeine tleine Riebjte verloren batte, davon entrobght war, wollte ez ibm nidjt gelingen. SIno ba vermodte auth Sarm Ott niht recht, aus det Geele beraus zu reben. Geine Worte fhoffen ins Leere, auf

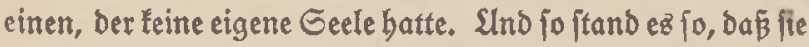
wobl füblten, Dá fie Freunbe werden tonnten, und fïh Danach

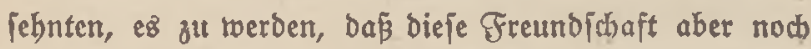
nid)t von Serz zu Serz fabren lonnte. Der 3immer. mann batte eben fein Serz verloren. (Er war burch fein Gdictfal bem 2 affertropfen gleid getworben, ber im Gtrom treibend immer neue Rachbarn hat; unb bas Qeben ift ifm nichtริ alฉ $\mathscr{W}$ andern und Epielen.

Sarm Ott berjuchte, jeinen Bruber mit Dem 3immer= mann zu[ammen zu bringen, und bat ifin. 2lber ber fagte bodmütig, wie er immer war, wenn er mit ben Brübern zujammentraf: "W̧as foll id mit neuen $\mathfrak{B} c=$

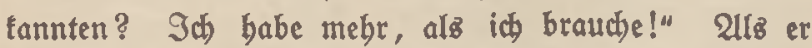
aber einmal eine Gtunde mit ifnen zufammen im $\mathfrak{B}$ anter Bürgergarten gejeffen hatte, two ber 3immermann bei einem Blale Bier bejonders gern in fein rubiges Plaubern geriet, hatfe er bod, roie es fobien, nichtz mebr gegen ifn; ja jeine Begentwart idhien ibm ange= nebm zu lein, zumal bies Geplauder über bies und Das, 


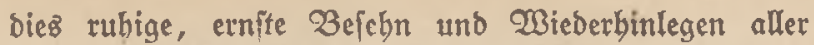
Dinge und SRenichen, ifn por Der Unterbaltung mit ben Brübern betwabrte, bie immer und immer wieber auf Saats und Seimat bindeutete, bie feine Natur zum Alufbäumen brachten. 


\section{Rapitel}

\section{Die Seilung bes 3 immermann}

Cęinez Tagez erzäblte Sorm Dtt bem Simmermann, (2) um ihm Bettrauen und Bertraulichteit zu zeigen, und um Feinem 2 ruber zu Dienen, Die (Beibidjte bon

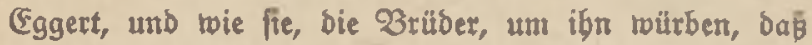
er fich rieber mit bem Giternbaus und Der Seimat vertriige, und bat ibn, freuntrich mit ibm zud pein, aber auch vorfictig, Damit er nidts verbürbe. "Dut bift ia

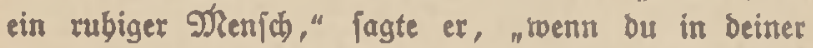
Weife ibm WBiberipruch tult, glaubt er bir; uns glaubt er nidft."

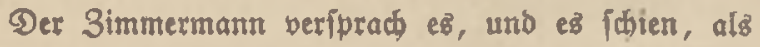
wenn ex in biefer Gache nidht allein, wie an allen anbern Dingen, ein fpielerijhes, fondern ein bergliches uno perfönlichez Intereffe bätte. (Fr trar nun meiftens mit babei, twenn fie bier ober fünf CDann ftart ben Qanburlaub verbracteten. Erit fpazierten fie eine Etunbe,

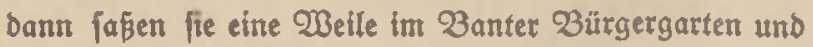
bann gingen fie zuweilen nod tweiter binaus, two in einem niebrigen fleinen Saal nod) einige Dutsend Mäbdjen bereit roaren, zu tanzen. Drausen auf Dem Deich und in ben Gtrá̄en ber Gtadt fpractien fie meiftens von Seimat uno Erembe, ibren Cinridtungen und Betrobnbeiten; im Wirtß̧auB, wo der 3immermann meiftem Betannte traf benn ex batte wegen feiner vielen Fabrten und feines offinen Wejens viele Betannte; ja, er war robl der Mann, ber in ganz Wilbelmbbaven die meiften Betannten batte -

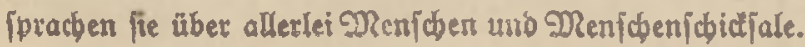


Was ber 3immermann aber aud immet plauberte: was für Gegenben ftiegen da auf aus allen Reeren! Was für Ghiffe tricben da über bie rilbe, toeite Geel

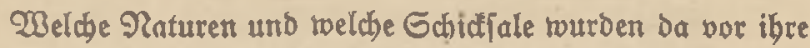
2ugen bingeftedt! Wie neugierig waren bie brei 2 ruber, roenn er anbub zu erzäblen; Denn fie raren alle brei gleiderweife nach bem Menjळenleben, bas zum bejten Teil noch vor ibnen lag, begierig! Wie borchte Sarm Ott und verarbeitete es in feiner tüchtigen, männlichen Seele; trie nabm et alles prattifh); roic trandote er ez immer auf jein Leben an, und má $e^{z B}$ am eignen Rơnnen und $W_{0}$ ollen, uno berwabrte ez für bie 3ulunft! Wie bergá ber twillde Eggert, baj er in Der Gegen. wart ber 3 rilber frembe, falte 2ugen macte: wie leudteten feine 2lugen, wenn er pon Treue und allem (Folent börte; wie bíp er bie 3äbne zufammen, wenn ein Unredjt geføab und ungejühnt blieb! Wie brannten bie 2lugen Dem jungen Reimer, Die jowiejo fळon Feuer genug batten: relde 23 underdinge börte er; rie twar er bei ber Gade! Wुic roupte er alleb, unb wie fonnte er ertlären, unb extlärte bigig, twas ber 3immernann unertlärt gelaffen oder miß̄adtet batte, wie lifitig iळlich er lïb binfer bie Geelen, uno exflarte, mas in ibren Siefen vorgegangen twar! Denn was in Der Tiefe ber Geelen vorging, das mupte ex jal Das ... twie er beimlich bei fich prablte... batte ibm Bott gejagt!

(5) twat da bejonder ein tleiner Nenid, ein Baber, ben jeine Befonnten Den Staliener, ober, roobl wegen feines grofen Ropfes und feiner breiten शaje, Michelangelo nannten; Der hatte viele Gabrten mit Dem 3immer- 
mann zujammen gemaht. Wenn Der ba war, unb bie beiben abtoedjfelnd bon ben gemeinfanen Crlebniffen erzäblten ober von Dem, raas fie bon mandiem fremben Dienjidenleben zu bören betommen baften, Der Sta $=$ liener bejtändig lächeIno, die Sände auzgebreitet, ber 3immermann rubig zurüctgelebnt, ibn genau beobachtend und bies und jenes richtigftellend und zulest das Ganze beurteilend: daz raren Etunden, Die vergingen, alz fliogen fie Davon."

Danach, in bem tleinen Gaal, fpracten fie über Mäbd)en und N(äbd)engefdichten und über glüđtiche uno unglücliche (Eben; ober fie iprad)en über (Eggert Dtt. Slno zuerit redeten fie immer wieber darüber, wie idjon er tanze! Denn ez war wirtlich ein Wunder Gottez, falbft für feine Brüder, ibren 23 ruder Eggert, Den fie

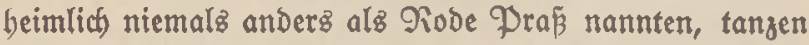
zu febn. Die linfe Edulter etwas hoch, wodurch er noch breiter jabien als er twar und feine bobe Figur fo etwas fraftooll Gtolzes befam, bob er bei jedem 2lufs taft Der Mufit mit einer jobungoollen Betwegung ben jobonen Ropf uno fuchte mit rajoin, idjarfen 2ugen Die Etrape, bie er ziebn wollte, unb gog fie Dann mif rwunbervollem Edhroung. Wie bas Näbden in jeinem 2lrm cine Geber war, ein Garnichtb! Wie er auf fie berabjah, fo fidber, fo felbiftoerftändlid, fo berrifd, uno bod) gütig und fremndich! $\Im a$, ez rar eine Freube, Eggert Ott tanzen zu febn; uno ez geifhah nidt felten, bejonbers zu 2lnfang, wenn ber Gaal noch nidst voll rar, Daß alle, bie ba twaren, 2ugen und 2ltem an, bielten, um ign tanzen zน feḅn. 
2ber es twar ein Reiber bei der Sactel Eggert Ott

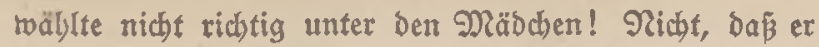

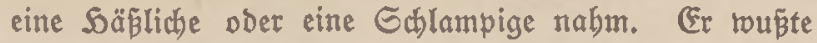

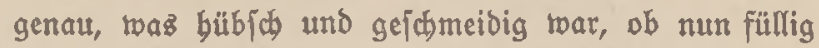
oder bager, und waz fauber ober unjauber war. 2lber er tümmerte fich nidjt um ben (Ģarafter bes Mäodhens! Er tanzte am meiften und am liebjten mit einem Näbden, Das in einem Bajtbof angejtellt war und feinen guten Ruf batte. Slnd er tanzte offenbar nidjt nur mit ibr, weil fie fhön twar und gut tanzte, fondern weil ifm auch ibre Eprache, ibre Interbaltung, ibre Geele gefiel! Surz, fie waren toährend bes Tanzes und in den Paufen twie einige, verlobte Qeute. SInd $e \bar{b}$ gab

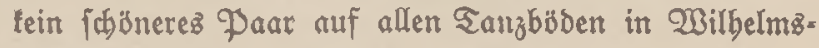
baven; aber es gab leiber aud fein roilderez, und feines, Das verwegener tanzte und fich feuriger anjah.

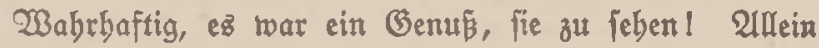
(c) on bieje 3ujammenitellung ber Farben! Diejer ribtliche Nenid) mit biejer Pedjibwargen! Ulno wie fie mit igren gefunden, weisen 3äbnen labten ... Gott modte twifien, über treldhe Dinge!

Die Brüber twaren forwiejo fđon in täglicher, ftän= biger Not um Robe Praß̄, סaß̄ er fich irgendwie gegen einen $\mathfrak{Z}$ orgejesten verjäbe, oder mit einem Rameraben in Gtreit fäme! ఇun tam biez bazu. Soarm zudte die Gaultern. Es twax ibm pallig unerlfärlich, wie ein

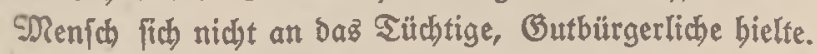
(Er felbft tanzte nidjt viel, und twenn er ez tat, nut mit cinem $\mathfrak{D}$ äbdfen, bie ihm ebrentwerte Wefannte als anItänbig und orbentlic empfoblen batten. Dor junge grenffen, Die grtbor. 
Reimer war tief befümmert. Er felbjt tangte nidbt; er fä mit einem allzuernjten (Beficht, mit einem reltfremben Grhein in ben jungen 2ugen, Da. Wie fonnte er, ber eine lleine, beilige Liebjte batte, ein anores Näbcien in ben 1 rm nelymen?! (5r fand bas grope, fa)male, buntle Nä̈bchen burchaus [chön, uno begriff feinen Bruber joweit roobl. 2lber jeine Pbantalie, bie immer bilbete, malte fd)limme oder verwegene $\mathfrak{B}$ ergangenbeit bätte, etroa einen

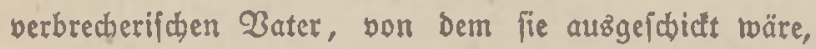
für fdharze SInternebmungen Den Selfer zu fuchen, ober etwa einen Liebiten, ber nun nächifens mit einem groben 2luftritt erfacinen und Rechenfdaft forbern würbe, ober Daß́ fie eine Gpionin toäre und einen böfen Plan mit Bruber Eggert bätte. Gie eridien ibm burchaus wie

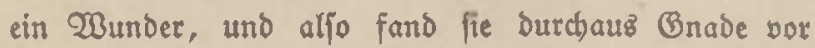
feinen 2lugen; aber ex fürd)tete, baß fie ein buntlez W3under toäre.

Die Brüber badten eine Seit - unb bas rat tbr Troft - Daß Bruder Eggert fich po weit mit jenem Dä̈bchen cinliepe, tweil er innen bamit feinen Srob, feinen Eigenfinn, feine Nidjtahtung ber Familie zeigen trolle. 2lls es aber 2bend für abeno fo reeiter ging, rurben fie ernftich bebrüdt, aumal auch ber 3immermann in ihre Eorge einfitimmte. E⿺ toar nötig, meinte er, Daß fie es ibm fagten, daß fie ein ernjtez Wort mit ibm (prächen; fo gefäb̆rlid auch wäre, ibm an ben Wagen zu lommen.

218 ex nun eines 2 benbs wieber von einem Sand mit ibr an ben Sijh zurüctlam, too fie mit bem 3immer- 
mann und Dem Staliener tmo andern Belannten faßen, fab ibn Reimet mit feinen guten, jungen 2lugen an und fagte mit Serzflopfen: "(Du jollteft roirtlich nid) mif Dem Mäbchen tanzen."

Er fubs auf, alg bätte ex Darauf getrartet, warf bie Gdulter boch und fragte gleichmittig: "Elnd toarum nicht?" "Weil fie nicht rein ift."

(Er fubr nod mebr auf; man mertte, rie er an fich balten muste, um ben Gtubl nicht ou zeridhmettern, Den er gefabt batte. "Rein?!" lagte er, "rein? Waz ijt rein in ber Welt?" $\mathfrak{F}_{\mathfrak{r}}$ war gleid roieder in feincm twilden Gram, und wollte fagen: $\mathscr{W B}_{0}$ bin id id)musig geroorben? Wer bat mid (d)musig gemacht? War ez nicht mein eigner Bater?

Der junge Reimer erfaraf uno preäte bie Sipven zujammen uno waß̃te nicht, was er weiter fagen jollte. Er war immer fo gró und ficher, wern er in einer Zorftellung, einem Zilde mar; wurbe es ibm abet Durch ein raiches Wort zerichlagen, bann twar et verwirrt. SInficher murmelte er ... er (prach) vom Bater ... "Es roar im Brunde nichts andres als Liebe, Eggent .... nid)tz als Liebe."

"Siebe?!" fagte er mit rilldem Soobn; uno bie ganze Giille feiner tranten Eeele brach beraus: "Riebe?! Eine fönne Gorte Riebe ... Salt' Deinen Mund!"

Sarm Ott mertte, Daß̧ da nichtż zu machen wäre. (5z war auch peinlich für bie andern. 2llo ftand er auf und fagre: "Somm, wir rollen gebn, Rcimer!" Und jum 3immermann geroandt, fagte er: "Wir wollen nodb eine Gtunbe im 2 ürgergarten firgen." 
Da gingen fie alle, bie mit am Tifł faß̄en, auth Eggert, ber ftarr und boje vor fid bin fab.

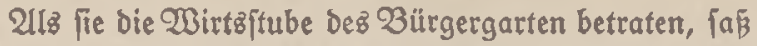
da in ber binterften Ecfe, über eine 3eitung gebeugt, ein alter Betannter bes 3immermannz und des Sta= lienerв. Es raar bet Rapitän Bolfelmann, ein großer, idwerer Mann von etwa viergig Sabren, fonjt Gegels [hiffölapitän, jekst Gteuermann auf einem alten Sorpedo. boot, Daz alz Berfebrizboot im Soafen biente. Der 3immermann und ber Staliener batten oor fieben ober acht Sabren unter biejem Rapitän Boffelmann eine idwere Fabrt mitgemacht, die mit ber Erplofion uno

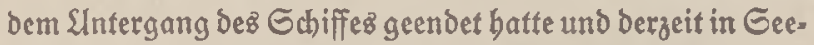
mannglteifen biel berebet tourbe. Geit jener 3eit batten fie ben Rapitän jabrelang nicht gejebn. Stun aber, in biejem legten $\mathfrak{J a b r}$, batten fie ibn bann und twann in biejer Wirtfchaft wiebergejebn; und hatten fich aud fison in einer furzen SInterbaltung Der gemeinjamen Not er= innert. Diejer fás nun aljo roieber ba in feiner Edte, fab auf, und erfannte unter ben Fintretenden feine beiben alten Matrofen, eriviberte ftumm und ernjt ibren militärifden (5ruß und beugte fich wieber über feine 3eitung. Utz fie Da nun faßen, verfudten Sarm Ott und ber Simmermann eine gemüflicbe Slnterbaltung zultande zu bringen. Aber bie füble, läfïge Art bes 3immermannz, bie fonjt fo gut tat, roolte in biejer erregten Gtimmung nicht einfd)lagen. (Eggert machte ein (Beficht, als twenn ex alles in ben Grund fhlagen wollte, und bet junge Reimer war blaß und fitill. Ulnd bas quälte roieber bie

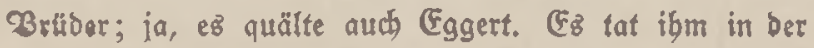


Siefe der Geele jammerleio, Daj jein junger 3 ruder fo traurig ba jap. aber toas rübrte er an feine rilbe Wुunbe?! Slno fo war eine peinlitbe Etimmung am Sijd. Seder wollte gern belfen und wuffe nicht twie. Der Simmermann twar aber aud nicht ganz bei ber Sache. (er batte fich fo gejegt, daßs er, wenn er mur cin wenig ben Ropf wandte, den Rapitän Boflelmann feben fonnte; und er fab oft zu ibm binüber; und feine Bebanten waren offenbar mebr bei ibm als bei ben Brübern.

(1) wollte ber Staliener, Den Reimers Befitht leio tat, Die Gache retten, und fing an, Den 3immermann zu necten, uno fagte: "E్ ijt ganz merfwürbig, 3immer= mann, mit treldhen 2lugen bu ben Räp'tn Boffelman anfrebit, grabe fo ... ja ... wie foll id fagen... alz wenn ou ein f(blechtez Betriffen gegen ibn baft. (58 ift mir fdon immer aufgefallen. Gag' boch mal: was babt ibr miteinander gebabt, was if nidt weį́?"

Der 3immermann runzelte die Gtirn und jagte gegent peine fonft jehr gleidhmütige Weije univillig: "Sch mit Räp'tn Bof̂elmann? Nichtz weiter, alz waz bu weíst! Sch mag ibn nicht, das ijt es! (Er ift mir irgendmic

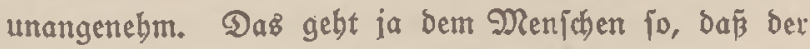
eine ibm angenebm $i$ if, ber andere nicht."

"Go," jagte Der Staliener vertwunderter ... "Du magit ibn nicht? aber warum gingit bu benn nadber boch mieber auf fein Gdbiff? (Es icheint mir im Begenteil, Daß̧ bu ibn gern bajt, ja, baßß du ifn nicht recht entbebren fannjt! 2luch jest baft ou dich wieber fo bingejekt, daß̄ bu ibn febn tannjt; und das tuft bu 
jebezึmal, twenn ex ba in Feiner Ecte fitt, und bie 2lugs: burger 3eitung lieft; benn er ift von 2lugsburg oder Da berun, und tatbolifch."

Der junge Reimer verjtand, daß̄ ber Staliener belfen sollte, und rar auch fofort neugierig, da er da etroas Geelifhes witterte. Alles Geelifhe war für iḅn, was für den Sagobund dasి Gud) ... Guch' des̊ Sägerz. (Fr rar immer auf ber Guche nad Menichenerlebniffen. "Das baft bu dem 3immermann i hon mal gelagt, Miduelangelo," fagte er; "und Der 3immermann ließ́

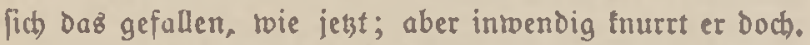
Du follteft ber Gache Doch einmal auf Den (Brund gebn, 3immermann! Sd) meine... in bir jelbft! Srgenb etwar ift da nicht in Oronung."

Der 3immermann lebute fich gurït und lagte in feiner rubigen Weije lächelno: "शicht in Oronung? Bei mir ift alles in Orboung."

"Dann erzäble mal, aber gründliç!" fagte Bruber Reimer birzig.

Der Bimmermann, bequem zurücfgelebnt, trolte anfangen ju erzäblen. Der Staliener, Die Sände reit vor fich auf $\mathrm{Dcm}$ Sifक, Duntel und tlein, von unten berauffebent, fprang ihm mit feinen buntlen 2lugen an, daßj er nichtz unterfdlüge. Der Simmermann fab ibn an uno fagte: „Eräbäl’ Du!“

2lber ber Staliener, Der wuß̈te, Daß er vor laufer Fifer und Wiperipruch nicht rubig erzäblen fönnte, faqte turz uno berauşforderno: "Bitte ... Du! ... Du bift bran!"

Da fing der 3immermann lächelnd und rubig an, frob, bei feinem geliebten, [pieligen Plaubern zu jein. 
Rabitän Bollelmann war fortgegangen. 21lmäblich

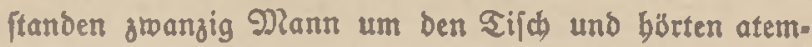
โอริ ชน.

"Sisrt alfo!" fagte der 3immermann. "Wir beibe, Nichelangelo und id), batten alfo - es find ungefäbr zebn Sabre ber - auf ber Dreimafterbarf "Befine" von Samburg angemuitert, und batten bei etwas unrubiger Gee, aber gutem Wetter, Reith verlaffen, unb legelten bei fdy wachem 2 ind ungefäbr in ber Söbe von Gunderland. Land twar nidjt zu febn. Sch ftebe gerabe am Ruber, und ber Gtetter. mann neben mir, uno wir fprecten von unferer Labung - Soblen, und Pulver in Siften - und rebe barïber,

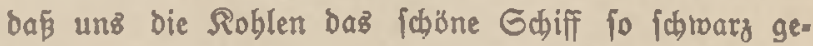
mact baben, unb tooju all bas Dulver bient, bas immer. fort über afle Deere gefdeleppt twirb, obgleich nirgenos Rrieg ift... genau in bem Qugenblid müfTen bie Roblen unter unz entweber beiß̄ ober berrüdt getworben jein... im felben 2ugenblict mur auch das Pulver angeftect tworben fein... genug: roie und woburd es getommen ift: ezs gebt plöglich eine furchtbare Betwalt Durd bas ganze Echiff... es traht und bridt und berftet... uno bann gebt bas ganze Mittelichif, mit Maften und Rettungobooten, und mit allem, toas brunten im Raum ift, in bie Söbe, binauf in bie Ruft! Э屯 jage euch: bie 2ugen, bie wir madten ... als swir wieber auf ben 3einen ftanden... unb biefer Rauch, bid und fhtwarz roie Blei, in bem roir um 2tem lämpften! SAnd twie ber idrwarze Staub fich etwas verzog, uno twir unz fdtwary twie Reger faben! Slno bor uns in ber Siefe nichts als bider, fhtwarzer Roblen- 
ftaub, und brüben, auf ber andern Geite Des 2lbgrunds, auf ber Zact, noch brei Matrojen . . . bie tibrigen waren mit in bie Sosbe gegangen, tot und zerriffen! Ulnd in bem ungcheteren, leeren Raum bor uns, in Der Siefe, palfhte in ztwei Etrömen, bick twie groei

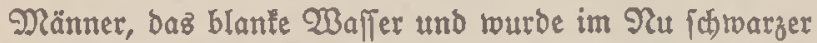
Roblenbrei. Ta ftanden wir ... und das Gdiff fant! Und weit und breit nichts weiter, als bier und ba an Sorizont cine bünne Rauchnolfe, nidjt mebr als von einer Hleinen Pfeife.

"Der Alte, Der fonft boch immer tat - Das wei pát bu -- alz wenn er auf allez gefajt war, ber immer, toenn twas Mertwüroiges vorfiel, mit feinem bummen: , Das babe idb jujt jo gedacht! bei ber Sond raar, lagte roobl zebn Minuten gar nidjtz. Dann belam er bie Gtimnte trieber, und rief benen nach vorn zu, fie follten ibre Rortweften nebmen und über Borb gehn

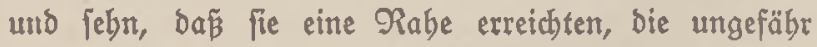
bundert Meter im Waffer trieb. Dann gab er bem Sungen und Dem Roch Die beiben Rettungsiringe, und zeigte Nicbelangelo uno mir bie Gräting, unb trieb unz an, Daß́ twir unz furtmadjten. Wir batten jebcr feirtan Stoft cbeat unterm $21 \mathrm{rm}$, ba lag Das Gajif auch

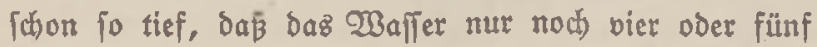
Gü nom Dect war. Da fitiés er ben Sungen, ber nidht red)t wollte, mit einem $\Xi_{\text {top }}$ über Bord, uno machte nach Gee zu eine Sanbbetwegung, alz wenn er aurb gegen uns bandgreiflich twerben toollte, da prangen wir binterbcr, und madtten, jeder auf eigne Gaujt, Dá wir uns vom Gdjiff fortwüblten, um bas ez fdonon gurgelte 
und fog. 24ls wit uns umjaben, bob ez fich gerabe vorn, und lag einen Augenblid, wie ein Pferb auf ben Sinterbeinen; Dann fant es Jutüct und beribwand.

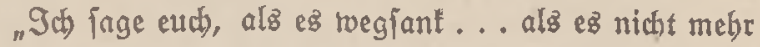
ba war, ba fing unje Tot anl Da twaren wir erft berlaffen! Die brei von ber 2 act trieben an einer Rabe; bie anbern zerftreut bier und da. Der Staliener war von mir abgetommen; und idh roar gleich) won 2 nnfang an etras zur Geite getrieben uno fhlug mid) mit cinem

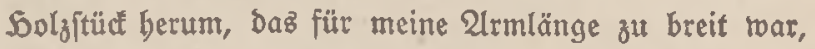
und fah auf jeder Welle, auf die ich trieb, in bie Ferme, und bachte: Serrgott... man mur boch gejelgn baben, Daß breitaufend Tons Roblen in bie Ruft gingen?! War es nicht eine 230 lte jo grof twie Englano? Edjof nicht ber SRaft mit einem Rnall gegen (Sottes Gtubl? Ratürlith baben fie uns gefeln! Slno fommen, unb holen uns aus dem $W_{a}$ fer!

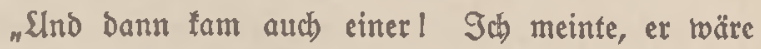
noch) tweit roeg, und fäbe unb nidjt. Aber ba fubr er fめon gerabe auf unz zu, und idh hidrte bie Gtimmen. (Fs war ein lleiner, breiter Gijhbampfer, fo einer won

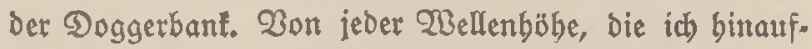
tam, überjah ich fein ganzes Dect. (Er fijhte exit bic an ber Epiere herauf, Dann bie vier um Den Majt, Dara unter bent Rapitän. Sab fab beutfich, rwie der Sunge in ben Rnien lag, und einen ber Leute um ben Leib faß̧te, als wenn bas Dedf ibm noch nicht fejt genug twar, uno Dachte noch: ber bat bom Geefabren genug und twirb Gd)ufter! Da fah ich plöglich, wie fie fid alle umfabn, unb, roie bie Marftjdreier bon ibrem Sifh berab 
tun, laut thers Waffer riefen... naळ allen Geiten. Ta wurden mir bie Bhlieber im talten 2 a fler fteif uno bie 2lugen treit; Denn id mertte, Dá̉ Fie midh nidj) faben! Ta (d)rie ich aus allen Leibestfräften! 2aber fie börten mich nicht, und laben nicht, Daß ber Gtrom midh von ibnen wegtrieb. Shre Edyraube fegte rieder an... Die andern Geretteten ... id fah $\mathrm{es} .$. gingen unter Ded ... Nur der 2llte ftand nod ba.

"Er ftand ganz allein ... TR ... bu fennt ibn ja... und ihr andern babt ihn ja zutweilen über feiner Seitung oa fitsen jebn ... fo ein bischen tofflig ftand er $b a . .$. ids reeij nicht, wir haben oft Darüber gefproden, ob er $\mathrm{X}=$ ober K.ZBeine bat ... oder was es fonfi ift... genug er ftebt nicht orbentlich ftranm uno gerabe twie andre Reute... Go ftand er ba, balb das Glas vor ben 2lugen, bald ofne Blaz, unb juchte, und fab Fich um. Slno idh lah fo an feiner Soltung, wie er fid) bejann, ob fie alle gerettet twären, uno twie er bestwegen mächtig nadbachte... SInd da ... Rinder ... als ich ihn ba fo ftehn jab... an ber niedrigen Reling, weit nach born gebeugt, alb wollte er mit feinen Augen bem, ber nod zu feblen idien, näber fommen, $d a$ id)rie id in meiner 2lngit noch einmal. Ulnd ztoar fabrie if Das Wort, mit dem twir ihn Damals nannten. Weil er nämlich, wenn ihm etwaž nicht rajch genug ging... und toas ging ibm raich genug?... immer mit fo bober, faufender Gtimme bom Sinterded berabrief, mit fo juhendem Son, und er mit dem Zornamen Suliuz bieß, nannten wit ibn ,Gchuuliug'; und er roupte, daß̧ bir ibn fo nannten. 
(Das alpo forie id ! $\Re(a, \ldots$ its fidrie fo laut id fonnte... Gduulius!... Uñ febt: das börte er! (Er brebte fid um, als wenn er in bie Geite geifochen twäre, unb gab Befebl, auf midh zuzubalten. Slno da fanden fie midb und fifdten mich auf.

"Der 2llte lagte biz Soull, wo uns ber Fifcher ab. lieferte, und auch nachber auf ber Fabrt nach Samburg

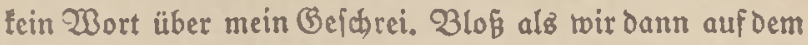
andern Echiff, bas fie ibm gaben, auf ber Roberta, twieber anmujterten, fagte er mal fo gan verloren uno nebenbei: "W3enn bu nod) mal wieber ichivimmit, tannft bu mich auch beim rechten Ramen nennen." Id) pagte: , (Das tu' ich fichet nicht, Räpt'n; Das nüßt nichts; Gie twürben mich nicht bören.' Da fhüttelte er ben Ropf, erftaunt über mich oder über fich, und ging nach achiern."

Go erzäblte ber 3immermann und fab gedantenboll bor fich bin und ichüttelte langfam und itumm ben Ropf. Dann twarf er eitren langen Blid nadh bem Sifd bin= über, an bem vorbin ber Rapitän gefeffen batte, uno fab ibn ba nicht mebr, uno fab Michelangelo an und fagte twieder rubig unb in feiner aiten, gleidmütigen खeije: "Id weib... ich babe irgend etroas gegen ibn... aber ich reeí nidht raz."

Die andern fpraden eine ganze Weile über ben Fall. (58 trar buch böd)ft rätfelbaft, marum oer alte getabe biejen Ruf gebört hatte! Der Staliener meinte, er babe eben lauter gerufen, $d a$ cz die lerste Not getwefen wäre.

Der Simmermann aber leugnete ez̉ entichieden. "Sक babe nicht lauter gerufen. Sh toar fojon ein bißsben vertlamt, und tonnte nicht mebr." 
(Fin anbrer meinte, Das eigentumliche 20 ort mit bem langgezogenen u bätte es getan. $\mathfrak{G r}$ bätte eben in feiner Not ebenfo ge [aujt uno gejubt, wie der 2lite vom Sinterbecf berab, wenn eş fitürmte; und bas wäre eben meitbin zu bären.

aber auch bas jchien nicht mabricheinlich.

Der junge Reimer hatte ftill Dageieffen, bie 2lugen auf Den 3immermann gerichtet. Plöglid), aนz langem

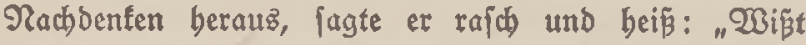
ihr was ... id will es euch fagen! (Es ift nicht bieş und

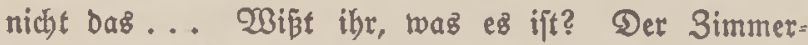
mann bat den 2llten lieb! $\mathscr{D a z}$ iff bat ex auth was gegen ibn!"

Gie faben itgn alle bumm an. Dann faben fie alle auf Den 3immermann. Der hatte plöglich die.3ähne ऊufammengebifien und fah ftarr, głübend über bas ganze (Beficht, auf ben jungen Reimer Ott: "Wie tommit bu barauf?" jagte ex verftört.

Der junge Reimer fagte, die brennenden Augen

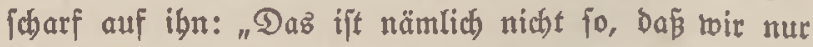
Sände Gaben, die langen fönnen ... fondern un re Geele, müīst ibr wiffen, Eam auch langen! Du fahft ben Alten ba ftebn, wie er in Not um ben einen war, uno bie Gee abjuctete! Da brannte bein Serg nadb ibm. Eben reil du ihn jo in rot um ben Finen jabjt! Slno ba riefít bu ibn mit bem Ramen, mit bem du ifn lieb batteit, uno langtejt mit beiner Geele nach ihm. Slno bie langte weiter, alż baz (కejఢ)rei von beinem Nunb! Biel weiter! Slno fo fam es an ifn heran, Dás er es börte! Du bait ign lieb, Simmermann!“ SUnd plöglich 
íbrie er laut mit funfelnben, wilben 2lugen: "Qüge nicht, Renjळ!"

Der Simmermann roollte ifn mit bisfem 3orn ans feber; aber plöslid) taumelte er auf, glïbenorot int (Beficht, jhhlug bie groß̄en braunen Sände vors (Geficht, und ging aus ber ₹ür.

(Fr war nod) nicht brausen, da rief diefelbe hobe Gtimme: "Slnd du, Eggert, bift auch fo einer! Dut baît einen $\mathfrak{S a \beta}_{\text {gegen Den }}$ Gater und gegen bie Soimat, reil bu fie lieb bajt! Das ift eš! Aber bu wirft bid noch eine Weile tweiter verifellen; denn bu bijt härter aโz Der 3immermann!"

Eggert Ott bí̈ Die 3ähne zujammen und murmelte: "Was foll unire Gache vor fremben Menichen?" 2 ber er toar boch unficher uno bí an feinen Lippen; uno fubr mit ber Sano überz Saar, rie feine Mutter ez tat. "Id) gebe," lagte er.

Da ftanden fie alle auf. Snd bie, bie um fie fitanden, traten mit fillen, ftummen Befichtern aubeinanber, uno gingen ibrer Wege, jeber an feinen Borb.

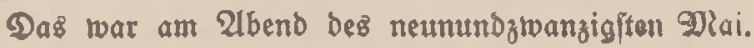




\section{Rapitel}

Die 3 egegnung vorm Elagerrat Q1"m andern 21bend fubren fie, alz ez dämmerte, rieber einmal auz Dem Safen.

Es ging bier und ba fo bas (Berede, alz wenn fich biesmal etrazz Ernftes ereignen tönnte. 2aber bie meiften glaubten es nicht; fie waren id)on ungläubig getoorden. Wenn bier und ba in einer Bruppe irgendeine un= rubige Bebauptung uno (Frmartung auzigeiprochen rourde, erroctte fie immer mieder Miftrauen.

Rachbem fie eine Racht auf ber Reede gelegen batten, fubren fie reiter. Sie tonnten nicht genaut wiffen, toohin bie Fabrt ging; aber als Selgoland in

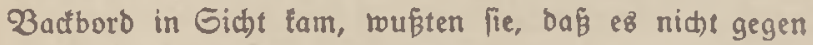
Englano ginge. $21 \mathrm{~m}$ felben Rachmittag marfen iie Unter uno blieben bis in oie शacht binein in 21n= gefictt bon Selgolano liegen. Ta batten dicjenigen die

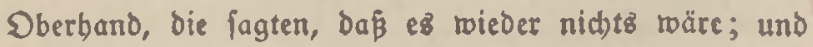
fie sourben mißmutig.

In ber Nacht aber fubren fie weiter und mertten am Wind, Daß fie rociter Surz nach Norden nahmen. Gie fubren auch ben Bormittag weiter, immer in mäbiger Fabrt und blieben nachmittags fo bei, bis um vier Slbr berum. Yor ibnen fubren, roeit ausgebreitet, nur an Rauchroolten fichtbar, bie Sorpedoboote, näber beran Die tleinen Rreußrer. Dann tamen fie, fünf Panzerfreuzer in Riellinie. $\mathfrak{B o m}$ Gros, nad dem lie binter (id) ausichauten, war nichts zu felyn.

Bald nach bier Ulbt ftand Sarm Ott mit einigen 
Sameraben im Santinended und fie iprachen wieder ein= mal über England: Daß̧ fie Die englifachen Matrofen immer lebr gern gebabt, two fie fie getroffen bätten. Slno einer, Den fie wegen feines witrbigen, grof̌en $\mathfrak{B}_{e}=$ fichts den Propjten nannten, ein rubiger, berftändiger Dann, erzäblte gerabe: "S币 war now brei Tage vorm Rrieg mit Englänbern zujammen... in Briftol... Pie lagen Da mit ibrem fleinen Rreuzer... Die fagten alle, Daßs Das G'erede vom Rriege stwilchen uns ein Unfinn räre; fie bätten ja bie bejte Greunbjhaft mit uns!" शein," lagte er und ichüttelte ben Ropf, "bie eng. lijhen ERatrolen ... bie baben biefen Rrieg mit unsి nicht gewollt und nicht gefuct)! Das baben andere getan! Sest freilid ... nun der Rrieg da ift... tun fie natürlich ibre Dflidt, wie twir fie tun."

(Fr rebete noch, ba fam einer in böchfter (File bie Sreppe binuntergeglitten uno fagte im Borbeirennen: "Rinder ... Dat geibt log ... bol' eb́r de Düroll!" und fprang voriber. 2lber fie glaubten nidd, und einige lachten tiber ifn.

Eg lwar aber noch teine Mimute vergangett, ba Görten fie laufen und rufen, und gleich barauf idbrillten Die Bootmannsppeifen und bie Rufe: "Rar Gdiff zum

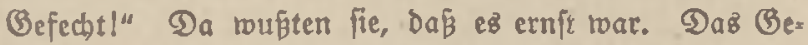
plauber war plïglich verifummt; bie 2lugen waren plöglid ernif, und es war, als wenn fie tiefer in ben Sobblen lägen. Räbere Betannte gaben fï noch raid bie Sand: "Nun, mach's gut!" Dann itoben fie auseinander. 3ebn Dinuten ipäter ftand Sarm Ott auf feinem Befechts. poften, feiträrţ bom Romntandoturm an Der Reling. 
Mit inm ltanden ba ein Seutnant und einige Gignalmaate und ein Obermatrofe. Yorne, vorm Surm, fab er im Saufen Der Offiziete zutweilen bas vertwitterte,

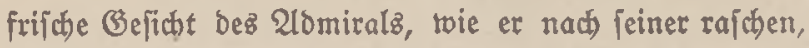
leb̧aften, liebenstwüroigen Weije den Ropf zu benen toanbte, mit benen et fpract. Sie waren im gantzen twohl zwanzig Nann auf ber Brücte. Slno alle faben nach vorn, two am Sorizont, gleich Hleinen, buntlen Rauchpuntten, fächerförmig ausggebreitet, bie Torpedo= boote fubren. $\mathfrak{B}_{\text {on }}$ unten, aus Dem Gchiff, borte man Trommel und Sorn. Fs brobnte und fumetterte ou iłnen binauf, fam näber, berifjwand mieder, und ver= fant in bie Tiefe ber Decte. In Bactborb in Rorb. wejten lag eine lleine $3 a b l$ von Gifhoampfern im tyell= grünen Meer. Ein Torpeboboot fubr an fie beran,

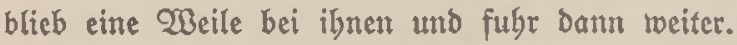

Uls er feine 2ugen abwandte, fah er, bap rwieder Funfentelegramme von Sand zu Soand gingen. Dam faben fie alle wieder mit großjem Eifer, mit ober obne (Bläjer, über Daz Neer nach) Norøen. Der Rapitäu, bei etwa fünfzig Sabren ein rafd)er Mann, ftand framm gegen bie Reling gelebnt, fein (Glaz vor ifm auf ber 3rüftung; Der Alomiral fragte ben langen, blonben Irtillerieoffizier irgend etwas; Der beutete auf ben Surm

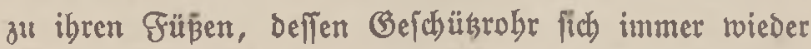
bob und fentte, um zu prüfen, ob alles in Oronung wäre. 2alle Bejtalten, die ba ftanden, Gatten fïh ges ftrafft und ftarrten unbetweglid übers Meer nad Norben. Sarm Otf beugte fich gerabe vor, ben 2lomiral unb Den Chef bez Gtabez, ber neben ibm ftano, zu felbn, 
und fand noch fo, ba rief ber 2lojutant bem Gignal= maaten, ber bid)t neben ibm ftano, mit jäher Bewegung gu: "Rauhnolfen! ... Gehn Gie? . . Det Geind!" uno gleich Darauf: "Sören Eic? ... Echüffe!"

Gie biclten alle ben 2ltem an. $\Im_{a} \ldots$ es twar

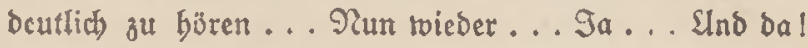
... Einer unierer llcinen Sreuzer idjofi ... man fá Deutlich Den bellen Feuerrauch. Bleich Darauf war ber Funfipruch ba und ging von शund zu Mund: Rleincr Rrenzer Elbing im Befecht mit leichten eng= lif̧ben Sireuzern.

(Bleich Darauf füblte Sarm Ott, wie Die (Erichütterung Dez Gdiffes ftärfer wurbe und ber Quftzug bart gegen ibn anfubr... twie ein beftiger Wrino, ja, faft roie ein Eturm. Der $2 u g$ bob fict); breiter, weiff (d)äumender (Gijht itieg über Der Bact auf, fotwoll bod unb warf fich auf, und braufte über bas ganze Zorjchifi. (Er fals noch cinmal nach ben Gijhbampfern in Dem Bebanten, Der ibm wunderlich burch ben Ropf \{hoB, ob es irgend. wie ein vartappter Geino wäre, und fab, twie ber Sunge, Det am Sect bes lețten und nädjiten Bootes ftano, twie in Berwunderung beibe Sände bob. Qa wanote er fich um, unb fah bie gange Teibe ber mähtigen Echiffe, Gaturm bod) vorm Sెug, in rajenber Falyut babin= ftürmen. SUnd ez fant ein Şefübl des Gtoljes und ber Freube über ihn. Sn Dem 2ugenblid trat ber Gignal= maat, ein einflibiger Menja, mit bem er faum befannt twar, ein wenig zurüe, fo baj ex neben ifim ftano,

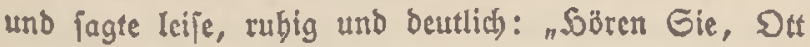
... es fällt mir fo ein... twenn mir eftwas juftob́t Grenffen, ote Britber. 
... bann fobreiben Gie einen netten, freundichan $\$$ rief

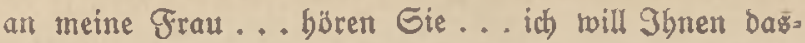
jelbe verjprechen ... $\mathfrak{E}_{88}$ ift io angenebm für bie 2ln: gebobrigen, wenn fie etwas Perjönlides erfabren."

Sorm Ott fab ihn rafd an unb nicte. "Mbgemadif fo!"

Ulz er fich twieder umbanote, fah er, rpie Der 2lo. miral mit einem gefpannten uno fragenden 2 (ubbrut in

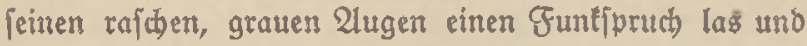
an feinen Etabsichef roiter gab. Der Feuerrauch ber Eleinert Rreuzer twar mun beutlid zu febn und ibre Gaüffe rollten faton balleno über bas IDeer. Cin Qäufer fam aus dem Surm, wieder einetl Funtiprud) in ber Sand. Bleidh Darauf fagte der 2bjutant neben ibnen:

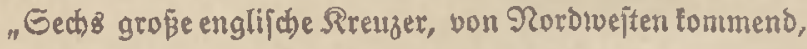
gefict)tet! "

Sarm Ott ftarte wieber äber bie Gec, mit gieriger Gecle nach born ftrebend, nach Dem Nenen, Betwaltigen, Das bie nächiten Gtunben bringen trüben ... Da phoflen fie trieber! ... Slnd ba waten zum erftenmal bie Miün Dungsfeuer ber feinblichen Rreuger... nur undeutlith

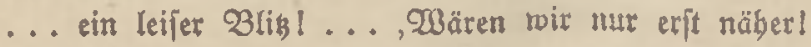

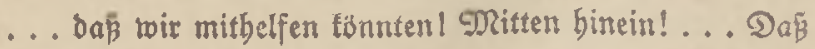

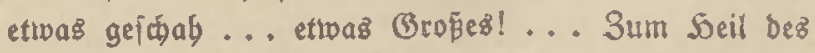
Zaterlandes und feiner Fot! 3um Ënde bes Rriegs!c Uber obgleid) alfe jeine Ginne fo nach born itrebten uno bie 2lugen wie Grallen frarr grabeaus übers Dicer

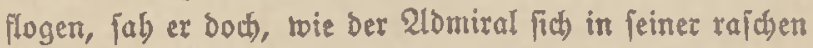
Weife gu Dem langen, Blonben Artillerieofizizier wandte und Dabei jene zierliche Betpegung mabte, bie ifm eigen twar, unb wie das Robr bes Surms 21nna, 
fdräg unter ifnen, ben ber Offĭgier nod cinmal prufte, gegen ben fernen, nod unfichtbaren Geind fich langlam bob und fentre, roic wenn ein Gtier oorm Un= griff ben Ropf bebt und fentt, die Rraft bes Ractens zu priffen... zugleich aber, in Demielben 2ugenblict ... flogen bie BeDanten rie Durch einen Gpalt, Der meithin Durch bie Ruft Fich auftat, auf Windesflitgeln,

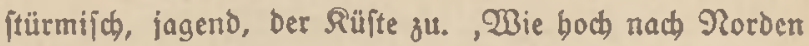
mögen twir fein?! Eind wir weit über bie Eiber. münoung binauz?! Sören Bater und Nutter Den jh)reren Donner, das furchtbate Grofien, bon Der Gee ber? Treten fie aus Den Säuiern uno iteigen auf die Deidhe und ftarren über bie $\mathfrak{W a t t e n}$ unb über bie blen= bende Gee und denten an ibre Rinber in ber Not ber Gd)lacht? (Es roiro eine grop̃e Gd)lad)t! Sch erlebe Das Gemaltigfte, was es gibt ... Wie lagte ber Offi" jier?... Wenn England in einer Geefdiladt geld lagen mird, andert fid bie Welt ... Wie gern [präche id noch mit 3 ruder Eggert! . . W Wenn ich nicht wieder, tomme, mus er nach Soauje gebn unb Grieden mit ibnen machen ... Frieden ... Das ift Die Sauptiachel Darauf tommt es anl' ... Whie Pfeile ... trie feurige Dfeile, grabeaus, fo flogen jähe, beipe Gebanten, Wünfde, Soffnungen, fichentliche 3 itten ... bald empor zu Bott, bald nach Often, ber Seimat zu, flogen, und tamen an.

Worn im Norbrweften, nicht mebr fern, laufen groei oder brei unjerer Hleinen Rreuzer ... Der Rauch flog binter ibnen ber... Dajwiften ber bellbraume Rauds ibrer feuernden Befchüze. Bang fern am Soorizont... man fiebt die Gdiffe felbit nicht... e eb ftebt da nur 
Raudy und es blizt da ... Das fint bie Feinde! Whie langlam es gebt, obgleid) Der (Bifdt weis̄ (d)äumeno über baş ganze $20 r j d i f f$ und bis an bie Brücfe fliegt. 3 wanzig Menfalen auf ber 2 rüde, Sunderte burd Eablize und Qb̈ber, ftarren nach ben fernen, fernen, Eleinen Rautchivolten . . Run wiro bas Mündungsfeuter beutlicher... Drei voer vier rote 2 tige zudén auf unb bellbrauner Tiauth ... ein furzer 2lugenblid ... mun fteigt um bie beutiduen Ehiffe Qualm unb $\mathfrak{B a f j e r g i j h t}$ auf, wie beller Dampf anzulebn, wie Ehleier, ber fie verbüllen will. Qlber nun ... Da! . . binter ben Heinen, fingerlangen, feindliden Edtiffen, ganz fern am Sorizont, ericheinen beutlid) neue Rauch molten ... böbere, breitere! Das find die gemeloten großen Echiffe bes Geindes! !

Sorm Stt fal) zur Geite nad, ben Sffizicren und wunberte fich, wie rubig fie dajtanden, wie fie beobachteten uno $\mathrm{es}^{\mathrm{B}}$ in alter Weije miteinander bejpracten. Der (Ebef bes Etabes nabm mit rubiger Betwegung ein Papier aus ber Mappe, fah binein, uno gab bem

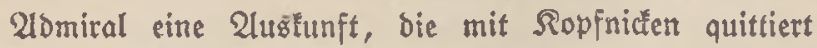
wurbe. Nur cin junger Leutnant, ber an bie Reling geprest ftand, murmelte bann und wann ein $\mathscr{W}$ ort bor

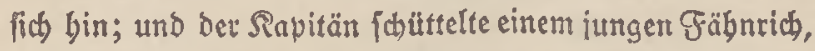
Der mit cincm bienjtficten 2luftrag an ibn berantrat, am 21rm und fagte mit fprübenden 2lugen: „शun ... freuen Gie fich, Gäbnlein? Greuen Gie fich? $\mathfrak{I n}_{\mathfrak{n}}$ fünf Minuten fino roir im Rampf!"

Soarm Ott börte esి. Tas Serz flopfte ibm plazlich (kh)er. (er batte eine Peigung, bie flache Sand bae 


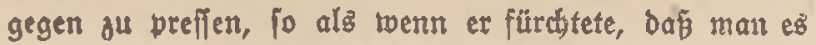

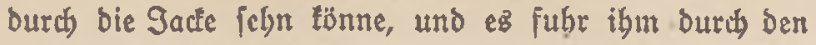
Ropf: ,Fin Sold bin ich nicht. Fin Shelb ift nur Greude. Sab bin erregt und untubig. Slnd er richtete fich auf

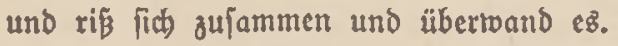

Gie jagten grade auf bie englijánen gropenen Gediffe zu. 2uch bie tamen heran; fie wurben größ̈er und gräßer. 2lber nun breben fie berum ... ja ... fie trollen im Bogen berumgebn und weglaufen. Fern, fo großs wie Männerfinger, fteben fie am Sorizunt, gantz Deutlich und Har; am Rauch, ber über ibnen binjagt, fieht man, wie fie dabinrajen. Es find fecthz grobe Edhiffe. Viach Eübolten toollen fie umbiegen ... Was jebn fie plisklich nach den Sürmen zu ibren Füren? Was fliegen unb meffen ibre Lugen über die Gee zun Fcind binüber? ... Da! ... cin 2 eben burdjs Gwiff ... ein ungcheuerez, Enatterndes Rrachen . . Das Ed)iff

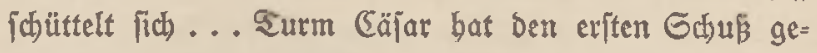
lölt... getwaltig, Neer und Simmel füllend, bricht er utber bie Gee. (Sleich darauf folgt Surm 21nna zu ibren Güßen. Nun, mit bellem Rnattern, aud) bie

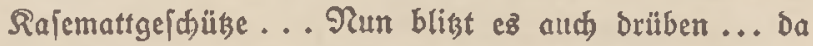
in Der Ferne, vom Feind ber... ja ... fünf glübende Puntte ... verfhiwunden ... शun ... fommt es? . . . tommt es? Da ... mit beulendem Gaujen ... in rajender Fabrt ... jubend und jaujeno... wie fie heranjagen! ... im felben 2ugenblid finb fie da . . 3rocibundert Neter vorm Gdiff idlagen fie inz Waffer ... ungcheure Bifd)tjäulen, einige bunfel, andere blendeno reeiß, fliegen auf. Cin ungebeures Getöje füllt bie Ruft, rollt, ftöst 


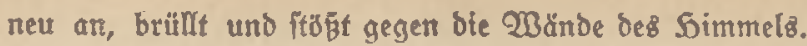
Wie abllofe rajenbe Bewitter, bie mit fobredlichem fnatternoen Donner um fie itebn. WBenn es von den beutid)en Gdiffen einen Eleinen Seil einer Getunde ein mal fbroeigt, bobren fie ben Donner vom Geind; aber gleid) roieber füllf bas ungebeure Betbife, roie von riefigen, jagenben Ungebeuern, Ruft und Meer. Eben Gaben einige Sürme mieber geichoffen ... Das Edhiff bebt now) von ben Ģlägen. Da tommen wieder feinds liche Granaten mit beulendem Gaufen in rajender Gabrt baber. Gie fdlagen vorn, bicht vor bem 3 ug und sur Geite inz Walfer; eine ungebeure Bifchtfäule fliegt auf, ftebt einen 2lugenblid, achtzig Meter boch, vor Dem Gwiff, uno abermirft bann das Borictiff und ben Rom.

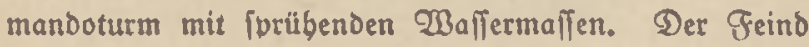
bat fid eingeidofien. Der Gtab gebt in Den Surm, bon ba aus die Edylacht zu leiten; ber 2lojutant, bie Gignalmaaten uno Qäufer geben auf die Reejeite, un nicht völlig ungefdiütst zu fein. Gie febn fich an uno nicfen fich fu und rufen fich irgendein $\mathscr{B B}_{\text {ort }}$ zu, aber

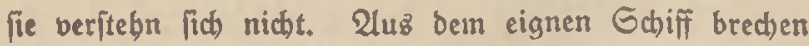
in langen Blizen mit ungebeurem Rnattern bie Gdjüfle; aus ber ganzen beutichen Linie bröbnt es wie Galven ungeheurer Bemitter; in rotgelbem Gathein leudten bie Ylike; in Gdjrefel uno Raud löfen fich Soimmel uno Erbe; Das Neer ift inż Zeben getommen; eş if mit groben, unrubigen Wellen bededt, bie fich twie von Gamerzen gequäIt übercinanber roerfen. Und in ber Ferne ... treit in ber Ferne, bod beutlich zu febn ... in ber Reibe bet fingerlangen Striche am Rano bez 
Decrez . . . vieder ... vieber... bas jäbe 2ufblizen ... ein bellbraumer $\Re$ auth $\ldots$... fchoffen!... Nein... bas war ber ztwcite ... ber fchiejt nicfit auf 4 เ $\ldots$ aber nun ... Da ... det erfe in ber Reibe! ... nun fommt czz ... Da ... toie tie berans beulen ... ivie fie poltern ... twic fie fich polterno durcts bie gequälte Gturmluft brängen! . . Da ... in jobret: licher Gabrt, mit ungebeurer Rraft und Gthivere, $21 \mathrm{~m}$.

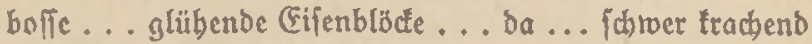
id)leggt es in bie Bactborbfpill ... eine $23 o l f c$ bon (t)musigem, buntlem Raud) uno Gtaub fliegt bausbo() auf, cin Gtüct ber 2Infertette, fo grobs twie cin Menja), fliegt am Rommanooturm vorüber. Ein Nann, Der an Geländer fid haltenb um die Summefie fommt, twirb von einem Eplitter getroffen uno fallägt nit Dem zer. fchmetterten Beftänge Die fieben Meter tief aufg Dect. Da liegt er ffill; feine Mütse mit dem fauberweinen Ramenşzug liegt neben ibm. Einen 2lugenblid balten fie bie Santo vorm Mund, ftehen fie im Sauth, bam fliegt er im Gturm vorüber. Wieber bebt baz̉ ge* waltige Shiff, bligen feine Sürme, raft fein Geuer anz ben Rafematten; bebt fich, fdüttert zujammen uno ftürmt toeiter; bas Waffer vorm 3 ug prübt bod und wirft fid über bie zertrümmerte Bact. Sie itchen rubig mit ftillen Befichtern, fharfen 2lugen, feltenen, abge. riffenen Worten, bie fie fid inz Ohr rufen ober fidh beuten. Gie fehen immer twieder nad) ben Gdjlizen im Surm, in benen bie (beichter berer Fidtbar find, tweldie Die Edladt unb bie Ediffe Ieiten. Die Geinde baben fidy eingeichoffen. (Ein zlveiter Sreffer fällt in bic 23 ad 
und reipt fie tweit auf; cin anbrer fकlägt in bie stveite

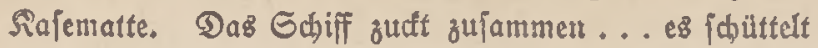
fich wie ein Pferb. Die eignen Galpen fracten ba= ztwifden. Mit fdredtichem (Gebeul uno riflem Gaufen, zutweilen mit lautem, ftopendem Poltern fäurgen bie Bes= ihoffe ber Geinde beran. Bon ben andern Echiffen bröhnt und fracht es in getwaltigen, ftö́nden alktorden.

Da ifit Der QRuf: "Räuferl"

Er pringt an Den G山lis: "Bom Turm Emil feine Parole! Feuett nidht. Fragen Gie, twann er roieber feuert, ob er Silfe braudbt."

Sonrm Ott lief achternaus und tam bis achter ben Surm; da fommt eine Galve ... einige ... zu fury

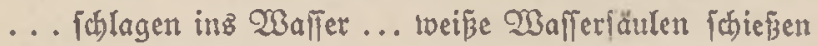
auf ... aber bie andre fchlägt vor ibm in bie Tiefe bezz

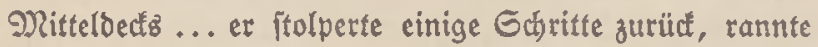
twieder vor, fam zur großjen Ireppe, die fieben शeter tief aufz Mittelocef binabfülyt, und fah auz bem Surm Bertba Rauch tommen. Pun idiept eine rote Flamme beraus. Fr glitt bie Sreppe himunter. Ein Offizier, Duntelgelb im Gejitht, bie Sand feit um den ser[doffenen, blutigen $21 m$, ftürgt nach Atem ringeno berauş, einen ftolpernden, rautidenden sistper nath fich giebeno. Sid aufrichtend, fragt er cinen anbern Offizier, ber vom Surm Emil berüberfommt, mit bertwuberter, pertwirter Gtimme: "Aluf wen ichiepent Sie benn?" Der veriteht ign wobl nidft ridtig, reipt bie 2ugen auf und fagt: "Nun, auf bie Engländer!" Der ßermundete fhüttelt Den Sopf und beutet auf feinen Surm und gebt fort. Der Dfïzier und Soarm Ott binter ilym bucten fid) uno 
febn in ben Surm; aber da ift nithts metr but belfen. Gie liegen zerriffen, berbrannt, im idjtwefelbraunen Dunjit rund um ifr Befdüb. Der Dffrier faptst Sarm Dtt am $\mathfrak{A r m}$ und nimmt ihn mit nad feinem Surnt und geb̧t binein. Soarm Ott fiebt binein: ein kurzez 2 ild beiß̈er 2lrbeit, ztwifhen bligenben, flingendem (Eifen... ein abgeriffener Son wilber Ermunterung ... das bes idüg ift roicber in Oronung, fann twieder feuern. Eine feinoliche Galve beult beran uno idlägt in Marsbäbe

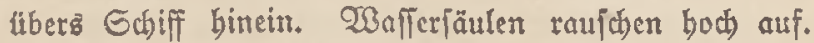
כon achtern ber läuft ein Tutef outchs Gdjiff, es zuct wie im Sdhmerz zuammen und fapt fich.

Er iprang bie Sreppe roicder binauf unb erftattete Neloung, unb jtmb wieber an feiner Etelle. Das Ediff batte won ber zerjholienen Wact ber Warjer überge= nommen, es bing (chief nad) vorn; ber (bijd)t fprang babcr überz Decl; aber bie Fabrt war unvermindett. Die (5ciduüse feuerten mif Mad)t; bas Gdhiff bebte unter

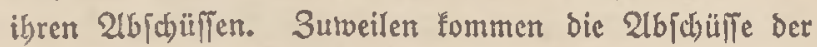

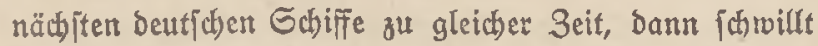
bas ungebetuerliche Rrachen an; ez füllt mit feinem wilden Sojen ben ganzen Simmel. Bon orüben aber, in ber Reihe der Engländer, bie in roilder Fahrt Dabinjagen ... Raud fliegt binter ifnen ber... blisen bie Nündungzfeuer, hallen bie mächtigen Donner. Nun tommen fie an!... Da ... nodh ele fie da find, fobiest bie, Zelotw . . o orei ... vier 2lbichüfie . . . bas Gdiff buctit fich bon bem ungebcueren (Drud, ichüttelt fich und hebt fich twieder, nun fommen fie... Wie fie beulen! ... trie fie fich jammerno, polfernd burch bie Quft 
quälen! 5arm Ott ftebt ftill, bie 3älyne zufantmestge. biffen... Die Soänbe am Seftänge... und fiebt ibnen entgegen: ,2Bie mertwüroig... wic webrlos ich bier ftebe! Eic tommen gerabe auf midh zu! 2uf Etim

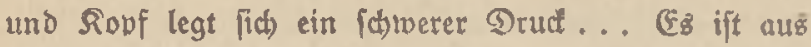
mit mir! Gei meiner Geele gnäbig!' Da! ... 3u weit nach vorn!... Dic eine ichlägt tvieber in bie

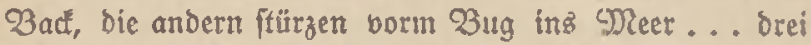

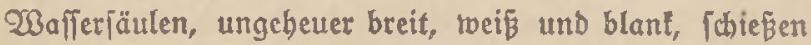
empor, tirchturmboch, jogen itber bas ganze Sdjiff bin biz über ben Marz, uno zerifbellen mit ungebeurem (Bifht auf Dects und Sürmen. 2lis fie eben reg find und bic Gidst wieder lar und bie viclen 2ugen wieber nach bem geinde febn, nach den fünf fingerlangen blizen. ben Gtriçen am Sorizont, beben fie jăh bic Sänte... unb zeigen Dabin ... fieb! ... fieb! Da ... ba! Das fechite in ber Reihe hat fich urplóslid getnanbelf ... SIm ungebcure Naffen und Etücte, bie glübend aufipringen, flacterf eine $W_{\text {Bolfe, }}$ twie ein Rleib von braunrotem gräßlidjen Glanz... unu fteht fie da, grau ... fdurectich ... tot ... nutn weht ber wind fie Dabinl Die Dä̈nner auf ber Brticte (ebn fich an, bie Lippen zufammengeprest... fie niden fich $34 .$. fie fagen ein turzes Wort, und ftarren rieder nach ber Feihe, und nad ber Räte in ihr. Eine bolle Breitfeite jagt beran, beulent, wie mabnfinnige Senfel fingend. (Fine (Erichütterung geht ourch das bchiff.

Fin Wint aus bem Galin bes Eurmes. Er ipringt beran. Er foll in ber शafchinenzentrale fragen, ob die (Bejhroindigfeit beibehalten merden taun. 
Er fpringt bie Sreppe ins Gignalbed und bie tweite Sreppe unter die Bact, und die britte Sreppe binunter. Ulm खallertant fteht ein Ganitätzopoiten ... bält ihn am 21rm und fragt ihn idreiend: "WBie ftebt gut?" Er nictte und twollte ibn fragen, ob hie viele Berwundete bätten; aber ber Rärm ber Majhinen uno ber Ubichüfie, bie eben Donnerno bereinoringen, ver= folingt jeine Gtimme. (Fr rannte Gteuerbord feite reiter Durch bie Rajematten ... Dachte: , Pönnte ich meinent Bruder nur einmal febn, ob ex noch lebt" ... glitt die bierte Ireppe binab und wollte in bie Maichinenzen. trale fpringen... in bem 2ugenblid fdlägt es mit fdorectlichem Rrachen, mit ungebeurer (Betwalt, feiträrtz bor ihm binter ben $\mathfrak{B u n f e r m a ̈ n d e n ~ e i n . . . ~ ( F i f e n ~ b i r f t ~}$ und iplittert... Das ganze Edhiff madt einen tleinen Gorung ... ein Gdreien ... ein Seizer, Dechfdrwary, ben פluno mit ben meißen 3ābnen geöffnet, tommt aus ber Bunfertïr und ibleppt einen Rameraden, Dem bas 3 lut von Mund und Gchentel rinnt, binter fit ber. Cinige Soeizer fpringen binzu, einer bringt, bie (5as". mażte vor, in bie Sür, in ber bie biter Rauchichraben ftebn. Zorüber. (Fin Gprung ... und er iteht vor Der $3 e n$. trale. 21n ber Sür itebn Seizer in Sroyer uno Sojen, Gdtweí(tüd)er um ben Salb, alte Süd)er um den Ropf, eilig, bie Befichter ounkel beftaubt, beiße 2lugen auß bunteln Söblen, uno machen Neldung von ibren Siej. feln ... e ein Unteroffizier faß̄t einen Süngeren am $2 \mathrm{rm}$ und fagt: "Rubig... Rubig! Der Gtabsingenieur ift nicht ba... Sm zroeiten SRajdinenraum!"

(Fr wanbte fich um, rannte ztwifhen ben rollenben 
Gäcten unb ichroarzbeftaubten, Ptöbnenden Seizern birourch, fprang ben Tiebergang binab und ftand int Seizraum. Der Gtabsingenieur ftand neben bem $\mathscr{W} a c t$ tbabenden und fab nach oben, too einige Leute auf ber

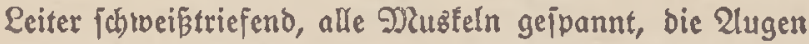

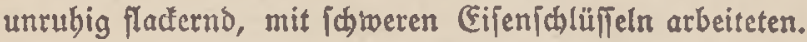
Er jab Soarm Ott ftebn und wintte inm, zu warten. Wclch ein 2ärm! Wie es gegen bie Obren anbonnert und brängt! Wie bie riefigen Feuer praffeln! Wie bie Soeizer arbeiten! Wie die Gdhaufeln ftóken, die Geuctüren bart auficlagen, bie Bentilatoren fau|en und pfeifen, nun im höchjten Son fingen. Sm Gprachrobr fdhreit cz Zejeble; in einem ftillen 2lugenblia b̆ört er Durch bie Leitung Dicht neben fid) ben Geuerbefebl von ber fernen 3 rücte berab:

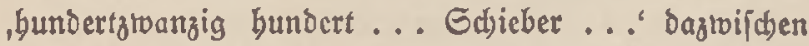
fern unర Dumpf Daş Donnern Der (Befdüke und von oben ber das Gtopien und Gdlagen gegen die Eifen-

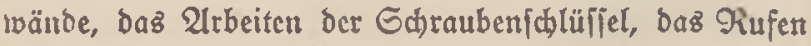
ber Nenfaben. Die Scizer bören und fehen nichts von allem, fie feben nichts alz bie Geuer. Salbnact, in

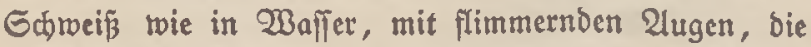
riefigen Gduaufeln und Gtangen in Den Sänden, ftófen uno fdüren fie in glühenden Maाen. Ein Naat phreif irgendeinen 3 ejebl ober fagt irgendein 20 ort ber (FrHärung; ein langer Soeizer lant bie ungebeure Gtange, bie auf einen harten 3 lod $(B l u t$ gejtopen ift, nidht allein ban. tieren; er ftöbt feinen Rameraden an, einen furgen, breiten; ber läßt bie Gd)aufel fallen uno faß̧t mif feinen mächtigen Fäu[ten zu; bie Muşfeln an feinem arm fpringen boch. In einer Bunfertür erīteint eine Beitalt, von oben bis 


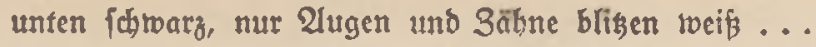
er frectit bie Sänbe aus ... ein Ramerad reidht igm einen Srunt Waffer.

Die 2lrbeit auf Der Leiter ift getan. Der Gtabs. ingenieur nimmt ben beiben Männern jelbjit bie Eifen= fablüjel ab. Er fiebt auf Sarm Ott, ber fpringt binzu unb erbält 2lntwort.

Er fpringt bie Sreppe micber hinauf uno rennt nads vorn. 2ls er burch ben Sajemattgang weiter pora läuft, ficht er vor fich) Dunfel und es tommt ibm ein idhrefcliger, füp̈licher (Geruch entgegen. (Fr twill zurüd, weil er meinte, er tönne nicht hinourch, uno toollte burch ben anbern Gang pilen, ba fab er einen Bertwundefen fich) abmüben, ben Gang entlang aus bem Gumit zu tommen; bic (basmasfe war ihm abgeruticht; cr machte mit bem verwundeten 21 rm eine matte, unbebolfene $\mathfrak{B}$ cwe: gung, fie fich roieder bors (Befidt zu legen. Da fprang er vor und fapte ignn und rí ign mit fidh und fah Dabei burch Die Sair bie zreite Sajematte voll Raud und branbigem Dunit, ftolperte über einen, Der ba zerrifīen in feinem 3 lut lag, uno fam mit glüclich bis an bie Treppe... Da, burch) einen Treffer, Der fdyrăg über $i$ hm in Lee bas Ted traf, vertwirt, liefi er ifn da liegen und jprang bie bobe Treppe bin= auf, um zum abmiral zu tommen, und fain um bie Riutmand bes Rommandoturms ... ba fah cr, im Ulmbiegen, Das SHäuflein ber Sameraben, mit benen er da geftanden batte, wie vom Eturm bingewebt, zbifden Surm unb Rcling bidit aneinandergeworfen, in ibrem Butte liegen. Der Lettnant, gegen bie Surmmanb 
getworfen, fकtwer blutenb, berjuchte fich zu erbeben, ficl aber roieber um. Er meinte wohl, Daß̧ Sarm Ott ber Ganität8̊gaft röre, und fagte: "Erft die anbern...erfít bie andern." Sarm Ott lief an ibnen vorüber und eritattete feine Meloung und fitand wieber an feinem Plaße, mit bem einen $21 \mathrm{rm}$ ben Qeutnant ftü̈end, ber tros feiner fdrreren Berroundung nicht non feinem Plake meidjen rollte, die toten Rameraden zu feinen Gü̈en. Fr badte in abgeriffenen Etöben, mitten in Not und Tod: Wenn Nutter mich bier läbe ... fo fteben!' Gleich Darauf flog brüben beim Geind Das britte Ghiff in Der Reibe in bie Ruft. Eine rotlila 20 olte ftand bis an bie 20 olten; bann brach fie zufammen. (Fr ftarrte noch bin, ba fitief ibn fein Rebenmann, ber Gignalmaat, an und mies zurüd. 2lis er bem weifenden $2 \mathrm{rm}$ folgte, fab er binter ibnen im Gitben ... nicht mebr fern ... grope Raudbrolten ... eine ganze Reibe mäbtiger Edhiffe in Riellinie in bober Fabrt ... meifen Bilcht boch vorm $\mathfrak{B u g} . .$. "Alnire Glotte!" rief Der MRaat... Da freute er fid)! Fine uns gebeure Wut unb 3orn übertam ihn. ,Giegen! Giegen! Dá̉ Diefe Qualen ... Diejer Sag ... nicht vergebens twaren!" Eine Galoe tam angefabren, beulend; eins ber Befकofie toälzte fich mit fducterm Gtofen und Poltern ... mit

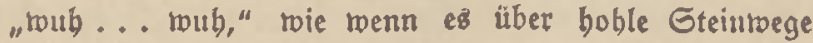
ginge, bur(t) bie Quft und fhlug inz Yorichiff, bicht unterm Surm. Das Echiff bucte fich und zucte auf; Ranch jhoí auf ... ex mupte bie Sand oor Den Nund balten ... Der Raud) flog voriber... ber Surm bielt.

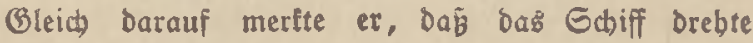
unb Rurs nach Rorben nabm, und balb Darauf, Daß̄ 
Drüben bie Gtridje fid genäbert batten. Slnb ptatt oier fubren ba nun adjt ober meun und 3 lig folgte auf 2 lig. Slno bie 3 lize beulten berüber und f fllugen ein; Das Gdiff bebte, fditterte ... trieder ... trieber. Wic mi Riejenbämmern! Runb! Eplitter, wie शenjchens türper groß́, jagten 1 iberz Ded, fielen berfteno gegen dic Wände ber Sürme. פas Gchiff lag unter Dem Feuer

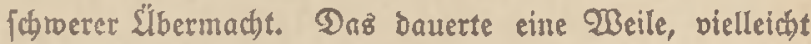
Jebn Dinuten; bann wurbe bie Quft biefig und untlat. Su gleicher 3eit ober gleid nachber tam auth bon bex anbern Geite Geuer. Sier und Da, zur Pinten und zur Rectiten, war ein leichter Rebel mit Raudh)ollen ent. ftanden, und Durch Den Nebel bligte es bier und da roie bon fernen, trüben, feurigen 2lugen; Dreifig oder fünfzig Wa|jeriäulen ftanden rund um bas jagende Edbifr, mie Gobe Riejenpoften und fiturzten mit tobendem Rauichen aufammen. (Blcich barauf lab er ein Sorpedoboot (iis) Dem Schif näberm uno längs̆leit tommen. In bem 2ugenblict trat ber 2lomiral aus bem Surm, fein Gtab binter ibm, unb begann bie Sreppe binabzugebn. Der Glaggleutnant twintte ihm ju. Er jab noch, wie Der Rapitän bem 2dojutanten, ber noch immer aufrecht zmijchen ben Soten ftand, irgendeine (Erquidung ztwifhen

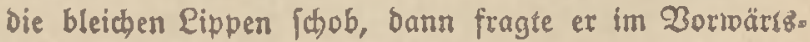
gebn ben Nädften, toaz loz toüre.

"Det Guntentelegrapb if beidjäbigt... voir geḩn auf ein andercs Echiff."

Da ftolperte er binterber, bie Sluget binter fich nach bem Reutnanf, Det im 2lm deš Rapitäns lebnte. 


\section{Rapitel}

\section{Ob, mein 2 ruber Reimer!}

$\infty$ ie gingen, der domiral voran, fein Etabschef mit ber Mappe neben ifm, gleid babinter ber lange blonde 2lrtillerienfizier, bann bie andern, übers Det. Die Solzleiter, bie zum Sorpeboboot hinabfübrte, fidroante und jdlug won bem erregten Waffer auf und nieber. Sorm Ott fprang binzu und half fie balten. Der 2lomiral fitieg in feiner frifden, rafch berwegten 2lrt binab, bie andern ifm nac). Sulest prang Sharm Ott binunter und lief ben andern nad), nad) born auf bie Brücfe. Das Boot brebte $a b$, orei oder vier fhwere (5ranaten idhlugen zrwanjig Meter oum Soot in Waffer und überwarfen fie mit ungebeuerem Gij dht, Der mit fohtwerem Slatjhen aufz Ded ichlug. Der 2domiral fah nodh einmal nach ber , Belon'; fie lag ba wund und fdhmusig; an ber Ecite und am

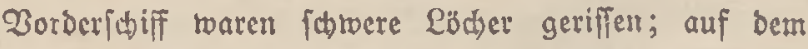
Dect, das jonit fo fhier und jauber twar, lag es voll

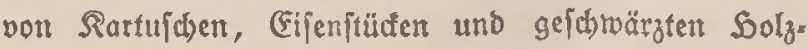
(plitfern; (Eifenbleche ftafen bod); mittichiffes am DlitfelDect Iagen einige Tote. In Dem 200 hnraum der Socizer

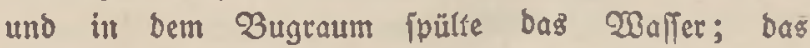
Echiff bing fduräg nach Bactbolo und lag vorn jebr thef. Sarm Ott bi质 Die 3ähne jujammen über ben Anblict und bachte mit tweher Angit an feinen $3 r u b e r$.

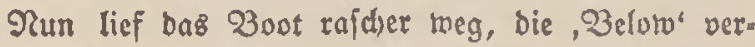

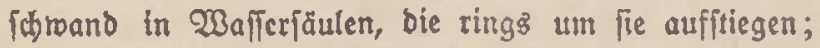
man fah nur noch unbeutlid an ibren grofenen Slmrifien, 


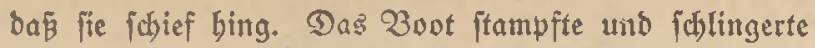
beftig; Sarm Ott bielt fich mit beider Sönden an ber brufthoben Reling. (Fin Gignalgajt, Der neben ibm itand, verfuct)te ihm etwas zu fagen; aber feine Gtimme ber= \{d)wand in Dem mächtigen Gaujen ber Zentilation und Dem Rractien und Donnern nah und fern, und bem 2ufrauichen des gequälten $23 a f f e r$ unb bem Rachball Des Getójez, Daz ben ganzen Simmel füllte. Ez war, als rocnn Meer uno Sinmel rajeno roären von bem Rajen ber Menfchenträfte. (Ein Kofer, unrubiger Rebel gog butch bie Luff. (Fs twar um acht llbr abends; bon Der Gonne war nichts zu febn.

Gie jagten Durdh bie jhäumenden, untubig roogen=

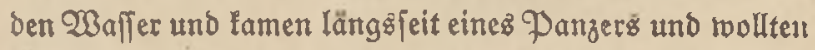

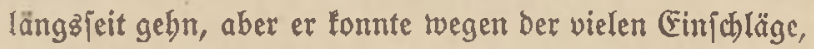
Die rund um ibn ins $\mathscr{W}$ affer fitürten, nicht ftoppen und lief reiter. Da liefen fie twieder volle Gabrt meiter, eine beflere Belegenbeit abzurbarten. (Es fwien, als ob

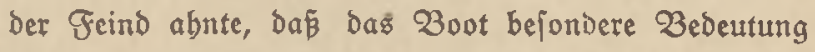
bätte; bie (Einlalläge famen bichter. Sier... da ...

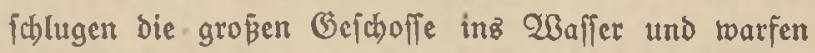
riefenbohe Gäulen auf. Slm ifnen zu entgebn, f̧oß

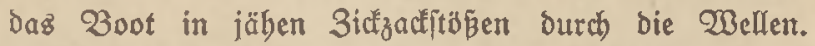
Sharm Ott ftarrte surch Ieichten Rauch und Nebel, Der bie ganze Welt erfï̈llte, vormärtż, Daż Gdbiff zu jehn, Das fie aufnebmen follte... mollte ez beutficher fehn uno beugte fich vor. In Dem 2lugenblict folug eine Granate eben binter bem Edhornftein gegen die innere 3ordtwand bes Boots uno barit, und ifre Eplitter

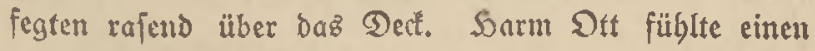
Erenfien, Die अ3rübir. 
Dumpfen Edhlag und empfano, wie ifm buntel murbe unt wic er fiel.

(Er errwachte wieber babon, da fagte: "Эd) glaube, er fann ftebn." (Er griff fich in ben Radfen uno griff an einen Dicfen Zerband; zu gleidyer 3eit füblte er, Das er lag. Da griff er wie in Ingit, in irgenbeiner Wabnworitellung, nach Dem Bein tno ber Sonto Des nächjten, lag in Den Snien und ridstete fich auf und bielt fich an ber Reling, fab vermundert um fich) und fagte: "203az war bas?"

Der Ramerab verfanto ifn nidjt und fah ibn

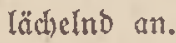

Er wanlte etwas, ftant aber, ríß an feinen 2 lugen und wurbe wieder Har und fah um fids, und empfand zuerft, daj ber Sag zu Ende gebn nollte. Die Gonne war nicht melgr da. (EB lag Daz erfte G(n)ummern über bem Meer. Dann erjt begriff er Das ungebeure Sojen um jich.

Daz Zoot lief mit einer Rotte andrer Boote in Lee Der großsen Sreuzer. Furdtbares Donnern uno Siracken füflte bie Quft uno fchlug biz zum Sinmel, ja, fhien bie Gdjoppung zu füllen.

In Dem 2lugenblia ging eine Bervegung burch bie Mannj(b)aft des Boots. Die Qeufe riditeten fict) auf. Finer rief: "Wir greifen anl" 20 om nächften $200 t$ klang ein jäber, wilder 2lufichrei, ein Surrarufen. Die auf ber Brilcfe ftanden vorwärts gebeugt und ftarten

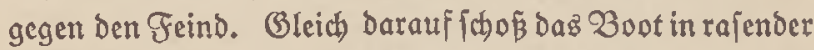
Fabrt vorwärtz, madte eine icharfe WGendung nach) Gteuerbord und fabó am Soet des näbjiten Sircuzers 
borbei. (Ez warf fïh in wilbaufïüumenden Rielrwafler bie rajend bin und her.

Soarm Ott twurbe munterer und flarer und fah um fich, und fah, bap der 2lomiral und fein Gtab

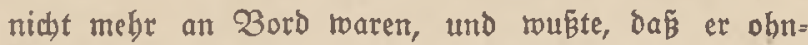
mächtig gerbejen war, und dar bie Sorpeboboote zum Ungriff vortwärtz ftürmten und cr mitten Darin war. Wie fie jagten!... Wie fie ftürmten! Gchräg vor ignen an Baclborto lag ein Heincr beuticher Sreuger, Feuer uno Raud) auf ifm, über igm; bellrote Glammen fubiefen bon ibm auf; Der Geino bejät ibn mit fohweren Bcidjoffen, uno um ibn fitebn wie riefige Wäbter bic

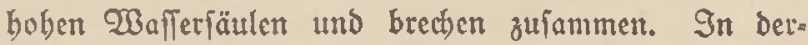
felben Richtung, weiter entfernt, liegen melvere große englip̣che Grtiffe finfent im Meer; einz brennt mit

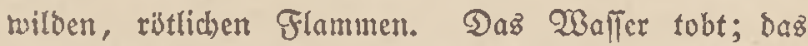
Boot wirb bin und ber getoorfen; Sarm Dtt bält fich mit beiden Sänden an ber Reling. (Bifd)t wirft fict) liber bas ganze Edhiff. Der Robrmeifter und feine beiden Qeute ftebn bis an die Rnie im Waffer. Go ftürmten fie auf bie Reihe der Feinde.

Da! ... Dal... ba find bie englifaren Boote! Soben Gdhaum vorm $\mathfrak{B u g}$, bichte Rauchtoolfen itber fich, jagten fie zrwijoben ben großen Edjiffen bindurch ... mabrbaftig, cbenro tühn wie rwir, ben Sod nicht

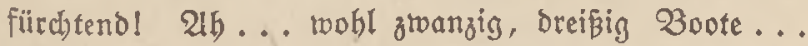
fiütmen fie beran, um ben furd)tbaren, 2lıgriff abzu= webren! Granaten auf Granaten beulen berüber, fallen ing Waffer. Śngebeute WBafler|äulen fiteigen auf. Gie fajiç̄on mit ben grö̈ten Ralibern auf dic Hlcinen 
Boore. D)az erfte, fchräg bor ifnen, wiro mittiçiffz getroffen; in Rauch gelyüllt bricht ez zujammen uno finlt. Sein Blid Dafin! Rein Blict! Weiter! Weiter! Die englifhen Boote näbern fich; fie ichieben. Eine Granate fauft bicht am Siapitän borbei tmo reiß̈t cinen Dann, ber neben ifm fteht, unb einen zlweiten, ber eben Die 3 tülfe betreten will, an Dect. Sarm Ott Frebt mit balbem 2uge, wie der cine von ibnen wie ein leerer Gact zujammen fält, wäbreno ber andre noch in Den Sinien liegt. Fin Ganitätzgajt beugt fich pofort über ibn; Soarm Ott roll binzuppringen; aber feine Rraft ift noch ou gering; Die Snie zittern ibm und er greift nadb Der Etange. Der Rommandant hat fid ungetwandt und fragt bertwumbert: "Wą war Daş?" befommit feine Introort und merft nicht ben Sammer binter fich. Das 3oot wendet fich. Eine Woelfe tommt jo boch, Da bas Tubrende in 2 affer verichroindet. Der Wiber= ftand bes Waffers wirft das Rohr gegen bie Brülle. Der Tobrmeijter, bom Robr getroffen, idlägt (d)twer gegen bie Brüdte, fällt uno bleibt liegen. Ein Treffer

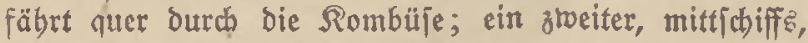
Durch Den Rutter, explodient auth nicht; aber bie $50 l z=$ unb Gijenfplitter treffen zwei Mann an ben Beinen. Der eine lann noch gehn und beriudt ben andern unter bie Brücfe zu โd)leppen, fann es aber nicht burdi. fübren und fegt ibn an-ben Gdornitein. Der Rom= mandant ruft dem Sorpebooffizier zu feinter Linten etroas zu; Der Reutnant, auf feiner andern Geite, legnt fid feit

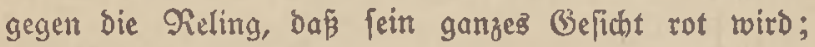
feine 2lugen quellen fajt auz ben Ropf. Der Sorpebo= 
offizier, fabrer vertwumbet, bält fich bennowh aufrecht und jafreit nod) fein Rommanoo: "Qoz!", Dann fällt er bem Rapitän in bie 21rme. Der Surpedo ftürmt wom Borb und jagt davon. (Fin englifhez Torpedo= boot, bas eben no(h) vorwärf̧̨rałte und feuterte, fährt langiamer; loz ... Vortibber! . . Ein andres brennt mit rötlider, breiter Glamme ... Borüber! ... Die beutichen Boote haben fich gewand; fie jagen wieber zurüd. Wie auz unjern Rreuzern bie Nündungżfcuer zuten!

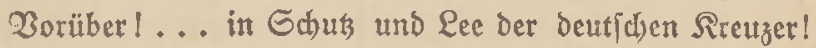

Gie liefen eire Weile, wohl ztwanzig Ninuten, in Lee Dabin, und bie Epannung ließ̧ nach und die $\mathfrak{B} e=$ roegungen ber Menichen twurben roieber langiamer. Der Leutnant fagte mit bobem 2 ufafmen: "Das baben twir gut gemacht, Serr Sapitän!" Der Sioch exichien mit Gleifhluppe und belegten 3roten. Sie á̃en, räbrend bie (Finfchläge über ben Rrewzern bimweg bier unb ba bas Waffer zu Gäulen boben und die Edjlad)t rajento reiter tobte.

Wieber Bewegung! Der junge Lcutnant fiebt e\& zuerft; er beutet mit dem 21rm nad) Dem andern Boot uno jhreit jubcind: "WBir fommen noth einmal 'ran!" Das Boot wendet fich und fhiept binter ben gropen Rreuzern berbotbrechend im rechten WBinfel gegen ben Feind. Ein Mann fieht uach ben Rreuzern zutück, Fiebt noct cinmal bin - und fchreit: "Ferr Sapitän . . . unire Rreuzer greifen mit anl" S̈lber baz Beficht des Rapitäns, ein rubiges nieberfächfifches Bauerngeficht,

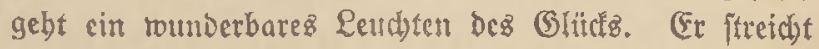


leije über ben 2ïrmel bes Mannes, alö renn cr if̆n ober den Beifit in ihm lieblofen will. So jagen fie gegen ben Geino! Ess ijt bämmerig getworben; Doch find bie Siorper der feindlichen Griffe beutlid) z̆u febn, fie

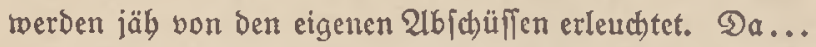
Die englifhen Torpeboboote! Sie brecten beran ... fie fonımen näber und feuern, Wajierjäulen um fiel $\mathscr{D a}$ ... einz brennt! . . e einz finft! Weiter! Weiter! Wie nah twir fonmen! Wie grob bieje Gajiffe! Wic furchtbar! शBie fie feucrn! Ibre grof́cn 2(bjüüfe fracten berftent berüber, bazroijchen, beller und rajcher, ihre Nittelgefdüßge. 2lber woir fürdbten unz nicht! Wir ftürmen in langer, fhräger Qintie Durch Die roirbeln=

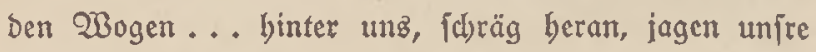
Danzertreuzer. Dem Wolf gleid, Der von ber Geite fommt und dem fortftitumenden Etier gegen dic Rippen fpringt, fo ftürmt bie ganze Deutidie Sraft bon Der Eeite gegen fie an. Ein fortwährender, ungeheuerer Donmer und nabes und fernes Rollen erfüllen die Luft biz zum Simmeläbogen. Die Serzen Der Menichen fino nichtz als Diejer eine Wilfe: an Den Geint beranzutommen,

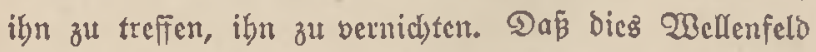
ihn nid)t allein geböre! Sie ftehn mit funfelnten 2lugen, mit geftrampften Sänden. Waas ift Leben? Nid)tz! Tiidhtz! Giegen! Giegen! (Fin Echiff ber (Englänber fhert atts, weid)t zur Geite. Ein andres hängt fdbief uno feuert nur nod) mit einem Geichüs. 3twei,

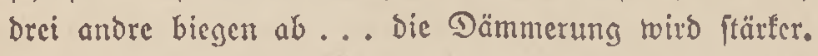
Rebel, Wolken uno Rauth licgen über Dem Meer... Die Engländer weid)en, Dreben $a b$ ! Gie wollen nidjt 
mebr aufz Gpicl fesen! Gie find yor ciner balben Etunde burch) zu viel Trümmer gefabren, haben zu viel Deribiijtung gemelbet erbalten! Gie biegen treg... fie breben $a b .$. und veridhroinden in ber $\mathscr{D}$ ämmerung, bie fich in biefem 2lugenblidf ifwer auf bas Meer legt.

Ez war lein Geino mebr ba... Da Rradien und Donnern war ftiller getworben. Nur fern im Torbweften bröbnt noch einmal ... nun wieber die Rafemattebreitfeite einez groß̈en Gdhiffes. . . nun fern im Gïden başelbe Donnern. Dazivifden bört man nun wieder daz Raujd)en und Meerez. Die Wellen fhlagen an und rauld über. Der WBind weht. Die Gtimmen Botteż Lommen twieber.

(Da brennt noch bas grope englifde Sorpeboboot. Unjer Boot raujcht heran, ob da noch cttons zu retten ift. Gie fommen vorfichtig längs̄jeit und ftarren bins über. 2lber ba fann fein Qeben mebr afmen; eś ift nichtz als ein Trümmerfelb, ein Wirrwarr von verbogenem

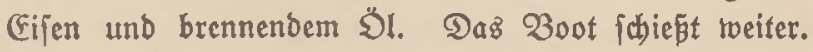
Da, ein zroeitę Boot, brennento, am Soef eine belle Etichflamme, toobl zrwanzig Meter bod, als ftünde ba eitt twilber, feuriger Gteuermann, daz $\$ 300 t$ zu Den Soten zu fübren.

Da frefft ein Nann bic Sand zur Geite und ruft: "Da ... Da!" und zeigt übers Waffer. Da fhim=

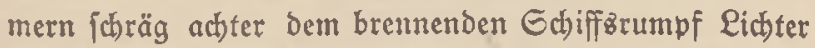
auf ben $23 e l l e n$. Eie fabren näher. Slno nun feben fie: ift ein Sreiz von Hleinen weiß̈lichen Flammen, ungefäbr fo groß̧ wie cin fleines 3immer; bie liegen auf bem unubigen 
Waffer, finten und fteigen. Gie tommen in langlamer Fabrt beran, und jebn inmitten ber Pidfter etraz roie einen gropen, breiten Gad won Gegeltudh; Darin ftehn Menichen, und beben bie Sände und rufen etras. Die meiften Deutichen beritebn fie nicht und bören ez nicht. Gie ftehn fojon Gdulter an Gdulter mit Sauten unb aużgeitrectten 21rmen, bie Ediffbrüchigen aufzubolen. Finer fagt zu Sarm Ott: "Werftebjt bu nicht, waz fie ¡dreien? Gie ¡hreien: No Baralong! No Bara. long!" शun beritand es aud) Sarm Dtt: "शlo Bara= long! No Batalong!" Saue binüber. Ver Nachbar bat bem einen, einem ganz jungen Menj(j)en, bie Sand gereicht und zieht ihn berauf. "Na ja ... twir glau. ben es ithon!" (Bleid) Darauf find fie alle, lieben ober act) Mann, an Dect, ftebn friereno, bod in wïrbiger Saltung, unter ihnen, werben an ben 21rmen ergriffen und bie Sreppe binuntergefübrt und betommen Sand= tücher und trodne Rleibung; einige find verwundet uno idroad) uno bred)en zu[ammen. Ein Maidsinenmaat, ber englifh twie feime Mutterfprache rebet, fragt einen Slnteroffizier atzs. Noch beritort von ber furchtbaren Gdlacht und erregt pon ibrer Rettung, plaubern fie auz, twas fie auf ibrer Geite gefebn batten... wie fie burch ein Trümmerfeld ihrer gropen Gdbiffe getommen wären; und nannten die Namen ber Gdiffe. Einem ber Beretteten, einem ganj jungen Nenichen, bem auf Der einten Geite yom Sals bis zum Rnie bie Rleioung in Gesen zerriffen und perbrannt berunterbing, ichneident Fie mit vorfïchtigen Sänden bie Gesen $a b$; Der Ganitätz: gajt jtebt fajon bereit. Der Bertwundete fiegt bie beiden 
Deutidjen, bie fich um ign bemüben, itnmer twicber an und murmelt immer rieber mit Icifer, rubiger Etimme, indem et ben Ropf idüftelte: "No Baralong! $\Re_{0}$ Baralong!" Dann bergebt ihm bie Rraft uno er wantt. Da nebmen Sarm Ott und ein andrer ibn in ben 2 rm uno tragen ibn unter bie Bact.

Als [ie ihn bingelegt batten, jagte ber Ganitätzgaft: "Romm mit, wir wollen auch unfre vier, bie noch an Der 3 rüute liegen, bierberlegen; fie liegen' bier beffer. Der Rampf fucint ja vorbei zu fein."

Sarm Ott, ber nun bollig twieber munter und bell war, obgleich bie Wunbe im Nacten beftig fomerzte, fab ben Ganitätsgajt an und jagte: "Bift ou nid)t auf bem Boot geweien, auf bem mein Bruder ift? Wcipt Du ... Der junge Freimillige Reimer Ott?"

Der Ganitätşgaft fah auf, fab ibn mit grošen 2lugen an und fagte: "\$a, ber Oft ift ez ja gerabe, ben wir bolen rollen!"

Sarm Ott fab ibn jäb vertwirt an und jagte in Rot und Qual: "Ict) bin auf feinem Boot?!" jagfe er .... "Lnס er ijt vertoundet? Sft es fdhlimm?"

Der Mann breitete bie Sände aus und fagte:

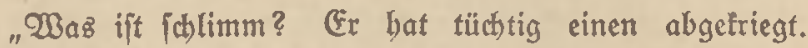
(Daß bu es nicht geiebn baft! Er ftano ja feine brei Gđritt von bir binter bem Ravitän! Romm mit... einer ift tot; aber ber Reutnant und dein Bruber uno cin orifter leben noch)... W Was tann ich jagen? Cir wird es ja boffentlich Durchbolen... Es traf ibn in bic Geite."

Sarm Ott lief unter bie Brücte und jah ba biet nebencinander liegen. Die Berbände leuchteten flar 
weî̉ im Duntel. Er rief jeincn ßruber beim Namen, aber befam Eeine 2lntwort.

"Der erfte ift mier 23ootsmaat... der ifit tot. Qein 23ruber ift ber oritte; er ift robl berwuftlos."

Sarm Ott fnicte neben feincm Bruber und ver= fuchte, jeine 2lugen zu jelgn. Die twaren geidlofīen. Uber ein 3utfen fubr bann und toann über fein (Befichs, baz totenbleid) uno zujammengejunten rar. (Es rwar రas (Gefid)t einez hagern Rnaben.

"Sojt du ibn verbunden?"

"So gut id fann," jagte ber Sanitätżgajt. "2lber ivir wollen zum nädhifen Sdiff gehn, onf fie in ärztliche Pflege fommen." Gie find alle vier fdiber vermundet.

Gie traten an bie Sür. "Gieb Da ... Da ift eins ... uno wir fabren fđ̆on längz feit."

(Das Boot fubr \ängs̄eit cincz groß̧en Rreuzerz, ber

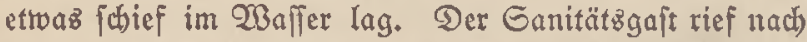
Sängematten. Dic $\mathfrak{i e r w}$ wmbeten nurben bineingelegt und an Dect getragen. Die Solgleiter wurbe angelegt.

Da fprang Sorm Ott auf die Brücfe, trat an ben Siapitän beran uno jagte: "Dbermatroje bon ber, Below ... Dtt, Läufer beim 2lomiral ... żurüđgeblieben wegen Bertwunoung. S屯 bitte, mit auf ben ßreuzer zu bürfen."

Die 2lugen bez Rapitänz glitten jucheno und päheno über Daz butlle Neer, über bą bier und da Edseinrorfer glitten; von Güben und Norden ber auz ber Ferne bounerten Dann und wann (Bejcü̈ge. Er wandfe

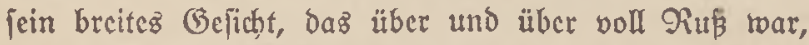
langiam zu bem Grager und veritand exit die vermirrte Eache nicht; Dann aber begriff er unb nictete. 
Dic Detwundeten warent johon an Ded Des Sireuzel: Mit einem grofien Gaz erreidte Soarm Ott bie Reiter, prang hinauf und ging binter ben Trägern ber. Slnter= rocgz, am Niedergang, begegnete ifm cin Natroje, ber ibm befannt cribsien. (Bleich barauf nicte ibm ein Obermatrofe zu, ein F. T. Gaft, Der ben 2lim in ber Binde batte ... Fein Beficht war braun verbrannt, und jagte: "Na mu, bift Du nicht mit bem 2lomital von Borb geganger?"

Da erft begriff Sarm Ott, baß er roieder auf fein altez Gathifi geraten mar.

Bermirrt, und froh, Dak bie, Below' nod fdy tbamm, in feinen Bedanlen von bem einen zum andern Bruder gerij|en, jtolperte er binter ben Srägern ber. 


\section{Rapitel \\ Der Rach tmarfach}

Q) 11 (Fingang zur Nieberganggttit begegnete ifm wicber 46 ein Befanuter und rief: "Wo lommit bu ber? Dit warjt boch beim 2lomiral?"

(Fr börte nicht batauf; er fragte mit angftoollen 2lugen: "Saft bu meinen 3 ruber gefunden?"

"Iawobll... Den babe idh eben noch geiebn ... Ich) glaube, er arbeitet in feiner Rajematte. Sbr Be= fdüus ift faputt."

Da atmete er auf, und ging weiter binter bent Sräger her, und fam in ben ßerbandžraum. Der ganze große Raum unb bie anftopenden Raumern traren polf von Bertwuldetl; in ber (chwachen Beleudtung ftachen bie bicken, fdneetweifjen $\mathfrak{B}$ erbände bart leuchtend herbor. Die meiften lagen Gdulter an Gdulter; einige, bie an

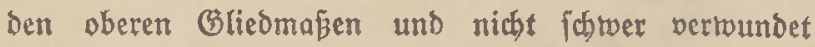
twaren, ftanden oder fnieten neben ben Liegenden uno fprad)en mit ibnen, uno bielten ibnen Waffer vor ben Mund. Einige, bie fatwere 3 ranbrounden batten, gingen wit wirren 2lugen umber. Der Pfarrer, einen dicles Berband um Sopf und Gdbultern - er toar in Der Rajematte, bie anzgebrannt war, ifwer vertwundet roorben -- mit Oynmacht lämpient, ging trokdem pon Nann zu Mann, bejorgte benen, bic Sunger und Turịt batten, bas Notige, ermunterte bie (d)wer Reidenden und betete mit Den Eterbenden. Det Oberitabşarzt, im weiß̈en Mantel, ftand unter Dem fdyarfen Pidt ber Gternlampe itber einen entblöpten Reib gebeugt und legte nun 3 inden barauf. 
Soarm Sat fab es unb bat bie Stäger, Dafí fie cinen Ilugenblidf bielten.

(Ter Oberftabsargt richtete fich auf: "Fertig," fagte er.

Da bat Sorm Dtt: "Vermundeter bon $5.3 .$.

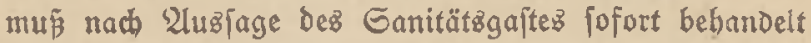
werben ... Berblutung ..."

Der 2lezt wintte, und ber Dertwunbete glitt in ber Sängematte auf Den Silch bor ihn. "Plag!" ... unb beugte fich über ibt und roollte nach Dem Qerband greifen. Da fuste ex, fab nach bem (Bejid)t, Bfffnete Das eine 2uge uno fagte: "Was foll bas? Der ift ja tot!"

Sarm Ott firbhte jammernd auf . . "Es ift mein Bruber," fagte er ... "porhin lebte ex noch."

Dic Iräger und bie Rabejtehenden börten es̃ und fahen mitleibig auf ifn und ben Soten. "Das tut mir Ieib," fagte ber 21rzt, "aber ez ijt nidjtz zu madjen. Die Augen find fhon gebrodjen ... Tad) oben!"

Da faß́ten bie Sräger wicber bie Sängematte, und trugen ibre $\mathfrak{Q} a j t$ ben $W_{\text {eg }}$ zurüd, und famen wieber aufs Mitteldect, und gingen nach vorn. $\mathscr{D} a$ lagen ba ichon viele, zrei lange Kieihen, Echulter an Gdulter, über je zebn cine Flagge. Da legten fie ihn nieber, boben ibn aus ber Sängematte und $\{$ hhoben ihn ein roenig beran,

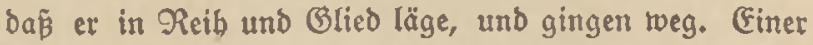
lagte im 2reggebn: "Nupt es bir nicht fo zu Ropf gelyn la Den eiren trifft es; am andern gebt's vorïber."

Er blicb ba in dumpfen Gedanfen ftelnn, roie von

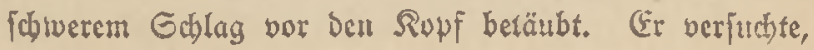


an ben Sofen zu benfen, an bie Elfern, an Brutoer Eggert; aber fie waren alle in Nebel und Dunft; et tonnte fie nicht jeben und nidht Denter. Salb unwifient, twas cr wollte, machte er fich auf ben $W_{e g}$ zur Raje= matte des Bruberž.

Da fam ber zreite 21rtillerieoffizier mit einigen zehn Nann über Ded uno rief ihn, mit anzufaffen. Slno fie

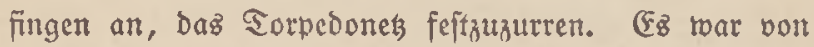

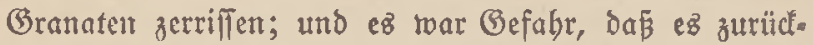
fohlug mb in bie Gd)raube geriet.

Ulв fie bei biefer Urbeit in bie Nälse der ztweiten Rajematte famen, die biz in bie Rohlenbinter binab zerftört toar, börte einter bon ibnen auz der Siefe leijen Silferuf. Gie bielten fofort an, bolten ein Sau berab und liepen einen Sann binunter. Der fam balo nit einem verivundeten Seizer berauf. Fr holte mit 2 redich und Rrämpfen 2lteut, und tlagte Dazrwifhen iuber fein Bein, Das geichrollen und framm im Beinfleio jap. 3 mei Nann trugen ifn fort. Die andern machten fich twieber an bie 2lrbeit am Nek. Go gingen fie bie ganze Reling entlang. Man tonnte in ber bellen Radt daz ganze Dect überiehen, wie esి voll Rartuifhen, Solz= ftüceten, Granatiplittern lag; ein Gamus von Roblenftaub uno Gawefel, ober was es mar, batte es bäßlich gelblid) gefärbt und madte es fd)lüpfrig. (Es toar ein unrubiges Rommen und (Gel)en auf Dem ganjen Echiff; fie arbeiteten, alle Mann, mit aller Rraft Daran, ez notbürftig ou fäubern uno zu ordnen. Das Echiff bing mit ber Taje febre tief und fallingerte Icife; c⿱ fubr, wie cz fabien, frbr langfamt. Einer Der Rameraben jagte leije: "Biel 
meiter bürfen wir nicht wegfacten; bann gebn mir gang

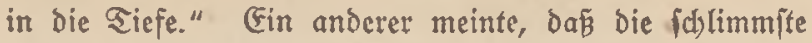
Befabr von Torpebobooten fommen milrbe. "Es ift ja runderlid)," fagte er, "Daß̧ fie nicht angreifen; roir treiben hier bod) allein und wie langlam!" Daz Ţaffer raujhte uno paljhte mit unbeimlichem (Geräujch in ben aufgeriffenen Scilen bez Gdjiffz, bejonders in ber Raje= matte, aber auch in ber Badf.

Qlz fie bas Nek befeftigt batten, fam der $23 e f e l l$, nach bem vordern Seffelraum fu fommen uno bort zit balfen, und ztwar eilig. Sie licfen, inbem fie mit igren Tajojenlampen ber $W_{\mathrm{eg}}$ exbellten, Durch bie langen (Bänge, an Sdlafenden, Soten unb Edhwerwermundeten vorüber, fprangen bie Treppen binab und faben gleid) Die Befabr. Die Want, die gegenüber ben Reffeln baughoch binaufgelt, ftant unter foldhem 2 afferonta

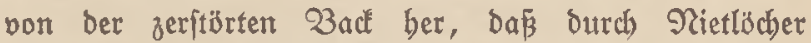

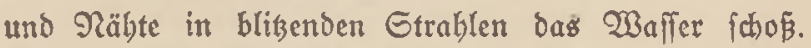
Unter Befebl bes erften Sfījiers arbeiteten Matrojen

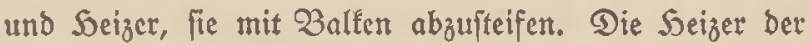
Freimache lagen bicr und ba herum, von Mübigfeit uno Ermattung überwältigt. Finige lagen oben auf ben Grätings uno falliefen, tobmübe; fie ertwadhten weder von der Gefahr des einfibiésenden CBafierz noch von ben frachenden Gdhlägen der थ̈rte.

2lls biele Arbeit beendet twar und bie Sälfte ber Selfer entlafien wurbe, verlié̉ auth Sarm Ott ben Raum. (Er Dachte jełt roicber, feimen 3 ruber zu juchen. aber ba fiefen fie auf einen andern Offizier, ber ifnen

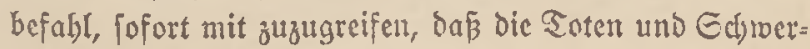


verwundeten und twaz ba itberall in ben Gängen und Sammern, an ben Sreppen und auf ben Dects im 2 cge lag, beifeite gefohafft würben. Gie fajten gleid mit an, trugen bie Soten, bie noch hier und ba lagen, too fie gefollen twaren, bie Sreppen binauf und legten fie zu ben übrigen, fammelten Srümmer in ben Feten zu Soauf, und ftellten wicber zurecht, tons nur berjojoben war. (Ez toar ein eifrigez \$in= uno Serlaufen uno Urbeiten über bas gange Echiff, in allen Räumen unb Gängen.

2lbet fo eifrig, ja ftürmifd fie anfafisten, boben und trugen, rifien, fhoben und fillten: immer wieder ftanden bier und ba lleine (Gruppen beicinander und erzäblten fith) ifre (Erlebniffe, fragten nach biejem und jenem $\mathfrak{B}_{e}=$ fannten, oder, too zloei nähere 3 ctannte fich roiederfaben, gaben fie fich ftumm bie Santo, daj fie fich lebend fanden. (Finige itanden fitll ba unb jaben mit wunderlid) leeren 2lugen vor fid hit. Andere fpract)en itber den 3uftand bes Gdyiffs, faben nach ber Bact, bie tief im Bafler bing und jagten einer zum andern: "Glaubft

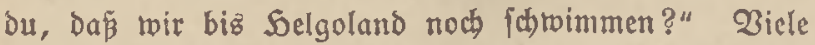
ftarrten immer mieber über bas̉ näd)tliche SNeer, idyüt. tclten ben Ropf und fagten: "Wie tommt ez, Dá fie uns nicht angreifen? ... Das ibre Sorpeboboote nicht Eommen?" Gie meinten faft alle, baj fie nod Gduneres erleben oder ibr Ende fänden, bebor der Norgen lam. Wetın ein barter Qaut fam, ein (Fifenftüat niederfiel, ein Bentil, eine Tür icharf zujhlug, zucten lie zu[ammen. 2lber Dann fam wieder und roieder über bie Gänge, über

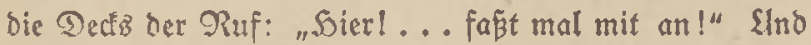


Fie traten toieber eilig auseinander und fitïrzten fith auf bic 2lrbeit. 2ls aber ber Stüdmeifter ibnen befabl, dent Surm jul lischen, Der ausigebrannt war, und fie binein= faben und bie berbrannten und toten Rameraben laben, murbe es ibnen fower; fie traten einer nach bem andern pon ber Sïr zurücf.

Da wich auch Sarm Ott zur Eeite; und ftand cinen 2lugenblict allein neben bem Surm uno jah überz Meer, und verfudte feine (Gebanten zu fammeln und bachte an Die Cltern; unb bifdete Gätze Dez fdyredtlichen Briefes, ben er morgen fhreiben mufite, wenn er bieje furcht= bare शacbt überlebte.

(er ftand noch) jo, da fam ein Befannter um ben Surm, fab itn und fagte: "Warum gebit bu nicht nuf

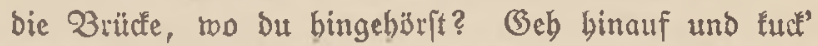
mit aus für uns! "

(Ta befann er fich, Daj ba bben jeine Station räre, toenn Der 2lomiralitab auch nicht mebr ba roar. Er fiteg bie grof̌c Steppe binauf und ging un ben Ront manboturm und traf an feinen Plag. Die Toten und bie Berwunbeten waren meggebrac)t. (Es ftanden da Mann an शann, wobl zwanzig uno baruber, Offiziere uno Nanniめaften, nebeneinander und frarten mit Den Bläfern socr mif freien 2lugen naw) allen Geiten über bas Neer. In ber פitte norm Sommanboturm erfannte er in bem fablen Graut Der Racht bie Figur bez Rapitänż, neben ibm ber $\mathfrak{B}_{3}$ ad toffizier. Er Gatte ba wobl eine balbe Etumbe geitanden, ba börte er, twie ber cine leije zum andern fagte: "(Ez ift ja ganz unerflärlid), Daß̧ fie nidjt fonmenl" Ganz fern im शorben lagen zrei belle Edjeine auf Dem Sorizont.

Exenffen, Dle Briber. 26 


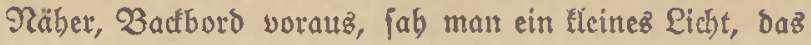
morfte; fonft war nichtz ju jeben als das duntle, ge=

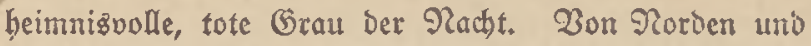
Güben ber war ferner Donner zu bören, fo fern, Daß man bas (Beräujd ber Gee, bie diefiger getworben taar,

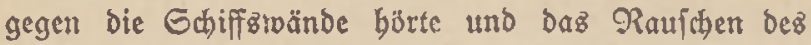
Windes. Wieder jagte eine Gtimme : "Wunderlich ..."

Da erichien wieder ein Lidjt. . . Sebn Sände tviejent barauf bin. Sm felben 2ugcnbliat bie Gtimme bes Rapitäns : „Grheinmerfer leuthten!“ Der Blendende Glanz flog über 2 Baffer. Da! ... 3wei englifhe Boote ftanden Darin ... grell beleuchtet ... twie ertappt. "2lh ... Das find fie! Feuer!" ... Eine Ealve fliegt binüber.

aber alich er idjiejt. $30 m$ Gdueinwerfer iplittert (Slaz und Netall in bie Siefe; auflatfd)ent follagt e8 auf Dect. Won ben Ėngländern berüber ein Edreien... Rauch und Geuer freigt auf ... (B (eich Darauf beleudftet

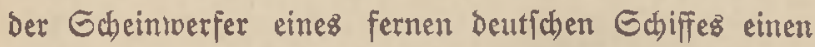

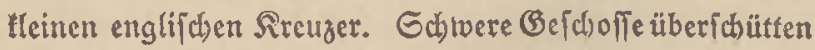
ifn, und plostlid brennt er mit ungebeurem Rrad)en lichterlob; ber Gchein fliegt biz in bie Wolfen; bie ganze Gee iff plöblich bell beleudtet. Eine Biertelftunde fpäter fabren fie ztwi idhen Drei brennenden, feindlidten $3 \mathrm{cr}$ (t) Durch. Gie ipred)en Darüber; aber fie jeben fid nicht an Dabei; fie jtelyen mit fpäbenden 2ugen und feben iiber bie Gee... Gie liefen von ben brennenden, lang=

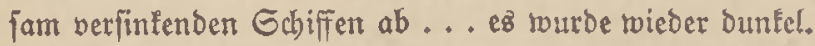

Sarm Ott, ber now) einige 3eit jtand, fühlte feine 23unde ftärter; und es lam ein Befübl Der Gchrbäd) über ihn, und er fürchtete, bøß̈ er nicderfiele. (Ec Dactste, 


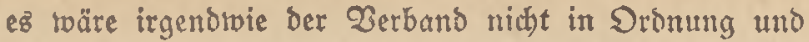
meldete fich $a b$ und ging mit Mäbe bie Treppe bin: unter und tam ins Qazarett. 2llB er Dort anfam, toar

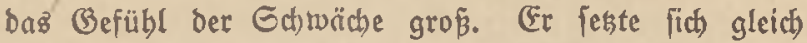
neben dem Eingang zu Güben eirez Bermundeten auf

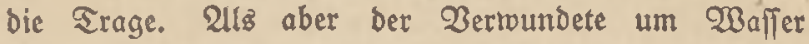
bat, itand er auf und bolte es ifm und fräntte ibn. (fx überiah Den ganzen Raum und ging auch in bie Rebenräume, bie aud) voll lagen, und jah, dẩ Bruber Eggert nicht unter ifnen war. Da ging er wieder in Den Sauptraum zurücf und fette fich micder. Fr batte

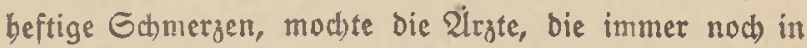
betiger Tätigteit waren, nid)t bemüben und wolle boch in ibrer Täbe jein. Der Raum fah twüjt und roirr aus; es war auch noch eine (branate bineingeichlagen. Berbrannte Betrgfegen, Sticfel, Rteider, fhwarzer Roblenftaub bedecten Den Zuben, über den das Waffer fhwappte. Einer laßs aufrecht und begoß mit bem Waffer, Daz er in einer Trinktumme pom Boden nabm, feine 3 ranbrwunde am $\mathfrak{B e i n}$; ein anderer, fhiwerer verbrannt und von oben bis unten in reige Binden ge= rwickelt, stwijhen benen bie gelbe 3 randalbe bindurch: brang, ging wie ein Mondjüchtiger, fteif, mit großen 2ugen, auf und $a b$; er rollte binaus, aber fie redeten ibm zu und er tehrte roieder um. Cinige waren über und über gefdient und perbunben, andere nur an einem Blied; einige lagen beroegungglog, tot ober im Eterben. Die meiften, leichter vertwundet, lagen auf bem Rutifen und faben mit fitilen 2lugen um fich und rauchten. In ben Göngen ftanden vicle, Die überbungrig und übernübe ivaren. 


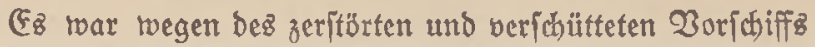
nicht möglich, an bie Qebensmittel heranzulommen; es gab nichtz als PeiB, in See gefod)t. Manche fielen un und lagen da toie tot. (Es war furchtbar beis in ben (Sängen. Biele auf Dem ganjen Echiff, und bejonderz in biejen Räumen, fürchteten, $D_{a \tilde{B}} \delta_{a B}$ Sd)iff nicht lange mebr werbe fibirimmen tönnen. Sie madhten fid) gegen= feitig auf mertwüroige (Beräufche aufmertfam, bie bon unten berauforangen, fo als wenn $23 a f f e r$ rauld te und fticg uno bie Mafdinen erträntte. Man muste ja aud) annebmen, Das bie englif̣chen Torpedoboote fich gerabe bies grope, to fhlwer wertwundete Echiff, bas mabr= (cheinlich werlaffen und allein jeinez $23 \mathrm{egz}$ z०g, zum Ungriff auвَuct)en rürben. Der Pfarrer biclt fid) inmer now) aufred)t, ging bon einem Werwundeten zum andern uno rebete iljten Mut zu: Selgolano täme bald in Gidst, unter beffen Sanonen wïrden fic Schus baben, und fïr ben fdblimmiten Fall wären einige unjerer Torpeboboote in der Säbe; ... uno brachte ihnen Sigaretten und Echofolade. Dann und wann ftimmte er einz ber alten Echullieder an, in bie alle, bie es nod) vermoditen, ein= fitimmten. Go trat er allent ein groper Sroflt und inmer neue Silfe. Eş famen auch Rameraben von ber Brürfe berab und erzäblten, wie fie vorbint den Torpedobootzangriff abgerwebrt bätten und $\delta a \tilde{B}$ Suntentelegramme angefoumen wären, nach benen bie Engländer fhwere Werlufte geljabt bätten; fo und fo viele grofje Gdbiffe des Geindes wären

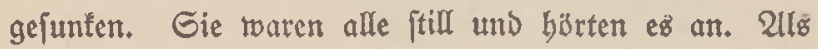
fie zu Ende erzăhlt batten, tat einer ber Bertwundeten einen langen börbaten Utenzug und jagte Dann: " Jienid, 
roenn wie to Sus fount?! So wat?!" Sn Der Gerne, im Norben, Görte man noch immer Sirachen won (Be= f(c)ütsen. Ës war immer ein gropjes Belaufe und $2 \mathfrak{r}=$ bciten burch Das ganze Gdiff.

Sarm Dtt jab unb bỏrte daz allez balb im Sraum. यlz er aber etroas Tieis zu fich) genommen batte, rourbe er wieber munter und toollte fich gerade aufmachen, tvicder nach der Brücte zu gebn, ba fam Der Bimmermann in Eile vorbei, eifernezs Sandwerlzzettg in Der Sand, erfannte ihn trok feines groß̋en ßerbandes und rief: "Dat?! ... Romm mif! Dein Zruder ift Da! Silf unz!"

Da prang er binter ibm her, bie Sreppen binunter unt fam in ben (Bang, ber zu ber Rammer fübrte, in ber gewifie eleftrifche Majchinen fteben. Es war da alles eine einzige Zerwültung, alles zerriffen, werbogen, werengt, bie 2uft f(hrectlich) heiß und brandig; born leuchtete ein fleines Licht; man hörte binter Den Wänben Waffer farrapper. (Ein Sfijier, bem bie 2ldjelitülfe verbrannt berunterbingen, und ein Nann Enieten feitwärts uno ftarten in das Dunfel. Der Offizier nabm Dem 3im= mermann bas furze Brecheijen ab, froch cin menig nad) vorn uno reidjte es einem, ber noch loeiter nach borne im Dunfer arbcitete.

Der Bimmerniann fagte leife: "Do find żivei Rame. raden eingefchlofien. Die andern baben ez arfgegeben, ifnen zu belfen, uno idh glaube audh nidts, Daßz da noch waz zu machen ift; es ifit da alles branoig uno glübeno; aber Der Offizier ba und bein Bruder rollten ez noch nicht aufgeben; fie meinen, fie roären vielleid)t nicht in ber Rammer, fondern im (Sang und lägen ba ohnmäd)tig, 
2lber nun bat ber Offigier auch faton ben (Blauben auf gegeben. Aber twir fönnen mit Deinem 3 ruber nichto aufîtellen ... er if̣t rein verrü ctt..."

3wifhen bem Slatichen bez Waffers börten fie daz Wudhten und Gtuhnen und baz wilde Atmen Eggert Otţ̇.

"Es faun ba nur einer anfommen, " fagte ber Bimmer. mann, "Der Raum i it zu eng."

(Dann borchten fie wicber. (EB war eine Qual, ez zu bisren.

"Eg gebt nicht," jagte der Offizier furz, "jegt geben Gie eb aufl"

Es bauterte wieder eine Weile.

Sarm Ott fonnte es nidht länger ertragen, et rief: "Bib es̉ auf, Eggert!"

(Fs Dauerte nod) eine WBeile; Da fagte Der Offizict furg uno bart: "Go, nun iit es genug!" Slno er und Der 3immermann, der fich beranorängte, rillen Eggert Ott zurüct, Da gleid) wieber, unb fitieß, als fie ign bielten, mit bem Ropf gegen die $23 a n d$.

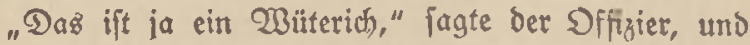
riß ibn reiter roeg ben Gang entlang. Die Pumpen, bie ex um Sand und 2 rm gervictelt batte, raren branbig und blutüberlaufen; und bic er um Salz und (Geficht batte, fdwelten; fie bielten ibn und riffen fie ibm ab. (Er war balb obnmädrig, fïbnte uno ächste. Da fhleppten fie ibn żurüct biz dabin, wo Der Gang breiter rurbe und bie Quft frifcher twar.

Da erbolte er fich allmäblich und exbob fich und 
ging, nach feiner Benobnheit immer bie Gdyulter hebent, ben Bang entlang, bis er an bie Sreppe fam. Dort balf fein Bruder ifm, und brachte ibn bie Sreppe bin=

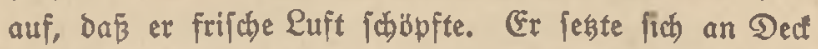
und fam wieber zu fich. CE ftanden, lagen und jaßen da mehrere Berwundete und Überniübete, Denen bas Lazarett ju beí̄ rar. (Fz raar noch Nact)t; aber ez war nidjt mebr to ountel. Die Morgendämmerung melbete fid) an.

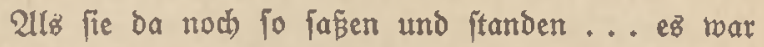
an Eteuerborb des Mitfeldectes ... Fammelten fich einige Sounfen, und bald trat ein Dffizier beran, Gunfentele= gramme in ber Sand, und berichtete ihnen mit lauter

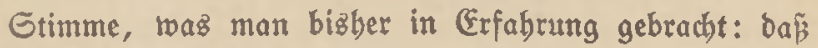
bie gewaltige englijh)e Flotte, boppelt fo ftark alz bie unjrige, in ben Rampf eingegriffen, daß fie verjucht bätte, unjere Flotte einzutreifen, bã abcr bie beutid)e

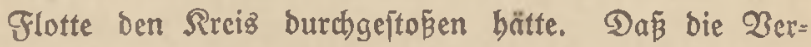
luifte ber (Englänber, foweit man biăber überfeben tönnte, boppelt jo grof trären als bie unjrigen. Slno er nannte bie Namen ber grobien englifhen Shiffe, bie fidjer untergegangen waren. Sie börten ibn fitill uno mit toägenden 2lugen an.

(3leid) Darauf fam ein anberer Offizier uno rief zut Mujterung in Divifionen, und alle Mann fammelten jid ouf bcur 2ldtermittelbeck, uno es twurocn bie शamen aufgerufen. 2liz ez allez feifftant, trat ber Rommandant bor und rebete in feiner lebbaften fübbeutfchen 2 Irt, ftolz und rafi unb freundlid): "Rameraben! \$hr babt euch tüdstig gezeigt, bie Rebenben und bie Soten ... 
To wie Das Baterland es ertwartet hat! 9 he habt bem Feind, ber bem beutichen Bolf Leben uno (Ebre nicht gönnen wollte, beutithe Rraft und beutidien शut gezeigt, und nicht bas aflein, fondern ifr habt nad) allem, twas

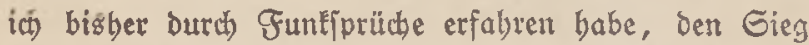
über ilyn Davongetragen! Bebentt, Rameraben: fie waren ausgefabren, uns zu vernichten! ffs war ibnen

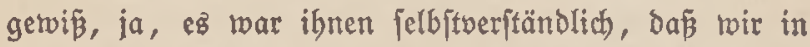
biejer शacht auf bem Grunde bez Neerez lägen! Das war ibr Blaube, uno war ber Glaube Der ganzen 23 cit! Slno nun? WBir haben ibnen miderftanden, ja, wir baben fie geidylagen! Die zroeibundert \$abre lang bie Serren auf allen Meeren ber Erbe roaren ... fie find zum erifenmal geivichen, uno baben Dent Titufen gezeigt!

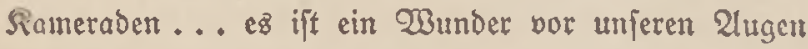
uno bor der ganzen Menichbeit ... es ift ein grofer Sag auf ber Erbe! Es mag num weiter fommen, wie (Sott beichloffen: Dies, was geicheben ift... was ibr wollbracht babt mit eurer Sreue und eurem tapferch Mut: Das twird zum Gegen toerden für unfer Deutictes פolf und zum Gegen für Die ganze Menfhbeit! \$br wifft aber alle, rvie unjer Raifer für bic Flotte gearbcitet hat, immer wach, inmer mutig, immer meerfrob ... Darum wollen wir ifn grüben in biejer Norgenftunde, Den Gründer dentidter Geegewalt: Es lebe der Raijer!“ Gie fielen alle mit groper smacht in ben Ruf eirt. Slno fie fitimmten auch alfe mit grofer Rraft ein, als ber lange Gtütulueifter bortrat und ein Sods auf Den Sommandanten ausbrachte.

Dann traten fie alle alseinander und fanden noch 
eine Weile bier unb ba in Soutfen urd unterbielten jich, langfaun uno bebächtig. 2lber bie Sinterbaltung wollte nicht wortwärtggehen. Slno twar ba ein fleiner Nenjich unter ifnen, ganz Hlein, aber von grö̈er, jtäm= niger 23 teite; Der batte ein Rinocrgefictst, uno war auch von Natur wie cin Rino. Den fragte einer, um fich falbit uno anbere zu ermuntern: "Pun, Peter, waz fagft benn bu?" Er fab fie alle mit feinen barmlojen Alugen an und fogte bann: "Sdh bätte es mir nidht jo gedacht! $\mathfrak{D a s}$ war ja brillah lebenzgefäbrlich!" $\mathfrak{D a}$ twolten einige auflacten, foroohl über bie Woorte, wie über die Zerwumberung, die auz Den WBorten flang; aber bas Rachen blicb ifnen im Salje ftecter.

Sarm Dtt ftand neben feinem firsenden Bruber... genau toie vor einem $\$ a b r$, ba er an Dedf bes fremben Dampfers neben bem Gizenden ftand ... er dadite in Diejem 2lugenbliat an jene Etunde... und fömpfte mit

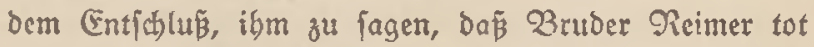
wäre uno feine breißitg Gabritt von ibnen auf bem Ded läge. Aber es mußte ja nun gejagt twerden. (Er be= ridtete bem 3ruber, wic er mit Dem Gtab von Bord gegangen und roie er auf Dem Torpeboboot Bruder Reimer fđlwer verwunbet gefunden bätte und wie cr wobl fdjon auf Dem Torpeboboot geftorben wäre, und Da nun bei ben andern läge.

Bruber Eggert fagte nichtz; ex ftarrfe mit f̧harfen, übernäd)tigen Llugen über baß̉ Waffer un fragte leife: "Wo liegen fie?"

Da gingen fie zujammen um ben Ttrm, und faljen fie da liegen. "Der febte in Der zrociten Reife... 
Dal" jagte Sarm, und trat beran und gog bie Flagge ein renig guxüft.

Sa, ba lag Bruber Reimer ... Der Wrabler ... Der Neugierige ... Der junge Seilige ... Der fleine Prophet ... ach, vielleid)t ein großer! ... einer von ben bunderttaulend edlen, jungen $G$ dhatjuchern und Wunberjebern, Soeil und 3ulunft bez Yaterlandez, viel, leidht der ganzen Welt ... nun zerbrocten ... zers

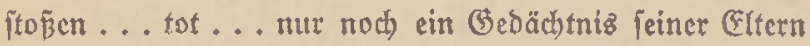
und Beidnifter, und cines Hleinen Mäbd)ens, uno ein Rranz in einer (Fiche, 24h Gott in Sinmel, reldye Not! (Er lag Da mit todernitem (Befid)t, als wenn et Rechenidaft gäbe, und frei und tiilyn alles.... allez verantwortete, roas er an Plünen in Der reinen, beißen Geele getragen. Dann becten fie bic Glagge wieber über ihn.

Der Wint twar ftärfer geworden und Daz Meer

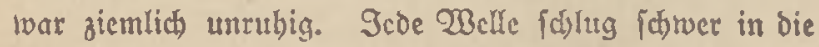
jerftörte Rafematte und raufhte ftürnend wieder binaus. Das Eđiff bing fo idtief, Dap bie Wellen über Dedt Iecten und bie Güre ber Soten nebten. Die Nacht twar bell; es ging leife gegen Morgen. Sief im Diten, nach Der Soeimat ou, erfichien leife Der erite Gtrich Des Norgenlidbtz. Gie fäen nebeneinanber auf dem Rabebaum im Ungefid)t ber Soten. Sarm fah ftill und traurig über bas Dieer nach O(ten und Dachte ant Den Sammer ber Ëltern; 3ruder Eggert neben ihm hatte die 5ände vor ben 2lugen und idluchzte bitterlid). Bon unten, aus bem Rozarettraum, fanten die werwebten Sïne bon bem alten Siev: 
It hab' ... mid ergeben ... mit Serz und mit Sanb... Dir Rand ... voll Réb' und Reben ... Du teure Seimatlanb ... Dir Rand ... voll Lieb' und Reben ... bu teure Seimatlanb ...

arz der Morgen böllig graute, erichien ein Pum=

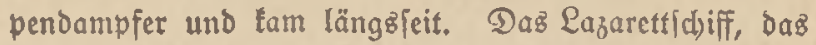
erichienen twar, fonnte wegen ber berwegten Gee now nicht anlegen. 2Un Backboro liefen zwei tleine Rreuzer alz Gdus für bas wunbe Gdjiff. Sm Güben ragte, nod) fern, Selgoland aus bem Mecr.

Uls Sarm Ott nach einer Gtunde, von feiner $\mathfrak{B e r}=$ wunbung uno aflem, was er erlebt, verftert uno zerfblagen auf bie Brücte lam, um cinen 2luftrag an ben Rommandanten zu beftellen, uno, an ben Offizieren vor= bei, Die mit übernäctigen Qlugen Daftanben, die Sänbe auf Der Reling, in Die Sür bes Surmes fah, trat ber Wachtofifier grabe an ben Rubergänger beran und fagte: "Sie freben bier jebt dreizig Gtunden ... geben Gie bem Slnteroffizier Das Puber!"

2lber ber Rubergänger, ein breiter, duntler Mann von etroa breibigig Sabren, fchüttelte den Ropf uno jagte follidyt und ftarr: "S d) bring' Das Gchiff in Den Safen."

Da bejann fich Soarm Ott auf peine Geele, auf Daş beite in feiner Natur. (Er fal) plöglich daş Fäbn= lein bor fich, auf ber Gtange jeinez Rades.

(Fr bís bie 3ähne zulammen und twanbte fid um, too der Rommunbant toüre. Slnd alż $\mathfrak{e r}$ ihn leit wärts vor der Tïr fteben $\{a b$, rid)tete er fid ftramm auf, und machte jeine Neldung. 


\section{Rapitel \\ al $\mathfrak{x}$ eit}

Q1 [z Sarm Ott ba nod ftand, fam ber Oberfeutnant, 21 fein früberer Divifionsoffizier, an ihm vorüber

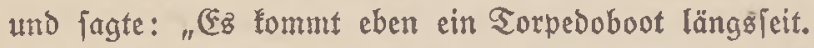
Wenn Gie wollen, tönnen Gie mitfabren, dá̧ Gie rwieder zu Shrem Gtabe fommen."

Da ftand ex auf und bejann fich einen Augenblicf, warf einen langen $\mathfrak{B}$ licf auf bie Flaggen und ging binunter, und judte feinen 9 ruber, uno fano ihn, uno fagte

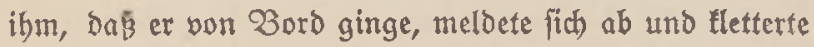
inz $\mathfrak{3}$ oot binunter, Das in ber beftigen 9 ünung fprang uno fdhlingerte. $\mathscr{D} a \mathfrak{B}$ Boot war fhon vom Ed

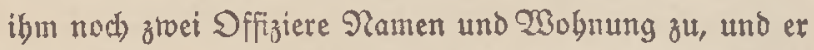

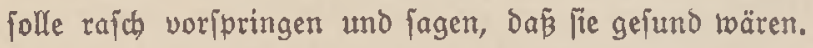

2lకz fie nach Dreiftündiger Fabrt - es mochte fo u!n neun \&4hr morgenz fein - am Dier anlegten, war ez da überalf idwarz von Menfchen, die auf die Gee binauşpäbten, und zeigten uno fragten, und riefen

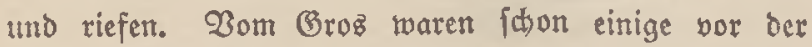
Gchleuje, und viele Sorpeboboote batten fljon aus Rai feiftgemacht. Bürger, Werftarbeiter, Rnaben, Frauen tamen mit erregten (Befichtern auf bie Matrojen zu: „Shr babt gefiegt!? Befiegt babt ifr? Befiegt? - Wievid haben wir verloten? $2 a z$ jagt ibr ... bie Pommern? ... Was jeio ibr für frre Rerle! ... Rein ... wer bas für müglich gebalten!... Shr babt gefiegt? ... Shr Ileinen Rerle über die grofen, bicten Eng=

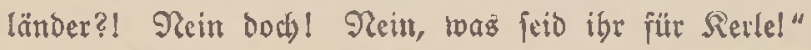


Die Matroien, Bleich, mager, mit einem ftillen Glanz in ben übernähtigen 2utgen, zäblten die feind= lichen Edhiffe auf, pon benen fie mußten, baß fie verloren waren ... "פa ... das Gdiff ... und das ... und

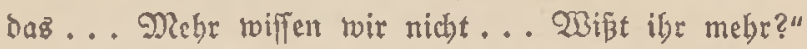

Bicle junge Grauen itanden ba mit gropen angit = bollen 2lugen und fragten bie, bic ans Land fomen, nad) bicjem und jenem Shiff, und gingen zum nächften, wenn tie feine 2lntwort betamen. Reben bem Sdups pen, ein wenigs abjeitz, ftanden zwei Maaten einez Rreuzers, ifre Frauten brängten fid) an fie; cine britte ftand ein wenig zur Geite, bie Sände bor ben weinen= ben 2lugen. Fin Gtrom von Bürgern, Matrofen, Grauen und Rindern Lam atz den Etraßzen Der Gtadt; biz mitten auf bem Damm ftanben die Thenfchen; z'wif hen ifnen burth zogen von ben intmer anfommenden Echiffen Matrofen in einģelnen Trupps, Orbonans zen, Sffiziere, bie irgendweld)en aluftrag batfen, alle erregt in Soltung und $\mathfrak{M}$ ienen, alle mit überwadjten (Gefictern, mancbe orbentlich getleibet, aber viele burd)= näfst, zerriffen, einige angebrannt, einige berbunden und blutend. Ein grof̧er Srupp Seizer, in Semb und Sofen, zerriffen, bie Gdwweiptïd)er แod) um ben Salz, über und über voll fdwwarzen Roblenftaubes, zlwei $B e r=$ wunbete in ibrer Nitte, zogen über bie $23 e r f t$, mit Iautem Bejang: "Deutichland, Deutid)land über alles ...!" Go wälyte es fich über bie 3 rücten in bie Gtadt, aus Der immerfort in ungebeuerem 3 ug, eilend, Iaufend, fragend, die Bewilferung frrömte. Sharm Ott hatte an einigen Gtelle פRüle tweitergufonmen. 
In cinem ber exfen Säufer läfte fich ein Torbedo= bootżoffigier, ein Mann von etwa fünfundoreibig Sabren, ber bumbert Edritt bor ibm gegangen twar, bom 3 ug uni trat in einen Sourgarten. Er rief jeiner jungen Frau, die auf Dem Balton erfdien, won reitem zu: "WBie geht es bem Rleinen?"

Geine Grau rief: "Geit porgeftern nad)mittag gebt ez ibm gut! Sh bin nidjt von feinem gegangen; ez toirb beffer mit ibm. Waß bedeutet bas Qaufen auf ber Gtraßje?"

"Frau," fagte er, "twir baben gefitern bie gröpte Geeid)ladht geid)lagen, die jemals in ber Gefdhichte gerwejen ift! Slno wir baben gefiegtl! $\mathfrak{l n b}$ ich bin mit Dabeigetwejen."

Die Grau bob bie Sände an bie Ghläfen. Borüber!

310ci Sorpebobootzoffiziere gingen eine 2 cile neben ibm uno er börte, rwie ber eine fagte: "S屯 twar mit meinem Boot bỉllig abgetommen ... id rougte von

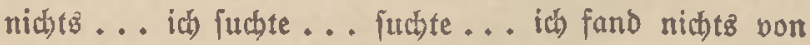
unjern Gdiffen. 2luz ben Gunfiprüd)en fonnten wir nicht flug twerben; ez war ein tolles Betwire bon Englän\ern, bie unz offenbar umgaben. Go ging ez die balbe Nadht... da, fo gegen Morgen ... po um brei Slbr ... betamen wir beutlichen beutichen Funfipruch: ,Wir follten uns zu bem bros fammeln.' ... D̂. ... da... ich batte nidjt mebr geglaubt, daj es noch ein deutiches Gros gäbel ... ba... if ez mir idwer geroorden, meinen Reuten bas zu fagen ... obne Trätuen! ... Es gab now ein deutjhes Broz ... und wir 
follten ung zu ibm fammeln!"... Die blanten Sränen ftanben ibnen in bert 2lugen.

Ein Sunge tam berangelaufen, bie Sände bull von Errtrablättern ... Die Menidben rifien fie ibm aus Der Sand: "England... vier groß̧e Sereuzer! Wir... bie Pommern ... die Wiesbaden ... Die ..." (Ein alterer Sandwerfer jagte: "Die Pommern ift fein newes und tein gropes Gchiff."

Die zitternde Etimme eines ganj jungen Dienits mäbdhens fagte: "Uluf ber ,Pommern' babe ich einen 3ruber." Der Snabe rannte an ihr vortiber. Eie fing laut an zu weinen. Flaggen raufliten fhon über ihr. Rund um Fie, aus̆ allen Grap̃en, rief ež: "Eieg!... Gieg!..." यlle Gtraß̄en, ganz Wilbelmōbaven war unterwegz, ftano an ben Pierz, auf Den 2 rücten, füllte bie Grraß̃en, zitterte vor Erregung, Srauer, FrettDe, Gtoly, Bangen

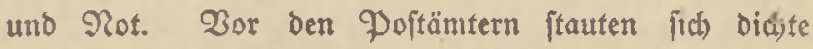
Saufen. Saufende von Sclegrammen flogen auz: Etaatz̈= bepeichen, Glottentelegramme, Gdiffatelegramme, Werfts telegramme; Depejdjen an Eltern, an Srauen, an Rinder uno Bräute. Die Abmirale famen von Borb. Die vorber niemand getannt, bie nun mit einemmal jeber Sinabe in Deutichland fanntel Der mit bem offnen, fchlichten, trobigen (Beficht, bas ift Gcheer; Der hat bas Banze gelcitet! Der ba ... mit ben flinfen 2lugen uno rafchen Berwegungen ... das ift Sipper; Der fübrte bie 2uftlärungzflotte, die Panzerltreuzer, Die vorangingen! ... Die Ielegraphen jagten es ins toeite Qano binaus! Wel( eire शachrid)t! Die ganze Riüte bebte vor (Frregung. 233eldh ein Lärm und cirte Greude in ben 
Etraßzen Somburg und Bremens! Tूeld eit Beredc in Den trufend fleinen, braunen Wirtštuben am Gtrand entlang! Welch ein Llufatmen und bobe, crnite Freube

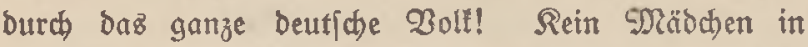
Deutidlano, das nidbt ein blaues Nüsenband über Den Welfen flattern fah! Siein (Ergrauter, der ez nicht auf ben Wellen treiben fab!

Slnd Dann fog Durch Willfelmshyaben ber lange, lange 3 ug ber Toten ... alleż jungeż, beftez 3lut ... Saufende Rameraden ftanden in Gonntagzeug um die offnen Gräber, im Geift zelntaujende $\mathfrak{B a ̈ t e r , ~} \mathfrak{T u ̈ t t e r , ~}$ Frauen, 3röute und Eleine Sinber; dabinter, ftill, ftols und weineno, daz ganze beutiche 2 olle. 2luf ber flachen Unbabe bei Rüitringen entftand über Nad)t ein weites, weites Gräberfelo, Grab an Grab, mit $\mathfrak{S o l}_{\mathbf{z}^{z}}$ tafel unb Ramen. Die Beitungen brachten immer ge= nauere Sunde... Der Raijer fam und begrüpte in jeiner frifhen Weije bie Sapfern, bie Steutn, ... audh bie suten.

Ia, ez twar ein Eieg getweien... ein Gieg über die grijpte Gewalt auf Der ganzen Crde!

यl\& bie Brüber Oft nach bem Echuppen gegangen waren, um nod einmal an bem fdymalen Garg ibres Brubcrs zu ftebn, batte Sarm vorber oen Brief an feinen Sater zur Poft gebradut, ber ben Tod meldete.

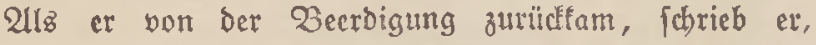
rubiger gemorben, einen jtweiten 3 rief, einen langent, langen Brief. Er erzäblte ben Eftern von den vielen fdisunen Gtunden, bie er mit Dem gefallenen Brmber zugebracht, und wie bor Sote immer, zu jeder Etunde, 
Da et mit Eggert sufammengetwejen, um Den Bruder getworben bätte, und ergäblte ibnen ausfübrlich bie leste Sufammentunft, ba er mit feiner flammenden liebe erit Den Simmermann und bann ben Eggert beftürmt, und Den exften niebergeroorfen, ben zreiten erichüttert batte. SInd Dann tribltete er fie: "9dh glaube, liebe Eltern, und Sb̆ glaubt es auch, baß̄ er für eine groß̧e und reine Gadbe fein Leben gelaffen bat, nämlid, Dá unjer Bolf jein altes (Frbe, und fein Recht und feine Ebre bebält", und idhlog mit bemielben Gedanken, mit bem Die ernfteften, frömmiten und gröbten ber Menjwbeit finh und andere getröftet: "Slno id fann nidht glauben, liebe Eltern, und 9 br glaubt auch nidbt, Daj foviel edles und beipes Leben und Geuer für biefe 3eit und bie Erwig. teit tann verlorengegangen fein!"

21 ls ex ben 3 rief fertig batte, zögerte er eineu Augenblid, Dann fdob ex ihn feinem Bruber Eggert binüber, ber mit blaffem, ftillem Beficht iğm gegenüber laßs, unb bat ibn: "Piez ihn, Eggertl“

Det zögerte erft und wollte nicht binlangen; Dann aber Dachte er wobl an ben toten 9 ruber und nabm ibn auf uno las ibn.

ats er ibn binlegte, jagte fein 3ruber: „Edbreibe Deinen Namen mit Darunter, Eggert!"

Aber ber andere foüttelte den rotflammenden Ropf,

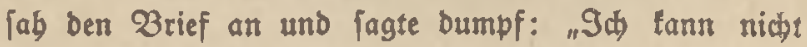
an ibn fobreiben."

Sarm fubr auf unb batte ein bartes Wort auf ber 3unge. Aber et bielt es jurüd, Da er bie ftarte Rot in (Befict feines Brubers fab. (5r ldob thm einen 
Bogen hin und fagte: "Go fabreibe bier auf Diejen

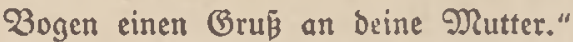

Das tat er mit gropen Buchftaben:

"Qiebe Mutter, es grüßt Dich Dcin Gohn Fggert."

2llB er die Groer binlegte, wilchte er fich mit bent Fiüden der fommeriprofígen Sand über bie 2lugen, ftand auf und ging binaus.

$2 / m$ vicrten Sag nad biefem ztwciten 2 rief fam bie Antwort von ber Niutter:

"Qiebe Rinder!

Ul's Dcin erfter Brief tam, lieber Sarm, trollte ich) es nicht glauben; benn er twar ja noch jo jung uno auch fo gefund, und rat noch faft ein Rind. Sch Dachte: Wie tann er fajon in Der Gdjlacht fallen? Bater roat auf Dem Etüct am Edafroeg, two Rüben bineimpllen, beim Eggen. Sh) und Emma Dadhten erit, er erfübre es früh gentg, uno wollten roarten, biz er nach) Soauje täme. Slno fo ftanden wir beiben armen Weiber lange 3eit am Genfter neben ber Rühentür und paßten auf, roenn er am Ende angetommen war, ob er robl noch eine Wende madte ober nicht. 2aber er eggte immer reiter, Wende nach Wende; und roir

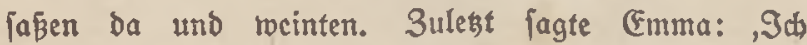

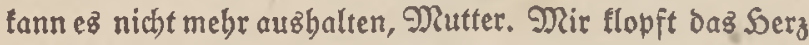
zu jebr, wenn cr am Ende if, $o b$ er num ummendet ober nach) Soaufe fonmt." Da jagte id): Ia, bann rill id bingebn und es ibm lagen.' 2lber ba fagte

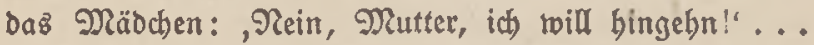
\$đ rounberte mich und fagte: $\mathscr{2} 3$ arum bu benn?... Du bift fonjt fo'n 3 angbür.' Da jagte fie, genau bie 


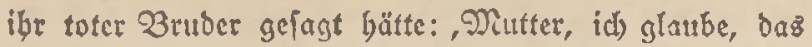
tann ich beffer als bu; bu bift zu raid für Bater. 3c) rill es ibm ganz langiam jagen, und it loill es ibm ridtrig fagen.' Slno ba ging fie bin, und id fal), wiefie neben ibm am Braben fá̉. Slino nachber famen fie Sano in Sand an, und $\mathrm{ez}^{3}$ lab aนz, alz wenn fie vom 2lbenomahl tämen. Qieber Sarm, roir banten Dir audh für Deinen fhänen Brief ... Sa, Daš mıffen wir alle, Daß er um eine reine Gache gefalten ift; und bas wollen wir alle glauben, folange wir leben, daß́ fein ervig Seil nicht verloren ift. Lieber Soarm, waz ift bet Menich in folcher গot, wenn er teinen Blauben bat! Paitor 3oblen lam gleid) an, wie er erfabren batte. Mein licber Sarm, fannit (Du nicht Ulclaub nebmen, Damit ich mich an Dir ein wenig tröten tann? O, und lag', tommt Eggert Dann mit Dir? 2(d), wie würde ich mich freuen, wenn meine 2lugen ifn wieberfäben!"

Soarm gab den Brief an Eggert und fagte: "Э屯) tann jest nicht Slrlaub nebmen. Gelbjt wenn id darum bäte, ez nübte mir nichtz; ich) tann nicht tweg. Eubr' Du bod bin! ... Su bod der Mutter jegt bie Liebe und fabr bin!"

2ber Eggert fab jeinen 3ruber mit 2lugen an, in benen ftand: , $\mathfrak{B i e}_{\text {ift }}$ ez móglich, baf bu mich fo gar nicht ver[tehif!" und f(büttelte ben Ropf twie por etwaz Ginnloiem, Slnbegreiftichem.

(Da fubr fein Bruber roicber auf, und zornig und ftur toie fein พ̧appen, Daz fteile Fäbnlein, fagte er: "Эđ) begreife esె nicht, (Eggert. . . und wenn id) neunzig Sabre alt rerbe! ... Wie ein Gobn feiner guten Dlutter, 
bie in fold fihluerem Letb fiat, cine foldhe 23itte ab. iblagen lann!"

Fggert blieb talt unb rubig im Befict; aber feine Gtimme bebte vor rotlder 2ufregung. "Slno id meiner [eits," fagte er, "tann bich nicht ver[tebn! Wenn ich ba anfäme ... im Dorf . . in . . aus ... io toürbe mich biejer anjebtr unb jener, und ber Dritte auch ... nicht rabar? Ta ich ba bin, werben fie mid bod an= febn! Gutul ... menn bu bas augibit, fo tann i屯 eళ nicht andern, baj id in jebem Gefidat bie Worte febn werbe: war er ber Pfeifer? Sat er jeine lleine Gdmefter unglünflich gentacht unb fein Eiternbaus zum

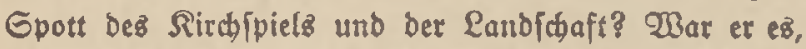
ober war ez ein andrer?" Llnb wenn ich diefe Be. banten in einem Befict febe, fo idlage id entroeber binein, ober iđ breb' mí, um und geb' mieber bavon. 2llio, twie foll ich babin gebn? Gage alles̃, twas bu willt! Gage, baß ber Seufel (Bott totgejolagen bătte und mit feinem weifen, golbenen Rleib fid ben ... aber jage nidjt, baßj id in bie Seimat reijen foll! Sch bin rein ... von oben biz unten ... uno bic Welt ift weit ... roie foll if ein Rarr fein und genau an Den einzig einen Ort gebn in ber weiten 2 elt, wo man mich für einen Gduurfen bält?! Soaft bu Yeritand ober nidpt?! "

(D) batte Sarm ja ichroeigen müfien.

aber war aud wirtlid teine Seit, um Slrlaub ju nebmen. Rein, es trar teine 3eit! WBie bart uno bitig mußste in ben näbsften Monaten gearbeitet werben! $\mathfrak{W a s}_{\mathrm{g}}$ war bas für eir Arbeiten, Rommen und Bebn, Selc. pbonieren, Funten und Gareiben beim Gtabe! Waş toar 


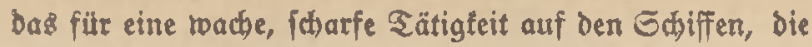
beil geblieben! Die Gळiffe, Die beil geblieben twaren, mutisten in biejem Gommer um io bärtern Worpoítendienịt tun; und Eggert Ott war auf ein anbrez Ediff getommen. Und überbaupt, twer bätte Ulrlaıb neb̧men mögen in biejen Monaten, in benen fo getwaltig gejdafft wurbe! Rein ... wie rwube in SRancten und Gtuttgart, in Sena unb Effen, in Berlin und Elberfelb, ach), in allen größ̈ern Etäbten, in allen $\sigma_{4}$ mieden bes ganzen toeiten Deutfhlanbs, in ben Heinen unb groß̄en, gearbeitet! $\mathfrak{A n}$ ben taujenden Heinen Inftrumenten, bie jerbroden und zerfplittert waren, an den fieben Meter langen Sanonen, bie berlest waren, an Dillionen शieten, bie aufgegangen, an ben taujend Dlatten, bie berbogen waren, an taujenden Beichoffen, bie berid)oflen waren, an taujend Robren und Reitungen, Refieln unb Räpten, Zentilen unb Gid)erungen, bie be(4)äbigt twaren! Was fauften bie langen 3üge mit bem, was fertiggeftellt toax, Zag und Nacbt burd bie Bebirge Mitteldeutílanbs in bie (Ebene binab, ben gropenen $\mathscr{W e r f t e n}$ au, nac) Samburg unb Bremen unb Gtettin, nad Siel unb Dansig, Wilbelmsbaven und Emben! Slnd rie arbeiteten Dort bie Sounderttaujende von Männern uno Frauen, fchtwangen bie Sämmer, bliejen die Bälge, lentten bie Gळlitten, fकlugen bie Nieten, löteten Die fianten, montierten bie Gtüde, prüften bie Mafchinen, bie tleinen und groṕen, pusten uno polierten; und rubten nach beutfder Weife nid)t eber, als bis fie blinten twie Epiegel! Sie batten fhon immer gern und mit Eifer gearbeitet während bes ganzen Rrieges; benn fie füblten ja alle, es bandelte

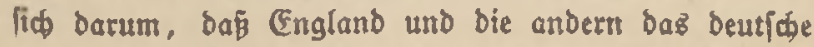


Bolf arm und Inechtij̄h mad)en, und es anfpucten mollten Gundert Sabre und jagen: "Das twar Deut jaland, früber voller Soffnung uno Ebre, jebtt weniger als einz ber fhrwarzen Walter, die England untertan!" Nein, fo follte nicts werben! Nein, gan anderb jolle es werden! Sumgefebrt follte es fommen! Wabrbaftig: Segt follte gefiegt, jebt follte Raum geihafft werben! Sa, fie batten fafon räbrenb des ganzen Ririeges, von bem erften Sag an, eifrig und feurig gearbeitet: für bie Brüber, bie an allen Landeşfronten fo unlagbar tobes. mutig unb feurig lämpften, uno auch für bic Glotte. פ(d) ja, für die treue, tapfre Flottel $\mathfrak{B}$ on der fie eincs Mlorgens, wenn lie in bie Fabril gingen, bören twïrben: fie ift nid)t megrl Die ungebeure, fofrectliche, llogige englifotse Glotte hat fie zerdrüdt! ... Da liegt fie ... im Grund ber Norbjee; und bic grünen Wogen gehn über fie bin!..." 2ber nun?! Gie batte triberitanden? Sie war wieder nad) Souje getommen?! $\$ a$, fie batte gefiegt?! Gie war befler, tüdtiger, energifder,

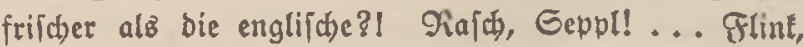
Inton! ... Gaat an, Scin! ... Rajd, rajめ)!

Rein ... Soarm Dtt tonnte teinen Slrlaub nebmen! Obgleich feinez Baterz ftillez (Bejict)t und feiner Mutter rocinende 2lugen ihn oft am Sage riefen: er tonnte nicht. Slno Eggert tonnte es aud nicht. Nein, aud) er mufte som Norgen bizz zum 2lbeno auf bem Dojten fein. Ez gab fonft in biefem Gommer viel Ullaub; aber auf peinem Poiten war viel Qlrbeit. Slnd überbies! Er muste ja boch feinen Sochmut pflegen, feinen S̈beritoly!? Muß̄te ín ftreicheln und itriegeln unb gegen bie Brult brücfen!? 
Es war ja bod fein Licblfes! (Fz war ja feine Saraft, fein Drunt, fein groß̄er, ftattlid idöner Stola! Manchem Renichen ift baz, twas feine G(t)ande oder fein Unglüd, oder fein Gebler oder feine Gdwähe ift, fein grober Gtolz! Mand)em i|t eben başfelbe zu gleicher 3eit beibez: fein Gtolz und feine Qual.

Da Eggert nach einigen Tagen einen Brief, ben

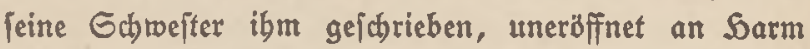
gegeben, und gelagt batte, er würbe ezs fo mit allen Briefen maçen, Die antämen - Denn er bătte niemano auf ber Welt, ber ibm mit Redt farreiben fönnte fam einez Sagz ein 3rief bei Sarm an, ben Söble Gubl icticte, Damit er ihn an Eggert weitergäbe. Sarm las ben 3 rief, und brachte ibn zur nächiten 3u[ammen. funft mit, zog ibn beraus, bebor Rameraden bingu= famen, und ichob ihn feinem 2 ruber $z u$, und fagte iđeinbar gleid)gültig: "Sier ift ein 23 rief von Söbfe Gubl für bich ... Den faunft bu bich robl übertoinden zu lejen."

Wor Eggert Ottz 2ugen ftand fofort ber grope (3arten mit ben alten, boben Objtbäumen im Ubend= fchein, und Darin, bor ben Bäumen, nidht weit vom Graben ... ja, trie bachte et ... das Räbden?... Nein, fie trar ibm zu fern und zu boch bazu ... Die junge Nutter? ... Sa, fajt feine junge Nutter ... ja, bas twar es wobl! ... im fommerlichen, weipen Rcio, bie fagte: "Gut'n Sag, Eggert Ott! Bift Du

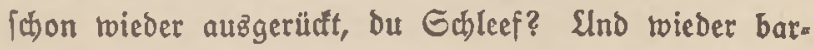

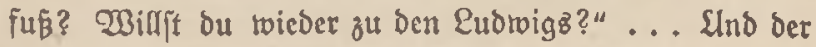
alte Peter, ibr Saglöbner, nahm die Pfeife ein twenig auz Dem Mund und fagte mit jeinem tlugen, jpöttijळen 
Qächeln: „Sajt bie 21rbeit binter bir, Eggert ... unb nun tommt dic 2lbenomulit?" Ulnd bann ftand er ein toenig, bie Eaube fwon in ber Soanb, und fie ipracben gemütlich miteinander über allez, tras ba ju Tebn unb gu bören war... pie rubig, verftändig, ein tlcin wenig nectend und angreifend, er altelug, todernit; und ber alte Peter ftand binter ibr und fog an feiner Pfeife. Slnd einmal batte er gebört, wie fie zu Peter gefagt batte: "Sd) weís nicht, wie es tommt, bas id fo gern mit bem Sungen fprede; er bat fo twas burchaus Wabres, twas fonft teiner bat. (Ex toürbe fich für bie 20 abrbeif verbrennen la|Ten roie ber alte $\mathfrak{S} u E$ in Ronitang. Sa, bas ift twabr, Peter! Du ... bu bift ia autb ein wabrbaftiger, alter Mann, aber Dow nidst po wie er. Du baft Der Gtute geftern zu biel Safer gegeben und lifgit mich jegt mit beinen 2 lugen an"... $\Im_{a}, b a s$ lab er im Beijt, ba er ib̧ren Namen börte. Es fitieg ibm ein trenig raarm unb frob ins Serz binauf. $S_{a}$, Da twar eine Etclle in ber Seimat, an bie er mit rubigem Serzen benten tonnte! Sidher, bie batte nie an ibm gegreifelt, nidat einen 2lugenblial Die batte lofort, wie fie jenes Berebe gebürt batte, gejagt: "Yerrüdt!" ... Sno er nabm ben Brief läffig vom Tij申 und las ịn. Gie labrieb:

\section{Rieber Eggert Dtt!}

Wir baben ja bier bem erfabren, baj Reimer ge= fallen ift, und es bat uns allen bitter leib getan. 2ule Rachbarn, nein, bas ganze Dorf trauert um ibn; Denn fie batten alle Das Befülyl, Daß er ein guter, feiner

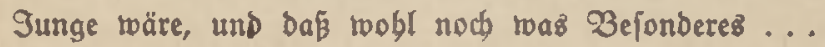


Bott tweī̄ waz ... aus ih้ getworden wăre. SIn nun ift Gonntag ... und iक fomme aus ber Sircbe, too Paftor Boblen ibm vorm 2ltar die Egrenrebe ges balten bat, unb eben, Da ich idreibe, läuten bie gropenen Bloden für ibn; und bie fleine, von ber er bie Snidhrift

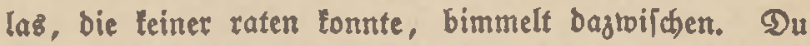
weiṕt, wie es mit \aftor $30 b l e n$ ift: wenn ber Sert, über ben er (pricht, nicht gand wetterfeft iff, mit Balten, Zoblen und Safen, bann verliert er ibn aus den 2lugen und gebt ins Weite uno 2Breite, und rebet von Dingen, bie nicht find und leiber aud nidt fein tonnen, und oftmals beffer aud nidbt find und fein follen; benn er ift ja trobl ein guter, aber tein prattifher Menid). Uljo bie Rirche twat faft boll, und rund um Deine Leute, bie bie ganze legte Bant an ber rechten Eeite füllten,

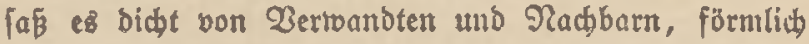
oufammengetluftert, und aud fonit traren bicle Qeute Da; und als Sanz Sotbburf ben Rranz burch ben groben Gteig trug und bor bem 2lltar auf bie oberite Etufe legte, Eggert, gleid linţ̇ von Pajtor 30 len, ba ging ein $23 e i n e n$ burch bie Rirdbe. E⿺ bängen nun aber aud fकon über breißig Stänge Da, alle gleich, im

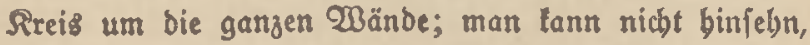
obne su treinen. Dann lan Pajtor Boblen ... ex ift mertroüroig, man mu位 immer feinen Namen nennen und fabreiben, wettn man von ibm fprid)t ober fofreibt; tein Menich in Sirchipiel fagt: ber Pajtor, ober: ber Soer Pajtor, fie fagen alle Pajtor Boblen, fogar bie Sinber ... offenbar weil er fo'n mertioürbiger Denjक ift und io einzig ... aber es gibt von ber 
Gorte bod manden, nur find fie fozufagen nidbt fo Deutlich wie er. Pajtor Zoblen blieb diešmal ganz genau bei ber Gache ... i id meine, er fonnte natürlid bon jeinen Rachttieren nicht laffen, obgleid) bie Gonne bell in bie Genfter und fdräg über ibn fiel, fo Daf man jebez feiner grauen Soare zählen fonnte... mir muß̧ten boch mit ibm in bie शacht binaus. 2lbcr wie ex fie mit Deinem Bruber Reimer zujammen= brad)te, bas rwar jebr fojön. Er jagte, er bätte im vorigen Gommer mal eine Nacht lang an einem groß́cn Seid geieffen, ant Wald in ber Soeide, unb bätte Das Rachtleben beobachtet. 2llz nun bie Racht ba= getweien wäre, wären Falter getommen über Falter... viele Sunderte ... aus dem Walbe ... von allen Geiten ... und bätten fị auf Den Scid berabgelaficu, und wären Darüber bingeglitten, bin und ber, unermüblich. Er bätte natürlich getwubt, fagte er Dann weiter, Dá́ fie oa über bem Seich im Fliegen Nabrung und Errfrijhung gejud)t uno geipielt bätten . . aber es wäre boch audy getwiß, Daß fie, röbrend fie fo über bem leife funfelnden Waller Dabinflogen, mit ibren groß̄en uno rounderbar flimmernden bunten Augen auf Das bunlle, fpiegelnde W3affer gefeben, und jeine Scimlichteit, feine Tiefe, feine Rätjel gefüblt uno gejpürt, und in Träumen jelt= fam tiefe Befüble und Gedanfen gebabt bätten: ... jo ... in Derfelben Weife zögen und flögen ftille, tiefe, jebnjü̈rige Meniळenjeclen aus bem Dunfcl und Didicht dez täglichen Rebens und Treibens heraus, und jentten Fid) berab, und flögen über ben Siefen der göttlichen शatur, und fäben im Fliegen tief binab in ibre rätfel= 
bolle, bunte Sicfe, unb grübelten über ibn in anbarbts. vollen, ftummen, ebrfürchtigen Rätfeln am Weltall unb ber Gdjapplung. Er rwolle nicht lagen, ba ein cinziger getwejen twäre, oblvobl er ein feltencr ge= welen ... nein ... es röären, befonders unter ben jungen Ereivilligen, viele Taufende gewejen, bie grü= belinb, ftaunend, cbrfürchtig, beiliger Gebnjucht voll, in

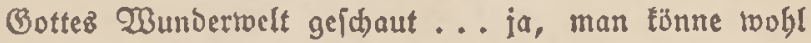
bebaupten, Daßß alle beutiden Geclen Diez Ebrfürchtige, Deuütige, Grübelnde an fich) trügen ... Necin, er wolle nicht jagen, daß in Reimer Ott ein einziger ge= fallen, aber er fei boch einer von ben 3ebutaufenden, um bie bas bettifbe $\mathfrak{Z}$ olt trauern müfTe, folange eв noch lebe ... neben ben traftoollen, fchönen, ftarfen, zufunftżs froben biele, bie feinen, zarten, fdjimmernden 3 lüten, nun von jeinem Baum geraufdt, 3cbntaujende, uns wiederbringlich verloren. So jagte er. Dann folop cr, wie er feine Rebe immer fdliejt: „2lber woblauf, woblauf! (58 bilft uns nichts ... Wir wiffen, was wir an unferm Glauben baben, und baß wir obne ifn nidbt leben tönnen ... WOir wollen glauben, daß̉ es

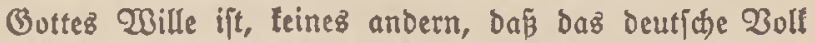
biefen $W_{e g}$ gebn muß̈, auf bem fo viele feiner Rinder fallen und liegen... ibm felbft und der ganzen Menid. beit zum zeitlichen und elvigen Seil." Go iprad) er. Du weist, wenn es ifgm glüdt, feine Gebanten bei ber Gtange zu balten, tann er trunderbar reden; und ich glaube, baß mein alter Peter recht bat, ber mich nach= ber fragte, twas mir (d)iene, ob Pajtor Boblen nicht ber Rlügfte im ganzen Land wäre. 


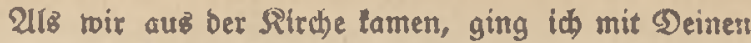
Reuten nach Curem Sauz; twir ipracben aker tein Wort miteinander; wir waren alle nicht in unz. Nur zulest, als ich allen bie Soand gegeben und reitergebn wollte nac) un $\{e r m$ Sof, lam Deine Dutter mir nath und fagte: "Du, Sosble, tönnteft bu nidbt mal an Eggert fchreiben, Daßj er auf Srlaub fommt? Gieb bod zu! Desin bu," jagte fie', "fitebjit ibm näber als wir alle miteimander; uno id glaube, bu tennit ibn auch befier !"

Ulno alfo idreibe id an Did. ... folvobl von mir autz, twie im Ramen Deiner Mutter. Rieber Eggett, Dein Etolz ift trant und bürftig. Wäre er ganz gelund, To würbeft $\mathscr{D}$ u rubig auf Stlaub bierberlommen, würbejt bei mir auf meinem Sof nobnen als mein $\mathcal{B}_{a}$ [t, toürbeit mit mir über bie Gelder und nach ber Rirche gebn, und rürbeit fagen: "Whas gebt mid ber Otfficte Sof an, und to und fo viele Nenidhen? ... id roobute bier auf bem Gublfकen Sof, unb gebe mit Sobble Gubl über die Gelomart, jebe in die Ruft, pebe ins Bejangbuch, febe nach ben Säujern ... Waz fdieten mich bie Menfiden?" 2lipo tomm uno fei mein Bajt . . .

3ruber Eggert legte ber Brief auf ben Sifd uno lagte: "Gie if ebenjo unverftänbig twie bu. Gie be= greift ebenjotwenig wie bu, Daß i申 veridiedene Befíter, bie ich fegn twürbe, in Geğen idjlagen würbe und bes̄-

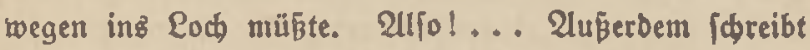
Fie, wie toenn fie meine OBroßjmutter ift..."

"Wie tannif bu nur to etroas fagen!" fagte Sarm

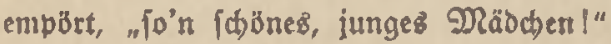




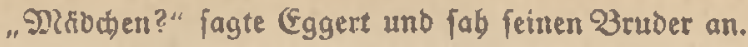
" Däbchen?! Sa, was benn fonjt?" fagte Soarm.

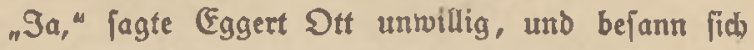
und runberte fich. "Ein Mäbrben ift fie ja am Enbe," fagte er mürri

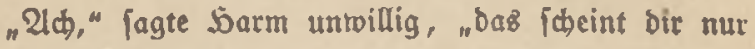
fo, tweil fie immer fo tmunderlid berftändig mit bir fchnatte, alz bu noch ein Snabe roart! Gie ift ein शäbdhen twie alle andern, uno bübich bagu."

"Warum beiratet fie benn nicht?" fagfe er zornig. "Wie alt ift fie? Gie muß ja gegen oreißig fein."

"Daş will iđ̆ bir lagen," fagte fein 2 ruber mit Würde. "Eritens bat fie ben ichönen Sof und ift alleinige Erbin; bas macht benn beibe Scile empfindlich uno unficher. Slnd greitenz ift fie von Patur etwas

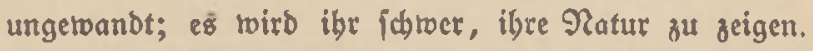
Gie seigte fie bisber, glaube id), nur gegen brei Nenf(b)n: gegen ibre Rutter, gegen ben alten Peter uno gegen bid. Sibrigens: einmal babe ich fie bod atth übermütig uno offenberzig gefunden. Sф twar einmal zufälig zu ibr binübergegangen, um eine $\mathfrak{B}_{e}$ [tellung zu machen. Da batte ibre Nutter gerabe Beburtgtag, und Da tam pie auf Den Bebanten und bolte eine Flajhe Sobannisbeerwein aus bem Reller. Gie leltert nämlich felbft eine befonders fö̉ne Urt von Sobamisbeertwein; er ichmectt wirllidy ganz mertwourbig fein unb vornebm. Wir faśen auf ber ßanl beim Goot, weipt bu: ibre Nitter und fie und id, und nacber tam noch ber alte Deter bazu. Gie liés die Glajde erit im Fimer tief in Den Goot binab, Damit fie tüblte. Sक febe fie noth, wie fie ba mit ibrer 
ichmuden, fallanfen Gigur ftatto unb ben Eimer binabs Drebte... ez war ba unter ben Bäumen fdjon bäm= merig und fie trug ibr weißes Rleio... Benug! Da trant aud fie bavon... und da, beim grveiten Glas, da fam $e^{B}, S^{(c)}$ fage bir: fie war gemüllich, red. jelig, übermütig, föftlich! Slno jo, babe id gebört, baben auch einige andre fie gejegn, fo an befondern Sagen; bcjonderz einige Mäbchen, die fie bejuchten. aber es find ronige, bie fie fo falin und die aljo wiffer, baßs fie ganz twie die andern ift, baß nur im Goot, in ben tiefiten Siefen, liegt. Benug, das

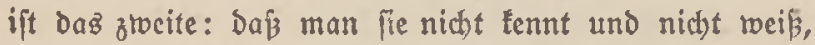
twie jung fie ift. Slnd bas britte ift, daßs fie für bie meiften jungen Qeute zu flug ift. Eie bat zu viel ge. lernt und lernt aud wobl noch... po in Runjt uno

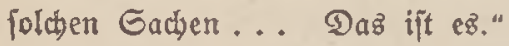

Bruber Eggent fä cine 3eitlang ftill, vermunbert und in Ginnen. Er raa ja inztrifchen ein erfabrencr

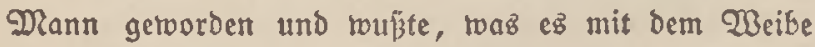
ift. Er batte aber mit biejen feinen neuten 2lugen nod nie auf feine Sugendfreundin gefelyn. Er twar tief in vertbirrten Gedanten. Dann fagte er: "Denn wirb fie wobl nie beiraten?"

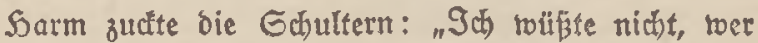

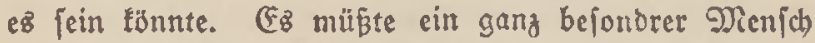
fein ... ein ganz und gar befonderer, und fo um vierzig ober noch älter, fo ein ganz rubiger, langfamer, orbentlicher Menjh, vielleicht gar ein Bclebrter von biejem Alter... 21ber bas geht uns ja nichts an! 21ntworte ihr nur balb, bafi unjre Mutter micder Deine Sandichrift fiebt." 
Er murrte ettwas ... "Wie . . was foll i d barauf antworten?" ftecte Den Brief aber ein. Rameraben famen, und fie iprachen bon andern Dingen.

Tein, auf Slrlaub fonnte roeder Eggert noch Sarm fommen. Gie bätten es̉ aud) Dann nicht tönnen, wenn fie ez getwollt bätten! Rein, ez̊ raar in biejem Gommer und Serbit eine bilde, beíke 3cit; ez mußte in biefem Gommer allzubisig gearbeitet werben. Rangen nid)t in Diejem jajrectichen Gommer bunderttaujeno Brïber an ber Gomme, ftürzten und jtarben in idrectlichem Rampf und Not? Ramen nidbt immer mebr Bulter und fielen über Daz beutfhe Yolf her, um mitzureígen und mitzu= rauben, wie fie meinten. $E_{8}$ war Stalien getommen! Ez tam Rumänien! Es orobte 2merifa! शein, wie lonnte man Urlaub nebmen! Nein, fie muß̈ten arbeiten... arbeiten... arbeiten, Tag und शacht... Daß̃ fie wieder tüchtig twurben, baj fie bem gewaltigen Geino wiberftanden, wenn er wicderläme.

גber bie englifdue Flotte fam nicht. Gie wagte es nid)t, beborzubred)en! Warum twagte fie ez nidht? Gie war fu jhiner verivundet.

Snd jo arbeiteten fie alle von Gtuttgart und Mün=

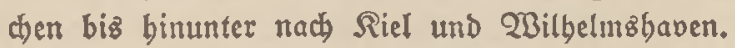

Ulı Der Sochfommet tam, da war allez roieber in Orbnung. Die ganze Flotte war rieber bergeftellt! $\ a$, Tie raar noch viel ftärter geworben! Slno war zu neuen Gdlägen bereit.

(2a bat Sarm Stt um Slrlaub und befam ibn. 


\section{Rapitel \\ Lišbetb}

C8 ror von biefem regenfwheren Gommer uno Soerbit ein jebr trüber Sag.

Der Water bolte ibn mit bem alten Gabwarzen und ber alten Gig vom Babnbof $a b$, fab ibn in jeiner Ftheuen, fitllen Weife nur tury an, fagte fein: "Na, ba bift ou ja!" und liē̃ ibn neben fid Plas nebmen und Das Pferd antraben. Yon Eggert jagte er Eein Wort. Den Soten erräbnte er nur einmal, gemiffermaßjen im Yorübergebn, fo roie man im Borübergebn einen ftillen Blid nach einem Rirchbof tut. (Er fragte: "Wirb unfer Grab ba bei euch rein gebalten?" Was joll man über einen geliebten Soten viel reben! Man gedentt feiner, indem man in Erinnerungen an ibn ber fintt, in ber Erinnerung an ibn noch einmal mit ibm lebt, und die gange Würze leines Lebens noch einmal mieder famecțt. Bon ben anbern erzäblte ber Bater, ১aß̧ fie gefunt wären. 2llz Sarm nađ Emma fragte, erfubr ex, Dáp fie räbreno dez gangen Gommers uno nun auch in ber Pflugzeit auf bem Sof von Bruber R!aus war, beffer Grau im Rindbett erfrantt und mit खeb und 2la nur einige bäusliche 2rbeit maden tonnte. "Gie ift ber 23auer," fagte ber Zater, "pflügt unb eggt, unb meltt und focht, alleż jufammen; und Dutter meint, baß fie lörperlich völlig twieder gefund ift. Slno auch ibre Geele, meint lie, ift nun wieder gand rubig. Sie gebt immer nod) zu ben Berfammlungen bei Gchufter cablers und wirb wobl eine bon 
Dicien jogenannten, Etillen' bleiben, weibt bu, eine non ben Grommen, die am Rirchgang nidut genug baben. Das liegt $j a$ freilid nicht in unfrer 2lrt unb Gamilie; fein Ott war fo, fomeit id denten fann. Zber folfen wir barüber flagen?! Nein! Dasె muß ein jeber mit fích felbjit abmadben. Findet fie Griede in biefem Glauben, fo twollen wir fie Darin laffen... Subrigens ift bein Bruber Rlaus jeit zebn Sagen auj Slrlaub zu . Gauje." "Wie gebt ez ibm?" fragte fein 3 ruber, "und was erzäblt er?"

"Du Iennit ibn ja," fagte Bater Ott. "WBenn man ibn fo reben bört, ift er immer obenauf." Slnd nact)= bentlich jegte er binzu: "Das bat ex von Rino an fo an fich gebabt. Ez fommt rookl bavon, bas er fít gegen feine Mutter webren muste, Die ibm immer etras am 3euge flicte und immer mit ihm herumftieß, weil et ibr nicht ftur genug war... und fo verfiftelte er fïh benn, als wäre er ein folcher. Wie es in Wirtlidbeit in feinem Innern auşîlebt, tweiß id nidht. Er wirb bod toobl oft genug im Eulenloch firsen... Da braupen." Dann fing ber $\mathfrak{B a t e r}$ an, mit ber Peitiche nach den eingelnen Sobfen att zeigen, wo biefer uno jenter ber Racbbarn und Betannten twäre, ob noch finter bem Pflug, ober in ber Etappe, oder an Der Front, uno ob er noh lebte und gefund räre. Alles, was er fagte, und twie er es fagte, fam now fatwerer und müblamer beraus als früber, und er fá⿱一⿻上丨 gebeugt ba und fah mit feinen ftillen, fhrerfinnenden 2ugen über bas reite, ebene, regenfuchte und fonmenloje Land. Die ganze Daubjcligtcit bes Randes in biejen ihtreren Sabren lag grenfren. Die grtiber. 
in feitrer Soaltung, in feirter Enkatye, tu Dem, was er fagte und twie ex ē̄ ausfpract.

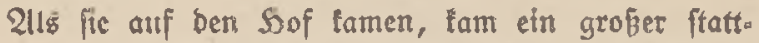
licher Mann in bunfler Sacte mit breiten roten Gtrei. fen an ben Soien aus ber Gtalltür. "Das ift unjer Kuाfe," lagte der Zater, "er beif́t Enmeon und ifit ein guter, freundictier Nenich, wie faft alle Rufien. Die Franzoien mögen wir nicht fo gern. Nandse von ibnen find mobl aud freundliche Meniden; aber viele fino unfreundlich und miderfeglich. Gie find uns auch frem. Der. 2lber bie Ruffen fino im grof́en uno ganjen roie twir felbit und gut gelitten."

2lı ex vom Wagen iprang und auffab, tam bie Mutter aus ber Sït, Sinder, twie immer, um fich. Gie gab ikm bie Sand uno lab ibn an; uno ex lah

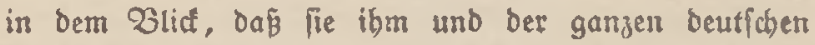
Glotte einen barten Worwurf Daraus mahte, Das et ibrent Reimet nicht mitbradyte. Gie fagte aber tein Wort non ifyn.

In ber Grube, von allen umringt, gab er noct einmal jebem einzelnen ber Sleinen bie Sand uno fragte fie Diez uno baš, rä̈brenठ bie Mutter bin- unઠ berging und bas Eflen rüftete. $\mathscr{B}$ om Soten rurbe tein 20 rt gefprod)en. 2luch won Eggert teinz. 2uber ieber erzäblte tbm, Daßi fie auf Dem Sof von 23ruber Rlaus getweien und Bruder Rlaus und Emma geiebn bätten und Daß Emma num twieber gand fräftig toäre uno auch munterer, wenn auch immer febr fith uno ernit, und toa Zruber Rlauş für grobe Dinge von Der Gront erzäblte. Das naren die beiben Lichtblicte bes Sau[es, unb bie follte 
Dee Brube:, Det aus Sot uns Fob tam, Der jeinen lieben Bruber batte fallen und fterben jebn, fofort zu formecten betommen. Dann aben fie uno verfucten Dabei, einander ju necten, und taten, als toenn fie nicht mertten, Daß Der Bater mit abtnejenden 2lugen da fá̧ und Daß bie Sand ber Rutter bann und roann über Das (Geficht fubr, Die Tränen abzuwifhen.

Ulz aber Dann ber Bater gegangen toar, um ben Gtoppel au pflügen, uno bie Rinber twieder fortgegangen waren, um auf bem Geloe Qैbren zu fammeln, und er

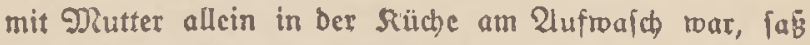
er auf ber $23 a f f e r b a n t$ uno redcte mit ibr über alleż. und fie fragte ibn mit zagender, rantender Gtimme nach biejem und jenem.

"Es fchien mir erit gar nicht möglich," fagte fie, "Daß̈ er tot jein töunte. Er ftano ja, fozufagen, den Drüter in ber Sorno, erje por Der Sür, die ins Reben fübrt."

„Sa, शutter, was foll ich bazu fagen?!"

"Soaft ou ibn tot gefebn?"

"Sa, Ditter, ich babe ihn auf bem 2lrm getragen, als er tobnund rat, und bann if er vor meinen 2lugen geftorben ... Wir batten auf unjerm Gdiff liber neunjig Tote, Diutfer, alle jung ...." "“

"Gag' mir," fagte fie meinend mit unficherer Gtimme, "was meinfit bu... to to ift er jegt?"

"Oh, Mutter," fagte er, "baran stweifle boch nidft! Wa Bott fo rounderbar uno feurig brennen tię, Das wirb er nicht auslofiden."

"W0 Denn?" fagte fie. 
"Ob, Nutter! . . Da frage bod richt! Wie viele Eterne ftebn am iveiten Simmel! Wiebiel Richt und Wunder ift in der ungeheueren Gdböpfungl"

Sie weinte und wijchte jidh mit bem Rüden ber

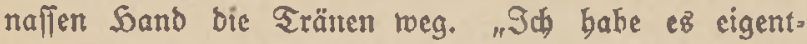
(ich) erft geglaubt, als bie (Slocten für ihn gingen."

Er jögerte einen Augenblicf, Dann fagte er leife: "Wo wart ibr da ... mo war Bater?"

Gie fhlucte an ibren Tränen, bann jagte fie: "Wir baben alle auf cinem 5 aufen gejeffen, um ben großjen Stubl am Geniter, auf bem Zater ein twenig austubt, wenn er vom Gelde fommt. Er fás da, uno da tamen roir alle gut ibm."

Gie weinte beftiger und arbeitete weiter. Dann fragte fie nach bem Raum, in bem cr geftorben toäre, und nad) bem Grab, und bibrte zu, twie er pon bem Begräbnizz erzäblte.

Sa, getwíp, bas Grab, das wollte fie cinmal lebn. "Sa ... ba rill ia cinmal bavor ftebn, Sarm, ganz

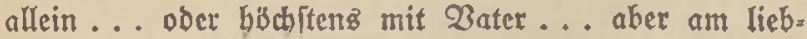
ften ganz allein!" Gic meinte beftiger. "Daz babe icf) armes $23 e i b$ boch boraus nor fo und fo siel andern,

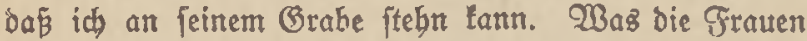
burdjmachen in biejen Sabren, Sarm, bas gelyt über alles Eagen und $\mathfrak{E r}_{\mathfrak{z}} a ̈ b ! c n$. Slnb babei ift es ja einerlei, ob

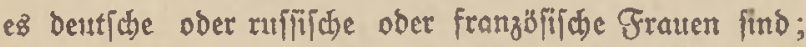
fie find barin alle gleid). Gie meinen, wir find nidat babei; und fie febn nidjt, daj fie über uns regrajen und itber uns bintreten."

Sie fbtwieg eine Weile; Dann fing fie von Eggett 
anl, und ftagte gencu nad) allen; und fab thn Dann unb trann mit ifharfem Blid an, ob er auth genau bie $\mathfrak{W a b r b e i t ~ j a g t e . ~}$

2lber er unterjhlug ibr nichts.. 2llz er oon bem wilden, fđwarzen Näbchen (prach, mit Dem er fo bäufig getangt batte, nabm jie es, zu jeiner Berivunderung, nicht fo jumis, fondern jagte: "Das baben meine Brüber auch io gemactst, als fie in feinem alter, io um zranzig, roren. Tachber baben fie boch alle gand ordentliche Mäbchen gebeirutet. Sa, gerabe bejonberz rubige und fillle; ber eine fogar cine Witwe in gejeg. ten Sabren. Sie batten robl daz Befübl, daß fie für ibre Slntul) eine Rubige, Gtille brauchten. Du jolft febn, er wiro es aud jo machen." Eg war ibr viel roidtiger zu bören, was für männlichen lmgang ex bätte; und fie war berufigt, als er berichtete, Dá er,

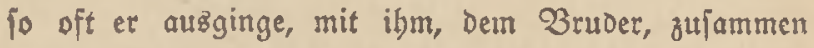
wäre, und als er ibr bie anderen ihilderte, bie bann mit babei traren: ben Simmermann, Den Staliener uno Die andern.

"Slnb was benflit bu," jagte fie, "rwann tommt er? Wann werbe i i ibn mieberjebn?"

"Wenn bu ign gern fehn willft, Mutter, fo toäre ez trobl möglich. $95 x$ müßtet einander etra in Soamburg treffen. Sierber tommt er nie mieber."

"Nie wieber?" fagte fie mit gropen 2lugen. "Nie mieber in bieje Gegend?"

(Er bob bie Gdultern. "Sth glaube nicht, Nutter. Snd id fann es aud peritelyn. Sieb, er wird in jedeut Beficht berumfragen: , (Blaubt Der, Daß̧ bu ber Pfeifer bift, 


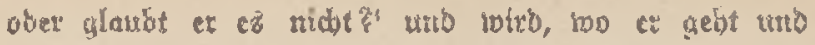
[tebt, ben Ruf: ,Sieb Da, Der Pfeifer!" binter fict Gerbören."

Gie fente fich auf ben Serd und fagte mif gebeng. tem Sopf: "Sch batte geracht," fagte Fie, "menn ber Sirieg aus wäre, follte er bei Söble Gubl auf Dem Sof fein; fie bat es ibm ia angeboten." Gie warf einen tafden, unfidern Blid auf ibren Gobn, weil fie cinen Geimlichen Bedanten babei batte. Gie batte fich früber nie jolde Bedanten gemadts. Eeit Fggert und Sable Eubl fich aber ichrieben und bie junge शachbarin auch fonft fo berzlichen 21nteil an ben Ottz nabm, wav ibr ber verwegene Gedanle gefommen, Dä́ da eine Scim. ftätte für Eggert wäre, ja, went bas Blüd es wollte, für lein ganzes Qcben. Sie tannte ja ibre Qeute, ibre 3rüber, bie in ber Sugenb io will und tounderlict getan und nachber... SAnb Söble Gubl?! .. Tunt, was wollte fie bent?... Gidier rollte fie lieber beiraten, alsz niobt beiraten. Slno war ex nicht ein

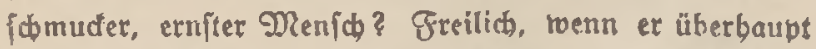
rricht mieber in bie Sheimat zuriidtommen toollte und Icnnte, bann war biejer ganze fäne Plan babin.

2lber ibr tluger Gobn Sorm bar ballig abnungs. loz. "Sф tann mir nicht benten," fagte er, "Dafi et jemals wieber bierber zurürtommt. (58 mübte fobon gnnz etwaz Bejonores geíd)ebn, fonift läß̨t er fíd biet nidpt trieber febn."

(Er molte nod mebr barüber fagen; aber er fab feine Nutter, in tiefe Bedanten verfunten, die 3ange in ber Sand, ins Geuer ftarten. Gie war mit all ibren 
Ginnen bei ibrem fernen, fornigen Gobn: waß da tooh!

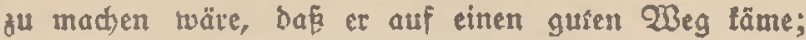
unb wie fein ferneres Leben robl fein toürbe.

2ll er $\{a b$, ba bie 2 lutter fo weifer roortloz träumte. ftand er auf und ging binaus vor bie Rüchentür und ging ums Souss, und ftand lange unter Dem Vorbau yor ber groben Sitr, wobin ber Regen nicht traf, เno jab übers Gelo, und wolte fich freucn, Das er nun endich einmal in ber Seimat träre, uno runberte fich im ftillen, baß cs ifm nidbt redft gelingen toolte.

Im andern Sage nach bem Mittagefien fagte die Dutter ou ibm, alz et trieder bei ibr in ber Sühe war und fita und wortlog berumitanto: "Du mufit ja zus ben Sbontens gehn! Du jolleft bich beute balin aufmachen unb von ba gleich au Rlaus fabren! (E\& märe ja möglich, Daf er früber wieber zu feinem Regiment zurüdberufen twïrbe. Du wirft ign boch febn wollen."

"Sa," fagte er, "ich mú ja zu इhomiens gebn." "Sa," fagte fie, "bas múst bu! Sund id weif auch, warum es bir nichet leicht mirb. SIno was ich etma nicht buste, bat thre Diufter mir erzäblt. Biel rifien wir ja beibe nicht; nut twas wir uns fo zufammendenten, und Daß ou ibr bisie bift."

"2ld, Nutter!" jagte er.

"2lch, Sungel" fagte fie in ibrer alten Soizigfeit. "Blaube boch nicht, DaE id für bid oder für fie werben roll!! Macht, was ibr troll!!"

"Run eben!" fagte er itolz und toürbig. "Ş⿻ will nidts mit ibr zu tur baben."

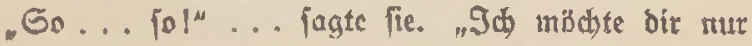


eins. fagen: fobtel th weís . . e einig roart ibr euch noch nictt! Snb bu twarft nidti ba! श2a ... und ba tam einer, ber ibr gefiel und ber um fie marb; unb da nabm lie ign. Slno num iff er tot... gefallen, wie fo biele ... tric bein 9 ruber und twie ibr Bruber ... (Ez lommt auf eins an, Sarm: ob bu bas (Gefübl haft, baß fie bich bamals wirtlich gern batte. Ez ijt eine Gache bes Gefühlz ... Dcż 23lutez, Rind."

"Ob fie mich mag oder nicht, bas ift mun ganz gleichgültig," fagte er talt. "Eేs lommt barauf all, ob id fie mag. SAnt baz ift nicht ber Fall."

"Weil bu febr boje auf fie bift, Sarm! Slno baz, mein Juuge, ift ein 3eid)en, Daß̧ Du fie immer nod lieb hajt! Slno baz iit auch ganz felbitberftändtict. Gie ifit ja immer noch Lizbeth Shomlen, diefelbe, die ou nor Jresi Sabren licbteft. 9 h) bitte bich, Sarm, bent nicht zu bart über fie! Glaube nid)t, Daß́ ez irgendein Näbden gibt, bas nur einen eingigen lieben und beiraten fonnte! Denle überbaupt nicht ju bart über Menithen! Denl an beinen 2ruber Eggert, was bem geiduab!"

"Eie roubte aber, Dá̄ ich fie lieb batte," fagte er zornig und bijle.

"Go ... Fie rußste es Dod! ... \$a, Sarm ... wher vielleidht war fie bamals noch nidht alt unb reif genug; fie roar noch) zu [piclig, ober bielleidht haft ou ez ibr nicht beutlich) genug gezeigt. (Du warit noch zu jung Daju. Der andie war jechs Sabre älter. 2aber mun bijt bu fünfundzmanjig, nun bift ou anderz, bift mebr. Und auch fie ift anders. (Fin Mäbd)en von achtzebn 
Lno eint bon groeiundroangig: it fage bir, Sarm, bas ift ein Unterichied! Tazu bebente, roas fie in-

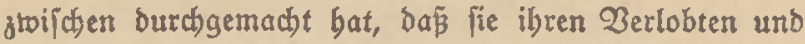
cinen 3 ruber berloren bat. Nun ... Du muñt bas alles jelbit wiffen! 2lber ich bente, ou fannit bir ges fallen lajien, baß ich mit bir barüber rebe! Bebe ich

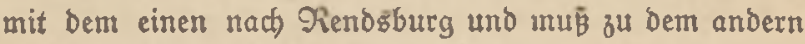
an fein (Grab, jo faun id) roobl aud) mit bir ein wentig auf bie Freite gebn."

(Er fah pie lächelno an und fagte: "Da babe idł auth nichtz bagegen, Mutter! Ganz unt gar nidbt! Uber ba ijt nun einmal nichtz zu madjen! Qisbeth Shomien lebe ich mit feinem 23lict micber an; bas ijt vorbei! Sch will bir nämlich was fagen, Mutter: fie hatte mich febr lieb! Das treís ich; das fann ich bir fagen! Ulnd barum eben war es fo fhlimm oon ihr!"

Gie lab jäh auf und fubr mit ber Sand burch ibr Saar: "Eo?!" jagte fie, "fie batte bich jehr ... jehr lieb... na Dann ...!" fie rollte fagen: , Damn biro fie es aut fertig bringen, bich wieber zu getwinnen... po tweit tenne idh Lišbeth Sbomien! ... und es ftand ibr

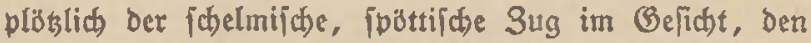
ibre Rinber fo gut an ibr fannten. "Dann geb nur! !" Fagte Fie, uno fie zeigte mit ber Feuerzange nach ber Sür.

"Sch roill beute nicht bingebn," pagte er; "beute

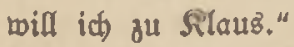

Er ging naw ber grobèn Diele und fpannte bent Gatrarzent an und fubr bavon, um feinen Brubet Rlaus zu jebn.

2lls er aber auf Den boben Weg tam, ba, too baß̉ 
Dorf Dümner woiro, und nur bier unt Da an Der Gtraß̧e und in ben Geliteru bie Siöfe liegen - es war auch beute mieber trübez, regnerif(heళ ber Thomienidbe 2 agent entgegen. (Fr fannte bas $\mathfrak{B e}_{\mathrm{e}}$ fpann ithon in weiter Gerne. Grau Sbomien, bie fonft nie felbft fuhr, fübrte bie Reine; Qỉbeth faß neben ibr. Er vrepte zornig die Lippen zulammen uno feime Ulugen murben tief; ba war ber Wagen fthon beran. "Nun, Sante," jagte ex, "feit rann tannịt bu fahren?" "2ld, Sarm," fagte fie unb biclt; "ich freue mich So febr, baßi ich did mal roiederiebel Wrillit du jut unz oder zu RIauz? WBie gebt ez bir? 2Bas baft bu allez erlebt!! 2ab! 2la! Wo iff mein Otto, Sarm, unb wo iff euer Reimer! Waßs für eine Seit, Sarm! Ob i屯 fabren tann?! Mein Sunge, was tann ich alles! Wir baben nut nod zroet Qebrlinge auf Dem Plab́, uno Dazu Den einen Befellen, Den Ulten! Daz ift alles! Und babei follen twir jwei Gduppen für bie Tiegierung bauen!"

Lisbeth neben ibre batte ibm auch zugenidt, febr

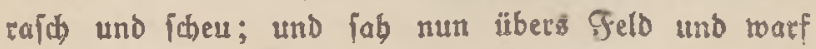
zumeilen einen blid nach ibin bin, febr tubig, aber

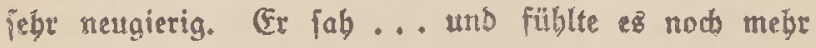
... ba Uud) ibr Beficht batte fid berändert. (F⿱ m war, als wenn es̊ etwas gröber und basurch flarer geworden twäre.

Die Nutter, die wobl belfen wollte, Daß̧ fie alle Orei über biefe erite Begegnung leichter bintweglämen, zeigte mit Der Deiffice nach Den einzelnen $50 \mathrm{sen:} \mathrm{"Uno}$ jo ift ez überall, Sarm. Sक् lage bir! Giehjt bu ba 
... ba, lint von Sanfeng Sof, ben פüngermaaen? Da ingt bie junge Grau Sormäblen brauf. Fin Ruffe läbt auf, und lie fäbrt ben Dünget auf̧ Gelo un๖ reist ifn vom $23 a g e n$. Eie hat auf ber Edyule mal Englifol) uno Granzolifich gelernt und was fonft noch alles? ... Und fiebit du da Den boben Robltwagen? ... ba fït ein 3roblfjäbriger orauf. Gein Zater fäbrt irgendro in Galizien einen Wagen mit 3 rot oder Granaten. Uno bier, fiebft bu, das ift die achrjäbrige, Heine Sochter von 3ab̧n, bie fäbrt mit bem belgif(t)en (Befangenen jur Etabt. Gie mad)t Bejorgungen unb er bilit ihr. Shr Bater iff bor Merbun, ibr 23ruber in Mazebonien. Und fiebit bu ba Das Rlaufenidhe Saus mit ben mert. würoig bellen Garben in Den Fenftern? Da ift bet Dann feit gmei Babren in Gibirien gefangen und ina befen ift bict in feinem Sauie feine Frau geftorben. Gein Land ift verpachtet, feine Rinder find zu Yer. wandten getan, Die Fenjter feines Souje vernagelt. Uno fieblt bu ba am grauen 2 eg das Sour bon Gämann? Da treten fie jedesimal bor Die Sïr, twenn ein Wagen ober ein Nienfch Den eirfamen Weg berauf. tommt, und boffen auf शad)ricbt bon ibrem eimzigen Eobn, ber in Grantreich bermint ift. Ez ift feine Soff. mung mebr, baß er noch lebt; ez iff fithon zwei Sabre ber; aber id glaube, Soarm: Fie merden noch nach stwanjig Sagren jo vor bie Sür treten unb buffen ... unb boffetl. Du fäbrif beute zu beinem 2 ruber? शun, aber morgen ober übermorgen tommit bu zu ung! Dein Ontel wiro fid) freuen, Sarm, und wir andern auch," und fie nidfe ibm su und fubr roeiter. Shre Sodjter toarf wieder 
einen langen, ernjten $\mathfrak{B}$ lid auf ibn, nidfe aud); und weg waren fie. Sie hatte bie Rippen nidht auzeinander. genommen unb ibre Qugen maten twach, aber fitll gewejen.

Er fubr tweiter. Echrectlid. ... wie fobön fie war! ... Und bie ermit nun! $\Im a$, nun toar fie fo, toie er fie damals begebrte ... verfändig uno feurig ....

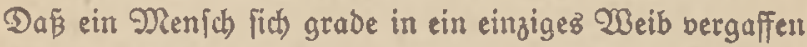

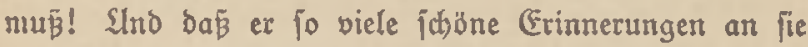
Gatte bon feinter Rindbeit an! Ginmal ... Das ftand igm plöblich vor 2lugen ... als fie jo ztölf Sabre alt getwejen und cr fünfzeln, batte er alttlug gefagt: "Sh glaube, deiut Water gibt bich mir nicht, tweil ibr mebr (Belo babt als twir." 2ber ba batte Fie ermift und bejtimmt gejagt: "WBenn id bid Dann noch lieb babe, twill ich idon

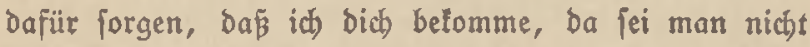
bange!" Sie batte, twern fie fo etroas fagte, fo rubige, feite 2lugen und eimen fo wunderlich) fichern 3 ug im Geficht; fie ruhte bann itt ibrer ftarten, lebenôbollen ఇatur, uno ba bernus fprach) fie fo. Sa, fie twar ein Menich voll ftartem, bolfem Qeben, Damalz fđon. Mit denfelbent 2lugen wie bamalz batte fie eben da neben ibm in ibrem Wagen gefefien. 2lif, fie trat nicht megr bie, Der er töje toarl Gie war nicht mebr bie Qadjende, bie Unernfte, Die $\mathscr{W}$ antelmütige! Gic war mun ein neuez Rätiel: noch vernirrender, noch ebroerlangender, nod begebrens. werter! 2l(t), ber Gethein um ibre liebe Beftalt war uod idbüner getoorben!

Go waren jeine Gebanfen eine ganze 3eitlang bet ibt, während er tociterfubr. Wber bann iab cr auf einem Folde zroci Ru|jen binter Pluggeipannen gefn. Da 
famen feine Bebanten wieber auf ben Sirieg. Slnd da überfiel ibn fogleich wicoer bie $3 e b r i d$ theit, bie Untub, bie er fhon geftern empfunden, als er unter bem Gd)eunen.

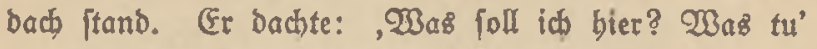
id bier? Wie tann id bier in bem fbönen, friebs lichen Lande umberfabren? Slnd nun gar über eill Näbden mir Bebanten marben?' ShD or fab im Beift, in ber Ferne, Gdjükengräben fïh Durd) bic Lanojhaft ziebn, und $a$ ab viele, biele eingelne Geftalten zeriftreut übers Gelb laufen, unto fab im Beijt frembe Gtäbte und lange Wangenzüge, und fah bie Flotte an Selgolanb votilber nad शorden fabren, tvic bamalz am lebten Maitag. (Er fab es gans betutlich), uno es rief ibn. Tlein, ber ganze Slriaub famedte ibm nicht. Slno plob; lich dachte er: Эक will beute nicht зu Bruber Rlaus fabren. Denn wenn idj ba bin, foll ich Dem erzäblen, rass id erlebt babe; und auth ex wirb mir feine Erreb niffe erzäblen. Sch will beute nidhtz bavon bören; id babe fhon Not genug bavon. Sd) will ein menig allein bleiben und auf bic Sreide fabren.'

Er blicb alfo nuf Dem großßen, breiten $23 e g$ uni fubr burd bie breite Gandid)ludbt ben ziemlid fteilen Weg nach ber Beeft binauf, und tam oben auf bie Seibe, und fubr im Garitt ben fanbigen Weg entlang, unb erging fid eine Beiflang in ftilien, freunblichen Gedanten: twie er bier als Sunge an Eonntagnachmit= tagen fich herumgetrieben unb fpäter, ein Fünfzebnjäbriger, einem alten 2lbeiterpaar ein Fuder Soide, bas fie bier gemälbt, aufgelaben uno nach Souje gefabren batte, und wie er robl aud) (päter noch, fo in Fribjabr = uno 
Sorbfttogell, Diefen Wieg gemacht, um butwh bie Beeltbürfer zu fabren. 2118 feine 2ugen Dann aber in oer Ferne die Soünengräber trafen, gerieten feine Gedantent twie bon felbft wieder in Den Rrieg. Er lab im Beift bie vielen Bräber an ben fronten, und bactte aut ant bie Soten pom Glugerrat, Die an Der jütif(t)en und (d) wediichen Rüfte begraben lagen. SAnd roieder befict ibn, twie ein gewappneter Mann, Der Bebanle: ,Was follit bu bier? 23as tuit Du bier? Rebr' micder um! Sier ift Griede... Du aber geborft in Den Strieg!"

(Er wambte das Pferb und fubr roieder nach ber Echlud)t $\jmath$, und war mit all feinen (Jecbanten bei feinen vielen Betannten in Wilbelmgbaven unb bei feinen Qeuten auf Dem Gdiff. Slns alles,, was er um fith fab, die ganze Soeimat und das Elternhaus, wat ibm nicht vorbamben, war ibm gleichgilltig, ja, rat ibm verleibet und fomecte ibm bitter. Bang in Der Gerne, in reiter Gerne, in einem untrirtlichen Blang und Schimmer, in fob̈nem פunft und Tebel, ja, Da ftanden Sheimat und Elternbaus im fonnigen, wonnigen Grieden. $\Im a, D a . . . g a n j$ fernel $\Im a$, wenn einft Frieden toüte! 3a ... Dann! Dann wollte er fich über bież allezి freuen! 2d, wie febrl 2lch, unjagbar! 2ber jent war Sirieg! und all feine Bedanten, und alle Tot und alle Freube, rebmütige, fकmerzliche Greude, moren draupen an ben Fronten und auf Den 23 ogen Der Rordiee.

2lls er nod fo fann, war er twieder bis gur Gchludit getonmen und fab Den 23 eg binunter. Ulno da fab er, leine

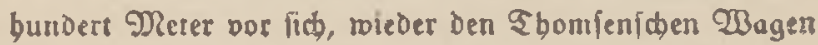
bie Galuct berauftommen; nur Qisbetb fáp Darauf. 
,Serr Gott, now einmal wieber!"

Gie bradten ibr Befpann beito ilbereifrig aus ter Gpur. In Der nähiten Minute fubren lie beibe ant. einander vorüber. Fr jab fie an uno grüste ernft uno fitlidt, tuno fubr weiter, fo in bem sornigen und ocrs mirrten Gebanten: Go ... baz ift überfanden.' Ullz et aber now nicht bumbert Gatitte gefabren soat, bürte er Ginter fich einen rechten WBeiberit)rei und gleich Darauf thre ängflliche, befeblende Stimme: "Sarm, tomm ber! Soilf mir!"

Er bieft bas Pferb an und fab fich um. Da wat fic mit bet ganzen einen Geite thres Wagens in den einige Gü tiefen Braben geraten, der neben dem $23 e g e$

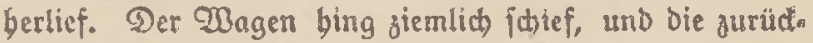
Goppenten Pferde twaren Dabei, Daś Slnglüd nod' fhlimmer zu machen. Gie jelbft toar abgefprungen uns ftand ratlos daneben.

Ex fitieg rom 2 Bagen und ging bie tleine Gtrecte

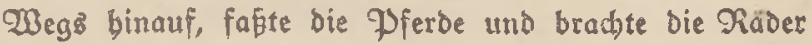
mit einiger Naüge aus bem Braben uno soieber auf Den Weg. Slm ctmaş วu fagen, fagte et: "Wie tam Derm DaE? ?"

Gie war fhon rot und fagte: "Bs tam io..." , Go! ... badte et tubl un's fold: , Du fabjt Dich nach mir um! $\$ a$, das muß man nicht tun." "शిun, fteig nut roieber auf," jagte ex, "ez ift afles in Ordx nung."

Gie twar febr rot, ba ibr baz Mig̈geidid in ber Sat gejchelsn war, als fie fich nads ibm umgefebn batte, in Der Frroartung und soffinung, auch er folte fid 
umiefn. Suno nun, ba es num fo anbers getommen war, rollte er ofute eint cingiges freundithes 2 ort roiebcr reggebn? Ez fprangen ih̆ pläbli bie Trämen in Die 2lugen.

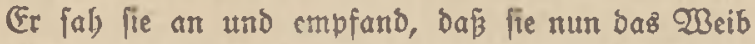
bar, ber Ramerab und Bleidagenofie, boh ber, vor bem man fich leine Blößje geben Darf, nicht einen 2lugen. blick. Crx fagte rubig und tübl: " शun roeinft bu!" "Эa," fagte fie, "nutn treine id " und bí̈ fich auf bie lippen und fab ibn an.

Er fonnte wegen biejer 2lugen nicht forttommen; er jagte fornig: "Wie fam es, Daß du fo machteft?" Gie bob leije bie fadnen Gdultern unb fab ibn rubig, wie wartent an.

"Wie fam es??" fagte er noch einmal.

Gie jab ihn now immer fo an mit Den fhönen, wartenden 2ugen, grade in feine 2lugen binein. Gie f(b)ämte fich nid)t... fie belannte fich fitll und trotsig jtt bem, was gefdebsen tar, unb wartete auf irgend etwas.

Da rif cr fie in 3orn und Liebe an fich unb bergte und füß̈te fie.

Slno Dann liéz et fie loz und fagte: "Nan geb! .... (E⿱ 口) ift jebt nicht 3eit für folche Dingc." Ulnd er gab ifre bie Sond und briatte fie feft und balf ibr in ben Wagen.

Gie jagte fein $200 r$; fie fah ign nur nod einmal crnfit und ftill an, und fubr babon.

Er felbit ftand ba noch einige 3eit, fdweratment, unjagbar glüctlid. 
"Gie ift mein! SDein! S๘b habe fie! Uch, wie

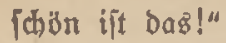

2lber gleich, plisblich, fhlug der Bebanle an ben Srieg bazmifhen. (Fr bob mit einem bittern (Befübl bie Gd)uttern: "Sirieg! Sirieg!' Slno ftieg in ben und futhr bie Gdyludjt binab und nath Sartie. 


\section{Rapitel}

\section{E $m$ ma}

Q1 $\mathrm{m}$ andern Zormittag - es war basfelbe neblige, 21 faji Dunfle 2 etter - trieb er fich twieder im Soaufe umber, ftand bier und ba berum und fab übers Feld ober liej fich diez und bas erzäblen, und twar nirgends bei ber Gache. 21m Nachmittag toollte er nun ben Befuch bei feinem Bruber machen. (Ta fant

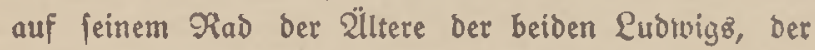
Gifcher, bie Eggertż Freunde geweien waren, beş und fagte: "Sofft du Rangetweile? Magit du ein bif̌chen fdippern? Dann foum mif nach been Safen und fieb bir mal an, wie auch ich mit jamt meinem alten Sabnt filirz Saterland tätig bin."

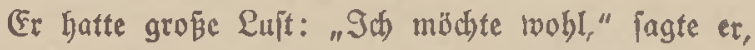
"aber ich muß notwendig z̆ meinem Bruber Silaus,."

Der Gifder fagte in jeiner lebhaften, Jufabrenden

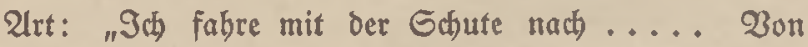
ba nad Dingerbonn find es teine zebn Minuten und bon ba z"l Rlaus teine zroanzig."

Er iprang inz Saus, bolte Den alten Regenmantel, ber da für jebermannz (Gebrauch am Gtänder neben ber Tür bing, fagte feiner Nutter 3eicteid unb war pofort auf bem Rab neben bem Rublvig. (Fs war ihm rie

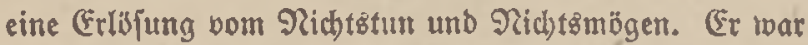
plistilid) wieder frob, ba er mun nach bem Safen follte. Oielleidft würbe er gar Rameraben febn und ein gemütliches 23 ort reden uito fragen tönnen.

Slnterwegz auf ber geraben Gtrape erzäblte ber 


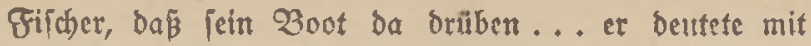
Det Sond nach Gilien... an ganz einfamer Gtelle läge, und Daß̧ er beute nadbmittag vieber eine Qabung übernebmen wolle. Gie roürben ibre Räber auf bie Gdute legen und von Borb aus rwieber beimtebren, rann ez ibnen paśte.

Gie erreidsten in einer balben Gtunde ben Safen, fubren auf ben Rai und fanden Den Eleinen Gdlepper fhon liegen und bie idwer belabene Gdjute fobon an getaut binter ibm. Die orci Männer des Gd)leppers

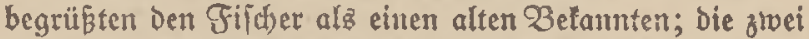
Mann, bie, biž über bic Obren in Ölrb̈cfen, am Soet ber Gaute neben Dem Gteuer ftanden uno now bies

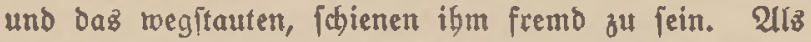
Sarm Ott fragte, was das für Qeute wären, jagte er: "Es find 2lrbeiter bier vom Ilarine= Depot, fic laben ein und aนв̈; biefe fentne idh nid)t; eร̃ find nicht imuner biefelben. - Sallo," rief er zu ben beiben binunter, "nebmt uns bitte die Räber ab." Der eine ber beiden Männer erbob fich oon feiner Qlubett - es roar ein älterer Mann mit einem rubigen, veridhlafenen Beficht - nabm Die Räber in Empfang und legte fie auf bie Labung vor fid); Der andere, fleiner uno jünger, unb, rie es fojien, etras Sinfer, blieb bei feimem Beritauen und Pacten. 2lz bie Räber binabgereicht waren, fprangen lie beide nach. Der fifcher ftellte fich an bas lange Ruber, Sarm Ott neben ibn. Der Gdhlepper madjte (iid) Ios und fam vom Rai $a b$, und fie famen in bie Mitte Dez Etroms.

(E\& twar gleich eine ftille, abgeidsloffene Welt. Mitten $29 *$ 
auf bem Grom ein Hleiterez, altes Rrtegsh hiff, einige Gduten breit und leet an Slfer. . . eir Edjleppzug ... zu beiben Eciten 2leferfelbcr und Biebmeiden, uno näber oder fermer in igren 2 äumen ftille $5 \not ̈ f e$, Heine Raten ... reci)tz por ifner in grauen Dunit, faum zu febn, bie lange, ruhig belvegte Linie der Geejt. Sarm Ott und Der Fifcher untcrbielten fich genüttich über biez und baz, toaz fie faben: ein 23oot, ein Erntefelo, einen Sof. Dajwildyen fragte ber Fildher nach Dem Tag nom Elagerral und Dem Qcben an 23ord; oon Fggert fprachen fie nicht. Der Fild ber wollte nicht babon an= fangen, weil er nicht recht munte, wic Sarm zu Feiner Familie ftnno, die bod bei (Eggertz Flud)t eine Rolle gejpiclt hatte; barm Ott feincricitz fagte fidh, Daßj ber Gijcler wupte, Daß̄ Eggert an Borb Der , Be=

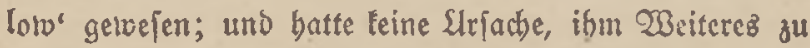
erzählen.

Sn ibrem Rürten ergäblte ber ältere ber beiben Gremben feinem Benoffen, inbem er bon beur auziging, ronz fie rund um fich faben, von andern Begenden in

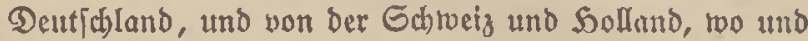
tvie bie $e^{-\beta}$ und jencz ba anders wäre. Er crzäblte in jener rebjeligen, etwas auforinglid)en 2 Itt, bie diejenigen an fich baben, bie niemals शlänner werben, bie immer Snaben bleiben, und werben lie act tzig Sabre alt, und bcimatlos und rubelos ourd) bas 2and uno durch bas Qeben wandern, obne 3wect und 3iel. Gein Benofle, ber jüngere und fleinere, antwortete mut mit einem $\Im_{a}$ oder Nein. $\mathfrak{D a s}$ Wetter wurbe trüber und regnerifder. Soarm Ott gog ben Regenniantel feft unt fids und 
brüdte bie Mühe tief ins Beficht. (Es fanm anth Wino auf.

2lı fie fo einte Weile gefabren twaren, ging ber Errom eine Errecte rocit burch einen idhilfigen Gee; uno ber Gdiffer, ber bis Dabin fdyarf auf lein Gteuer geadtet batte, jab fich um, unb bat ben Ulten binter find, ibm feinen Eübwefter bu reid)en, Der unter bem Sect lag. Der 2llte börte auf mit jeinem Berebe und

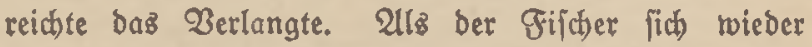
umbrebte und wie vorbin wieder ftanb, bie Sand am

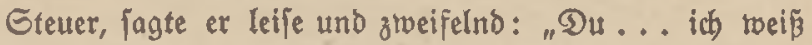
nid)t... baft bu ibn nid)t crfannt? ... Ter Rleine binter uns ... if bas nicht euer früberer Rned)t ... twie bieß er boch . . . weiṕt bu . . der Sinfer, der Mats tias 2Imborn?"

Sorm Ott fubr berum, als menn ibn einer geftochen bätte, ftarte den Gremben alt, und etfannte ibn

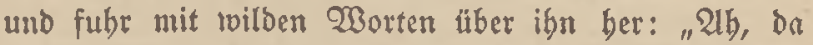
bifit $\mathscr{D} u ! \ldots$ Du $! \ldots$ Du $! \ldots$ Dfeifer Du! . . Warum bift bu gerabe bierbergetommen? ... Willift bu nod mebr Sinbeil antichten? (Dod) nicht bei uns?

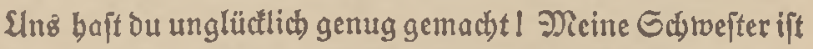
(d) mer franl getworben burdh bich, und hat nod iest feine Grcube am Qebent und wird fie wobl zeiflebens nidjt wieber haben; bas Leben meiner Gdlweiter bajt $\mathfrak{D u}$ auf bem Berviffen, du Sund! Slnd mein Bruber ift deintet. lvegen (d)redlich beid)uldigt worben von leinem eigenen Vater uno bat in $\mathfrak{S} a \tilde{\beta}$ und Not fein Elternbaus berlaffen! Sno wir alle, Bater, Mutter uno (Bejd) wifter und bie ganze Familie, find feitbem unglüdtiche, zerrif = 
fene Qeute! Das alles haft bu berictuldet! Slnd balt

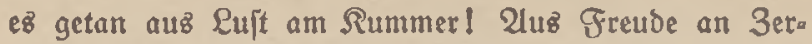
ftörung! Ober waz für ein Seufel bid getrieben bat!"

Der Rnecht fá̉ mit entiegten, bleichen Rippen, bie 2lugen niebergeidlogen; aus jeinem Dunbe tam ein langfame Gtöbnen, wie Wimmern. Der Qllte fä mit offenem Mund nebell jeitrem jungen Benoffen uno ftarrte ibn an, uno jagte bann leife, mit billig veräns Derter Gtimme: „S, Ramerab ... Ramerad! $2 B a s$ ift bas für eine böfe Rede! $\mathfrak{B a z}$ baft du für fdhtwere Dinge auf Deinem Bewiffen!"

"(Befteh!" fabric Soarm Ott, an allen Gliebern bebeno, "geiteb, Da andrer!"

Der Rnecht ermiderte mit mübjamer Gtimme, 21ngit=

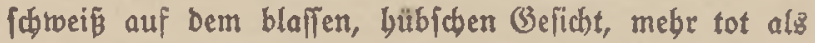
lebendig: "Sch bin erit gejtern von Röln bierbergetommen; ich roubte nicht, traz ich) angerichtet batte. $\Im_{a} \ldots$ th habe es getan ... aber bas ... das ... babe ich nicht geroollt!"

"Tu baft es gebörtl“ idirie Sarm Ott bem Fifder ชu. "Dิu baît es gebört!"

"Sh habe es gebärt," jagte Qubroig ernit, "ich bin Beuge; und id freue mich wegen Eggert."

"Dann bin ich fertig mit bir," rief Sarm Ott, fab ign noch einmal mütend und veräctitlich an, und randte fich twieber um, und fab Lubroig neben fich mit funlelnden, erregten 2lugen an, unb roollte noch ctraas jagen.

aber in bemfelben 2lugenblicf bürten fie die beiden Näuner binter fid aufipringen. Der Fiīber uno er 
warfen fich berum, in bem unwillfürlicben Blauben, baß fie von biuten überfallen würben; in benrfelben 2lugen= blič aber warfen fich Der Qltbeifer und ber Fifher über ben Rnecht, Der fhon balblwegs über 2 ord twar, bielten ibn an Sacie und 21rmen, und jogen ben fich rajeno $20 \mathrm{cb}=$ renden wieder an Dect.

"Donnermetter!" fagte Der Fifdher, "Das ging prompt," und feuchend und finfter meinte er: "Wुeipt Du, Soarm Ott... bu und bcine Qeute, ifre feid ein biß̈ben zu idjarf gegen anbre. Deine Eittern modten aud uns nie leiben, weil wir anbre Qeute find alz fie. Dáb ou biejen bier nicht magit, bas ift ja in Ordmung.

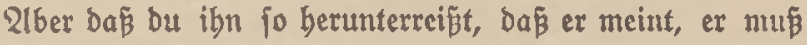
aus dem Reben jpringen, das icheint mir boch nicht richtig. Der bier ift lein (h)lechter Dienich), baz fiebjt ou beutlich; Denn fonit näbme ex fich bas nicht fo zu Soerzen, waz er angerichtet bat, Gag' ibin ein gutes Wortl Gag' ifm irgend etraz!"

"Эक) tann nicht!" fagte Soarm Dft iteif.

"(B)ut, bann fann ich es," jagte ber Fif山er. "Du bift jegt rubig" rief er, uno richtete ing auf, "und ftebjt bier neben mir, bier! Go! Und nun werbe mal vers nünftig uno erzäbl' mal: twas baft bu bamals gemacht?"

Der Rnecht vermod)te lein Wort berborzubringen; er verfuctite e8; aber feine Gtimme verjagte ifm. Endich verftanden fie, Daß er fagte, er bäte um cinz: wenn ez möglich) räre, nibdute er mit (5mma reben.

"Gelbftwerfändich if́t bas möglich," rief Qubroig. "Eclb|toerfändidi! Cobo ift Emma, Sarm? Sit fie noch) bei Rlaus?" 
Soarn Ott bié fid) auf bie lippen und fagte bifter: "W̉enn er will, fann er ja bingehn und mit ibr reden; aber nid)t länger als zelnn Ninuten, bann ift es aus!"

Der Gifdjer zudte die Gdjultern und jagte: "2lch, warum nicht länger?" unt fagte in feiner frilden, lebendigen Weife: "Gei nicht jo hart, Sarm Ott! Da a bu bich nidt verfiebit, wie Dein $\mathfrak{Z a t e r}$ fich an Eggert weriah! Man lam nie wiffen, waz einer Gache zuz grunde licgt, recißt ou, gand tief zugrunde. Sör', bas Befte ift, ifr fteigt bier aus! Sbr babt bier teine zranzig Minuten zu Rlans' Sof. $\mathfrak{L a} \mathfrak{\beta}$ ibn mit bir gelnn, unb lá̉ ibn ba mit Emma reden! Sch bin zebn Sabre älter als bu; id) rate bir gut."

(Er pfiff nach Dem Ed)lepper binüber, lię̧ balten, fog bas Beiboot beran unb lię̃ bie beiben einjteigen, ftieg felbft nad und ruderte fie an Qand. Aln einer Stänle legten fie an und ftiegen alts; ber Fija)er fubr wieder an Borb.

Die beiben anbern machten fich auf ben $28 \mathrm{eg}$. Sarm Ott grofis und fdhlant mit feiner ftolyen, berrift)en Soltung; ber Rnecht etwas unter SRittelmaß̄, etwas binteno, abet fonjt eine geichmeidige Bejtult mit rajhen, lebenżvollen Sügen im bübfd)en, bier im Norben etwas frembartigen, bräunlict)en (Beficht.

Alz lie eine Gtrecfe gegangen raarelt, twutbe ber Sinectit ein twenig rubiger. Er bolte einige Male fditwer 2ltem und jab zu feinem Begleiter auf, und jab ja roobl burch allen 3orn uno Sochmut einen Gdhein von Befintlichleit in feinem ftolzen, berrifhen (belicht; ex atmete nod einmal fdhiver auf und fragte Dann mit leijer, 
Fchranfender Etimme nach bem Bater, nad) ber Mutter und nact) ben Rteinen. Sarm Dtt antwortete mit einem furzen, mürrif̧chen Wort. Da líbieg er roieder. Nach einer $W_{\text {eile }}$ wagte er trieder anzufangen uno bat mit gróker Serglichleit, ifm zu fagen, welche Rranflyeit ez Denn bei Emma wëre, und Dann, wo Eggert benn toäre. 2lber Sarm Dtt fubr auf: "Edweig," jagte er, "fonft feblag' id) bich nieder!"

Der Rned)t bí fich auf die Lippen unb fagte: "Wenn ich es bir alles erzäble, der Reibe nach, tvie es getommen ift, fo mirft bu nicht jo bart bon mir benten, Gicher nidt!"

Aber Sarm Ott anthortete nicht mebr.

So gingen fie fidweigend ibren $23 e g$. Soarm Dtt frob, Dá̃ cr ben Ulyprung alles Unbeils twie an einem Gtrict neben fich fübrte, mit jeinen Gedanlen bei Eggert,

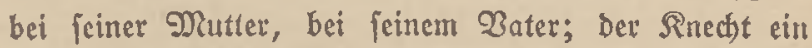
wenig binfeno, mit langen Gchritten, um mitzufonmen, nun fdweigfam, Das Befitht berionnen in tiefen, fdweren (Bebanlen, die ilym Mübe madten.

Go famen fie an bie Beeclt beran und auf ben Gand. weg, ber unter bem 2lbbang entlang fübrt, uno erreidten Den Soof.

Die Heine, fümmerliche Grau batte fie fommen jelnn und tam ihnen aus ber Sür entgegen, ihr jüngltez, vor ad)t 230 chen geborene Rind auf Dem 21 rm, die andern an ihrer Gdürze. "O," [agte fie, "Da bift bu, Sarm! 2(d) (Bott ... und Reimer fommt nicht mit Dir! Ulı Eggert roobl aud) nicht! Slaus ift nid)t zu Saule, Sarm; er ift nad) Et. Margaretben und will jebn, ob 
ex unsె eine Rub taufen tann. (Er bätte eigentlich fchon wieber bier fein fobnen; id toerbe ibm fagen, dab er unz immer vergifft. Ex bat es fo an jïh, Sarm, wenn ex feine 2ligen bon umb abtwendet, bat er uns ber geffen. Sieh ... und ba ift cuer früberer Snecht! Seipt er nicht SMattias? Guten Tag, Mattiaz!"

Ulis fie jo weit war, fah fie bie 2 critörung in ben (Befictern ber Beiben uno bactste nun endich an bie Dfeiferci, ftuthte uno jagte bedrüt: "Sommt berein uno trinlt eine Saffe Raffec."

Sarm Ott wollte ben Snecht nid)t ins Sauz laffen und ging am Saub entlang und fagte: "Shly roollte Emma furechen. Wie gebt es ibr?"

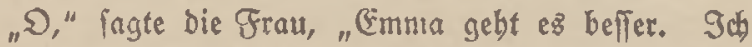
glaube, bie Gorge um mich odir bie Riebe ju mir bat lie tvieder gefund gemad)t. $2 B a z$ bat fie mir gebolfen,

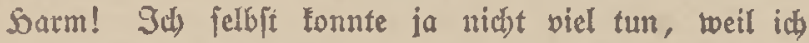
Daz Rinb erwartete; Dazu batten alle Rinder Der Reilge nach ben Reuchluften. Neit, wie babe ich bier zu. gejeften! Nein, bätte id in biejem Gommer Crmma nidht gebabt, wo toäre id ba geblieben?! Tente bir, fie bat mit uniern netten, fleifigen Granzofen die ganze Frübjabrsbeftellung bejhofft, Dann bie ganze Crnte; uno nun bat fie bie fechs Soltar an Soeibjtieg gepfligt. Eie nuв um dieje Seit nad) Saute fommen. Sie fagte beute Mittag, io um Geierabend toäre fie fertig."

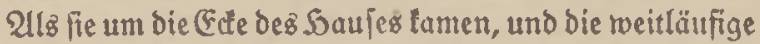
Sofftelle vor fich batten, mitibren 2 luffabrten, Sduppen unb Wagenichauern, bisten fie von ber 3 ufabrt ber, bie Durch

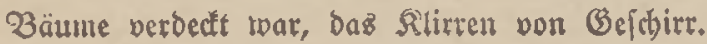


"Da foumt fie fohon," fagte Die Grau, "Dann fag" ibe man guten Tag. Sab rill unterbes̃ raịch binein= gebn und ein renig abenbbrot macben." Slnd ging zurüd; ibre Rinder um jie.

In bem 2lugenblict famen die Pferbe ausె Dem Baumgang heraus, binter ibnen ber Befangene mit feinen breiten, roten Etreifen an ber Sole. Darauf Daż zreite Gefpann mif bem Pflug auf ber Galeife, und binter ifgm (Emma in grautem, jienlich furzem Fello. fleid, über tnb über mit Gtaub bcbect, mit nacten

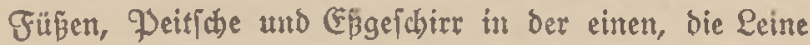
in ber anbern Sond. Eo ging fie, bie 2 ugen geientt, gand in Gedanfen, Ginter ibren Pferben ber, ben beiben Wartenden entgegen. Eie war nun ein richtiges nieber-

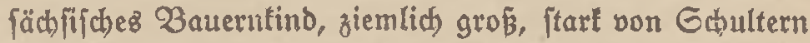

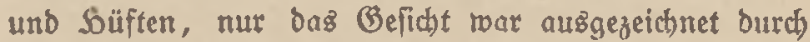
feine edle Länge unb Biegung, durch bie ez etwas 2Altes, (5oles uno Grobartiges belam, fo als wenn fie wobl ein beimlich Rinb von einem uralten, vornebmen (Befdelect) wäre. Slutb bas war fte ja audh; Denn ibre Borfabren waren intmer freie Bauern getwefen, won uralter 3eif ber. Shr Z3ruber fab bas nich). Zrïber febn Gdjreftern nicht fharf an, und noch weniger gered)t. (Er fab nur, Dá fie über ibre Sahre ernit war.

alz fie einige zroanzig Gdjritt beran war - fie waren allein auf ber Sofitelle - ibrie ber Rnedst leife auf. Da fab fie auf, und fab ifn und den 23 ruber.

In bem 2lugenblicf lag Der Sinecht fichon zu ibren Füßen: "Liebe . . liebe" . . . fagte er, unv tonnte nidst mebr jagen. 
Eie bellgte fich über ihn uno lwollte ilym etroas fagen.

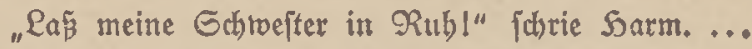
"Natn bör' an, Emma! ... Es ift fo, wie id) bir ba. mals fagte ... er ift ber Pfeifer! (Er hat ez jelbjt gejagt. Tun will er um (snabe bettcln uno fich ein= (c)meid)eln."

"Tu bift ber Pfeiferl?" fagte Emma Ott leije, mit jäher Bläffe und offnem Mund ... "Warum bajt ou Daz getan?"

"Weil cre ein Gdurte ift!" jagte Soarm Ott.

Aber fie Görte nicht darauf. Gie bob den Rtuienden auf uno wandte ibr Beficht zu ífrem Bruber und fagte: "Er foll eв unz erzäblen." Gie fap̧te ibu an Der Sano: "Romm, bu jollit ç unz erzäblcn."

Eie rief Dem Befangenen zu: "Pierre, nimm mcine Pferbel" gab ibm bie Pferbe und ging nadb bcm offenen Wagenidhuppen, jegte fich auf bie Wagenbeichlel und fagte: "Erzäbl" unz, wie ez getwelen ift."

Da erzäblte ber Rnecht, zuerft mit bebender, ftoctender Gtimme, bann allmäblich ruhiget. (Ex pprach nur zu Emma. Es twar, alz wenn er bett andern 3ubörer gänglich bergeflen bätte.

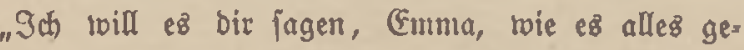
wejen uno gefommen ift ... Sch bin in füblicten Baben, bidht an ber Odhweizer (Brenze geboren. Mein Bater war ba Qebrer in einem ziemlid) groß̉en Dorf. (Er war ein rechtlicher und angefelner Mann; aber er ftarb idion, ald ich eben feine Gd)ule verlaffen unb auf daz Geminar gebn follte; meine Nutter war idon 
früber gefftorben. Da ich mun elternloz toar, fam id nach bem $\mathfrak{W}$ illen meines $\mathfrak{B a t e r s}$ zu einem Onfel, ber in Soln feinen Wobnfits batte, und nach feinen Briefen, Die er an bie Eltern fobrieb, bort in guten, nubigen Berbältriflen lebte. (Gr war aud in der Sat ber ebren. werte Mann, den mein Bater im Ginn hatte; aber fein Qeben war, was er bem Zetter immer verjblwiegen batte, jeb̆r unrubig und febr fonderbar. (Er twar nämlich Befiger

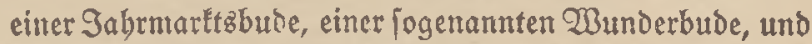
zog Damit Durch Wejtfalen, und fpditer am liebjten Durch Sannower und Gdlesmig= Soljtein. Shl war nod) ein

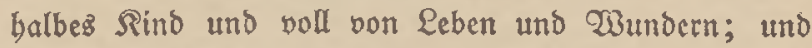
ba gefiel mir biez Dajein, zumal meir Onfel ein freund. licher Menfich twar unb an bie Wunder feiner $\mathfrak{B}$ ube fozujagen felbjt glaubte. Denn er war eill Menjid, ber immer boll Freube, Edjelmerei und Etautren twar; und toas mich anging, fo hatte id), gleich ifm und dem ganzen (Beid)led)t meiner Plutter, bie alle Gpieler und Beiger getwejet twaren, bic Reigung, ez gern zu erleben unb zu be= febn, toenn bie Menjchen genedt wurben und fid freuten und lact)ten. So lernte id) Denn mit 2 crgmïgen mancjez Gcbelmenftüa und toas barauf binaustief, und befonders Iernte id, alferlei Rünfte mit meiner Etimme zu machen. Go zog ich benn mit ibm und feiner Frau, bie mir beide wie Eltern waren, won Ort fu Ort; bis mein Ontel in einer lleinen Gtabt in Sonnover, wo wir am folgenden Sag auf einem $9 a b r m a r t$ unfre Riülte zeigen roolten, beftig erfrantte. Fr ftarb am folgenden \&bent, tvähreno burd) bie Wände Des 3eltez von aillen Geiten Die Mufif und bas Lärmen Der Menge und bie Echritte 


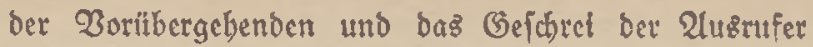
fam. Neine Sante fand biejen Tob bes Onfels natür= (ich): er ftarb, wie er gelebt hatte. Nidy aber batte bies Eterben ftill und nachbentlid gemacht, und id änberte in biefer Racht, $b a$ id an feinem ichmalent

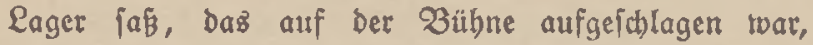

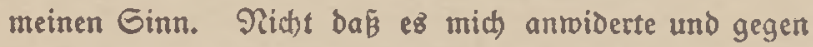
meine Ratur getwefen wäre, was ich bizber getrieben batte; aber id batte plöglich bas beutlidae Befübl: ,Gentg nun biervon! Benug! Run muß ein anorez Qeben tommen! $\mathscr{D} \mathfrak{u}$ bift Doch auch deiner Eltern Rind, Die im ftullen Dorf faß̉en und glü̈tlich roaren!' Slno ich eriunerte mich meines fitillen, vornebmen (Elternbaulez uno

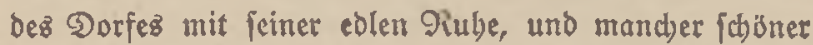
Bilder und Erlebniffe aus meinten Rindertagen; uno ids batte plöglich eine beftige Gebnjucht, biç ganze un. rubige Wandern uno dicz laute Sreiben aufzugeben. (58 rar mir roic einem Sinde, bas allein aus bem Dorfe binaugiging und fich tweiter und weiter wagte;

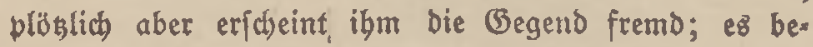
tommt 21ngit, und eilt und rennt rieder bem altbefannten Dorfe zu. (Es roar aud grabe bie 3eit für mich, ba man anfängt, ernft unb befinnlich zu rverben; ich war achtzebn. (a) fagte alfo meiner Sante meinen (Entfchluß́, bertaufte in ibrem 2luftrag, traz mir befaßen, fübrte fie nach Ristn zu ibrer Familie, und rollte mid bavonmader. Da ftatb auch fie; und id begrub fre. Gie hinterlief mir, was fie mit ibrem Mann zufammen ertworben batte; $e 8$ war nidht viel. $S_{4}$ tat $e z$ aber auf bie Epartafle bort, uno babe es feitben jäbrlid) vermebrt. 
"2l18 ich num fo gang allein in ber VBelt twar und tun tonnte, เwas ich) roollte - meine übrigen Bertwandten waren mir über meinem Wanoerleben unbetanut geblieben - bejchlor ich, an bie Plordice zu gelon; Demn von allen Randidjaften, bie id) gefebn batte, batte mir bie weite, groje Ranbfhaft biejer Begeno am bejten ge= fallen; ez bat ja ein jeber Renich in jeber Gadje peine bejondere Ricbe und Reigung. Sh) batte ben beimlid)en Plan, ich wolle mich bier in biejer (Gegend einmal nieber. laffen; ob als Ranomasun ober rie fonit, wufte id noch nict). 9 ch war aber burum nitht in Gorge, benn ich war wach und mod)te arbeifen, und verifand Das Gparen; ez folle mir ichon irgendivie gelingen.

"So machte id mich benn auf und fam an bie शorb. fee uno fab mir bie garze Riufte an, Qandidbaft und Dienjhen, biente erfit in einen Baugch häft in einer Ilcinen Gtadt, und verdingte mich Dann bier und ba alz Sinecht, Denn ich merlie, Daß̄ ich am meiften Reigung uni Freude batte, ein Landmann a fein. Go tam id benn auch) zu euch.

"Sh) randte mich am liebiften an Sōfe, auf benen biele Simber waren; Denn id batte Sinder pebr gern. Sc) founte ftundenlang mit ibnen fpielen, und bie Rinder liebten mich auch. Sch zeigte ibnen allerlet Runit= ftücle, bie ich in meinem Sabrmarftgleben gelernt batte,

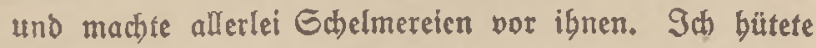
nich aber, jene anbern Rünjte zu zeigen, burch bie ich berubmt geroejen war, vor allem bie Begabung, meine Gtimme zu verindern. Nur zrocimal liés id mich Dazu verleiten. (Einmal - ich babe es bir erzäblt pder an- 
gebeutet - ba batte id mich zu cincm alten einfamen Bauernpaer vermictet, Daz, a[s id) mich ifin perdang, bie ganze Gdjar ber Sinder ifrer Todjer bei fich hatte. (58 waren lauter muntre Sinder, unb idh bad)te, id twilrbe ba gute Sage baben. 2ber am andern Sag i jagte ber ßauter Mutter und Sinber obne Brund aนz bem Saule und zeigte fich auch in allem andern fo geizig und idäbig, Daß id in einen regnerifhen Winter ichlimme Sage batte; idh reiß nicht, waz mich melyr fräntte, oet Beiz meincr 2 rotgeber voer ibre Rinderlopigteit. Benug, es ibberfam mid), fie zu verwirren, inocm id bie beiben alten Rube, die fie im Etall batten, fich miteinander unterbalten liefß. Sh babe es dir erzäblt.

"3wei Sabre fpäter tan id zu eut). Sक batte gebacht, baf ich es bei euch Eefonders gut baben toürbe. Die Rinber geficlen mir..." er jhtwicg einen 2lugenblid ... Dann aber nahm er feinen Mut zufammen, bob Den Ropf und jagte: "Sक) roill ez allez fagen, wie $\mathrm{CB}^{\circ}$ iit, unb es ift ja aud feine Edjande... I I fa fab bich, (Emma; und von ba an war id) fo glüflitit, twie id nie fuir mich mislich gebalten batte. Seder Menich bat fein bejonbres und fajt inmer merftwürbiges Gdjictial. Sa) batte fo viele Mäbchen gefebn, von Miunfer binautf biz Dänemart, uno $e B$ batte feine mir von STerzen gefallen, obroobl ich in allem toie anbre junge Männer

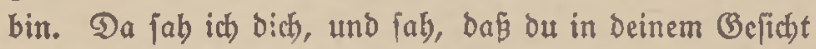
und beiner Figur und in beinem ganzen 2 ejen cinem Bilde äbulich twarft, das in unfrer Dorfitrdye auf bem altar ftano. (Es war bie beilige 2lmna, die fid) zu ifrem Rino Maria binabseugt, um ibm ein Gtücf 23 rot 
3u geben. Dicicz Bill batte ich als Rimb, als ich mit meinem Bater täglich zur Meffe ging, über bie Mapen lieb geroonnen. Neine Mutter rar geftorben und ich rourbe pon einer Rachbarin nicht aufs bejte betreut. 21ber ez muß noch etroas (Bcheimes dazu gefommen fein, eine beinliche Sinneigung und Qiebe zu biejem Bild mit feinem ernjten, edlen (Befid)t unb feiner Saltuttg über Dem Sitito. 2lls id

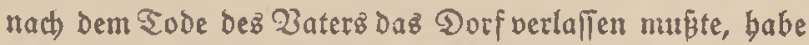
idh bie lethte Gtunde auf Den Sinien vor bem 3 ilde gelegen. Benug: als ich Dich auf eurem 50 f zum exptenmal jah, war id auber nir vor Greude. (D) marft Das Ebenbild jener

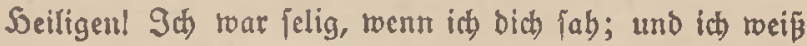
nicht... fieb, man bat $\mathrm{ez}$ ja zuweilen, daß auf einem Sof ein Rnedit breipig ober bierzig Sabre lang han/t und jein ganz̧s Qeben lang blibt - id dente mir, oft, weil or ein beimlicher und ideuer, vielleidht gat unberwufter Licbbaber Der Frau iff - jo wäre viclleicht ich immer auf euren Sof geblieben, unt wäre jo alt uno grau geworben, felig in beiner Näbe zu fein. 2aber ba fam es anbers! Sch lann nicht ganz genau jagen, ob da nod, andre Ulriachen roaren, Daß ich es tat - eine (a)lechle toar ficher nidjt barunter -; aber grwei tamn id nemnen. (Fz war ba einz auf eurem $\mathfrak{S}$ of, was mir gar nicht gefiel. Daz war, baj ibr fo für euch) lebtet, fo in Der Familie, to obne Slmgang mit andern Meniden, und fo fremo und roortfarg roat, twem ibs andre Menichen jabt. Sbr wart euch immer felbft genug, und id mertte wobl, Dap dies Benebmen nicht allein Gabeubeit, fondern audi) eine 2lit Sodnut war. \$hr wart boch eigentlid alle

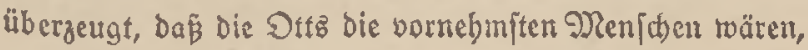


und weder Rat noch Silfe nod Slnigang nötig bätten. S(b) aber, ber ich aus einem freundlichen, febhaften Bolfzs ftamm bin und in Dem $\mathfrak{Q}$ ben und Selfen ber $\$ a b r m a r t t$ : leute meine Rintobeit zugcbracht batte, meinfe, Dá gut für euch röre, für jeden cinzelnen, wenn er mits teilfamer, zutraulicher, gefellicjaftlicher uno, wie iक) auch) meinte, bemütiger witroe. Slno twie ich bas empfant, fom mir ber Bebanle, dấ Qeuten, gut tun wiurbe, went ibr mal aufgerüttelt würoct und aus eurer Finjamfeit und eurem Gelbftifolz ein wenig berauzgetwerfen würbet. SlnD ich Dachte bejonbers, Daji $c z$ auch bir gut toäre; benn bu twarit ein fleinez einjantez, felbftgeniigfames Ding, unt $10 u$ bteft es nicht.

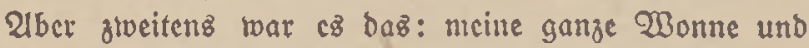
Qujt war, mein Ginnen bei Sag und bet Radt, wie id)

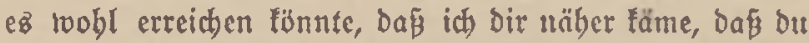

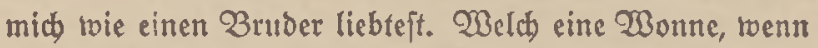
id) es erreichen tönute, wenn ich bir jagen bürfte, Da (Ebenbild jener Seiligen wärit und bas id bich aljo (4)ont won meincr Rinobeit an in meinem Soerzen getragen, uno

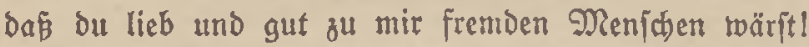

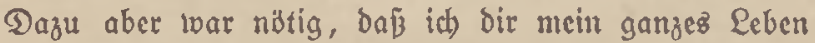
erzäblte. (Daz aber wurde mir bitter (d)wer! Denn id) füblte ja beutlich, wic bimmelweit Deine uno Deiner Ganilie 2 elt und Weltanfidst von meinem früberen Qeben und Sreiben entfernt war. (Finmal verjuthte ids ๕в, dich fachte Darauf billufübren uno vorzubereiten. Эф) erzählte bir bie Gdjelmerei mit ben beiden Rüben; aber id) ragte Dann nicht, ez weiter zu fübren. Slno

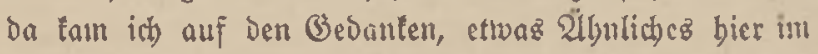


Sauje jelbit aufzuftellen. Sch badite, idh loolfe bann, twenn alle bertwirt uno genceft wären, bir fagen, wie ich) es angeftellit bätte, und twollte fo zugleich mit bir ein fleinez,, wie ich Dachte, harmlofez (Bebeimnis baben, roie auch auf biejem Wege leichter über bie Brücte fummen, Darüber ich sidh und bie 9 cinen in mein vers gangenes $\mathfrak{L}$ ben cinfübren tisnte. Da aber tam ez jo ganz anderz, fo fdyrectich. Sh mukte nidjt recht, twaz ein Eranter uno zarter Menich twäre. 2uß̄er bem 3 ruch meines Beines, ba i bofimauer gefallen twar, loar id nie franl getwejen, batte auch mit flanten Nenfd)en fcinen Slmgang gea babt. Sक rat entiebt, verzmeifelt, als ich bich $\mathrm{et}^{\mathrm{t}}=$

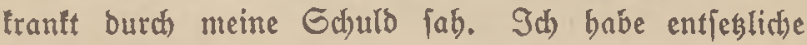
Tage perlebt; vom Mlorgen bis fum 2lbend habe id mich angeflagt. Die Rammer an bem Pferbejtall bat langez, bitftes Weinen gebört burch) die langen Winter= näb)te. $\Im_{(d)}$ gab alle meine Soffinung auf; id meinte

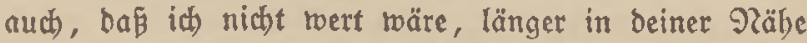
zu jein, nachbem id) burd) beine (Frfrantung bid unb bie Dcinen fo unglütlich gemacht barte; und ich rollte bich) nie roiebericlin. Slno fo, ba ich nicht belfen lonnte und nidit beilen, was id angerichtet batte, ging ict)

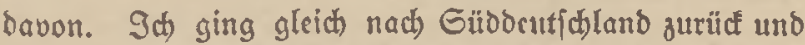
erfubr nicht, oas bu crnftlich und bauernd frant getworben

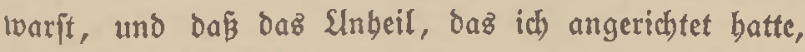
nod) vicl, viel weiter gefreffen batte, baj Der $\mathfrak{Z a t e r}$ Eggert irtitimlid) bej(fulbigt uno aus bem Sauz gejagt

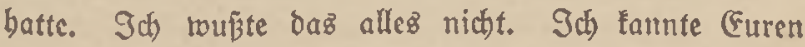
f(b) weren Ginn nod) nicht vollig! Ia) lebte brei Sabre 
in Sot und Scintweh babin, und batte feitte Frcube am Qebert. Immer bachte ich an bich zurüd. 3ulest fonnte ich ez nicht mebre ertragen; ich muste bidh bieberfebn, wie bu geworben twarfit, ob bu robl groǵs geworben trärjt und etradjen. Denn fieb, ich mú ja jest alles fagen, und ich bitte bich) um alle Seiligen, erfidriaf nid)t bavor: ith twar infrwifden ein Mann getworben, unb

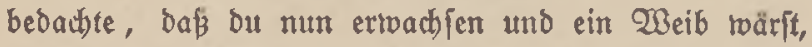
und id) ioufste nun, baß ich bich noch anders lieb hatte. Bergib mir ... wemn id bich erfdhredfe ... ich ...

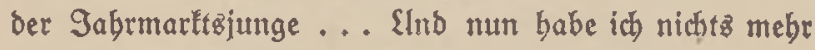
zu fagen ... Gag', baj ich wieder weggebn joll aus biefer (Gegent, fo geb' id reg; ober fag', baj idh bei bir bleiben foll, baß bu mich beffer fennen lernft."

Sie batte ibn bie ganze 3eit, wäbrend er gejproden hatte, unentwegt mit crniten und [tiflen 2lugen angejebn. शun foüuttelte fie ben blonden Ropf uno jagte idhlidt und nur vermundert: "Wie foll ich bich twegidicten? Ou bajt ja nichtz bifez getan. Slno bu bift mir lieb rwie feiner. Du warit mir immer fchon lieb."

Sharm Ott batte bie ganze (Erzäblung mit ftillem,

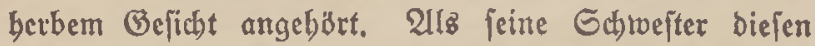
Gag jagte, fallug er bie Sände zulammen und mandte fich $a \mathfrak{b}$, alż wenn er gebn wollte. "Slnd bein Bruber Eggert?" fagte er.

Eeine Gdwwejter jab ibn rubig an und jagte: "(Ex bat uns ja nidjt unglüflidy ntacben wollen, Sarm ... Das waten twir ja felbjt... bie twir unfreundlich, fdueu, zornig, unitberlegt und vielcs andre raren."

"Nun," fagte er fornig, "bann fannft bu ibn ja 
roleber auf ben Sof fübren, und er tann wieder Sinect bei uns werben; und dein 23ruber Eggert ..."

"Эa," lagte fie, unb es ging zum crftenmal nach Sabren ein Qächeln über ibr erniftes Bejicht, "uno renn ez pfeift, werbe id nicht mebr erfhreden; und Eggert wito Bater vergeben; und Eggert tvird auch Nattiaz vergeben."

Der Bruber wandte fï ganz ab, wie ein Menfd), Der einfiebt, bas feine Worte vergebeng find: "Sh will nidbt länger mit bir ftreiten. Sd) will febn, toaz id) วu tun babe. Es roird eine bitter[üẼ Gtunbe füt Mlutter, aber eine bitterid)trere für Water werden."

Gie fab ibn mit foridbenden 2lugen an. "\$a," jagte fie, "tweil er nun reí, baß er (Eggert falich) berurteilt bat. (Es twird inm bitterbart fein. Ia, id will auds tommen und will ibm belfen," und wie ibr 3twillingzs. bruber Reimer feste fie binzu: "Sh glaube, Das tann iú." "Sa," jagte er, "wenn du bas fannit, Dann tu $e 8$ mur, es twird febr nötig fein!" Slno rwandte fich ab uno ging langiam nach) bcm Soauje zu. 2liz er abcr einige Ghritte gegangen war, ben Sopf tief in ịhtweren Bebanten uno bie Edultern bebeno roie fein 2 ruber (Eggert, tid)tete er fich toieber auf, und fah fich nach feiner Sdlvejter um, und jagte mit weicherer Etinme: "Somm noch eintge Sdritte mit; ich möble bir now etroaz fagen."

Gie fam beran uno ging tebent ibm.

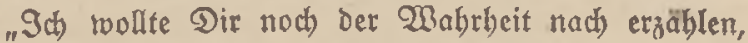
bás ex alz er erfubr, waz er mit feinem Rarrenjtüd angerichtet batte - wir waten auf dem Waffer, als id) ez ifm fagte - über Bord pringen mollte. OBir 
Gieften ibn mit brei Nann mit aller Nälye bavon zurüct. Sa, bas loollte ich bir nod) jagen! Alles toas wabr iff! SUnd bu mußst nun twîfen, was ou tuit." Slno Dann gab er ibr bie Soand, und nidfte ifr freundlicher วu und ging fopfichüttellio bavon.

(Fx ging in bas̃ Soaus und in bie Rüche und jagte

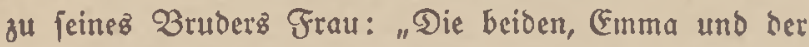
Rnedt, wollen noch ein twenig miteinander reben. Nachber laß̧ bir von ibnen crzäblen, waz fie bir zu fagen baben. Id rill nun twicder nad) Saus."

Die fleine Frau börte faum auf baz, waz er fagte. Gie beritand nur, dap er obne gegeffen ă baben, fort wollte. "Rlauz bat unz wieber mal bergeflen," fagte fie mit ibrer fingenden, unendicl) guten Gtimme. "Ev vergifít unz immer."

Er tröftete fie und ging.

2lßz er, auf ben Ganbreg zu gebend, nod einmal über bie Sofitelle $\mathfrak{a b}$, fab er feine junge Edyefter noch unter bem Tach bes Ed)uppenz fiţen. Shre Sände

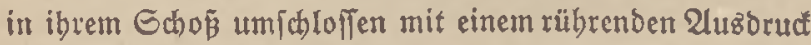
ber (Büte bie Sände bes Sinechtz, ber vor ibr Eniete; und fie rebete mit ibrer langfamen Gprache tröftend auf ifn ein. Der Granzoje itants unter der Sitr.

Ullz er bas Saltz erreidte - es toar fajon bunfel -, war ibm nudb fo wirr bon bem Erlebniz, dap ex belchlobi, bis zum andern Morgen barüber zu ichweigen. Er erzäblte Den Eltern, twaz er mit Lubwig erlebt bätte,

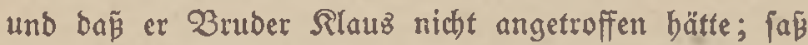
now eine Weile bei ibnen, unt ging Dann idlafen. 


\section{Siaptel Mebr Befenntuiffe}

Q1 ${ }^{m}$ andern Morgen, als bie Rleinen zur Ed)ule waren, und Der Gater, Der fchon auf Dem Geld gewejen war, aufftebn wollte, um wieber binaużugehn, fagte Soarm: "Sh habe eud noch etroas zu fagen. Shr müß̈́ genau zubören."

Stnd er erzăglte langfan und beutlid, wie er mit dem Rubrig auf bie Gdulte getommen, wie Rubwig ibn auf ben Fremben aufmerlfam gemadt, wie biefer Grembe Der Rnecht getwejen, wie Der $\Re$ necht inz Waifer getwollt und gebeten batte, ibn mit ëmma reden zu lafien, und wie ber Sinecht zu erzäblen angefangen bätte.

Die (Eltern batten atemloz zugebört, Der Zater nad) feiner (Bcwobnheit willig idstreigend, allez Qeben binter den tiefen, fpäbenden 2lugen, bie Mutter bann und wann mit furzen, beftigen 2luzrufen: "Tein Doch!" ... "S Gott!" ... "Weiter, Sorm!" "WBeiter, Sharn!" unb Dergleidjen. 2ltz er aber mit feinem Berid)t zu Der Gtelle fant, wo Der Rnecht erzäblt batte, wie er mit feinem Ontel auf Sabrmärtten betumgezogen und da mitgeipielt und befonoerz allerlei Rumlfftutute mit ber Etimune gefonnt bätte, follug Die Mutter bie Sände boch und fdyrie mit cincm feligen 2usơbrude im Bcfict: "Eiebfit bu, Yater? Eiebjit bu? O, mein Serrgott! Giebft bu? D, freu' bid) bods mif mir! D, gefegnet

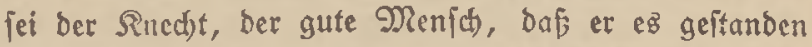
hat! $\mathcal{D}$, geiegnet jei er! $\mathcal{D}$, idh will ibu tüffen! $\mathcal{O}$, mein Serrgott! Plun ift er tein von Gdbuld! Nun 
ift biefe Rot bon illm genommen und von tulfer ganzen Gamilie und bon unjerm Saujel Bater, ich bitte bich, Dent nicht Daran, Dá bu ibn befchuldigt baft! Tein, Daran benfe nicht! Dent nur baran, baß̄ er unjकulbig ift, und freue bich mit mir, daß roir ein gutes, orbentlides Rind baben! Gieh, mun find fie twieder, alle gehn, bie ids nods babe, guter Leute Rinber! O, twenn ich in biejem Uugenblid ftürbe, wie felig rürbe id binfabren zu Reimer uno zu meinen beiben Rleinen,

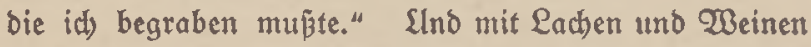
fagte fie: "Er war nicht burch feine Edsuld berloren; er ift auch braußen in ber Welt nicht verborben!"

Der Bater jagte nichts̃ ; ez̉ fiturgte zu plöglid, auf ilyn ein. Er fá mit bebenden Lippen ftunım da, toten.

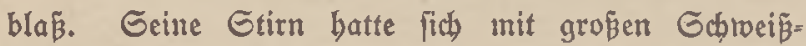
tropfen bebectt. Die Sand, Die er, alB bie Erzäblung zu Enbe ging, auf ben sifch gelegt batte, flog bin und ber.

Gcin Gobn batte fich ïberlegt, wie er ibm gur Silfe föme; er lagte rubig: „Plutter, baß Eggert ganz obne Eduld ift, barfit bu nicht fagen. (Fr bat Bater und

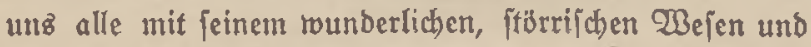
Dá̄ er immer zu Den Lubroigz lief, biel Qૈંrger gemad)t. Slno tweil es fo ftand, meil ba roobl Slrjact)e vorlag, Darum meinte Zater, Daß er unz bicz angetan hätte, biez, toaz jo bosbaft und jo fdhlecht erjobien und twas unire (Emma fo frant mad)te." S̈ber bas (Befitht ber Nutter blizte ein (Betwirr von Freude, Pitteid, Rummer und Gtol\}. "In, ßater, fo ift $\mathrm{cB} !$ Go wie Sarm es lagt! Ein Ed)lingel roct er! freilid)! Ein tüd)tiger Gdjlingel, ein lisiger IRenj(b)! 
Und bas hat ex bon mir! (Es ift meine Gduld, 3 ater ... aber ..." bic Sränen ftürzten ibr aus ben 2ugen, "ein Berborbener und $\mathfrak{B e r l o r e n e r ~ w a r ~ e r ~ n i c h t , ~}$ Bater. Da baft bu bich geirrt! Da baft bu bich wirllich geirrt." "Und bas bätte ich nicht follen," fagte Der $\mathfrak{B}$ ater mit gitternben Lippen, bie 2lugen ftarr por fich bin auf bie Erbe. "Irren ift menichlich, Bater," jagte Soarm.

"Zater," fagte bie Mutter uno fallang ben 2 (rm um feinen Radien - es roar Das etftemal, Dá̈ cin

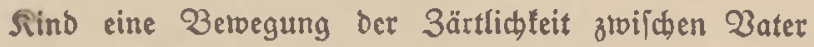
und Mutter fab -- „פ, $\mathfrak{O}$ ater ... id bitte bich ... wenn bu auch traurig bift, weil ou ibm unrecht getan

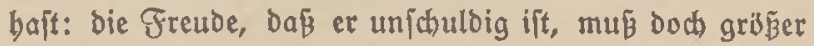
fein, viel, viel gröberl" Gie fhüttelte ibn an ben Gdultern: "Sobr bod, Zater, wach' auf! Sour' bod aนf นกฉ!"

Der Zater umflammerte ibre Sand und jagte mit

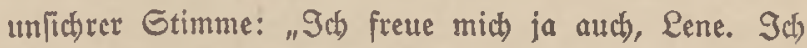
freue mich, ich fann nicht fagen, wie febr, um feinettrillen und um euretwillen. 2lber was mid) angebt, fo ift es furchtbar für mich, bas ich mich jo verfebn babe. Den einen hat mir ber Rrieg genommen; ben anbern babe id) felber mir genommen. \ah babe ein gropesz Snred) begangen, ein fel)r gropę̧, ein ganz unbes greifliches, und bas nicht vetgeben werben faum, Dafi ich an meinem eignen 3 lut fo gezroeifelt babe. Fr ift mir nun für inmer genommen. Er bird nie wieber , Zaḱer' zu mir fagen, weil id) Echlectitez von ibm geglaubt babe ... Slnd ... baz febt ibr noch nicht ... febt... nun bin id erit redit bange um ibn jelbit! ... 
Shr meint: (Es ift num alles gut! 2lber jeht, er roito mun nuch) vicl ftolzer twerben. (Fr wito fich nun zeit" Iebenz bor bie 3 rujt falagen uno fagen: $\mathfrak{Z}$ lan meinem eignen Bater und von der ganzen (Bemeinde bin id) bejduldigt uno verleumbet tworben! ... und unidyulbig! unichulbig!" Slno er johlug fich leife gegen sie 3ruit. "Sch bin roobl froh, ja, baz bin iđt, um ihn und um bich uno um unō alle. $\Im a$, baß cr num gerechtfertigt ift vor unz uno" - er machte eine Betwegung, alz wenn er baz ganze Rirbipiel vor fich bätte - "vor Der ganzen Ge= meinde ... 2lber für ibn und für mich ..." ex idüttelte

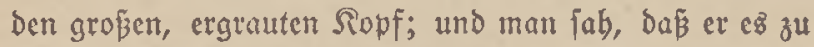
erlennen und zu verfteben verjuchte, und es nicht vermodhte. "Yater," fagte Sarm, "ich) glaube, bu mufit bicje ganze Gacke, bieje Gatuld mit Eggent und bir, tiefer faffen, Damit bu fie richtig veritebft. (ch babe ez euch nod) nicht erzäblt, was ber Rnted t jagte, wie er bazu gefontmen räre, uns den Edjabernact anzzutun. (Fr jagte, $\mathfrak{c} z$ bätte ilhn geärgert, oấ tvir, unjre ganze Familie, fo was abgeiondertes, Eigenlinniges und Sood)mütigez gebabt bätten, und er Gätte gedacht, $D a \tilde{\beta} e z$ unz gut tun würbe, wenn wir mal eill wenig ange= griffen, gefränft' und geärgert würben; twir twären nicht Den anbern Menj(d)en gleich, fondern bielten uns für twaz Bejonderes. Go ungefäbr war ber Einn jeiner Worte. Du wirit bich erinnern, Putfer, baf ich (chou banals, vor brei Sabren, als es̊ eben ge 4 d)eben war, zu Dem Refultat fam, Daß biez ber Argrumb zul ber ganzcn Begebenbeit feit lönnte; und als nun geftern abend Der, Der uns dieje Niederlage beigebradgt bat, 


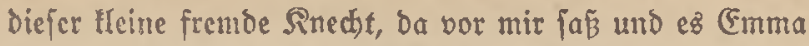
auseinanderieste, ba begriff id erît red)t, Daß er nicht unred)t batte. (E⿱ Wir Otten ... uns triffi ja twobl biele Deutiche... wobnen zu febr vor ber übrigen Menichbeit jeder in jeinem Figenen, und waren zu blinto für allez andere. Wir roundern uns zu fehr über anbre Menichen, wie fie andrer 21rt find. Wir reipen bie 2ugenbrauen zu boch gegen bie anbern Nenichen, und zwat aus Sod)mut. Dutter ift ungered)t gegen jebermann, jogar gegen ibr eigen 23 lut. Feimer lat mir erzäblt, rwie fie jogar mal auf ibre eignen Sinder gejd)olten und fid in einer langen Rete über fie getwundert bat ... da= mals am Babndamm in Nendsburg, Nutter! Gie meint, ibre 21rt ift bie einzig richtige und bered)tigte. Sa, id) weís, Nutter, daß Zater viel Mütbe von Diejer beiner Rechtbaberei gebabt hat. Du vergifit immer, Dás brüben überm Deich auch Menjchen molynen! 21ber bir, Yater, geljt ez ebenfo! शimm ez nicht bije, baß̧ ic) св jage. Da twucbs (Eggert vor beinen 2ugen auf! Du fannteft boch Mutter! Du Eannteft boch Mutterz Drei 3 rüber! $\mathscr{D}$ batteft ibre 2 eife in beinem Qeben erfabren! Du mußjteft erfennen, baß Eggert ganz

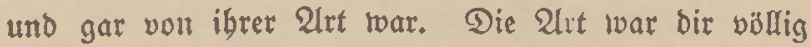
fremb. Es war baz Begenteil won beiner 21rt. Wher Lat fie nidyt bas Recht, zu exiftieren? Ober ift fie hoff= nungśloz? Sft Mutter nicht cine gute, trette Grau? Slno find ibre 3 rüder weniger braudbar und angejebn als ber Durchichnitt der Menichen bier? Aljo bättejt bu Eggerts 2lrt nebmen müffen, twie fie war. Du 
battejt fagen müfen: 2lubre Geelen, anbre 2irt, ambret Weg! Daŝjelbe bätte aud Eggert benten mü|Ten, alв er bich und beine 2 int richtete und verurtcilte. $(\mathfrak{x}$ bätte beine fo andre 21rt verfegn milifen, anertennen, leben lafīen müifien! Genug... wir Dtten, wir twaten jeber zu viel und zu jebr für uns jelbjt ba, twir ließ̧en uns jeder nur won feiner eignen Platur rafen; roir bjüten zu viel nur in unz felbịt binein! $\mathscr{D} a z$ i i grunde liegt! Daber fain daz Ulnglüct, und baher wurbe ez fo grōil Das ift mir geftern und erfit recht beute nacht lar getworben! Nicht ber Rnecht hat bie Gdulb, fondern bie Galuld liegt in unz falber. Slnd renn bieje Pfeiferei und Diefes Qeio mit Emuna und Eggert, und biefer (đ)rectliche Rrieg mit feiner grofisn Not ... Reimers Sod ... uns etras cinbringen foll: fo mú eв bas fein, baßs wir ben Menjhen zugetaner, Demütiger, gutraulid)er, gütiger werden. $\mathfrak{B}_{a z}$ aber bid) bejonterz

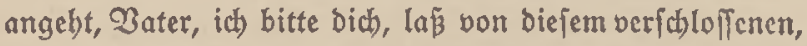

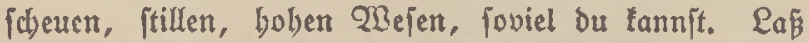
auch von biefer $\mathfrak{B e r}_{\text {ztweiflungl }} \mathfrak{S} a$, aud fie ift ein Gtüd Sochmut! Demütige bich ... vor bir felb|t! $\mathfrak{B}_{e=}$ Dente: Du bifit ein Menic); Du fannit irret. Eage zu bir: ,Eggert bat etwas Gaulb; id babe etwas Echulb, alle Menijhen baben etraz Gduld. WBas aber Eggert angeljt, fo will ich weriuchen, auch ibn ba binuterzu=

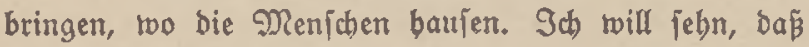
ich aud bies ftortrifhe uno bäumende Wferd sweder in unjern Gtall zurïffübre. Snd bann rollen wir bie Türen won Saus uno Gtall uno Serzen weiter aufmachen! 9a, das nüffle toir! Wir mülfen die Genfter nach 
Det Welt toeifer Bffrten, und 2 sind und Somue, tno trobl gar ben Eturm in unjer Sauts Iaflen. Sa, roir wollen von nun an hellere, freundlichere, vielleidbt bemütigere Renfthen reerden!“

Die Diutter batte fitll fitgebort, ifre 2ltgen mit Ingft und Gpaunung auf ben $\mathfrak{B a t e r}$ geridtet. (Der $\mathfrak{B}$ ates hatte bie 2lugen zur Erbe. als er nun fhrnieg, fagte er Iangiam und in Ginnen: "Sh) Dante bir, mein Gobn, bas bu bas alles gefagt bajt. F̧z ift wobl wabr... (c) glaube ... ez ift vielez wabr ... ja ... ja ...

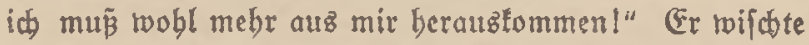

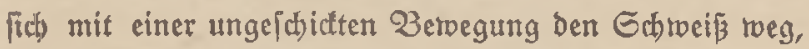
ber in grofen Tropfor auf ber blaffen Etirn ftand, und lagte mit einem (Befictst, Das bie 2lugen feiner Frau mit Sränen füllte: "Эफ) muß wohl [ebn, baß ich nod) über einige Gräben hinmeglomme. Sa . . ja ... bu haft ez wobl recht gejagt, Sarm!"

2llz er bas gejagt hatte, etjhien bie lange, ungejchidte Figur von 3 ruber Rlaus und jeiner Frau in ber Für. Fr trat in Felograu; die Salsbinde ragte treit cus dem Roct= tragen und er batte fich warm gelaufen. Gie mollten den Bruber Sorm jebn unb dic grope Begebenbeit mit Dem Rnecht mit ibm befprechen. 2lber zuerft erzäblte er pon ber Ruh, bie er getauft, lobte die $\Omega$ uhb, und mebr noch feinen Sandel, und erzäblte, wen er untermegz getroffen bätte. "2lber es ift mir in diefem Slrlaub immer fo, als wenn bie Gtimmen ber Menf(t)en, die mit mir Fpredjen, auz einer groß̧en Entfernung tommen," lagte er. "S̈berbaupt, als went allez, waz̄ id bier febe uno toas bier geishieht, nicht nabebei pier nidst roinflid) ift" 
Er war munter unt guter Dinge. "Man birb bicr nicht rearm," lagte er "bie 3eit ifĭ zu lutz, um roicoer ordentlich in ben ganzen Betrieb bincinzutwumen; uno fo byat man benn fein rechtes Soèz für bie Gachen. (Gebt es bir auch fo, Sruber Soarm?"

"Mutter," lagte bie \#leine Grau, "wie mertwüroig er ift, Daz tannft bu bir nidjt Denfen! (Fr firgt jeden Ubent, roent bie Rinder zu $\mathfrak{B}$ ett find, am Wall binter ber Echeune, balb oben barauf, bald unten mit bent Sopf drüber tweg, raucht and fudft ins Feld; und toenn man ibn ruft, fiebt er einen ganz rounderlich an, io als toenut er fich einftrueilen nod) nid)t befinnen fann, wo er eigentlich) ift. Slnd er ift boch bei Grau und Rinol (Fo ift ein mertwultoiger Menja), jage ich dir! Er jagt immer: ex vergiēt unz nicht; aber cr vergi ß̈t ung Doch! Blaubjit Du, Dak er ba braupen Seimmeh nad) unz lont? Sicine Epur, fagt er!"

Sarm fagte läbelnd: "Daz Reben bier ift ibm eben ungewohnt, Marie! Zedente bod), Daß er nun fchon andertbalb Sabr Tag und Tactit in Felde roobnt, roie ein Fuchs oder ein \$rafel Zon biejer Geluobnbeit fann er eben nicht plöglich laffen. Gei nur frob, Dab bu ihn nicht eines abcnos, toenn ou ibn fuchit, mit einer alten Gorle an ber Bacte auf Dem Bauch rut= fabend mitten auf ber soffitelle findeft!"

"शein!" jagte bie fleine Grau, und joüuttelte erptaunt Den Ropf. "Waz peio ihr Miänner Dod) für mertmürDige Menfwen!"

"Sa!" jagte Rlaus munter uno ftolz. "Tas find mirl" 
Dann fingen fic bon bem Rnecht ant. Gie bätiell ihn gar nicht zu fehn betommen, fagten fie. Emma toäre zu ibnen in bie Gtube gefommen und bätte ifnen bie ganze (Gefchichte erzäblt. Dann bätte fie ihm nach bem Safen zu Das Geleit gegeben.

Dic Hleine Frau (prach ilyre Bermunderung über bie Gache auz uno meinte, nun toürbe cs ia mit Eggert allez gut iverben. Gie batte weiter feinen Ge= Danten barüber.

Raus fubr fich mit bem roten Sajdentud) üker bie fable Gtirn unto fagte: "शlatürlich wird alles gut," und idhielte nach bem (Beficht bez Zaters und jah, Dafis ber roicber cimmal niđ)t "biż zu Ende felyn fonnte", tnie bie Nutter zu fongen pflegte. Gie batten immer alle das ftille, Dumpfe Befuibl, dañ ber $\mathfrak{B} a t e r$ am (d)werften am Leben trug. Gie fagten ez ifm aber nicht, uno (prad)en auch nicht ciner mit bem anbern barüber. Es blieb bei Dem fillen unb bumpfen Befübl uno Mitleiben.

Gie practen nod cine Weile von biejer Endse unb tamen bann auf lanbwirtichaftlidye Dinge. Bom Firieg vermieben fie zu reden. Daun ging ber Bater binaus, nach ber 2trbeif zu jebn, bic Mutter binter

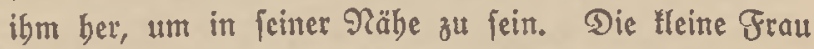
batte angefangen, an cinem Gtrumpf zu frricken, ben fie mitgebracht batte, und berfiel nach ihter Weife in cin Dumpfes Ginnen.

Da wintte Slaus jeinem Bruber mit den 2lugen uno ging mit ibm binaus. Auf ber Diele fagte er: "Raunjt bu bas anzblulten, fo immer in ber 
Gtube zu figen? शa ja, bu alz Geemann, bu tommit ja aus̊ ben Rammern uno Gtuben. Sđ) taun Daz nicht extragen." Slno ex ging mit ibm burds ben Garten bisิ an den Graben. Eeitwärţ̊ vom Graben lag ein verlotenes, lleincs Gtücf Gand uno Slntraut, Darin twar eine Ruble von Miannstiefe. Er pette fith auf ben Ranb ber Ruble, raudbte beftig, fah mit langen 2ugen über das Feld bist und fagte: „Sier roar unjer lieblter Epielplah, alg twir Rinber toaren ... und nun firze id biet rieber."

Soarm börte nidht auf bie Woorte. (Er mar mit feinen Bebanten bei feiner Gdblociter und pagte: "Sch habe ben (Eltern noch nid)t gejagt, Dafi (Emma den Snecht licbt, und zroar ïber alles! (Es ift ficher, Daj fie ithn beiraten twirb. Dent bir!"

Slaus legte fich lang bin, ftüßte Den 2 lim bequem auf ben Rand Der Siuble und fagte gemütlich: "Ratür= lich twird ez fo tommen! Ulnd warum nidts? $\mathfrak{L a} \beta$ fie Dod)! (Er ift ja ein fdhmucter, Efeiner Rerl. SAno Daß ex tein Siefiger ift, und Eatbolīh), und bier Sned)t war...

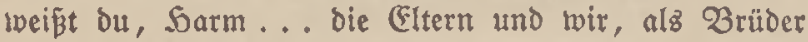
... twir müffell unz eben befbeiben. (Ez ift fo twie mif ben Pferden bei Der 2lrtillerie! 3uerfí, al\$ ber SRrieg anfing, batten fie bas fhïnfte Borbergejchitr. Du bätteft es nux febn follen! 21lles fein uno bübjh)! 2lber nun ift alles bürftig, geflicft, und bei ben meiften fehlt esz ganz. . eill biscben von verbrauchter Srenje, bas ift allez! Ulno io ijt es überall. Esz ift alles bürftig getourben. Ulnb am meiften an jungen Männern! Wenn fie ben Sinecht beiratet... toenn fie ibn licb bat ... gut?" 
Sarm biß fich auf bic Sippen. (Ez war feinem $E_{t a l}$ febr hart, unb er fdrwieg lange. Aber bann iiberbadte cr, twaz ihm ber 3 ruber gejagt batte, uno ç fóicn ihm, alz reun ex recht bätte.

"Giel," fagte Rlaus, unb peine Gtimme toantte, "wenn bu ba brausen bift, da an Der Front... traz

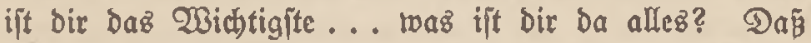

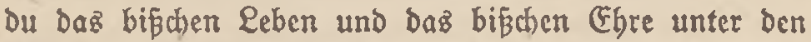
Siameraben baft! Das ift alleş! 2llles andre ift Rebenjacte. Laß fie biejen Mann nebmen und Rinder bervorbringen! Wir brauden Rinier. Gage audh nicht, Daßj fie ou gut für ihn ifft qBeifit bu ... fie iff etroas feltiam, bas ift bod) Hlar! Sie fteht jozulagen ctraas abfeits in ber Ecfe ber $\Re_{\text {enf }}$ b) beit. Er aber if ibr Gegenftüc. Er. Ftebt vielleidit cin wenig in ber cntgegengeicsten Effe. Gich, unb das ift gut! Go verben dic Sinder, bic von ibnen beiben entftebn, wieber mitten im Qeben fitehn! Wialft bu bich aljo grämen? Qeben... Bruber! Das̉ if́t eș! Taz ift in biefer Beit allez."

Sarm fiel ber fo ganz andre, fbiwere Son auf, mit Dem Bruber Rlaus fprach), und jagte: „Es war wohl fojlwer ... Diejen WBinter, ba in Galigien?"

23ruber Rlaus atmete bod auf unb jagte $b c=$ brüft: "Fs liegt ja woobl fo in ben Deutid)en, Daß wir mebr leiften wollen, als wir fömen. W3ir waren alles ältere Qcute und fonnten nidtit vid ... unb fo übernabmen tvir unz immer. Wie iđwer if bas $\mathfrak{M a r}=$ fhieren im polnijhen Gano, Sarm, mit ber ganzen $2 \mathrm{e}=$ padung! Sd) fage bir, da fiebjt bu in manches Geficht voll Frenfien, Die Brllber. 


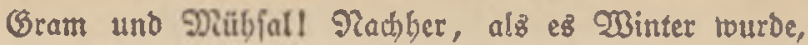
fa)leppten trir uns mit ben großjen Baumftämmen uno ben Gandläđen $a b$, bom 2lbend biż an ber Morgen. Ulnb bann fam ber bobe Gdnnee uno es murbe bitter

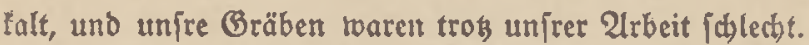
(5z war fdlimmer, Sarm, als bie Güubje und es batten, bie in ber ఇacht vorüberftrichen. 2(ber trir alten Rerle bilfen Dic 3äbne zu[ammen; wir Dadsten: c8 gebt fürs Baterland, und wir müifen fteben uno ausbalten. Da brach mander pon unz zulammen ... Ulno Dann famen bie wilden 2lngriffe." (Er ichüttelte Den fhon eişgrauen Ropf uno fagte leife: "Wir tonnten unire Soten nidt begraben, Sarm; wir batten teine Seit, und bie Erbe twar fteinig und gefroren... Wir ftapften über fie tweg, unb tocnn uns bie Rnie nicht mebr trugen, legten toir uns neben fie. Ando igre

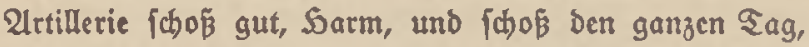
und twir fapen und ftanden $D a$, und bachten: , Srifft ber

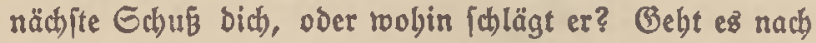
Sott, trann Dann? (Bebt es nach Dem 3ufall, wann Dann?' Ind Dann, To in ber 2bendoäumerung, wenn wir tobmübe waren von 21rbeit, TBacten und Frieren, Danı prongen fie brüben aus ibren langen, langen Bräben ... fo reit wir feben tonnten... und liefen beran. Dann rutrben wir lebenbig. Wir fprangen auf uno fhrien. (E\& twur ba nur wenig bügelig. Wir lonnten fie falt immer febn uno immer fbiefen; uno fie rarfen fid bin und lagen und fholfen; und wir fdrien und fatofien gegen fie an. Slno meiftens tamen fie nid)t bis an uns beran; fie gaben es att; und trohen twieber zurüdf; 
unire (Geldolle, uber uns weg, follugen tradtent in igre liegenden und triechenden Reiben. 3reimal aber famen fic boch beran! Snire Orabtwerbaue, weift ou, waren zu bünn und zu jकlecht und itanden nicht orbentlich. Gie tamen beran, und tamen bindurch. Ta iprangen twir aus den (5räben ... id aud), Sarm! Эa) bin tein Soeld, reipt ou .... ich babe nie an strieg geod)t, ich babe nie cin Sier töten tönnen... aber id iprang aut mit berauz. Wir fdbrien - wir fino ba alle platt. Deutich, einige Somburger barunter - : Soaut Gdiet börn אiopp!' und bann auf fie. $\mathcal{E}_{\xi}$ twar ein graufiges Gdreien. Sd) bergeffe nie fein (Befitht... id meine ben, ber auf mich zurannte... er toat fidon atemloz uno ganz von Ginnen; mein Rebenmann tat ibn ab ... mein Ticuenmann ... Go lagen wir da adbt 2 Bochen lang, und ftarten über das weite, frembe Pand, in Den Sod und Seufel baujte und allez Entietzen, baş bu bir benten tannit. W3eißst bu nod) ... a als Rinder batten wir folch Braufen ... unjagbar . . we wetn wir Dachten, in einer fchlimmen Gturmnad)t über bas

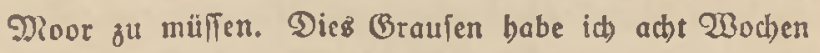
lang getragen. Slno auch jest, two wir in rubigerer Erellung lagen, da bei 2 reft = Ritomst berum ... twenn nachts über die meite (Ebene in Der Gerne ... tweithin ... ber belle Feuerichein liegt, io ift uts allen, als nenn twir am Fand Der Frbe lägen und por uns ift bas Reich ber Qual uno aller fichreflichen uno unmenichs lichen Dinge. Slno fo ift es ibnen ba brüben - idf meine den Ruाাen - wobl audb. Der Sirieg, Sarm, ifit von Gott gemacht, DaßB Die Menjchen micoer Das Fürchten 


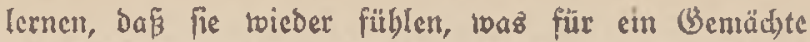

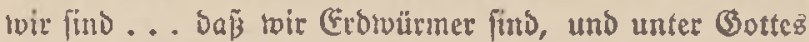
(c)recutitichen Sänden."

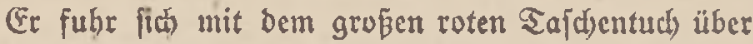
bic table Stirn und bas fhon graue Saar, und ftarrte vor lich bin. "Da bei Elagerrat," fagte et, "battet ibr robl aud einen fdweren Sag! Slnd ibr babt es ja injofern ichlimmer, als ibr nicht auf bie Erbe fallt, renn ihr fallt; über eud) und unter curd ifit ber Tob. aber fo idhlimm wie wir habt ibr ez boch nicht. Weil ibr eud nicht io nabe fommt, Sarm! Tas ift

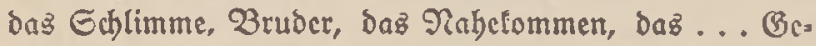
ficht in (Geficht! Das gebt über Menfdyengefübl. Slno wanm jull bas allez enden, Sarm? Gic find zu viele. Wenn

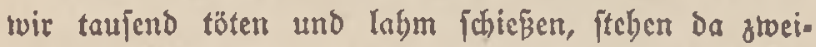
taujend Teue an ibrer Gtelle. Wir aber, twir fino immer wicber biefelben, bie voran müffen. Wenn wir einige Wochen lang gerubt baben, müjīen wir rieber nad) born, uno wenn wir cinige SRonate feine $\mathfrak{B}$ crlulte gebabt baben, Dann werden wir auf bie Baljn gejekt und Dann wiffen wir fhon, bann beipt ez: twir follen un bie Gtclle, two bie Flamme am bỉchiten ialägt." Er atmete fdiver: "Ia, jo ift es! ... Noch fieben Tage, dann ftehe id wieder irgendro .... irgenbwo... am Rande der Eroe, und farre in baz Reich ber Qual!

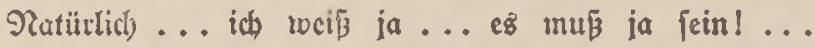
Gelbjterftändlićn... ez muß fein jo! Dariiber jage

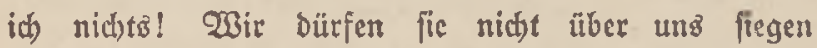
lafien ... fic fräfen unz ja mit Saut unb Saaren ... Qbei id)wer ift eg, Bruber Sarm." 
Go redete Bruber Rauz. Gein Befiht, von Gommen. brano uno fdyerer 2irbeit ifton vor bem Rrieg gefurdit und verwittert, twar jełt mitbe und verfallen, und feine Zlugen faben aus tief zujammengesogenen Sb̈blen pet. 3trcifelt in bie Ferne.

Eie idwicgen lange. Dann fragte ibn ber $\mathfrak{B}$ tuder: "Wie ift eş ... hajt bu da ein paat Rameraben, die bir näber ftebn?"

Bruber Rlaus bachte nach; Dann jagte ex in ber= jelben langfamen, lebenzfremben 2lrt: "शäber fteljn? Wir fethn uns alle gleich) nab, \{0zujagen Gdulter an Gdulter geprejt ... 2lber bod ... ja . . . ez gefiel mir einer, cin Rleiner, aนż ber Begend von Kendsburg. (E⿱ toar ein Qcbrer, unb ein Elciner, bürftiger Nenih. 2lber ex ift gcfallen, Damalz, alz wir auß ben Bräben mū̃ten. Er jagte zu mir: ,2Beift bu, Ott, fagte ber tleine, fitlle Dienfक, ,id) bin ctroas turzlichtig; id fann nicht gut ichiefen, und fechten tann idh atth nidht. 2(ber, fiebjt bu, ics bin Lebrer, und von einem Lefrer erwariet man, bab er ein gutes Beippiel gibt. Ulnd po habe if mir gebacht: iđ tann einz: : ich tann alz erfter auz bem (Braben fpringen und voranlaufen; ;a, baz fann ic), unto bas will ich) benn auch tun. Sinb renn ich bann falle, fo babe ich boch aud) toas für mein Yaterland getan, fo \#rin und bürftig id bin.' Eo fagte er. Ulno to machte er es benn aud, Der tleine Rerl ... Er lici voran. Llnb ba befam er bie Rugel ... (ir batte Frau und Rind."

Sarm rofpte tein $\mathfrak{3}$ ort bu fagen. Der Sammer bez ganzen Rriegez batte ibn roieber willig in Den 
Sänben. (Et ftano auf uno fagte: ${ }_{n}$ Slomm, laßj uns tricber zul den Grauen gebn."

Tach einer lurzen Slnterbaltung bei Silib gingen Sitas unt feine Grau wicder nach ibrem Shof hurüc.

21m Nahmittag war Das id Bne Wetter miencr Das bin; es regnete roieder; und frarm Ott mukte nicbt techt, waz ex mit dem ₹ag anfangen follte. (Fs war ibm, alв̈ wenn er nun allez beiebn und bejorat hätte, was et bier gu tun batte, uno dá̉ es bas beite wäre, ja, Daß cinzig Rid)tige, er ginge wieder Dabin, toobin er gehörte, auf baz großje Gdiff und zu feinem Doiten und zu 3ruder Eggert. Er ftand eine Weile bei Dem Bater, ber an einem boppelicharigen Pflug banticrte, und banach eine 3eit lang bei ber Nutter, die im ricielnden Fiegen, einen alten Gad über Die Gdultern, Sartuffeln für זen aniern Nittag aušnabm. Dann ftand er noch eine 3citlang in Der Sammer, tro bie Rinder bahei roaren, bem Ruflen, Der fich einen eben verlesten Finger tüblte, mit Silfe ber Gibel ben exften Unterricht in Der Deutifhen Evrache zu geben. Die Llnterbaltung mit ibm ging ichon gang gut. (Er itano, uno lab ibnen ju, und tat auch einige Fragen an ben Befangenen; und ta ging eine Wrcile: Ramerad bin und Ramerab ber.

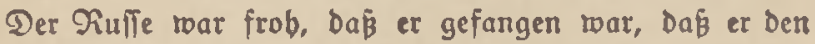
Sirieg binter fich batte. Er batte bell $2 \mathrm{rm}$ um Die Rlcinfte gelegt, Die tleine rotbaarige Wiebte, Die zu= traulicb neben ibın fáb.

Dann ging er vor bie Sür und ftand ba lange, wäbrend der Regen binunterriefelte. Er fab nac ben Sisfen in Der Ferne und Die ganze Breite Dez Dorfes 
entlang unb in ber Gerne nad ber lleinen Etabt. (Fr rofite nun, wer im Gelo, wer verwundet, twer gefallen war, und empfand, roclche beife Rot, berbzerreinende Qual, bangez Soffien, qualoollez Gebnen unter all biejen (Dächern baufte. Die ganje Soeimat twar bbe: Die Nänner im Felo; bie in bet Soeimat geblicben, bedrüctt uno unrubig; bie frausen in Mäbe uno Qual; bie Rinber verwirrt uno veritïrt, fo alş fiäfen bie (Erwac). Fenen, bie bicien Rrieg betrieben, tief in Günden! Snd er Dachte wieder: ,Rrieg! ... Rrieg! . . Gei nicht frob! Lact) nicht! EDad) tcine Pläne! Gicbe, es bat teinen Ginn! (Ez ift ja lein Nen[chenleben! Die Siugeln fliegen!"

Er berlebte nod fieben Tage fo, ein rubiger, teile nebmenber, freunblidber Gaft. 2lber feine Gecle unb fein Ginnen waren im Rrieg bei ben fämpfenden 3 rür bern. Alm zebnten Tag verließ̃ er micber die Seimat, gefáten Nutes, an fcinem Scil feinem 20 olt zum Fricben zu verbelfen. Bruber Rlaus war (d)on einige Tage vorber abgefabren. 


\section{Sapitc! \\ U 233}

9) Iร Sarm Ott in Willy fiđd, Daß̧ er mit feinem 3ruber nicht mehr auf bemfelben Echiff twar. Eg twar ba eirte Beränberung eingetteten. Er fand ibn aber aut anbrer Gtelle, und ging mit ihm in bic Stadt und crzäblte ibm fofort auf ber Giraße bas 2 efenntnis bes Rnechts und Dazu aud) die jelige Greube ber Mutter uno bie Not beż Baterz̃. Danach erzäblte cr ilbm auth, wie er alles übrige angetroffen batte, und was cr von Ermma uno Slaus uno Den Rleinen Gutes zu bericbten batte. "Slnd nun," jagte er zulegt, "fdjeint mir, fannjt bu bids in Altenfiel wieber Febn Iaflen. Der Rnectst uno fie alle da jorgen Dafür, Dá bie ganze Eache fo befannt wirb, wie fie gelvefen ift. (Es bält bich aljo nun kein Dleníh melyr für Den Pfeifer."

Bruber Eggert fiteilte fïh, Daß̧ man fürchten fonnte, er ficle bintenüber, und fagte ausbrechend unb bod). muitig - man börte ordentlid) bic twilde Greude in fcinen Worten: "2llerbings fann ich mich jest roieder febn Iaffen! Sa, ich will mich fogar mieber felyn laffen! Gobalb ich nur Slrlaub befommen fann, will ich bin! Sch) will midh ben Qeuten zcigen, und will aud am Sof vorübergefn, ben Eicbentweg entlang! 2lber web bem Nenichen, fage id) Dir, ber es rogt, mich anju= reben ober mir auch nur zuzuniden! Sal werde bie 2ugen aufreisen und ibn fragen:, 5Jaben wir Echweine ottlammen gebütet? Goviel ich tweip, nicht! Sक tenue 


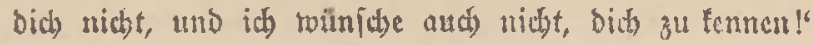

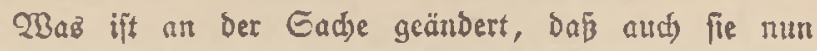
wiffen, twaz ich immer fwon toute, nämlich, Daß̧ ich es nicht getatt babe!? Das Edlimme, das ßerruchte, Daz Ulnerträglic)e, Daz Zerrüctmact)ende ift, Daß fie ez geglaubt baben! Daß́ fie geglaubt baben, id ... ich .... wolle meine Familie unglüưtich und verädttlich madten... ich ... id l“" (Er rollte lagen: Der für jeden einzeinen von eudf fiebenmal burdiz Geuer gegangen wäre! Er ichlutg fich bor bic 2 rujt umb twar fo Iaut und rillo, bá Etimme bat, boch jitller ju fein, baj bie Late nidhts mertten. "Эa, ja, ida will jest binl" jagte cr. "Эal) will bin, fobald ich Slalaub babe, und will mid twie cin Eteinpfabl nor Der Rirche aufuflanzen, bidht an ber Etraje, vor ber Rircbe, Daß̄ fie fich an mir ärgern follen, jolange ids lebe!"

Soarm fchwieg traurig; roar bollig troftlos unb Dunlel in feiner Eeele. Putlos fagte er: "So ... bann iff ba aljo nichts zu madhen. Dann if́t ez mit bir uno mit uns für alle 3cit unfres Lebens verichüttet, unb es twäre bas bejte, menn Gott es jo machte, baj bu überhaupt nid)t zurücffämft... Sch mache bir feinen Bortwarf, Das bu fo wilb bift, das fid alles in bir

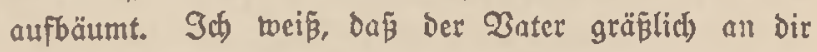
gehanoclt bat. Grabe bith, ber bas feurigite Soerz baf, Dic) zu bejduldigen, Daß̄ bu bic Deinen verftören unb fum Epott machen trollteft! aber bu must boch auth veritebn, Eggert, Daß, 「o wie ou überfकnell und zu.

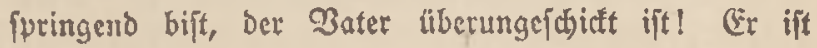


feelifds unficter, ja, jozufagen farbenklinb. (Et bat fich Da eben verbauen! Wir fino alle Menicben."

Eggert Drt hörte jeßzt Ivenigitenz an, waz̉ Der Bruber lagte; ja, er tonnte tun, ba er vor jebermann id)uldos baftano, feinen Bruber anjebn uno mit ibm über bie Gad)e reben. Ulfo betam fein 3 ruber feit Sabren zum erftenmal roieder ben Gtrabl feiner berrijden 2ugen, alz er zornig fagte: "War er mein Zater? Soatte id fieb= fobn Sabre mit ibm im felben Soaule gelebt? alfo idhreigl Meine Mutter will id febn... ja, bie twill ic) febn!... Denn die hat immer an midh geglaubt,

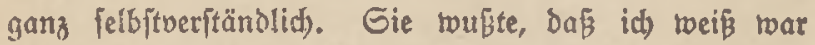

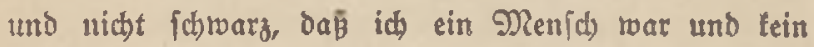
Untier. Gie hatte bas (Gefübl in fich, in jeber ibrer Fingeripigen! Ebenjo Reimer ... aber ber ift tot ... 2lbet bie andern?... 3ebn Gathrtt vom Leib oder ia fallag' ibnen ben Gääbel cin!"

"Pun . . . ich bin auch nod) ba," jagte fein 2 ruder, "und bann Sobble Gubl."

"Эa, Die auch."

"Da tanujt bu bingebn, und Mutter tann dich ba bejuchen."

„Sa, bon anderm teben! Safit bu ficjon gebïrt ... eह̉ tpcrben

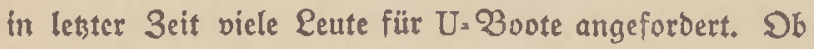
fie raß Bejonbres bamit blanen, twei id nid)t. Benug... bu wirft natürlich deinen Doften nicht berlaffen mollen;

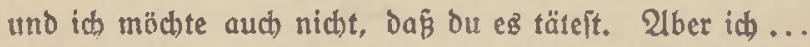
ich babe midh gemeldet und bin angenommen. Sob bin jegt

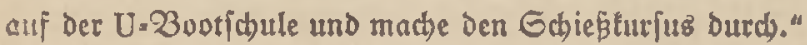


Soarm Ott fagte bebrilatt: "Ith bachte, bie Eltern bätten nun fhon genug 2lngft: Der eine gefallen unb noch stwei zu Gctiff, und Der vierte im Gelo... aber id) tann oidh verftebn."

"Woer weiß," fagte Egaert in feiner rafden vorfprin-

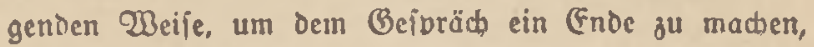
"vielleicht fabren wir eines Sages mit bundert U= Zouten nach Echottland binauf, unb brecben Da in ibre Säfen uno mrachen alles turz und tlein... Benug, wenn wir Denn noch meiterfämpfen mü|fen, fo twird mir dies am beften gefallen." (Fr atmete langfam und boch auf.

Sarm Ott freute fich über Den neuen frifhen Son, ben Der 3ruber in Der Reble batte. F roar tlar, baß e ibm mädtig gut getan, Daß̧ bie Beiduldigung und Das Mipiprauen nicht mebr zroifthen ibm uno den 5 Men. iden ftand, Doñ nun eine reine, menn audb gornige Gache geichaffen roar. (Ez raar biefer ftolzen Geele

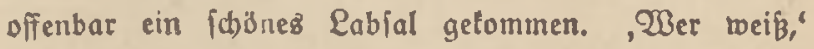
bachte er in feiner mutigen Weife, vielleicht gebt eళ mun tweiter fo: er mirb fo allmäblich immer beller uno gütiger werden; und ez tommt bod) noch alles zum (Buten." 2llo blieb Sarm beim 2lomital, unb tat bei Den Serren des Gtabes feinen Dienlt, und ftand bor ber

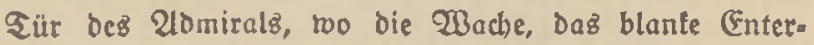
mefier an Det Edulter, auf und abgebt; uno Eggert baufte in ber $\mathrm{U}=23$ otichule und im Nutteríd)iff, und ftand im Sunern dez Surms, und riß das Qul auf und pprang ang Beichüb und griff nacb Den Rurbeln; binter ibm ftund, wie bingebert, Der Ramerad, die Branate in Der Sand. . 
Sllto fo fam ber Winter 1916/17.

Diejer barte Winter ... Da die Frauen in ben grofen Gtäbten ftundenlang in Iangen Teilyen trartent vor ben Qäben ftanden und wenn's gut ging, mit einem fümmerlichen flcinen Einfauf, oft gentig aber mit leeren Rorb wieber betmtamen ju ibren Sindern ... da po viele Rinder fo oft, fo oft hungrig und weinend in ibren Betten lagen und bie armen Mä̈tter von Ritto zu Sino gingen im Dunteln, und ibre Ripfe ftridsen und mit heipem Gdbluchzen gute $\mathfrak{B}_{\text {orte }}$ agten, die ifnen im Munde ftecten blieben... Da neben Den Üngften um bie Teuren braupen an ben Fronten Sunger und Rälte burch Das

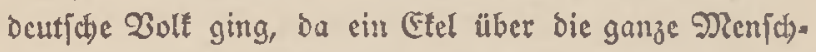
beit, ja über bie ganze Echispiung burdh unire Ecelen ging, bie foldh Morben unter Mäunern uno fold Leio über die fdulblofen Sinber und Grauen zulie巨... o a alfe $\mathfrak{S e r g e n}$ inner und immer bas eine fragten: wanu fommt Daz Ende? Wann fheint wicder Die Gonnc? Gott, wann ift trieber Qeben Seer unb nidht Waahnjinn?

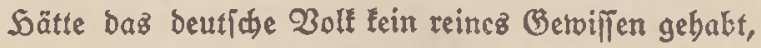
fo bätfe ez den Rampf aufgegeben. 2lber das ganze beutfhe $\mathfrak{B o l f}$ batte ein reineb Betwiffen, ein jeber Mam, Der Raifer und jeine Regierung und die Ronige, uno die Fübrer und alle $\mathfrak{B c a m t e n , ~ u n d ~ b i e ~ B u ̈ r g e r ~ u n d ~}$ Bauern und 2lrbeiter, unb bic Frauen und Finder. Gie batten alle cin reines Berwifen. Gie roüten alle: wir baben biejen Srieg nidjt exjounen, nidjt getwolft, nicht vorbercifet, nictst angefangen. Sott im Simnel twciß $c 8$ unb wirb einjit über unz alle richten. Wir wollten den Gricben, Büte, Berftünoigung, Reber unb 


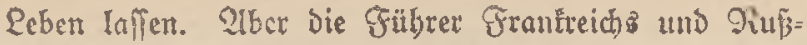
landos glaubten an 3eidoen uno $2 B$ Bnder, bie an Simmel

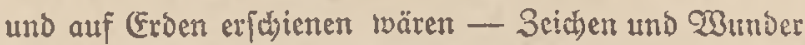
waren falfch -; unb bie Reichen Englanbs meinten, fie boären noch nid)t reidh genug, und fonnten nid)t anjebn, Daß̧ trir tüctig und ftarf und reich murben; und fo tam

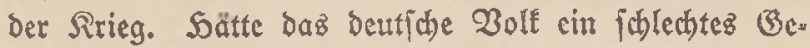
rifilen gehabt, fo bätte es bas Gdywert finten laffen uno bätte gejagt: , CEs ift genug Dez Tobes uno bes Frauent= und Rindertweinens! Macht mit mir, mas ifr wollt! Gott mirb richten zwifhen eud und mir." 2lber nun hatte baz ganze deutiche $\mathfrak{B}$ off ein reines

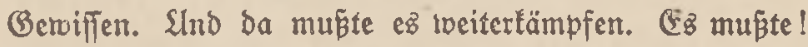
Denn das Gemifien, zumal bas germanifhe, ift ein

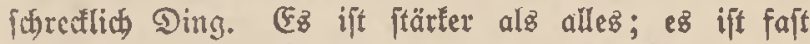
fitärfer uno trofjiger alz Gott unb Gottez Miacht.

2lio fämpfte Das beutīhe $\mathfrak{B}$ olt uno peine $\mathfrak{B e r b u ̈ n =}$ Defen tveiter, auch in biejen $\mathfrak{B i n t e r . ~ E c i n e ~ M a ̆ n n e r ~}$ laurdeten uno falichen, gruben uno bauten in ben bitterLalten Räbten, ftanden in Den berichneiten Gräben, wachten tief unten in Söhlen uno Bänger. Geine Flotte, bie tapfere, ftarfe wom Glagerraf, fubr binaus

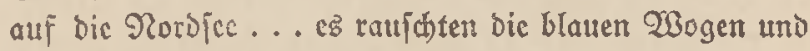
boben fid vor bem 3 ug ...., uno feine fleiten Gdiffe, bie flinten Torpeboboote, Edaum überm Det, jagten durd)g nächtliche Meer uno fuchten ocn Feind. Slnd jeine Grauen und Rinber crtrugen tociter 2̂̉ngite tno (Entbebrung.

Uber fo tapfer und tiachtig bas beutjhe Zult auch) tãmpfic, und fo oft $\mathrm{cs}$ anch) fiegte, num id)on falt brei Sabre lang... ç fonnte inmer noch nidgt burdb= 
firgen! Eв raaren ซึน viele ber Feinde. Englanb, baz frolje, bas machtoulle, Das lügen= und liftenreiche, Daś von 2̈ngften gebezte, verfübrte immer mebr Buslter unb jagte tie in ben Rampf. Einem ungebeueren, eden, rnfenden Tiger gleid), bie mäd)tigen Gübe im twirbeln. den Meer, wälzte ez fich in feiner Straft um bie ganje FrDe, und rî́ mit feinen rajenten Dranfen bie Froe uno bie Bolfer auf, Daß̧ fie mit ibm für feine शlacht und feine Ebre und feine Meinung von ber 2 belt Łänıften.

Wer ihafft ein Ende? Wer fhafft ein Enbe? 3reei germanijhe Betwiffen gegeneinander . . . einz, Das alte, veritocte und berirrte, bas von feinem Recb)t redet und meint fein Beld, und von Bott und meint feine CDad)t... Das andere, bas junge, frilche, tübne ... Das ift bet Sod ber Menjubeit! Wer ichafft ein

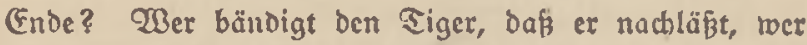
lähnt ihm bie rajende Siraft? $\mathfrak{B c r}$ nimmt ibm ben (Blauben unb ben 2Rut, daßj er etwig fiegen, raffen, rauben und berrifen uno die Welt befigen foll?

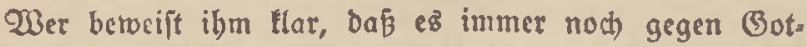

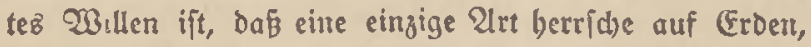
fondern baf er will, dá̉ fie buntfarben bleiben foll, feinen 2lugen zu Befallen, daß $\mathrm{ibm}$ ein Surm von Zabel oder

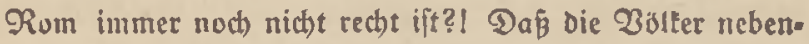
einander und als 3 rüber mitcinander leben follen?!

21b... toie fie arbeiten!... Sieb Doch, wie fie arbeiten! ... Wie fie in Den Wुerfftätten in Münd)en unb Gtuttgart, in Sena uno Grantfurt an fcinen Piachinen, an peintid genauen 21pparaten mägen uno proben, 
beobaciten und ridjten! Wie fie in ben grofen $5 a l l e n$

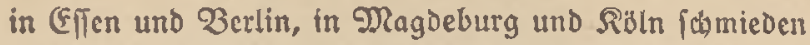
und idhreiß̄en, biegen unb bobren, bäimmern uno löten! Wie fie in ben Säfen von Samburg uno Siel, Danzig und Gtettin fügen und paffen, belorchen unb proben, bemannen unb ing Waffer lafen, beben lafen und finten... ein tleinez Fabrzeug ... cin Epielzeug ...

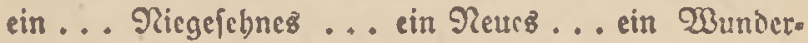

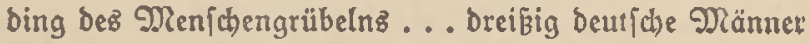
barin ... nun ein $\mathfrak{W u n b e r b i n g ~ D e u t i d ) e r ~ S r e u e ! ~}$

$\mathscr{W a z}$ treibt es in bem turzen, talten Wintertag, bei Rebel uno Gonnenichein uno tief in Der talten Nacht fein Spiel im Safen?! Sreibt und fintt... und liegt am Brunb ... und jagt burch bic Siefe ... und bebt fid pieber ... unb jagt vortoảrts, in feinem 3 autcb die oreif̧ig

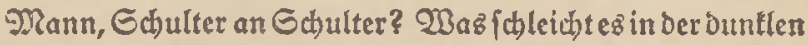
Winternadyt aus bem 5 afen und firebt ber शordjee zu... und da ... unb ba ... und bort noch einer ... und da... ez find ja robl mebr alz hundert?! Wabrbaftig, wie fie fo

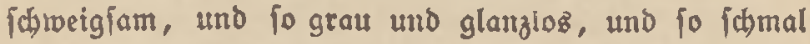
uno beroegungslos babingleiten ... trabrbaftig, jener bat recht gebabt ... Das find Ratten! . . Was mollen die Ratten?... Was fabren fie binaus zu bundert, binter Itnen bie rirbelnde Gee?

Torbsittich der Sbemiemünbung, in ber Sicfe, bie langen, raufitenden Wogen Der Rorbjee über fich, itebn bie oreī̄ig Rann in ibrer Mafdine, jeder an feinem Poiften in ber beifen, fettigen Luft, bager gemorden, bie 2lugen tief in Den Söblen, bie Rleidung ölourch. tröntit, feit vierzebn Sagen untertocgs. 
Sor viergebn Sagen waren fie in eince fierntlaren Nadjt Durch Den Sanal gefabren, ben Surm über Waffer, bie orei Wadythabenden bie 2lugen nadh allen Geiten. Da batte ber Obermatroje plöblich) mit ber Soand nach Gübuft gebeutet, toottlos ... ftill, mit tlopfentem Soerzen

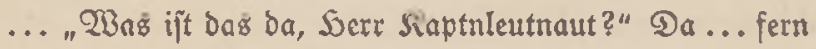
ill Siidojt, am nächtlidben, blauen Simmel, flogen golo Dene Gtribe gen Simmel, wirr Durcheinander . . . immer

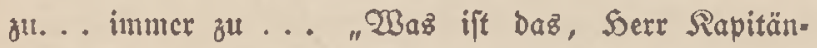
leutuant?" Sord ... es rollt Donner berüber ... Da batte Der Rapitänleutnant Dem Sbermatrojen auj bie Gdulter getippt und batte Icife gejagt: "3u breien beraufl" Slnd ba waren fie beraufgetommen, inmer Drei nach) orei; uno er batte zebnual mit betn 2(rm bin= übergerviefen; unb batte zelynmal immer mit derjelben leifen, rubigen, exnften Etimme gejagt: "Die Gront in Flandera! ... Ind fie batten binübergeftart, wortlos, atemloz, uno raren twieder binabgeflettert. Sn der Gtunbe batten fie fich vorgenommen: fie wollten ocn Brübern Da belfer ... Den 23rübern bort unter bem feurigen Etrcifen, unter bem Brïlen Der Ranonen.

Der Rommandant, ein lleiner Nann mit Bartlojem,

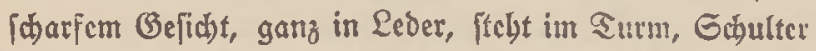
an Echulter neben ibm Wadjtoffizier uno Eteterman. Durdb bie Gcheiben bringt ein grüncr (Dämmerfichein,

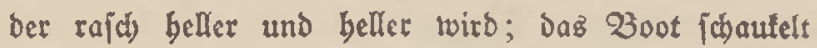
ftärter. NRun iff das Gebrobr beraus; ber Rommanbant fiebt auf bas Glas. Fr ift cinen 2ugenblic nidht im 3ils. Es ift cine lange, bobe Dannung und noch frill am Morgen, und Durd) 26olten und 2Bellen bridyt 
id)räg cin exfer Gdbein von Richt, und vermirt bas Ganze. Nid tz zu febn? Rein, nichts ... Doch ba, im Weften ... vor der bunflen Wolfe taum zu fehn ... gar nicht mebr fern, ein Dampfer mit Rurz non England ojtrbärtz.

Der Rommandant nennt ben Rurz . . Das Gebrobr beridinindet mieber ... Das Boot roenvet und fährt Dcm Dampfer entgegen, pöllig tweggetaudit ... ein Sln= fid)tbares, ein Wejenloję . . cin (Garnid)tร̇! . . Eine entieslidhe, furdytbare Waffe! (Fin [dredflicher Geinb! 3wanzig Minuten ...

Der fiommandant läpt twieber auf Eebrolntiefe gebn ... Vorfichtig . . . baz lange, gierige 2luge rectt fid herants. Sa ... ç ṫ timmt.

Uuftauchen! ... OBeichüsmannfdyaft Hlar!

Die vier Damu ipringen beran. Das Boot bebt fich. Das Ruf fliegt auf. Die vier Dlann fpringen heraus unb ftehn am twaffertriefenden (Befdüks und lisjen bie 3urringzి.

"Günfjig bundert! ..."

Eggett Ott ftebt gebeugt, bic beiben Rurbeln in ben Sönden. (Fine Welle rau[ht fnieboch übers Dedf. "Eener!"

Der Gduß tradt. Mit rajendem Gaujen, Wind und $W_{0}$ gen überfd)reiend, heult bic (Branate übers Neer ... zu kurz!

"Einundfünfaig bunbert!"

"Fruer!"

Die fitst fáon beffer...

(Die britte figt gut ... Dlittichiffz, aus bem Wañer, Erenffen, Dle Brüber. 
fdiebt ein jäber beller Schein auf; Rauch fteigt bod). (Er verjut)t abzuoreben, aber ftoct. Der Gduj bat die Majchine getroffen.

शun! ... nun feutert auch er! ...

Slnt idjieß̄t gut!

2luf ibn! . . Der traf mieder! Wieber Mittjđiffв! Eplitter und Rauch gebn bod.

2lber ba tommt vom Surm ber Ruf vom Romman. Danten. (Er bat im Wieften, in rajender Gabrt beran= fchiésend, zhei ... drei Sorpeboboote gefichtet.

"Tauchen!"

Die 3urringz fejt.... Fine Granate beg Freindes beult noch eben über fie roeg... Dit raichem Eprung in ben Surm binab ... eilig burch bie Räume ...

(2) $2800 t$ fintt. Weggetaucht fäbrt es mit bödfiter Rraft auf ben פampfer zu, Der ichief, aber noch fdtwimm. fäbig auf ber Gtelle liegt. Lange Minuten vergebn.

Taulend Meter...

2(c)t bundert ...

"Sorpedo tlar! ..."

Eggert Ott fiteht idjon am Gprachrobr.

(Ta find fdon bie Rommandos. (Er ruft fie weiter. "Qoz!..."

(Fin Rud gebt butch bas 3out ... ein 3ittern ber Ränge nach ... fie fiteb̆n alle obne Betwegung, atemlos ... Die 2lugen liegen tiefer nod) in ben Sobblen ... Sit Das nicht mebr als fünfzig Gefunden? ... wie

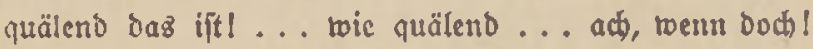
... Da! Ein [d)twerer metallifher Rlang bringt zu ibnen betüber ... 
Tun bimunter in bie Sicfe... Gdnell! Ednell! Go! ... Nun find fie in Eidherbeit!

Der fommandant gibt ben neuen Rurz. Die $\mathfrak{B e}=$ füüвmanni baft cräblt, was fie erlebt. In Eggert 2ttz 2lugen brent bie Erregung.

Der Dafdinift fragt: "Wie grop toar er, Scrr Raptnleutnant?"

Der Riommanbant fiteht fison über bem Qlobbregifter gebeugt: "Ob. fo ... viertaujend ... marten Gie ... ba iff cr $\{$ d)on! . . bier... Die Coldhejter von ber Lermictlinie ... hat trobl Rebensmittel bolen follen bon Danemark ... vicrtauieno groeibundert."

"Gol ... Die baben fie Denn aljo reniger ..."

"Waz gibt's ди פRittag, Rach? ..."

"Eie icholien aber gut!"

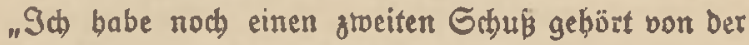
andern Geite... ganz beutlid... gleid nachbem unjer Sorpebo gefelien bat ..."

"9a ... ja ... (id) aud)! ..."

"Das war ber exite Gaús oon ben 3eritörern."

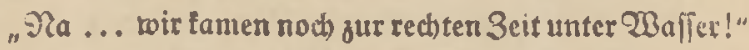

Bierzig Dinuten lang find fie unterm Meer ver= fchlounden. Dann tauchen fie vorfichtig auf Ecbrobrtiefe auf. Der Rommandant fiebt in Den Epiegel... Sa, ba liegt er ... mit ftarfer Edhlagfeite ...

"In zeln Minuten ift ex meg. Dic Mannlịaft ifi ficion über bie Reling."

Das Gebrobr verfamindet rieber.

Fine Gtunde lang fabren fie twieber unter $\delta \mathrm{cm}$ Decre, wollig weggetaubt. Wu find fie? Sin, mer form 
Daz fagen? Waaz fino fie? Cin trejenlofez Ding, ein Nid)ts . . e ein (Barnichtz.

Wie weit ift bas Mcer! Wie idjön gebn bie Woogen! Wie glüdlich ift England! O, England! O, England! WBie grop uno reid) und mäditig bift bu ... Wohin, Räpt'n?

शad) Folfeftone! ... Nach Sarmid)! . . शach Sondon! ... Mit S̆ won Rofton! ... Gifchbclaben von Bergen naw Sull! Ein leidter Rreuzer auf ber Gabrt von Gcarborough nach Dover! Qtlle Engländer? alle Engländer! . . . Wer hat bie meiften Gdiffe? ...

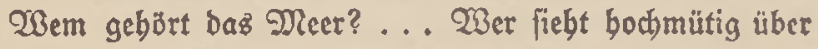
Meer und Qänder? ... O , England! D, England!

Daz Meer ift unrubig und bas Echiff tief belaben: vorn (Brubenbol fich fdiwer und fdwantend in jebes Wellental und wenn

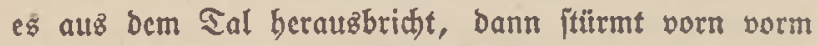
3ug, wohl zebn Meter bod, gelbrociper Bijht cmpor. , 2lber wir macten boch zrölf Rnoten, und beute abeno find wir am Pier von Sarwid. Wir tamen immer ... twir famen immer an ben Dier von Sartwid), uno trinfen einen Grog im London Sotel und fiken nachber nod) in ber Sneipe von Saction. Smmer!! ... WBenn

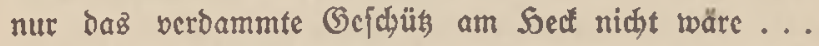

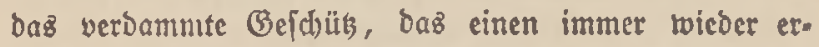
innert ... immer róeber erinnert ... Dá̈ ... Der alte Rapitän anf ber 3 rüdte, ein gropes, etroas alt.

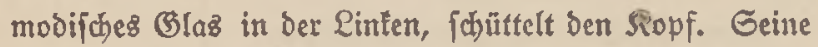
2ugen find übernächtig, feine Soänbe zittern von llber.

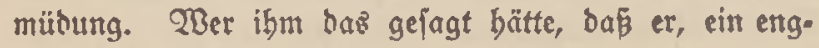


lifcher Rapitän, fich auf bem Dieer fürdłten müffe! 2lıf bem Meer, bas England gebört, fo lange cr und feine Väter benfen fonnten! Ta ... twas ift Daz? Da ... an Gteuerborb! .... Er beif́t dic Lippen zujammen und wirb blaßs. Die ganze Mannj(jaft - fie bat feit vors geftern, jeit fie Chriftiania verliésen, fein 2luge jugemacht, und ift wirr, verängftigt, übermibe -... itart jitbroefträrts, wo ber Dampfer, ber noch cben rulig und tlar lief, plibslid), in Rauch gebüllt, litill und tot

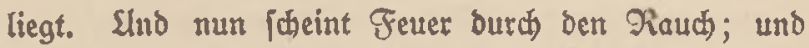
fern über bie Wogen fommt ein Gtō̄ uno cin Rut.

Gie vergeflen cinen 2lugenbliaf bie Wadje. Dic icjmerzenven 2lugen, überwad)t uno überangeitrengt, ftarten auf ben fetnen Feuerjhein.

"Wir machen Dod zroulf Meilen, Gteutmann?" "Sawobl, Rap'tän . . z zöli Mteilen."

"Go ... 10 ..."

"Das (ื) tnal [đtmedfen, Rap’tän."

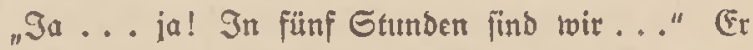
mollte fagen: in Eidjerbeit, ichäntte fid) aber, es zu fagen, und jagte nod) einmal: "Dann find wir..."

In bem 2lugenblid brüllt ber Sioh, ber mit einer Taje Tee bie Britufe betritt, Daß von einem Ende bes Edjiffz zum andern ballt:... "There ... ooh ... ooh ..." und beutet mit ber Sand über Бect.

„Damned ... Fire! Fire!"

Det Englänber ift stloas frither da ... Es fino etwa dreiß̄ig bunbert ... Eeine erfite Branate fault 
Didft über Eggett Dttz Ropf uno fhlägt feitte flvangig

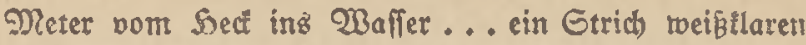
Waliers brobelt unb ipringt auf wie ein Quell. Am Befiange feitgebalt ftebt er, gebeugt, bic Rurbeln in Den

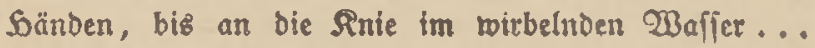
"... ift singefteilt ..."

"Fetter!"

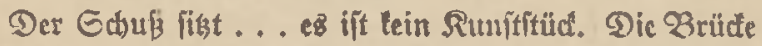

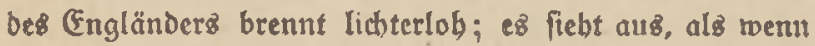
ba eine zerrifiene rote Gaḅe ftebt, won beftigem Win gezerrt.

Da ... unterm Sect getroffen! ... Er bat fein Seill...

Berbammt ... trie gut er fahiept!

"Ednefl taudien! Edunell" ... Daß̉ fie dem rolitenden Geuer entgeben!

Eggert Ott langt mit ber rechten frand nach ber

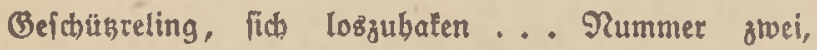
früber fertig, fpringt eben an ibm norbei...

Da tommt noch eine Branate, mobl bie lefte bon

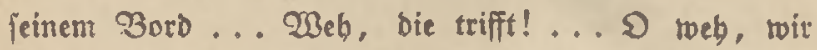
fino bin! ... Das ift ber Eod!

Tlummer grei, neben Eggert Dtt, fliegt zur Geite roic benn ein zerriffener Mantel burch die Ruft fäbrt. Nummer brei, Eggert Ott, ichlägt bart gegen bie Reling ... Die beiden Offiziere, vom Quftoruct gegen die Surme mano geid)lentert, reiß̄en fich wieber bod, rufen um Sollfe für ben Geitürżten; grmei Nann fpringen aus dem Surm, faffen tmb id)ledpen Eggert Dtt berein uno gieben thn binab; bie Rute folägt au; Da\& 2 oot tautbt roeg. 
2athunbzranzig Männer bordhen atemlos. Nodh

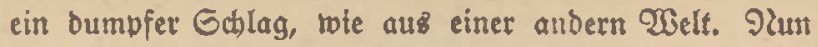
Fino fie in Eidherbeit, im Eđope Dez Neereš.

"Was war es? Wo? ... Sịt Webrens tor?" "Ott aucb?"

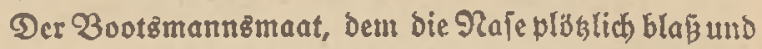
fvin geworden ift, tniet über Eggert Ott und reipt immer mebr fidneetweipe Watte aus bem aufgeriffenen Raîten. "Der rechte $2 \mathrm{rm}$ ijt ganiz zerrifien ... gleid) an ber 2 dafel .... Serrgott, traz bat ber Menich für

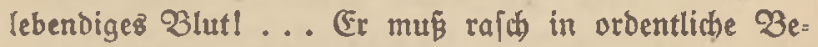
banolung, Serr Raptnleutnant!"

Der Rommanbant, ber fich aud über ibn gebeugt bat, rid)tet fich mit einem giuct auf und ruft $\delta \mathrm{cm}$ Eteuermann zu: "Gîjojüdoft, Gteuermann ... mit aller Rraft!... Fs ift cin rafder und braver Mann." 


\section{Rapitel \\ (Der Pflüger}

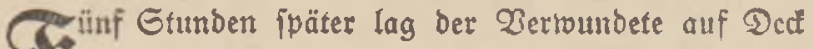
einer fleinen bollänoifchen $\mathfrak{3 a r f}$, bie nad) Rotter= Dam fubr.

Dort, in Rotterbam, lag er mandfe $\mathfrak{3 0 h e}$ in treucr Pflege, bie nötig war, ba auch bas Gchulterblatt verlegt toar.

Der Sirieg ging feinen fobredticten (Bang toeifer. Sm Weiten ftürmten Franzojen uno Englänber mif grisßster Nad)t gegen uns an und überwanben unz nidf; in Güben zun zebnten uno elften Nlale bie Stalienter. Elnjre Gtärte war unjer gutez Bctvifien, unjer Seer und unjer Wille. Elnje Soffinung toar bie Bertwirtung, bie über Rūlanto getommen war; uno unire U-Boote, bie Tag unb Tlacht an Englands Qeben

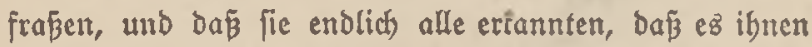
nid)ts half, Daß all ibr Rämpfen bergebens twat und fie nur immer tiefer ins Elend bradte.

Go verging ber Gommer, und ez rourbe Serbift. Da wurbe er nad) Deutichland übergefübrt und lag im Marinelagareft auf ber Bebdel bei Soambutg, ein 3 ett nebett hundert anbern Betten. 21m Sag banach fä

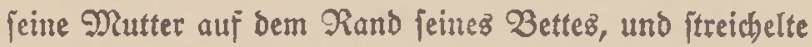
den einest 2lrm, ben er now batte.

Geine Mutter erzäblte ibm bon affen babeim; aud) vom Bater. "Znter íhict dir Grüßę, lieber Eggert... 2(h), Eggert ... Du weipt nid)t, wie esె Batel weh

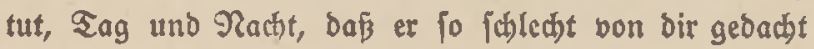




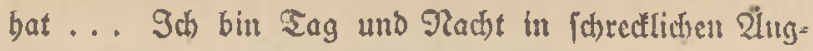
ften gelvefen, er fünnte fich ein Leib antun."

So fagte fie und fitrichelte feine Sand; und er

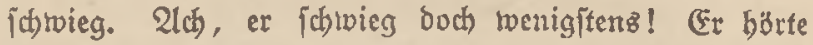

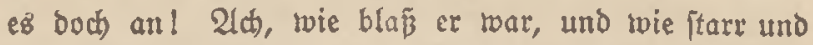
verifändig er ausfah, um zehn Sabre älter getworoen; und mit wie bitterm (Geficht cr balag! 2lch, fie füblte ez biz in ihr Soerz binein, was ez für ign und feinen Gtolz bebcutete, Daß $\mathrm{er}$ Den $21 \mathrm{rm}$ verloren batte! Aber er zeigte ihr boch, Daß̧ er einez Serzents mit ihr lwar; er brüctte ibre Sand feít in ber fcinen und fagte leije: "Mutter!" 2(d), er hatte im (Brund, in ber tiefften Siefe, ein tweid)es, ja überiveid)es Sory. SRran mubte nur an ibn glauben, unb noch bazu feiner bediurfen; bann war er Der Gütigite auf ber 2 elt.

Dann Kam bie Mutter mit iGrem Plan beraus. Mit bem Plan, den fie und Söbte Gubl beredet batten.

2ls Söbte Subl won feiner Bertwundung crfafren batte, toar fie gleich getommen unb batte fich nad) allem erfunbigt. शach adt Sagen war ite twiebergefommen und batte gefagt: "Sch roill ibm jest fatreiben, Sante Qene, jo Dies und $\delta a s \ldots$. da Soof alleż roieber lebendig mirb. So ... two bie Siere jefon, und ras wir ausfäen wollen, uno fo twas. Su fhreibft igm ebenjo von Deinen Sieren und Dem Feld, nichtz von Menichen. Qluf DRenictsen ift er bappig. Dit joldhen Briefen rollen wir ifn fo einige $200(j)$ birbalten und [ebn, was er antwortet. Nachber aber muß̃t ou bin... cinterlei, ob nach Rotterdant oder nach Samburg ... und muß̃t ifn mitbringen; und er mú 
bier Eci nir auf Dem Sof fein. Tann ift ex nidyt bei jeinem Sater; aber ex ift bei bir. Sth glaube, bas

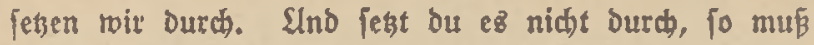

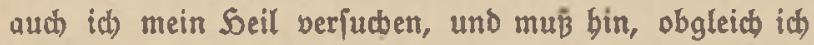
Ungit babe, in ein 2azarett zu gebn. Pidtst regen Wunten uno Sob, Sante Rene, bavor bin idh nicht bange; aber wegen ber vielen 2lugen, bie mit einem lwandern, wenn man fo zwijtyen ben Betten bindurch= gebt; id) babe das mal auf einem Bilb gejebn, two bic Raiferin fo burch ein Lazarett ging. Эab bin ja nidht Dic Rniferin; aber id babe einen etras ungeidhidten, langen Gtapf, und idh treiß̈, baß̧ fie alle nact mir jebn; und toenn id bas tweí, twerde id rot, und twenn ich rot twerbe, werbe id noch berlegener und ftofie tro. míglid) gegen ein Bett an uno mache irgendeinem

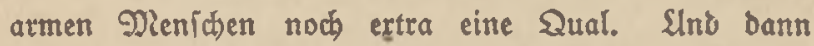
weißst bu, Sante Rene, wie es ift! Die Mannsleute haben lcidt etwas Bejonberez in ifrem Blit... fo ... ,ad), cin Weib!" Weíßt ou, id bin ja nidft prïbe; id) bin ja bier anf bem Lanbe gró getoorben und treif́,

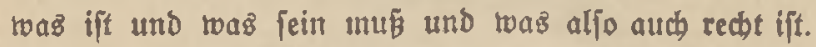
2lber man ärgert fich boch immer ein wenig, twenigiten

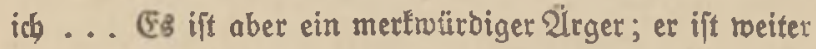
nicht unangenehm . . . Dod . . twas twollte id fagen . . ." So batte fie gejagt; und bas war bie längfte Reoc getweien, bie fie in ibrem Leben zu citter Gremben gebalten batte. Gie war ganz rot vor Glüct und Er. regung, Das fie fich anbot ju belfell, und dap fie fo viel geiagt hatte.

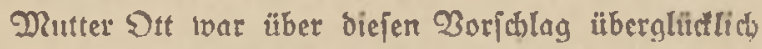


getweien; unb nun fap fie auf bem Sanb feincz Bettes uno redete auf ibn ein. Gie bebandelte ifn oorfichtig, wie ein robes (Fi. 2la, fie tannte ibn fo gut uno jeine bDje Wunde! Tidat allein bic an Der Edbulter, aud die größere, bie intwendige. "Söbfe Gubl bat ben $20 r$ " jchlag zuerfit gemacht," fagte fie. "Sa官 bu nicht glaubịt, (Fggett, ich bätte es ibr nabegelegt, oder gar fie barum gebeten. Slno menn ou nicht barauf eingebft, tommt fie felbit bierber. (D) follt nur auf ibrem Sof und auf ibren Geldern fein, da tann bir tein Menich nabe fommen. 2(ф) bitte, Eggert, tu e8, beiner Nutter zur

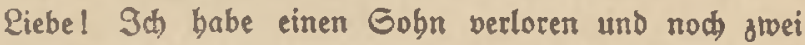
in Rrieg," und fie weinte.

Die Rameraben in allen anbern Betten faben mit fitllen 2lugen anf bie reinenbe Mutter, bie fo itattlich uno noch fo frifa) ausiab, aber leiber ia in idymarzer Rleibung twat. Gie batten alle ben einen Gedanten; fie bachten alle: $9 a$, num bentt fie an ben andern, ben Soten, unb Dá̉ biefer, Den fie mit glwci träftigen tleinen Ürmchen geboren batte, nun einarmig ift! Ulnd ficher bat fie auch fonjt ibre Not nit ibm! Wabrbaftig, ein leichter Gobn iff ber nie gerbejen ... twie trogig und bitzig er ausfitebt, und nun gar einarmig! $\Im_{a}$, ia … bic Grau ba bat ichreren Rummer!' Ulno fic waren alle, alle, bie ba lagen, die beiben langen Reiben entlang, voll von fdrweren, ftillen Bebanten; und eine Qaft von fitller Sratter, won Trauter um bic Millionen tweinender Mütter, lag auf bem gansen Eaal. Slnb Felbit ber lleine fihmale Seizer, Der ba immer noch vom Efagerrat ber lag, unb bem fie aeitern toieder sin Gtïc* 
gefunder Saut über cine verbrannte Gtelle gelegt batten, verjuthte cin tocnig Den Slopf zu beben und bie Nutter

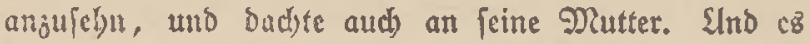

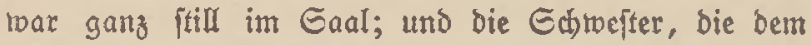
Dbermatrojen bie idjectlich ichwere 3 unde vom Granats fplitfer am Sberibentel verbant, bielt ein twenig inne, und fab ftumm bie Betten entlang.

Eggert fühlte, baj alle Rameraben in ben Betten, ber ganje Eaal, auf feine Dlutter laben und jeber an feine eigne Dlutter Dachte, und füblte, twie gut eg war, Dá er in jeinem (Eleno nod) eine शlutter batte. Gonit batte er ja nichts auf ber Welt. Ginen Bater batte

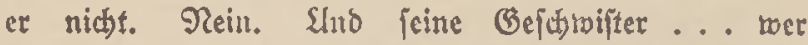
iwubte, ob fie affe an ibn geglatbt batten! Emma iedenfallz nid)t. slberhaupt ... die Mutter ... ja, bie Mutter . . Daz if cben B̧lauben obne 3weifel ... whe 3tweifel. Ex hatte in feinem Gtolz nod) ein wenig Neigung, fich noch ein toenig zu fträuben; aber bie Mutter ...! SInd tven Sübfe Gubl ihr Wort raht.

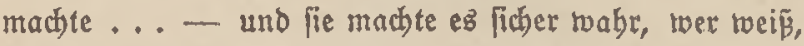
viclleicht jubon morgen - und fam mit ifren langen Gtapfen und ibret Berlegenbeit den ganzen Gaal enta lang ... nein ... es war fohon genug, dap fie jest alle berlaben und über feine शutter und feinen berlorenen $\mathfrak{A} r m$ iprachen und $\mathrm{DaE}$ es Der rechte toäre und nidht ber linte, uno bag̃ er ganj weg toäre, mit Gtumpf uno Gticl. Uber cr brauchte tein Mitfelb! Er toullte

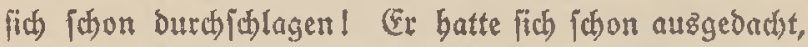
twas er wollte. Er wollte auf irgendeinett gropsen Sof für Roft und Quartier Einjtano nebmen, tmo jidy 
Mübe geben, his baf er alles betreiben fonnte, was mit bem linten 2lkm allein möglich räre. Ecit er auf bem Ded ber bollänoijhen Bark nieder zur Befunung getommen war, bis beute, war bas immer fein शad)= Denlen und (Brübeln getwefen: twie belfe id mir jelber obne Jieniduenbilfe?! (Er batte fich auch ein Buth gefauft, Das über bieje Gache bandelte. Wenn er Dann einige Sabre fo binter fich batte uno in ber Lanowirtidaft gut betwandert wäre und (chaffen fonnte,

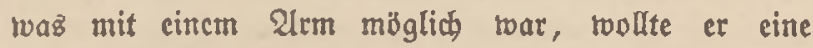
Gtelle alz Berwalter puchen. Genug ... er witrbe Fids

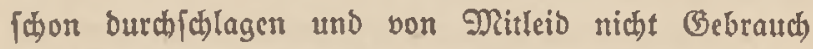
machen! 2lber nun bicz 21ngebot von Sobbe Gubl... Er war ba ganz ungeftött bei ibr. Sa, ja . . . er fomute ba gut allez üben ... und ibr alter Peter würde ifm helfen in Dem, twas er regen feines (Gebrechens nötig batte.

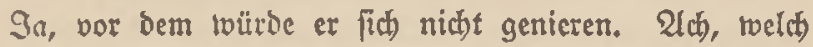
ein Elenb ... obne ben red)ten 21 rm, ben beften Selfer!

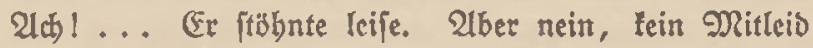
aunehmen. Sein Ditteio! ... In ... nur von dentn: von ber Mutter uno vom alten Peter und von Sisble Gubll Slnd bie Sand der Nutter itreichelte immer

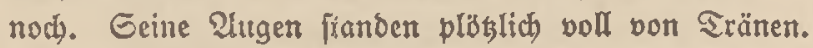
${ }_{n} \Im$ ab) twill es!" fagte er leife.

Sierzchn Tage fpäter bolte Sbble Subl ibn bom Balynbof ab und quartierte ibn in ber Giebelitube, aus beren Fenftet ex Den Zateršbof nicht fefhn tonnte, cin.

2lళ fie von Der Gtube beruntertam unb ibrer Mutter gegenüber am Geniter $\bar{\alpha} \bar{\beta}$ und in ben Barten und ïbers Feld fab, mar ibe (seficht filler als fonft, fo baji ifre 
Mutter fie mit ibret gütigen, reichen Gtimme fragte: "Geblt Dir etwas, ober bat er bir nicht gefallen?"

Gie Dachte nid)t lange nach; Denn fie batte in ibrer langen (Fir amfeit Die Beroobnbeit angenommen, auf fid) felbjt ơ achten. "Nein," fagte fie in ibrer rägen. ben, langiamen und ftoctenden Weife, "es tut mir nidht leid; aber id) trundere mich liber mich felbit, Daßj th mir nicht gefagt babe... Daß̄ er nun tein Sunge mebr ift. SlnD Das fidwere Erlebniz und Das lange Sranten= lager bat ibn wobl nod) rajd)er wadbjen la\|fen, ich meine inwendig uno austwendig."

Die Ditter fab in ibrer Gorge und Riebe rieder einmal eine Soffnung, bie fie oft fhon batte tommen uno get): febn. Fs war ibr leib, ihr Rino zeitlebens lesig zu febn. Gie fagte in Gorgen uno (Gram: "Befällt er Dir nun nid)t?"

Gie fab bie Plutter mit ibren wabrbaftigen, fdönen 2ugen an uno fagte, wäbreno ein leifes, pöttifibes Läd)eln - liber fich felbft - ïber ibr Beficht ging: "Er gefält mir wohl . . . aber es ift dod) eine befondere Sache ... id fitebe vor mir felbit boch efwas munderlid Da... jest."

"21c," fagte bie פlutter in threr gütigen $\mathfrak{B e i f e , ~}$ "Da mad)' Dir mur feine (Bedanten!"

"פlein," fagte fie, nod) immer bie 2lugen in benen Der Mutter, to als wenn fie fagen roollte: ich belüge mich nicht und bids auch nicht ... "aber ich tweí ja nicht, ras jest ift und toas vielleidjt twerbent tann. Und barüber mundere ich mich unb argere mich ețaş."

"Nun," jagte bie Mutter, "Ia twie es Imufen mig." 
Dann fduregen fie beibe. Die Dutter bachte in Die 3utunft binein und bachte, e\& rürbe ibr lieb jein, เvenn es fo mürbe. WBieviele Mäbchen beirateten einen Mann, ber jünger ift, uno es gebt ebenjo gut, wie mit andern Ebben. Die Süngere derfant wieder in Das Ginnen, in bem fie vorbin getweien war, und Dadte: , Э由 batte mir wobl gefagt, daß̃ er älter getworden wäre; aber id batte nicht gemupt, wie es fein würde. (Fr rar ein Sunge, und ift nun ganj und gar ein Minnn uno bat auch bie 2lugen einez Mannez. Nein, id muß mich wirflich zufammennehmen! Qber wie fonnte

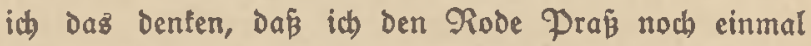
in Diejer Weife anjebn uno leiben müdte! (Fs ifit tiberlyaupt nicht gu fagen, was man mit fich und andern exlebt .... aber befonoers mit fich !

(Daun fing fie an, es fid auşobenten, nach allen Geiten. Denn fie twar ein rubigez, veritändigež uno reines Menichentind. Slno es fchien ibr, als wenn ibr gar nichtz Befieres geichebn tünnte, als renn bie Gache jo laufen rollte und ibr ganges Leben in biejer Gang bineinginge. Slnd ba es ibr fo gut fdicn, roolte fie fich auch ibrem TBunich nicht wiberiegen. शein, Das wollte fie nidit! Sie wollte fid freilid bïten, dẩ fie in ibren Gedanfen nid)t zu tief in biejen Lebenz̧plan bineintäme, aber int übrigen bie Eache ibren Lauf gebn laffen. , $\mathfrak{L} \tilde{3}$ ibn tun, twas er will, Dachte fie. Slno roieber, ba fie fo bachte, flog über ibr Befidt, bas noch immer ein toenig rot war, bas tluge, ein wenig fposttlicbe Qäcbeln, bus ibr felbit galt und bas ibe fo gut itand.

2Im andern Tag (d)on, in aller Erübe, zog er mit 
Dem Pflug uno ben Pferben auf baz Etïl gegen Ofien, wo Eommergerfte getwefen twar, ou pflügen. Llno ber alte Peter ging neben ihm, um zuzugreifen twenn es etwa nidit ginge. Sie batten ein Paar junge Wferbe vorgejpannt - bie älteren waren im Rrieg -; aber es raren ein Waar rubige, gewande Tiere, und er bachte, es ruirbe fo gebn; bie Erbe war da auf bem

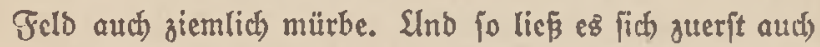
gut an; ja ganz und gar io, wie er ez fich in Rotter. Dam, auf feinem Bett liegend, taujenomal ausegedact) batte; und er ichicte in feinem Gtol ben alten Peter weg. 2ber allmäblich batte er boch grope פübe, nicht mit bem Pflug, obgleid) ez ein (d)weres Ding war; aber mit ben Pferben. (Fr hatte feinen $2 \mathrm{rm}$ burd) lange S̈bung mähtig gefräftigt; - aber die Pferbe gehord)ten nicht verftändig genug ber Leine und mactsten ibm viel $\mathfrak{A}$ rbeit. Er mußste an ben Enden ben PFlug wieder und rieber зurüứjiebn, bá bie Gurube fofort gut anjeste, benn Pfujdertram roollte er nicht madjen; Daran wollte er fids nicht crit geröbnen. Das nabm ighm viel Rraft. SIno er batte, waz er widt bedad)t, von bem langen Rrarten. lager ber in ben Rnien uno Rnöcheln noch nicht bie alte Gtärte wieber.

Gine Gtunte lang ging er fo auf bem breiten Gtüd attf uno $a b$, bie Lcine faräg um bie Gethultern; ber Icere 2̈rmel flog in bem frif̧en Oftwinb, ber von ber Beeft bertam, zur Geite... ba hatte er am Ende bez Gtül's nicier bcjonberz fकlwer gu arbeiten, um bas Shanbpferd in bie Furdye au bringen... Snmer micier mufte er zurüfgehen... 2ֶ̈rger tam bazu, 
fein bisige 3 lut walle auf . . . und ba verfagten ibm plöblic) bie Rnie, benen er zubiel zugemutet batte, unb er fing an zu zittern. Er ftand und atmete fibiwer...

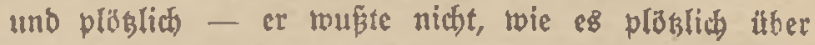
ibn fam - weinte er beftig.

Slno da fam Sible Gubl ... Sic batte ibn yom Dielenfenjter aนษ์ gejebn, wic er mit bem Pflug aus? opg, uno hatte mit Eorgen beobachtet, wie es ginge,

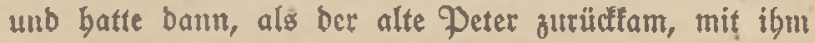
gerebet. Der batte ichon bie Edhultern gezult und gelagt: "Es twiro noch nicht fo gut gebn, wie cr fid bas ausigebacht bat; es wiro noch mand)e bittere Gtunbe für ibn geben." Gie batte ibn auszgejd)olten, $\delta a \tilde{\beta}$ cr fich batte wegfchidten laffen, unb batte weiter am Genjter geftanden und binubergefebn. Slnd als fie gefebn batte, wie feine Rnie allmäblich erlafmten, roar fie nad fur. zer Ŝlberlegung über bie Soffitelle uno bie Wreibe ge= gangen, unt ftand nun bei ibm; und or reinte.

(Fz tat ibr fabrectlich leib, und fie fing aud) an zu tweincn.

"Rieber Eggert," lagte fie, "tomm . . . lomm;" uno fie wollte ibn an Den Grabenrano fübren, baj er fith nieberiçe.

dber er twifcthte fid über bie 2lugen unb blieb da ftehn, bic Sand am Pflug.

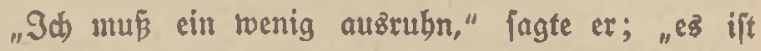
Das erfemal. Es wiro allmäblid beffer werben... So wie id) jest bin, bin id) ja faum bie Rojt wert." "Bitte, Eggert," bat fie, "rede nidgt fo! $\mathrm{LaB}_{\text {bir }}$ 3cit! Eei munter! (D) battefit boch immer guten

Erenffen, Die Briber. 
Dut, alter Robe Prab! Du bift ja nidbt bef frem. Den Reuten; bu bijt ja bei mir!"

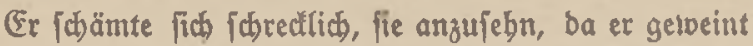
batte. Er jagte freundlicher, faft janft: "(Feb jest; id twill langlam wieber anfangen. 9 b will mir Seit laffer. Beb mur!"

Da ging fie und befabl Dem alten Deter, Das ex einige Etücle beiter an ber Friebigung ber Fettroibe arbeitete, uno baj er thn nicht aus ben 2lugen verliere. Cr aber pflïgte reiter.

Er plügte biefen Sag und ben andern Sag, alle Sage. Ulub toenn es audi nod lange nid)t fo ging, wie es nth feinter Meinung follte, wie er in Geift und in bet (Finbildung fertiggebrad)t batte, jo tam es boch nicht twieder

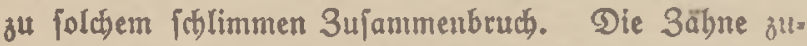
fammengebiffen, oft genug finfteren (Befid)ţ, brad)te er bie Pflügerei au Enbe, und zog mit feinem Gejpann auf eis anberes Geld, und bejorgte auch bas; und mtarbte auch allez andere ganz allein: [pannte an und aus, brachte eฮె und bolte es]; und baftelte am Ge/dirt und Pflug, twas noitig war. SUno fo ging ezs alles recht gut. Wei ober renn er fonft mit Sabte Gubl und igrer Datter zufammen war, ftellte er fich, als wemn nichts feblte ober mangelte. Wenn fich beim Effen eine SIngef wictlich feit zeigte, börte man ibn atmen und bätte ibn rot twerben felan fönnen, aber fie jabn nicht auf; und nut einmal zog Sobbte Gubl, obne ein 20 ort zu jagen, feinen Sellet an fich, und zerfinitt $i b m$, ras er nidt hatte zeridnei-

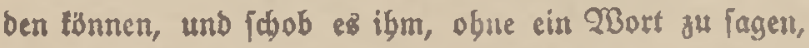
wicter bin. 
Gie batte cin Gtübctjen fïr fids allein, bie Heine Eaffube neben bem Gaale; ba ftand ibr Zett und über ibrer Rommobe, auf einem breireihigen Boto, ibre 3üder: Gechs Zände Boetle, etrvaz von Gontane, etwas von Raabe, Storm gand, Reuter aud. Zuf ber Geniterbanl, bic in betn alten Saufe febr tief rar,

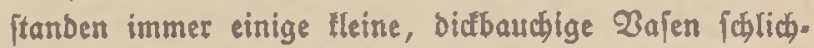
tefter Form, bie fie immer wieber anders binftellte und mit immer neuten Blumen füllte; baran batte fie ihre Freube. Finez Sagb, gegen 2lbenb, als er ungefäbr vierzebn Sage in ibrem Saufe rar, ftant fie ba bor Dem Epiegel; uno batte jeine Gonntagsjacte angezogen, bie fie fith alt feiner Stube gebolt batte; unb probierte fie vor bem Gpiegel. Gie glaubse nämliđ, bemertt au baben, Daß ibn ber webende, leere 2̈̈mel genierte. Nun batte fie ben ganzen Silrmel nach innen roeggeftopft unb probierte, wie es aus[ab; aber

Ta wollte es ber 3ufall, dak et auf feiner Euche nach ibr, um ibr etwas zu beftellen, burd) bie Gdhlaf. ftube ber Nutter bereintam uno fie fo fab.

(Er wurbe bla und bi fíp auf bie Rippen. "Was madjit bu Denn ba?"

Gie erfaraf robl nod mebr als er, unb jagte ver. legen, aber rubig unb bedäbtig, indem fie ibn mit ibren bübjळen, guten unb llugen 2lugen - bie immer ein gut Seil ernjter waren, als bie Sache verlangte freundlid anfab: "Ěs fam mir fo vor, Eggert, alsె wenn es bich genierte, baß bu ben leeren 2irmel truggt, und num wollte ich probieren, ob eb beffer autzfiebt, twenn Der Û̉rmel gand weg ift." 
"(2)az fiebt nicht gut aus," fagte cr, "meinft bu,

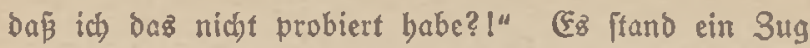
von fálimmer Bitterteit it feinem Beficht, und es atmete ichroer auf und wollte rieber gebn.

"Eggert," fagte fie in Gorgen, "bleib nody! (Du glaubit mir, Da i ich es nur beinctwegen tat?"

(Er bob bie gefunde Gd)ulter und fagte mit bitterm, verlegenen Räsbeln: "Du joljit ja nicht mit mir auf ben Wlab fommen, Söble; es Eann Dich ja bier uno auf bem Gelde nicht ftoren."

Da trat fie rafd auf ihn zu, und umfapte freundlich bittend feine Gd)ultern und fagfe: "Eggert, benl nicht fo bon mir!"; unto fie fifreidyelte bie Etelle, wo ber $21 \mathrm{rm}$ fehlte. "Ez ift boch) für unళ̊ alle geid)chn, Eggert!" Uno ibre Alugen roaren plöglich voll von Sränen. "Eag' mir ... ift Die Etelle ganz beil?"

"Sa," [agte er, "aber ich fpreche nidjt gern bavon."

Gie ftreidyelte fie rieder und jagte: "Dut must nicht Dentell, Eggert, Dẩ idh mich Davor ideue... vor

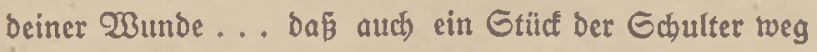
ift ... bas mußst bu nicht glauben! . . Das ift mir eine (Ehre, (Eggert ... ich) lyabe bid) nur viel, viel lieber Darum ... uno un geh, Rooe Đrá̃!" Sno fie fab ign nod) cinmal mit

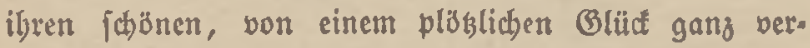

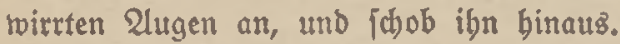

Er batte fie nie fo nab gefebn, uno in jold)em (STüct uno (B) laıt. Er ftolperte verwirtt über bie Ed)tolle, und bachte: twie gutt fie iǰ ... und twas für fdobne 2lugen fie bat! Go fand er fich, unter der Sut ber brei guten Menidten, in ben Gtuken uno Gtällen und allf beln 
Gello zured)t. 2lts vierte tam bagu peine Mutter, bie Dann und roann nach Feierabend auf eine balbe Gtunde herüber fam und bei Den Frauen fä́, und barnach eine Weile mit ifm allein über bie Sofftelle ging. Er gab auch Den Reinen bie fie benn gerabe mitbrachte, bie Sand. Ulnd als eines Sags das Süngite, die Hleine ncunjährige Wiebte, ein flein freundliches, rothaarigez Ding mit bitb= fhem, flugem Geficht, aber etwas abitebenden Obren, burd) Den trodenen (Braben Fletterte und ifn auffuct)

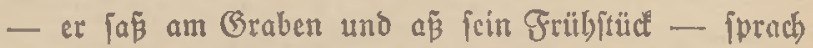
cr ganz sutraulich und freundich mif ibr, fragte nach ibrer "Puppe und nach Der Edule, und gab bem flei= nen Ding, Daz, twie ihm plöblich fdhien, ein wenig bla twar uno wohl auch für fein Bolf und Waterland mit litt, won feinem $\mathfrak{B r o t .}$

$21 \mathrm{~m}$ anbern Gonntag, als bie Mutfer wicder berüber= gefommen war und banad) mit ibn vor bie Sür trat, jog fie einen zerfnicten Gelobrief aus her Tajche und pagte: "Sth wollte eฉ brinnen nid)t jagen, Eggert; Du tannit es ibnen nadber ja erzäblen . . bier ijt ein Brief, ben bat ein Ramerab von Rlaus uns gejhrieben. Raus ift berroundet." Ulno fie gab ibm Den Brief. Err lautete: Licbe Frau Dtt!

Mir gebt es noch immer gut und ich boffe bas̄felbe auch von (Eud). Snocm nun mein Frettro nir jagte: Gdreib ez meiner Mutter, bie ift ftärfer; meine Grau ift nur idtrach, fo fareibe idh Ihnen, bas er vertwunbet ift, aber nidht zum Sode. Snldem nämlich die Gdhwarzen ftürmten, tamen fie bis an Den Drabtverbau uno lagen Da auf bem 3 auch, und ein Snteroffizier und acht 
Mann lagen bundert Meter vor ber Front, unt jitolien auf bie Gdwarzen, und Da waren er unb id babei. 2ber inbem twir leine rechte Dectung batten, blop ben tleinen Sridter, roar ber Unterpffizier und ein andrer bald tot unb gtwei twaren sertwunbet und bucten fich rweg und einer mubte fid inmer übergeben; und twir andern twaren mebr Frbe, als Menjojen, indem twir uns . fo einwüblten, und bem einen lagen bie 2lugen aus bem Gababel und bem anbern tief bineir, fo verichieden find bie Raturen. SAnd da wollten wir benn

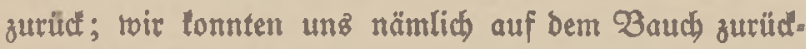
ibleiden. 2ber ba tam ein getriffer Friech Baub, ber bat fajon Das (Fijerne Rreuz zreiter und fobielt nach erjer Rlaffe; ber aljo tommt unb jagt, wenn ez möglich ift, jollten twir Den Sridfter balten; es iff ficherer für bie Rompagnie. Er bat ez aber laum gejagt, ba bat er einen Gdupi in ber Gdhulter uno fact zujammen. Da wollten twir benn erjit recbt zurül; denn jeber Menich bat fein Reben lieb; und alfo fagte id): Qeute, lagte ich... rir baben alle Grats unb Rinder zu Saus; (id) glaube, wir fosmen mit gutem (Betwifien zurïdgeben.

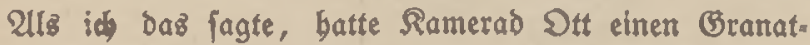
iplitter burch bie Sand und auth an ber Gdulter und blutete unb jab aus, wie ber gelbe Lebm, in bem trir lagen; aber er [agte boch: Waas bat ber 23aut gemelbet? (Da bucte ich mich zu Friech Baub, ber neben mir lag,

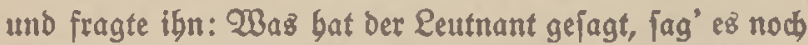
mall Der fagt: Shr tönnt jurüctgebn; aber ez if ficherer für bie Sompagnie, toenn ibr bleibt, bat er gejagt. Da fagte Ramerab Ott: Эa, Reute ... bas ift ja twabr, Daß 
wir Frau und Rindet baben; i⿱山口 babe jogar fünf lleine Rrabaten ... fagt er ... aber, twenn es po ift, twenn er bas gejagt hat, Daß̄ es für bie Rompagnie fidherer ift, Dann müfien wir bas Loch bier balten und wenn toir uns ben Sob babei bolen. Da blieben twir benn aljo, und ba befam Ramerab Ott noch einen Edus Durch) ber 2lrm - aber er (h)ob noch immer unb twir autb; aber zulegt tourbe er obmmädtig. Wir bielten aber bie ganze Stellung und was bie Schwarzen find, bie gingen $a b$. Tactber fam ber Leutnant und aud ber Sauptmann, ber bas Bafaillon bat; und id muß̧te es erzäblen, uno ba ichictte mich ber Souptmann mit meinem verftauthten Daumen in bas̃ Felolazarett, und idi) follte dem Ott fagen, daßj er Das (Fijerne Rreuz be. fäme. 218 iळ $\mathrm{Da}$ antam und ber Daumen vieber richtig ftano - er war ganz umgebogen - war er

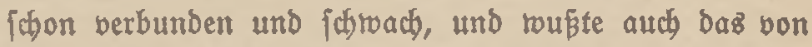
Dem Eifernen Rreug fdon uno fagte blö: , Sdjreib

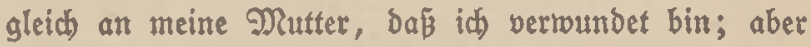
Der 2lazt fagt, ich werbe wieder gejunb. Und vergí Das mit Dem Eifernen Rreuz nicht!! .. Eben böre idh,

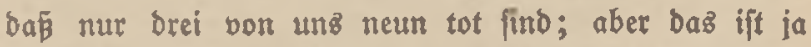
aud falimm genug; fie baben alfe orei Grau und Rinder. Nir gebt eв noch gut und ich bुoffe bas̄jelbe aud von (Euch. Mit Brup Guer Landifurmmann Sowen Gtehn, ge* bürtig aus TMeldorf.

Er ließ Den Brief finten.

"Was jagft ou?" fagte fie.

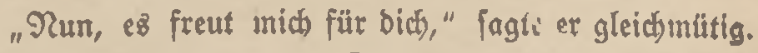
Gie tämpfte mit ben Tränen: "EFs ift niळt red̆t 
von bir," fagte fie, "Dcine Familie zu verleugnen. Wir baben immer alle auf Egre gebalten."

"Soabt ibr?" fagte er bitter und babnifth. "Sct) meinte, ibr bättet mal einen in den Gdjmus gejtopen!" "21d), Eggert!"

"Lap Das, Nutter! Daran änberit bu nichtz. Du reist, wie ich) zu bir ftehe, bamit must bu bich bes gnügen." Slno er ftreichelte ibr ben 2lum und begleitete fie ïber bie ganze Soffitelle biz an ben $\mathfrak{B e g}_{\text {e }}$

Sa, gegen feine Mutter war er gut. 2lber gegen alle übrigen Menjhen war er voll eifiger Feindjhaft. Es wurbe im ganjen Rirchipiel bavon geredet.

(Ez fonnte nicht ausbleiben, baß er einmal auf bem Felbe - ba bie Gelber an einigen Gtellen aneinander fitiézen ober auf Dem Feloweg oder auf ber Dorfítrape jeinem Bater begegnete. Daz twar benn auth fthon einige Dlale gejdebn; uno er raar unberveglia, Das eifige (Befict)t grabeauz, an feinem Vater voribbergegangen. (Fz batte auch wobl bier uno ba einer verjucht, ein älterer Mann, ber ben muntern Sungen gern gebabt batte, ober ein Racjbar und Racbbarstino, ober fonft ein munterer Dorfgenoffe, ein Wort mit igm zu reben oder ifu übers Geld ein Wort juzurufen; aber er hatte nichts

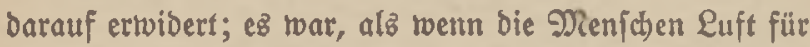
ibn mären. Nur mit einem Rameraben, Der aus dem Gelte getommen war und berlwundet war twie er, batte $\mathrm{er}$ einige Worte gerebet; aber er war bem Mann roie ein Frember borgetommen. Er $\bar{a} \mathrm{ab}$ in allen Derwanden uto Befannten uno bent ganzen Rirdhipiele bie, roelde cine Seitlang geglaubt batten, daj er jenes 2lufiebn 
und jenten Gpott unb jenes Seid iber fein Etternlyats unb feine Gamilie gebradt batte. Cr war in bic Seimat zurücfgelebrt ... ja er war gern zurïlfgetehrt! 2ber er twar gelommen, um ibnen zu zeigen, twas fie ibm alle bedeuteten ... dás fie ibm nichtz twaren... gar nichtz; unb um ibnen zu zeigen, ia, um ihnen zu zeigen, lvaz Sodfimut toäre.

Wenn er im Dorf zu tun batte, ging er, ben leeren 2ïrmel in ber Tajche ber Sacte, weoer lints noch rechts febend, freil und grabe wie ein Pfabl feines Wegż. Gonntagz trug er einen bejonderz guten, bunflen Unzug, ben cr aufz jorgfältigite bielt, eine fchmale filberne, feine Ulbrette über Der Wejte, Das Zanb bes Eifcrnen Rreuzes uno eines mectlenburgi Der Brult, und ziwar auf ber redsten Geite, ba, wo er bie 2 unde batte. 2 nzug und Slgrfette batte ex fich in New Gjorl für bort erworbenes Gelo gefauft; es war ifyn cin 3cichen und Betrcis, daßj er bamals, bon jeinem Dorf und alfen Menfden serworfen und in bie Grembe gejagt, achtzebnjäbrig, bod) tapfer und ernjt feinen $W_{e g}$ gegangen twar; und er rollte, bar bie Leute bas jo anjabn... bicje Nenjchen! .. Dicje... bie ibn jo erniebrigt batten! ... bieje Sunbe! ... (Ez witrgte ifn, wenn er barast bachte; und er rourde blaß̧ im Befict)t. Nichts mit ibnen gemein! Pein, nichtz uno niemalz! Welche (Finbiloung von bem Lebrer, ber freundlic) mit ibm hatte reden rollen! Weld ein Srr. tum von Pajtor Boblen, ber greimal über ben Graben geiprungen und zu ibm gefommen aufz Felo, und ibn

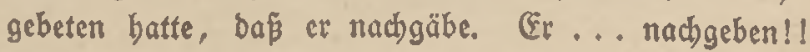




\section{Sapitel}

\section{(Der Sobannibbermein}

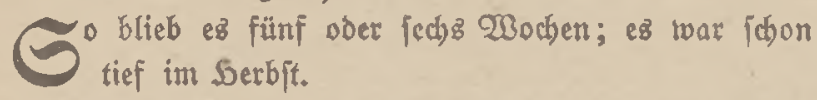

Da fah Sbbte Gubl eines Rachmittags dent Bater Ott auf ben Sof aufommen. Gie fagte fich gleid, baj ex ficher gefebn batte, daß Eggert mit einem Guber Safer nach Der Etabt gefabren toar, und Daß̄ er feinetwegen mit ifnen reben roolte; und wat in bem Gedanfen be= brüdt, ba fie erwog, wie fd) toer es ibm rar zu fprechen, und nun gar über biefe fahtrerige Eache!

,2lch Gott,' dachte fie - benn fie war intwendig ganz reojelig und bielt lange Gelbitgejpräche -, ,bas miro eine fotwere Stunde für uns beide! Эđ) meine für

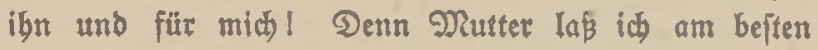
aus bem Epiel; Dic hat noch mebr शrot Dabon als ich. $\mathscr{W B a}_{a}$ ex wobl will! Wenn er feinten Arbeitżrod anbätte, twollte id) nod) nidts jagen; aber er bat jeinen Gonn= tagezrod angezogen, und will aljo ficher ettwaz ganlz

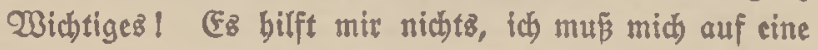
Etunde ja und nein, und Eähe bon brei Worten gefaj̃t machen, biz er bann endlid) jur Gache fommt! Sch treiß, twas ich tu: Sch twill ifn auf bie Banl am Goot bugfieren, da babe is renigiten twann einen Wagen auf der Gtrape zu meiner Interbaltung !"

Gie ging ibm bis vor bie Sür entgegen und jogte

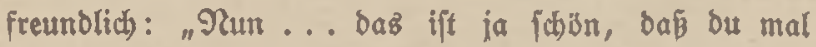
Fommft, Onfel Ott! Somm' mit! Wir wollen auf Der Banl figen ... Da in Der Gorne." 
"Sa," jagte er, "ich wollte mal nawi euch jebn!" "Sa... bas wax red)t von birl"

(Er ging ibr boran und fegte fich langjam unb umftändlich auf bie Bant, legte ben $21 \mathrm{rm}$ auf bie Lebne

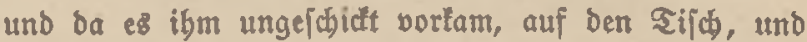
da ihm bas auch nicht paflenb fhien, in ben Gđop.

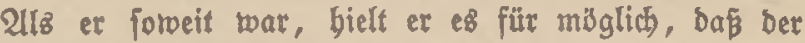

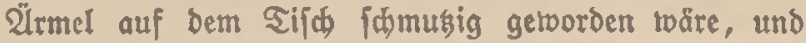
brebte ibn um und wifchte $i b n$ ab, obtwohl ba nichts zu wifden rar, und fing bann benfelben Etellungstwechjel bon born an. Dann jagte ex einige Gäbe übers $\mathscr{W} e t t e r$ und fragte nach ber Dutter. Dann fing ex bon ibren einzelnen Feldern an, und fam bei jedem Geld auf einz

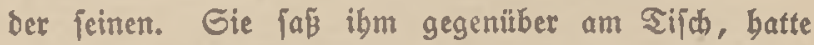
einige Gtrümpe vor fich auf ben Sijd gelegt und ftopfte baran. Ulnd jagte ungefähr biejelben Gäze, bie er jagte, und toar zu ungejकidit und jobeu, um zu fagen: ,Onfel Ott, it merte ja, bu bajt etwas Edhtoeres, ganz

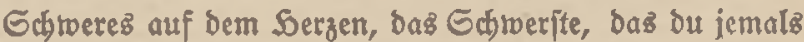
gebabt bajt. Fang boch babon an!' unb batte ein berz=

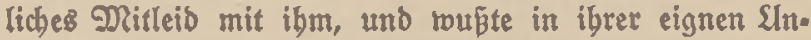
geidioflidfeit nidjt ein und aus. Sie wußste inmer gañ genau, waş fie wollte, und banbelfe im allgemeinen ganz ridtig; aber fie tonnte fich nicht in Worten auts iprecben; fie prad immer nur in 2lndeutungen uno

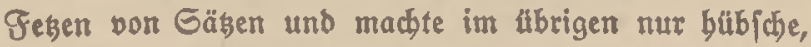
\#luge 2lugen. Go fapen fie fids eine balbe Gtunde fteif und ungefdictt gegenüber.

Endlich ertrug fie ez nicht länger, übertwand fic und fagte: "Eggert ift guter Dinge, Ontel Ott!" 
"Eo?" jagte er, und ihlvieg eine Seiflang.

"Er bat bie fieben Sotktar zu Oiten gand allein umgepllïgt. E⿺s ijt gut "rumgetommen."

2al) (Bott, ba waren fie ja wieber bei bemjelben Begenitano.

Da nabm fie all ibren Plut zujammen unb fité bervor: "Was nun wohl weiter mit ibnt wirb, Ontel Ott?"

Bater Ott twifchte fich mit Dem Rücten ber Sand

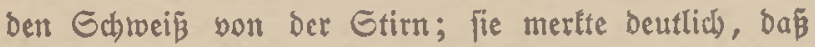
fie fich nun ber Gache näberten ... "Es ift ja man gut, Dá̉ et joviel arbeiten fann. (Es fino fo viele Qüdéen ba, Sobble, unter ber jungen Diannịjaft. 2ulle, bie wiedertommen, müfien bart 'ran."

"Sa, Daz müfen fie... แnd Eggert..."

"Эa, und Eggert auds)."

Tein, das war nicht zu ertragen! Gie war fo bs pe, ba jî fie rot wurbe, und bad)te in einer richtigen fleinen

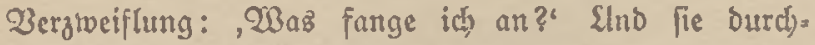
fuchte mit gefduärften 2lugen und zu[ammengezogenen Brauen daz Bild, das fie vor fich batte: bier zur Eeite im Brünen ben Goot, den Garten mit feinen Serbftblumen, uno bort Daz Etüct Etraßze, Daz bie Bäume freilieben. Das tonnte ibr alles nichts belfen. 3ur ORutter laufen? $\Im a$, bie twiltbe lie mit ibren guten 2lugen anlächeln und wiirde mit ilyrer freundichen Gtinme božbaft lagen: "Er ijt ja zu dir gefommen! Eieb Du z", wie bu mit ibm fertig wirit." 2lber ploshlich flog Das lluge, id)elmifdhe Qädbeln über ihre (Beficht. Eie ftand auf und jagte: "WBarte einen 2lugenblid"! \$d) tomme gleid) wieber." 
Nad) cinigen Nimuten war fie trieber $D a$, eine weritaubte Flaiche und zwei blisende शBeingläjer von mittlerer Bräße in der Sand. "Go," lagte fie perlegen, "í) will Dir toas zugute tun."

"Deern, Drern," jagte or uno wijhte tiber feine Gtirn, "waz baft du ba? Sd, bin ja gar nidbt gewöbnt, auch nur eisen Tropfen zu trinten."

"Эक) auth nicht," jagte fie faft zornig; "aber... es ift von meinem Sobaunisbeertocin, follt bu wiffen." Und fie fotentte ein; und fie tranten beide.

Das crite (Blaz balf nod) nidbt, weder ibm, nod) woran fie bei all ibrer Rlugbeit gar nictit gedacht batte ibr felbft.

2lber als fie am àveiten genippt batte, twar fie felbft io treit, twie fie ign batte haben wollen. "Srint nur, Onlel Ott," fagte fie fdjon redst orbentlid) und glatt, "Du bift fo ein groper unb langer Nann; bu lannit Dod) ztwei Glas trinfen! Gigen wir bier nicht ganz gemütlich)? Warte, idj rill bie Glaidse etwas falt fteller."

Und fie ftand auf und trat an ben Goot, fitllte bie Flafd)e in ben (Fimer und ließ ifgn an ber Rette in bie Sicfe gebn und ftand mit porgebeugtem Ropf und beobs ad)tete, wie er fant und unten aufichlug. Dann fam fie

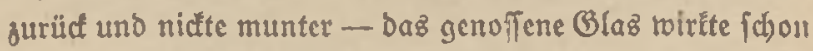
mebr - und fagte: "Slnd nun muft Serzen bajt! Эch glaube, ou willit mir etmaz ganz $\mathfrak{B}_{c}$ fondrez lagen. Wabrjchcinlich über Eggert. Salt Du eime Gorge um ibn? Nischteit bu etwas vonibm? Tumb̈dtcit natürlich gern, baß er toicber gut Greund mit bir toirb. \a, 
Darliber bente ith auth nach, Sag und Sadat, Onfel Dttl Gag" Doch blofi, wie bringen wir bas gujtande!"

Bater Ott tourde nun aud etwas munteter und freier. Gotweit wie fie, war er aber noch nidt. "9a," fagte er, "Du baft gang recht. Iक wollte... id wollte ... Dir toas fagen utber Eggert ... und grade über biefe Gache."

Gie legte ibre Rnie aufcinamber, ftübte ben (Eabogen auf ben Sijh, fab ibn mit ibren bübiden tlugen Alugen an unb fagte bebaglid) unb zutraulit): "Denn man zu, Ontel Ott. Wir find ja ein Paar alte Greunbe! Demn Ieg man โов! शact)' feine Umiłtänbe! Romm, wir trinten nod cinen Gdilud! Sit ex nicht gut getworben? Die Näbchen, bie im vorigen Gommer zu meinem Beburtstag bier waren, fagten, er toäre wie ber føönfte Staubentwein. Radher bebaupteten fie, id) bätte cinen tleinen Gdivipz gebabt und in toäre rebjelig getwejen twie noch nie. 2ber twic tam man von anberthalb (5las Wein rebfelig werben?! Das ift nicht ber Wein, bas ift baz Sers!

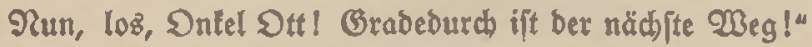
Bater Ott nahm umptändlich Das Blas und fegte eż umịtändlic roieber bin uno fagte munterer und mit gelofterer 3unge: "Sa, benle bir, vorgejtern, als i屯 mit Deinem alten Peter an eurem Garten entlang ging id rollte nad meinet Saferftoppel febn - jab id Eggert ... ber uns nicht fab und börte . . . unter beinen 21pfelbăumen ftebn. Er batte bir ja toobl gebolfen; uno fab bir nun nach, roie bu ben ziemlid idstoeren Rorb, ben du mit beiden Sänden angefaßjt battejt, nach bem Souje binauftrugit. Wir faben igm grabe in bie \&ugen, 
er aber fab uns nidht; et tat nidjt, ftand ba und fab bir nach. 2llz twir nun eine Gtrede tweifergegangen waren, fagte ber alte Peter gu mir: ,Sait bu ez ge=

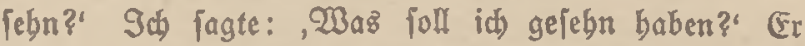

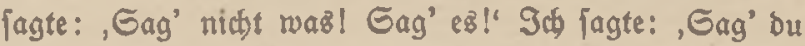

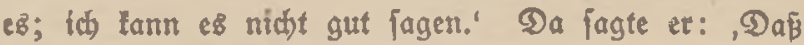

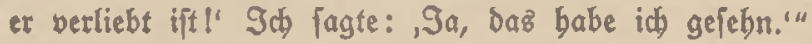

Sie batte ifn räbrend feiner Kebe mit gerunzelten 2ugenbrauen und ibre ibjönen 2lugen fharf und faft f4hmerzbaft auf ibn gerichtet, angejebn; benn es peinigte thr empfindjames Befübl aufs beftigfte, baß bon ihrem Inneriten geredet nurbe, obgleids es zhei alte Reute getwejen waren; aber jugleich büpfte ibr bas Soerz vor Ereube. 2lber ba fie nun ibren eignen Wunf auf? idjönfte im trodnen batte, war fie gleid bercit, ble Gtumbe auszunuten, um mit cinem fo gropen unb toürs Digen Nann ein Hleinez Epiel zul treiben und ihn zu tweiterer Rede zu bringen; benn fie war ein rechtes Weib und zu allem Epiel aufgelegt, nur dá̧ fie es fonft tmmer mehr intwendig treiben muste, im Beift, roell fie ou jheu war, ez yor ben Nen/chen gu tun. Nur mit ibrem freundlichen Nütterchen ichelmte fie zuweilen mit brolligen $\mathscr{B}$ orten uno einer nectenden Berregung ber Sönde und nut bann, wenn es duntel war ober boch Dammerig. Nun aber twar fie ja vom Wein guter Dinge und gelojter 3unge. Wlio jeste fie ein ermftes, faft befümmertes Beficht auf unb jagte: "Эh tann mit nicht benfen, Ontel Ott, bá er mich lieb bat; ich bin fajt fünf $\ a b r$ slter als er unb bin immer fo idfrectlich fitill und ernjt." "Rint)," fagte Bater Ott, Dem nun aud ber Wein 
Die Geele und bie 3unge gelöjt butte, "Das ift ja grabe Daż Ridttige! Waz bat man Da crlebt!"

"Erzăbl"!" fagte fie eifrig und nicfte ibm beftig zu. "Эa," jagte Bater Ott und war guter Dinge, "Da war bic fabüue Otti Sargenz, bic von Wejterbeich, tweipt Du... jest bat fie ja fothon graues Saar! Die fagte, fie toollte zeitlebens bei ihren Brübern oon Sof zu Sof gebn und bei Den Sind= und Rranterbetten, Sochzeiten unb Taufen belfen; und trieb es aud) fo, bis fie breiunboreißig twar; fie war cin großjes uno fluges Mäbchen! 2ber ba fam ber fleine, ctwas fnicfebeinige Saufmann Dumm, fechs oder feben Saljre jünger und einen Guß fleiner als fie, faufte und bandelte in Der ganzen Rano. (c)aft, lad)te fie an und nedte fie. Gie nabm ibn erft gar nid)t etnit, fie badjte: Das ift ja tein Mann ... twab ift Der?" 1 ber das änderte fich bann jebr. Gie bat ibn gebeiratet und ift nid)t unglüctlich getworden."

Eie nicte ifm ou und jagte eifrig und lebbaft: "Weißrt Du noch mebr fo werglvidéte Gälle? 2uber einen meiß id) auch ... ja ... einetl ..."

Uber er war nun im 3ug. Eein überwollez Serz, fein Geift, Der taujent Sage Beonulen erroogen uno Billoer gemalt, und fie nie an ben Mann gebradt, quolf num über. (5r fä nach) 2trt cines Snaben zu

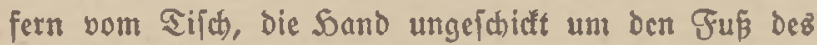
(3lajes. "Wergib bein Woort nicht," jagie er eifrig, ja begeiftert. "Dann war da bie Sanna von Dollen,

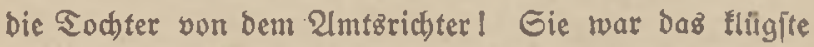
und tüchtigfte Mäbd)en in ber ganzen Lanoịchaft, und gar verniogend bazu. Gie fum nicht zur Ebbe . . . fie reiple 
bierbin und babin . . . und blieb immer lebig . . . und wurbe fünfundoreißig ...2 2lber bann beiratete fie! ... unb wen? ... Was bentft du: wen? Einen Heinen Violin. fpieler, einen lebenbigen, lujtigen, quedfillbernen, fdyrorzen, Hleinen Rerl, einen Rerl, fag' id bir, ber nidjt cirse Minute rubig auf einem Gtubl firker fonte! Sie lacbte über ibn, folange fie lebte - fite ijt mun fabon tot -; aber fie batte ibn gern."

Gie nidte lebhaft, tippte auf feinen 2 lrm und fagte rajch, um endich einmal zu $\mathfrak{2 B o r t}$ zu fommen, ronach es fie fehr brängte: "Эa, und nun vergín bich jelbjt nicht, Ontel Ott! Bitte, vergíp bich felbjt nicht! Sante Qene bat mir mal erzäblt, wie es getwejen ift. Sie war erft acbtzebn uno tat nichts weiter als arbeiten uno lacfien, unb dachte nicht an Sciraten. Smo als ifre Mutter zu ife lagte: (Du, Lendjen, weifít bu, wer bir twas mill?', Mir?' lagte fie. , Oer lange Reimer Ott! Da lahte fie fich unter Den Sifh), und ladte fo, DaF fie immerfort fatrie:, (EB tut fo toeb, es tut jo reeb; und id tann es bod nidft lafien! $\$ a$, und bant toar Fie boch neugierig, und iprach mit bir. Und bann berlor fie ibren Bruber in 2 att, und wurbe menigitens ein wenig empt. Slno in Winter barauf liebte fie bid

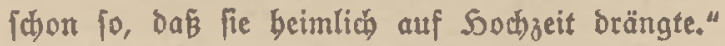

"Sa, fiebit bu," fagte Reimer Ott eifrig; mit glänzenben 2lugen: "Daş iךt eż, wovon wir reben! Ter Unterfchied ... Das ift das Rechtel Sund bas ift (8) mun auch mit bir und Fggert."

"Bott, nein!" jagte fie. "Wenn mir Das einer bor grestfen, Die Brtüber. 


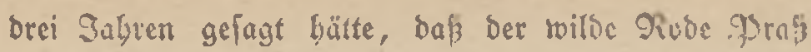
noci) mal mein Mann trïrde... Der Dumme Sunge, Der barfü über meine Grähen und Felder fprang! 2lber reiat bu, Onfel Ott, " Fie läd)dte uno fpottete über fich jelbit und twunderte fich ... "פu glaublt nicht, roic Fomild es mir gegangen ift! Gang zuerit, als id) (echrachn twar, ba bachte ich, id) wollte einen Offizicr haben, id batte mal einen über ben Martfpla geljn febu in all feinem Etant. Danach, als ich fo achtzchn,

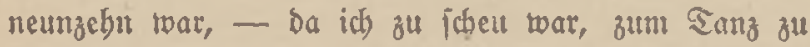
gelon, las ich viel ... ich) glaube in ctron überflugen Büdbern, -- ba fann ich mir fo aubi, dapi ich viels leidjt nal einen Geleísten baben wollte! Der follte bier auf bem Sof leben uno arbeiten, twic er loolte, wäbrend ich) für bie Gelder porgen wollte. Sch glaube, ez follte fo'n Runfigclebrter fein! 2ld) Bott ... in verftand nicht viel bavon ... uno bu verftehit gar nichto bavon. Sürer ... êे ift bod cigentlid) allez altmobif d) und langlweilig; bis auf ben Ritter, ber unir gut ge= fält. Rennit bu ben Ritter, Ontel Ott! ... Secin? ... Ift auch nicht nistig. Sutveilen dactete ich jugar

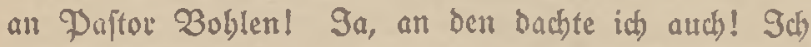
rollte ibn penfionieren uno mit all jeiren Gduränfen und dewn ganzen 3eug in ben Gaal feren. 2lbet zus Icsty fam ich bcim Lanomann an! $\mathfrak{a}$, Dabei bin ich zulest angefommen uno babei bin ich nun fajon einige Sabre. Sch rollte cinen ordentlichen, exilfen und wabr. baften Mann haben ... bier auf meinem Sof, ben id) to liebe ... und wenn er noch fo fablicht wäre! Uber meine Gdbubeif war mir immer in જreg. TRen 
mir mal einer gefiel, io beim Ronzert ober Pferbe: renuen, fo fonnte id es ibm nidht zeigen. Sm Gegen= feil, id) zog immer bie 2luger gleich) fraus, weil ez mir nicht recht war, Daj er thir gefiel, ober weil id fürchtete, er tönnte es merfen, daß er mir geficl; unb jo bacbte er Dcлn: , Waz für ein unfreundliðez, übercrnftes Näbchen," uno ging an mir vorüber. Und nun?! Nein! Daß Der Fiode Praß es cirmal mürbe, ber allereinfachfte und fhlimmfte, Daran babe ich nidht gedacht!"

"Siebjt bu," fagte Bater Ott wieber, mit leudten= ben 2ugen, "bas ift es! Der Unterichieb . . Das ift bas Richtige! (Fr bat viel von ber 2 rt feiner Putter, ift rafd, zornig, ungerecht ... Du aber baft meine 2lat, bijt id)werfällig, unficher, langfam; und bas Reden wiro bir idfucr."

"Sa," fagfe fie, "Da baft bu recht" uno mit einer ungeidjicten 3 ewegung mit ber platten Sand auf bell

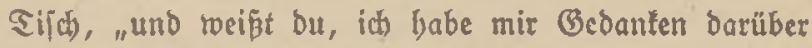
gemadht, warum es fo iff und fo fein mü; ids meine: bap grabe fo veridicbene SRenichen zueinander hin: gezogen werben! Stell bir blok vor, wenn ez nidjt jo röre: twenn gleich uno gleid fich) liebten: Der Weiche bell Weidjen, Der Ulufithre ben Unfichren, Der 3ornige ben 3ornigen, ber Runblöpfige ben Tiund:bpfigen! Was würbe bas für Sinber geben! Die Figenidaften der Eltern mitrben fich in ben Sintern verboppeln und gäbe die unleiblichlten Erjjeinungen: ez gäbe Letute, bie fo zornig twären, bá̉ fie alles, toas fie fähen, zet. fchinetterten, und Reute, die fo runblöpfig twären, Da lic ftatt eines Ropfez cine'Regelfugel bätten! Pun aber 
läpt bie शatur biejentigen Fin lieben, bie verjhieben untereinander find, unb erreicht Damit, Daß̉ bie Riuber mit ibrem Wejen uno ihrer 2 rt roieder in Der 2 Ditte Der Gdjopfung ftebn. Slno fo lift es benn fein W3under, Daß id) Eggert fichon fo lange gern babe. Früber, fo= lange er noh ein Sunge war, als Sungen; aber nun, feitoem ex wieber ba ift, als einen Nann!"

Go faßen fie nebeneinander auf ber Bant und brautbten bie beiben (Bläjer nur, um fie bin- uno berzuichieben, um ibre Reben zu befräftigen, umb Dachten nicht an Srinten, fonbern nur, Dás fie ibr fonft immer fo verbaltenes, fo übervolles Soerz auş rebeten immer weiter mit lebendigen 2lugen, ein leifeß, glütlitchez Rot auf Den Wangen.

"Qlber nein," fagte fie, "Daß̈ bu ... bu . . Ontel Ott als Brauttwerber fommit! $\Re a$, ez war ja aud ein Slnternebmen, was? ?!"

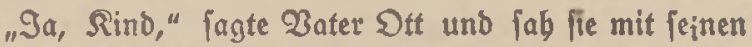
tiefen, notvollen, gläubigen Rinderaugen, den red)ten Weilynachtzantgen, an: "Iథh Dente und dente ja nur Sag und Nacht Darüber nach, wie ich ibm trgend etwa

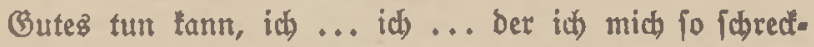
lich an ibm vergangen babe! Slno ba bachte ich, id toollte biejen (Bang für ibn mad)en! $S_{a}$, und das ift ja mun gut abgelaufen!" $\mathfrak{F r}$ zog jein großßez, buntes Tajdentuch bervor und wijdte fid über Die Gtirn, auf Der Die Gdbweiptropfen itanden.

Sbre graben 2lugenbrauen batten fich frauz zu[ammen. gezogen, uno fie fab vor fich bin auf ben Sifch. Dann fagte fie langfam: "TBeißzt bu, Onfel Ott, eB ijt nicht zu glauben, 


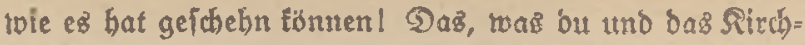
fpiel von ibm glaubten, lag thm taufeno शeilen fern. (Fr thug bich und bie ganze Familie und bie ganze Seimat in einem guten, reinen Serzen und auf den f̧änben. (Fr mar be: reit, immer uno überall für ieine Nenfchen burch Getuer unb Rauch zu gebn; Das bat er bei Gtagerrat berviefen, als er fich bei bem Rettungsiveriuch die fotrere 3 ranbmunde gebolt bat. Ulno ba mupte ibm diefes robe Benebmen auf ben Sals gelaben merben 1 (Tas überwindet er nicht, Onfel Ott. 2uch unfre Berlobung und (Fbe roird baran ni(h)t ăndern. Ou tannit glauben, id) toerbe Sag uno शactit baran arbeiten, Daß̧ er milder bentt. 2lber ich füble

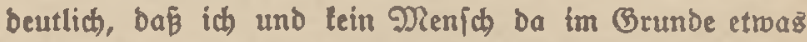

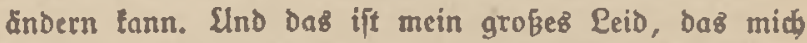
quält, i申 tann nicht jagen twie Tehr. Denn fieb, Ontel Ott ... es ift fhlinm, wenn ein Nenfकh, und nun gar ein junger unb ein feuriger, eine bälig vereifte ... eine glaubenzlofe Gtelle in ber Geele hat." Gie jah mit zufendem Mlunde por fích nieber; Sränen traten in Łọre 2lugen.

"3a," fagte 2 ater Ott, "Dab lift ezl" Slnb num

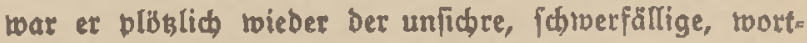
large Reimer Dtt. (Er berjucte, bie rechte Sand in Die Sajde feiner Soppe zu iterfen, fand fie aber nicht in bet gewobnten alten Gelojoppe unb wupte richt, was et mit ber Sanb beginnen follte, unt legte fie

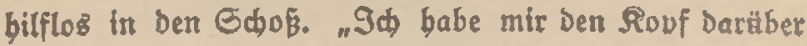
gergrübelt," fagte er mutlos mit bin= unb berfucbenden 2luger. "Oiebit bu, ich finde mich ba nidtt fo leidft

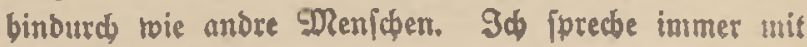


mix felbjt; und ba toar mir eine 3eitlang, als tocun idy imwendig ztwei loäre uno in 3ant mit mir felber geriet.

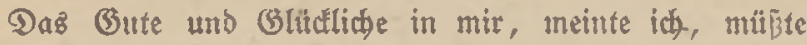

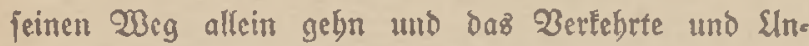

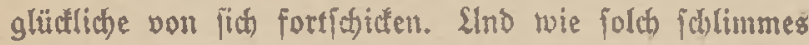
(Brübeln meiftens enbat, Das tweifft ou wobl. 21bar (Bott bat mich belvabrt unb Grau uno Rinber, Die immer, Tag unt Nadft, ttm mid waren. Uber bie

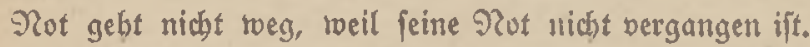
2lber id weip nicht, was idh dagegen tum foll. Oitels

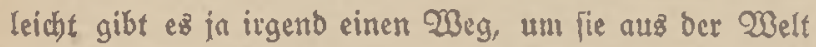

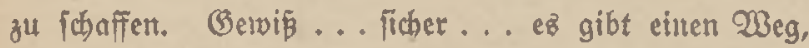
aber id) finbe ifn nutr nicht, weil ich Ju ungejchictt bin, und Paftor Boblen tvelן auch teinen ... \$a ... ja ... Slub benn will ids nun gebn, Sojble . . und benn grüp̈ Narie; id) nreine beine Nutter ... id fage ja

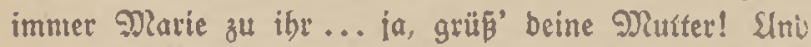
benn will idh nun gebn. Sa, uno id babe ibm nun boch ein twentig gebolfen, Sibble... babe ich nicht?

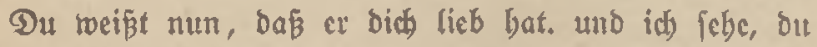
bajt ibn aud gern uno willit itgn nebmen. $\Im a$, ids babe ibm boch ein wenig gebolfen. Aber freilich, bie alte, grofe Not bleibt, das fehe id) roobl ein. Das (ciz"...

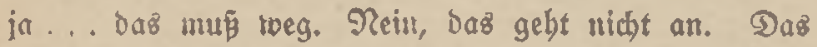
muß roeg. Einen $3 o r n$ im Serzen tragen, einen $S_{a}$, und das zeitlebens ... das ift troftlos,..."

"Эa, Das ift es, Onfel Ott."

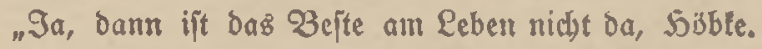

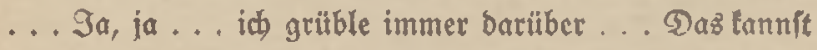
bu glauben... toie es möglids ift, ign bavon zu erlojen 


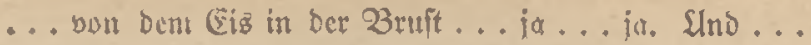
ith will es bir fagen: ich glaube boch beinab . . . idh bin cinem guter Bebanfen auf bet Epur! $S_{a}$, id glaube beinab. Ich twill morgen vor Der Rircljzeit mal gut Waftor Boblen gebn und nit ibm barüber reber. Frei= lich ... (eicht ijt es nicht." $\mathfrak{E r}$ itand fitfl unt jah auf bie Erde, und ploglich) ftanoen ibm bicle $\sigma_{\text {dhmei }}$ tropfen auf bex Etirn, und er twat jäly blä getworden uno peine Soände flogen. "Zlber went ich ibm cine Liebe erweifen und helfen fann ... Soffentlich ift ez Dunn nicht wieder vertebrt, Sobbtel" Slnd er lab fie mit feinten gläubigen, bilflofen Rinbernugen an.

"WOaz ift es Demn, Onflel Ott?" lagte fie in jübent Gorgen. "YBaz meinjt du? Willit bu esิ mir nicht jagen?" "Nein, nein!" jagfe cr. "Gag' mir, twie ilt ež ... gelyt ex morgen in bie Rirche?"

"Эa, Das bat er gejagt. Er will morgen in bie Rircl)e."

"Ev ... po ... Run bann will id mun alfo gebn, Rind! Эa, dann will ich nun geben! Slub bann gritis" Deine Ditter!" 


\section{Rapitel \\ Bater Ott}

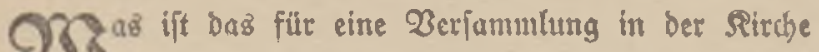
von Altenfiel, twenn fie gut bejudbt ift! W3elde Erjheinungen! Weldje Perjönlid)leiten! Welde (Bes Danfer geben einem ba Durd) ben Ropf! Ez ift nidt zu veriteben, daḱ bie Menichen nicht an jebem Gonntag ober bod an jebem zreeiten in bie Rirche geben, gumal wenn fie geborene 2lltenfieler find ober bod lange Sabre ba gelebt baben! An biefem bellen, fonnigen Serbittog waren im Sauptteil alle Bänte vollbefebt. Ez waren nidjt allein bicienigen ba, bie immer augegen fint uno bie ben Bottezbienft überbaupt ju einem

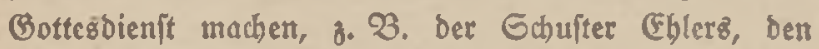
fie ben Soiligen nennen, ber fich nact) alter Gitte immer verneigt, twenn Der Name Des . Seilands gefagt

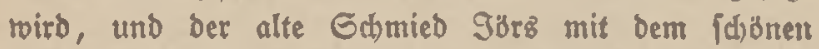
weiken Sopf und Der rounderwollen Saltung - wie ein alter 3aum, Der lich zur Erbe neigt und bald ftitrzen wirb - ber in feiner ganzen (Erfideinung allein icton eine Wrebigt iff, unb toas für cine; uno bie alte Antie Teut, bie im eriten Rriegsjabr ibren Gobn, Den Rebrer, verlor, für ben fie ibr bübicher, tleines Saus das gange Sabr binburd fo blizblant bielt, immer in bem (BeDanten an bie lurzen vierzebn Sage, ba er mit jeinen Rinbern von Altona berüberfam uno ibr geebrter unb geliebter Gaft toar; unb ber alte Sbom8 Sbedenz, ber nod immer von feiner Grau in die Rirche gejbidt wirb - wäbrent fie bie Guppe todit uno an ibn 
Deutt - blö, wesil el in feiuer Sugeno ein übernütiger

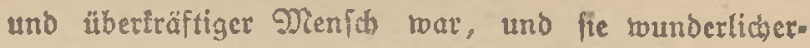
weife immer noch im Gimn bat, bas er, wie in leinen Sugendtagen, auth jest noch nach allen Geitent aus. brechen unb ausfकlagen tönnte, und ber Rirci)gang alfo für ibn nútig fei, obgleid er nun vierzig 3abre lang bas rubigfte Leben einez Sagelßbners fübrt und über fiebzig Sabr alt ift und ein alter, guter und fitler ßater unb Broboater; und bie junge fünfundzroanjig. jäbrige Sad)ter, von Kubolf Anbers, bie immer unter einer ribtliben Wolte einbergebt und nicht tweís, twas ifit, uno roie und sarum fie anberz ift als bie andern शäbd)en. Sie arbeitet vom früben Norgen bis in bie Racht auf Dem freld und im Saus ibres 2aters, und ppricht nur bas, wasి zur 21tbeit gebist, und fitht Gonntags fill und fumm in ber Rirche rwie ein Gdaf, Das träumend unb von je!ber in feinen Gtall gebt. Nicht allein biefe toaren ba, bie immer tommen; jondern ez moren and bie ba, bie nur alle brei, vier Woden tommen, und auth diejenigen, bie nur breiober viermal im $9 a b r$ erfibeinen. Was fab man ba fut (Beftalten! Weldye Raturen! Welces Reben! Da ift ber Gattler Roboe, ber fich immer fo jegt, baj awijhen bem Pajtor auf ber Rauzel unb thm eine biffe Solzäule ift, aus teintem anderen Brunde, weil ex einmal alz Rinb ein Fünfgroiłenitüa vom Rabentif gejtoblen bat und fich besivegen beute noch blagt, unb fürdftet, bafi bet Pajtor plötlich bas Wort Gủnde nenst, trobei ex nicht allein beftig errötet, fonbern aut zujammenzudt. Da ift ber lange, Düne Seintid Sbobe. 


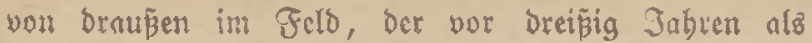
Rateinjchüler in ber Gtabt ein feiner, getwandter Stunge und als freitwilliger Sllan in Sannover fait ein Bect roar; aber alluäblich wutbe er immer einfacber an Rieibung und auch an Geift und Ecele, unb ift jebt wott allen Bauern in Leben und 2 int Der fimpelife, ja fait cint 21nitop. Die Reute fagen, es fei nictsts als Bequemlichteit; in Wirflichfeit aber - man merte $c$ B an feinem bebüchtigen, langiamen und frifijchen $\mathscr{B}_{\text {ejen }}$ -- war ez robl fo, baj er in bem ganzen Betu ber Penfdhen, ja vidleid)t ber ganzen Edjb̈ping, wie nan fo fagt, ,ein Saar gefunben bat', unb fid) mun vorgenom= men bat, es geiviffermaßen in feiner ciufach)fen, fimpel=

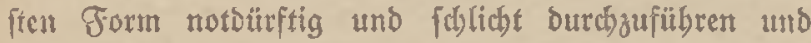
fich tweiter nicht mit ilym einzulaffen uno zu befaffen. Sn einem fatbolijden Lanbe wäre er cin Mönch geworden. Unb ber Sirte 2loolf 3oblen war ba, ber Better von Pajtor Boblen, der Ginter jeber Gtrople bes Bejangz eine $\sigma_{\omega}$ leife fingt, gantỏ allein, bic burd bie ganze Rirche flingt. Cinige jagett, er madte es fo, weil er itt Feiner Rinbleit bei Qebrer Bramm in Wuljenbujen in die Gdule gegangen ift, ber nods ein felbifgelebrter Sdulmeijter rar; andere fagen, er tut es, tweil ez ibm fo paśt, wie ja benn alle Edjäfer fo etruas Rechtlojes unó libergreifendez, ja fo etwas Eigentummibriges baben. 2lber es ift roobl angunelymen, Das es bas Dieer ift und

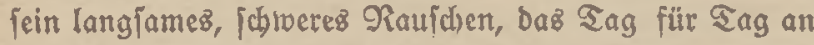

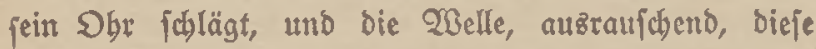
Gatroingung und Ghleife an fich bat. Diefe unb viele andere raten ba. Uno oben vor Der Orgel fá̃ Rebrer 
Dartenz, bet Gtelloertreter für hen richtigen Organijten, ber als Reutrant in Flandern in Felbe lag. Er Gatte bie cine band breit auf die Sende geipreigt und bie andere fdyon an ber ridbtigen Etclle auf ben Tajten.

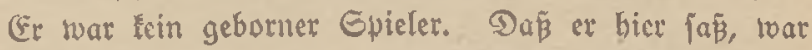
fein tapferer und trenter vaterländifcher Silfäbienlt. Ër probte jrübmorgens, er probte abentos, er probte nad)tz im Gdlaf; ex probte immer, uno immer in 2ingiten. Er probte leiber autb), wäbrent Paftor $30 b l e n$ prebigte, und verga fict in Cifer und Pot uno brüdte zu tief auf; uno es fulbr ein Orgeljitoß beftig uno brobeno, rnie bas Gericht Gottes anbeuterto, buth bic Rirthe. Slnd zulcht maren auch zlvei beripätete Edhtwalben Da, hie audb noch Dazu gebörtell; Denn Daz eine Fenfter ftanto ben ganzen Gommer bindurch allein igretwegen offen. Gie waren da, bamit die Rleinen, die dic Drebigt nidjt begriffen, aber Durchaus in bie Rirche getwollt batten, auper ber iḅnen ganz rätielthaften uno

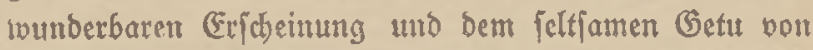
Wajtor 23oblen nod eine bejondere 2lugentweide bätten.

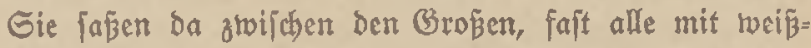

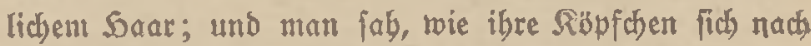
ben Gothwalben ricteten und twelih ein 2luffebn cz bei ibnen gab, als fie einmal nebencinander am 2ltar auf

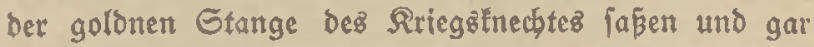
bübich aufatitifjerten.

Alle bieje raren ba und noch biele andere. Wiele, viele von ibnen waren fijwarz gefleibet und batfen foon angefangen zu treinen, als pie ben Tiaum betraten und Die Rränze faben; benn runoum an Don blautueip ge. 


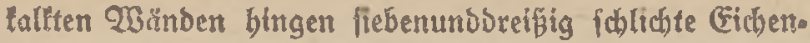
tränze für die Befallenen. Gie naren aufgebangt, fo Inie fie gefollen waren ober wie bie Beftätigung ibres Sobes angetommen trar, Der Reibe nach; nur Reimer Ottz Rranz bing ein roenig bejonbers, nämlich an ber Wand von \aftor Boblents Gtubl. Daß batte ber Pajtor Boblen fo beftimmt, weil er ibn bejonbers lieb gebabt und ihn unterrichtef batte, unb weil er von ben Befallenen ber Süngite twar, faft noch ein Rnabe.

Pajtor 23oblen fam; unb ging mit jeiner gró̧en mä山tigen (Bejtalt ben (Bang entlang; alle twanbten bas (Beficht, wie ex fo langlam in tiefen Bedanten, ben grofien Ropf gebeugt, den Gang entlang tam. Dann ließ̉ ex fingen, nad feiner Senobnbeit eins von ben altbelannten, fichern, feurigen Riedern; biešnal, 2lllein Gott in ber Soib jei Cbr', und bielt Dann in rubiger, wïroiger Saltung uno Gorm Den 2lltardienit. Dann tam ber Drebigtgejang.

Slid nun ftand ce ba auf ber Ranzel unb twartete, baj Det Beiang zu Ende ging und Die Gdbleife feincs ßetter, Des Sirten. Er ftand da febr gebeugt. Uber bas trar ja auch riditig, ba ex jebe Predigt aus ber Siefe aufbaute, und aljo exit in ber Siefe toüblte und grub, uno bamn erft allmäblid, trern er bie Dredigt bober unb böber baute, fid aufridbtete unb fraffte und rieber jung rourbe twie ein 2loler, ber über 2 Belt unb Meer fliegt. Fr a ab über bie Bemeinde bin und nabm mit feinen iharfen, flimmernben 2lugen jeben eingelnen wabr. Da figt Sbiclen vom Safermeg ... bat viel zu piel Gtertriben gebaut ... unb renn es notb bie 
rechte Gorte taire! 21ber perbienen! Verblenen! ... Da fint Rlaus Shun, bat Ulrlaub... er jäbrt ba

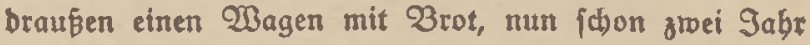
lang! WBie er fich trobl nad) feinem bübichen tleinen Betwe fe jebnt! Da fint die Witwe von Sarren Deterz... in Polen begraben auf einem Sügel bicht überm शjemenfluß ... Da figt die arme Dlutter Blaa8̊ ... jtoei blübende Esbne liegen in Glandern ... Da figt Reimer Ott mit Soarm, bem Simmermann, auf Slrlaub oon Wilbelmb̆haven; er muß beute Mittag trieder abreifen ... bas grope blonde Näbden neben ibm ift Lisbeth Shomien ... Slnd ba binten, neben meinem Zetter, bem Sirten, firt aud Eggert, ber an ber Goulter unb aफ, an ber Geele fdrwer Berwunbete, Der Sodjmütige, Der Gtarte, ber Rrante... bilf Gott, Dá er beute gejunb roiro!" Das Serz Hlopfte Pajtor Boblen fo, Dafa er bie Sand brauf legte... Dann begann er zu predigen.

Ez lag feinen Dredigten teine Rirchenlebre zugrunde, ilberbaupt teine Lebre ober gar ein Gyftem; es lag ifr nid) $t 8$ reiter zugrunde als ber (Blaube an ben mübfamen, gropen, beiligen Ginn ber Welt, und ber Gđüpfung. Er betete biejen groben beiligen Ginn Der Welt an; und ber Blaube Daran war ibm fein ein unb alles, fein 5 alt in jeinem Leben. $\mathfrak{I}_{a}$, fonft wutrbe er berfinten! 2aber er fab biejen gropien guten Ginn ber Welt melyr, roie er in ber gropen, weiten Natur unb im Nenichenleben in (Fricheinung trat, als wie er in ber Bibel jtand. Sa, wenn bie 2 Bibel gegen bie शatur anging ober auch nur anzugeben fdien, Dann nabm er teine Rüdfid)t. Ridst, Daß er roie ein Rart gegen fie anftürmte! Nein, er bog fie; er berifhob fie; 
1und nut roesn es gar nicht anders ging, fobob et lie ganz z"tx Geite. Die Tatur und Daš Reben, baz fie jeigte, bas ging ifgm thber alles! $!$ (Ex war benn auch eir

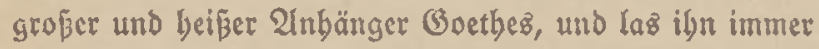
wieder, biefen großjen 2lusweiter und Erbeller unferes

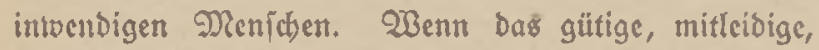
Deutiche Semut Gris Reuters peine beilende 2ltbeit an feiner vertwunbeten Geele getan batte, bann ging er ă Goetbe. Slno er prebigte Denn aud im 2 ejen uno Ginn Boethes. Tlatirlich war da ein grofer, groper

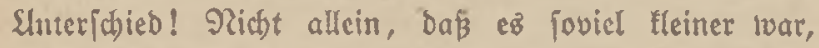
was ex jagte - obtoobl (joctbe auch zuroeilen Näuje und (Efirg gcprebigt bat, nad) feinem eigenen Beftänbnis - fondern ez war auch) Dutntler. Dlan mertt ja auf allen Eeiten bei (Boethe, dā́ er als looblbabender Leute Sind gut unb weid) und geliebt aufroud); 叉aftor Boblent aber batte bis̆ tief in ben falten rufigen Serbjt

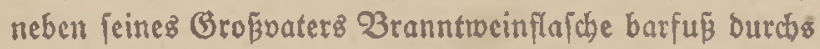
Watt getrabt. Ulub wenn Boethe bie Gabe ber Ges funbbeit uno bez [d]önen Majes mitbefommen, po batte Paftor Boblen die follimme Rrantheit mitbetommen.

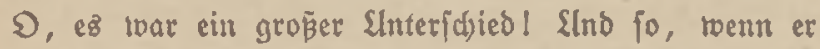
aud) von शatur Boctbifd füblte und auch predigte... jo war es cine bejonnere 21rt (Boetbe; es twar ein mitib. feliger und ein buntlet.

Es war ein Blüct, baj et bente nicht in jeiner Cinleitung, wie fonft oft, irgendein Sier aus Watt, Gelo ober Seide abmalte und vorfübrte, genat, gründich, lebrhaft, cis wenig zu umfiẗublich - ganz mie ber alternbe Guetbe - fonjt bätte biejer Gottebdicnit für 


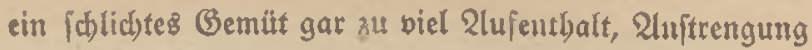
und \&ufregung gebracht, fonbern nichts roeiter vorbuadbte, als eine Tagweroung, cinen Gounenaufgang, wie er iln einit als Rnabe in Boot, Draußen im Watt erlebt batte. "3uerit," fogte er mit feiner rubigen, gütigen, eintoringliçen Gtimme, die ben 3 ubïrer immer neugierig erbielt, "als ich im Boot crwadte, lag nod) bie शadjt

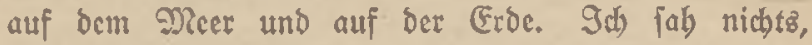
loas bavon rebcte, bas cin Sag werben würbe; ja, $c s^{3}$ trar fo ftill uno fo ohne Reben unt fo ountel, das man Den Glauben, dấ von fich wiez. Aber Dann tam als erftes ein Wint auf, der webte von Offen ber und berülyte bas Sorz wie ein Sauch und eine Ooraljnung einer andern 3eit; aber eริ war nicbr eine Warnung alß eine Derbeiß̄ung; benn der 2 sind war hat und falt und tat cinem eljer weh als toobl. Danach fam eine Mabre, bie mit einzelnen Gabreien, bod bben und ganz alfcin, auch nad Often zu flog. Uber ibr Echrei war bart und flang beijer und verloren, und fajt feindlich über bie weite, tote Edjopfung. Danadh entftallo bas erfte (5rau, fern im Often, über ben Wälbern und Sciben. Wber obgleich es Da mur nicorig uno geouctit fanb, mübjam wie ein blaffer Edhild, grünlid), faft feindlid) ... fam boch ein (Befübl ernjter Ertwartung (ther mid), uno id ftand im Boot auf und fab Dabin. Danach fam Daz 2 tüllen ciner Rub vom Deid) ber und Dann bas erfte Gdreien

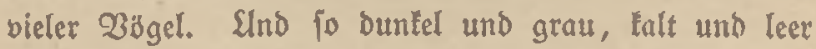
nod) alles wax ... das ganze ungebeure Rund ber Ratur um mein Boot ... ich muthe boch ein roenig frob. 
Es fobien mir bie erfite Gtimme, die zu mir iprads; Denn bie Pracht batte nidht zu mir gerebet. Danach lam bas 2ufujtebn ber Sieridaren, Der taujende Miobren unb Tüten, Riebige und Enten und aller andern Bögel; und bie Kelt und bas Neer rwurden ficttbar, auf-

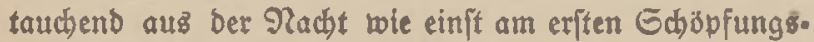
morgen. Da rourbe mix bas Soer frob und ficher, unb

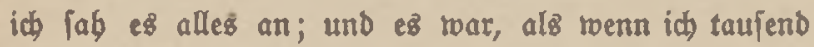
Ungen batte. Uno bann fam eine Etille, eine gró̉e, beilige Gtille, und bann, fern vom Oiten ber uiberm 20 ald, ber erife Grub bes Sagez, Der erifte Gtrabl ber Gonne. Da wogte in mir, bem Fleinen Rnaben, won groper

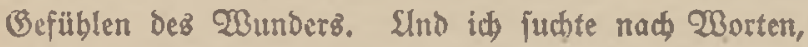
und brath, ba id cigne nicht fand, in verborgenten in bie Worte aus, bie id in ber Gaule gelernt, unb bie wir nun eben gefungen baben, Die vor Gunbertfünfzig Sabren Der alte fromme, andäcttige Profefior in Reipzig gebictitet bat: Die Sinmel rübmen Des Eroigen Fbre ... umo id jagte bas Qied vor mid ber. Und bieje Berje waren bas erjte Mal in meinen jungen \abren, Daß etwas

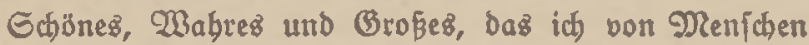
übertommen, mir ins (Bemüt fichlug, uno fich mit meinem Bemüt verband und an meiner Bildung fein Seilchen beitrug. Nöge es auch beute jo jein ... für manchen vou (Euch. Misge bas Mort eines wabrbaften, guten und flugen Menichen, bas ich mun borlefen will, an feinem Seil unjer Bemüt erbauen ... bas fo teicht, fo leidst in Srümmern und gerrifen liegt."

Slno Dann laş ex aus bem gefäbrlid)en und fobinten,

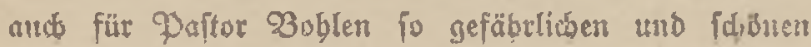


nhten Rapitel bes Römerbriefes bie troftreidyen fajönen lekten fünf Berje vor: "Wher will un icheiden von Der Liebe Bottes? Sribjal, oder 21ngft, ober Ber= folgung, ober Sounger, ober Blope, ober Fäbrlidleit, ober bas Gdjwert? Wie gefdrieben ftebt: Slm beinet= willen werden wir getötet ben ganzen Sag; rir finb geachtet wie Galachtichafe!... 2lber in bem allen ïbertwinden wir weit, um beşwillen, ber unz gelicbt

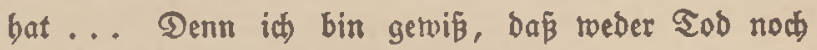
Peben, weder Engel nod, Gürftentum, nod) (Betoalt, rober (Gegenwärtiges noch 3utünftiges, roeder Sobes now) Siefes, now) feine andere Rreatur ... mag uns fueiben von ber liebe Gottes, die in Cbrifto Seju ift, unierm Serrn."

Und Dann legte er โo8, aแs der Siefe peiner eigenen armen, mübfamen, vergrïbelten Geele, jeiner tranfen Eeele, feiner mitleibigen, feiner in ber Tiefe itürmifhen Eeele. Er pprach zuerit von bem vorhergehenden 20 ort Des adten Rapitcls: von bem Bangen uno Geufaen Der Rreatur. (Er fprath bon Dem Eebrei ber Mabiven

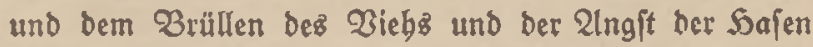

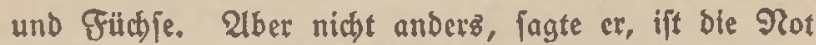
Der Menid)beit. 24ud fie ift ein Etüct ber Rreatur! Wie nüubfam fei ibr 2 eg gelvejen burdi Sabrtaufende: im Rampf mit wilben Sieren und wilbem Wafler, mit Peit uno Gatrindjucht, mit Feuer und Edjwert! Sund po wäre es biz auf bie beutigen Sage. Die Nenfabbeit bätte wobl viele Sabre lang gedacht, es wäre nun Friede und Freube fïr fie da ... all Febb' bätt' mun cin Enbe! 2lber nun wäßten wir: twir wären imımer nod Frcnffen, Die Brllder. 


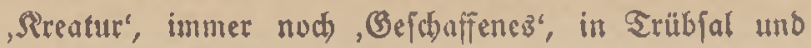
2nglt, in Sunger und $B$ löß̄e, in Gährlichleit und Gumert! $D$, welh eine Not in Diejen Sabren! Sind run iprach er in berzbetwegenden 230 rten von ber Not biefer Seit. Wie rwir unz quälten in unjerm BewifTen, Daßs bie ganze Nenidbleit gegen uns ftände und tvir twäßten nicht warum. Sat Gott unz das gute Ge= wiffen gegeben ober ber Teufel? Dns bat Boft getan! Er iprad) von ben Gefallenen, ben Zertwundeten und Reibenden, von ber 2Ingit und Qual Derer, bie unterm Feuer ausbarren. Er nannte bie शamen Der jungen Witwen unb ber meinenden Mütter. Er

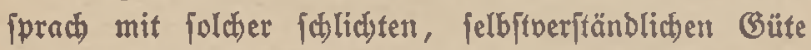
und Ergriffenbeit, obne allez Gerede uno Betue; er nannte bie Namen mit foldher $\mathfrak{B e i d}$ beit ber Etimme, mit folcher Liebe; er umgab bie Namen und Nenfuen mit to gropen Ditteio im Serzen, ba仿 fie alle an feinen 2lugen bingen. Nan börte nur bann unb twann ein Gdlutben und ein foblweres 2ltmen. Gie ftanden nun alle unfer ber Not. Gie empfanden fie mun alle; aubi) bie, bie noch berjhont geblieben twaren. Gie füblten nun alle mit ben Leibenben, ben Beichlagenen, ben Erjhlagenen, Den Weinenden. Gelbit bie Rinber vergaßen bie $\sigma_{d}$ walben und faben unentwegt mit gropen fitllen 2lugen zu ibm auf. Sie febnten fich mun alle, alle, grof und flein, alt und jung, nad) cinem 2lus: reg... fie jaben num alfe zu ibm auf in bem Be= Danten .... Nun, fomm! bald ... tomm balo mit beinem Sroft, toenn Du einen weip̈t!'

Slno er wufpte einen! 2ld, nut ein Menif, ber 
rwirllit bie Qual bes Menjheulebens erfabren hat, nur ein Weinenber, ein Sammernder, eln 3erfdlagener folle ein Prediger fein! Nur jein Rlagen ift echt; nur fein Qachen ift ed)t! 2(d), Pajtor Boblen braud)te ja felbit cinen Sroft! Wie bätte er fonjt leben tönnen, er mit leiner Rot und Ginde, mit feiner Rrantbeit, Die er immer wieder Günde nannte, Darum, reil er fo ftarfe Qtrme batte, Daßj er fie nach feiner Meinung bätte ïberwinden mulfen! 2af, er fannte ja bas Grauen in ber Nact) im bden, wilben Watt und dic Not einez trei. nenben Serzens!

Zlip iprach er voll ber Liebe, bie Gott zul uns bat! Er begann von alten 3eiten ber. Wie trots aller Not und allen (Grauenz bie Menjchbeit bod) immer an einen guten, tiefen Einn bez Lebens ge= glaubt! Wie bie beften Beifter barum gerungen baben ... um biez, Trobs alfedem', um dies, , Tennod'! TBie Dies "Dennody", biejer Wiberjpruch und Gegen $a$ a, Das grope, ichaurig faböne Bebeimnis der Menichen. feele und, nod) dem gropen, mitleibigen Blauben bes 2lpoitels Paulus, das Gebeimnis aller Rreatur, bcr ganzen Edjäpfung, twäre. Die Epannung, bie Gebn: fucht, bas trosige, Dennod: Das ift bas Leben ber Gdjupfung! Die, Dennodleute": Das waren bie gropent Seiligen ber Meniabeit! Die gejugt: , Slno ob mir autb Leib uno Eeele beridmaditet. . . Dennodh bleibe ich [tetz an birl' Golche, Dennoch'seute wären bie vornehmiten aller Seiben unb auth bis alten Propheten getweien. Uus ber Tiefe beraus glaubten fie all ben Bott und an einen gropen beiligen Willen! Soldh ein, Dennod"= 
Mann war aud ber Seilant getwejen, ex bet grofie von allen, weil ber gröfte und reinfte in biefem Blauben! Goldse (Denrod'seute raren aud alle grojen Deutichen! $\Im_{a}$, Das gebörte immer zu einem gropen Deutichen, anbers belam er nicht Diefen Ramen im Dentijhen Bolf: twent er nidyt ein, Dennod'-Mann getwefen, wie Rutber uno Lefing es raren, und Serber und (Boetbe, und Friedrid) Der Broße, und ber alte Raijer und Biżmara!! Slno Dann lagte er - mit bebender Etimne - wie er ... Daftor Boblen ... nicht leben wolle ... nidht einen Sag .... wenn er nicht diejen Gauben bätte! Er, Daftor Boblen, wiffe, waz Sot wäre uno totz baz Geufzen ber Rreatur fei! 2lber er wiffe auth, waz Blauben und Blaubens Gegen feil Slnd er ermabnte fie mit grofer 23etwegung bcz Serzens, mit ben gütig. fiten Worten, mit Den unge/chidtejten, rübrendien $\mathfrak{B}$ p loegungen feiner gropien Sänbe: fie müdten bod) alle Diefen, Dermod". GIauben baben, biez Eigentümlichite

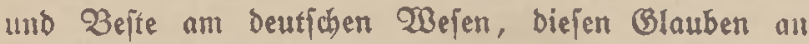
Bottez beilige Riebe ... tros alle bem! Thidtt finen, fagte er, two bie Epsitter fiken! Nitht finen, too die 3weifler fizen! Ob einer twenig von ber Qual des Rebens rifje, ob ciner unjagbar jumer ge-

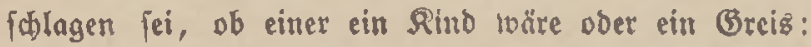
jeber mobte biejen boben beiligen Glauben im Juergen tragen, als fein beftes unb belligites Befigtum: Daß über ben Gternen ein (Bott einen feinen, fabünen, reinen Ginn ber Welt in feinen Sänden babe, ben wir artar nod nidbt erfennten ... bow unjere Soten etfennen ibn ...; uno liber ben Ëternen ba wirb er einit tagen! 
Slitb bann fprach er jum britten: $\mathscr{W} \mathrm{cmn}$ es benm nun fo wäre, went benn mun bas beutich toäre, biejen Blauben fu baben, tutb fie alle, weil fie ans alten beutichen Befhlechtern mären, ibn twie von felbjt im Serzen trïgen: To follten fie aud banach leben, vom Rorgen bis zum 2 fend. Als bie, weld)e an ben guten Ginn bes Lebenz glauben: lähelno, freundlich)! 2llz bie an ben reinen Ginn bes Lebens glauben: reines Serzens ! 2 lls bie an den beiligen Ginn, des Lebens glauben: anbächtig unb ernit! "Giht unjere B̈efangenen!" fagie er, "twie fie unter uns leben: wie fie ftill mo frieblich ibres Weges gebn, wie fie lähthelnd ober ernit uns grifien, wie fie mit unjern Rinbern ipielen unb fremo= lid) firb, obgleirh fie boch alle, alle, woll beifer Gebn= fudist nact ber lieben Soeimat find ... fo wollen aurs

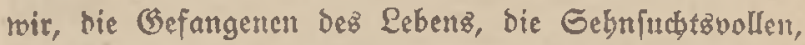
bie Wandrer, miteinander immer gütig fein, inunct freunblich, immer mitteilfam, immer eimficitig, immet vergebent, unb wenn wir gefeblt, albbitfe tuent ... als bie ba füblen unb rwiffen: fie wanbeln vor ben tyeiligen, febenden 2lugen Gotte8, nor Dem Ricbenton, vor bem Ginner Dez Lebens, bet แnz zแ fich jiebt, ber unz bier seitlid uno bort etwig bei fich baben laill, oa, no alle Not ber Rreatur, Des Befthaffenen, Des noch Werbenden, eill Enbe gejumben, und bic Erlb̈ung ein= getrcten ift!"

218 er endete, war er tros feiner gropenen Gtätfe mühe und ftügte fich făber auf feine Särbe. 2ab:r er ließ zur Oermunberung aller ben gropen Ropf nidst finfen, um ftill fur fich jul beten; fonbern er bebieit 
ibn aufgerichtet unt lab nach bem (Enbe bet Rirche, nach) Dem Ottichen Gtubl.

Uno ba geidab ettwas Erifulutternbes. Sie birten eit (Geräuí ... börten jemand auts ber Banl treten, unt als fie, voll unerflärlicher Mad)t gegrwungen, fich umjaben ... die ganze Ritche ... ba jaben fie ben alten Reimer Ott ba fteben, in feiner fdiweren, bageten, gebeugten Bröbe, mit einem rïbrent unbebolfenen, abet leudtenden 2lusbruct in feinem großen Gefidt. Ev lagte langfam uno bettlid): "Sth babe meinen Gobn Eggert befchuldigt ... bejchuldigt ... ich twill 216 . bitte tun ..."

21 is er fo weit war, prang fein Gobn Sarm, ber

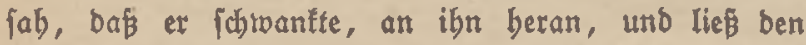
Gallenben auf bie gliejen gleiten.

Pajtor 20 ollent atmefe fdotwer und fagte mit jitternber Stimme: "Er batte eళ̊ mit mir abgemad)t, baß er 2bbitte fun roolte, bamit fein Gohn wieder Grieben mit ben Denichen mache unb wieber glüđlich würbe ..."

(Er lonnte nidbt weiter iprecher. "Wir trollen mun auseinandergebn," fagte er. Slno er iprach Den Gegen, Der feit uralten Seiten rund um Den Eroball gebeugte und ftürzende Menichen getrojptet und geboben bat. 


\section{Ravitel \\ Zerföhnung . . . Der Rrieg}

Fagert Ott war gleith nach ben Worten uno bem Q Sinfall bes Zaterz aus ber Sirche gelaufen unb mit langen Echritten nach Dem Eublichen Sof gegangen; fein lecter Z̈rmel batte fid aus ber Safde geloft uno

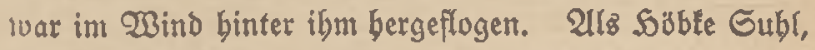
Die fich erfit überzeugt hatte, twie mit feinem 2 ater ftanb, binter ifm ber nach Sauje tam, erzäblte fie erft ibrer Mutter, bie nicht in ber Sirche getwejen war, mit flie. genben 230 rten, was geidheben rar, und fragte bann, 100 er twäre. 2lber bie twitß̈te es nidht. $\mathcal{O} a$ ging fie Durch ganze Sous uno baun burd ben Barten. Slno Da ftanb er unter bem alten Zirnbaum aur Graben, Dort, top fie fich fruber itber ben Braben bin fo oft mit ihm unterbalten batte und ihm bie reifen Bimen binübergetvorfen batte.

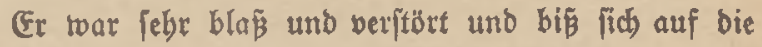

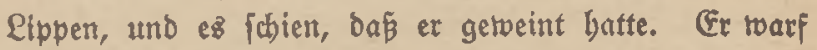
einen rajuen 3 lid auf fie und fagte: "Ift er wieber bochgefommen?"

"Sa," [agte fie, "ich ging erfit bann aus ber Sirche, als id) [ah, Da⿱⺈ es eine fhtwere Ohnmadt twar."

Er ftarte weiter Hiber Das Geld nad) Dem EItern. haus binüber und jagte: "Eben baben fie igu nach Saus gefabren ... mir fhien, er lag nicht, er faß̧"... Er atmete beftig und (d)wer. "(Ex hatte bas roirtlich nicht nötig gebabt!... शRein, bas twar nidht nỏtig!"

Gie fab ibn mit ihren gütigen, jo berebten 2ugen 
an - ibre 2lugen mujten inmer für fie reben, ba ber Munb nidit recht tonnte - unb fagte bedichtig: "Ob es nöfig twar ober nicht... i id finde ... es madjt ithm große Egre, Eggert! ... Ober meinlt bu baß Begenteil? Gürchteft bu baz Gerede, bas num roieber tuber die Otten lozgehn wirb?"

Er fubr auf und fagte mit flammenben 2lugen: "E\& foll fich einer unteriteben und ein 2 ort itber meinen Bater [agen! ..." Snd bitterlid aufreeinento fagte er: "Der befte Menji) auf ber ganzen Welt!"

"Er twar immer fo, Eggert!" fagte fie langfam und vorfidtig.

"Das treís id) ja!" fagte cr wilb. "WBaz meinft Du, rarum id) fonft fo rafend gegen ibn gelvefen bin?!

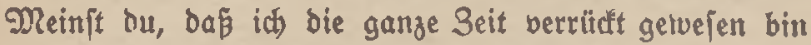
um nichts und wieber nichts?!"

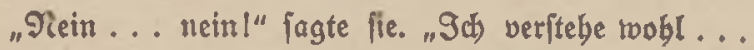
fo war es!... Ulnb nun?" Sie gog bie Brauen fo

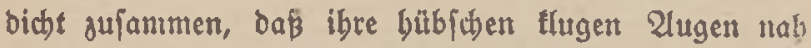
beieinander ftanden, und fab ibn unfagbar frogend git: tig alt. "Slnb nun q" pagte fie noch einmal.

"Slnd nun?" fagte cr zornig ... "Sd) mus ja nun bin! פaz ift ež."

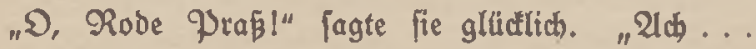
Das ift recht!"

"9a," fagte ex mit zornigen Tränen in ben 2lugen, "es bilft nun nichts ... iథ mús nun bin!... Slno Das gleid)... Daf es ibur folctie idfredtiche Rot ge= madt bat... Dab babe id nicht getwupt!... (Ev

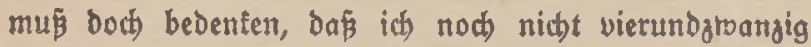


bin! Rann ich benn banteln twie ein Dreipiger? Tas nut er boch bedenten?!"

"Er twirb es aud bedenten, Eggert! Gei nut ftill! Soum! Sal geb' mit bir!"

„Sa ... twenn bu mitgebjt... dann trird es viel leichter!..." (Er griff nad) ibrer Sand und britdite fie und prepte fie gegen feine 3 rult. Er batte ja leine Jtoeite Santo, fie feftzuhalter.

Go gingen fie $\mathfrak{A r m}$ in $\mathfrak{A}$ rnt burd ben Barfen. Ul'̆ fịe an ber Bant uno bem Goot vorbetfanen, blteb fie ftebn und lagte: "Dein Bater twar geftern bei mir ... wir baben faft awei Giunden bier auf ber Banl gejeॉen."

"Er war bier?" fagte ex vertwunbert. "Was wollte

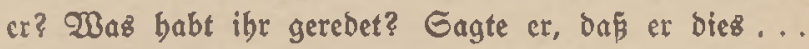
Dies in ber Rircthe tun roule?!"

"Nein," fagte fie, "er batte etivas anbres auf bem Soergen."

"Etwas andres? Was benn?"

"Goll id eళ [agen?"

"Sa," fagfe ex, "fag' boch..." (Er war wüllig abnung:los.

Ste war rot und völlig verwirt, und lounte es nidst fagen. Dann [tié, fie es rajch uno fajt unfreundicls berbor: "Er bat ben Freitwerber gelpielt! Ex lagte, but bätteft mich gern... er uno der alte Weter baben es gejebn ... fagte er."

(Ex fab fie mit einem bilflojen 23lita an; und fab bann weg, gand wie ein Sunge, ber unter einem 2lpfelbaum gefunden rwirb, ber nidjt in feines Baters Barten fteht. 
Da trubte fie, wie es um ibn ftand, und getwaun

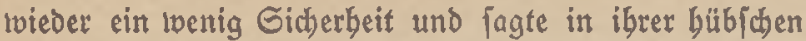

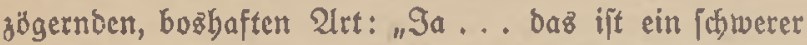
Sag ... für bids, Rode Prấ! ... Erit follit du nun mir ein guteg 2 ort jagen unb bann brinem Bater ... po wie Paftor Boblen vorbin in feinem oritten Setl geforbert bat ... Da fitchit ou nun, und haft..." fie tollte fagen: "all beinen 2 Bik verloren."

"... Slnd bajt nur ben einen 2 rm ..." fagte er.

Da legte fie trieber, mit rajcher, gütiger Betwegung, wie um feime wunbe Geele zu f̧ü̈rsen, fo tric fie vor vier Wodten in ibrem Etübdhen getan, ben 21 rm um feine verftümmelte Echulter uno fagte wieber: "2l h, Eggert! Darum bijt bu mir ja nut viel, viel lieber! Daz̈ ift ja fuir uns alle gefdebn!" Sand ba fie einmal fo lveit war, füpte fie ifn rafh unt icheu... gand uns gejchidt; Denn fie batte ez nod) nie getan. Sie wat unjagbar berwizrt, unb war in biejem 2ugenblid bie Echinfte im ganzen Lanb.

Da rißj er fie an fiळ, nit feitrem einen $2 \mathrm{rm}$, und tüfte fie ganz finnloz, ganz aus Rand und $\mathfrak{B a n d}$, und

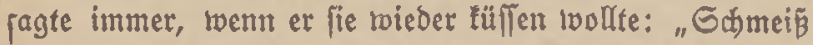
mebr Birnen berüber! Nebr! Debr!" ... Der ridtige, unvernünftige Robe Praß́!

Sie lagte gar nidjtz. Sie touste nicht, twie ibr gefdab. Das wat ibr Berlsbuiz.

Ulక fie die Sofitelle feines Yaters erreichten, ftand ber Sbomieniche Wagen ba vor ber Sïr, und Sarm itans abfdiebfertig neben jeiner Mutter.

यlङ fie Eggert fab, fobrie fie laut auf und lief igm 
entgegen unb umfaß̧te gu fagen mit ibm, uno zog ibn in bie Tiar und zut feinem $\mathfrak{Z a t e r .}$

Sobble Gubl blieb brauñen und ftand bei Sarm, Det nun in Den $23 a g e n$ ftieg unb fich neben ben Befangenen, Den Rufien Gymeon, jeste, ber bie Leine fübrte.

"Romm gefund mieber, Sorm," lagte fie ... "Wo 1/t Riฉbetb?"

"Im Barten und tweint," fagte er mit jtillem Befeficht ... "Wir mögen tcinen $\mathfrak{A b}$ dhieb vor ben Reuten,"

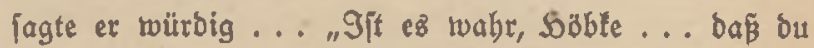
und Eggert einig miteinanoer feib?"

"Sa," fagte fie, und wurbe rot, und fab ibn nit ibren zulammengezogenen 3 rauen an.

(Fr [chüttelte ibre Sond und [agte freundlic) lächelnd: "Wie verlegen bu bift... unb wie bübich es bir jteht! ... (Beb' zu 2isbeth, uno lag' ibr ein paar freundicte Worte!"

\section{Damif fubr et ab.}

U1в peine Nutter twiener auz Der Gtube tam, allein .... Eggert war noch bei feinem Water geblieben war er fojon auf bem breiten $20 \mathrm{eg}$, ber zum Babnbof fübrt.

2uf bem Babnbof traf er fijon eintge Betannte, Die gleid ihm ben Slrlaub binter fich batten. Gie fragten einander: "शa ... aud twieber los?" ... unb juctten die Edultern uno fagten: "Wुas ift gu madjen? Gie wollen 
ia Keitun Frieben geben!" Dann fanden fie ba berum, unb fpracben in ibrer rubigen, langfamen Weife oon Der Fabrt uno ben Gtationen und bent Lufentbalt. "Du bajt es nicht fo weit!" fagten fie. 3wei wollen nad Flandern, einer nad) Rubland, einer unch Rumänien. Der mus̃te fünf Tage untertoegz fein.

In 2 bteil trm er bann mit anderen Rameraben zufammen unb es gab roieber biefelbe Snterbaltung: über bie Fabrt, über ben Rrieg, über ben Grieden. Gie waren nidht fröblid); fie twaren nidht traurig; ibre Geelen waten bon einer burten Notwenbigteit umllammert und eingeglwängt, von ber Notrwentigleit, weiter Rrieger ju fein, fern von ber Seimat und bem fremblidien Leben ber Familie uno bez $3 e r u f 8$, beimatlofe Wanderer, in Rampf unb Rot.

2luf bem Babnbof in Samburg batte et eine Gtunde 2ufenthalt. Dic Heine Sajhe mit ber $20 a ̈[$ be in ber Sanb, ging er grabe und fhmud, febr fauber getleibet, roie ber Geemann es fich leiften lann - ber Rant. folbat fommt gleich twieber in Lehm und Dreet - bie grofe Soalle auf und $a b$, ftand mal bier und ba an ber

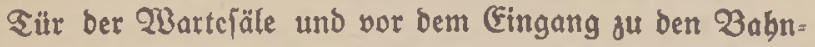
fteigen, und ging Dann rwieder tweiter, und Dad)te an blez und Das, an jeine Braut, an jeine Eltern. Mit ftillen, ebrfürchtigen (Bedanten gebad)te er Reimers, mit inwendigem Rächeln bez Brubers Rlaus, mit Greuben nun Eggettz, mit Rube ber jungen Edtwelter, bie nun fion verbeiratet war. Wenn er benn felbit nidts toieber= fänte ... es toürbe nun aud obne lign gebn. (Gs mufste ja obne ibn gebn. 2uch Lisbeth mute febu 
... adh ... nicht fo tueit benten! Den Ropf bod balten! Smmer Denten: $\mathscr{W}_{\mathrm{enn}}$ nux bas Gäbnlein flattert!

Die gamze große Salle wimmelte von Felograuen und Ratrofen. Die einen tamen, wie er, bon ibrem Slrlaub und toarteten auf Weiterfabrt, fucten und trafen Rame. raben und rebeten fie an, und fammelten fich zu Saufen. Indere tamen eben won ben Fronten. (Fs war wobl gerade ein 3 ug angetommen und bie 2Angefommenen mifdenten fich eben mit ibren 21ngebibrigen, Die warteno geftanden batten, ober gingen, um ibre Weiterfabrt be=

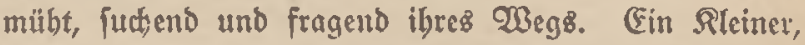
3reiter, Der runb um feinen Bärtel Dafete gebunden trug, Darunter einen ganzen tteinen Etall mit jungen frelgifhen Raninchen fïr jeine Rinder babeim, juchte (ich) mblbjam und eilig feinen $\mathscr{Y B}_{\mathrm{eg}}$; ein anberer, ein ftämmiger, fleiner Rerl, Dunfelbraun on bramitige Be: ficht, liep fich won einem Matrofen ben Laib 23rot und Die Eifenbaube befeftigen, bie bom Sornifter berabge. glitten waren; Ganitäter fülyrten in eirtem Roljtubl einen Verwumbeten nad) bem Wartejaal; ein anderer ging bicht neben einem boben, ichönen Slnteroffizier, Der

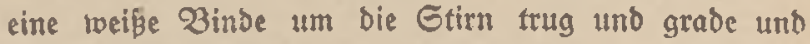

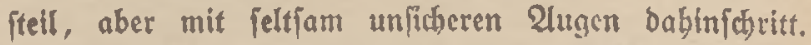
Trainjolbaten, in idweren Gtiefeln, Plnttfiiper, mübjam

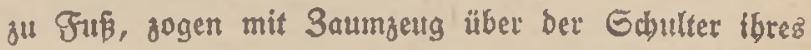
Wegs; ein langer Felograuer, ein groper Mienjc), flarbrifben Dreat bis an bie Süften, in all feinem Gamus uno ber 2ubgeriffenbeit feiner lebmgrauen Rletoung wumbericbön, wollte fich, als er plöblich foviel 
Zürgerliche und Grutuen [ał), ein wenig (chämen, aber ein älterer Mann nidte ihm zu und jagte: "Edmud fo!" Da lächelte er unb ging mit jeiner Mutter roeiter.

Slno in allen Befichtern war nicht Leib, nidjt Rujt; fondern immer Dasfelbe: ber 3wang, bie शot, bie bittere Notwendigfeit, bie Seimat noch meiden, und Seimmeb uno Gdhuts, Rot und Rampf noch loeiter tragen zu mïiTen. 2luв der Tiefe betuf donnerten bie 3üge, die fie bin= und bertrugen, bies reifige, beutiche Yolt, diez

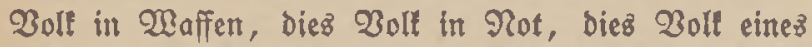
einjigen eire gered)te Gacte zll baben por ber Menjableit.

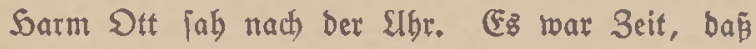
er nach feinem Babnfteig ging. (Er warf noch eines

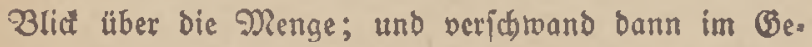
Dränge Der Brauen.

\section{组国代}

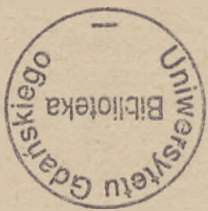





\title{
B.Grote'fhe Berlagżbuchbandlung, Zerlin
}

\section{Werfe von Buitab Srenfien}

\author{
Einzelausgaben \\ Die Ganogräfin
}

Roman. 76. Eaujenb. Bebeftet 4 2N., gebunben 5,50 ID.

\section{Die oret Betreuen}

Romar. 120. Saufend. Gebeftet 4 श., gébunber 5,50 2 .

$$
9 \text { в̈rn }
$$

Roman. 248, Saufenb. Gebeftet 4 פ, gebumben 5,50 शR.

$$
\text { Silltgenlet }
$$

Romau. 149. కaujenb. Bebeftet 5 2R, gebumben 6,50 $\mathfrak{2}$.

Das Leben bes Seilands

Boltsaugabe. Gebeftet 50 PF.

Weter Ploor Gabrt nach Sub toeft

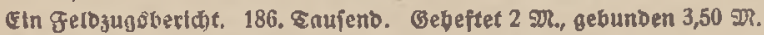

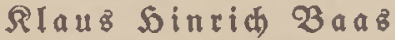

Roman eines Gelf-mabe-2rannes. 77. Taujenb. Geb. 5 Dr., geb. 6,50 श2.

Der Ulntergang Der Q Un a Soltmann

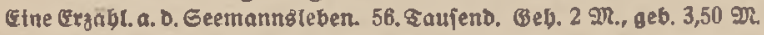

Sönte Erichien

Gchauplet. 2. Iuftage. Bebeftet 2 פr., sebunben 3 gr.

$\mathscr{B}$ i $8 \mathrm{~m}$ a $r$ af

Eptroe Exzăblung.

(3urzeit vergrifien.)

Sammelausgabe

Somane und Erzäblungen

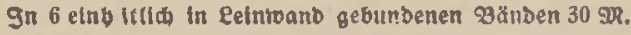

$$
\begin{gathered}
\text { Illustrierte Ausgabe } \\
\text { Эorn घb! }
\end{gathered}
$$

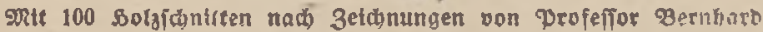
Winter. GroB-Dttav. In Ceinwant gebunben 20 D?. Elebbaber-

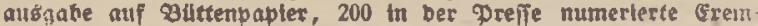
place, in Ceber gebumben $80 \mathrm{gr}$. 


\section{(5. Brote'fdhe Berlagäbudihaublung in Bertin}

\section{(5uftav Frenffen / Sörn ubl

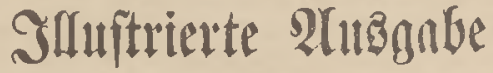

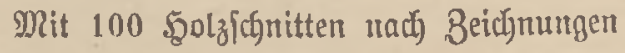

voll

Frofefjor Bernhard $\mathfrak{B i n t e r}$

(5)rop $=$ Sltaw * Sebunden 20 Mart

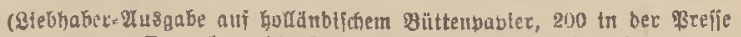

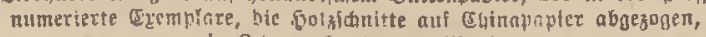
in Reher geburben 80 Mart)

Berlag von Banbenthoef \& Siuwrent in Bottingen

\section{Dorfuredigten}

pnกt

(5) itav ซrenifen

1. פanb 28.-29. T|b. 2. פanb 23.-25. т) 3. Banb 20.-22. Tib.

(bebuticen je 8 wt. Gejamtausabe gebunben $6.50 \mathrm{Mt}$. 


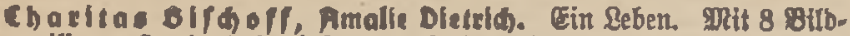

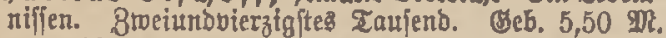

- Bilder aus meinem Eebsn. Mit Jehzzehn \$oübilbern umo

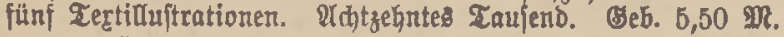

Dissor Blath gen, Bedidte. Reue, vermefirte Rus gabe. Oeb. 4 M. walther ou zt, Det derfunlene Berrgott. Btoman. Beb. 4,50 \$?. Guflof Didbuth, wie dex Eeutnant Eubertus von Barnim fid verloben wolfte und anderes. Movellen. (5eb. 4 DR.

Eenn edMein, Murillo. Dritte Tuflage. Seb. 3 M.

- -, Gertha. Moman. Dritte Muflage. Beb. 8 M.

- -, Ebemis. Roman. Bmei Bänbe. Beb. 9,60 Mr.

- - Der mbnd vour Aventin. Nobelle. Bierte 2ufflage. Beb. $4 \mathrm{~m}$.

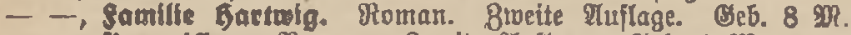

- Rpparifios. Roman. 8meite Ruflage. Seb. 8 MR.

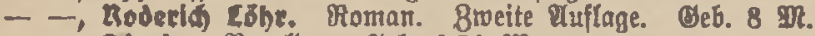

- -, Adotjo. Novellen. Beb. $6,50 \mathrm{~m}$.

- -, Die Gexe von Glauntad. Btunan. 8tweite Xuflage. Geb. 8 PR.

P. Don der Elbe, Der Butgermeijlerturm. CEin Moman aus

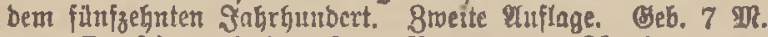

- - Jn reinen sußlapfen. Fioman aus guneburgs Borzeit.

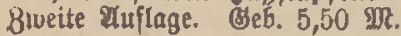

- ullav Salte, Die Gradt mit den goldenen Cfirmen. Die

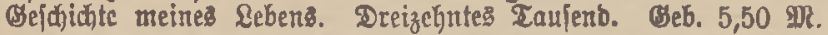

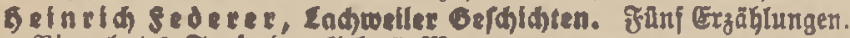
Bierzegrntes Taujent. Geb. 5 פt.

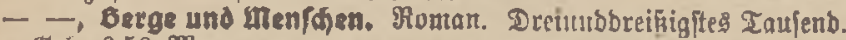
(5eb. 6,50 9.8?.

- - Dllatus. Cine Crzăglung aus Den Bergen. Sicbzeḅnteż Tau\{eno. ॠeb. 4,50 $\mathrm{DR}$.

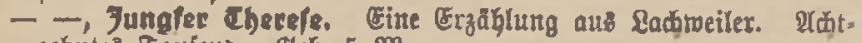
Jegntę Tauferd. Bet. $5 \mathrm{M}$.

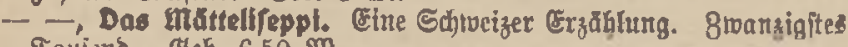
Taujent. \$eb. $6,50 \mathrm{M}$.

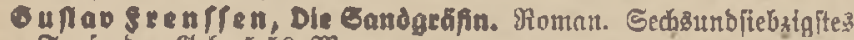
Taujenb. ऊeb. $5,50 \mathfrak{M}$.

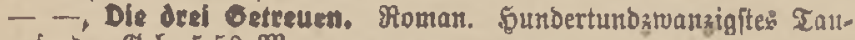

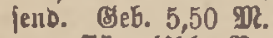

- - Frm 4hbl. Moman. Bweifurbertactutunboiersigftes Taujent. (ste6. 5,50 $\mathfrak{D}$.

- Billigenlef. Ftoman. Sunbertneuntrobietzigftes Taujent. (beb. 6,50 $\mathrm{Mt}$. 
(5rote'fde Sammlung v. Merien zeitgenoff. Sdyriftiteller

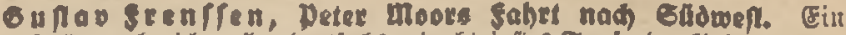

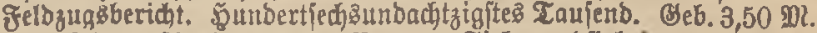
- -, Klaus Gineid Baas. Roman. Siebenunbifebrigftes Taujento. Ceb. 6,50 M.

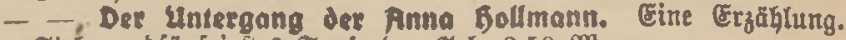

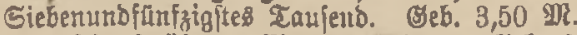

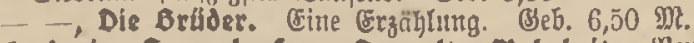

cudwig 6 ang ofer, Doppelte Wabthelt. Neue Robellen. Sec̆ltes tauiend. Geb. 5,50 פ̃R.

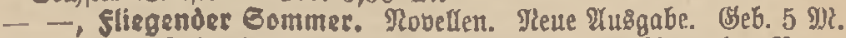

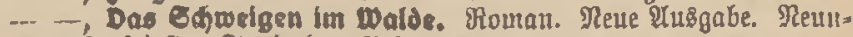
urofünfzigitę Laujent. (\$eb. 6,50 פIt.

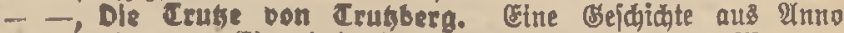
Domini 1445. Einunboierzigftes ¿aujenb. (\$eb. 5,50 Mt.

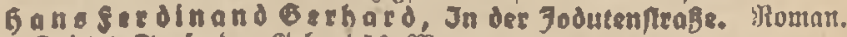
Drittes raujeno. (Seb. 4,50 פít.

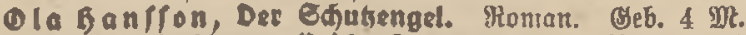

5ermann 6 ef

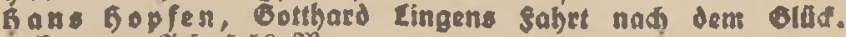
Roman. Geb. 5,50 免.

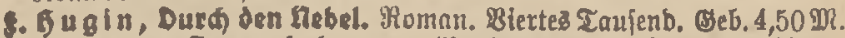

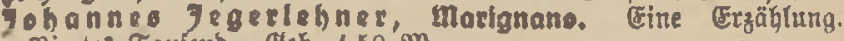
Biertes Taulenb. Seb. 4,50 खn.

- Detronella. Homan aus bem Sodggebirge. Drittes rau. fenb. अeb. 4,50 gm.

- -, Srenzwad der Gobuefzer. Cine Erzăblung. Giebenteg Taúentb. Beb. 2,50 פ1].

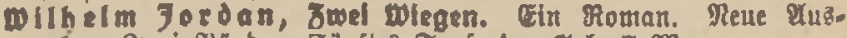

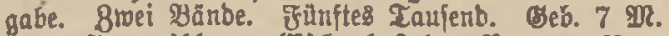

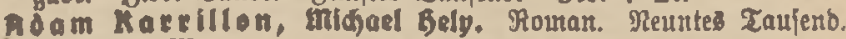
๑5. 5,50 910?.

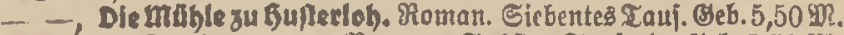

- O domina mea. Romar. Sechites Taujeno. Beb, 5,50 Dr.

- -, Im Lande unfecer Urentel. Drittes Iaufenb. Beb. $5 \mathrm{ML}$

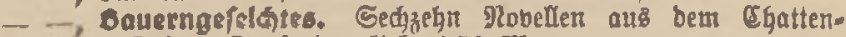
lanbe. Drittes Zaulend. Beb. $4,50 \mathrm{M}$.

- Fdams Broboater. Roman. Geb. 5,50 פD.

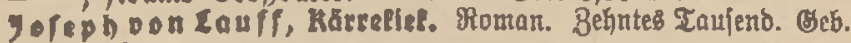
$5,50 \mathfrak{D R}$.

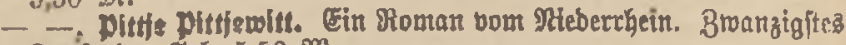
Zaufent. ઉeb. 5,50 खlt.

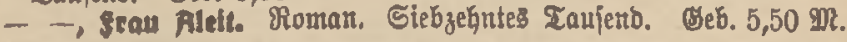


9o leph o on Laulf, Die Canjmamfell. Foman. Siebjehntes Tauiend. Beb. 5,50 M.

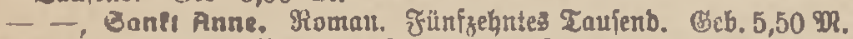

- - Revelaer. Nontan. Sedjebnte Taujeno. (Jeb. 5,50 D?.

-. Lux aeterna. Ronan. Elftę Taujenb. Beb. 5,50 $\mathfrak{M}$.

-, Die 6rinffoulte, Homant. 3twälftes Taujento. Beb. 5,50 UR.

-- -, Anne. Bufonne. Ifoman Eirunozmanzigftes Tauf. Geb.5,50M.

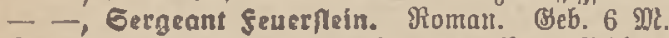

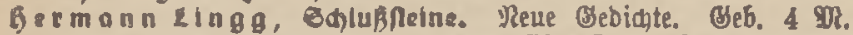

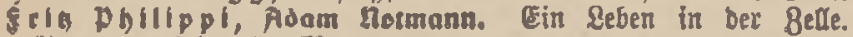
Homan. \&eb. 4,50 12 .

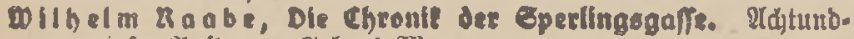
neumzigfte Yuflage. Beb. 4 gi.

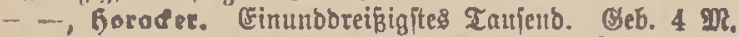

- Unrubigr BAfle. Ein Jivmian aub Dem Săfulum. Giebente थuffege. ญeb. 4 in.

-, Jm alten Eifen. Eine Erzäglung. Siebente 2uflage. Beb.4 92.

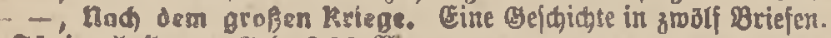

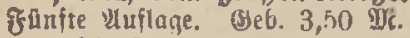

- -, Dir Kinder oon finfenrode. Udate Uuflage. Beb. 4 II.

-., Galb må, bolb mehr. Erzăblungen, Gftzzen, Reims. Brweite Huflage. Eeb. 4 IJt.

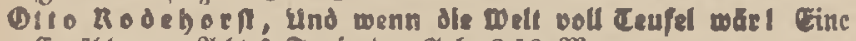

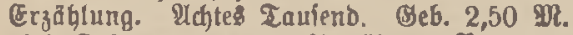

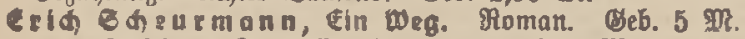

- Abpirs. Sedis Erzinhlungen. Beb. 3 M.

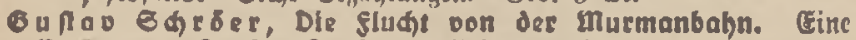
(Erzöblung. Fünftę Taujent. Beb. 2,50 פl.

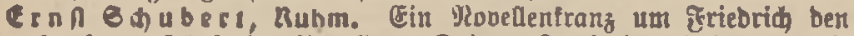
Bruber. Firnfzern Mrovellen. Dritte Tauferb. (8)b. 4,50 gR. - Der Eturmmino Bottes. 8rei Erzäblungen. Beb. 5 MT. Gein rít Wolfgang Beldel, Det Dogal Colldan. Steun Er-

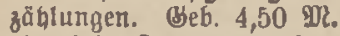

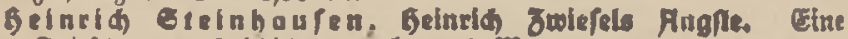
Svieblagener Beídidte. Geb. $5,50 \mathrm{MR}$.

Tonrad e efmann, Bohémiens. Romau. C̈eb. 6,50 $\mathfrak{R}$.

3 obannes e colan. Auf det anderen Gelte. Streifalge am Dntario-Gee. Geb. $3 \mathrm{MD}$.

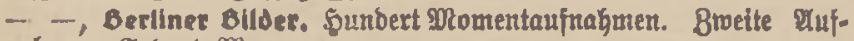
lage. (3eb. 4 פIR.

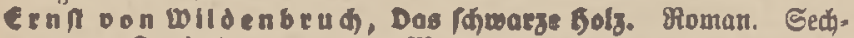
zehnte Tauiend. (reb. 5,50 $\mathrm{m}$.

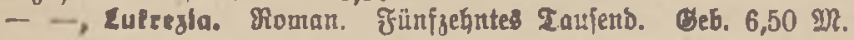




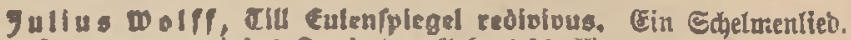

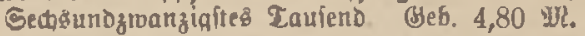

- Der Karfenfänger von Bameln. Eime Ruentiure. Siebelt-

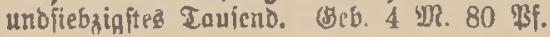

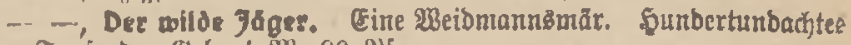

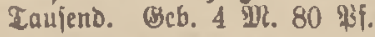

- - Cannbăurer. Cin Minurefang. 8wei Bänbe. Bierutb. vierzigfte Tauiend. Meb. $8 \mathrm{M}$.

-. Lurlei. Eine Romanze. Siebzigftes Iaufent. Beb. 6 MR.

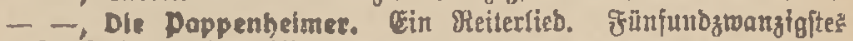
Tauieno. Beb. 6 घlt.

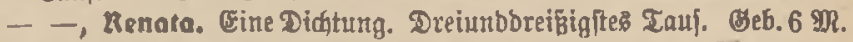

_- Der fliegende Golländer. Eine Seemanthăage. Siebenutro. breípigftes Taufent. Beb. $5 \mathrm{M}$.

- - Afralide. Didhtung aus ber Beit ber probençatifhen Trou-

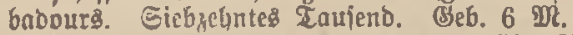

-_ - Der Landstuedhs von Cochem. Ein Sang von ber Mrofel. Dreiundzrmanzigftest Tauiend. Geb. $6 \mathrm{M}$.

-... - Der fahrende ङhüler. Eine Diditung. Biezzehntes Tau. lent. Beb. $6 \mathfrak{G R}$.

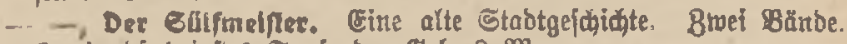
Brvéunbjechzigftes Taúenb. Beb. 8 Mz.

- Der Kaubgraf. Cine Geídidte aus bem 5arzgau. 8weiunb. fiebzigfte Tauient. Geb. $7 \mathfrak{M}$.

- Das Krat der Gagenolze. Fine Geiratsgejdidute aus bent Reálartal. Bmeiumbvierzigftes Zaujenb. Beb. $7 \mathrm{M}$.

- Das fówarze Weib. Roman aus bem Bauerntriege. Finf.

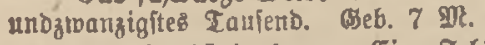

_- Die Gohlonigsburg. Eine fregbegcididhte aus bent 280 s. gau. Dreiunobreifigftes Taujenb. Eeb. 6 \$?.

- 3 welfel der Elebe. Moman aub ber Eegentwart. Cinunb. gtwanglgites Tauferib. Beb. 6 MP.

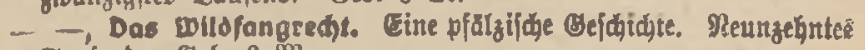
Taufend. Beb. 6 M?.

_.. Der Bodrenfpirgel. Eine Beidjidte aus ber johenftaujer. zeit. 2idtzehntes Zaujent. Beb. 6 MR.

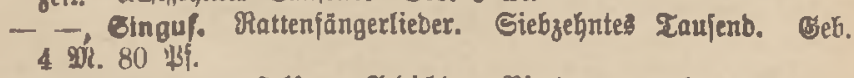

- Rus dem selde. Gebidite. Bierte, vermegrte eluflagc. 다. 2 ฏ. 50 \$i. 
Johanneg Jegerlehner, Orenzwadt der Edweizer. Eine Errzählung von ber \&renzbejęurg. 7. Taulento, Beh. 2 MR., it : Rappband geb. $2.50 \mathrm{Mr}$.

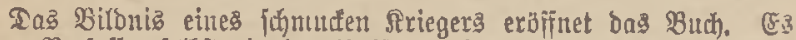

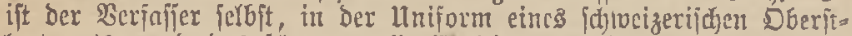

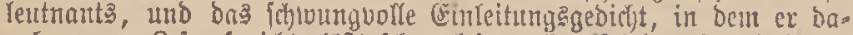

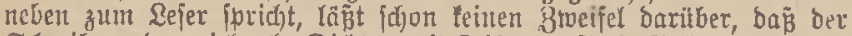
Sđreiber ober vielmethr Didjter mit Reif unt Seefe Eolbat iit. Das

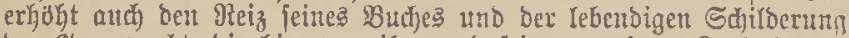

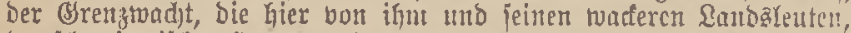

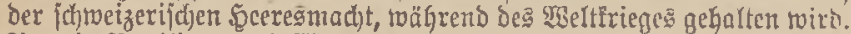

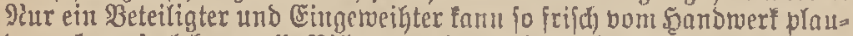

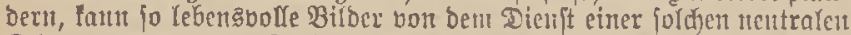

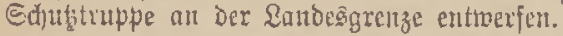

Der Micichabote.

Gupav $\sigma_{\text {d }} \mathrm{r} B \mathrm{er}$, Dle fludt von det murmanbahn. Starf

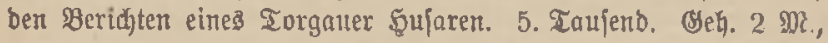

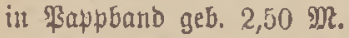

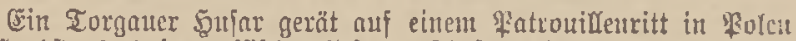
im Serbft 1914 in rulitidje (Sefangen[thajt uno wirb mit anbern Eeibensgenofien in vierwöchiger fahts in Biefmagen nad) Sibirian

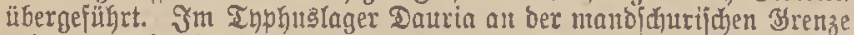

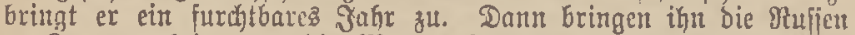
fil 81wantgånbeiten an bie Murmanbahn, no ber Storbut ruitet. Dort gefingt es ihm, mit brei frameraben zu fliehen. Hnter fajreds

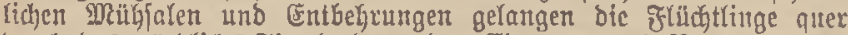

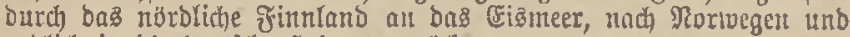

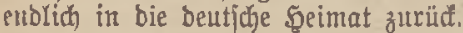

Diefe Dorgänge beriç)tet ber Berfaffer in [ajlidtem, treuhergigem

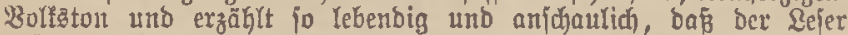
aufS ftärffte gefeffelt und ergriffen wirb. Man hat bie Empfinbuntg,

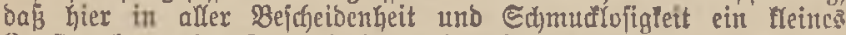

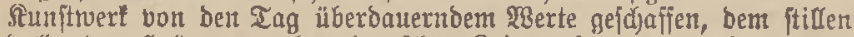

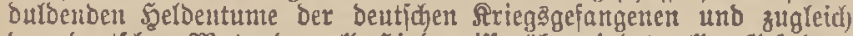
bem bettichen Mute, Der alle Shinberniffe übertvindet, allen Befahtent

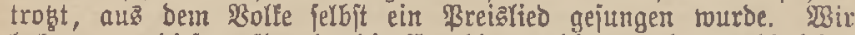

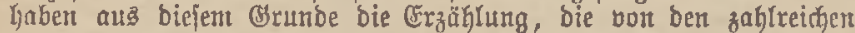

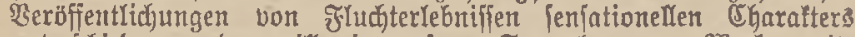
unterichieben twerben mill, in unjere "Eammlung bou $23 e r t e n$ zeito genbifificher Edhriftifteller" aufgenommen. 
Grote'\{d) Sammlung v. WBerfen zeitgenoif. Sdjriftfteller

\section{(1) No Nodeborn, und wenn die Melt doll Ceufel wärt}

Ein Beridht, wie tleine Leute ben gropen ftrieg miterlebten. 8. Taufeno. Geh. 2 M., geb. $2,50 \mathrm{M}$.

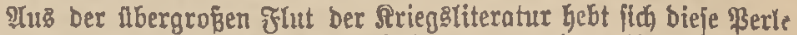

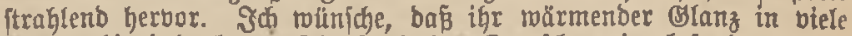
Serzen Gineinteuchtet. Die Seele Des Deutichen, im bejonberen bes

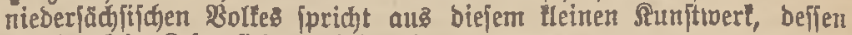
gauber tein Lejer fich entzieben fann.

Täglidje Funbjめau.

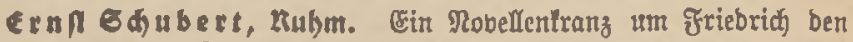
Broßer. 3. Taujeno. ऊеদ̆. 3 Mr., geb. 4,50 MR.

(Ein Buth, ridht aus ber Beit geborent uno bod für biefe Beit gefdrieben, afnumg\$los, umabjidttify. (Ein Buch bon firieg und Бclbet, but Tragobien hakeim, bie bet Rtieg oraupen injzcnicrt, bon

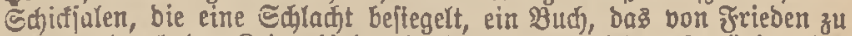

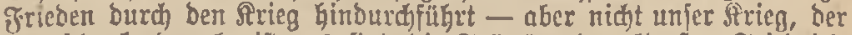

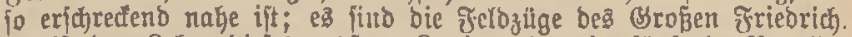
⿷匚⿱

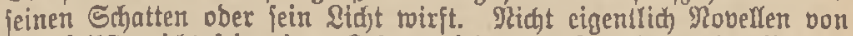
ifm felbit, nidjt jein eigen Reben miro auggeidjlachtet. $\mathcal{E r}$ ift nur bas Sdjiffal in biejen Robellen, er ift ber glühenbe Sintergrunb, bor bem bie Silhouetten pteken, er ijt ber Drgelpuntt ber gantzen Sar. monti. Und weil wir fein \&eben nur jo in anberen SSejditfen finben, weil wir bem Wirten jeiner ferjanlidefeit in Bropem uno sileinem begegnen, begreifen toir ben IImjang jeiner \$serjönlidteit,

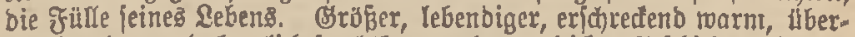
wältigenber uno herrfich-furchtbarer afs aus bicten (sejhichtsfolianten tritt bex (Brobe Fris aus biefem unauffäligen Buch herants.

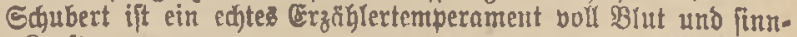
riffer Sraft.

Der Tag.

Ten eigenartigen Bauber, ben bas Benie auf leine Umgebung, aber auch auf frern[tehenbe ausె̈bt, Yernen wir ebenfo fenter, wie bie furctitbare, rücfithts]lofe Iragil feines getwaltigen Widfens. Dhne alles ßathos, ia mit einem halb farfintidjen Unterton, vernehnen

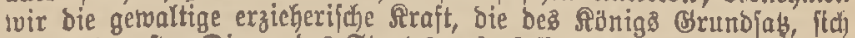
jelbit als eriten Dienter bes Staate auizufaffen uno in biejem Diente zu verzehren, auf alle ausibbt, bie mit ihm irgenbroie zu tum haben.

Es ift ein ftarles Talent, bas fith in biejen mit ber Sehicharfe unb ber fidgeren \$anb eites Menzel gejehenen Bitbern offenbart.

Der Türmer. 


\section{(5). (Srote'\{die Berlagbudhhandung in Berlin}

\section{Gdriften zut Zeit und Gerbiate:}

1. Bändchen: Buflav Frenfien, Ein Brief. 2. Aluflage (21. biß 10. Iaujenb). Startoniert 40 师f.

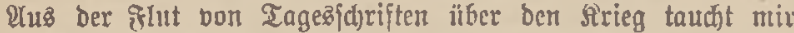
cine fefte Injel von bleibenidem 2Bert "एin Brief" mieres berbor= ragenden Dichters (B) fta $\mathrm{D}$ Frenifen auf. (5) ift eine Darfellung

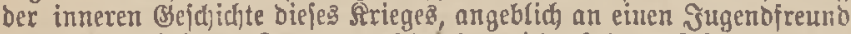
in ben Bereinigten Staaten gejđjreben, jebenfalls auj शtmerifa al? ftillen Ieilbaber Des englifhen Siriegsgeichöfts zugeipikgt.

Diefer Brief birgt ein gut Stind bichterijder sunit. Durd bie politijule Feftitellumg idflingt (id) ein Faben bon \$anblung: Dcv Freunb in almerifa fibst berlnifen unter lauter Freinden Deutid)lanbs; felbit jeine Edroefter hat fich bon ihm abgemanbt; unter bem 21; prafl ber englijdjen Rügen begiunt er zแ zmeifeln, ob fein für Deutid)= lanb gefallener Sofn für eiute rcinliche Eadje in Den Tob gegangcu itt. Dal hat ex fich an frenfifen um gilfe in ber Geelennot gerwants. Hno mit bem Gtift bes Dichters zeichnet biejer bie Berechtigfeit bcr

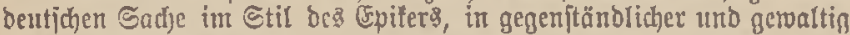
cinbringentoer Doritellung.

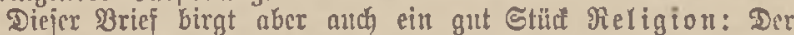
"laftor beften Sinnes ift in Jrenficu nieber erwact), ocr Berfafier ber fajflicten Dorfprebigten, und er eifert bem Sciland nach: benut ex prebigt gewaltig und nicht tnie bie Edjriftgeleljrten. Bejonoers bie 2hbjhnitte, Die fidh Dem hinterhältigen Eingreifen 2 meritas zutwenden, erheben fin zu ber fittlirfen (\$röße und Borngemalt biblijher \$ropheter.

Bor alfem entfaltet ber Bricf eine Fille politifher und

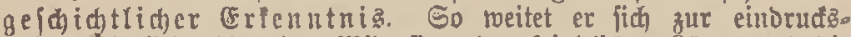
vollen luberficht über ben Biberfinn ber feindidjen Qügen unb bie Reinheit unjerex Eadje. Serwifie Feitftellungen wirfen Doppelt uber zeugent, meil fie von cinen freien, unabbingigen, ja eigentoilligen Schriftfteller auşgehen.

ßrofefior Eugen Wolff-Stier.

1. Bänbden: Beinrid Brinter, Abrif dec Befdid)te der Balean. Maaten. Mrit ztuei fiarten. (Geb. 2 Mc.

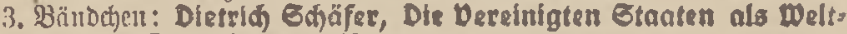
madi)t. Startoniert 50 \$广̃.

4. Bäntochen: C. A. Bratter, Die Etaatenbildung in der nord= amerifanifonen Union. Mit einer Sarte. Startonicrt 1 g)t.

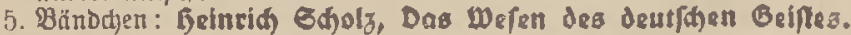
Rartoniert 1 MR.

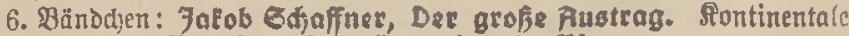
oier atlautifche 8ufunft? Sartoniert 75 \$f.

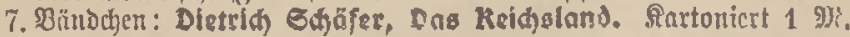



BIBLIOTEKA UNIWERSYTECKA GDAŃSK

\section{zytelnia IIBG}

BIBLIOTEKA UNIWERSYTECKA GDAÑSK 